\title{
Novel Syntheses of Nitrogen Heterocycles from Isocyanides
}

\author{
DISSERTATION
}

zur Erlangung des

mathematisch-naturwissenschaftlichen Doktorgrades

"Doctor rerum naturalium"

der Georg-August-Universität Göttingen

vorgelegt von

Alexander Lygin

aus

Krasnokamensk, Russland

Göttingen 2009 
D7

Referent: Prof. Dr. A. de Meijere

Korreferent: Prof. Dr. U. Diederichsen

Tag der mündlichen Prüfung: 
Die vorliegende Arbeit wurde in der Zeit von November 2006 bis Oktober 2009 im Institut für Organische und Biomolekulare Chemie der Georg-August-Universität Göttingen durchgeführt.

Für die Überlassung des Themas, die hilfreichen Diskussionen und Anregungen sowie die ständige Unterstützung während der Arbeit möchte ich meinem Lehrer, Herrn Prof. Dr. A. de Meijere, ganz herzlich danken.

Der Degussa(Evonik)-Stiftung danke ich für die Gewährung eines Promotionsstipendiums. 
Dedicated to Tonja and Masha 
Each player must accept the cards life deals him or her: but once they are in hand, he or she alone must decide how to play the cards in order to win the game

Voltaire 


\section{Table of Contents}

A. INTRODUCTION AND BACKGROUND ....................................................5

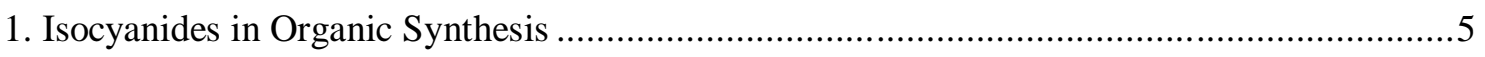

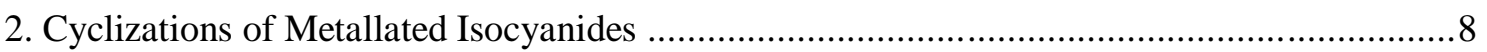

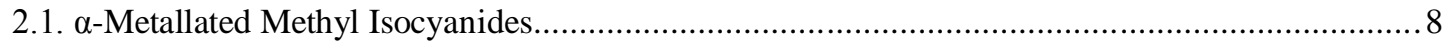

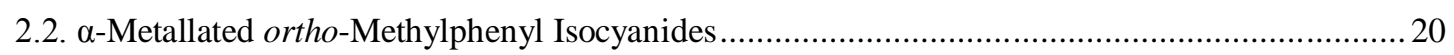

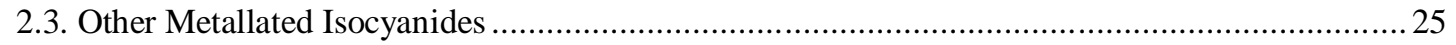

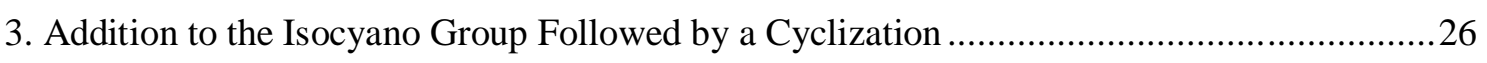

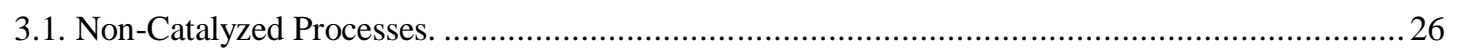

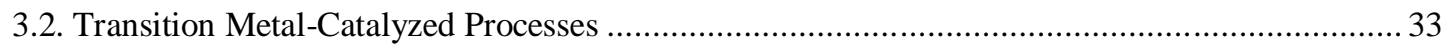

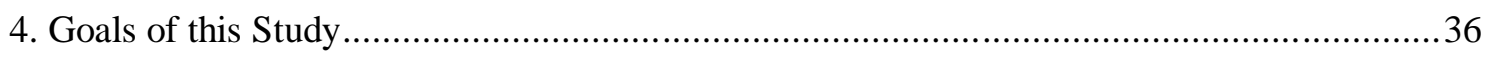

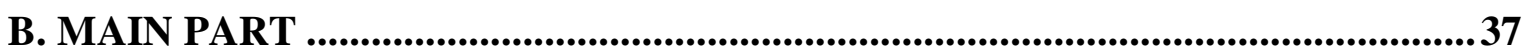

1. Oligosubstituted Pyrroles Directly from Substituted Methyl Isocyanides and Acetylenes.....37

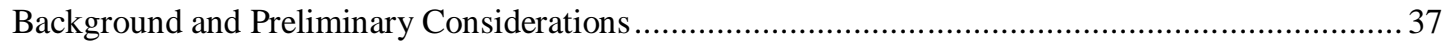

Synthesis of 2,3,4-Trisubstituted and 2,4-Disubstituted Pyrroles....................................................... 37

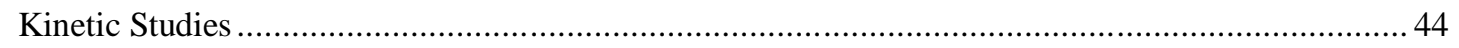

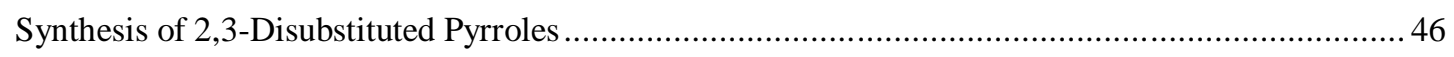

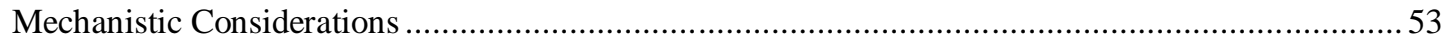

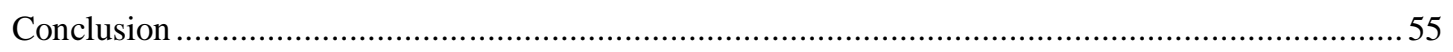

2. ortho-Lithiophenyl Isocyanide: A Versatile Precursor to 3H-Quinazolin-4-ones and

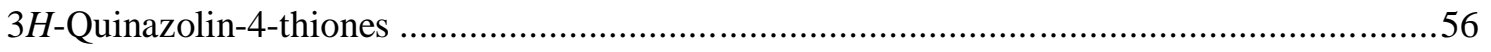

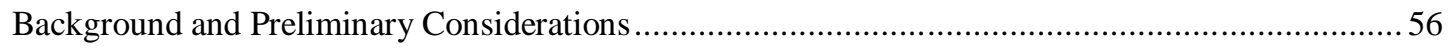

Synthesis of 2-Substituted Phenyl Isocyanides by Reaction of ortho-Lithiophenyl Isocyanide with

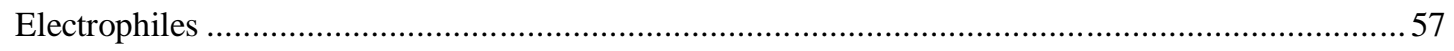

Synthesis of Substituted 3H-Quinazolin-4-ones and 3H-Quinazolin-4-thiones ..................................59

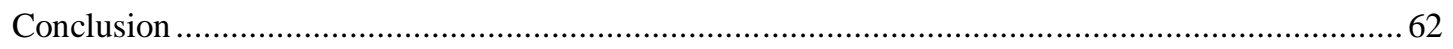

3. Reactions of ortho-Lithiophenyl (-Hetaryl) Isocyanides with Carbonyl Compounds Rearrangements of 2-Metallated 4H-3,1-Benzoxazines 


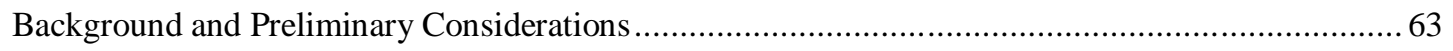

Reactions of ortho-Lithiophenyl (-Hetaryl) Isocyanides with Carbonyl Compounds ....................... 63

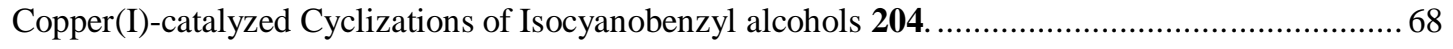

Novel Rearrangements of 2-Metallated 4H-3,1-Benzoxazines .............................................. 71

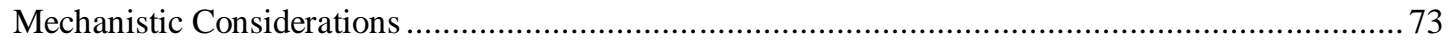

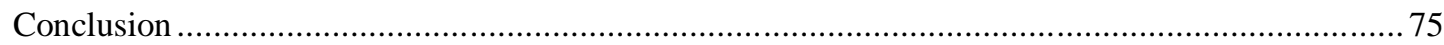

4. Synthesis of 1-Substituted Benzimidazoles from $o$-Bromophenyl Isocyanide and Amines... .76

Background and Preliminary Considerations ..................................................................... 76

Optimization of the Reaction Conditions for the Synthesis of 1-Benzylbenzimidazole .................... 77

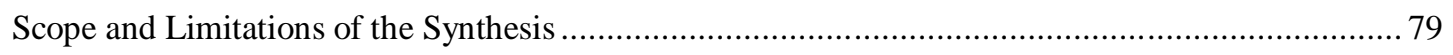

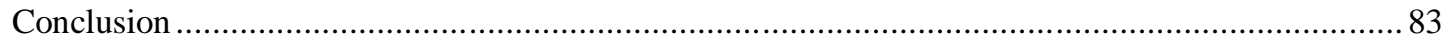

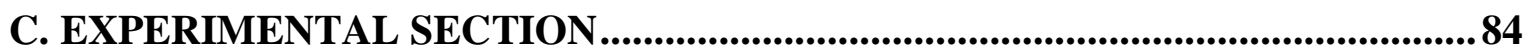

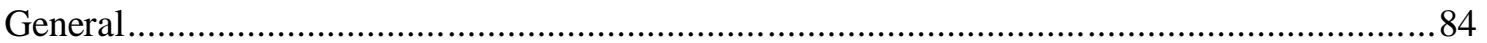

Experimental Procedures for the Compounds Described in Chapter 1 "Oligosubstituted Pyrroles Directly from Substituted Methyl Isocyanides and Acetylenes". .86

Experimental Procedures for the Compounds Described in Chapter 2 "ortho-Lithiophenyl

Isocyanide: A Versatile Precursor for 3H-Quinazolin-4-ones and 3H-Quinazolin-4-thiones" . 101

Experimental Procedures for the Compounds Described in Chapter 3 "Reactions of

ortho-Lithiophenyl (-Hetaryl) Isocyanides with Carbonyl Compounds - Rearrangements of

2-Metallated 4H-3,1-Benzoxazines"

Experimental Procedures for the Compounds Described in Chapter 4 "Synthesis of

1-Substituted Benzimidazoles from $o$-Bromophenyl Isocyanide and Amines"

D. SUMMARY AND OUTLOOK

E. REFERENCES AND COMMENTS

F. REPRESENTATIVE ${ }^{1} \mathrm{H}$ AND ${ }^{13} \mathrm{C}$ SPECTRA OF THE PREPARED 


\section{List of Abbreviations}

\begin{tabular}{|c|c|c|}
\hline Ac & $=$ & Acetyl \\
\hline acac & $=$ & Acetylacetonato \\
\hline AIBN & $=$ & Azabisisobutyronitrile \\
\hline BINAP & $=$ & 2,2'-Bis(diphenylphosphino)-1,1'-binaphthyl \\
\hline $\mathrm{Bn}$ & $=$ & Benzyl \\
\hline $\mathrm{Bu}$ & $=$ & Butyl \\
\hline CHIRAPHOS & $=$ & $(2 R, 3 R)-(+)$-Bis(diphenylphosphino)butane \\
\hline $\mathrm{Cp}$ & $=$ & Cyclopentadienyl \\
\hline $\mathrm{nCR}$ & $=$ & n-Component Reaction \\
\hline DIOP & $=$ & $O$-Isopropyliden-2,3-dihydroxy-1,4- \\
\hline & & bis(diphenylphosphino)butan \\
\hline $\mathrm{DBU}$ & $=$ & 1,8-Diazabicyclo[5.4.0]undec-7-ene \\
\hline DCM & $=$ & Dichloromethane \\
\hline DDQ & $=$ & 2,3-Dichloro-5,6-dicyanobenzoquinone \\
\hline DMF & $=$ & $N, N$-Dimethylformamide \\
\hline DMSO & $=$ & Dimethyl sulfoxide \\
\hline dppp & $=$ & 1,3-Bis(diphenylphosphino)propane \\
\hline $\mathrm{E}^{+}$or $\mathrm{El}$ & $=$ & Electrophile \\
\hline Et & $=$ & Ethyl \\
\hline$e e$ & $=$ & Enantiomeric excess \\
\hline EWG & $=$ & Electron-withdrawing group \\
\hline cHex & $=$ & Cyclohexyl \\
\hline HMPA & $=$ & Hexamethylphosphortriamide \\
\hline KHMDS & $=$ & Potassium bis(trimethylsilyl)amide $\left[\mathrm{KN}\left(\mathrm{SiMe}_{3}\right)_{2}\right]$ \\
\hline LA & $=$ & Lewis acid \\
\hline LDA & $=$ & Lithium diisopropylamide \\
\hline LiTMP & $=$ & Lithium 1,1,6,6-tetramethylpiperidide \\
\hline $\mathrm{Me}$ & $=$ & Methyl \\
\hline MTBE & $=$ & Methyl tert-butyl ether \\
\hline NP & $=$ & Nanoparticles \\
\hline $\mathrm{Nu}^{-}$or $\mathrm{NuH}$ & $=$ & Nucleophile \\
\hline $\mathrm{Ph}$ & $=$ & Phenyl \\
\hline 1,10-Phen & $=$ & 1,10-Phenanthroline \\
\hline
\end{tabular}




$\begin{array}{lll}\operatorname{Pr} & = & n \text { Propyl } \\ \mathrm{cPr} & = & \text { Cyclopropyl } \\ \mathrm{THF} & = & \text { Tetrahydrofuran } \\ \text { TBDMS } & = & \text { tert-Butyldimethylsilyl } \\ \text { TMEDA } & = & N, N, N^{\prime}, N^{\prime} \text {-Tetramethylethylenediamine } \\ p \text { Tol } & = & p \text { Tolyl } \\ \text { TosMIC } & = & p \text { Toluenesulfonylmethyl isocyanide }\end{array}$




\section{A. Introduction and Background}

\section{Isocyanides in Organic Synthesis}

Isocyanides have been first described independently by Gautier ${ }^{[1]}$ to be formed in the reaction of silver cyanide with alkyl iodides and by Hofmann ${ }^{[2]}$ upon treatment of aniline with chloroform in the presence of potassium hydroxide (the so-called carbylamine reaction). Because of the extremely unpleasant odor of the simplest (and the most volatile) isocyanides, efficient methods for their synthesis have not been developed for a long time, and therefore these compounds have long been underinvestigated. The chemistry of isocyanides received a significant boost when reliable methods for the synthesis of isocyanides, on a wide scope, e.g. the dehydration of formamides ${ }^{[3]}$ and the carbylamine reaction of amines employing phase-transfer catalysis ${ }^{[4]}$ appeared in the literature. The carbon atom of the isocyano group often exhibits carbene-like reactivity that is reflected in the resonance structure 1a (Scheme 1). Conversely, the linear structure of isocyanides is well represented by the dipolar resonance structure 1b. Such unique properties of the isocyano group, which may function both as an electrophile and as a nucleophile coupled with the now easy availability of a wide range of isocyanides have turned these compounds into indispensable building blocks for organic synthesis. ${ }^{[5]}$

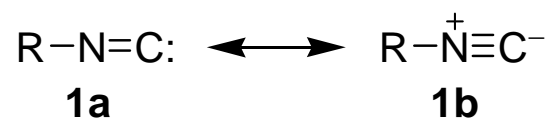

Scheme 1. Resonance structures of isocyanides.

The diversity of transformations, which isocyanides can undergo, includes various isocyanide-based multicomponent reactions, e.g. the Ugi and Passerini reactions (Scheme 2), ${ }^{[6]}$ other (Lewis acid-catalyzed) cocyclizations utilizing isocyanides as onecarbon donor (e.g. depicted on Scheme 3$)^{[7]}$ as well as their transition-metal catalyzed insertions, ${ }^{[8,9]}$ oligo- and polymerizations. ${ }^{[10]}$ Arguably the most important applications of isocyanides are toward the synthesis of various heterocycles.

Isocyanides are also well-known to participate in different types of radical processes to provide various heterocycles. Once generated, the radical intermediates readily undergo addition to an isocyano group to produce the corresponding imidoyl radicals, which in some cases are capable of subsequent cyclizations to give heterocyclic compounds. 
Passerini 3CR

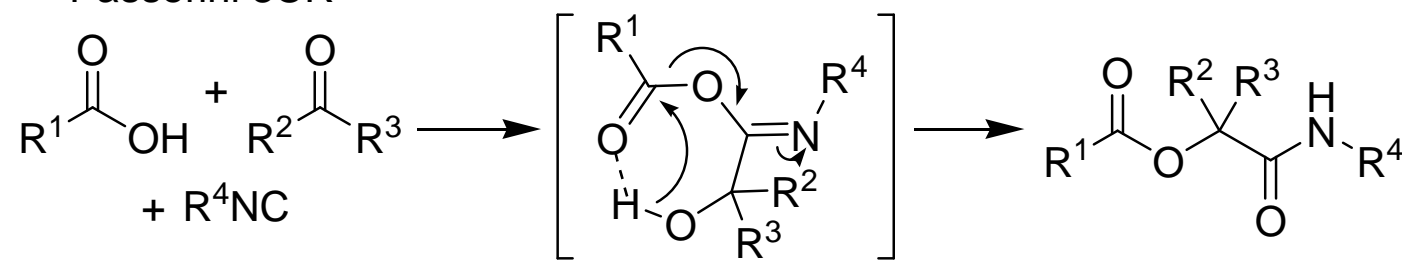

Ugi 4CR

Mumm's rearrangement

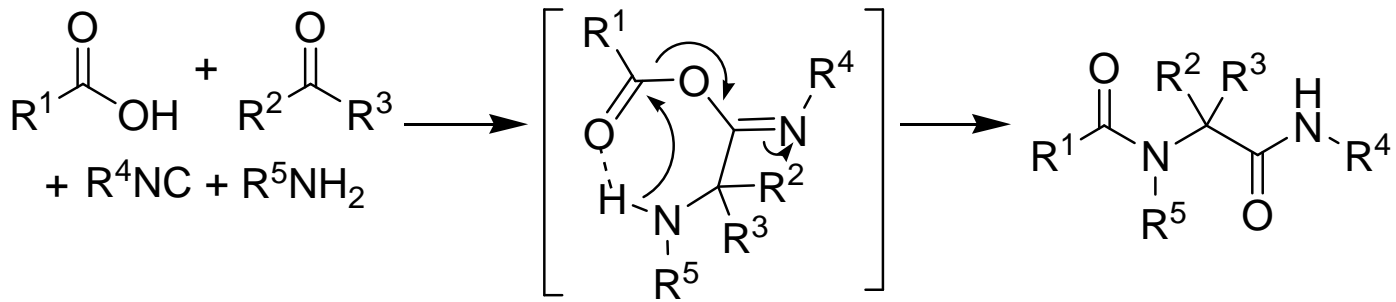

Scheme 2. The three-component Passerini and the four-component Ugi reaction.<smiles>C=Nc1ccccc1C(F)(F)[Mg]</smiles><smiles>CC(C)=C1Cc2ccccc2C1=O</smiles>

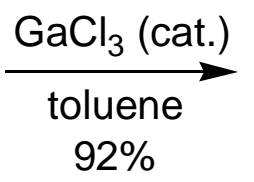

$92 \%$

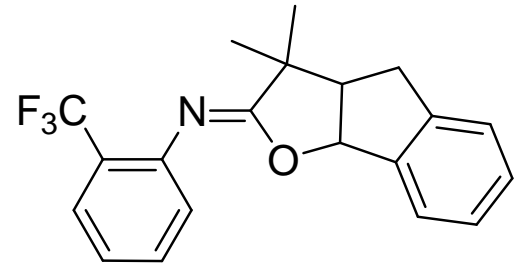

Scheme 3. An example of a formal [4+1]-cycloaddition of an $\alpha, \beta$-unsaturated carbonyl compound with an isocyanide. ${ }^{[7]}$

One of the best known and important processes of this type, which has been developed by Fukuyama et al., is the synthesis of indoles $\mathbf{3}$ by treatment of $o$-isocyanostyrenes $\mathbf{2}$ with tri- $n$-butyltin hydride and the radical initiator azobisisobutyronitrile (AIBN) (Scheme 4). ${ }^{[1]}$ The resulting 2-tributylstannyl indoles 3 can be converted into 3-substituted indoles of type $\mathbf{4}$ simply by acidic workup, but more importantly, they provide a convenient access to various 2,3-disubstituted indoles of type 6 by Stille cross-coupling reactions. The tributylstannyl derivate $\mathbf{3}$ also reacts smoothly with iodine to provide the 2-iodoindole $\mathbf{5}$, another useful substrate for subsequent modifications, , which has been shown to undergo various cross-coupling reactions. ${ }^{[1]}$ 


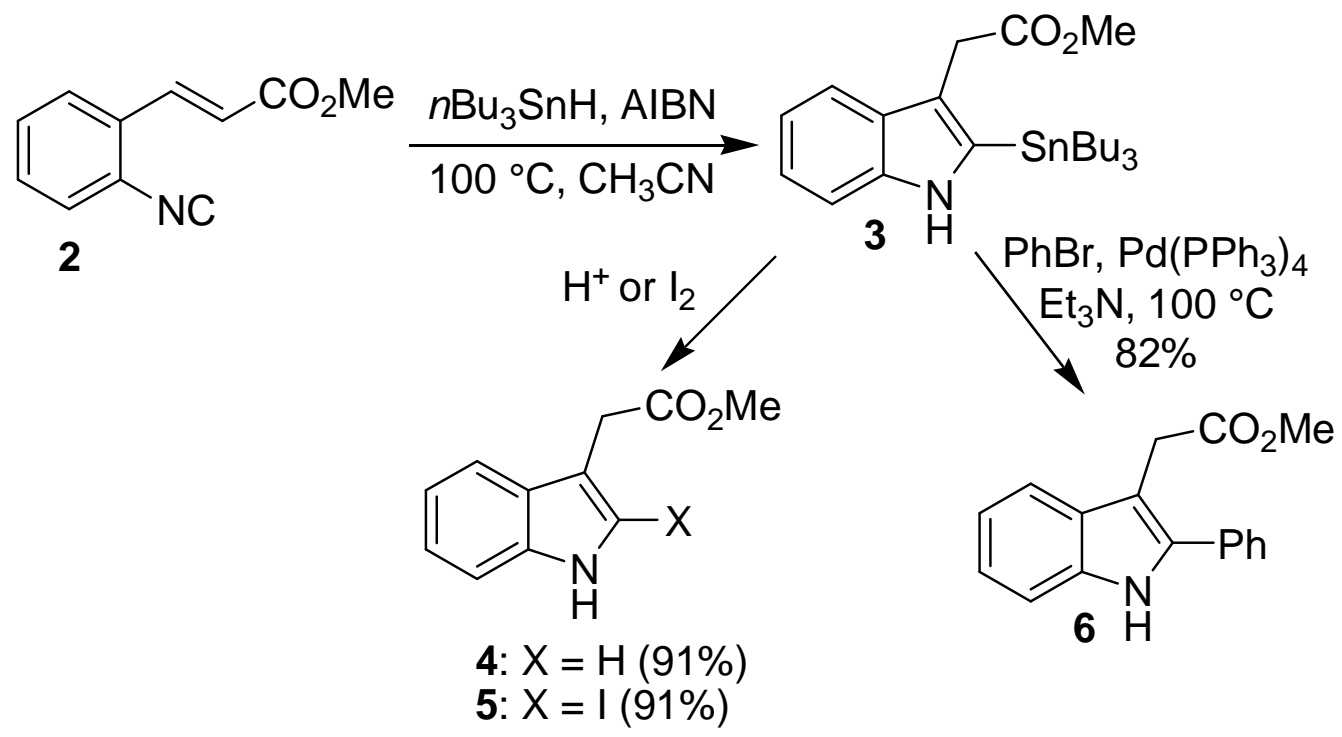

Scheme 4. The Fukuyama's indole synthesis. ${ }^{[1]}$

Diverse sequential radical cocyclizations with isocyanides, a representative example of which concerns the synthesis of (20S)-camptothecin $\mathbf{8}^{[12]}$ as depicted in Scheme 5, have previously been reviewed by Curran et al. ${ }^{[13]}$

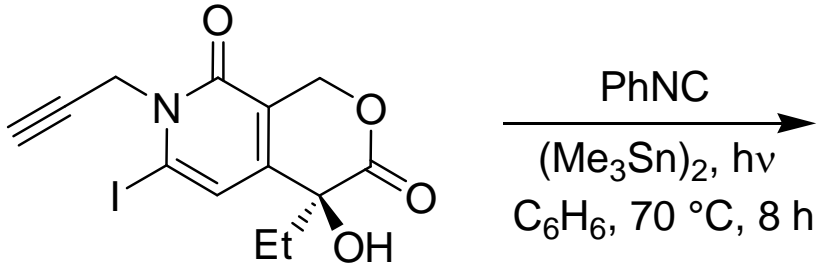

7<smiles>CC[C@]1(O)C(=O)OCc2c1cc1n(c2=O)Cc2cc3ccccc3nc2-1</smiles>

(20S)-camptothecin

Scheme 5. An example of a sequential radical cocyclization of $\mathbf{7}$ with phenyl isocyanide. Synthesis of (20S)-camptothecine (8). ${ }^{[12]}$

Two other (non-radical) general types of cocyclizations leading to the formation of heterocycles from isocyanides, should be considered more closely as they are more relevant to the experimental work of this doctoral study, namely: 1) cocyclizations of metallated isocyanides and 2) formal $\alpha$-additions onto the isocyano group followed by a cyclization. This concise overview might help us to understand that has been previously done in this area and help to imagine new possible directions of development. 


\section{Cyclizations of Metallated Isocyanides}

\section{1. $\alpha$-Metallated Methyl Isocyanides}

The electron-withdrawing effect of the isocyano group enhances the acidity of $\alpha-\mathrm{C}, \mathrm{H}$ bonds, and this was first exploited by Schöllkopf and Gerhart ${ }^{[14]}$ in 1968. Since then, $\alpha$-metallated methyl isocyanides of type $\mathbf{1 3}$ (mostly deprotonated isocyanoacetates) have been shown to participate in various types of cocyclizations leading to different nitrogen- containing heterocycles. Several reviews on this topic had appeared by $1985 .{ }^{[15]}$

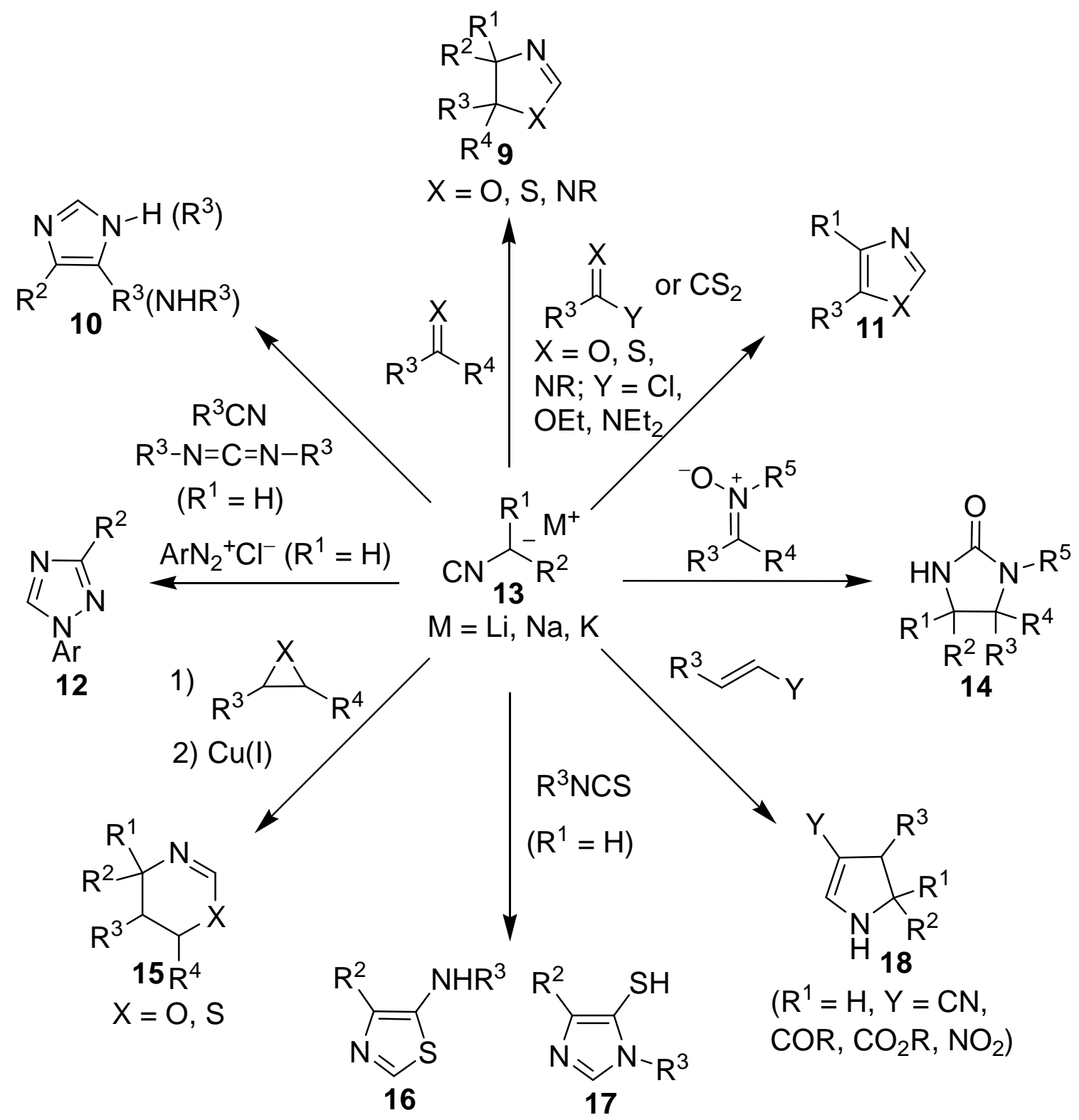

Scheme 6. Various applications of $\alpha$-metallated substituted methyl isocyanides $\mathbf{1 3}$ reviewed previously. ${ }^{[15]}$ 
The main types of transformations reported therein as depicted in Scheme 6 include syntheses of 1,3-azoles 10, 11, 16, 17 (azolines 9), pyrrolines 18, 1,2,4-tetrazoles 12, 2-imidazolinones $\mathbf{1 4}$, and 5,6-dihydro-4H-1,3-oxazines (-thiazines) $\mathbf{1 5} .^{[15]}$

One of the most important applications of $\alpha$-metallated methyl isocyanides is undoubtedly in the preparation of 1,2-disubstituted pyrroles by their reaction with nitroalkenes. ${ }^{[16]}$ In this so-called Barton-Zard pyrrole synthesis the nitro group on the alkene 19 serves two purposes, namely to activate the double bond in 19 toward Michael addition of the deprotonated isocyanide and to provide a leaving group for the conversion of the initially formed 2-pyrroline $\mathbf{2 1}$ into a $1 H$-pyrrole $\mathbf{2 3}$ by overall elimination of nitrous acid and subsequent 1,5-sigmatropic hydrogen-shift in the 3H-pyrrole 22 (Scheme 7).

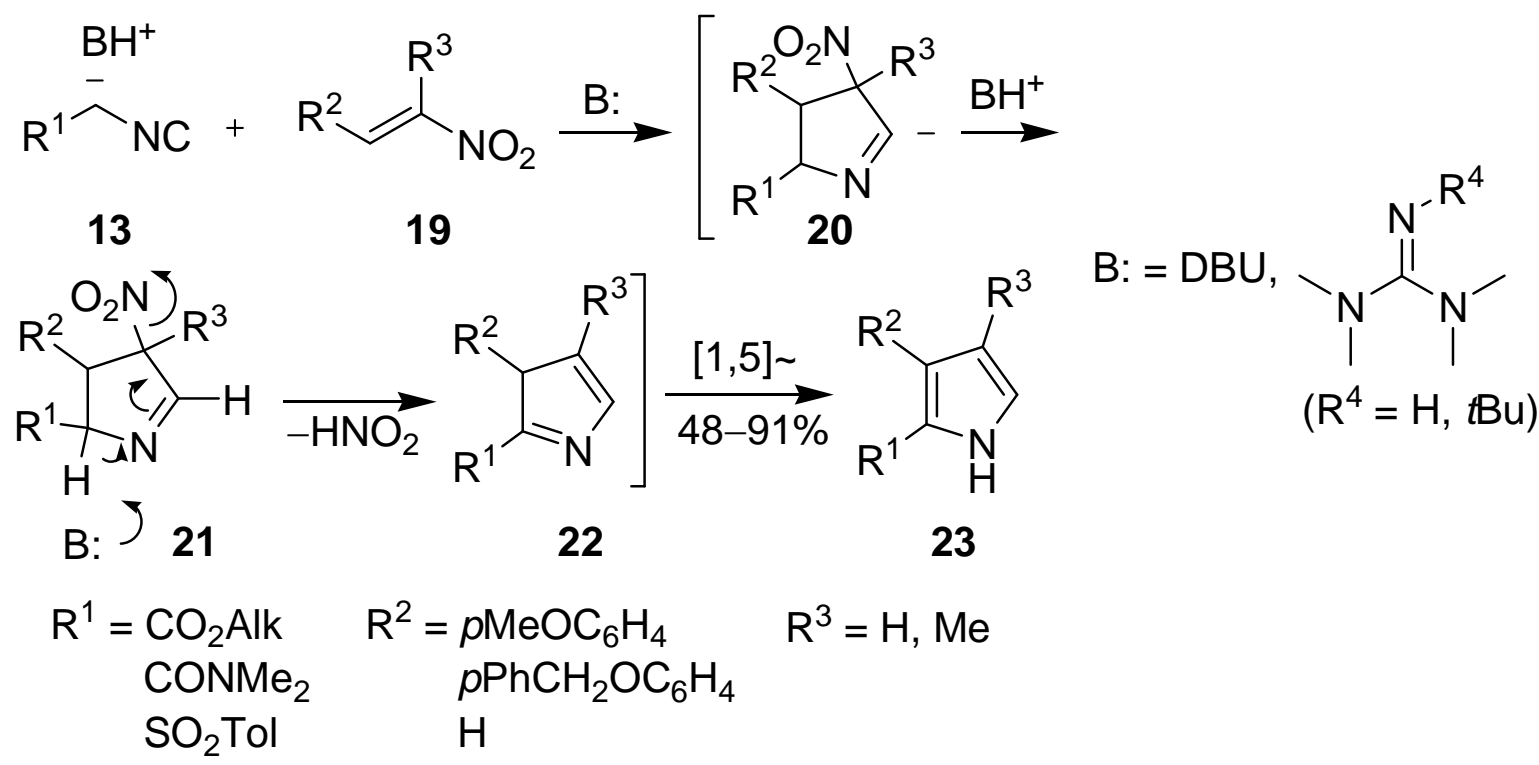

Scheme 7. The Barton-Zard pyrrole synthesis. ${ }^{[16]}$

The nitroalkanes required for this synthesis are easily accessible by an aldol-type condensation of nitroalkanes with aldehydes (Henry reaction); they can also be generated in situ from $O$-acetyl- $\beta$-hydroxynitroalkanes (Scheme 8 , eq. (1)). ${ }^{[16,17]}$ When a non-ionic superbase like 31, which is about $10^{17}$ times more basic than 1,8-Diazabicyclo[5.4.0] undec-7-ene (DBU) is employed instead of DBU, the respective pyrroles are obtained in excellent yields (Scheme 8, eq (2)). ${ }^{[18]}$ The same base 31, has been shown also to be superior over DBU in the synthesis of oxazoles $\mathbf{3 0}$ by reaction of acid chlorides 29 and anhydrides with methyl isocyanoacetate $(\mathbf{2 5}-\mathrm{Me})$ providing the products fast and in almost quantitative yields. ${ }^{[18]}$ 
<smiles>[R]C(O[C@@H]([R])C([R])[N+](=O)[O-])[N+](=O)[O-]</smiles>

24

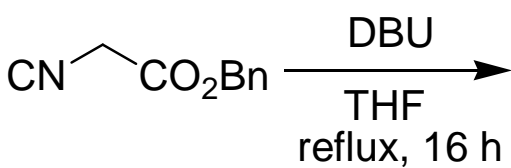

25-Bn

$53-76 \%$

$\mathrm{R}^{1}, \mathrm{R}^{2}=\mathrm{Me}, \mathrm{Et},\left(\mathrm{CH}_{2}\right)_{2} \mathrm{CO}_{2} \mathrm{Me}$<smiles>CCC(OC(C)=O)C(CC)[N+](=O)[O-]</smiles>

27<smiles>COC(=O)CC#N</smiles>

25-Me<smiles>CNCCOC</smiles>

25-Me<smiles>[R]c1c[nH]c(C(=O)OCc2ccccc2)c1[R]</smiles>

26<smiles>[R]C(=O)Cl</smiles>

29

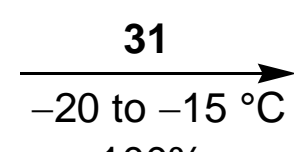
$100 \%$<smiles>CCc1c[nH]c(C(=O)OC)c1CC</smiles>

28<smiles>COc1cc(C)cc(OC)c1OC</smiles><smiles>CN1CCN2CCN(C)P1N(C)CC2</smiles>

Scheme 8. In situ generation of nitroalkenes in the Barton-Zard pyrrole synthesis. Some applications of the superbase $31 .^{[16,18]}$

The quality and the type of the solvent, particularly the absence of radical inhibitors such as BHT which is routinely added to commercial THF, have been shown to influence the rate of the reaction as well as the pyrrole yields. ${ }^{[19]}$ tert-Butyl methyl ether (MTBE) has been found to be better than THF in this reaction.

The reaction of ethyl isocyanoacetate 25 -Et with certain nitroaromatic compounds, e. g. 9-nitrophenanthrene (32), also provided the corresponding pyrrole $\mathbf{3 3}$ fused to a phenanthrene moiety (Scheme 9). ${ }^{[20]}$ Polycyclic aromatic nitro compounds with decreased aromaticity gave the corresponding arene-annelated pyrroles in good yields while simple nitroarenes such as nitronaphtalene and nitrobenzene turned out to be less efficient or even failed in this reaction. ${ }^{[20]}$

Alternatively to nitroalkenes, $\alpha, \beta$-unsaturated phenylsulfones 35 can be employed in the synthesis of pyrroles 36 with the same substitution pattern as in the Barton-Zard method (Scheme 10). ${ }^{[21]}$ This reaction proceeds with elimination of phenylsulfinic acid $\mathrm{PhSO}_{2} \mathrm{H}$. 


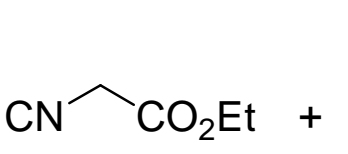

25-Et

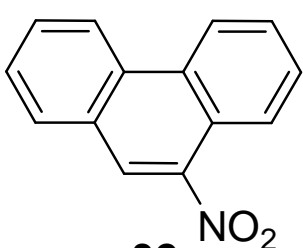

32
$\underset{\mathrm{THF}, 20^{\circ} \mathrm{C}}{\stackrel{\mathrm{DBU}}{\longrightarrow}}$

$75 \%$

Scheme 9. Synthesis of pyrrole 33. ${ }^{[20]}$

The phenylsulfones of type $\mathbf{3 5}$ are easily accessible e. g. by sulfenohalogenation of alkenes with subsequent $\beta$-elimination of hydrogen halide from the resulting adducts. $\alpha, \beta$-Unsaturated nitriles, which conveniently prepared by condensation of substituted arylacetonitriles with aldehydes, in turn have been shown to react with deprotonated isocyanoacetates $\mathbf{2 5}$ to provide, after elimination of cyanide, 3,4-diarylpyrrole2-carboxylates in moderate yields. ${ }^{[22]}$

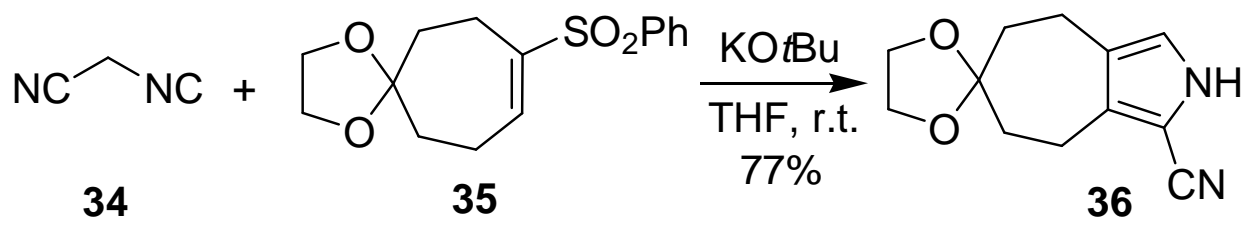

Scheme 10. Synthesis of pyrrole 36 from $\alpha, \beta$-unsaturated sulfone 35 and isocyanide 34. ${ }^{[21]}$

Polarized ketene $S, S$-dithioacetals of type 37 or $N, S$-acetals 38 (Fig. 1) represent further suitable counterparts for activated methyl isocyanides in the synthesis of 2,3,4-trisubstituted pyrroles. ${ }^{[23]}$ These base-induced reactions proceed with elimination of methylthiolate and loss of the respective substituents $\mathrm{R}^{1}{ }^{[23]}$<smiles>CCC(C)=C(C)C(C)C</smiles>

37

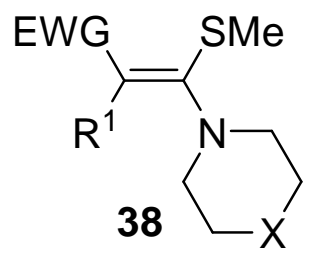

$\mathrm{EWG}=\mathrm{NO}_{2}, \mathrm{CN}, \mathrm{COMe}, \mathrm{COPh}, \mathrm{CO}_{2} \mathrm{Et}$

$\mathrm{R}^{1}=\mathrm{H}, \mathrm{CO}_{2} \mathrm{Et}$, COMe, COPh

$\mathrm{X}=\mathrm{O}, \mathrm{NCO}_{2} \mathrm{Et}, \mathrm{NCH}_{2} \mathrm{Ph}$

Figure 1. Polarized ketene $S, S$-dithioacetals 37 and $N, S$-acetals 38. ${ }^{[23]}$ 
The Barton-Zard methodology has been employed in various natural product syntheses, such as that of pyrrolostatin and its analogues ${ }^{[24]}$ as well as chromophores for biological systems. ${ }^{[25]}$ Importantly, the pyrroles synthesized from $\alpha, \beta$-unsaturated nitroalkenes or phenylsulfones posses a substitution pattern perfect for the construction of porphyrines. $^{[20,21 \mathrm{~d}, \mathrm{e}, \mathrm{f}, 26]}$ Thus, reduction of the ester group at position 2 of the pyrrole 39, succeeding acid-catalyzed cyclizing condensation with an excess of methylal (formaldehyde dimethylacetal) and subsequent oxidation led to octaethylporphyrin $\mathbf{4 0}$ in $69 \%$ yield over three steps (Scheme 11). ${ }^{[18,26]}$

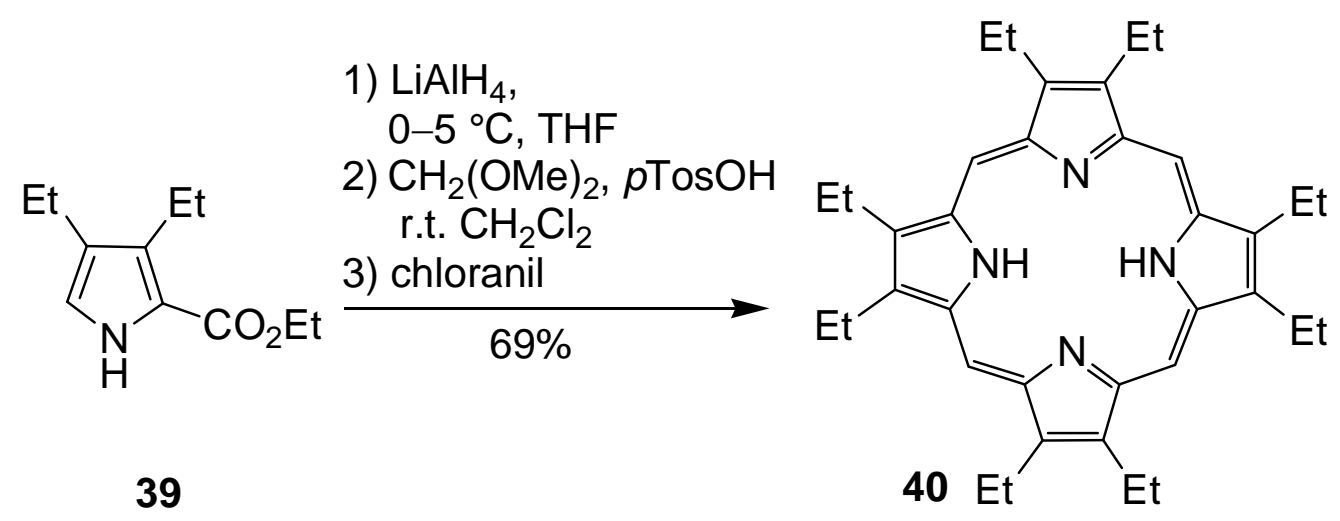

Scheme 11. Synthesis of octaethylporphyrin 40 from the pyrrole 39. ${ }^{[18]}$

The most frequently used $\alpha$-isocyanoalkanoic acid derivatives contain ester groups as acceptors and are easily accessible from the corresponding amino acids. Some acceptor substituents on methyl isocyanides, e. g. the tosyl group, capable of further elimination under basic conditions, may bring some synthetic advantages toward particular heterocycles from isocyanides. Tosylmethyl isocyanide (TosMIC, 41-H) ${ }^{[27]}$ introduced in organic synthesis and employed for various purposes by van Leusen, has become a classical reagent for the construction of 1,3-azoles and pyrroles. ${ }^{[28]}$ Thus, it reacts under basic conditions (with elimination of TosH): with aldehydes to provide oxazoles, ${ }^{[29]}$ with aldimines to give imidazoles; ${ }^{[30,31]}$ with acceptor-substituted alkenes to give pyrroles (Scheme 12). ${ }^{[32]}$ The latter reaction, known as the van Leusen pyrrole synthesis, is of particular importance, as pyrroles are widespread among naturally occurring biologically active substances and their synthetic analogues. Pyrroles thus prepared from isocyanides 41-R, can be further elaborated. Thus, $\alpha$-trimethylstannyl-substituted TosMIC (41-SnMe 3 ) employed in this reaction, provides an access to 2-(trimethylstannyl)pyrroles, which could be further derivatized e. g. by Stille cross-coupling reactions with aryl bromides. ${ }^{[33]}$ 


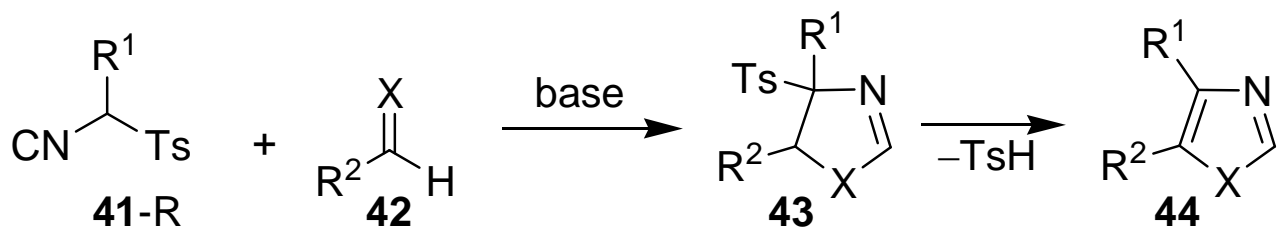

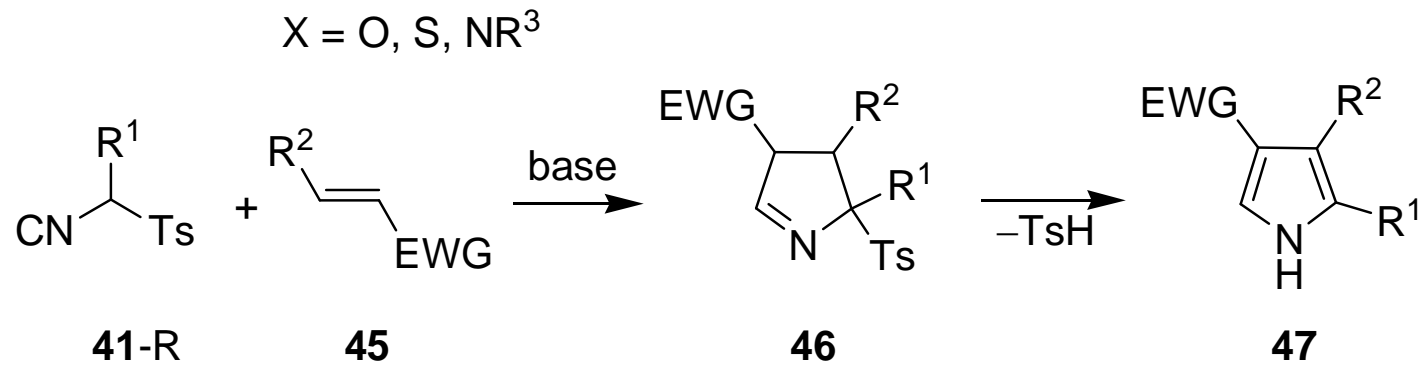

Scheme 12. Synthesis of various 1,3-azoles from tosylmethyl isocyanide and its derivatives 41- $\mathrm{R}\left(\mathrm{R}=\mathrm{H}\right.$, TosMIC). ${ }^{[28-32]}$

Interestingly, mono- and 1,2-disubstituted arylalkenes (preferably with electronwithdrawing substituents) have been shown also to provide 3-aryl- or 3,4-diarylsubstituted pyrroles, respectively, in moderate to good yields by the reaction of TosMIC in the presence of $\mathrm{NaO} t \mathrm{Bu}$ as a base in DMSO. ${ }^{[34]}$

A base-induced reaction of 1-isocyano-1-tosyl-1-alkylidene methyl isocyanides $\mathbf{5 1}$ with unsaturated compounds of type $\mathbf{4 9}$ furnished azoles $\mathbf{5 0}$ capable to undergo a subsequent pericyclic reaction and aromatization by means of DDQ to give various benzoannelated heterocycles: indoles 52, benzimidazoles $\mathbf{5 4}$ and benzoxazoles $\mathbf{5 5}$, respectively (Scheme 13). ${ }^{[35]}$ Apparently, a strong base such as potassium tert-butoxide deprotonates the isocyanide 51 to furnish the isocyanoallyl anion 48, which cocyclizes with acceptorsubstituted alkenes $49\left(X=\mathrm{CHCOR}^{3}\right)$, aldehydes $(X=\mathrm{O})$ or imines $(\mathrm{X}=\mathrm{NR})$ to provide the corresponding azoles.

Another example of an acceptor-substituted methyl isocyanide in which the acceptor is a good leaving group, benzotriazol-1-yl-methyl isocyanide (BetMIC), has been reported by Katritzky et al. to be sometimes superior over TosMIC in the synthesis of oxazoles, imidazoles and pyrroles. ${ }^{[36]}$

In addition to base-mediated reactions, the catalytic versions of some of the corresponding cocyclizations of substituted methyl isocyanides with unsaturated compounds have been intensively investigated. Copper(I), silver(I) and gold(I) salts are most frequently used catalysts for the aforementioned syntheses of heterocycles. Thus, $\mathrm{Cu}(\mathrm{I})-, \mathrm{Ag}(\mathrm{I})-$ or $\mathrm{Au}(\mathrm{I})$-catalyzed reactions of substituted methyl isocyanides with aldehydes (ketones), ${ }^{[37]}$ 


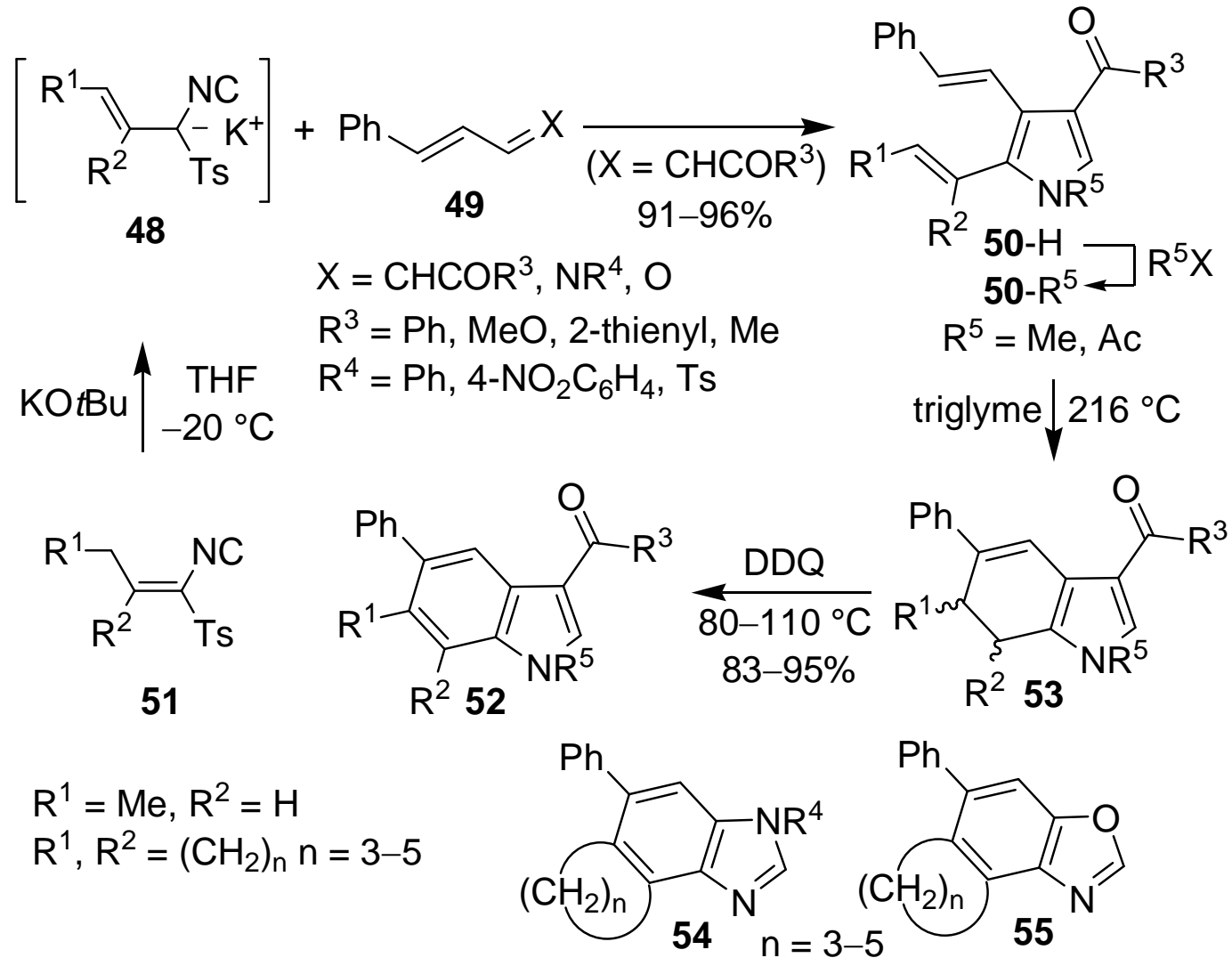

Scheme 13. Synthesis of indoles 52, benzimidazoles 54 and benzoxazoles 55 by sequential construction of an azole ring and a benzene ring. ${ }^{[35]}$

imines, ${ }^{[38]}$ as well as various Michael acceptors ${ }^{[39]}$ have been reported. Such catalytic variants have some obvious advantages over conventional (base-mediated) reactions, i. e. atom economy, ${ }^{[40]}$ and the possibility to use base-sensitive substrates as well as to be able to obtain the respective products diastereo- or even enantioselectively. The asymmetric synthesis of synthetically useful 4,5-disubstituted 2-oxazolines 57 by an aldol-type condensation of aldehydes with substituted methyl isocyanides containing an electronwithdrawing group has first been reported by Ito et al. in 1986. ${ }^{[41 \mathrm{a}]}$ Thus, in the presence of 1 mol\% of a $\mathrm{Au}(\mathrm{I})$ complex with chiral bis(diphenylphosphino)ferrocene ligands of type $\mathbf{5 8}$, the reaction of methyl isocyanoacetate $(25-\mathrm{Me})$ with aldehydes gave the respective trans-disubstituted $(4 S, 5 R)$-oxazolines in high yields (83-100\%) diastereo- and enantioselectively (Scheme 14). ${ }^{[41]}$ Isocyanomethylcarboxamides, ${ }^{[42 a, d]}$-phosphonates ${ }^{[42 b]}$ and $\alpha$-ketoesters ${ }^{[41 \mathrm{f}]}$ have also successfully been employed in this cocyclization while the reaction with other $\alpha$-substituted methyl isocyanocarboxylates proceeded notably slower than with methyl isocyanoacetate (25-Me) and sometimes with decreased stereo- and 
enantioselectivity. ${ }^{[41 \mathrm{c}, \mathrm{d}]}$ The silver complexes with ligands of type $\mathbf{5 8}$ were found to be superior over their gold(I) analogues for the reaction of aldehydes with TosMIC ${ }^{[42 \mathrm{c}]}$ and provided the corresponding trans-(4R, 5R)-5-alkyl-4-tosyl-2-oxazolines in excellent yields with high degrees of diastereo- and enantioselectivity (up to $86 \%$ ee).

(R)-(S)-58<smiles>[3H]C([3H])=O</smiles>

56

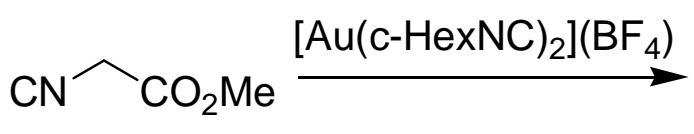

25-Me

$\mathrm{R}^{1}=\mathrm{Ph}, \mathrm{tBu}, \mathrm{cHex}, \mathrm{iPr}, \mathrm{Me}$, $(E)-\mathrm{CH}=\mathrm{CHnPr},(E)-\mathrm{CMe}=\mathrm{CHMe}$<smiles>[R12]CCN(C)C(C)c1ccccc1P</smiles>

$\mathrm{Fe}$

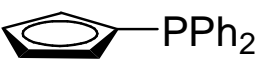

(R)-(S)-58

$\mathrm{NR}^{2}{ }_{2}=\mathrm{NMe}_{2}, \mathrm{NEt}_{2}$,
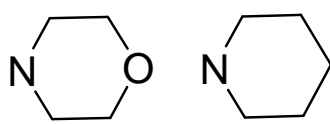

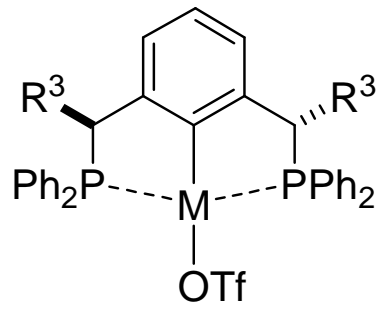

59a: $R^{3}=M e, M=P d$

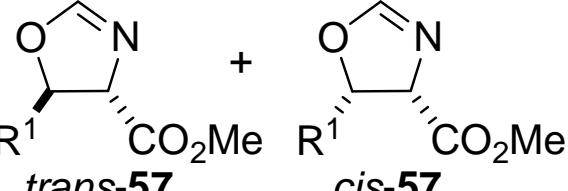
trans-57 cis-57 trans-/cis- $>80 / 20$ ee $72-97 \%$ 
Some Pd(II), Pt(II) and Pt(IV) complexes of chiral PCP- and PNP pincer-type ligands with a deeper chiral pocket around the metals have indeed been successfully employed in the asymmetric synthesis of 4,5-disubstituted oxazolines, although with inferior results when compared to the above mentioned $\mathrm{Au}(\mathrm{I})$ complexes. ${ }^{[44]}$ Among them, the best diastereoand enantioselectivities have been observed with depicted in Scheme 14 complexes of type 59a (trans/cis: $45 / 55$ to $91 / 9$; trans: low ee $(<30 \%)$; cis: $42-77 \%$ ee) ${ }^{[44 b]} \mathbf{5 9 b}$ (trans/cis: 56/44 to 93/7; cis: low ee; trans: $13-65 \%$ ee) ${ }^{[44 c]}$ and $\mathbf{6 0}$ (reaction with TosMIC: $>99 \%$ trans $(4 S, 5 S) ; 25-75 \%$ ee; reaction with 25-Me: low stereoselectivity). ${ }^{[44 d]}$

The $\mathrm{Au}(\mathrm{I})$-catalyzed reaction of alkylisocyanoacetates (25-R) with $N$-tosylimines (61) afforded the respective cis- $(4 R, 5 R)$-2-imidazolines 62 (in contrast to reactions with aldehydes) enantioselectively with the ligand $(R)-(S)-58$ (Scheme 15$).{ }^{[45]}$ Interestingly, the combination of the same ligand $(R)-(S)-58$ with bis-(cyclohexyl isocyanide)gold(I) tetrafluoroborate afforded the respective isomer trans-62 diastereo- and enantioselectively. cis-2-Imidazolines could also be synthesized diastereoselectively with achiral $\mathrm{RuH}_{2}\left(\mathrm{PPh}_{3}\right)_{4}{ }^{[46]}$ as a catalyst and diastereo- ${ }^{[47]}$ and enantioselectively with some chiral $\operatorname{Pd}(\mathrm{II})$-pincer complexes. ${ }^{[48]}$ trans-Stereoselective synthesis of $N$-sulfonyl-2-imidazolines by a $\mathrm{Cu}(\mathrm{I})$-catalyzed reaction of $\mathrm{N}$-tosylimines with isocyanoacetates has also been reported. $^{[49]}$

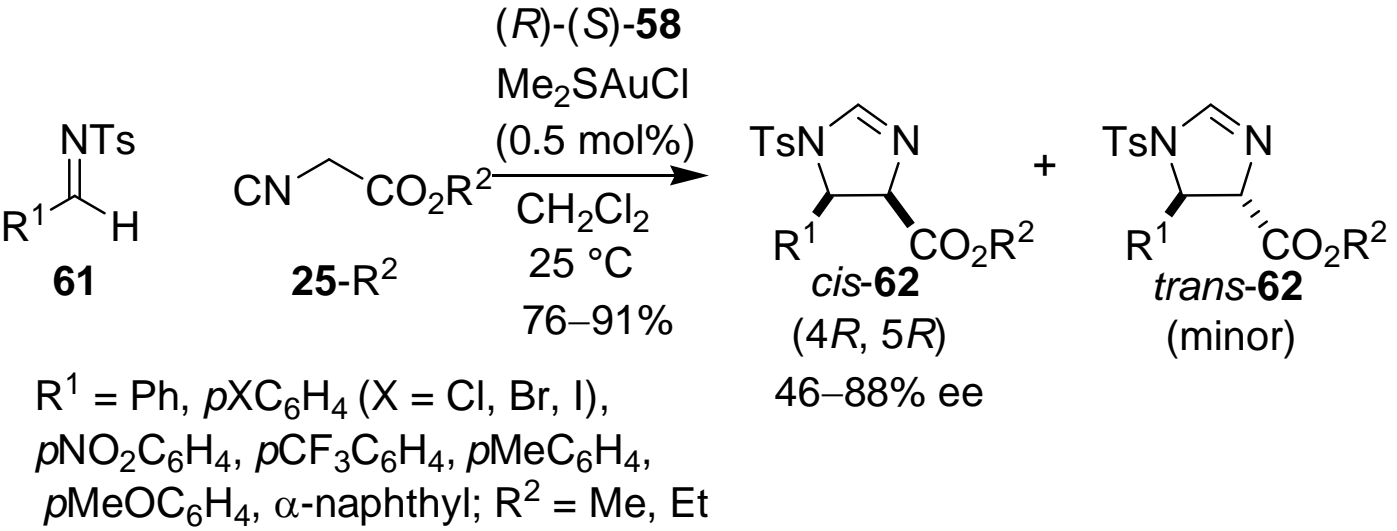

Scheme 15. Asymmetric synthesis of 4,5-disubstituted imidazolines 62. ${ }^{[45]}$

Low catalyst loadings and high degrees of diastereo- and enantioselectivity make such aldol-type reactions (especially their $\mathrm{Ag}(\mathrm{I})$ and $\mathrm{Au}(\mathrm{I}) / \mathbf{5 8}$-catalyzed variants discussed above) extremely valuable tools in organic synthesis. 
The efficient synthesis of oligosubstituted pyrroles $\mathbf{6 5}$ by a formal cycloaddition of isocyanides 63 across the triple bond of electron-deficient alkynes 64 has been reported independently by Yamamoto et al. ${ }^{[50]}$ and by de Meijere et al. (Scheme 16). ${ }^{[51]}$ In our group this reaction has been performed both in the presence of bases such as $\mathrm{KO} t \mathrm{Bu}$ and KHMDS and catalytically $\left(\mathrm{CuSPh}, \mathrm{Cu}_{2} \mathrm{O}\right.$ and metallic $\mathrm{Cu}$ nanoparticles have shown the best results in this case). Importantly, only the base-induced variant allows to efficiently employ substituted methyl isocyanides $\mathbf{6 3}$ even without electron-withdrawing groups, e. $\mathrm{g}$. benzyl isocyanide, for the synthesis of pyrroles. Yamamoto et al. have reported similar results on the catalyzed formation of pyrroles 65 with $\mathrm{Cu}_{2} \mathrm{O} / 1,10$-phenanthroline as the catalytic system of choice. A broad scope of isocyanides 63 and acetylenes 64 have been involved in this catalytic reaction. Recently, a similar solid-phase $\mathrm{Cu}_{2} \mathrm{O}$-catalyzed synthesis of 2,3,4-trisubstituted pyrroles $\mathbf{6 5}$ by a reaction of polymer-supported acetylenic sulfones with methyl isocyanoacetate $(\mathbf{2 5}-\mathrm{Me})$ has been reported. ${ }^{[52]}$

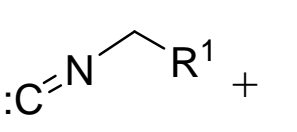

63<smiles></smiles>

64<smiles>[R]c1[nH]cc([AsH2])c1[R]</smiles>

65

$\mathrm{R}^{1}=\mathrm{CO}_{2} \mathrm{R}^{3}\left(\mathrm{R}^{3}=\mathrm{Me}\right.$, Et, $\left.\mathrm{BB}\right), \mathrm{Ph} \quad \mathrm{R}^{2}=\mathrm{Me}, \mathrm{CH}_{2} \mathrm{OMe}, \mathrm{cPr} \mathrm{CF}_{3}, \mathrm{Ph}, t \mathrm{Bu}$ $\mathrm{CONEt}_{2}, \mathrm{CN}, \mathrm{P}(\mathrm{O})(\mathrm{OEt})_{2}, \mathrm{SO}_{2}$ Tol cHex, $\mathrm{N}$-morpholino, $\left(\mathrm{CH}_{2}\right)_{4} \mathrm{OH}, \mathrm{CO}_{2} \mathrm{Et}$ $\mathrm{EWG}=\mathrm{CO}_{2} \mathrm{R}^{3}\left(\mathrm{R}^{3}=\mathrm{Me}, \mathrm{Et}, \mathrm{BBu}\right), \mathrm{CN}$, COMe, $\mathrm{CONEt}_{2}, \mathrm{SO}_{2} \mathrm{Ph}, \mathrm{P}(\mathrm{O})(\mathrm{OEt})_{2}$

Scheme 16. Synthesis of 2,3,4-trisubstituted pyrroles 65 from substituted methyl isocyanides 63 and alkynes $64 .{ }^{[50 a, 51]}$

Yamamoto et al. have also reported the regioselective phosphine-catalyzed formation of pyrroles 66 from the same starting materials 63 and 64 (Scheme 17). ${ }^{[50]}$ This interesting organocatalytic transformation has been found to give best yields in dioxane at $100{ }^{\circ} \mathrm{C}$ with bidentate phosphines such as dppp as catalysts. The proposed mechanism includes the addition of a phosphine $\mathbf{6 8}$ onto the activated C-C triple bond of an acceptorsubstituted alkyne $\mathbf{6 4}$ to form a zwitterionic intermediate 70, which in turn deprotonates the isocyanide $\mathbf{6 3}$, releasing the alkene 71. The strongly electron-withdrawing phosphonium substituent attached to to the double bond of $\mathbf{7 1}$ leads to a reversion of the 
<smiles>[R7]CN=[CH]</smiles>

63<smiles>[R]C#C[AlH2]</smiles>

64<smiles>CC(C)(C)O[Mg]O[Mg]</smiles>

$18-79 \%$<smiles>[R]c1c[nH]c([R6])c1[14CH3]</smiles>

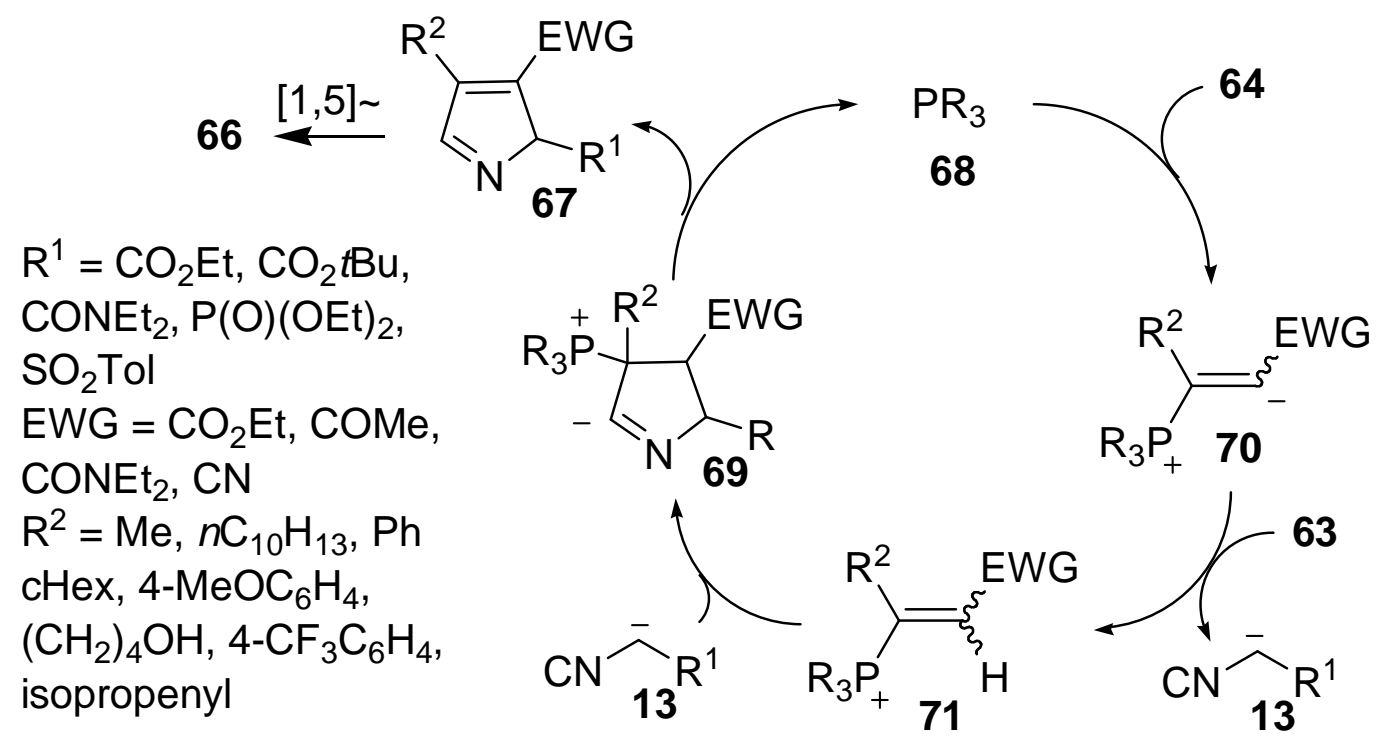

Scheme 17. A plausible mechanism for the phosphine-catalyzed formation of pyrroles 66 from substituted methyl isocyanides 63 and acetylenes $64 .{ }^{[50]}$

normal reactivity (Umpolung) of this derivative toward a nucleophilic attack of deprotonated methyl isocyanide $\mathbf{1 3}$. Thus, the formal cycloaddition of $\mathbf{1 3}$ onto the double bond of 71, followed by elimination of a phosphine in the first formed intermediate 69 leads to $\mathbf{6 7}$ and a [1,5]-hydrogen shift finally provides the pyrroles $\mathbf{6 6}$, the regioisomers of 65. This method represents an important supplement to the previously discussed synthesis of 65, although it is applicable only to methyl isocyanides with electron-withdrawing substituents.

Substituted methyl isocyanides such as methyl isocyanoacetate (25-Me), have been observed to efficiently undergo a dimerization leading to imidazoles under $\operatorname{Ag}(\mathrm{I}), \mathrm{Au}(\mathrm{I})$ or $\mathrm{Cu}(\mathrm{I})$ catalysis. ${ }^{[51,39]}$ The catalytic heterocoupling reaction of two different isocyanides 72- $\mathrm{R}^{1}$ and 34 developed by Yamamoto et al., provided various 1,4-disubstituted imidazoles 73 usually in high yields (Scheme 18). ${ }^{[53]}$ The most efficient catalytic system was found to be $\mathrm{Cu}_{2} \mathrm{O} / 1,10$-phenanthroline. Aryl isocyanides $72-\mathrm{R}^{1}$ with various substituents and some acceptor-substituted methyl isocyanides (63) were successfully employed in this transformation, while the reaction of phenyl isocyanide with benzyl isocyanide afforded only traces of the respective imidazoles. 


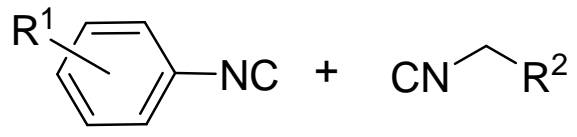

72- $\mathrm{R}^{1}$
63
$\stackrel{\mathrm{Cu}_{2} \mathrm{O}}{1,10-\text { Phen }}$
$\underset{\mathrm{THF}, 80}{\mathrm{C}} \mathrm{C}$

$62-98 \%$

$\mathrm{R}^{2}=\mathrm{CO}_{2} \mathrm{Et}, \mathrm{CO}_{2} \mathrm{tBu}$

$\mathrm{PO}(\mathrm{OEt})_{2}, \mathrm{CONEt}_{2}$

4-TMS $\equiv$, 1-naphthyl,2,6-Me

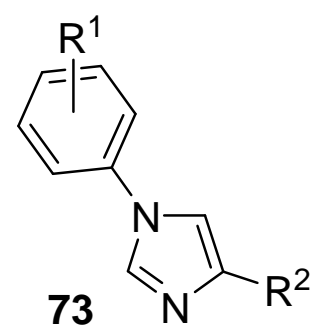

$\mathrm{R}^{1}=2-\mathrm{OMe}, 3-\mathrm{OMe}, 4-\mathrm{OMe}, \mathrm{H}$,

$4-\mathrm{CO}_{2} \mathrm{Me}, 4-\mathrm{CN}, 4-\mathrm{NO}_{2}, 4-\mathrm{Cl}$,

Scheme18. $\mathrm{Cu}_{2} \mathrm{O}-$ Catalyzed synthesis of imidazoles $\mathbf{7 3}$ from two different isocyanides

72-R and 34. ${ }^{[53]}$

The rhodiumcarbonyl complex-catalyzed reaction of ethyl isocyanoacetate (25-Et) with an excess of a 1,3-dicarbonyl compound 74 (2 equiv.) represents another catalytic approach toward substituted pyrroles (Scheme 19). ${ }^{[54]}$ The reaction of isocyanide 25-Et with carbonyl compounds produces unsaturated formamides of type 76, when performed in the presence of a stoichiometric amount of a base such as BuLi or NaH. ${ }^{[55]}$ The same transformation occurs also with $\mathrm{Rh}_{4}(\mathrm{CO})_{12}$ as a catalyst at $80{ }^{\circ} \mathrm{C}$ as well as selectively and in high yields leads to formamides of type $\mathbf{7 6} .{ }^{[54]}$

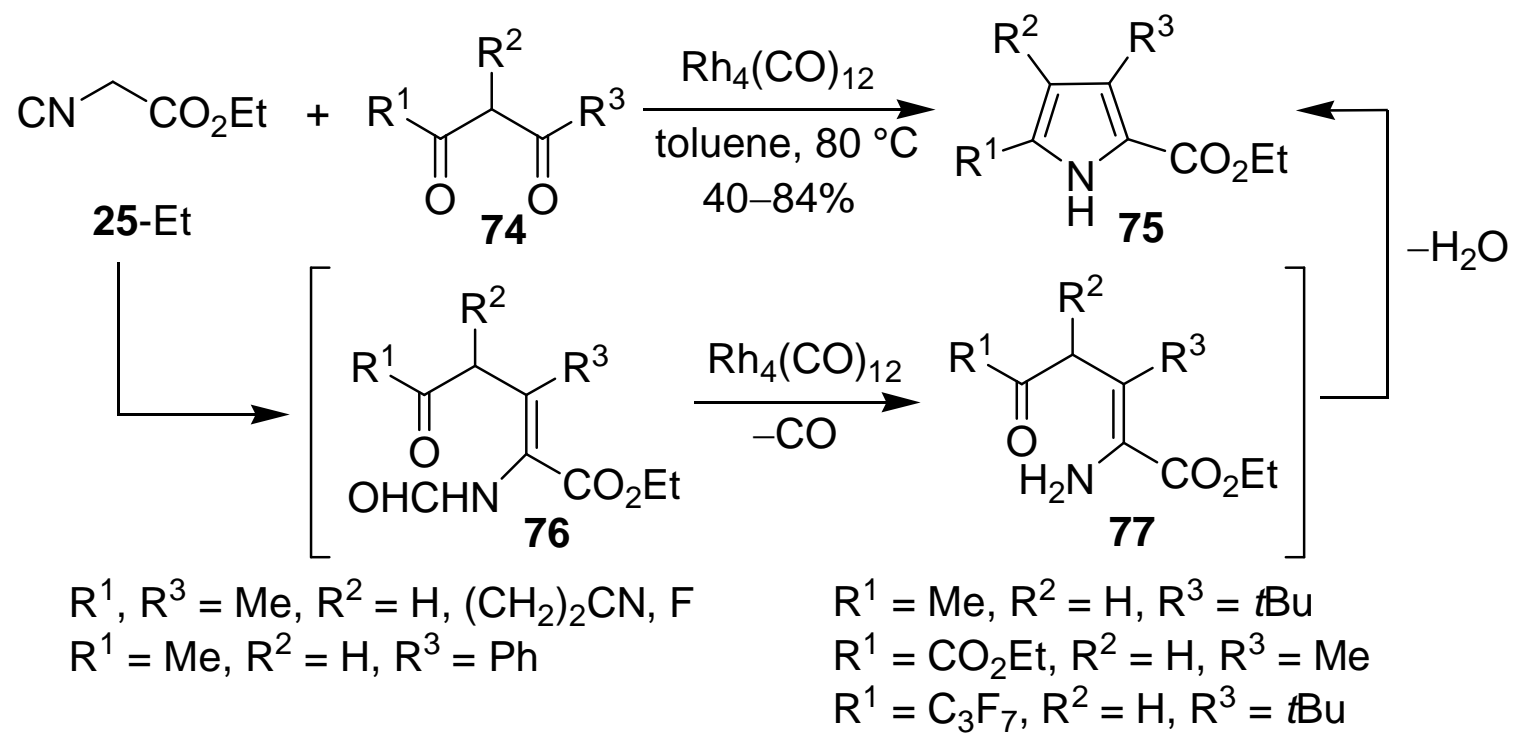

Scheme19. Synthesis of tetrasubstituted pyrroles $\mathbf{7 5}$ by a rhodium-catalyzed reaction of ethyl isocyanoacetate (25-Et) with 1,3-dicarbonyl compounds $\mathbf{7 4} .^{[54]}$ 
When 1,3-dicarbonyl compounds are used as substrates in the reaction with 25-Et, the rhodium-catalyzed decarbonylation of initially formed $\mathbf{7 6}$ was observed, and the amine $\mathbf{7 7}$ was formed, which is well set up to undergo cyclizing condensation to give the corresponding pyrrole 75. The cocyclocondensation of 25-Et with non-symmetric 1,3-dicarbonyl compounds $\left(\mathrm{R}^{1} \neq \mathrm{R}^{3}\right)$ leads to the corresponding pyrroles regioselectively when the substituents with essentially different steric or electronic demands were used.

\section{2. $\alpha$-Metallated ortho-Methylphenyl Isocyanides}

The second type of metallated isocyanides, widely used in organic synthesis, are substituted ortho-methylphenyl isocyanides. Ito, Saegusa et al. first achieved the smooth deprotonation of $o$-methylphenyl isocyanides $\mathbf{7 8}$ by means of lithium dialkylamides in diglyme and utilized the thus obtained lithiated isocyanides $\mathbf{7 9}$ in versatile syntheses of various substituted indoles (Scheme 20). ${ }^{[56]}$ When the reaction was carried out in THF or $\mathrm{Et}_{2} \mathrm{O}$, the addition of lithium dialkylamide onto the isocyano group became a competing process, decreasing the yield of indoles. An unsubstituted methyl group is lithiated selectively in the presence of a substituted one. $o$-Methylphenyl isocyanides with $\mathrm{R}^{2}=\mathrm{H}$ afforded the respective 3-unsubstituted indoles in high yields $(82-100 \%)$ when lithium diisopropylamide (LDA) was used as a base, whereas for isocyanides substituted at the benzylic positions, lithium 2,2,6,6-tetramethylpiperidide (LiTMP) was the base of choice to provide 3 -substituted indoles in good yields (62-95\%).

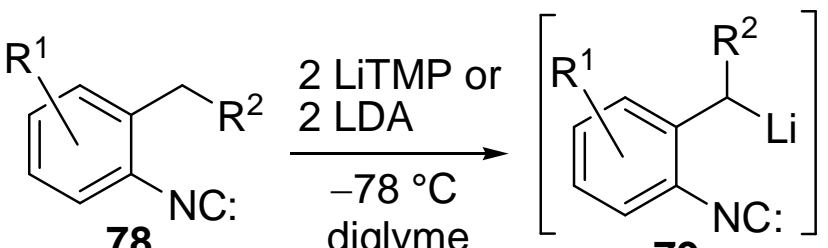

79

1) 2 LiTMP, $-78{ }^{\circ} \mathrm{C}$

2) $-78^{\circ} \mathrm{C}$ to r.t.<smiles>N#Cc1cccc2c1CCCC2</smiles>

81

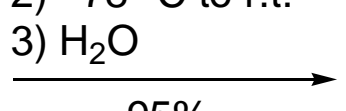

$95 \%$

Scheme 20. Synthesis of indoles via lithiated $o$-methylphenyl isocyanides $79 .{ }^{[56]}$ 
Using an excess of the base ( 2 equiv.) dramatically improved the yields of indoles which suggest, that the lithiation must be a reversible process. The tricyclic 1,3,4,5tetrahydrobenz[c,d]indole $\mathbf{8 2}$ was obtained when 5,6,7,8-tetrahydronaphthalen-1-yl isocyanide $\mathbf{8 1}$ was used as a starting material.

Different sequential reactions including the in situ modification of the $o$-methylphenyl isocyanides and employing different electrophiles have also been reported by the same authors. Thus, the cyclization of $\mathbf{7 9}$ at temperatures below $-25{ }^{\circ} \mathrm{C}$ followed by trapping of the reaction mixture with various electrophiles such as alkyl halides, acid chlorides trimethylsilyl chloride and epoxides provides $N$-substituted indoles 85 exclusively in moderate to good yields (Scheme 21$){ }^{[56 b]}$

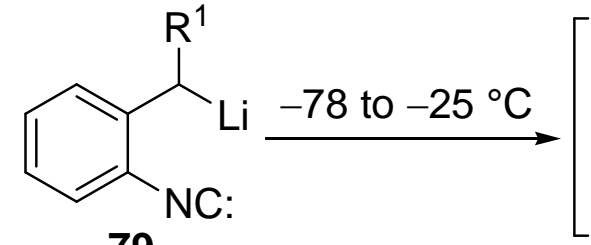

79<smiles>[R]C1C([Tl])=Nc2ccccc21</smiles>

83<smiles></smiles>

84

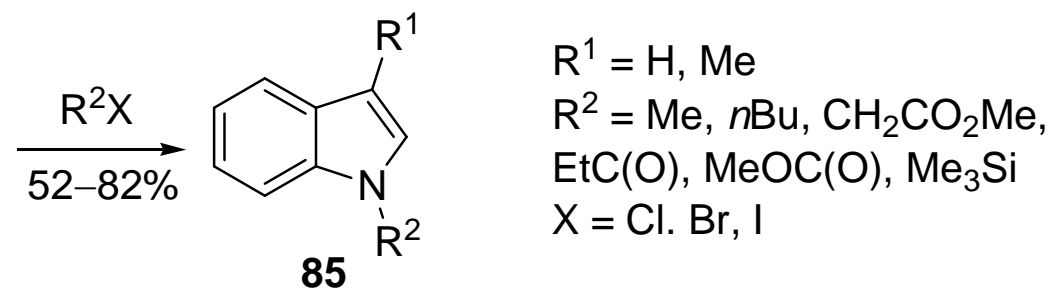

Scheme 21. Synthesis of 1,3-disubstituted indoles $\mathbf{8 5}$. $^{[56 \mathrm{~b}]}$

Ito, Saegusa et al. reported, that acceptor-substituted $o$-methylphenyl isocyanides can be conveniently converted into the corresponding 3-substituted indoles under $\mathrm{Cu}(\mathrm{I})$ catalysis (Scheme 22). ${ }^{[57,58]}$<smiles>C=Nc1ccccc1CC(C)=O</smiles>

86

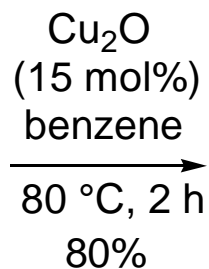

$80 \%$

Scheme 22. $\mathrm{Cu}_{2} \mathrm{O}$-catalyzed synthesis of 3 -acylindole $\mathbf{8 7} .{ }^{[57,58]}$ 
This method usefully supplements the approach to substituted indoles via lithiated $o$-methylphenyl isocyanides (vide supra). Thus, in the $\mathrm{Cu}_{2} \mathrm{O}$-catalyzed reaction some functional groups, such as keto carbonyl groups are tolerated (3-acylindoles of type 87, for example, could not be prepared by means of benzylic lithiation) ${ }^{[58]}$ while the base-mediated variant does not require acceptor substituents in the side chain of the aryl isocyanide. ${ }^{[56]}$ The key intermediate of this process is supposed to be an $\alpha$-coppersubstituted (acylmethyl) phenyl isocyanide, which undergoes an intramolecular insertion of the isocyano group into the newly formed $\mathrm{C}-\mathrm{Cu}$ bond to provide, after isomerization and protonation, indoles of type 87. The evidences for intermolecular insertions of isocyanides into copper(I) complexes of "active hydrogen" compounds like acetylacetone, malonates and others ${ }^{[59]}$ support this assumption.

$\alpha, \alpha$-Disubstituted $o$-methylphenyl isocyanides of type $\mathbf{8 8}$ in turn furnished the respective 3,3-disubstituted-3H-indoles 89 in moderate to high yields (Scheme 23). ${ }^{[57]}$

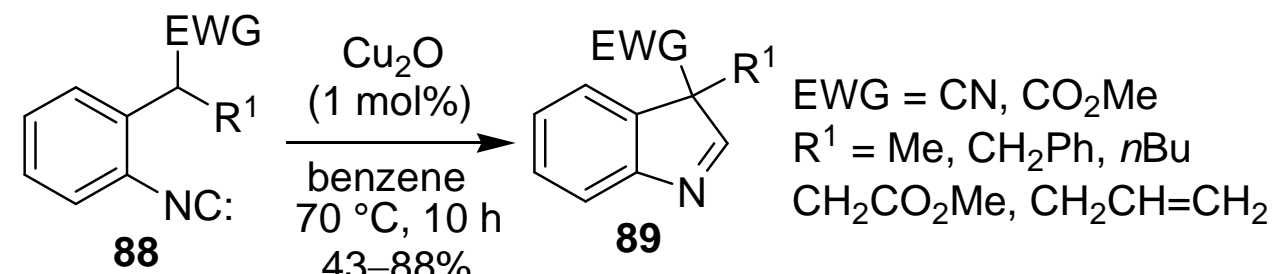

Scheme 23. Synthesis of 3,3-disubstituted $3 H$-indoles 89. ${ }^{[57]}$

Various substituted $o$-methylphenyl isocyanides could be prepared by alkylation of $o$-(lithiomethyl)phenyl isocyanides with alkyl halides and reactions with other electrophiles, such as epoxides, trimethylsilyl chloride, dimethyl disulfide, ${ }^{[56 \mathrm{~b}]}$ aldehydes (ketones), ${ }^{[60]}$ isocyanates and isothiocyanates, respectively. ${ }^{[61]}$ The corresponding adducts may be involved in subsequent base-promoted or $\mathrm{Cu}(\mathrm{I})$-catalyzed cyclizations to furnish indoles and other benzoannelated heterocycles. Thus, adducts of type $\mathbf{9 0}$ of reaction of $o$-(lithiomethyl)phenyl isocyanide (97) with isocyanates can undergo two types of $\mathrm{Cu}_{2} \mathrm{O}$ catalyzed cyclizations providing 3-substituted indoles 91, benzodiazepine-4-ones 92 or both of them depending on the substituents present (Scheme 24), while in a base-mediated cyclization of $N$-substituted $o$-(isocyanophenyl)acetamides 90 (and analogous thioacetamides), indoles of type 91 are obtained exclusively. ${ }^{[61]}$ 
<smiles>N#Cc1ccccc1CC(=O)Nc1ccccc1</smiles>

90

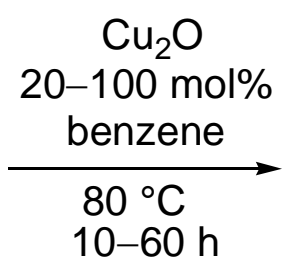

\begin{tabular}{ccc}
\hline $\mathrm{R}$ & $\mathbf{9 1}(\%)$ & $\mathbf{9 2}(\%)$ \\
\hline$n-\mathrm{C}_{4} \mathrm{H}_{9}$ & 0 & 85 \\
$c-\mathrm{C}_{6} \mathrm{H}_{11}$ & 25 & 58 \\
$t-\mathrm{C}_{4} \mathrm{H}_{9}$ & 20 & 0 \\
$\mathrm{Ph}$ & 75 & 0
\end{tabular}<smiles>NC(=O)c1c[nH]c2ccccc12</smiles>

91<smiles>[R]N1C=Nc2ccccc2CC1=O</smiles>

92

Scheme 24. $\mathrm{Cu}_{2} \mathrm{O}$-catalyzed cyclizations of $N$-substituted $o$-isocyanophenylacetamides 90. ${ }^{[61]}$

The reaction of $o$-(lithiomethyl)phenyl isocyanides 79 with aldehydes (ketones) at $-78{ }^{\circ} \mathrm{C}$, hydrolysis of the reaction mixture at the same temperature and subsequent $\mathrm{Cu}_{2} \mathrm{O}$-catalyzed cyclization of the respective isocyanoalcohols 93 prepared in this way, furnishes 4,5-dihydro-3,1-benzoxazepines 94 in high overall yields. An analogous cyclization of the adduct 95 of $o$-(lithiomethyl)phenyl isocyanide (97) with 1-butene epoxide leads to 4H-5,6-dihydro-3,1-benzoxacine 96 in $42 \%$ yield (Scheme 25). ${ }^{[60]}$

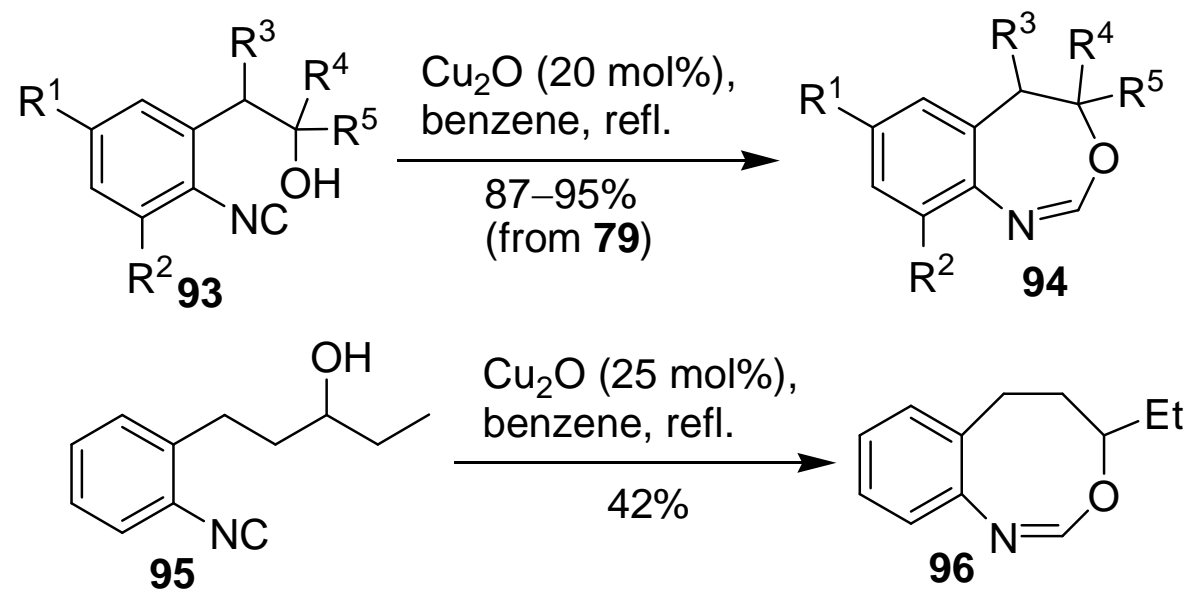

Scheme 25. Synthesis of 4,5-dihydro-3,1-benzoxazepines 94 and 4H-5,6-dihydro-3,1-benzoxacine $96 .{ }^{[60]}$ 
Substituted o-methylphenyl isocyanides prepared by functionalization of $o$-(lithiomethyl)phenyl isocyanide 97 can undergo hydrolysis to provide anilines, and subsequent cyclization of the latter by the reaction with an adjacent keto or ester group provides 2 -substituted indoles $\mathbf{9 9}^{[58]}$ or 1,3,4,5-tetrahydro- $2 H$-benzazepine-2-ones $\mathbf{1 0 1}$, respectively (Scheme 26). ${ }^{[62]}$ These representative examples show applications of isocyanides as masked amines.

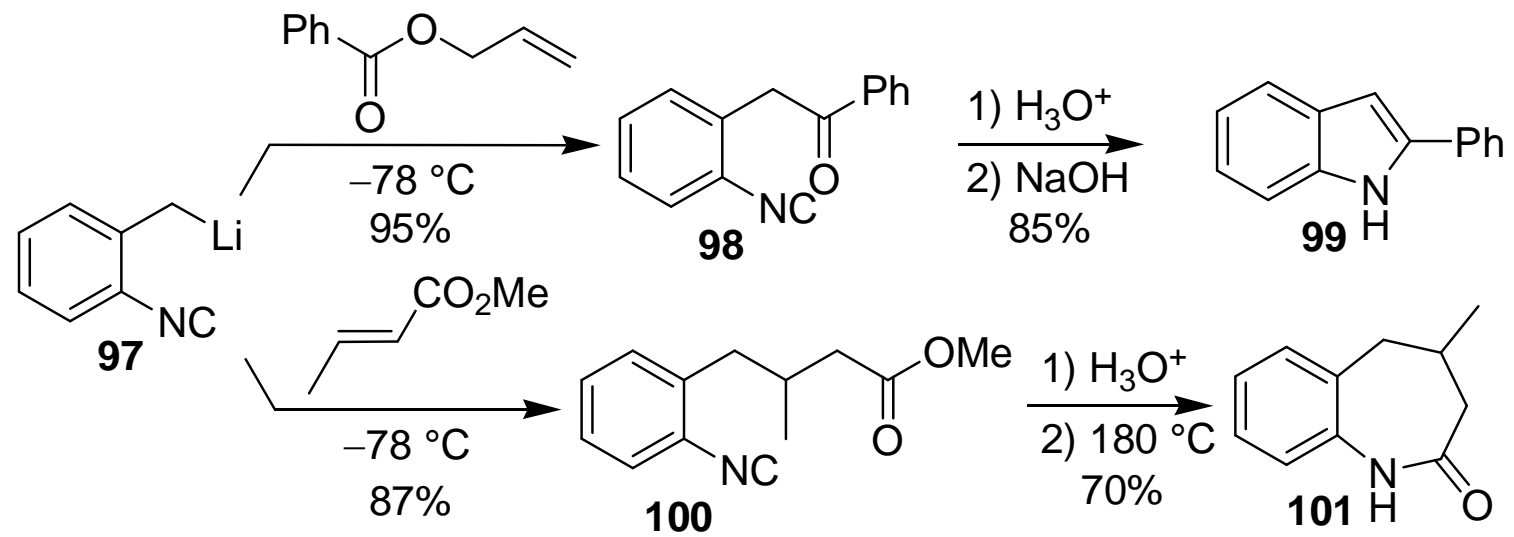

Scheme 26. Synthesis of indole 99 and cyclic amide 101 from $97 .{ }^{[58,52]}$

On the other hand, the adducts of $\mathbf{7 9}$ with aldehydes (ketones), isocyanoalcohols of type 93, have been reported to undergo a further Lewis-acid catalyzed rearrangement to $N$-formylindolines 103 (Scheme 27). ${ }^{[63]}$<smiles>[R7]c1cc([R2])c(N)c(C([R3])C([R7])(O)PCC(C)C)c1</smiles>

Scheme 27. Synthesis of $N$-formylindolines $\mathbf{1 0 3}$ by Lewis-acid catalyzed isomerization of isocyanoalcohol 93. ${ }^{[63]}$ 
The reaction is supposed to proceed with initial formation of the dihydro-3,1benzoxazepines 94 by Lewis acid-catalyzed insertion of the isocyano group into the $\mathrm{O}-\mathrm{H}$ linkage. This initial product undergoes heterolytic cycloreversion and re-cyclization of the zwitterionic intermediate of type 102 to yield the $N$-formylindolines 103. Dihydro-3,1benzoxazepines 94 prepared independently, in turn undergo the same Lewis-acid catalyzed rearrangement to provide $\mathbf{1 0 3}{ }^{[63]}$

An interesting precedent of a catalytic $\mathrm{C}, \mathrm{H}$-activation on 2,6-dimethylphenyl isocyanide (104) and some other similar aryl isocyanides by ruthenium complexes 106 and 107 leading to indoles $\mathbf{1 0 5}$ has been reported by Jones et al. ${ }^{[64]}$ along with interesting mechanistic investigations of this transformation. ${ }^{[64 b]}$ Unfortunately, this method implies harsh reaction conditions $\left(140^{\circ} \mathrm{C}, 94 \mathrm{~h}\right)$ and has only a very limited scope. Moreover, the thermal instability of $o$-methylphenyl isocyanides as well as (reversible) insertion of isocyanide into the $\mathrm{N}-\mathrm{H}$ bond of the newly formed indole molecule decreases the yields of final products and prolongs the reaction times. ${ }^{[64]}$<smiles>[C-]#[N+]c1c(C)cccc1C</smiles>

104

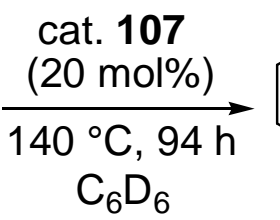

$70 \%$ (isolated yield)<smiles>Cc1cccc2cc[nH]c12</smiles>

105<smiles>[R][C@]1([2H])P(C)CC[P]1(C)C</smiles>
$106, \mathrm{R}=\mathrm{H}$ 107, $R=$ naphthyl

Scheme 28. A ruthenium-catalyzed formation of 7-methylindole 105. ${ }^{[64]}$

\subsection{Other Metallated Isocyanides}

Kobayashi et al. have reported on the synthesis of 4-hydroxyquinolines $\mathbf{1 1 0}$ by a magnesium bis(diisopropylamide)-induced cyclization of keto ester (or keto amide) 109. The latter is generated in situ by a Claisen-type condensation of ortho-isocyanobenzoate 108 with magnesium enolates of alkyl acetates or $N, N$-dimethylacetamide (Scheme 29). ${ }^{\text {[65] }}$ On the other hand, 2-(2-isocyanophenyl)acetaldehyde dimethyl acetals of type 111 upon treatment with an excess of LDA at $-78{ }^{\circ} \mathrm{C}$ in diglyme furnish 3-methoxyquinolines 112 in good to high yields (Scheme 30). ${ }^{[66]}$ The intermediate lithiated isocyanide 114 is believed to arise by deprotonation of $\mathbf{1 1 1}$ at the benzylic position, subsequent elimination 
of lithium methoxide to give the corresponding $o$-isocyano- $\beta$-methoxystyrene $\mathbf{1 1 3}$ followed by lithiation of the latter at the $\beta$-position.
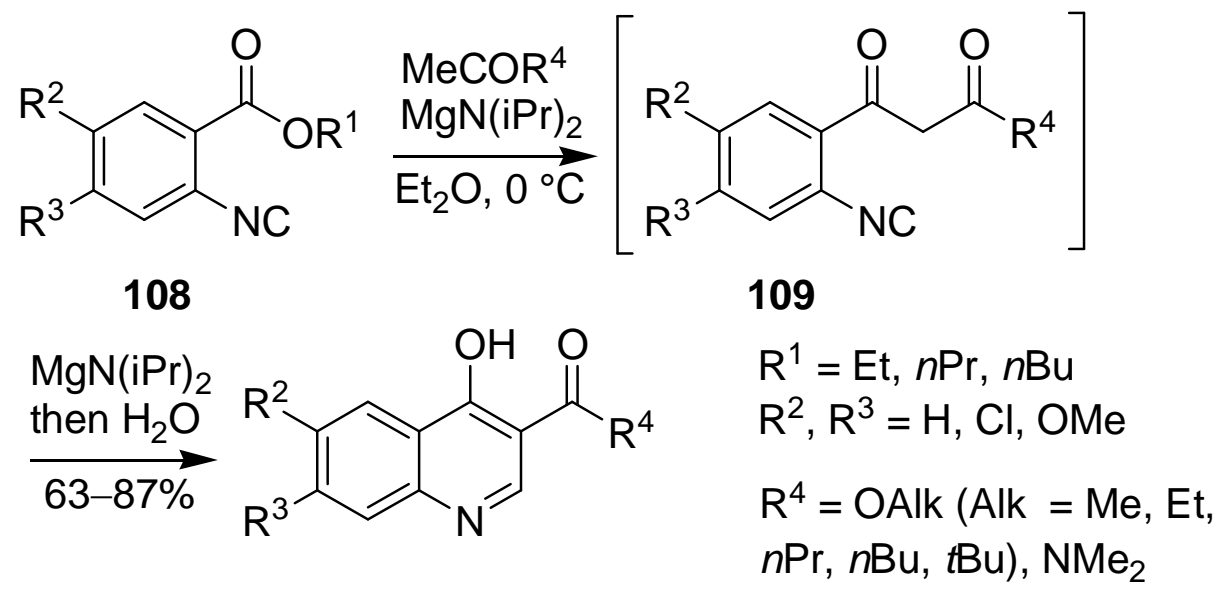

110

Scheme 29. Synthesis of 4-hydroxy-3-quinolinecarboxylic acid derivatives 110. ${ }^{[65]}$

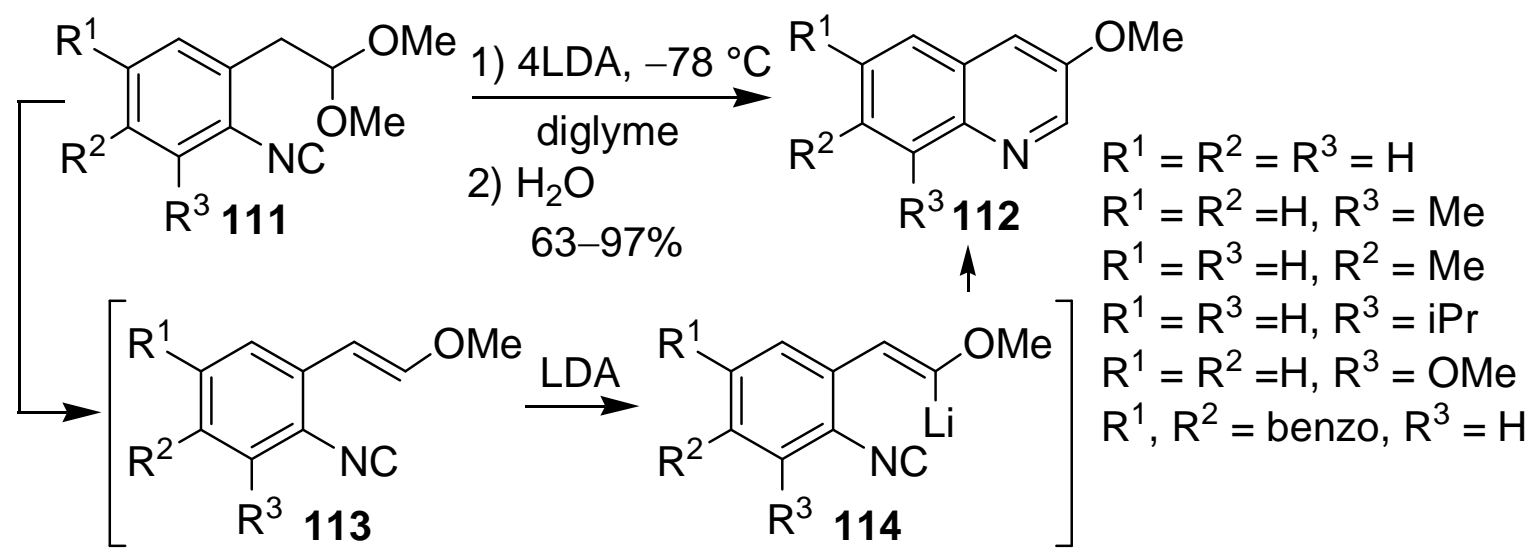

Scheme 30. Synthesis of 3-methoxyquinolines 112. ${ }^{[66]}$

\section{Addition to the Isocyano Group Followed by a Cyclization}

\subsection{Non-Catalyzed Processes.}

Organolithium $^{[67]}$ as well as organomagnesium ${ }^{[68]}$ reagents have been shown to undergo $\alpha$-addition to isocyanides to provide metalloaldimines, which can undergo cyclizations to give the corresponding $N$-heterocycles if there is an appropriate adjacent functional group. Thus, the addition of $t \mathrm{BuLi}$ to phenyl isocyanide (115) followed by a directed ortho-lithiation assisted by TMEDA has been reported to lead to the formation of the 
dilithiated aldimine 116, which in turn can be trapped with various elementchlorides to provide various benzazoles 117 in moderate yields (Scheme 31). ${ }^{[69]}$

1) 2 tBuLi<smiles>CN(C)c1ccccc1</smiles>

115 $\underset{\text { 2) TMEDA }}{\stackrel{\mathrm{Et}_{2} \mathrm{O},-78^{\circ} \mathrm{C}}{\longrightarrow}}$

r.t.<smiles>CC(C)(C)/C(Cl)=N/c1ccccc1Cl</smiles>

$\underset{0^{\circ} \mathrm{C} \text { to r.t. }}{\stackrel{\mathrm{MCl}_{2}}{\longrightarrow}}$ $37-68 \%$<smiles>CC(C)c1nc2ccccc2[nH]1</smiles>

117

$$
\mathrm{M}=\mathrm{S}, \mathrm{R}_{2} \mathrm{Si}, \mathrm{R}_{2} \mathrm{Ge} \text {, }
$$

$\mathrm{R}_{2} \mathrm{Sn}, \mathrm{RP}, \mathrm{RAs}$

Scheme 31. Addition of $t \mathrm{BuLi} /$ ortho-lithiation of phenyl isocyanide (115). Synthesis of benzoannelated azoles $117{ }^{[69]}$

Using an excess of the bulky $t \operatorname{BuLi}$ ( 2 equiv.) and adding the isocyanide to the organolithium reagent has been found to be crucial for the effective formation of $\mathbf{1 1 7}$. The resulting conventional benzazoles (benzothiazoles) as well as some unusual benzazoles (e. g. benzoazosiloles, benzoazogermoles etc.) have been investigated and compared from the viewpoint of their possible aromaticity. ${ }^{[69]}$

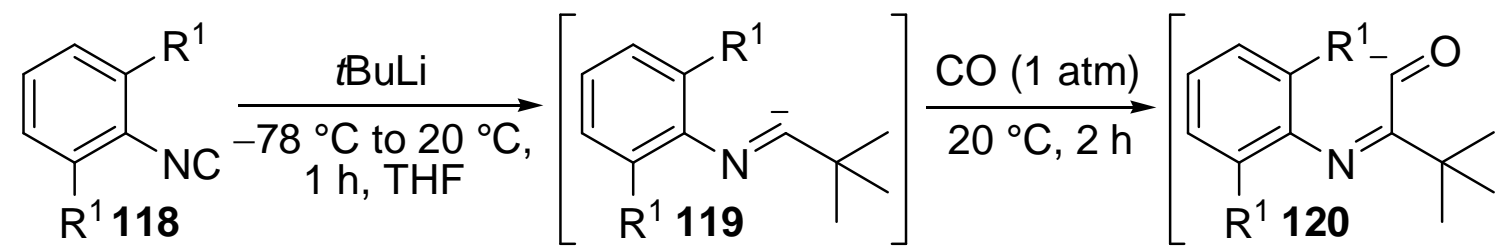
$\mathrm{R}^{1}=\mathrm{Me}, \mathrm{Et}, \mathrm{iPr}$<smiles>[R7]C1=CC=CC([R7])C1=NC(=O)C(C)(C)C</smiles><smiles>[R12]C1=CC=CC2([R7])C1=NC(C(C)(C)C)=C2[O-]</smiles><smiles>[R16]C1=CC=CC2([R17])C(=O)C(C(C)(C)C)=NC12</smiles><smiles>[R12]c1cccc2c1N=C(C(C)(C)C)C2([R7])[2H]</smiles>

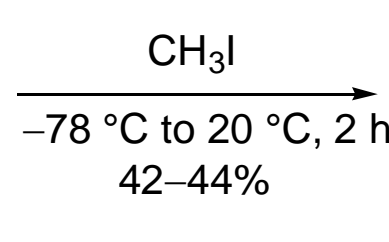<smiles>[R16]c1cccc2c1N=C(C([R])(C)C)C2([R])OC</smiles>

Scheme 32. Synthesis of $3 H$-indoles $125 .{ }^{\text {[70] }}$ 
To avoid possible ortho-metallation after the addition of $t \mathrm{BuLi}$ onto the isocyano group, Murai et al. have used 2,6-dialkylphenyl isocyanides 118. The resulting deprotonated aldimines 119 have been trapped with carbon monoxide to induce a complicated cascade of transformations leading, after treatment with methyl iodide, to $3 H$-indoles $125 .{ }^{[70]}$ The proposed mechanism starts with the formation of the aforementioned lithioaldimine 119, which is transformed to the reactive acyllithium intermediate 120, upon treatment with CO. The formation of the non-aromatic ketene $\mathbf{1 2 1}$ followed by a cyclization to alcoholate $\mathbf{1 2 2}$, its tautomerization to the ketone $\mathbf{1 2 3}$ and final alkyl group migration afford the deprotonated $3 H$-indole $\mathbf{1 2 4}$, which reacts with methyl iodide to finally give the isolated 3-methoxy-3H-indole 125 (Scheme 32). ${ }^{[70]}$

A convenient and efficient synthesis of 2,3-disubstituted quinolines $\mathbf{1 2 7}$ by the reaction of nucleophiles such as alcohols, amines and sodium enolate of diethylmalonate with ortho-alkynylphenyl isocyanides $\mathbf{1 2 6}$ has been reported by Ito et al. (Scheme 33). ${ }^{[71]} \mathrm{A}$ related diethylamine-induced 6-endo-dig cyclization of $o$-isocyanobenzonitrile $\mathbf{1 2 8}$ afforded 2-diethylaminoquinazoline 129 in quantitative yield (Scheme 33).<smiles>Cc1ccccc1C#CF</smiles>
126 NC

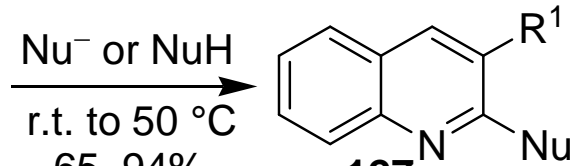
$\mathrm{R}^{1}=\mathrm{SiMe}_{3}, \mathrm{Bu}, \mathrm{cHex}$, $\mathrm{CH}_{2} \mathrm{OMe}$, Ph, 1-c-hexenyl $\mathrm{Nu}=\mathrm{OMe}, \mathrm{NEt}_{2}$ $\mathrm{CH}\left(\mathrm{CO}_{2} \mathrm{Et}\right)$<smiles>N#Cc1ccccc1N</smiles>

128

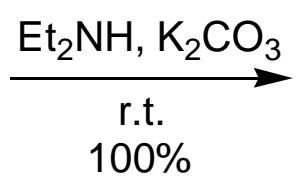
$100 \%$<smiles>CCNc1ncc2ccccc2n1</smiles>

Scheme 33. Synthesis of 2,3-disubstituted quinolines 127 and 2-diethylaminoquinazoline 129. ${ }^{\text {[71] }}$

In the crucial step of both of these processes, the imidoyl anion, initially formed after the addition of a nucleophile onto the isocyano group, is supposed to undergo a $6 \pi$-electrocyclization, subsequent isomerization and protonation to give 127 or $129 .{ }^{[71]}$ Known reactions of other potential precursors of heterocycles, 1,2-diisocyanoarenes $\mathbf{1 3 0}$, with nucleophiles are limited to that with Grignard reagents. Quinoxaline oligo- and 
polymers 131 (Scheme 34) with different order of polymerization depending on the substituents, isolated after hydrolysis of the reaction mixture of such 1,2-diisocyanoarenes with alkylmagnesium bromides, apparently arise from successive insertion of isocyano groups into magnesium-carbon bonds. ${ }^{[72]}$

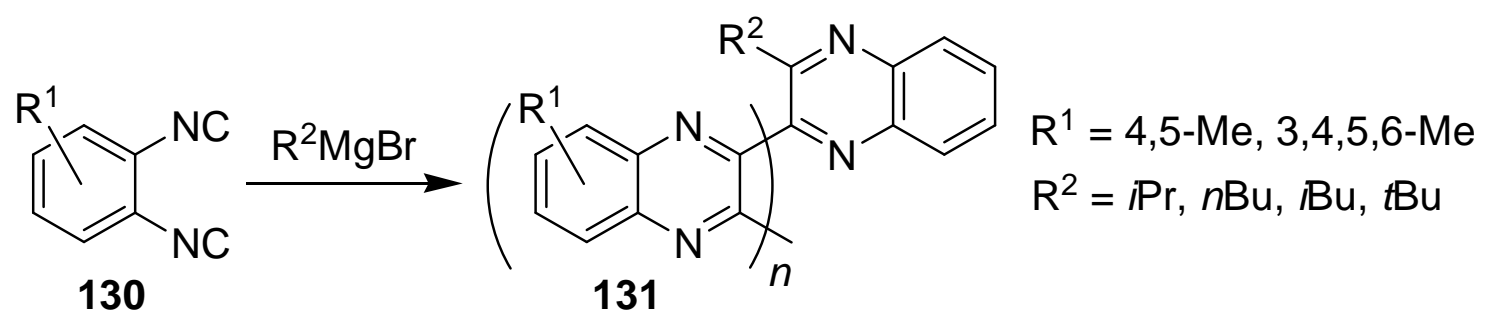

Scheme 34. Oligomerization of 1,2-diisocyanoarenes (130) by treatment with Grignard reagents. $^{[72]}$

Kobayashi et al. have shown, that $o$-isocyano- $\beta$-methoxystyrenes such as $\mathbf{1 3 2}$ can be employed in the synthesis of 2,4-disubstituted quinolines 135 (Scheme 35). ${ }^{\text {73 }]}$ Organolithium reagents, lithium dialkylamides and lithium thiophenolate undergo an $\alpha$-addition onto the isocyano group to provide the imidoyl anion 133, which after a cyclization and subsequent elimination of methoxide, gives quinolines $\mathbf{1 3 5}$ in low to high yields.
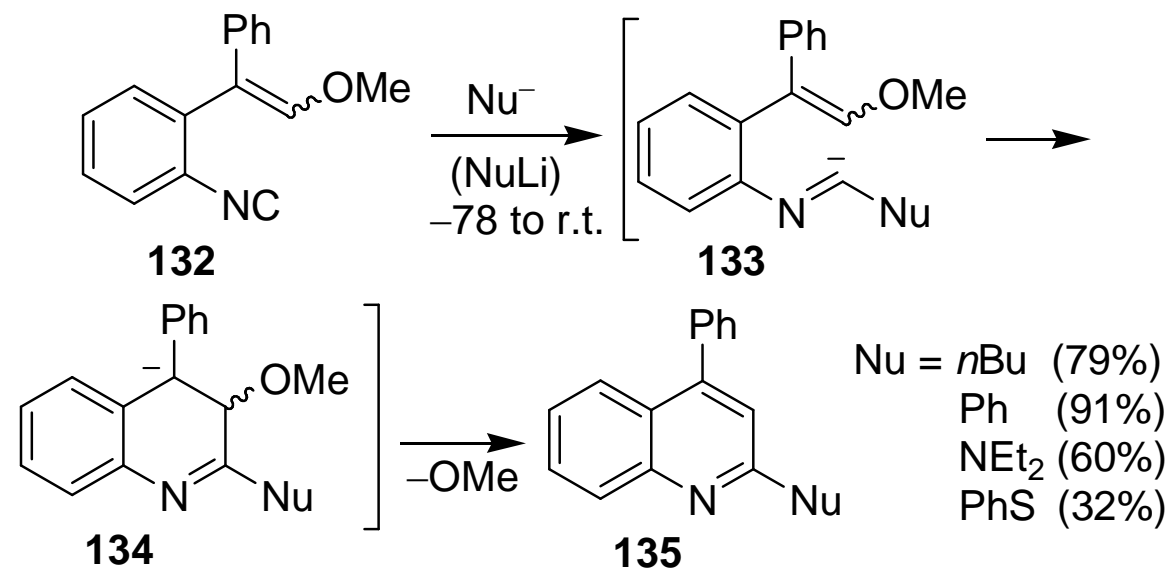

Scheme 35. Synthesis of quinolines 135 by addition of nucleophiles to $o$-isocyano $\beta$-methoxystyrenes 132. ${ }^{[73]}$ 
Independently, Ichikawa et al. have reported on a similar reaction of organometallic reagents with $\beta, \beta$-difluoro-o-isocyanostyrene (136) leading to 2-substituted 3-fluoroquinolines (137) by 6-endo-trig cyclization of initially formed acyllithium

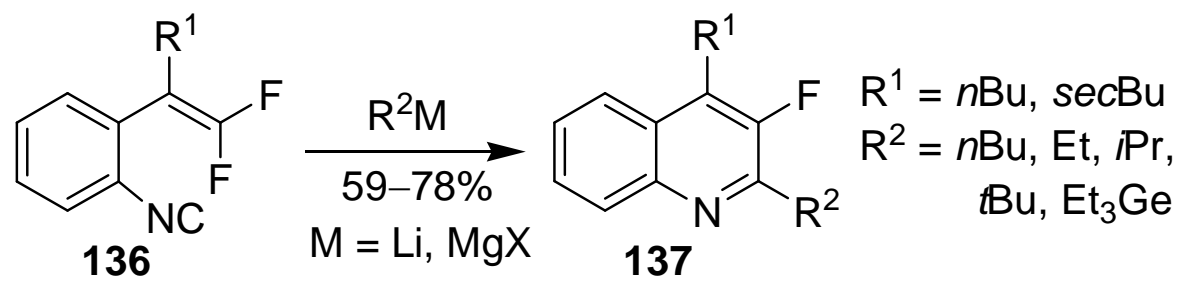

Scheme 36. Synthesis of 2,3,4-trisubstituted quinolines $\mathbf{1 3 7}$ by reaction of organometallic reagents with $\beta, \beta$-difluoro- $o$-isocyanostyrenes $\mathbf{1 3 6}{ }^{[74,75]}$

intermediates with elimination of a fluoride anion (Scheme 36). ${ }^{[74]} n \mathrm{BuLi}$ reacts to give a complicated mixture of products, whereas sterically encumbered $t \mathrm{BuLi}$ leads to the formation of the corresponding quinoline in $78 \%$ yield. Alkylmagnesium reagents less reactive than alkyllithiums, have also been successfully employed in this reaction as well as triethylgermyl- and tributylstannyllithium. ${ }^{[75]}$

Isocyanides have been known to react with acyl halides to provide the corresponding $\alpha$-keto imidoylhalides. The products of these insertions such as $\mathbf{1 3 9}$ derived from 2-phenylethyl isocyanides of type 138 have been reported to undergo subsequent $\operatorname{Ag}(\mathrm{I})$-mediated cyclizations to form 1-acyl-3,4-dihydroisoquinolines 141 in moderate to good yields (Scheme 37). ${ }^{[76]}$ The authors suggest, though without any evidence, that transient acylnitrilium cations of type $\mathbf{1 4 0}$ are intermediates in these reactions under ionizing conditions (Ag salts) while in the presence of Lewis $\left(\mathrm{SnCl}_{4}\right)$ or Brønsted acids $\left(\mathrm{CF}_{3} \mathrm{SO}_{3} \mathrm{H}\right)$, the corresponding protonated or coordinated halo iminium derivatives 139 play the same role. Apart from dihydroisoquinolines obtained by this method, the furanand indole-annelated products of type 142 and 143 (Scheme 37) have been synthesized in the same manner in good yields. The generality of this method and very mild conditions make it a useful supplement to the classical Bischler-Napiralski synthesis of 3,4-dihydroisoquinolines and the respective isoquinolines. Compound 144 with the skeleton of the alkaloid erythrinane has been also conveniently prepared in a two-step onepot procedure from the 3,4-dihydroisoquinoline of type 141. ${ }^{[76 \mathrm{~b}]}$ 


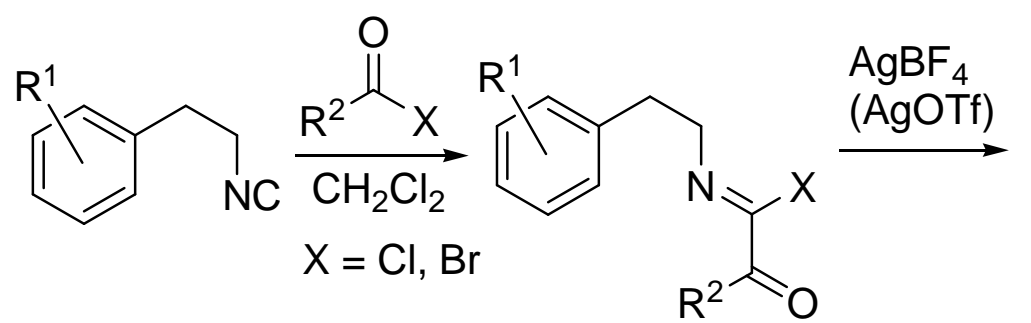

138

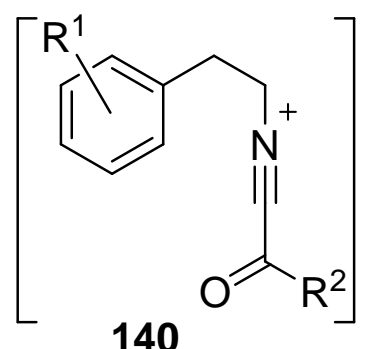
140<smiles>[R]C(=O)C1=NCCc2occc21</smiles>

142<smiles>[R]C(=O)C1=NCCc2c1n(C(=O)OC)c1ccccc21</smiles>

143 139<smiles>[R7]C(=O)C1=NCCc2cc([R17]([H])([H])[H])ccc21</smiles><smiles>COc1cc2c(cc1OC)[C@]1(N3CCCCC3)C(=O)CCCC1CC2</smiles>

144

Scheme 37. $\operatorname{Ag}(\mathrm{I})$-mediated cyclization of 2-ethylphenyl isocyanides $\mathbf{1 3 8} .^{[76]}$

3,4-Donor-disubstituted 3-phenylpropyl isocyanides of type $\mathbf{1 4 5}$ which are homologous to the previously discussed isocyanides $\mathbf{1 3 8}$, also smoothly undergo addition of an acid chloride with subsequent $\mathrm{Ag}(\mathrm{I})$-promoted cyclization to furnish 2-acylbenzazepines 146 (Scheme 38, eq. (1)). ${ }^{[77]}$ However, similar isocyanides of type 147 with another substitution pattern, instead of forming products of type 146, tend to undergo spiroannelation of the corresponding intermediate imidoyl chlorides to give, after in situ desilylation and tautomerization, spirocyclic $\Delta^{1}$-piperidienes 148 exclusively in good yields (Scheme 38, eq. (2)). ${ }^{[77,78]}$

Similarly, the addition of the acyl chloride $\mathbf{1 5 0}$ onto the isocyano group of the isocyano silylenolate 149, subsequent $\mathrm{AgBF}_{4}$-mediated cyclization of the corresponding intermediate and final deprotection of the tert-butyldimethylsilyl ether provide the 2-acyl $\Delta^{2}$-pyrroline 151, a key intermediate in a total synthesis of the alkaloid ( \pm )-dendrobine (152) reported by Livingouse et al. (Scheme 39). ${ }^{[79]}$ Some other unactivated alkenes have later also been employed in this $\mathrm{Ag}(\mathrm{I})$-mediated cyclization to provide the respective 3,4-dihydro-2 $\mathrm{H}$-pyrroles or 3,4,5,6-tetrahydropyridines in moderate to good yields. ${ }^{[80,81]}$ 


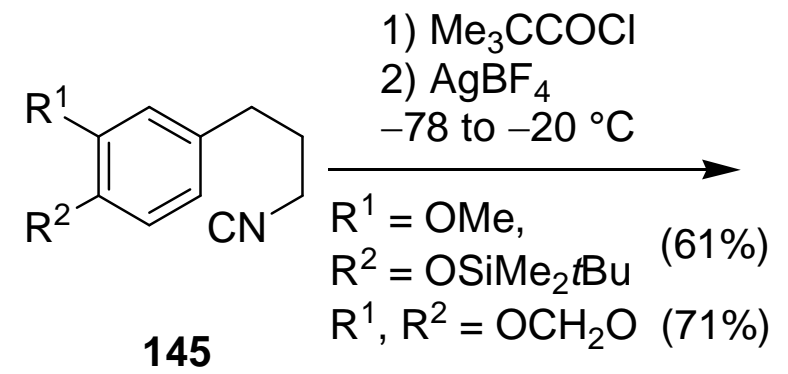<smiles>[R]c1cc2c(cc1[R])C(C(=O)C(C)(C)C)=NCCC2</smiles>

146<smiles>[R16]C(=O)C1=NCCCC12C=CC(=O)C=C2OC</smiles>

Scheme 38. Cyclizations of arylisocyanopropanes 145 and $147 .{ }^{[77,78]}$<smiles></smiles>

149<smiles>COC(=O)C=C(C(=O)Cl)C(C)C</smiles>

$88 \%$

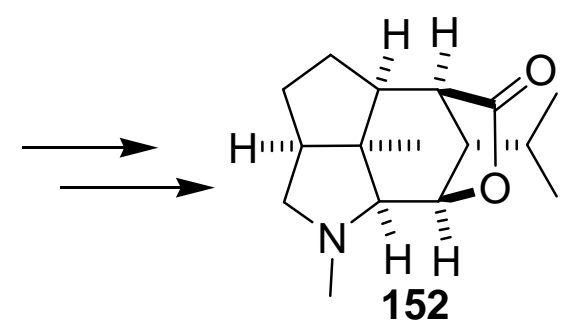

$( \pm)$-dendrobine

Scheme 39. Synthesis of 2-acyl $\Delta^{2}$-pyrroline 151, an intermediate in the total synthesis of ( \pm )-dendrobine 152. ${ }^{[79]}$

Similarly to acid chlorides, arylsulfenyl chlorides ( $\mathrm{ArSCl})$ react with isocyanides leading to unstable $N$-alkoxycarbonyl- $S$-arylisothiocarbamoyl chlorides such as $\mathbf{1 5 3}$, which are capable of further cyclization if an appropriate adjacent functionality is present. Thus, the adducts of isocyanides $\mathbf{1 5 6}$ with ester or amide moieties have been shown to undergo subsequent cyclizations to 2-arylthio-5-alkoxyoxazoles $154^{[82]}$ and 3-alkyl-2-arylthio-1,3- 
diazolium-4-olates 155, ${ }^{[83]}$ respectively, upon treatment with triethylamine (Scheme 40). Similarly, dichlorosulfane $\mathrm{SCl}_{2}$ reacts with two equivalents of the isocyanide 156 to provide, after amine-induced cyclization, the corresponding 2,2'-bis(oxazolyl)sulfide. ${ }^{[84]}$ The reaction of ethyl isocyanoacetate with dichlorodisulfane $\mathrm{S}_{2} \mathrm{Cl}_{2}$ unexpectedly led to the formation of thiazolo[5,4-d]thiazole-2,5-dicarboxylate 157 (Scheme 40). ${ }^{[84]}$ The mechanism of this complex transformation proposed by the authors (not presented here) includes cleavage of the S-S bond at an early stage followed by a cascade of further transformations. ${ }^{[85]}$

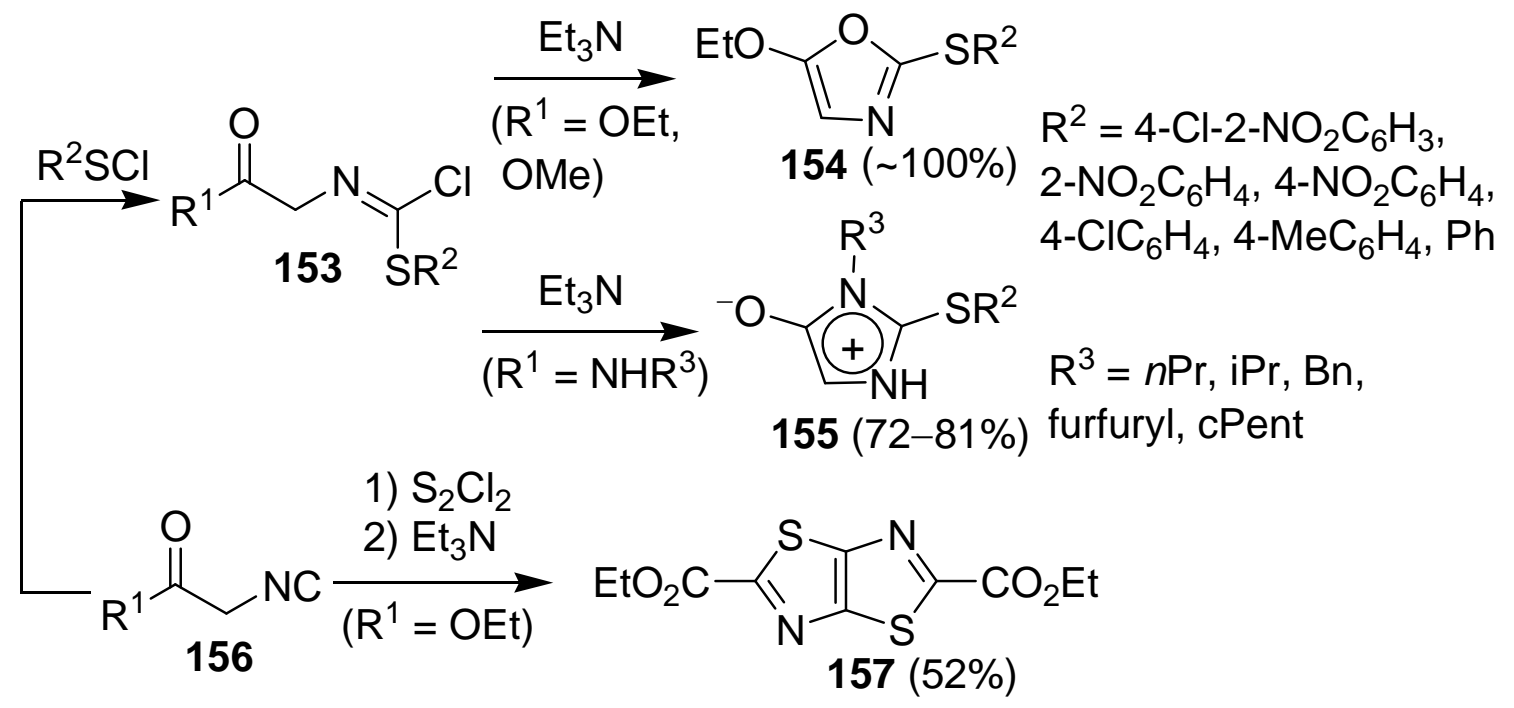

Scheme 40. Reactions of isocyanides $\mathbf{1 5 6}$ with arylsulfenyl chlorides and dichlorodisulfane followed by $\mathrm{Et}_{3} \mathrm{~N}$-induced cyclizations. ${ }^{[82,83,84]}$

\subsection{Transition Metal-Catalyzed Processes}

Aryl isocyanides have been shown to react with selenium to form isoselenocyanates. ${ }^{[86]}$ The same reaction with alkyl isocyanides in the presence of a base followed by reactions of these isoselenocyanates with amines or alcohols to give selenoureas or selenocarbamates, respectively, has also been reported. ${ }^{[87]}$ With $o$-halophenyl isocyanides $\mathbf{1 5 9}$ as substrates in this reaction, the resulting selenocarbamates $\mathbf{1 5 8}$ have been efficiently transformed into the corresponding benzoselenazoles 160 in a CuI-catalyzed one-pot process. ${ }^{[88]}$ Secondary alkyl- and arylamines, $n$-butylamine as well as imidazole were converted into the respective 2-substituted benzoselenazoles $\mathbf{1 6 0}$ in high yields (Scheme 41, eq. (1)). 
When alcohols or thiols were used instead of amines, 2-oxy- or 2-thiabenzoselenazoles (161) were obtained in high yields under essentially the same conditions as previously, but without a base. Aliphatic alcohols and phenols with electron-donating substituents gave remarkably higher yields than 4-methoxycarbonylphenol (48\%), while all tested thiols, both aromatic and aliphatic, provided the corresponding products 161 in high yields (Scheme 41, eq. (2)). ${ }^{[88]}$

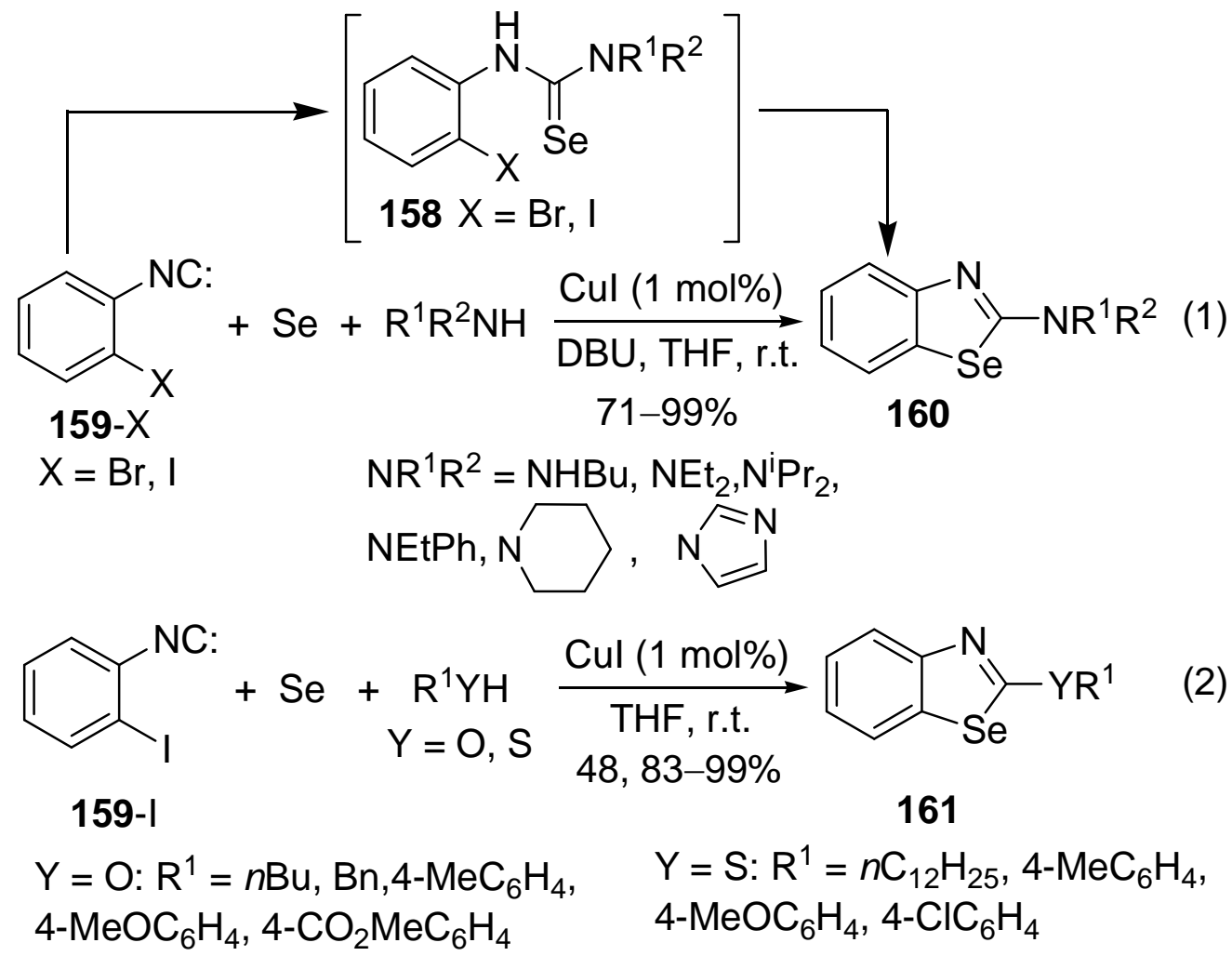

Scheme 41. Copper(I)-catalyzed synthesis of benzoselenazoles 160 and $161 .^{[88]}$

Further investigations revealed, that ortho-bromophenyl isocyanide $(159-\mathrm{Br})$ can form 2-aminobenzoselenazoles 160 even without a copper catalyst, though the reaction proceeds more slowly and only at elevated temperature $\left(100{ }^{\circ} \mathrm{C}\right)$, but 160 wasformed even at ambient temperature from the ortho-iodophenyl isocyanide 159-I. This led the authors to propose that mechanistically, the cyclization might proceed through an intramolecular nucleophilic aromatic substitution of the initially formed selenolate $\mathbf{1 6 2}$ via an intermediate of type 163. As the role of copper in facilitating this process remains unclear, the possibility of an alternative route including a copper-catalyzed cross-coupling reaction via intermediates of type 164 should not be ruled out either. ${ }^{[8]}$ 


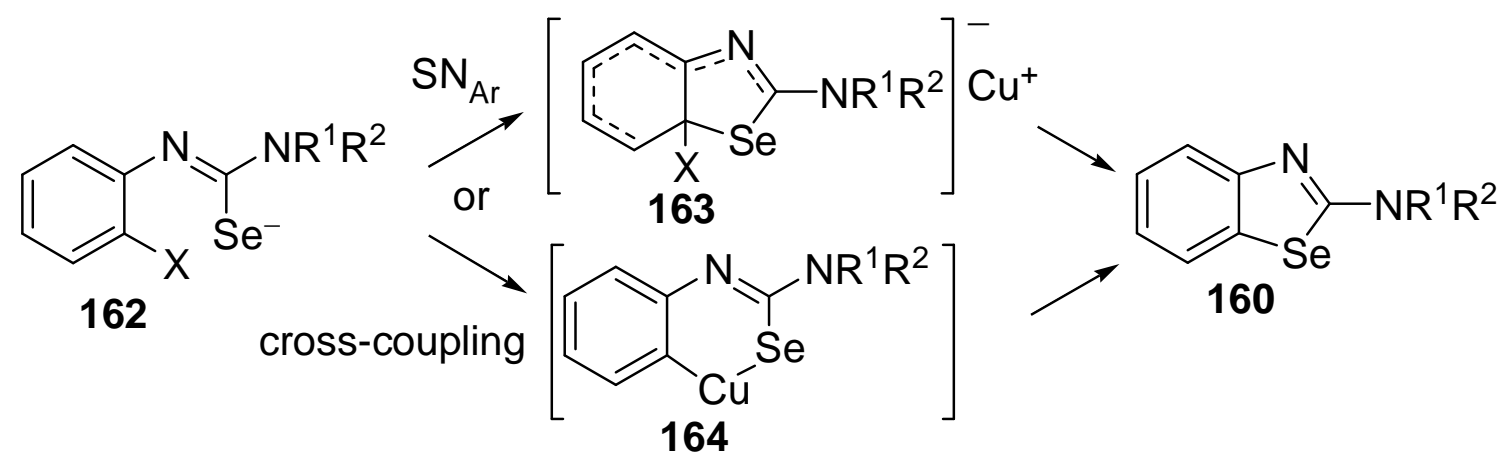

Scheme 42. Proposed mechanisms for the formation of benzoselenazoles $160{ }^{[89]}$

The same authors have also extended their earlier developed tellurium-assisted imidoylation of amines with isocyanides ${ }^{[90]}$ and used the thus formed intermediates 165 in a copper(I)-catalyzed one-pot synthesis of 2-amino-1,3-benzotellurazoles $\mathbf{1 6 6}$ (Scheme 43). ${ }^{[88]}$

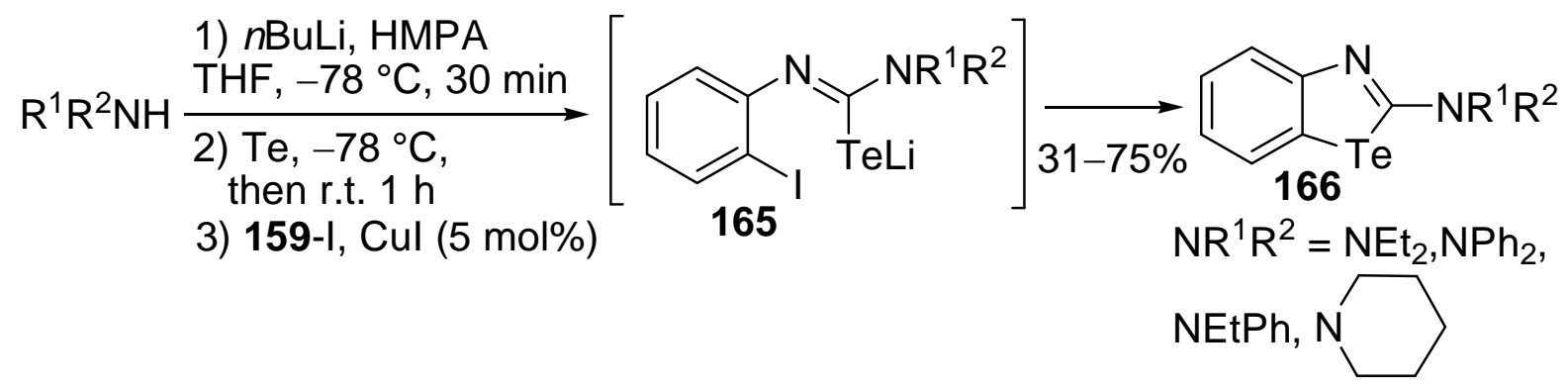

Scheme 43. The synthesis of benzotellurazoles $166 .^{[88]}$ 


\section{Goals of this Study}

Critical analysis of the relevant literature revealed, that although a plethora of useful processes, for the construction of nitrogen heterocycles from isocyanides are known, there are still a lot of gaps to be filled. Particularly, the metal-catalyzed processes still remain limited, although evident interest of researchers has recently been devoted to this topic. Thus, three different directions of research work have been chosen after the first promising experimental tests confirming some theoretical suppositions:

1) Synthesis of substituted pyrroles:

- Further elaboration of a pyrrole synthesis from substituted methyl isocyanides and acetylenes previously developed in our group. An extensive study of the scope and the limitations of this method as well as an investigation of the mechanism of the copper-catalyzed reaction

- Extension of this method to the use of terminal unactivated acetylenes for the synthesis of pyrroles

2) Chemistry of ortho-metallated aryl isocyanides:

- Development of methods for generating ortho-metallated phenyl isocyanide and its heteroanalogues as novel building blocks with a potentially broad scope of synthetic applications

- Investigation of the reactions of ortho-lithiophenyl isocyanide with various isocyanates (isothiocyanates) focusing on the synthesis of pharmaceutically relevant heterocycles and naturally occurring alkaloids

- Investigation of the reactions of ortho-lithiophenyl isocyanide with various carbonyl compounds focusing on the synthesis of heterocycles

3) Synthesis of benzimidazoles:

- Development of an efficient (catalytic) approach to substituted benzimidazoles and related heterocycles by the reaction of ortho-haloaryl isocyanides with primary amines 


\section{B. Main Part}

\section{Oligosubstituted Pyrroles Directly from Substituted Methyl Isocyanides and Acetylenes ${ }^{91}$}

\section{Background and Preliminary Considerations}

Oligofunctional pyrroles play a pivotal role among five-membered heterocycles, being basic constituents of numerous natural products, ${ }^{[92]}$ potent pharmaceuticals, ${ }^{[93]}$ molecular sensors and other devices. ${ }^{[94]}$ Therefore, considerable attention has been paid to develop efficient general methods for the synthesis of pyrroles, ${ }^{[95]}$ and in recent years, their amount has been significantly extended. ${ }^{[96]}$ Some methods of pyrrole synthesis such as Barton$\operatorname{Zard}^{[16]}$ and van Leussen ${ }^{[32]}$ syntheses (vide supra) are based on isocyanides. Among them, the addition of isocyanides 63 onto the triple bond of acetylenes 64 developed by Yamamoto et al. ${ }^{[50]}$ and de Meijere et al. ${ }^{[51]}$ is the most direct and therefore one of the most promising (see Scheme 16 in Introduction).

Various 2,3,4-trisubstituted pyrroles 65, bearing sulfonyl, dialkoxyphosphoryl, trifluoromethyl, cyano and secondary amino groups have been previously prepared in one step from readily available acetylenes and acceptor-substituted methyl isocyanides. ${ }^{[51]}$ As a continuation of the work started in our group by O. Larionov, the scope and limitations of this pyrrole synthesis were systematically investigated focusing on the copper-catalyzed variant. Terminal acceptor-substituted acetylenes have not been employed in this reaction so far as well as both teminal and internal unactivated acetylenes. This provided a challenge for a further development of this direct pyrrole synthesis.

\section{Synthesis of 2,3,4-Trisubstituted and 2,4-Disubstituted Pyrroles}

In this study, particular attention has been paid to aryl and hetaryl-substituted acceptor acetylenes 64, as only a few examples of such compounds have been employed earlier. The substituted methyl propiolates $\mathbf{1 6 8}$ have been routinely prepared from the corresponding terminal acetylenes 167 by lithiation with $n \mathrm{BuLi}$ followed by a reaction with methyl chloroformate (Scheme 44). The thienyl-derivative $\mathbf{1 6 8 g}$ was prepared according to a literature procedure from thiophene and tetrachlorocyclopropane $\mathbf{1 6 9}$ (Scheme 44). This interesting one-pot transformation furnished $\mathbf{1 6 8 g}$ in $95 \%$ overall yield. 

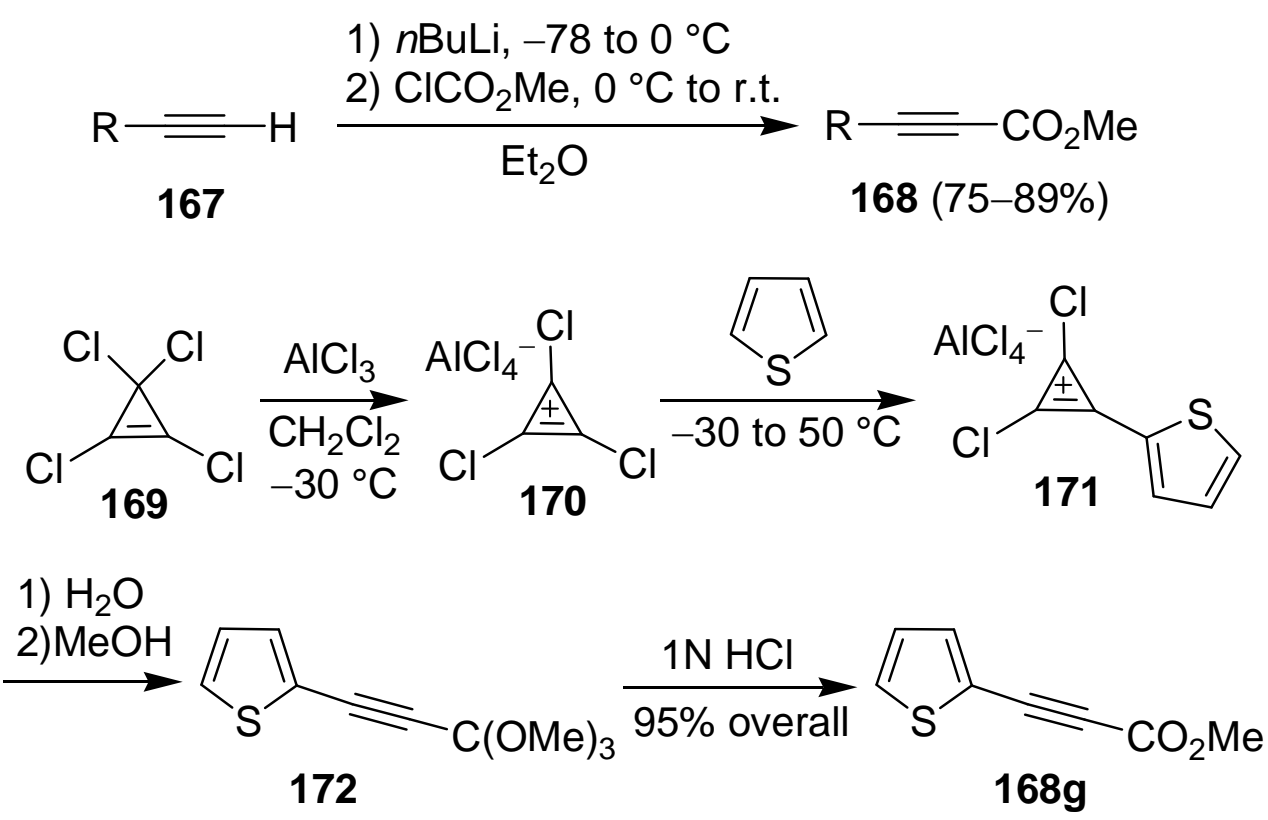

Scheme 44. Synthesis of substituted methyl propiolates 168.

With thus prepared methyl propiolates 168, various new pyrroles have been synthesized (Table 1). Both $\mathrm{CuSPh}$-catalyzed (at $85^{\circ} \mathrm{C}$ ) and $\mathrm{KO} t \mathrm{Bu}$-mediated reaction of methyl cyclopropylpropiolate (168a) with ethyl isocyanoacetate (25-Et) proceeded smoothly to provide the corresponding pyrrole 173ba in 87 and $89 \%$, respectively. Methyl (1-methoxyethyl) propiolate $\mathbf{1 6 8 b}$ afforded the pyrrole 173ab only in $54 \%$ yield in a $\mathrm{CuSPh}$-catalyzed reaction with 25-Me in the same conditions, although the conversion of starting materials was quantitative according to NMR data of the reaction mixture. The dimerization of isocyanide $\mathbf{2 5}-\mathrm{Me}$ to form imidazole of type $\mathbf{1 7 4}$ is most likely the main side-reaction in this case. Aryl- (hetaryl-) substituents in acetylenes 168 were expected to cause reduced reactivity towards nucleophiles. It was reported earlier, ${ }^{[51]}$ that the reaction of ethyl phenylpropiolate with tert-butyl cyclopropylpropiolate was quite sluggish at $80^{\circ} \mathrm{C}$, but readily furnished the corresponding pyrrole at higher temperature $\left(120^{\circ} \mathrm{C}\right)$. Other acetylenes with aryl- $(\mathbf{1 6 8 c}, \mathbf{1 6 8 d}, \mathbf{1 6 8 e})$ and heteroaryl substituents $(\mathbf{1 6 8 f}, \mathbf{1 6 8 g})$ were also efficiently converted into the respective pyrroles 173ac-173ag using this method (entries 3-7). 
Table 1. Various 2,3,4-trisubstituted pyrroles 173 prepared by the formal cycloaddition of substituted methyl isocyanides $\mathbf{6 3}$ to acetylenes $\mathbf{1 6 8} .^{[97]}$
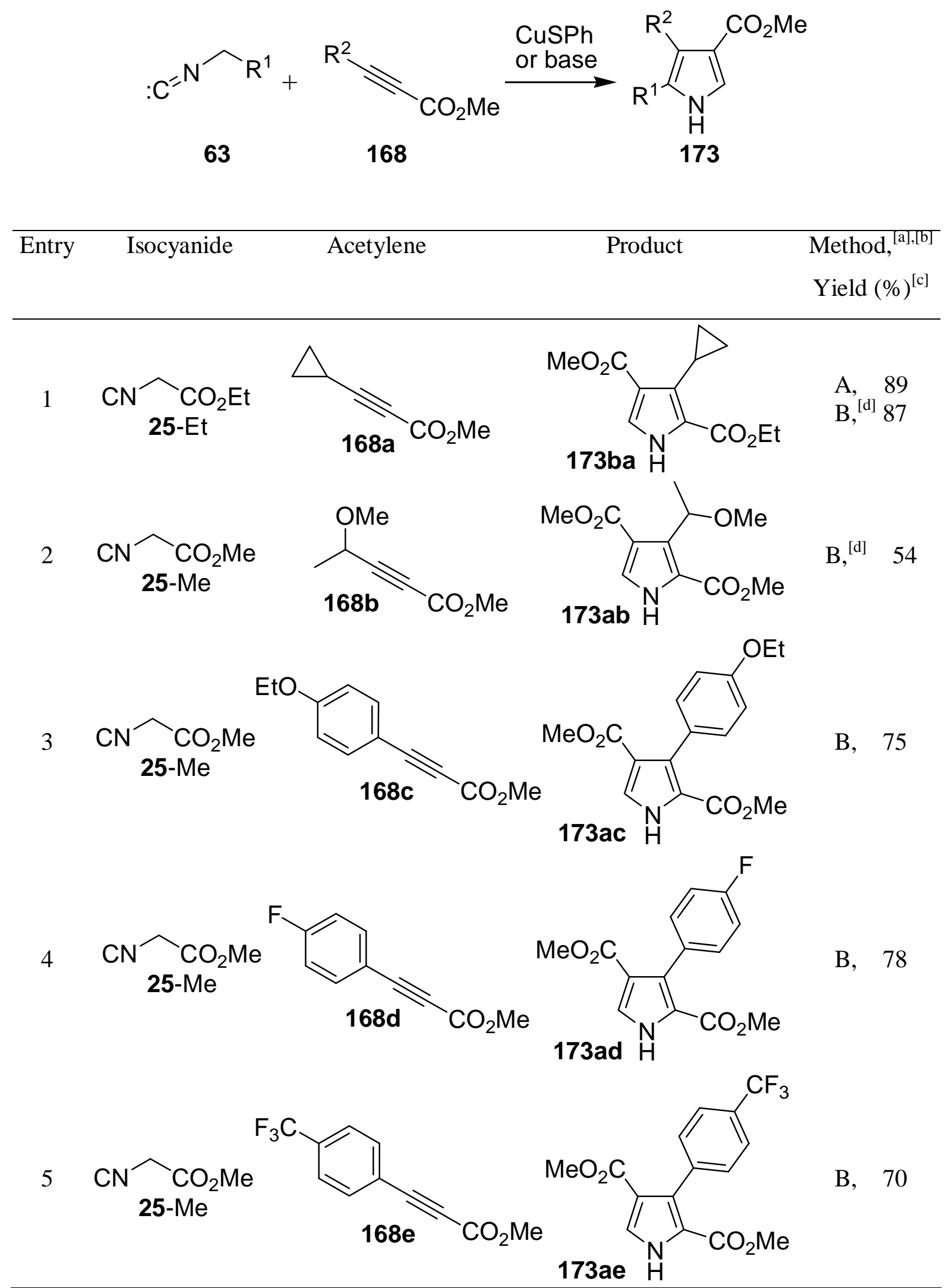
Table 1 (continued). Various 2,3,4-trisubstituted pyrroles 173 prepared by the formal cycloaddition of substituted methyl isocyanides 63 to acetylenes 168.

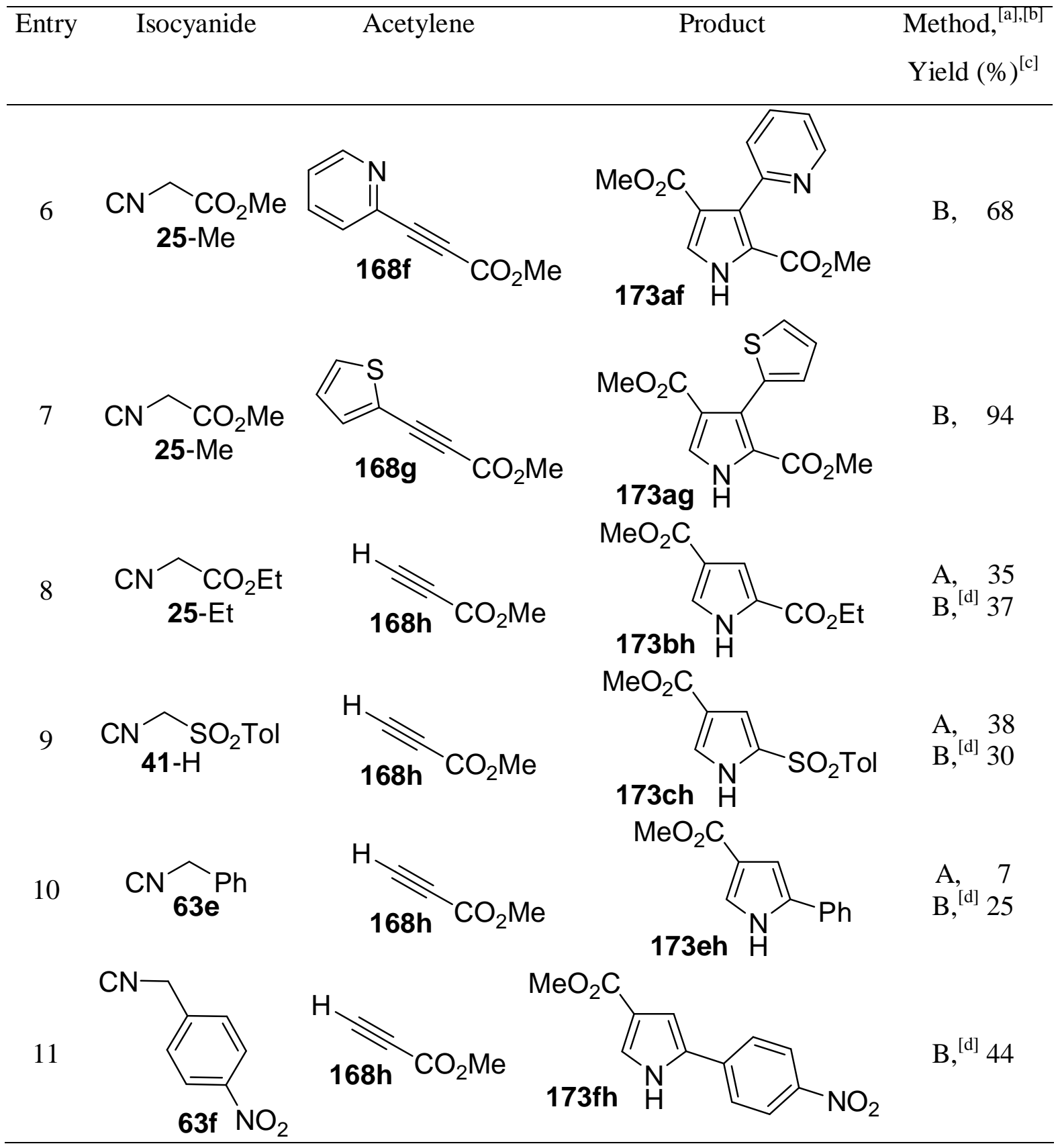

[a] Method A: Addition of $\mathrm{KO} t \mathrm{Bu}$ (1.2 equiv.), $1 \mathrm{~h}$, then $1 \mathrm{~h}$ at $20^{\circ} \mathrm{C}$, THF. [b] Method B: $\mathrm{CuSPh}(5 \mathrm{~mol} \%), \mathrm{DMF}, 120^{\circ} \mathrm{C}, 12 \mathrm{~h}$. [c] Yield of isolated product. [d] The reaction was carried out at $85^{\circ} \mathrm{C}$. [e] The reaction was carried out at $60{ }^{\circ} \mathrm{C}$.

With electron-acceptor substituted terminal acetylenes, the yields of pyrroles $\mathbf{1 7 3}$ were dramatically lower. Thus, the $\mathrm{CuSPh}$-catalyzed reactions of isocyanides $\mathbf{6 3}$ with methyl 
propiolate $168 \mathrm{~h}$ led to the corresponding pyrroles 173 in only $25-44 \%$ yields, and in the presence of $\mathrm{KO} t \mathrm{Bu}$ the yields of pyrroles 173 were also low (Table 1, entries 8-11). It is known, that methyl propiolate $168 \mathrm{~h}$ easily dimerizes to give dimethyl hex-2-en-4-ynedioate both under base ${ }^{[98]}$ and copper(I) ${ }^{[99]}$ catalysis, complicating this reaction. Even with an excess of $\mathbf{1 6 8 h}$, the yields of pyrroles 173 were not any better.

The copper(I)-catalyzed variant of the reaction is of great interest, because it may bring along certain advantages in cost, efficiency and compatibility with base-sensitive substrates. Different solvents were tested in the copper-catalyzed cycloaddition of p-toluenesulfonylmethyl isocyanide (TosMIC, 41-H) to methyl cyclopropylacetylene carboxylate (168a). Dimethylformamide (DMF) turned out to be the solvent of choice giving a better yield of pyrrole 173da than any other tested solvent (toluene, ethanol, ethyl acetate, acetonitrile, 1,2-dichloroethane, dioxane).

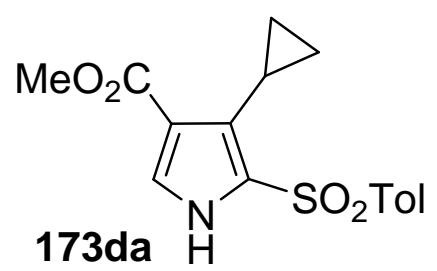

Figure 2. The pyrrole 173da.

Among all copper catalysts tested, copper(I) thiophenolate and preactivated nanosize metallic copper powder in DMF at $90{ }^{\circ} \mathrm{C}$ turned out to be the most efficient, providing the pyrrole 173ba in 93 and 92\% yield, respectively (Table 2, entries 1 and 2). With copper(I) oxide as a catalyst, 173ba was obtained in a slightly lower yield of $78 \%$, whereas other copper compounds gave inferior results. Surprisingly, some copper(II) compounds (copper(II) acetylacetonate, copper(II) acetate, entries 12, 13, respectively) catalyzed the formation of $\mathbf{1 7 3 b a}$ as well, and gave even better results than $\mathrm{CuI}$ and other copper(I) halides. Copper(II) compounds are supposed to be (fully or partly) reduced by isocyanides to the corresponding $\mathrm{Cu}(\mathrm{I})$ salts, which actually catalyze the reaction.

It is conceivable, that this reaction could be used for many other applications, for example, in biological systems, if it fulfilled the demands of Sharpless' so-called "click" chemistry, ${ }^{[100]}$ i.e. provided good yields and could be carried out at low temperatures. 
Table 2. Optimization of the copper catalyst for the synthesis of 173aa. ${ }^{[a]}$

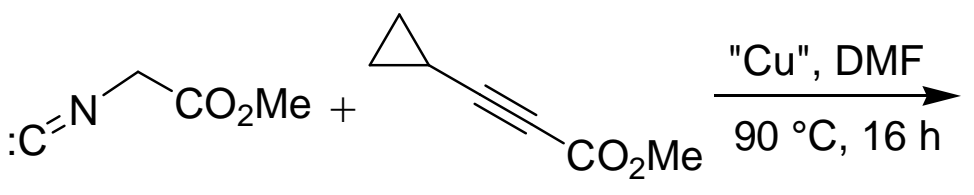

25-Me

$168 \mathrm{a}$

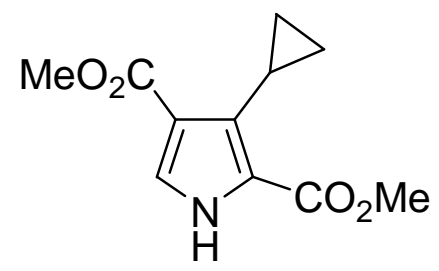

173aa<smiles>CCOC(=O)Cn1cnc(C(=O)OCC)c1</smiles>

174

\begin{tabular}{ccc}
\hline Entry & $\mathrm{Cu}$ catalyst & Yield of 173aa $(\%)^{[\mathrm{b}]}$ \\
\hline 1 & $\mathrm{CuSPh}$ & 93 \\
2 & $\mathrm{Cu}-\mathrm{NP}^{[\mathrm{c}]}$ & 92 \\
3 & $\mathrm{CuSePh}$ & 45 \\
4 & $\mathrm{CuSHex}$ & 52 \\
5 & $\mathrm{CuPPh}_{2}$ & 39 \\
6 & $\mathrm{Cu}_{2} \mathrm{O}$ & 78 \\
7 & $\mathrm{Cu}_{2} \mathrm{~S}$ & 37 \\
8 & $\mathrm{CuCl}$ & 6 \\
9 & $\mathrm{CuBr}$ & 10 \\
10 & $\mathrm{CuI}$ & 3 \\
11 & $\mathrm{CuCN}$ & 24 \\
12 & $\mathrm{Cu}(\mathrm{acac})_{2}$ & 24 \\
13 & $\mathrm{Cu}(\mathrm{OAc})_{2} \bullet \mathrm{H}_{2} \mathrm{O}$ & 19 \\
14 & $\mathrm{CpCuP}(\mathrm{OMe})_{3}$ & $89^{[\mathrm{d}]}$ \\
\hline
\end{tabular}

[a] Reagents and conditions: 25-Me (1.1 mmol), 168a (1.0 mmol), copper salt (5 mol\%), DMF (2 mL). [b] Determined by ${ }^{1} \mathrm{H}$ NMR with hexamethylbenzene as an internal standard. [c] The abbreviation $\mathrm{Cu}-\mathrm{NP}$ stands for preactivated nanosize copper powder. [d] The reaction was carried out at $20{ }^{\circ} \mathrm{C}$ with $10 \mathrm{~mol} \%$ of catalyst and, according to TLC, was completed within $2 \mathrm{~h}$. 
With the intention to achieve this kind of pyrrole formation at temperatures lower than $70{ }^{\circ} \mathrm{C}$ (the lowest temperature employed in this synthesis so far), it was attempted to prepare a copper(I) compound, that would decompose to metallic copper at low temperatures. It is known, that cyclopentadienylcopper compounds ${ }^{[101]}$ show interesting catalytic properties and serve as sources for copper of high purity, as they decompose at relatively low temperatures. ${ }^{[102]}$ Thus, Saegusa, Ito et al. reported that the cyclopentadienylcopper(I) tert-butyl isocyanide complex catalyzes Michael-type additions of compounds containing active hydrogen, to acrylates and acrylonitrile. ${ }^{[103]}$ Indeed, $\eta^{5}$-(cyclopentadienyl)trimethyl-phosphite-copper(I) at $20{ }^{\circ} \mathrm{C}$ efficiently catalyzes the reaction of 25-Me with 168a providing the pyrrole 173aa in $89 \%$ yield within $2 \mathrm{~h}$ (Table 2 , entry 14). However, all attempts to use this copper catalyst in the reaction of 25-Et with both terminal and internal acetylenes without acceptor substituents, failed. Under the catalysis of $\mathrm{CpCuP}(\mathrm{OMe})_{3}(5 \mathrm{~mol} \%)$, the isocyanide 25-Et dimerized to the imidazole $\mathbf{1 7 4}{ }^{[39]}$ in $85 \%$ yield at $20^{\circ} \mathrm{C}$ within $16 \mathrm{~h}$.

All catalysts (except nanosize-copper powder), which demonstrated moderate and good activity in the pyrrole formation $\left(\mathrm{CuSPh}, \mathrm{CuSePh}, \mathrm{CuPPh}_{2}, \mathrm{Cu}_{2} \mathrm{O}, \mathrm{Cu}_{2} \mathrm{~S}\right)$, have one common feature, namely a $\sigma$-donating character of the counterion. Saegusa et al. reported that copper(I) tert-butoxide with similar electronic properties, reveals a strong affinity toward $\pi$-accepting ligands like isocyanides, and this has not been observed for common cuprous salts. ${ }^{[104]}$ This feature of copper(I) compounds with $\sigma$-donating ligands may be ascribed to the enhancement of back-donation from the copper to $\pi$-accepting ligands, such as isocyanides, caused by increasing of electron density on $\mathrm{Cu}$. Enhanced affinity of copper(I) compounds with $\sigma$-donating counterions to isocyanides appears to be crucial for the pyrrole formation. $\mathrm{Cu}(\mathrm{I})$-Isocyanide complexes are known to abstract hydrogen from so-called active hydrogen compounds and to produce organocopper(I) isocyanide complexes, ${ }^{[37 \mathrm{a}, 105]}$ which can undergo cycloadditions to form various heterocycles. In view of this, it is an open question, how copper(0) can be an active catalyst for the pyrrole formation. Metallic copper powder is known to dissolve in cyclohexyl isocyanide under an atmosphere of nitrogen to form a zero-valent copper-isocyanide complex, which can undergo an oxidative addition of a C-halogen bond. ${ }^{[106]}$ Apart from the catalytic activity of metallic copper in the pyrrole synthesis demonstrated by de Meijere et al., Yamamoto et al. later reported, that metallic copper efficiently catalyzes the formation of imidazoles from two different isocyanides. ${ }^{[53]}$ These results indicate, that copper(0) isocyanide, like copper(I) isocyanide complexes, are able to deprotonate compounds with active hydrogen. 
To prove this hypothesis, the enantiomerically pure isocyanide $\mathbf{1 7 5}^{[107]}$ was synthesized from $L$-isoleucine. Indeed, 175 underwent complete racemization upon heating at $85{ }^{\circ} \mathrm{C}$ for three hours in DMF in the presence of pre-activated copper nanoparticles (5 mol\%).

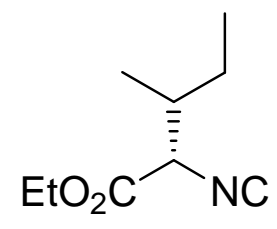

175

Figure 3. Chiral isocyanide 175.

\section{Kinetic Studies}

Some simple kinetic studies were performed to determine the reaction order with respect to both the isocyanide 25-Et and the acetylene 168a in the $\mathrm{Cu}(\mathrm{I})$-catalyzed pyrrole formation. The initial rates were estimated from the concentrations (determined from the ${ }^{1} \mathrm{H}$ NMR spectra employing hexamethylbenzene as an internal standard) of pyrrole formed

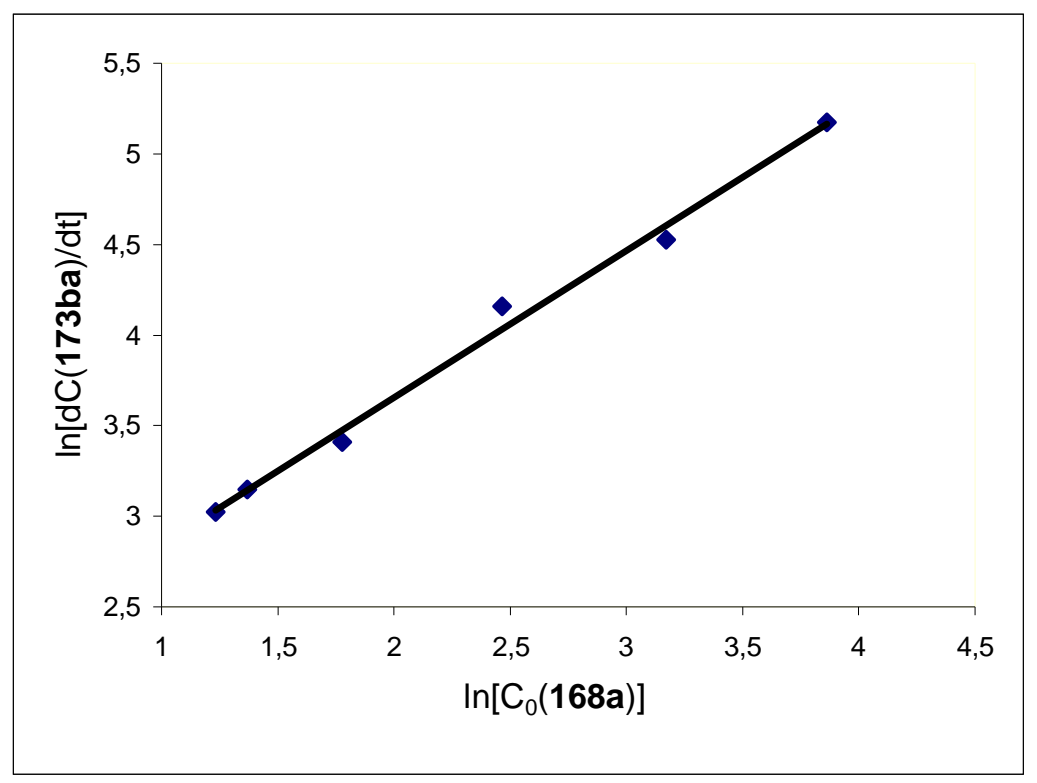

Figure 4. Determination of the reaction order with the respect to the acetylene 168a in the initial phase of the formal cycloaddition of 25 -Et to 168 a in DMF at $85{ }^{\circ} \mathrm{C}$ catalyzed by $\mathrm{CuSPh} . \mathrm{C}_{0}(\mathbf{1 6 8 a})=$ initial concentration of $\mathbf{1 6 8 a}$. 
after 3 min each at constant initial concentrations of isocyanide 25-Et $(0.438 \mathrm{M})$ and different initial concentrations of acetylene 168a (varying from $0.021 \mathrm{M}$ to $0.291 \mathrm{M}$ ). The reactions were carried out in DMF at $85^{\circ} \mathrm{C}$. The dual logarithmic plot of $\ln [\mathrm{dC}(\mathbf{1 7 3 b a}) / \mathrm{dt}]$ versus $\ln \left[\mathrm{C}_{0}(\mathbf{1 6 8 a})\right]$ gave a straight line, the slope of which indicated (Figure 4 ) an order of 0.81 for this reaction with respect to the acetylene $\mathbf{1 6 8 a}$.

Analogously, the initial rates of the same reaction were estimated from the concentrations (determined from the ${ }^{1} \mathrm{H}$ NMR spectra employing hexamethylbenzene as an internal standard) of pyrrole formed after $3 \mathrm{~min}$ each at constant initial concentrations of $\mathbf{1 6 8 \mathbf { a }}$ $(0.424 \mathrm{M})$ and different initial concentrations of 25-Et (varying from $0.037 \mathrm{M}$ to $0.183 \mathrm{M}$ ). The dual logarithmic plot (Figure 2) gave a straight line, the slope of which indicated an order of the reaction of 1.29 with the respect to the isocyanide 25-Et.

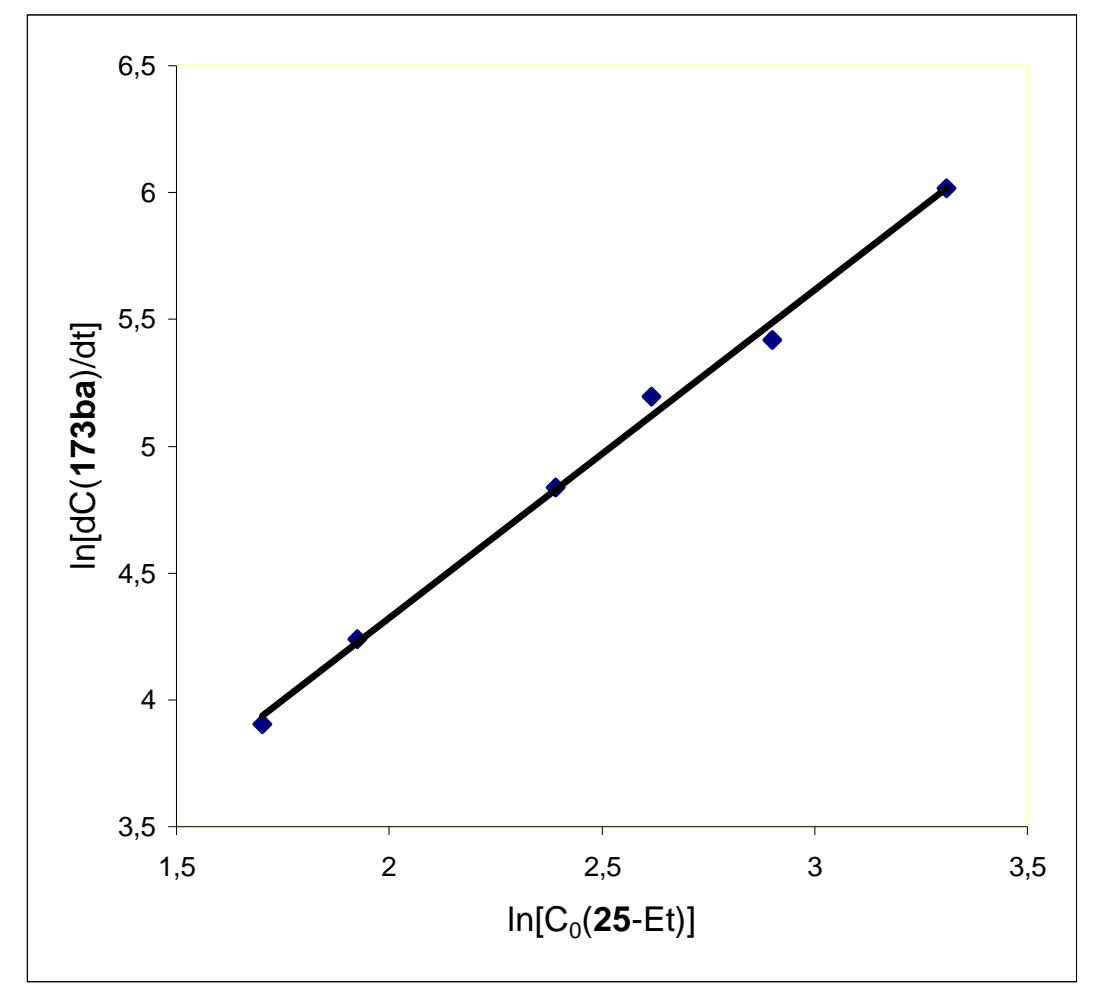

Figure 5. Determination of the reaction order with the respect to the isocyanide 25-Et in the initial phase of the formal cycloaddition of 25 -Et to $168 \mathrm{a}$ in DMF at $85{ }^{\circ} \mathrm{C}$ catalyzed by $\mathrm{CuSPh} . \mathrm{C}_{0}(\mathbf{2 5}-\mathrm{Et})=$ initial concentration of 25-Et.

These experimental data are in agreement with an overall second order of the reaction, i. e. first order with the respect to both, the acetylene and the isocyanide. 


\section{Synthesis of 2,3-Disubstituted Pyrroles}

Although acetylenes without electron-withdrawing substituents have not been used earlier as cycloaddition-partners for isocyanides in pyrrole syntheses ${ }^{[50,51]}$ under usual conditions, an attempted reaction of 3-hexyne (176) with ethyl isocyanoacetate (25-Et) at elevated temperature $\left(120^{\circ} \mathrm{C}\right)$ in the presence of 1 equiv. of copper(I) iodide as a mediator and 5 equiv. of cesium carbonate as a base, gave a trace of the pyrrole 177 after $16 \mathrm{~h}$.

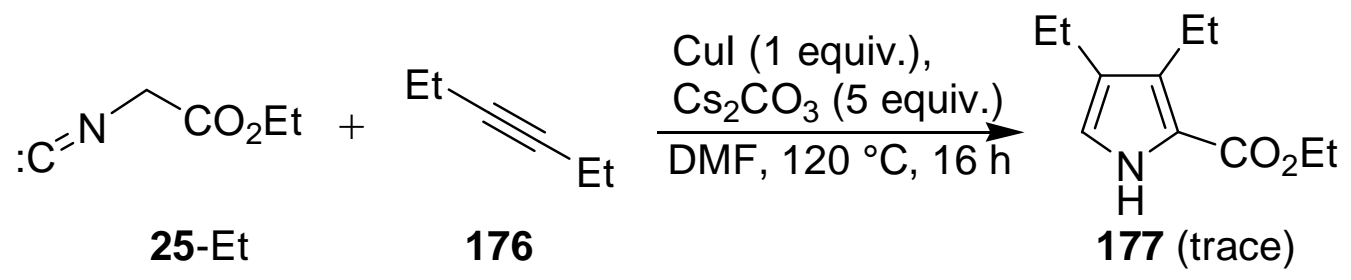

Scheme 45. Formation of pyrrole 177 from unactivated acetylene 176 and 25-Et

Terminal acetylenes turned out to be more reactive under these conditions. Thus, ethyl 3-n-butylpyrrole-2-carboxylate $\mathbf{1 7 8 b a}$ was obtained in 29\% yield from 1-hexyne and ethyl isocyanoacetate (25-Et) (Table 3, entry 1). The best yield of $\mathbf{1 7 8 b a}$ in this reaction was achieved at $120{ }^{\circ} \mathrm{C}$, being almost the same as at $140{ }^{\circ} \mathrm{C}$, while at $100{ }^{\circ} \mathrm{C}$ it was significantly lower (entries 3, 2, respectively). Different bases were tested, yet lithium and potassium carbonate were less effective than cesium carbonate, giving rise to 15 and $19 \%$ yield of $\mathbf{1 7 8 b a}$ respectively, under the same conditions (entries 4, 5). Tertiary amines $\left(\mathrm{Et}_{3} \mathrm{~N}, \mathrm{EtNiPr}{ }_{2}, \mathrm{DBU}, \mathrm{DABCO}\right)$ were less effective than alkali carbonates, giving less than $10 \%$ yield of $\mathbf{1 7 8 b a}$ under the same conditions. Although DMF was used as a solvent in most cases, $N, N$-dimethylacetamide worked as well (entry 6), in toluene 178ba was obtained in a lower yield of 23\% (entry 9). With catalytic quantities of CuI, only traces of 178ba were isolated, while 1.3 equiv. of $\mathrm{CuI}$ did not provide an improvement compared to an equimolar quantity. Among the mediators used, CuOTf $\bullet .5 \mathrm{C}_{6} \mathrm{H}_{6}$ was completely ineffective as well as $\mathrm{Cu}_{2} \mathrm{O}$, while $\mathrm{CuI} \cdot \mathrm{P}(\mathrm{OMe})_{3}$ gave 178ba in $10 \%$ yield. $\mathrm{AgOAc}$ was slightly worse (27\% yield of $\mathbf{1 7 8 b a}$, entry 8 ) than $\mathrm{CuI}$, and in view of the significantly lower prices of copper salts, no further silver mediators were tested. Surprisingly, copper(II) trifluoromethanesulfonate also achieved the formation of $\mathbf{1 7 8 b a}$ in $21 \%$ yield (entry 7). 
Table 3. Optimization of conditions for the synthesis of $\mathbf{1 7 8 b a} .^{[\mathrm{a}]}$

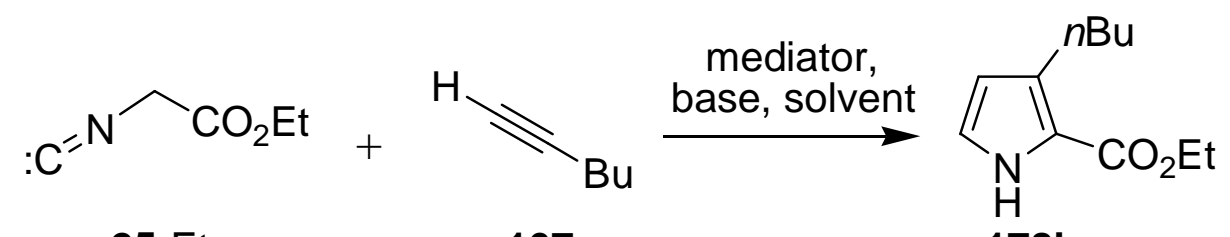

25-Et

$167 a$

$178 \mathrm{ba}$

\begin{tabular}{|c|c|c|c|c|c|}
\hline Entry & $\begin{array}{l}\text { Mediator } \\
\text { (equiv.) }\end{array}$ & $\begin{array}{c}\text { Base } \\
\text { (equiv.) }\end{array}$ & Solvent & $\begin{array}{c}\text { Temperature } \\
{\left[{ }^{\circ} \mathrm{C}\right]}\end{array}$ & $\begin{array}{c}\text { Yield }^{[\mathrm{b}]} \\
(\%)\end{array}$ \\
\hline 1 & CuI (1) & $\mathrm{Cs}_{2} \mathrm{CO}_{3}(5)$ & DMF & 120 & 29 \\
\hline 2 & CuI (1) & $\mathrm{Cs}_{2} \mathrm{CO}_{3}(5)$ & $\mathrm{DMF}$ & 100 & 10 \\
\hline 3 & $\mathrm{CuI}(1)$ & $\mathrm{Cs}_{2} \mathrm{CO}_{3}(5)$ & $\mathrm{DMF}$ & 140 & 28 \\
\hline 4 & $\mathrm{CuI} \quad(1)$ & $\mathrm{Li}_{2} \mathrm{CO}_{3}(5)$ & $\mathrm{DMF}$ & 120 & 15 \\
\hline 5 & CuI (1) & $\mathrm{K}_{2} \mathrm{CO}_{3}(5)$ & $\mathrm{DMF}$ & 120 & 19 \\
\hline 6 & CuI (1) & $\mathrm{Cs}_{2} \mathrm{CO}_{3}(5)$ & DMA & 120 & 30 \\
\hline 7 & $\mathrm{Cu}(\mathrm{OTf})_{2}(1)$ & $\mathrm{Cs}_{2} \mathrm{CO}_{3}(5)$ & DMF & 120 & 21 \\
\hline 8 & $\operatorname{AgOAc}(1)$ & $\mathrm{Cs}_{2} \mathrm{CO}_{3}(5)$ & $\mathrm{DMF}$ & 120 & 27 \\
\hline 9 & $\mathrm{CuI}(1)$ & $\mathrm{Cs}_{2} \mathrm{CO}_{3}(5)$ & toluene & 120 & 23 \\
\hline
\end{tabular}

[a] All reactions were carried out with $1 \mathrm{mmol}$ of the isocyanide 25-Et and $5 \mathrm{mmol}$ of the acetylene $167 \mathrm{a}$ in $10 \mathrm{~mL}$ of solvent in a sealed vessel with stirring and heating for $12 \mathrm{~h}$. [b] Yields of isolated product.

The yield of $\mathbf{1 7 8 b a}$ could be further improved by gradually adding the isocyanide 25 -Et to a mixture of the copper mediator, cesium carbonate and the acetylene 167a in DMF kept at $120{ }^{\circ} \mathrm{C}$ (Table 4). This procedure with a stoichiometric quantity of $\mathrm{CuI}$ provided the pyrrole 178ba in $36 \%$ yield (entry 1). $\mathrm{CuBr} \bullet \mathrm{SMe}_{2}, \mathrm{CuBr}$ and $\mathrm{CuCl}$ were equally effective, and all three of them were better than $\mathrm{CuI}$ (entries 2, 4, 5). But with a substoichiometric quantity (0.1 equiv.) of $\mathrm{CuBr} \bullet \mathrm{SMe}_{2}$, only a trace of $\mathbf{1 7 8 b a}$ was formed. The ratio of reagents had a big influence on the yield of pyrrole as well. The yields of $\mathbf{1 7 8 b a}$ were best, when two and more equivalents of isocyanide were used, whereas with the ratio of $1.5: 1$ and $1: 1$ of 25 -Et to $167 \mathbf{a}$, the yields of $\mathbf{1 7 8 b a}$ were 48 and $43 \%$, respectively (entries 8 , 9). Interestingly, with an excess of the acetylene 167a (2 equiv.), 178ba was obtained in 
$63 \%$ yield based on the isocyanide, indicating that the use of either an excess of the acetylene 167a or an excess of the isocyanide 25-Et are equally effective.

Table 4. Further optimization of conditions for the synthesis of $\mathbf{1 7 8 b a} .^{[\mathrm{a}],[\mathrm{b}]}$

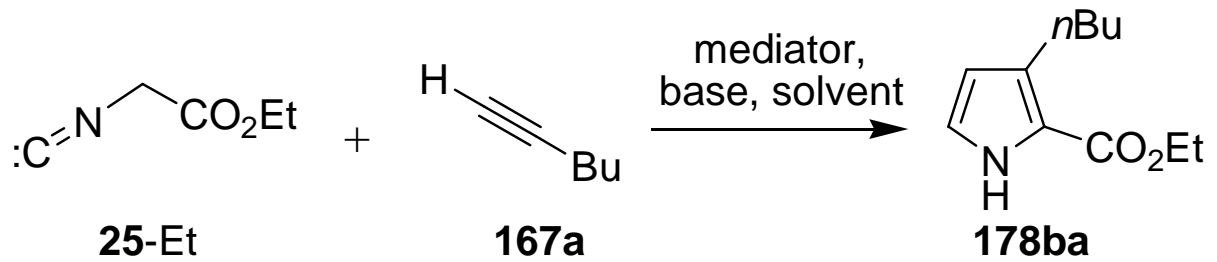

\begin{tabular}{|c|c|c|c|c|c|}
\hline Entry & $\begin{array}{c}\mathbf{2 5 - E t} \\
\text { (equiv.) }\end{array}$ & $\begin{array}{c}167 a \\
\text { (equiv.) }\end{array}$ & $\begin{array}{l}\text { Mediator } \\
\text { (equiv.) }\end{array}$ & $\begin{array}{c}\text { Base } \\
\text { (equiv.) }\end{array}$ & $\begin{array}{l}\text { Yield }^{[\mathrm{a}]} \text { of } \\
\text { 178ba }(\%)\end{array}$ \\
\hline 1 & 1 & 1 & CuI (1) & $\mathrm{Cs}_{2} \mathrm{CO}_{3}(5)$ & $36^{[\mathrm{b}]}$ \\
\hline 2 & 5 & 1 & $\mathrm{CuBr} \cdot \mathrm{SMe}_{2}(1)$ & $\mathrm{Cs}_{2} \mathrm{CO}_{3}(5)$ & $64^{[\mathrm{b}]}$ \\
\hline 3 & 1 & 1 & $\mathrm{CuBr} \bullet \mathrm{SMe}_{2}(0.1)$ & $\mathrm{Cs}_{2} \mathrm{CO}_{3}(5)$ & $\operatorname{trace}^{[\mathrm{b}]}$ \\
\hline 4 & 1 & 2 & $\mathrm{CuBr}(1)$ & $\mathrm{Cs}_{2} \mathrm{CO}_{3}(3)$ & $64^{[\mathrm{c}]}$ \\
\hline 5 & 1 & 2 & $\mathrm{CuCl}(1)$ & $\mathrm{Cs}_{2} \mathrm{CO}_{3}(3)$ & $64^{[\mathrm{c}]}$ \\
\hline 6 & 3 & 1 & $\mathrm{CuBr} \cdot \mathrm{SMe}_{2}(1)$ & $\mathrm{Cs}_{2} \mathrm{CO}_{3}(1)$ & $70^{[\mathrm{b}]}$ \\
\hline 7 & 2 & 1 & $\mathrm{CuBr} \cdot \mathrm{SMe}_{2}(1)$ & $\mathrm{Cs}_{2} \mathrm{CO}_{3}(1)$ & $70^{[\mathrm{b}]}$ \\
\hline 8 & 1.5 & 1 & $\mathrm{CuBr} \cdot \mathrm{SMe}_{2}(1)$ & $\mathrm{Cs}_{2} \mathrm{CO}_{3}(1)$ & $48^{[\mathrm{b}]}$ \\
\hline 9 & 1 & 1 & $\mathrm{CuBr} \cdot \mathrm{SMe}_{2}(1)$ & $\mathrm{Cs}_{2} \mathrm{CO}_{3}(5)$ & $43^{[\mathrm{b}]}$ \\
\hline 10 & 2 & 1 & $\mathrm{CuBr} \cdot \mathrm{SMe}_{2}(1)$ & $\mathrm{Cs}_{2} \mathrm{CO}_{3}(1)$ & $63^{[\mathrm{b}]}$ \\
\hline 11 & 2 & 1 & $\mathrm{CuBr} \cdot \mathrm{SMe}_{2}(1)$ & $\mathrm{Cs}_{2} \mathrm{CO}_{3}(0.5)$ & $\operatorname{trace}^{[\mathrm{b}]}$ \\
\hline
\end{tabular}

[a] Yields of isolated product. [b] Method A: A solution of the isocyanide 25-Et (1-5 mmol) in $5 \mathrm{~mL}$ of DMF was added dropwise at $120^{\circ} \mathrm{C}$ within $2 \mathrm{~h}$ to a mixture of $\mathrm{Cs}_{2} \mathrm{CO}_{3}$, the copper acetylenide generated in situ from the acetylene 167a and the copper(I) salt in 5 $\mathrm{mL}$ of DMF, and the mixture was stirred at $120{ }^{\circ} \mathrm{C}$ for $12 \mathrm{~h}$. [c] Method B: A solution of the isocyanide 25-Et $(1 \mathrm{mmol})$ and the acetylene 167a $(1 \mathrm{mmol})$ in $5 \mathrm{~mL}$ of DMF was added dropwise within $2 \mathrm{~h}$ at $120{ }^{\circ} \mathrm{C}$ to a mixture of $\mathrm{Cs}_{2} \mathrm{CO}_{3}$, the copper acetylenide generated in situ from the acetylene $\mathbf{1 6 7 a}(1 \mathrm{mmol})$ and the copper(I) salt in $5 \mathrm{~mL}$ of DMF, and the mixture was stirred at $120^{\circ} \mathrm{C}$ for $12 \mathrm{~h}$. 
Table 5. Synthesis of 2,3-disubstituted pyrroles $\mathbf{1 7 8}$ and $\mathbf{1 7 9}$ from the isocyanide 25-Et and terminal acetylenes $\mathbf{1 6 7}{ }^{[\mathrm{a}],[\mathrm{b}]}$

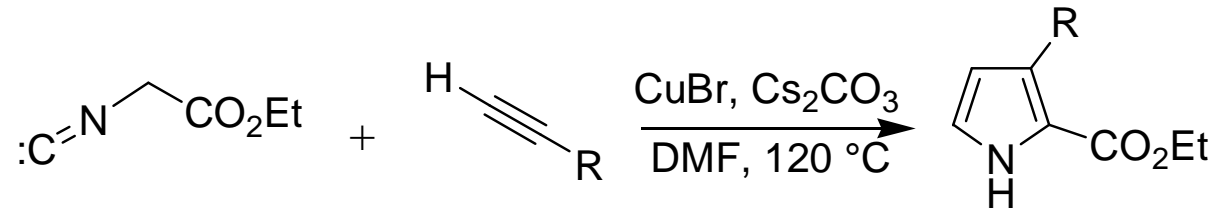

25-Et<smiles>O=C1OCCc2cc[nH]c21</smiles>

179

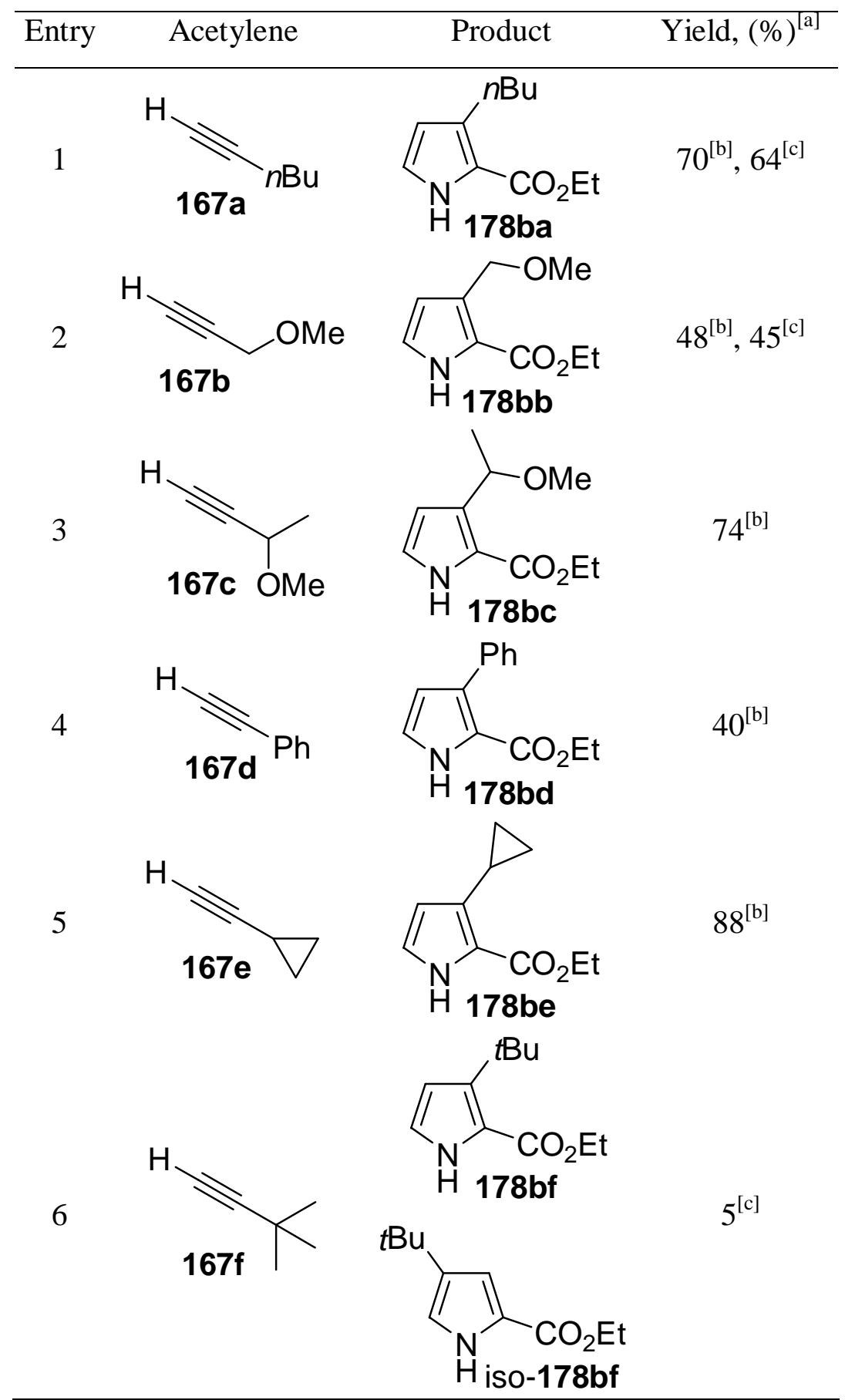


Table 5. (continued) Synthesis of 2,3-disubstituted pyrroles 178 and 179 from the isocyanide 25-Et and terminal acetylenes 167 . $^{[\mathrm{a}],[\mathrm{b}]}$

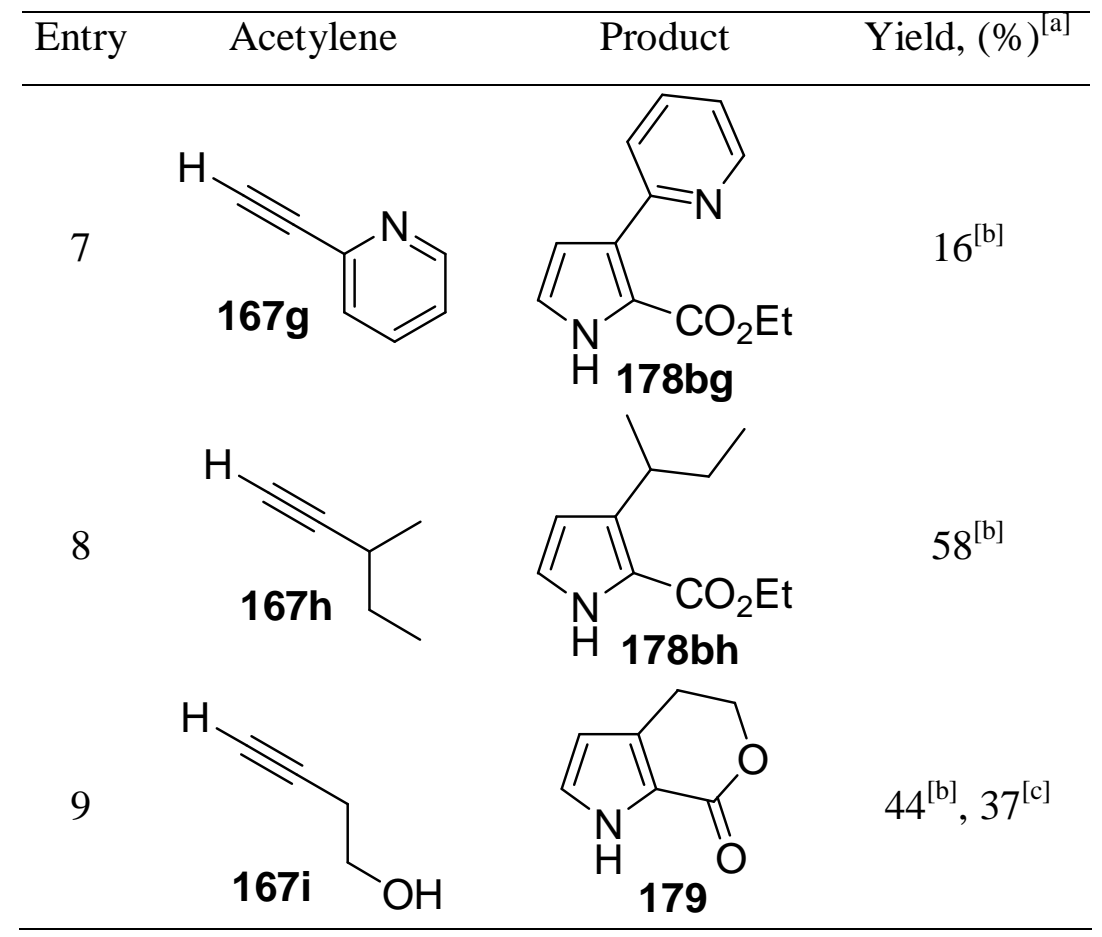

[a], [b], [c] See footnotes under Table 4

With the optimal conditions for the $\mathrm{Cu}(\mathrm{I})$-mediated cycloaddition in hand, the reactions of ethyl isocyanoacetate (25-Et) with various terminal alkynes without acceptor substituents were carried out (Table 5). 1-Hexyne (167a) afforded the pyrrole 178ba in 70 and 64\% yield, respectively (entry 1), according to methods A and B (for details see footnotes under Table 4). 3-Methoxy-1-propyne (167b) with its donating methoxymethyl substituent, gave a lower yield of the pyrrole $\mathbf{1 7 8 b b}$ (48\%, entry 2). Bulky substituents $\mathrm{R}$ attached to the triple bond in $\mathbf{1 6 7}$ also led to decreased yields of the corresponding pyrroles $\mathbf{1 7 8}$. Thus, 167h with a sec-butyl group gave the pyrrole 178bh in 58\% yield (entry 8) compared to $70 \%$ of $178 \mathrm{ba}(\mathrm{R}=n$-butyl). Phenylacetylene $(\mathbf{1 6 7 d}), 2$-pyridylacetylene $(\mathbf{1 6 7 g})$ and tert-butylacetylene (167f) afforded the corresponding pyrroles 178bd, 178bg, 178bf / iso-178bf in 40, 16 and 5\% yields, respectively (entries 4, 7, 6). In the latter case, a $5: 1$ mixture of the 2,3-178bf and the regioisomeric 2,4-disubstituted pyrrole iso-178bf was formed. The yields of pyrroles from cyclopropylacetylene (167e, entry 5) and from 3-methoxy-1-butyne (167c, entry 3) were the highest, although both of these acetylenes contain $\alpha$-branched substituents. The cycloaddition of 25-Et to 3-butyn-1-ol (167i) was 
accompanied by intramolecular transesterification of the ethoxycarbonyl group in the initial product, leading to the lactone-annelated pyrrole 179 in $44 \%$ yield (entry 9).

Various other acceptor-substituted isocyanides 63 were compared with 25-Et in their CuBr-mediated formal cycloadditions to 1-hexyne (167a) (Table 6). With its bulky tert-butyl ester moiety, 25-tBu, gave a lower yield of 178ca (47\%, entry 2 ) than the ethyl ester 25-Et gave 178ba (70\%, entry 1). $p$-Nitrophenylmethyl isocyanide (63f) afforded the corresponding pyrrole $\mathbf{1 7 8 f a}$ in $20 \%$ yield only (entry 3 ). The methyl isocyanide with a diethylaminocarbonyl (63g), a dimethoxyphosphonyl (63h) and a $p$-toluenesulfonyl group $(41-\mathrm{H})$ did not form any of the respective pyrroles at all, although the consumption of the isocyanide was complete in all these cases (entries 4-6). All 2,3-disubstituted pyrroles 178 obtained in this way were colorless solids or oils except for pyrrole 178fa, which was isolated as red crystals. Indeed, a red color is typical for many other known 2-(4-nitrophenyl)-substituted pyrroles: 3,4-dimethyl-2-(4-nitrophenyl)-5-phenyl-1 $\mathrm{H}$ pyrrole and 2-(4-nitrophenyl)-3,4,5-triphenyl-1H-pyrrole, ${ }^{[108 a]}$ 2,5-bis-(4-nitrophenyl)- $1 H$ pyrrole, ${ }^{[108 b]}$ 5-methyl-2-(4-nitrophenyl)-1H-pyrrole, ${ }^{[108 c]}$ 5-phenyl-2-(4-nitrophenyl)-1 $H$ pyrrole. ${ }^{[108 d]}$ 
Table 6. Synthesis of 2,3-disubstituted pyrroles 178 from various isocyanides $\mathbf{6 3}$ and 1-hexyne (167a). ${ }^{[\mathrm{a}]}$<smiles>[R]CN=C</smiles>

63<smiles>[R]c1[nH]ccc1OCCC</smiles>

178

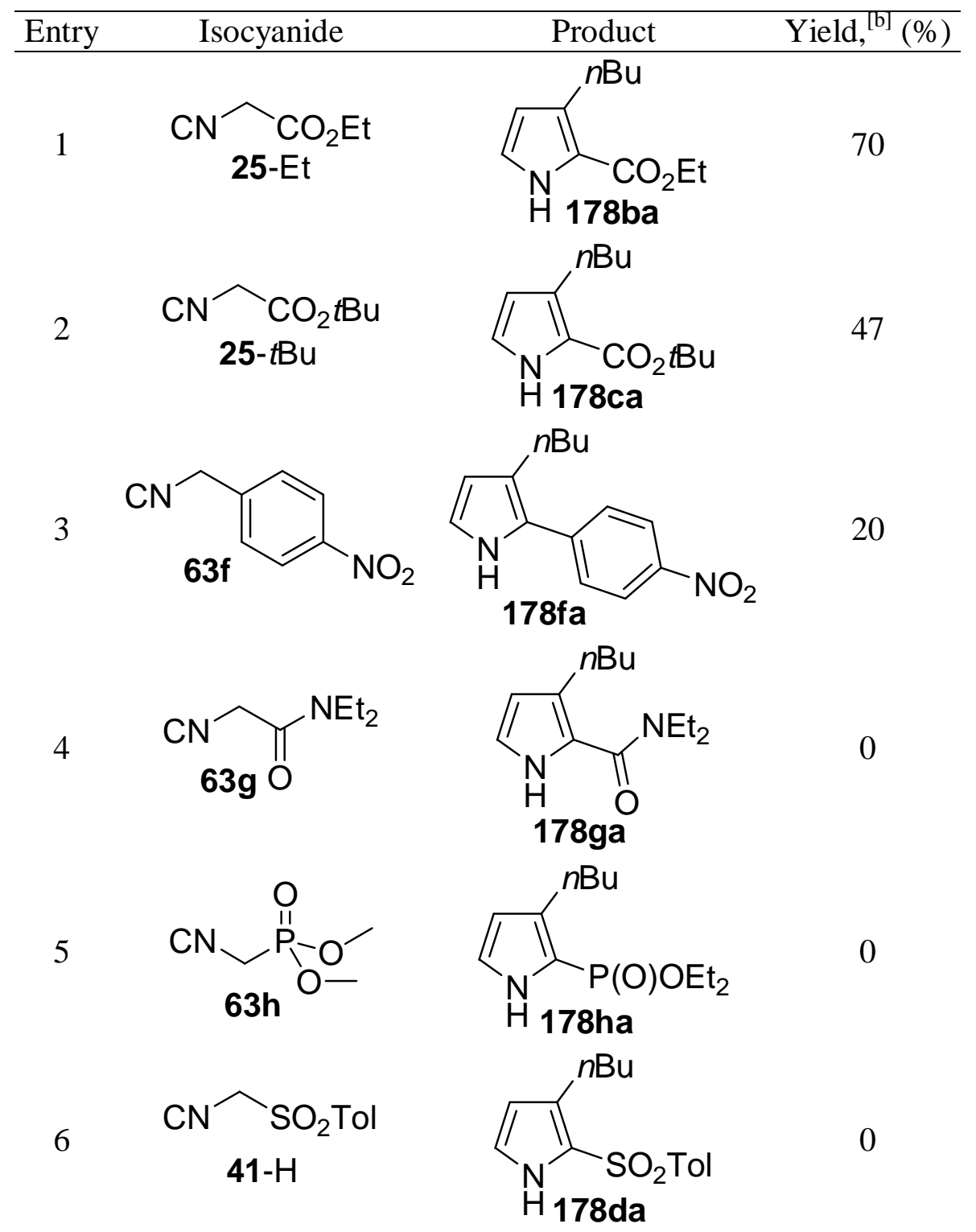

[a] A solution of the isocyanide $63(2 \mathrm{mmol})$ in $5 \mathrm{~mL}$ of DMF was added dropwise at $120{ }^{\circ} \mathrm{C}$ within $2 \mathrm{~h}$ to a mixture of $\mathrm{Cs}_{2} \mathrm{CO}_{3}$, the copper acetylenide generated in situ from the acetylene $167 \mathrm{a}$ and $\mathrm{CuBr}$ in $5 \mathrm{~mL}$ of DMF, and the mixture was stirred at $120^{\circ} \mathrm{C}$ for $1 \mathrm{~h}$. [b] Yield of isolated product. 


\section{Mechanistic Considerations}

A plausible mechanism of both the base-mediated and the copper(I)-catalyzed pyrrole formation from substituted methyl isocyanides $\mathbf{6 3}$ and electron-acceptor substituted alkynes 64 can be proposed (see Scheme 46).

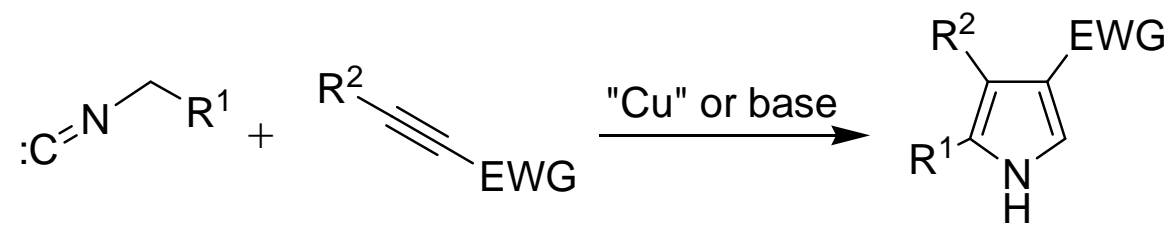

63

64

65

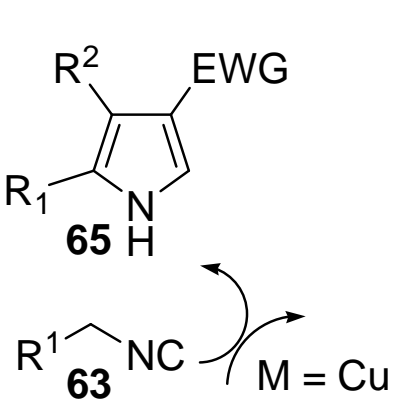<smiles>[R7]C[13CH2][13CH]</smiles>

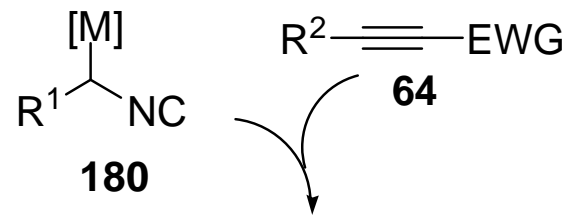

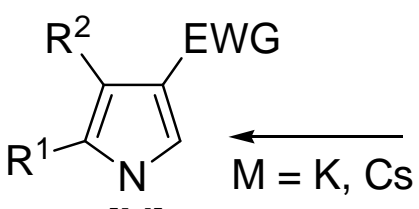

[M]

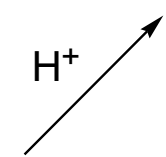

181<smiles>[R]c1[nH]c([Y19])c([14CH3])c1[R2]</smiles>

182<smiles>[Y19]C1=NC([R])C([R])=C1[AlH2]</smiles>

184

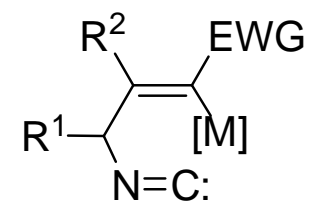

183<smiles>CC[13CH]C</smiles>

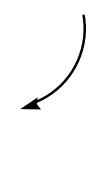

$$
\mathrm{M}=\mathrm{K}, \mathrm{Cs} \text { or } \mathrm{Cu}
$$

Scheme 46. Proposed mechanism for the formal cycloaddition of an $\alpha$-metalated isocyanide 63 across the triple bond in an electron-deficient acetylene 64.

The initiating step is the formation of an $\alpha$-metalated isocyanide $\mathbf{1 8 0}$. Not only $\mathrm{Cu}(\mathrm{I})$ compounds, but also metallic copper powder and $\mathrm{Cu}(\mathrm{II})$ salts (to some extent) are expected to be active in the formation of such a species. Subsequent Michael-type addition onto the triple bond of an activated acetylene $\mathbf{6 3}$ furnishes an unstable vinylorganometallic compound $\mathbf{1 8 3}$, which readily undergoes cyclization to the $2 \mathrm{H}$-pyrroleninemetallic species $\mathbf{1 8 4}$. The latter then experiences a 1,5-hydrogen shift to form 182, and protonation of the latter by the isocyanide $\mathbf{6 3}$ gives the pyrrole $\mathbf{6 5}$, 
completing the catalytic cycle for $\mathrm{M}=\mathrm{Cu}$. The intermediate 184 could also be protonated first, and then undergo a 1,5-hydrogen shift. There is no experimental evidence favoring either one of the two possibilities.

In the base-mediated pyrrole formation, Counterions like $\mathrm{K}^{+}$and $\mathrm{Cs}^{+}$, which are harder than $\mathrm{Cu}^{+}$presumably lead to the $N$-metallated pyrrole 181, which does not deprotonate to any significant extent a new molecule of isocyanide 63, and this therefore requires a stoichiometric quantity of a base for the pyrrole formation in good yields.

The pyrrole formation in the copper(I)-mediated reaction between substituted methyl isocyanides 63 and unactivated terminal acetylenes 167 can be rationalized as follows (Scheme 47). Carbocupration ${ }^{[109]}$ of the copper acetylenide 185 by the deprotonated isocyanide 180 followed by cyclization of the thus formed intermediate 186 would lead to the $2 \mathrm{H}$-pyrrolenline-4,5-dicopper derivative 187, which after 1,5-hydrogen shift and twofold protonation would give the pyrrole $\mathbf{1 7 8}$.
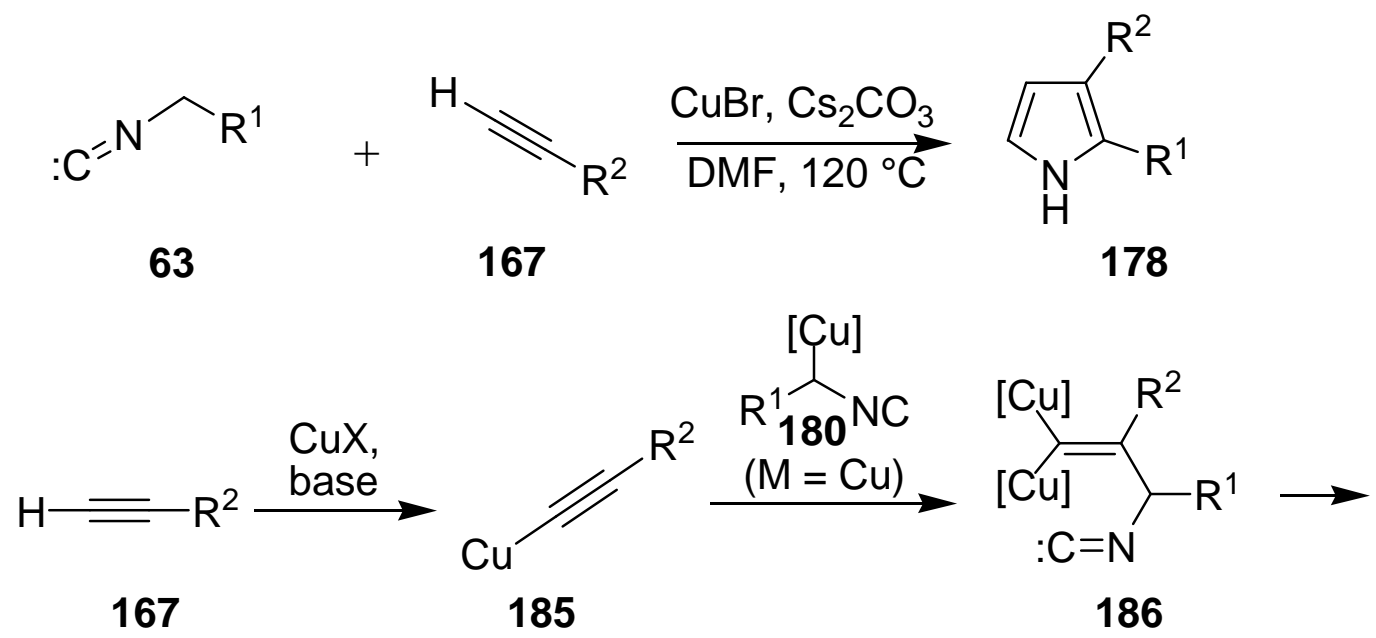<smiles>[R]C1=C([AlH2])C([AlH2])=NC1[R7]</smiles>

187

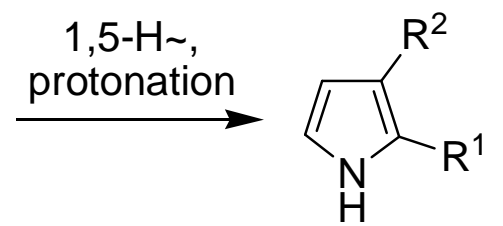

178

Scheme 47. Mechanistic rationalization of the copper(I)-mediated reaction of isocyanides 63 with a terminal acetylene 167 to yield a 2,3-disubstituted pyrrole 178. 
To support this hypothesis, hexynylcopper ${ }^{[110]}\left(\mathbf{1 8 5}, \mathrm{R}^{2}=n \mathrm{Bu}\right)$ was prepared separately and treated with methyl isocyanoacetate $(\mathbf{2 5}-\mathrm{Me})$ in DMF at $120{ }^{\circ} \mathrm{C}$, both in the presence of base and without it, to furnish the pyrrole 178aa in 28 and $30 \%$ yield, respectively. In addition, a reaction of 25-Me with a twofold excess of 1-deutero-1-hexyne (167a-D) employing method B (see footnotes under Table 4) was carried out (Scheme 48).

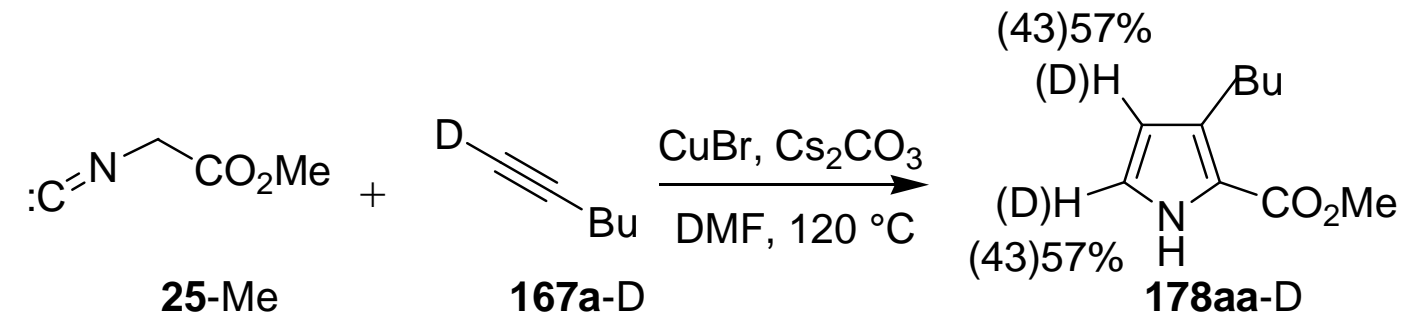

Scheme 48. Formation of the partly deuterated pyrrole 178aa-D.

This reaction furnished a mixture of pyrroles 178aa-D with approximately equal deuterium incorporation (43\%) at positions 4 and 5 , as evidenced by a ${ }^{1} \mathrm{H}$ NMR data. This fact confirms the intermediate formation of a $2 \mathrm{H}$-pyrrolenline-4,5-dicopper species $\mathbf{1 8 7}$, which is deuterated or protonated by $167 \mathbf{a}-\mathrm{D}$ or $25-\mathrm{Me}$, respectively to give pyrrole 178aa-D or 178aa-H, respectively.

\section{Conclusion}

The direct formation of pyrroles from substituted methyl isocyanides $\mathbf{6 3}$ and acceptorsubstituted acetylenes 64 under copper(I) catalysis represents a convenient route to 2,3,4-trisubstituted pyrroles and 3,4-disubstituted pyrroles 173 with sufficient functionality for further elaboration. The newly found route to 2,3-disubstituted pyrroles 178 from substituted methyl isocyanides 63 and non-activated terminal acetylenes (167) mediated by copper(I) compounds further enhances the versatility of these pyrrole syntheses. The prepared derivatives can also be easily transformed into pyrroles of higher or lower order of substitution according to established protocols. ${ }^{[11,112]}$ 


\section{2. ortho-Lithiophenyl Isocyanide: A Versatile Precursor to 3 H-Quinazolin-4-ones and 3H-Quinazolin-4-thiones ${ }^{113}$}

\section{Background and Preliminary Considerations}

Three major types of metallated isocyanides have been reported earlier (vide supra) to undergo subsequent cycloadditions to provide various heterocycles (Figure 6). Interestingly, ring metalated aryl(hetaryl) isocyanides have been elusive so far and hence the possibility of constructing heterocycles therefrom has not been explored. We envisaged that ortho-metallated phenyl isocyanides and their heteroanalogues could also be versatile precursors for certain types of heterocycles and considered that the elaboration of efficient method of its generating would be of great interest.<smiles>CC(C)(C)C([Mg])[Al]</smiles>

$\alpha$-metallated isocyanide Schöllkopf et al.<smiles>Cc1ccccc1N=O</smiles>

$\beta$-metallated isocyanide unknown so far<smiles>Cc1ccccc1N(C)O[Na]</smiles>

Ito, Saegusa et al.
[M]

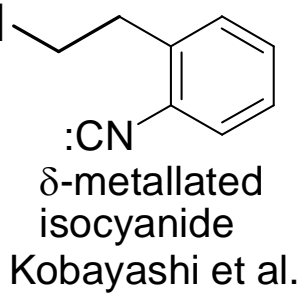

Figure 6. Different types of metallated isocyanides.

Thus, the reaction of ortho-metalated phenylisocyanide $\mathbf{1 8 8}$ with an isocyanate RNCO would provide $N$-metalated 2-isocyano benzamide $189(\mathrm{X}=\mathrm{O})$ capable of further cyclization to form metalated $3 H$-quinazolin-4-one 190. The latter can be trapped in situ with various electrophiles to provide a convenient access to substituted $3 H$-quinazolin-4ones 191 (Scheme 49).

This would be extremely useful, as $3 H$-quinazolin-4-ones have been reported to possess a vast range of biological activities, including analgesic, anti-Parkinsonian, CNS depressant, and CNS stimulating as well as tranquilizing, antidepressant, and anticonvulsant effects. Some of these compounds also act as psychotropic, hypnotic, cardiotonic, antihistamine agents, ${ }^{[114,115]}$ and possess cardiovascular activity as well as antiinflammatory activity. ${ }^{[114,}{ }^{116]}$ Quinazolinones also inhibit monoamine oxidase, aldose reductase, tumor necrosis factor $\mathrm{R}$, thymidylate synthase, pyruvic acid oxidation, as well 


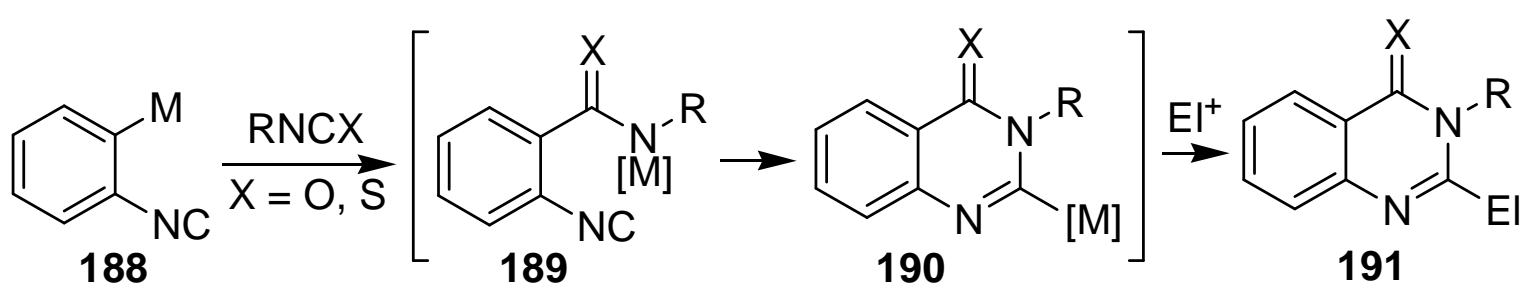

Scheme 49. A proposed approach to substituted 3H-Quinazolin-4-ones and 3H-Quinazolin-4-thiones 191 by a reaction of ortho-metallated phenyl isocyanide with isocyanates (isothiocyanates).

as acetylcholine-esterase activity and are antitumor, antiulcer, antiplatelet aggregation (glycoprotein IIb/ IIIa inhibitors), ${ }^{[117]}$ and hypoglycemic agents. ${ }^{[14,118]}$ They are also potent antibacterial, antifungal, antiviral, antimyco-bacterial, and antimalarial agents. ${ }^{[114]}$ Therefore, not surprisingly, they have been included in the list of molecules with "privileged structure" ${ }^{[119]}$ for combinatorial chemistry, capable of binding to multiple receptors with high affinity. ${ }^{[120]}$ Some derivatives of $3 H$-quinazolin-4-ones occur as natural products ${ }^{[121,122]}$ (Figure 7). Many of the numerous reported syntheses of these heterocycles start from anthranilic acid or its derivatives, but none of them uses the advantages of isocyanide chemistry. ${ }^{[123,124]}$<smiles>[R]C1CCn2c1nc1ccccc1c2=O</smiles>

Vasicinone, $\mathrm{R}=\mathrm{OH}$ Deoxyvasicinone, $\mathrm{R}=\mathrm{H}$<smiles>O=C1c2ccccc2-n2c1nc1ccccc1c2=O</smiles>

Tryptanthrin<smiles>[R]OC(=O)c1ccccc1-n1c(C)nc2ccccc2c1=O</smiles>

alkaloids from Aconitum plants

Figure 7. Some naturally occurring $3 H$-quinazolin-4-ones. ${ }^{[121,122]}$

\section{Synthesis of 2-Substituted Phenyl Isocyanides by Reaction of ortho-Lithiophenyl} Isocyanide with Electrophiles

To investigate the possibility of generating ortho-metallated phenyl isocyanide, two possible precursors for halogen-metal exchange reactions, ortho-bromo- and ortho-iodophenyl isocyanides $159-\mathrm{Br}$ and 159 -I were synthesized. The iodo derivative 
159-I turned out to undergo fast ( $<10 \mathrm{~min})$ transmetalation reactions, when it was treated with $n \mathrm{BuLi}, t \mathrm{BuLi}\left(-100{ }^{\circ} \mathrm{C}\right)$ or $i \mathrm{PrMgCl} \cdot \mathrm{LiCl}^{[125]}\left(-78^{\circ} \mathrm{C}\right)$ in THF. The target ortholithiophenyl isocyanide could also be obtained from the bromo derivative 159-Br, synthesized from inexpensive 2-bromoaniline. The best and most reproducible results, in this case, were achieved with $n \mathrm{BuLi}$ in THF at $-78{ }^{\circ} \mathrm{C}$. Different electrophiles were tested in their reaction with ortho-lithiophenyl isocyanide (188-Li) generated in situ in this way (Table 7). ${ }^{[126]}$ The respective 2-substituted phenyl isocyanides (192) were obtained in high yields (79-88\%), except for 2-formylphenyl isocyanide 192c (55\%).

Table 7. Synthesis of 2-substituted phenyl isocyanides (192).

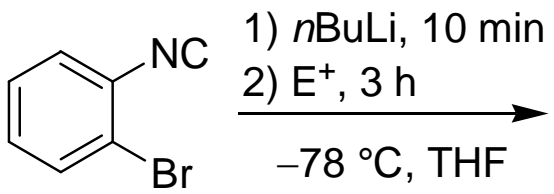

$159-\mathrm{Br}$<smiles>Cc1ccccc1F</smiles>

192

Electrophile

[a] Yield of isolated product

The standard reagent for the electrophilic installation of a formyl group, $N, N$-dimethyl formamide, in this case led to 2-(formylamino)-benzaldehyde 196, which presumably was 
formed by base-catalyzed hydrolysis of the initially formed 1,3-benzooxazine derivative 194 under the aqueous work-up conditions (Scheme 50).

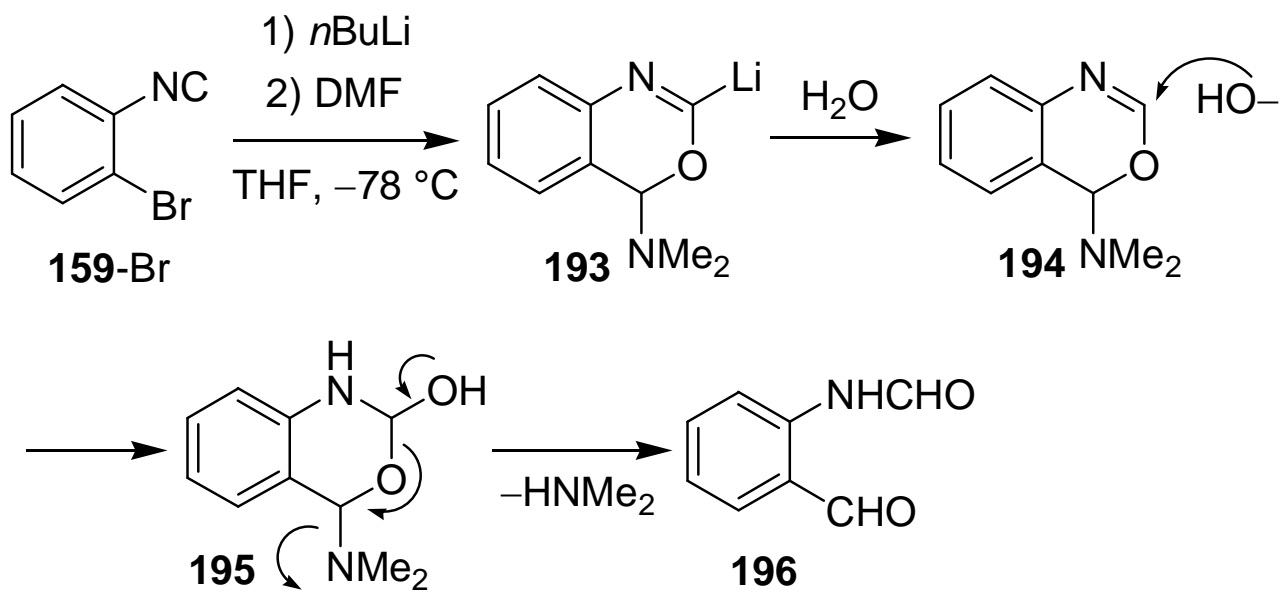

Scheme 50. Reaction of 159-Br with $N, N$-dimethylformamide.

The 2-substituted phenyl isocyanides prepared in this way can be used for many purposes, particularly in multicomponent Ugi-Passerini reactions ${ }^{[6]}$ or for the synthesis of correspondingly substituted anilines, to which isocyanides can easily be hydrolyzed under acidic conditions. $^{[127]}$

\section{Synthesis of Substituted 3H-Quinazolin-4-ones and 3H-Quinazolin-4-thiones}

When isocyanates and isothiocyanates were employed as electrophiles, cyclic 3H-quinazolin-4-ones (-thiones) 191 were formed in high yields (69-91\%) (Scheme 51). Typically, the reactions with isocyanates were carried out at $-78{ }^{\circ} \mathrm{C}$ and quenched with water at the same temperature, but in the case of isothiocyanates the mixtures were gradually warmed to $-40{ }^{\circ} \mathrm{C}$ before quenching.

In contrast to these reactions of a ortho-lithiated phenylisocyanide, $\alpha$-lithiated isocyanides have been reported mainly to give bis-adducts with isocyanates, ${ }^{[15 b]}$ indicating that the metalated five-membered heterocyclic intermediates formed in that case, were much more reactive than the lithiated derivatives of type 190 - $\mathrm{Li}$ formed from the $\beta$-lithiated isocyanide. This makes it possible to further diversify the 2-substituent of the $3 H$-quinazolin-4-ones (-thiones) 191 by trapping the intermediate 190-Li with a second electrophile $\mathrm{El}^{2} \mathrm{X}$ in situ. 


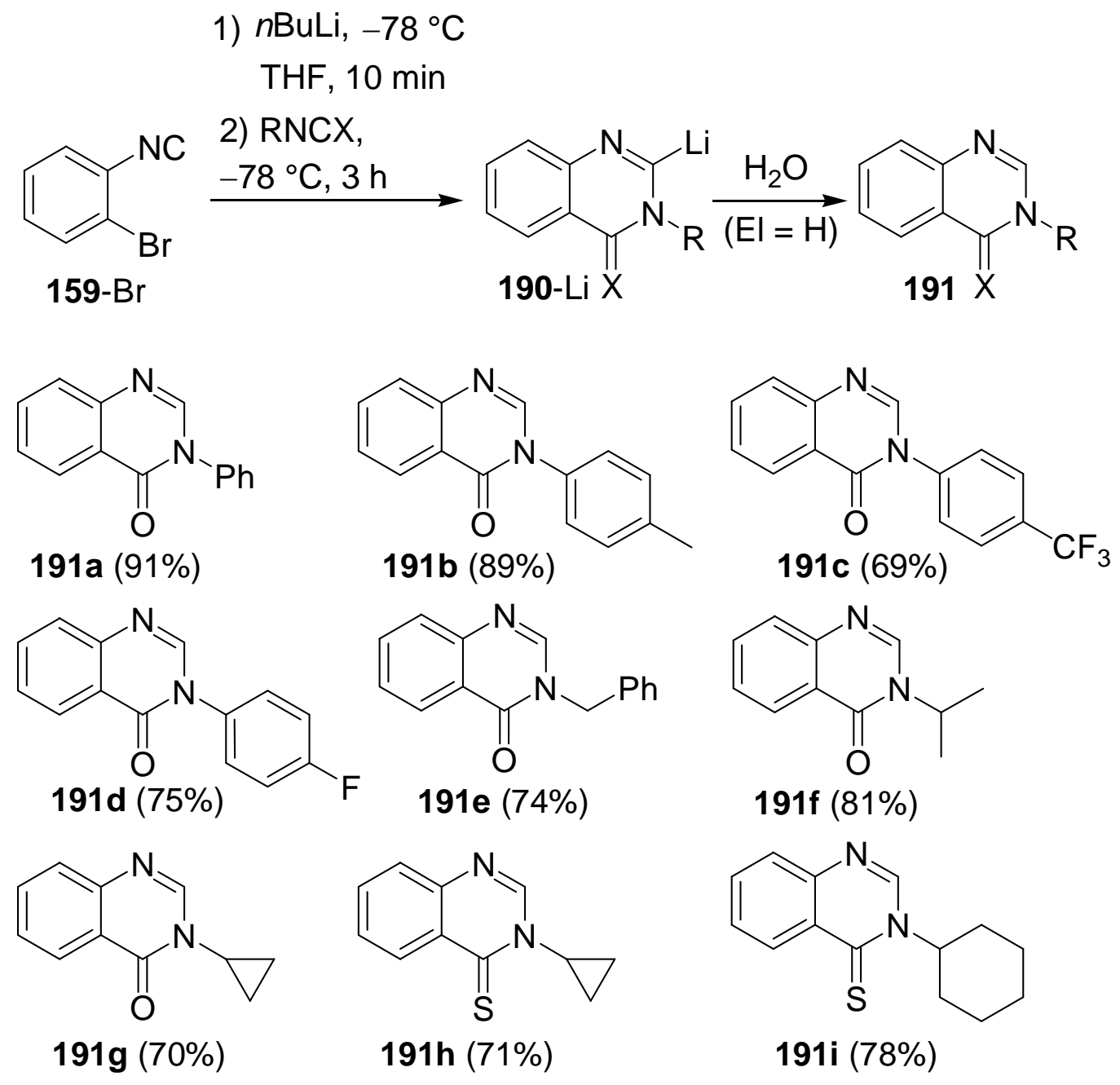

Scheme 51. Synthesis of $3 H$-quinazolin-4-ones $3 H$-quinazolin-4-thiones 191.

Various 2,3-disubstituted 3H-quinazolin-4-ones $\mathbf{1 9 1 j - o}$ could thus be conveniently prepared from 2-bromophenyl isocyanide 159- $\mathrm{Br}$ in a three-step one-pot sequence (Table 8). 2-Halo-3H-quinazolin-4-ones of type $\mathbf{1 9 1 m}$ have been reported to undergo substitution with nucleophiles ${ }^{[128]}$ and also participate in different radical cyclization processes, ${ }^{[129]}$ which opens an access to a large variety of substituted $3 H$-quinazolin4-ones. Copper-catalyzed couplings of aryl thioethers of type 191k with aryl iodides have also been reported. ${ }^{[130]}$ 
Table 8. The synthesis of 2,3-disubstituted 3H-quinazolin-4-ones 191.
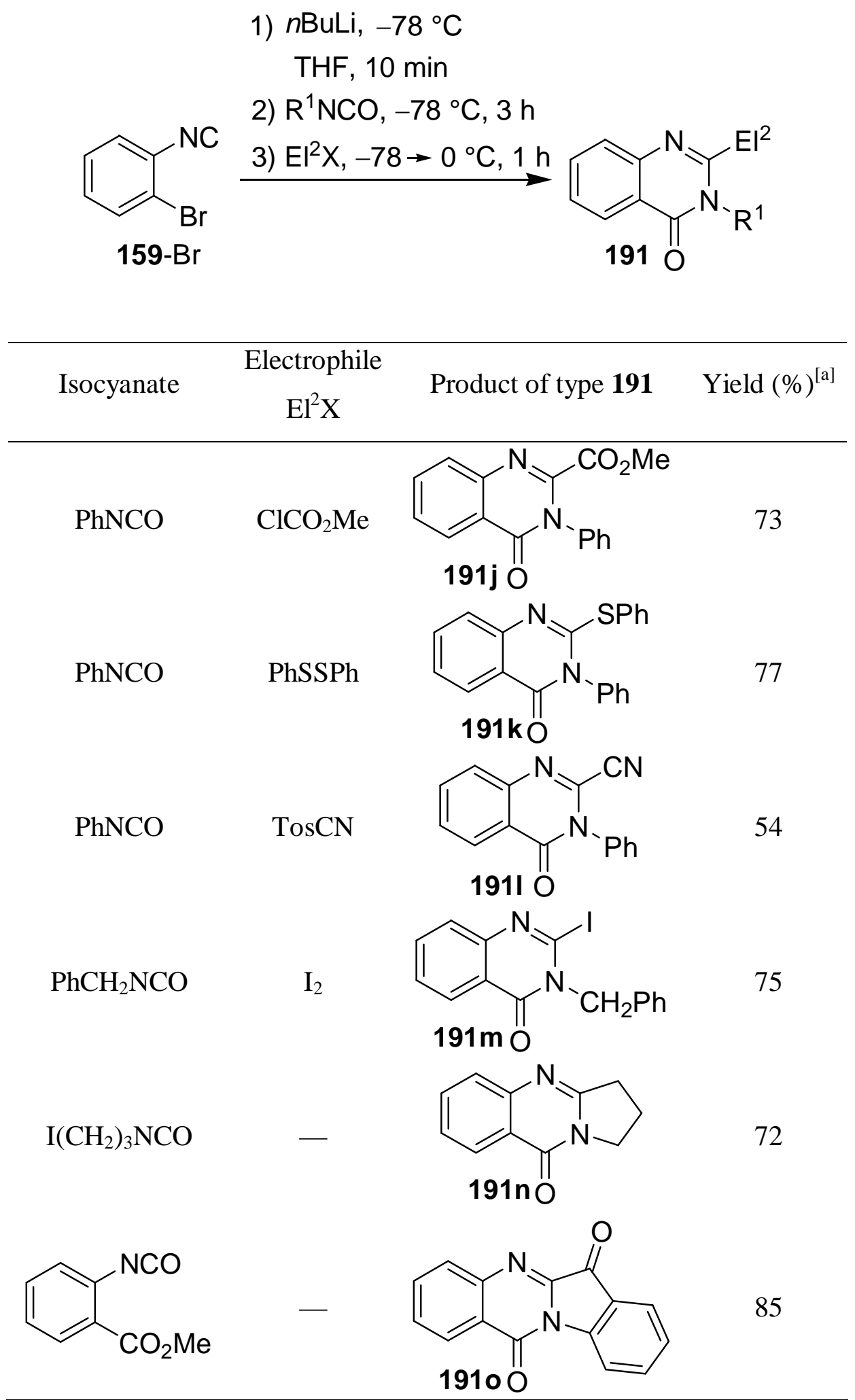

[a] Yield of isolated product. 
Reactions of the lithiated intermediates of type 190-Li with electrophiles can also occur intermolecularly, when the initially employed isocyanate already contains an appropriate functional group. Thus, 3-iodopropyl isocyanate and methyl 2-isocyanatobenzoate in one step gave $3 H$-quinazolin-4-ones 191n and 1910 in 72 and $85 \%$ yield, respectively. Both deoxyvasicinone $191 \mathbf{n}^{[131]}$ and tryptanthrine $1910^{[128 a, 132]}$ are naturally occurring alkaloids with important biological activities.

\section{Conclusion}

In conclusion, 2-substituted phenyl isocyanides are easily obtained by halogen-lithium exchange of ortho-bromophenyl isocyanide (159-Br) and subsequent trapping of the thus generated ortho-lithiophenyl isocyanide $(\mathbf{1 8 8}-\mathrm{Li})$ with electrophiles. This strategy has been effectively employed for the new three-step one-pot synthesis of substituted $3 H$-quinazolin-4-ones (-thiones) (191) including the naturally occurring alkaloids deoxyvasicinone (191n) and tryptanthrine (1910). 


\section{Reactions of ortho-Lithiophenyl (-Hetaryl) Isocyanides with Carbonyl Compounds - Rearrangements of 2-Metallated 4H-3,1-Benzoxazines ${ }^{133}$}

\section{Background and Preliminary Considerations}

In the previous chapter, we reported that ortho-lithiophenyl isocyanide (188-Li), generated by bromine-lithium exchange on $o$-bromophenyl isocyanide $(159-\mathrm{Br})$, can be employed for the synthesis of 2-substituted phenyl isocyanides 192 as well as $3 H$-quinazolin-4-ones and $3 H$-quinazolin-4-thiones 191 (Scheme 52). ${ }^{[13]}$

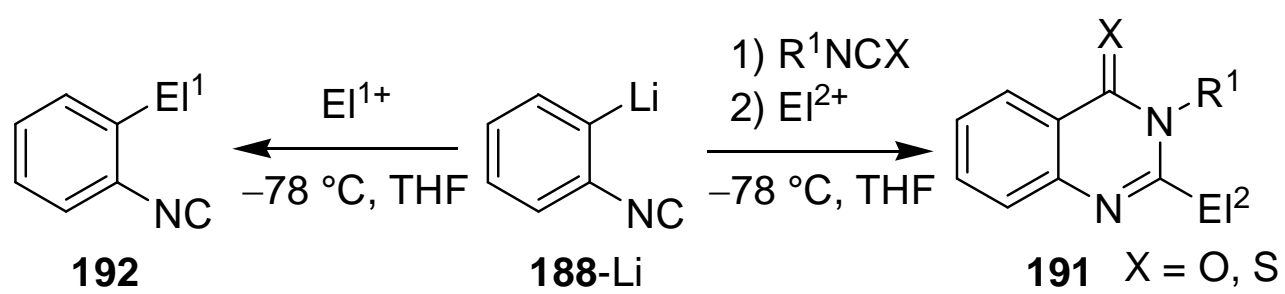

Scheme 52. Previously reported (Chapter 2) utilizations of ortho-lithiophenyl isocyanide (188-Li). ${ }^{[113]}$

For further elaboration of the chemistry of ortho-lithiophenyl isocyanide, we investigated its reactions with aldehydes, ketones, and carbon dioxide in details with the aim to develop an approach to substituted 4H-3,1-benzoxazines 201 and $4 H$-benzo[3,1] oxazin-4-ones 199, respectively (Scheme 53). To broaden the scope of this method and to show its generality, we also intended to generate and employ in synthesis of various heterocycles some heteroanalogues 200 of ortho-lithiophenyl isocyanide 188-Li.

\section{Reactions of ortho-Lithiophenyl (-Hetaryl) Isocyanides with Carbonyl Compounds}

Treatment of ortho-lithiophenyl isocyanide (188-Li) with aldehydes $(\mathbf{2 0 2 a}-\mathbf{i})$ at $-78{ }^{\circ} \mathrm{C}$, and hydrolysis of the reaction mixture at the same temperature led to ortho-isocyanobenzyl alcohols 204 rather than the corresponding 4H-3,1-benzoxazines 201 (Table 9, entries 1-9). This may be due to a predominance of the initial alcoxide adduct 203 in the equilibrium with the lithiobenzoxazine 198. 
<smiles>O=c1oc([AlH2])nc2ccccc12</smiles>

197

2) $\mathrm{El}^{1} \mathrm{X}$<smiles>O=c1oc([Al])nc2ccccc12</smiles>

199
1) $\mathrm{CO}_{2}$<smiles>[X]c1ccccc1N=[N+]=[N-]</smiles>

188-Li

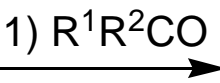<smiles>[R]C1([R7])OC([AlH2])=Nc2ccccc21</smiles>

198

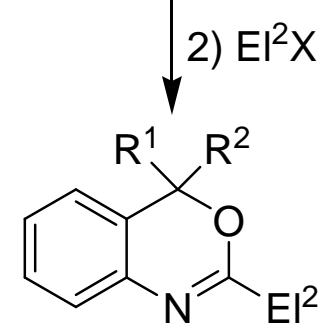

201

Scheme 53. Further elaboration of chemistry of ortho-lithiophenyl (-hetaryl) isocyanides.

The same behaviour was observed upon addition of $\alpha$-metallated isocyanides and ortho-(lithiomethyl)phenyl isocyanides to carbonyl compounds and epoxides, which produced the respective acyclic isocyanoalcohols rather than corresponding 5-, 7- or 8-membered heterocycles $9,{ }^{[134]} 94$ and 96, ${ }^{[60]}$ respectively, (Figure 8) upon hydrolysis of the reaction mixture at low temperature.<smiles>[R]C1([R6])N=COC1([R])[R]</smiles>

9<smiles>[R]c1cc([R])c2c(c1)N=COC([R5])([R5])C2[R2]</smiles>

94<smiles>BrC1CCc2ccccc2N=CO1</smiles>

96

Figure 8. 5-, 7- and 8-Membered heterocycles previously obtained by reactions of metallated isocyanides with aldehydes, ketones and epoxides. ${ }^{[134,60]}$

The reaction of 188 -Li with ketones $(202 \mathbf{k}-\mathbf{m})$, however, after hydrolysis of the reaction mixture at $-78{ }^{\circ} \mathrm{C}$, led to 4,4 -disubstituted $4 H$-3,1-benzoxazines 201 in all cases (entries 11-13). This may be caused by the Thorpe-Ingold conformational effect, ${ }^{[135]}$ which places the alkoxide more closely to the isocyano group, and thus favors the cyclization of $\mathbf{2 0 3}$ to 198. 
Table 9. Reaction of 188-Li with aldehydes and ketones succeeded by quenching with water at $-78^{\circ} \mathrm{C}$.

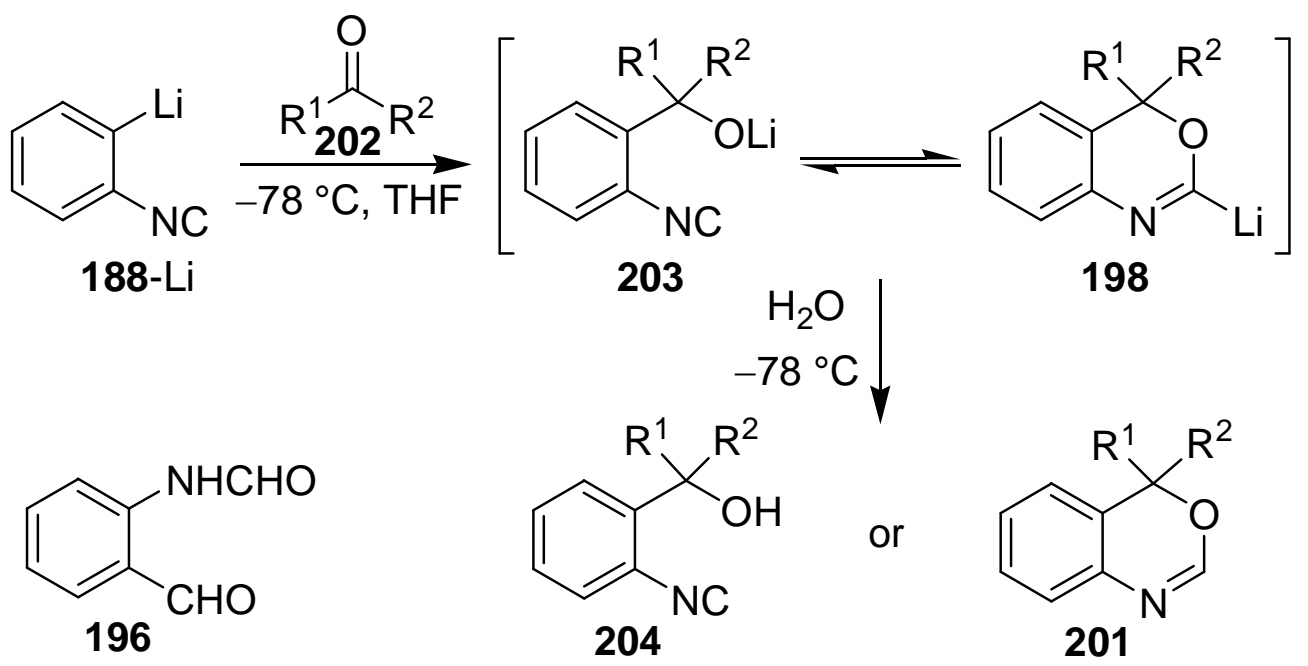

\begin{tabular}{|c|c|c|c|c|c|}
\hline Entry & $\begin{array}{c}\text { Carbonyl } \\
\text { Compound } 202\end{array}$ & $\mathrm{R}^{1}$ & $\mathrm{R}^{2}$ & Product & $\begin{array}{c}\text { Yield }^{\mathrm{Ia \top}} \\
(\%)\end{array}$ \\
\hline 1 & $\mathbf{a}$ & $\mathrm{Ph}$ & $\mathrm{H}$ & $204 a$ & 84 \\
\hline 2 & b & $4-\mathrm{MeOC}_{6} \mathrm{H}_{4}$ & $\mathrm{H}$ & $204 b$ & 83 \\
\hline 3 & c & $4-\mathrm{ClC}_{6} \mathrm{H}_{4}$ & $\mathrm{H}$ & $204 c$ & 89 \\
\hline 4 & d & 4-pyridyl & $\mathrm{H}$ & 204d & 82 \\
\hline 5 & $\mathbf{e}$ & $\begin{array}{l}\text { 2-(5-methyl- } \\
\text { thienyl) }\end{array}$ & $\mathrm{H}$ & $204 \mathrm{e}$ & 78 \\
\hline 6 & $\mathbf{f}$ & $\begin{array}{l}\text { 2-(5-methyl- } \\
\text { furyl) }\end{array}$ & $\mathrm{H}$ & $204 f$ & 88 \\
\hline 7 & $\mathbf{g}$ & $t \mathrm{Bu}$ & $\mathrm{H}$ & $204 \mathrm{~g}$ & 80 \\
\hline 8 & h & $\mathrm{iPr}$ & $\mathrm{H}$ & $204 h$ & 36 \\
\hline 9 & $\mathbf{i}$ & $\begin{array}{l}\text { 1-(2-methyl- } \\
\text { 2-butene-1-yl) }\end{array}$ & $\mathrm{H}$ & $204 i$ & 70 \\
\hline 10 & $\mathbf{j}$ & $\mathrm{Me}_{2} \mathrm{~N}$ & $\mathrm{H}$ & 196 & 76 \\
\hline 11 & $\mathbf{k}$ & $\mathrm{Ph}$ & $\mathrm{Ph}$ & $201 k$ & 48 \\
\hline 12 & 1 & $\mathrm{Ph}$ & $\mathrm{CF}_{3}$ & 2011 & 78 \\
\hline 13 & $\mathbf{m}$ & $\mathrm{Me}$ & $\mathrm{Me}$ & $201 \mathrm{~m}$ & 52 \\
\hline
\end{tabular}

[a] Yields of isolated product. 
It might also be due to enhanced thermodynamic stability of the cyclized 198 over the non-cyclized form 203 for the cases with $\mathrm{R}^{1}, \mathrm{R}^{2} \neq \mathrm{H}$. Upon treatment of 188-Li with dimethylformamide and subsequent addition of water, 2-(formylamino)benzaldehyde (196) was isolated in $76 \%$ yield, apparently arising by hydrolysis of the initially formed 4H-3,1-benzoxazine 194, as has previously been discussed (Chapter 2). ${ }^{[113]}$ Obviously, in this case the $\mathrm{NMe}_{2}$-donor group facilitated cyclization of 203 to 198 . Although 2-substituted 4H-3,1-benzoxazines are well-known compounds, simply accessible from the respective $o$-aminophenylcarbinols, ${ }^{[136]}$ there is no generally applicable method for the synthesis of 2-unsubstituted heterocycles of type 201. ${ }^{[137]}$

Yields of the final products 204 and 201, respectively, were high from all non-enolizable aldehydes and ketones except for $\mathbf{2 0 1 k}$ from benzophenone (202k), which has two large substituents, that might sterically encumber the addition of 188-Li (entry 11). The yields of $204 \mathrm{~h}$ from isobutyraldehyde $(202 \mathrm{~h})$ and of $204 \mathrm{~m}$ from acetone $(202 \mathrm{~m})$ were significantly lower, probably because 188 - Li can abstract a proton from $202 \mathrm{~h}$ and $\mathbf{2 0 2 m}$ in competition with adding to them (entries 8, 13). The reaction of ortho-lithiophenyl isocyanide 188-Li with 3-methylbut-2-enal (202i) afforded the 1,2-adduct 204i in $70 \%$ yield without traces of the 1,4-addition product (entry 9). Unsaturated alcohols of type 204i, previously prepared by addition of substituted vinylmagnesium bromides to $\mathrm{N}$-(o-acylphenyl)formamides, have been shown to undergo a Lewis acid-catalyzed cyclization followed by rearrangement to 1 -formyl-1,2-dihydroquinoline derivatives. ${ }^{[138]}$ The adducts of ortho-lithiophenyl isocyanide (188-Li) to carbonyl compounds 202 can also be trapped with electrophiles other than water (Table 10). Thus, the initial adduct (203d) of 188-Li to pyridine-4-carbaldehyde (202d) upon treatment with methyl chloroformate afforded the acyclic mixed methyl carbonate $\mathbf{2 0 5}$ in 56\% yield (entry 1), while the adduct $\mathbf{1 9 8 1}$ to 1,1,1-trifluoroacetophenone (202I) was trapped with methyl chloroformate and ethyl bromoacetate to furnish the 2-substituted 4H-3,1-benzoxazines 2011- $\mathrm{CO}_{2} \mathrm{Me}(45 \%)$ and 2011- $\mathrm{CH}_{2} \mathrm{CO}_{2} \mathrm{Et}(47 \%)$, respectively (entries 2, 3). Addition of iodine to the same reaction mixture from 188- $\mathrm{Li}$ and 2021 and subsequent aqueous work-up gave the oxo derivative 206 (77\% yield, entry 4). The initially formed 2-iodo-4phenyl-4-(trifluoromethyl)-4H-benzo[1,3]oxazine (2011-I) apparently undergoes rapid nucleophilic substitution by water and enol to ketone tautomerization during the work-up procedure and/or column chromatography on silica gel. The analogous 2-chloro derivative (2011-Cl), generated by treatment of the adduct of $188-\mathrm{Li}$ to $202 \mathrm{l}$ with $N$-chlorosuccinimide as an electrophile, also could not be isolated and afforded 206. 
Table 10. Reaction of 188-Li with carbonyl compounds 202 and trapping of the metallated intermediates with electrophiles other than water.

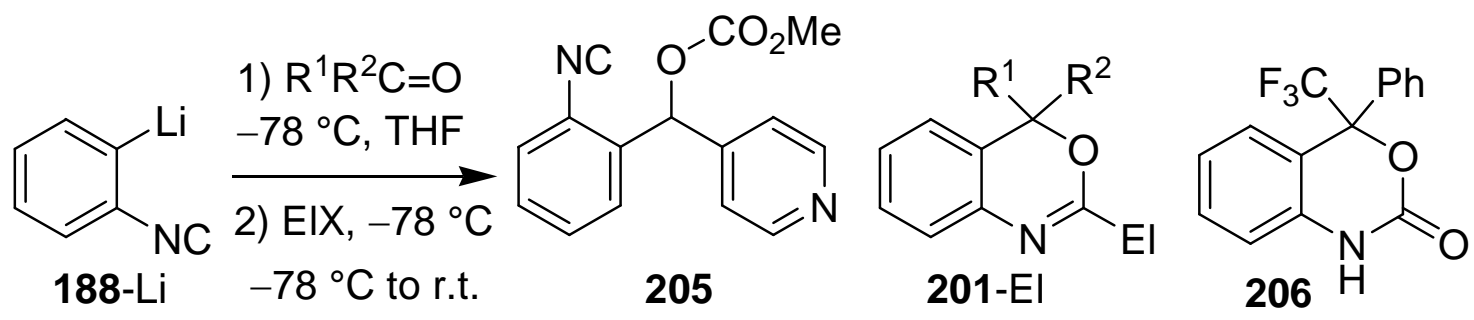

\begin{tabular}{ccccc}
\hline Entry & Carbonyl & Electrophile & Product & Yield $^{\lfloor\mathrm{a}\rfloor}$ \\
& Compound & ElX & & $(\%)$
\end{tabular}

$202 R^{1} \quad R^{2}$

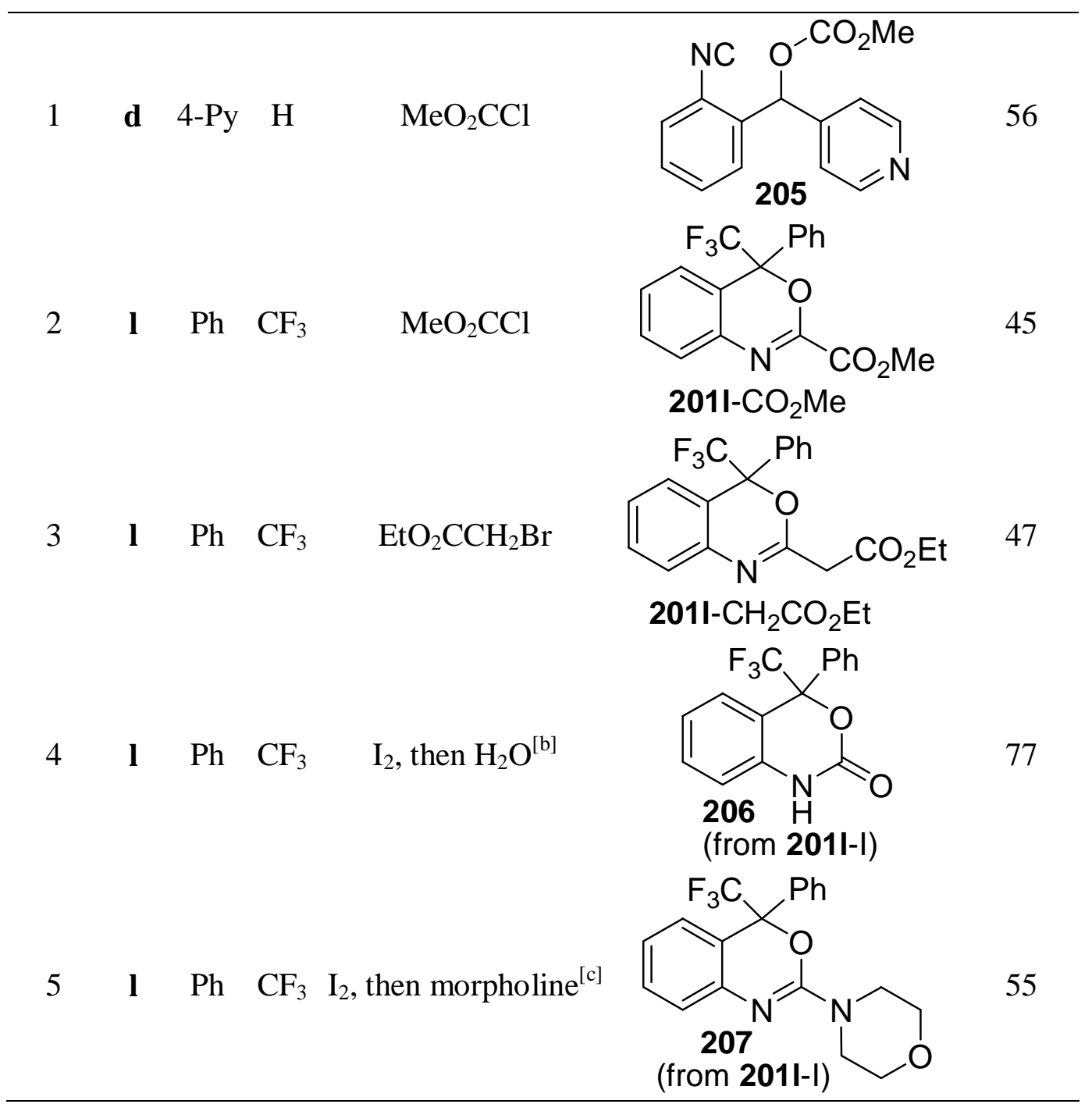

[a] Yield of isolated product. [b] Aqueous work-up procedure. [c] Morpholine was added before aqueous work-up. 
The same reaction mixture from $188-\mathrm{Li}, 202 \mathrm{l}$ and iodine upon treatment with morpholine prior to the aqueous work-up led to 2-morpholinylbenzoxazine 207 in 55\% yield (entry 5). ortho-Lithiophenyl isocyanide 188 - $\mathrm{Li}$ also reacts with carbon dioxide at $-78{ }^{\circ} \mathrm{C}$ to initially form lithium ortho-isocyanobenzoate $\mathbf{2 0 8}$, which equilibrates with the 2-lithiobenzoxazin4-one 197. The latter reacts with iodine to furnish 2-iodobenzoxazin-4-one (199-I) which readily undergoes in situ substitution by added nucleophiles such as water, morpholine and aziridine to provide the correspondingly substituted 4- $H$-benzo[3,1]oxazin-4ones $^{[139,140]}$ 199-Nu and isatoic anhydride 209 in a one-pot four-step procedure in moderate yields (Scheme 54).
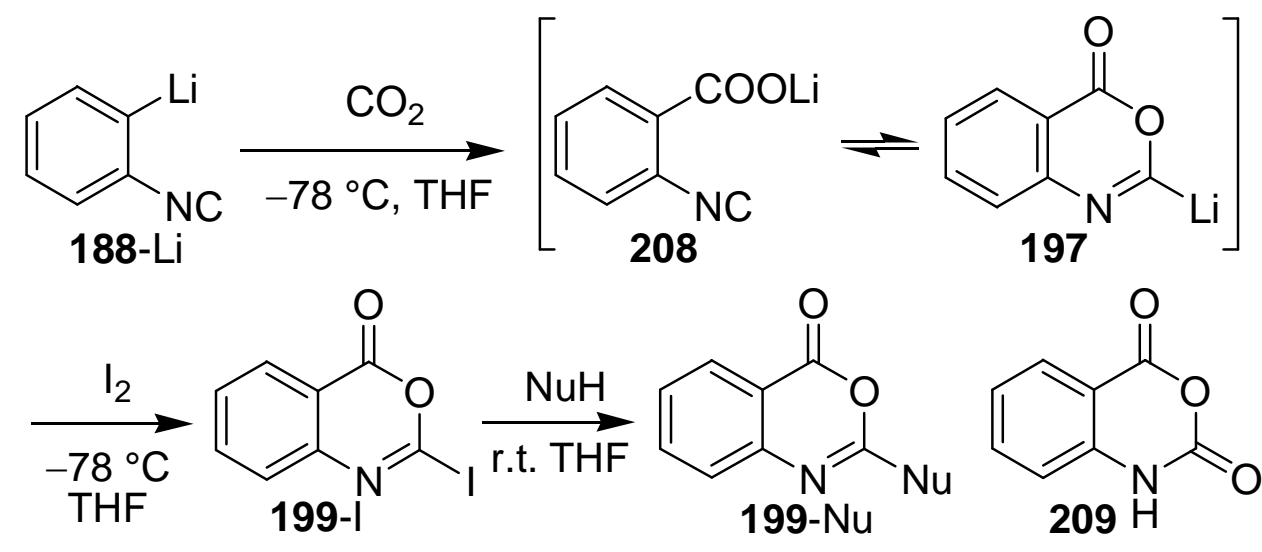

$\mathrm{NuH}=$ morpholine; 199-morph (45\%)

$\mathrm{NuH}=$ aziridine; 199-azirid (50\%)

$\mathrm{NuH}=\mathrm{H}_{2} \mathrm{O} ; 209$ (61\%)

Scheme 54. Synthesis of 2-substituted 4H-benzo[d][1,3]oxazin-4-ones (199-Nu) and isatoic anhydride 209.

\section{Copper(I)-catalyzed Cyclizations of Isocyanobenzyl alcohols 204}

The isocyanobenzylalcohols 204 with $\mathrm{R}^{2}=\mathrm{H}$ obtained from 188-Li and aldehydes were found to undergo cyclization to the corresponding $4 H$-3,1-benzoxazines 201 under $\mathrm{Cu}_{2} \mathrm{O}$ catalysis in high yields (Table 11, entries 1-5) in the same way, as it had previously been demonstrated for the synthesis of 4,5-dihydro-3,1-benzoxazepines 94 and 4H-5,6-dihydro3,1-benzoxazocines $96 .{ }^{[60]}$ 
Table 11. $\mathrm{Cu}_{2} \mathrm{O}$-Catalyzed cyclization of isocyanobenzylalcohols 204 .<smiles></smiles>

204

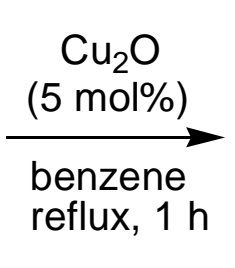<smiles>[R]C1OC(=N)c2ccccc21</smiles>

201

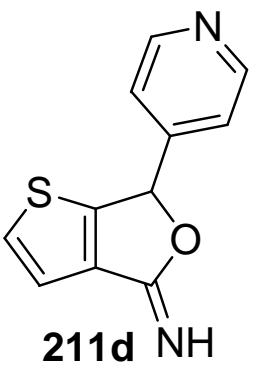<smiles>COc1ccc(C2OC=Nc3ccccc3C2c2ccc(OC)cc2)cc1</smiles> 
Table 11. (continued) $\mathrm{Cu}_{2} \mathrm{O}$-Catalyzed cyclization of isocyanobenzylalcohols 204 .

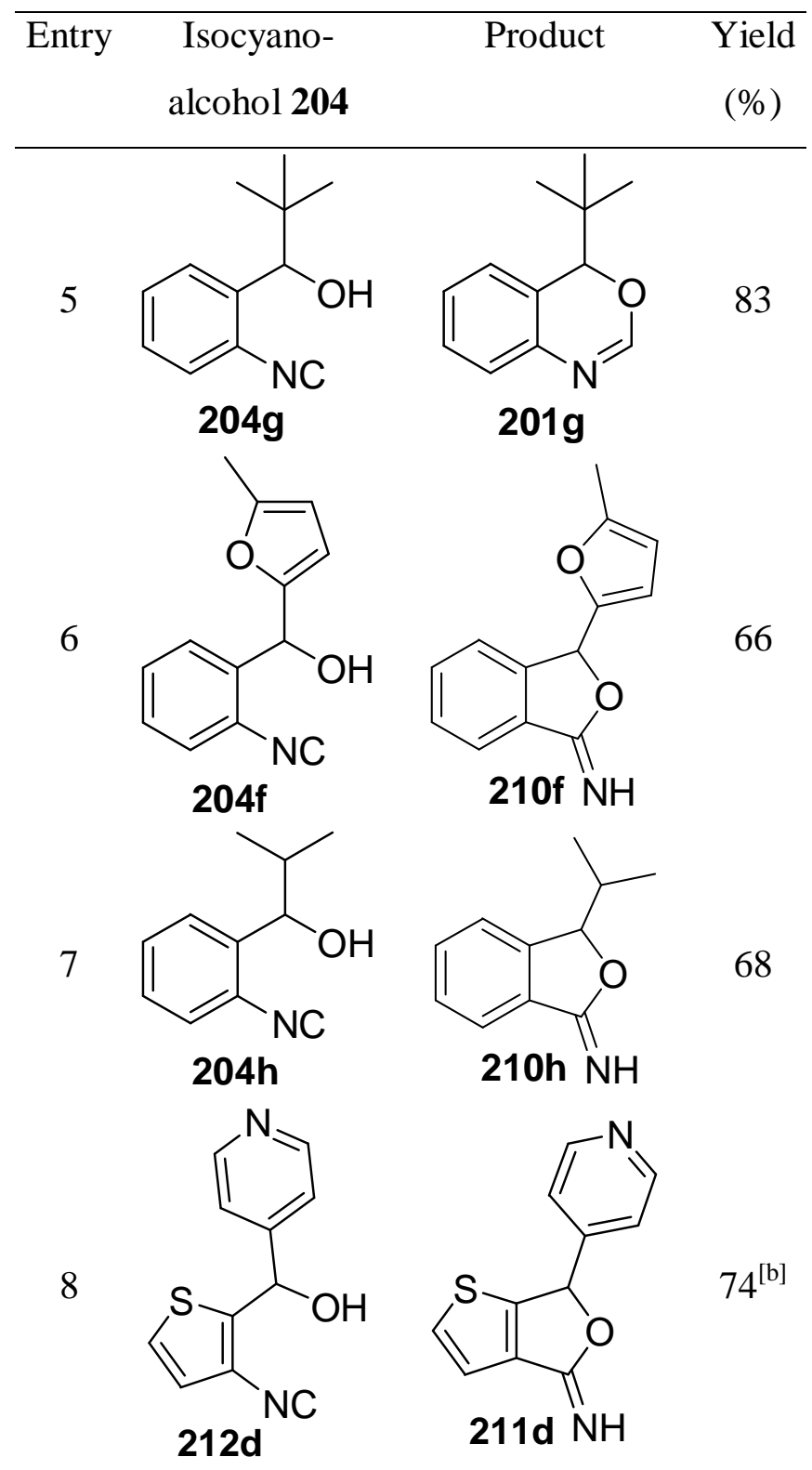

[a] Yield of isolated product. [b] Total yield for addition and subsequent cyclization, the crude isocyanoalcohol 212d was used for the transformation without purification. 
Treatment of the isocyanobenzylalcohols 204 with bases such as DBU and $\mathrm{KO} t \mathrm{Bu}$ also led to the target 4H-3,1-benzoxazines 201, although in lower yields. Such 2-unsubstituted compounds turned out to be unstable in acidic as well as in basic media, but could be isolated by flash chromatography on silica gel pretreated with triethylamine.

In the cases of the isocyanobenzylalcohols $204 \mathbf{f}, 204 \mathrm{~h}$ and $212 \mathrm{~d}$ (the latter was used in the cyclization step directly after its formation from 3-isocyano-2-lithiothiophene (216) and pyridine-4-carbaldehyde (202d) without purification by column chromatography) the arene-annelated tetrahydrofuranimines 210f,h and 211d, respectively, were obtained unexpectedly as the sole products. Products of this type and indolin-2-ones 215 were also formed upon warming to ambient temperature of the reaction mixtures after the addition of ortho-lithiophenyl isocyanide (188-Li) and ortho-lithiohetaryl isocyanides 216 and 218 to various carbonyl compounds (Table 12). The latter two organolithium reagents were generated with equal ease as $\mathbf{1 8 8}$-Li from the corresponding bromohetaryl isocyanides.

\section{Novel Rearrangements of 2-Metallated 4H-3,1-Benzoxazines}

Apparently, the lithiated intermediates of type 198 can undergo ring contraction to form the lithiated precursors of $\mathbf{2 1 3}$ or $\mathbf{2 1 4}$ upon warming to ambient temperature of the reaction mixture obtained after addition of lithiated isocyanides 200 to carbonyl compounds. All three compounds of type 198 with trifluoromethyl substituents obviously rearranged to iminophthalanes 2100 and its heteroanalogues 2171, 2191, respectively (Table 12). The other examples only furnished indolin-2-ones $\mathbf{2 1 5 n}, \mathbf{2 1 5 k}$ and $\mathbf{2 1 7 k}$, respectively. Compound $215 \mathrm{n}$ was isolated after the reaction of $188-\mathrm{Li}$ with pyridine-2-carbaldehyde (202n) and subsequent treatment of the reaction mixture with water at $-78{ }^{\circ} \mathrm{C}$. In this case, the coordination of lithium by the pyridyl nitrogen may have played a crucial role in shifting of the equilibrium from 203 to 198 and facilitate the rearrangement to the lithiated precursor of 214. Indolin-2-ones (2-oxoindoles) of type 215 represent an important class of heterocycles with a wide range of biological activities, ${ }^{[141]}$ while only a few isobenzofuran-1(3H)-imines (iminophthalanes) of type $\mathbf{2 0 0}$ have been described previously. ${ }^{[142]}$ 
Table 12. Addition of ortho-lithioaryl isocyanides to aldehydes and ketones with subsequent rearrangement.

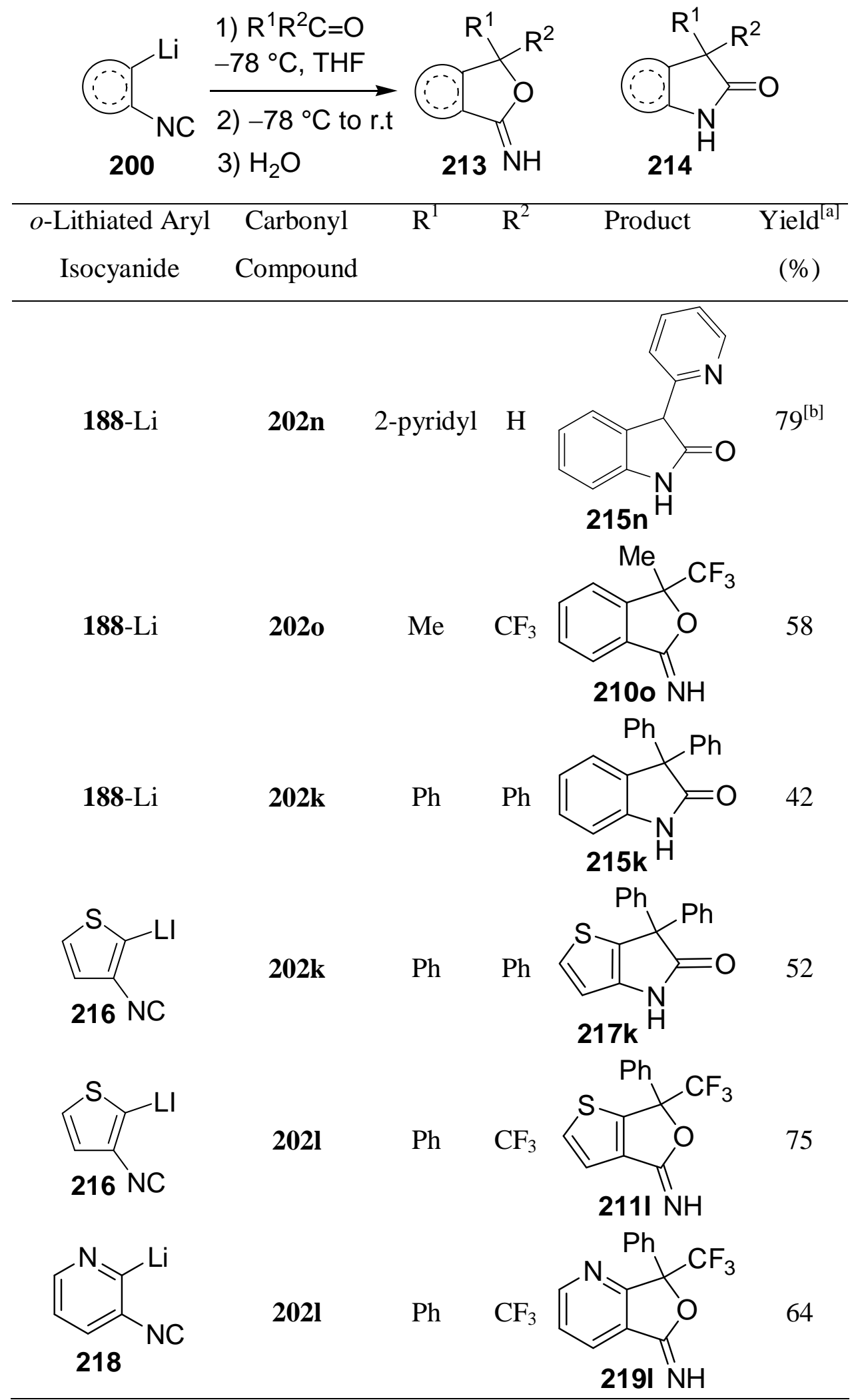

[a] Yield of isolated product. [b] The reaction mixture was treated with $\mathrm{H}_{2} \mathrm{O}$ at $-78^{\circ} \mathrm{C}$. 


\section{Mechanistic Considerations}

The only known ring contraction of 2,4-diarylsubstituted 4H-3,1-benzoxazines with formation of $3 \mathrm{H}$-indol-3-ols proceeds in strongly basic media and was rationalized mechanistically as an intramolecular nucleophilic addition of 4-deprotonated benzoxazine 220 followed by epoxide opening (Scheme 55). ${ }^{[143]}$ However, the above mentioned benzotetrahydrofuranimines and indolin-2-ones obviously cannot be formed in such a way. Formally, the isobenzofuranimine of type $\mathbf{2 1 0}$ and the indolin-2-one of type $\mathbf{2 1 5}$, respectively, could arise from the initially formed 2-lithium $4 H-3,1$-benzoxazine of type 198 by a [1,2]-migration of the aryl group next to nitrogen or of the alkyl group next to the oxygen atom and subsequent protonation.

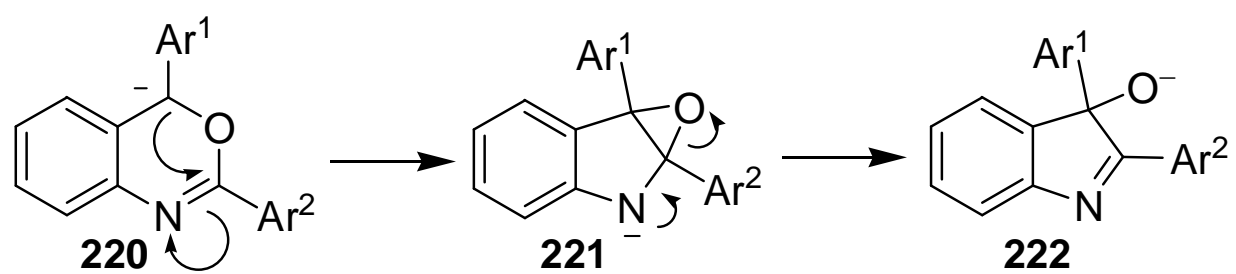
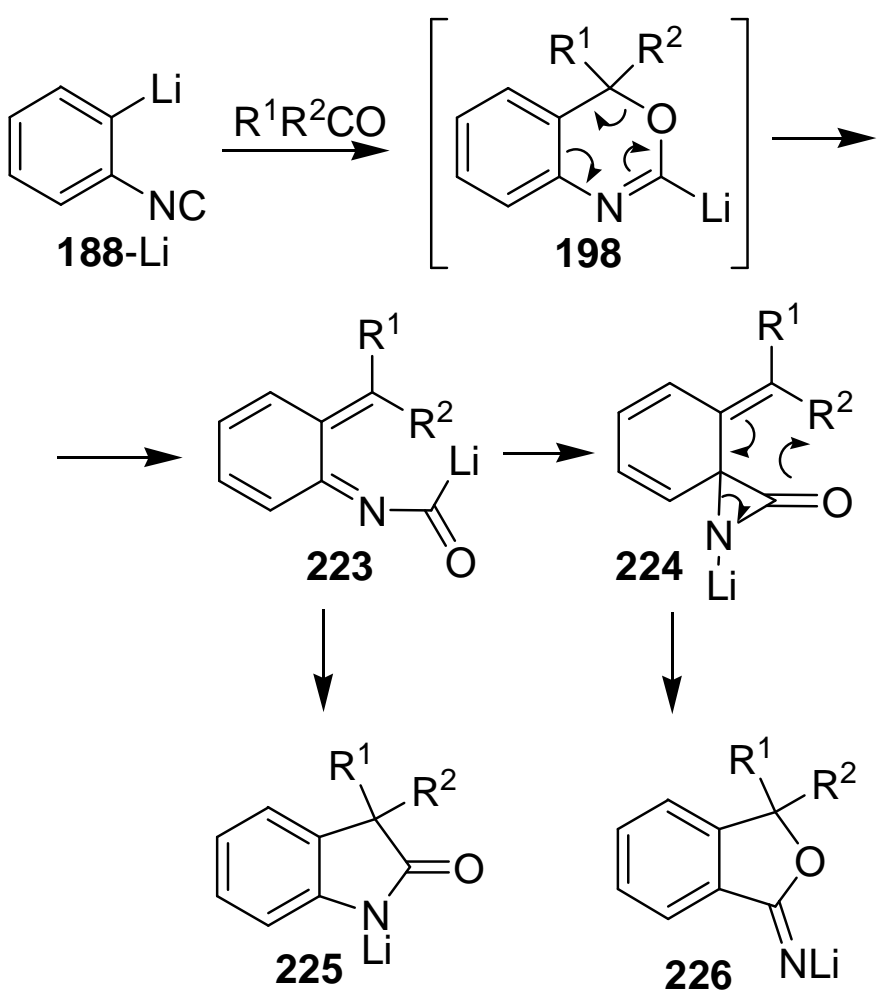

Scheme 55. A known ring contraction of 2,4-diaryl-3,1-benzoxazines ${ }^{[143]}$ and proposed mechanism for the reaction of $\mathbf{1 8 8}$-Li with ketones. 
Rearrangements with [1,2]-migration of an alkyl group from an oxygen and from a quaternary nitrogen atom to an adjacent carbanion center have been known for quite some time as Wittig ${ }^{[144]}$ and Stevens rearrangements, ${ }^{[145]}$ respectively. Yet, the stereoelectronic requirements make such [1,2]-migrations unlikely in the case of 198. More probably, the intermediate 198 undergoes a pericyclic ring opening to yield 223, which by intramolecular 1,4-addition would furnish the lithiated indolin-2-one $\mathbf{2 2 5}$ or by intramolecular 1,2-addition and subsequent $6 \pi$-pericyclic reaction of the resulting 224 provide the lithiated isobenzofuranimines 226 (Scheme 55). ${ }^{[146]}$

On the other hand, in the $\mathrm{Cu}_{2} \mathrm{O}$-catalyzed transformations of isocyanobenzylalcohols 204 to 201 and 210 , the process starts with the coordination of an isocyano group to the $\mathrm{Cu}(\mathrm{I})$ species, and this is succeeded by nucleophilic addition of the hydroxyl group to thus activated isocyano group in $\mathbf{2 2 7}$ to yield, after deprotonation, the metallated 4H-3,1-benzoxazine 228 (Scheme 56).

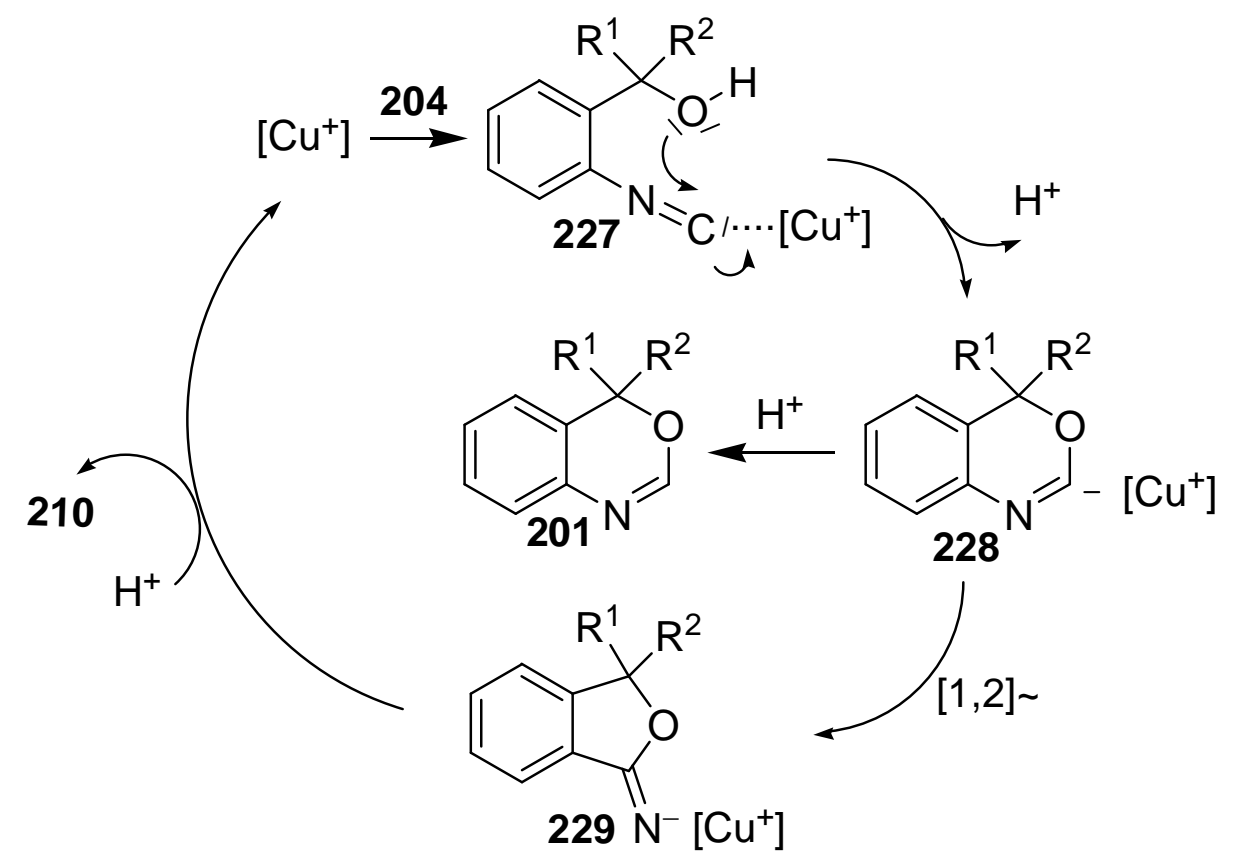

Scheme 56. Mechanism of the $\mathrm{Cu}_{2} \mathrm{O}$-catalyzed cyclization of isocyanobenzylalcohols 204.

The latter rearranges just like 198 to provide the deprotonated isobenzofuran-1(3H)-imine 229 which, after protonation, forms 210. Alternatively, the intermediate 228 can be protonated directly to yield the 4H-3,1-benzoxazine 201 as was also observed experimentally. The transformation of $\mathbf{2 2 7}$ to $\mathbf{2 2 8}$ may be also regarded as an isocyanide 
insertion into an $\mathrm{O}-\mathrm{Cu}$ bond, but not as its insertion into $\mathrm{O}-\mathrm{H}$ linkage ${ }^{[147]}$ because the product of such a process, the $4 H-3,1$-benzoxazine 201 is not converted to 210 under the same reaction conditions, as was confirmed by a control experiment. ${ }^{[148]}$ Interestingly, the predominant formation of $\mathbf{2 0 1}$ or $\mathbf{2 1 0}$ from $\mathbf{2 0 4}$ is intricately controlled by the type of substitution. Thus, 204h $\left(\mathrm{R}^{1}=\mathrm{i} \mathrm{Pr}, \mathrm{R}^{2}=\mathrm{H}\right)$ gave the isobenzofuran-1-(3H)-imine 210h, while 204g $\left(\mathrm{R}^{1}=t \mathrm{Bu}, \mathrm{R}^{2}=\mathrm{H}\right)$ provided the corresponding benzoxazine 201g exclusively. The isocyanobenzylalcohols $\mathbf{2 0 4 f}$ and $\mathbf{2 1 2 d}$ with furyl and thienyl moieties, afforded selectively isobenzofuran-1-(3H)-imine 210f and thiophene-annelated tetrahydrofuranimine 211d, respectively, whereas all other aryl-substituted isocyanobenzylalcohols 204a-204d gave the corresponding 4H-3,1-benzoxazines 201.

\section{Conclusion}

In conclusion, the reactions of ortho-lithiophenyl isocyanide (188-Li) and other ortho-lithiohetaryl isocyanides $(\mathbf{2 1 6}, \mathbf{2 1 8})$ with aldehydes, ketones and carbon dioxide furnish, apart from the expected isocyanobenzylalcohols 204, 4H-3,1-benzoxazines 201 and $4 H$-benzoxazin-4-ones 199-Nu, also iminophthalanes of type $\mathbf{2 1 0}$ or indolin-2-ones of type 215, respectively, by two novel rearrangements of the intermediate 2-lithio $4 H-3,1$ benzoxazines (198). 


\section{Synthesis of 1-Substituted Benzimidazoles from o-Bromophenyl Isocyanide and Amines ${ }^{149}$}

\section{Background and Preliminary Considerations}

Compounds containing a benzimidazole moiety possess a wide range of biological activities and therefore represent "privileged" structures having a significant importance in medicinal chemistry. ${ }^{[120,150]}$ In fact, certain compounds of this type with high activity against Hepatitis $\mathrm{B}$ and $\mathrm{C}$ viruses have been identified, ${ }^{[151]}$ others have been found to be potent lymphocyte specific kinase (Lck) inhibitors, ${ }^{[152]}$ nonpeptide thrombin inhibitors, ${ }^{[153]}$ and antiallergic agents. ${ }^{[154]}$

The classical construction of the five-membered heterocycle in benzimidazoles involves the reaction of an $o$-phenylenediamine with a carboxylic acid or one of its equivalents under harsh dehydrating conditions. ${ }^{[155]}$ Alternatively, several transition metal-catalyzed syntheses of benzimidazoles and related systems have been reported recently. ${ }^{[156]}$ The following precursors have been typically used so far: 2-haloacetanilides, $N$-substituted amidines, $\quad N$-substituted $\quad N^{\prime}$-(2-halophenyl)amidines and -guanidines, $N$-substituted $N^{\prime}$-(2-halophenyl)ureas and -thioureas to give the corresponding 2-substituted benzimidazoles. We envisaged, that a different convenient access to 2-unsubstituted benzimidazoles, which remained elusive so far, could start from primary amines and ortho-haloaryl isocyanides, which have already shown their versatility as building blocks for various other heterocycles. ${ }^{[88,113,133]}$ Isocyanides are known to react with amines in the presence of copper ${ }^{[157]}$ as well as other metal salts ${ }^{[158]}$ to form amidines in excellent yields. Amidines formed from ortho-haloaryl isocyanides in such a way ought to be able to undergo an intramolecular copper-catalyzed $N$-arylation ${ }^{[159]}$ to furnish benzimidazoles. As both steps require the same type of catalyst, one ought to be able to perform them sequentially in a one-pot operation. This process would provide synthetically useful 2-unsubstituted benzimidazoles which can be further elaborated by attaching various substituents at the 2-position e. g. by means of lithiation/electrophilic substitution ${ }^{[160]}$ or transition metal-catalyzed C-H-activation ${ }^{[161]}$ as well as cross-coupling reactions ${ }^{[162]}$ of the easily accessible corresponding 2-halobenzimidazoles. ${ }^{[163]}$ 


\section{Optimization of the Reaction Conditions for the Synthesis of 1-Benzylbenzimidazole}

The reaction of $o$-bromophenyl isocyanide $(\mathbf{1 5 9}-\mathrm{Br})$ and benzylamine $(\mathbf{2 3 0 a})$ was chosen as a model system for the optimization of reaction conditions (Table 13). Cesium carbonate was found to be the best base, giving higher yields of 1-benzylbenzimidazole (232a) than potassium carbonate (entry 3), potassium phosphate (entry 1), lithium or potassium tert-butoxides (entries 4 and 5, respectively) and triethylamine (entry 6).

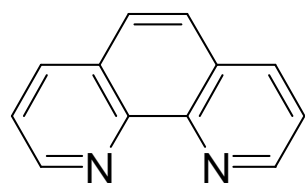

L1<smiles>c1ccc(-c2ccccn2)nc1</smiles>

L5<smiles>CN(C)CCN(C)C</smiles>

L2<smiles>O=C(O)c1ccccn1</smiles>

L3<smiles>Oc1ccccc1-c1ccccc1</smiles>

L4<smiles>CC(C)C(=O)C1CCCCC1=O</smiles>

L6<smiles>CNCCNC</smiles>

L7
$\mathrm{PPh}_{3}$

L8

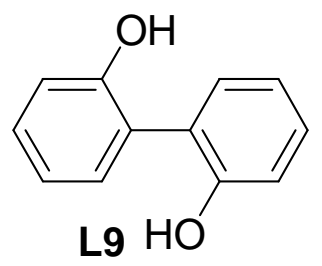

Figure 9. Ligands tested for the synthesis of 232a (see Table 13).

With the latter, the formamidine 231a (52\%) was isolated as the main product along with the benzimidazole (232a) in low yield (11\%). Formation of 231a was also observed in other cases, in which 232a was obtained in low yields. This indicates that the initially proposed sequence of an $\alpha$-addition of the amine to the isocyanide and subsequent intramolecular amination is operational, and apparently the second step is more affected by the conditions used. Dimethylformamide turned out to be the solvent of choice, as the reaction in other solvents (DME, dioxane, toluene, DMSO) afforded 232a in lower yields (entries 7-10). Various ligands L1-L9 (Figure 9) usually employed in copper-catalyzed arylations of amines, have been tested. 1,10-Phenanthroline (L1) and 2-phenylphenol (L4) furnished the best results (68 and 65\% yield of 232a, entries 2 and 14, respectively), although the ligand effect was not as significant as one would have imagined. Replacement of $\mathrm{CuI}$ by $\mathrm{CuBr}$ has almost not changed the yield of $217 \mathbf{a}$ (68 versus $70 \%$, entries 2 and 20), while $\mathrm{Cu}_{2} \mathrm{O}$ was far less effective (entry 21). 
Table 13. Optimization of the reaction conditions for the synthesis of 1-benzylbenzimidazole (232a).

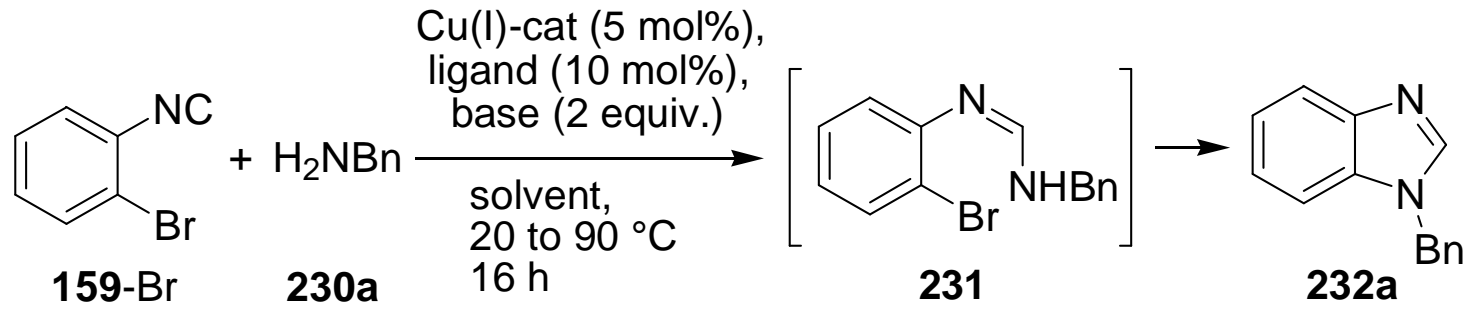

\begin{tabular}{|c|c|c|c|c|c|}
\hline Entry & Catalyst & Ligand & Base & Solvent & Yield $(\%)^{[\mathrm{a}]}$ \\
\hline 1 & $\mathrm{CuI}$ & L1 & $\mathrm{K}_{3} \mathrm{PO}_{4}$ & $\mathrm{DMF}$ & 56 \\
\hline 2 & $\mathrm{CuI}$ & L1 & $\mathrm{Cs}_{2} \mathrm{CO}_{3}$ & DMF & 68 \\
\hline 3 & $\mathrm{CuI}$ & L1 & $\mathrm{K}_{2} \mathrm{CO}_{3}$ & DMF & 27 \\
\hline 4 & $\mathrm{CuI}$ & L1 & $\mathrm{LiO} t \mathrm{Bu}$ & DMF & 58 \\
\hline 5 & $\mathrm{CuI}$ & L1 & $\mathrm{KO} t \mathrm{Bu}$ & DMF & 36 \\
\hline 6 & $\mathrm{CuI}$ & L1 & $\mathrm{Et}_{3} \mathrm{~N}$ & $\mathrm{DMF}$ & $11^{[\mathrm{b}]}$ \\
\hline 7 & $\mathrm{CuI}$ & L1 & $\mathrm{Cs}_{2} \mathrm{CO}_{3}$ & DME & 54 \\
\hline 8 & $\mathrm{CuI}$ & $\mathbf{L 1}$ & $\mathrm{Cs}_{2} \mathrm{CO}_{3}$ & dioxane & 37 \\
\hline 9 & $\mathrm{CuI}$ & L1 & $\mathrm{Cs}_{2} \mathrm{CO}_{3}$ & toluene & 14 \\
\hline 10 & $\mathrm{CuI}$ & L1 & $\mathrm{Cs}_{2} \mathrm{CO}_{3}$ & DMSO & 42 \\
\hline 11 & $\mathrm{CuI}$ & L2 & $\mathrm{Cs}_{2} \mathrm{CO}_{3}$ & DMF & 56 \\
\hline 12 & $\mathrm{CuI}$ & $\mathbf{L 3}$ & $\mathrm{Cs}_{2} \mathrm{CO}_{3}$ & DMF & 49 \\
\hline 13 & $\mathrm{CuI}$ & none & $\mathrm{Cs}_{2} \mathrm{CO}_{3}$ & DMF & 38 \\
\hline 14 & $\mathrm{CuI}$ & L4 & $\mathrm{Cs}_{2} \mathrm{CO}_{3}$ & DMF & 65 \\
\hline 15 & $\mathrm{CuI}$ & L5 & $\mathrm{Cs}_{2} \mathrm{CO}_{3}$ & DMF & 58 \\
\hline 16 & $\mathrm{CuI}$ & L6 & $\mathrm{Cs}_{2} \mathrm{CO}_{3}$ & DMF & 59 \\
\hline 17 & $\mathrm{CuI}$ & L7 & $\mathrm{Cs}_{2} \mathrm{CO}_{3}$ & DMF & 40 \\
\hline 18 & $\mathrm{CuI}$ & L8 & $\mathrm{Cs}_{2} \mathrm{CO}_{3}$ & $\mathrm{DMF}$ & 57 \\
\hline 19 & $\mathrm{CuI}$ & L9 & $\mathrm{Cs}_{2} \mathrm{CO}_{3}$ & $\mathrm{DMF}$ & 32 \\
\hline 20 & $\mathrm{CuBr}$ & L1 & $\mathrm{Cs}_{2} \mathrm{CO}_{3}$ & $\mathrm{DMF}$ & 70 \\
\hline 21 & $\mathrm{Cu}_{2} \mathrm{O}$ & L1 & $\mathrm{Cs}_{2} \mathrm{CO}_{3}$ & DMF & 26 \\
\hline
\end{tabular}

[a] Yield of isolated product 232a. [b] In addition, the intermediate 231a was also isolated in $58 \%$ yield. 
Different methods of reagents addition to the reaction mixture as well as temperature conditions have been tested. Thus, when a solution of benzylamine (230a) and 159-Br was slowly added at $90{ }^{\circ} \mathrm{C}$ to the mixture of the other reagents, no benzimidazole (232a) was formed at all. Carrying out the operation first at r.t. within $2 \mathrm{~h}$, then gradually (within $30 \mathrm{~min}$ ) warming the mixture to $90{ }^{\circ} \mathrm{C}$, and then keeping it at the same temperature for $14 \mathrm{~h}$, gave the best yields of 232a. Other $o$-halophenyl isocyanides were also tested towards the same transformation. $o$-Chlorophenyl isocyanide $(159-\mathrm{Cl})$ did not provide the corresponding benzimidazole neither under the best conditions found for $159-\mathrm{Br}$ nor at increased temperatures up to $140{ }^{\circ} \mathrm{C}$. $o$-Iodophenyl isocyanide (159-I) with benzylamine (230a), on the contrary, furnished benzimidazole $232 \mathrm{a}$ even at $50{ }^{\circ} \mathrm{C}$, but in $22 \%$ yield only. The conditions optimized for $159-\mathrm{Br}\left(90^{\circ} \mathrm{C}\right)$ applied to $159-\mathrm{I}$, gave 232a in $40 \%$ yield. Accordingly, it was not considered meaningful to test other temperatures for 159-I, and work was focused on the use of $\mathbf{1 5 9}-\mathrm{Br}$ for the synthesis of benzimidazoles $\mathbf{2 3 2}$.

\section{Scope and Limitations of the Synthesis}

Employing the optimized conditions for 232a, various $N$-substituted benzimidazoles 232b-l have been synthesized from $o$-bromophenyl isocyanide $(159-\mathrm{Br})$ and primary amines 230b-l (Table 14). $n$-Alkylamines and benzylamines in general gave slightly better yields of benzimidazoles $\mathbf{2 3 2}$ than sec-alkylamines like cyclopropylamine and cyclohexylamine (entries 10 and 11, respectively), while 2-methoxybenzylamine with an ortho-substituent still afforded the corresponding benzimidazole $232 \mathrm{f}$ in $65 \%$ yield (entry 6). Amines with decreased nucleophilicity, such as 4-trifluoromethylbenzylamine and 4-methylaniline (entries 9 and 12), furnished the corresponding benzimidazoles in slightly lower yields $(55,40 \%$, respectively). The twofold reaction of ethylenediamine with 159-Br afforded the 1,2-di(benzimidazolyl)ethane 232e in $42 \%$ yield (entry 5). The reaction of $o$-bromophenyl isocyanide $(159-\mathrm{Br})$ with tert-butylamine $230 \mathrm{~m}$ surprisingly did not provide $N$-tert-butyl benzimidazole $232 \mathrm{~m}$ at all. The major product, isolated in $38 \%$ yield, was identified as 1-(2-bromophenyl)benzimidazole (232n). 
Table 14. The synthesis of $N$-substituted benzimidazoles 232 .

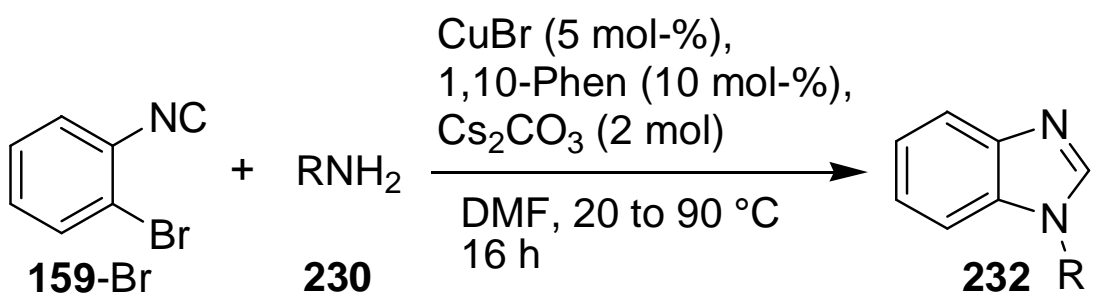

Entry Yield, (\%)


Table 14 (continued). The synthesis of $N$-substituted benzimidazoles 232 .

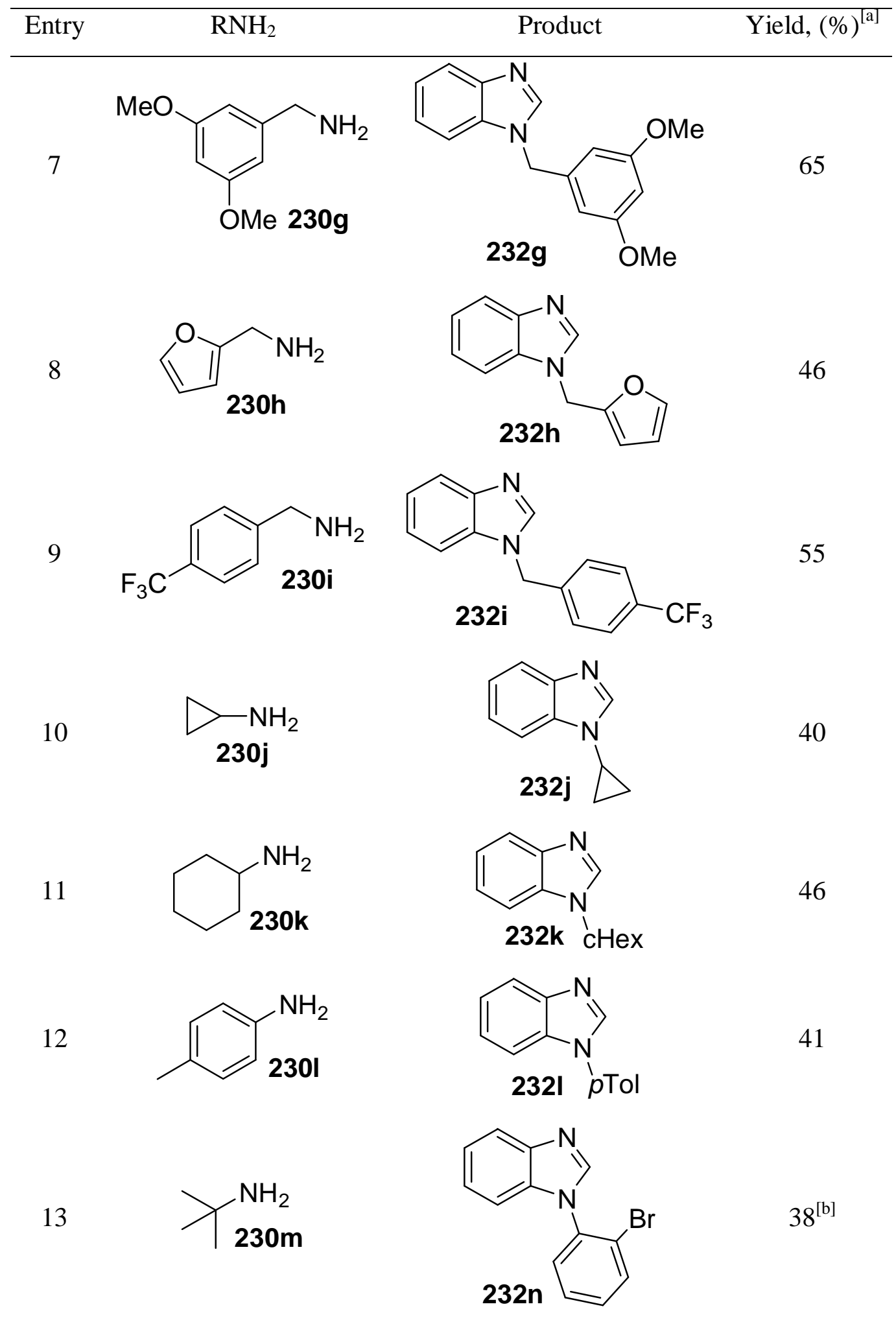

[a] Yield of isolated product. [b] Only the depicted product 232n was isolated and identified 


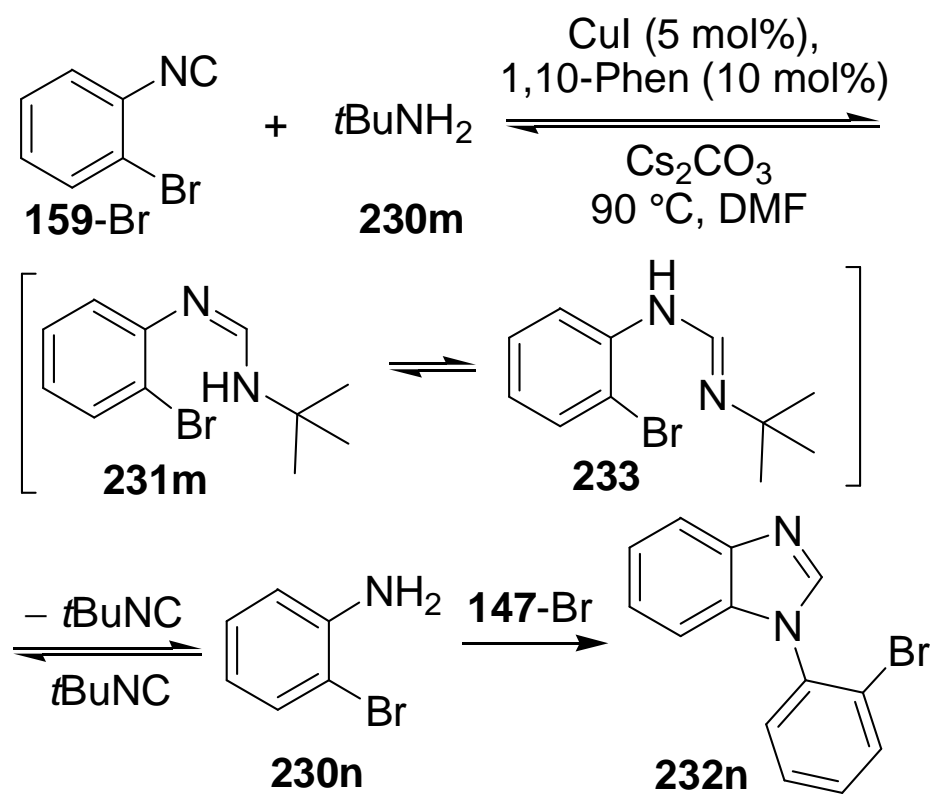

Scheme 57. Proposed mechanism for the formation of the benzimidazole $232 \mathrm{n}$.

The formation of $232 \mathbf{n}$ (Scheme 57) can be rationalized assuming a reversible addition of tert-butylamine onto the isocyano group of 159-Br. Similar reversible additions of $\mathrm{N}$-unsubstituted indoles onto aryl isocyanides have previously been observed in a ruthenium-catalyzed formation of indoles. ${ }^{[64]}$ The corresponding formamidine $\mathbf{2 3 1}$, due to its bulky tert-butyl group does not undergo cyclization to the $N$-tert-butylbenzimidazole (232m), but equilibrates under the basic reaction conditions with its tautomer, the formamidine $\mathbf{2 3 3}$, which would reversibly release tert-butyl isocyanide and form $o$-bromoaniline (230n). The latter would react with $o$-bromophenyl isocyanide $159-\mathrm{Br}$, still existing in the reaction mixture, just as 4-methylaniline does (see Table 14, entry 12), irreversibly forming benzimidazole 232n. In a control experiment, the reaction of $159-\mathrm{Br}$ with $o$-bromoaniline (230n) under the same conditions also provided the benzimidazole 232n in $42 \%$ yield. $^{[164]}$

To broaden the scope of the new method, 2-bromo-3-isocyanothiophene (234) was employed in the copper-catalyzed reaction with amines. Indeed, the three examples 235a, 235c and 235d of the the less common 3-substituted $3 H$-thieno[2,3-d]imidazoles 235 (Scheme 58) were isolated albeit in slightly lower yields (49, 44 and 44\%, respectively) than the corresponding benzimidazoles. 


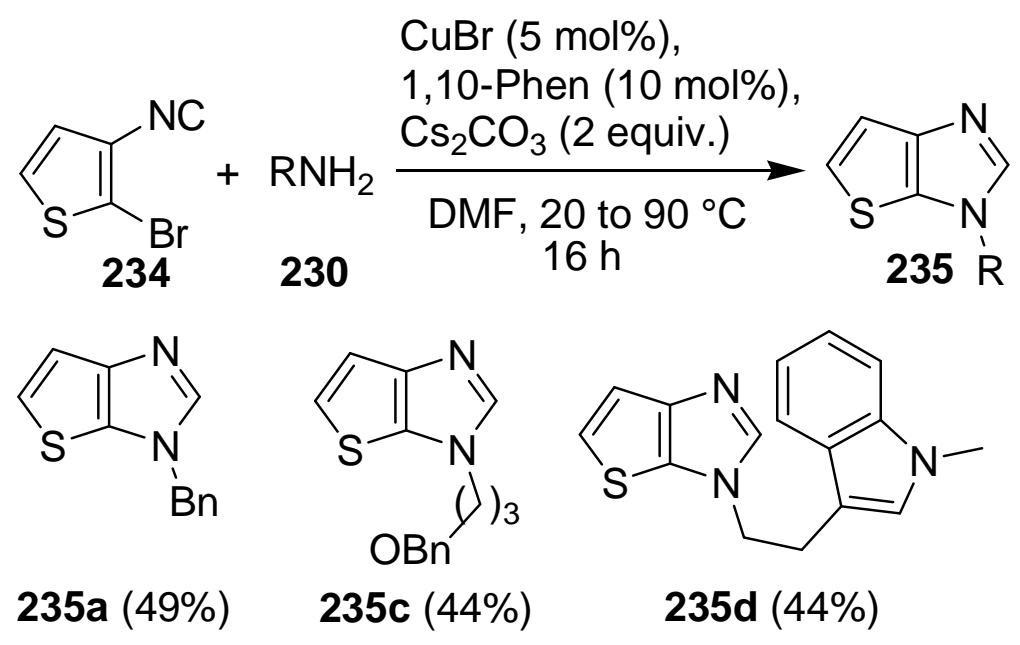

Scheme 58. The synthesis of 3-substituted 3H-thieno[2,3-d]imidazoles 235.

\section{Conclusion}

In conclusion, a novel copper-catalyzed synthesis of benzimidazoles from $o$-bromoaryl isocyanides and primary amines has been developed. This new sequential reaction consisting of a copper-catalyzed addition of an amine onto an isocyano group followed by a copper-catalyzed intramolecular arylation of a thus formed amidine provides a convenient access to 1-substituted benzimidazoles 232 and related 3-substituted $3 H$-thieno[2,3-d]imidazoles $\mathbf{2 3 5}$ in moderate to good yields 


\section{Experimental Section}

\section{General}

\section{Reagents and Chemicals}

Diethyl ether, tetrahydrofuran, 1,2-dimethoxyethane, benzene, and toluene were distilled from sodium benzophenone ketyl, dichloromethane and dimethylformamide from molecular sieves $4 \AA$, acetonitrile from $\mathrm{P}_{4} \mathrm{O}_{10}$.

Commercial nanosize copper powder (Aldrich) was preactivated by heating in vacuo $(0.05 \mathrm{mbar})$ at $150^{\circ} \mathrm{C}$ overnight, and was stored under Ar. The activity of the thus prepared catalyst does not deteriorate within at least 2 weeks.

The following compounds were prepared according to the corresponding literature procedures:

Methyl isocyanoacetate $(25-\mathrm{Me}),{ }^{[165]}$ ethyl isocyanoacetate (25-Et),${ }^{[165]}$ tert-butyl iso-

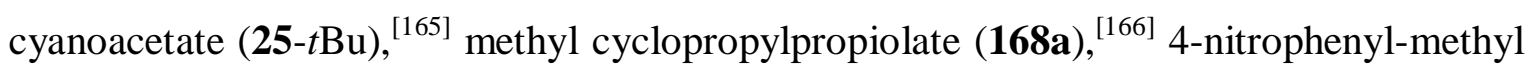
isocyanide (63f), ${ }^{[167]}$ methyl 3-(4-fluorophenyl)propiolate (168d), ${ }^{[168]}$ methyl 3-(4-trifluoromethylphenyl)-propiolate (168e), ${ }^{[169]}$ methyl 3-(thiophen-2-yl)propiolate $(\mathbf{1 6 8 g}),{ }^{[170]}$ methyl 3-(pyridin-2-yl)propiolate (168f), ${ }^{[171]}$ cyclopropylacetylene $(\mathbf{1 6 7 e}),{ }^{[172]} \mathrm{N}, \mathrm{N}$ diethyl-2-isocyanoacetamide (63g) ${ }^{[173]}$ dimethyl 2-isocyano-1-oxoethylphospho-nate, ${ }^{[174]}$ $\mathrm{CpCuP}(\mathrm{OMe})_{3},{ }^{[101]}$ 1-deutero hexyne-1 (167a-D),${ }^{[175]}$ cyclopropylisocyanate, ${ }^{[176]}$ 3-iodopropyl isocyanates, ${ }^{[177]} 3$-aminothiophene, ${ }^{[178]} 3$-(benzyloxy)propyl-1-amine (230c). ${ }^{[179]}$

All other chemicals were used as commercially available.

\section{Separation and Identification of the Compounds}

Chromatography: Analytical TLC was performed on $0.25 \mathrm{~mm}$ silica gel $60 \mathrm{~F}$ plates (Macherey-Nagel) with $254 \mathrm{~nm}$ fluorescent indicator from Merck. Plates were visualized under ultraviolet light and developed by treatment with the molybdenephosphoric acid solution. Chromatographic purification of products was accomplished by flash column chromatography, as described by Still and coworkers ${ }^{[180]}$ on Merck silica gel, grade 60 (0.063-0.200 mm, 70-230 mesh ASTM)

NMR: Nuclear magnetic resonance $\left({ }^{1} \mathrm{H}\right.$ and ${ }^{13} \mathrm{C}$ NMR) spectra were recorded at 250, 300, or $500\left({ }^{1} \mathrm{H}\right), 62.9,75.5$, or $125\left[{ }^{13} \mathrm{C}\right.$, APT (Attached Proton Test) $] \mathrm{MHz}$ on Brucker AM 250, Varian Unity-300, AMX 300 and Inova 500 instruments in $\mathrm{CDCl}_{3}$ solutions if not 
otherwise specified. Proton chemical shifts are reported in ppm relative to the residual peak of the deuterated solvent or tetramethylsilane: $\delta(\mathrm{ppm})=0$ for tetramethylsilane, 2.49 for $\left[\mathrm{D}_{5}\right] \mathrm{DMSO}, 7.26$ for $\mathrm{CHCl}_{3}$. For the characterization of the observed signal multiplicities the following abbreviations were applied: $\mathrm{s}=$ singlet, $\mathrm{d}=$ doublet, $\mathrm{t}=$ triplet, $\mathrm{q}=$ quartet, quin = quintet, $\mathrm{m}=$ multiplet, as well as br = broad; $J$ in $\mathrm{Hz} .{ }^{13} \mathrm{C}$ chemical shifts are reported relative to the solvent peak or tetramethylsilane: 0 for tetramethylsilane, 39.5 for $\left[\mathrm{D}_{5}\right] \mathrm{DMSO}, 77.0$ for $\mathrm{CDCl}_{3}$.

IR: Bruker IFS 66 (FT-IR) spectrometer, measured as $\mathrm{KBr}$ pellets or oils between $\mathrm{KBr}$ plates.

MS: EI-MS: Finnigan MAT 95, 70 eV, DCI-MS: Finnigan MAT 95, 200 eV, reactant gas $\mathrm{NH}_{3}$; ESI-MS: Finnigan LCQ. High resolution mass spectrometry (HRMS): APEX IV 7T FTICR, Bruker Daltonic.

Melting points: Büchi 540 capillary melting point apparatus, uncorrected values.

Elemental analyses: Mikroanalytisches Laboratorium des Instituts für Organische und Biomolekulare Chemie der Universität Göttingen. 


\section{Experimental Procedures for the Compounds Described in Chapter 1 "Oligosubstituted Pyrroles Directly from Substituted Methyl Isocyanides and Acetylenes"}

\section{Methyl 4-Methoxy-pent-2-ynoate (168b)}

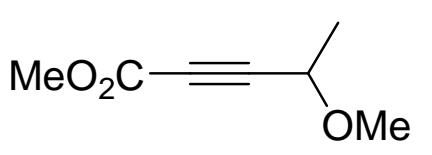

To a solution of 3-methoxy butyn-1 (4.45 g, $53 \mathrm{mmol})$ in anhydrous diethyl ether (200 mL) kept under nitrogen was added dropwise with magnetic stirring at $-78{ }^{\circ} \mathrm{C} 2.5 \mathrm{M}$ solution

of $\mathrm{n}$-BuLi (22 $\mathrm{mL}, 55 \mathrm{mmol})$. After stirring at $-78{ }^{\circ} \mathrm{C}$ for $30 \mathrm{~min}$, the mixture was warmed to $0{ }^{\circ} \mathrm{C}$ and methyl chloroformiate $(5.48 \mathrm{~g}, 58 \mathrm{mmol})$ was added. The mixture was stirred for $3 \mathrm{~h}$ at r.t. and quenched with saturated solution of ammonium chloride $(80 \mathrm{~mL})$. The organic and water phases were separated and the water phase was extracted with diethyl ether $(3 \times 50 \mathrm{~mL})$. The combined organic phase was dried over anhydrous $\mathrm{Na}_{2} \mathrm{SO}_{4}$, filtrated and solvents were removed under reduced pressure. The residue was distilled (10 Torr, b.p $85-90{ }^{\circ} \mathrm{C}$ ) to give $6.09 \mathrm{~g}(81 \%)$ of product as colorless oil ${ }^{1} \mathrm{H}$ NMR $\left(300 \mathrm{MHz}, \mathrm{CDCl}_{3}, 25^{\circ} \mathrm{C}, \mathrm{TMS}\right) \delta=4.18(\mathrm{q}, J=4.5 \mathrm{~Hz}, 1 \mathrm{H}, \mathrm{CH}), 3.79\left(\mathrm{~s}, 3 \mathrm{H}, \mathrm{CO}_{2} \mathrm{CH}_{3}\right)$, $3.42\left(\mathrm{~s}, 3 \mathrm{H}, \mathrm{OCH}_{3}\right), 1.47 \mathrm{ppm}\left(\mathrm{d}, J=7.8 \mathrm{~Hz}, 3 \mathrm{H}, \mathrm{CH}_{3}\right) ;{ }^{13} \mathrm{C} \mathrm{NMR}\left(75.5 \mathrm{MHz}, \mathrm{CDCl}_{3}\right.$, $\left.25^{\circ} \mathrm{C}\right): \delta=153.5(\mathrm{C}), 86.8(\mathrm{C}), 76.5(\mathrm{C}), 66.4(\mathrm{CH}), 56.7\left(\mathrm{CH}_{3}\right), 52.6\left(\mathrm{CH}_{3}\right), 20.9 \mathrm{ppm}$ $\left(\mathrm{CH}_{3}\right)$; MS (EI) $m / z$ (\%): 142.1 (30) [M+ $\mathrm{M}^{+}$, 99.1(28), 59.1(40), 43.1 (100); IR (KBr): 2992, 2940, 2826, 2239, 1727, 1436, 1256, 1115, 1076, 1044, 996, 913, 752, $623 \mathrm{~cm}^{-1}$.

\section{Methyl 3-(4-ethoxyphenyl)propiolate (168d)}

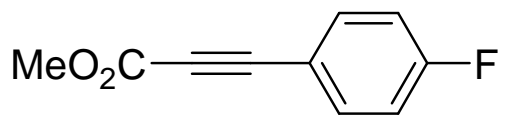

Methyl 3-(4-ethoxyphenyl)propiolate (8.98 g, 88\%) was prepared analog to methyl 4-methoxy-pent-2-ynoate from 4-ethoxyphenyl acetylene (7.3 g, $50 \mathrm{mmol})$ and methyl chloroformiate (5.2 g, $55 \mathrm{mmol})$, after recrystallization from hexane/benzene as colorless solid, m.p. $55{ }^{\circ} \mathrm{C}$. ${ }^{1} \mathrm{H}$ NMR $\left(300 \mathrm{MHz}, \mathrm{CDCl}_{3}, 25{ }^{\circ} \mathrm{C}, \mathrm{TMS}\right) \delta=7.52(\mathrm{~d}, J=9.0 \mathrm{~Hz}, 2 \mathrm{H}, \mathrm{Ar}-\mathrm{H}), 6.87$ $(\mathrm{d}, J=9.0 \mathrm{~Hz}, 1 \mathrm{H}, \mathrm{Ar}-\mathrm{H}), 4.05\left(\mathrm{q}, J=7.3 \mathrm{~Hz}, 2 \mathrm{H}, \mathrm{CH}_{2}\right), 3.82\left(\mathrm{~s}, 3 \mathrm{H}, \mathrm{CO}_{2} \mathrm{CH}_{3}\right), 1.42$ $\operatorname{ppm}\left(\mathrm{t}, J=7.3 \mathrm{~Hz}, 3 \mathrm{H}, \mathrm{CH}_{3}\right) ;{ }^{13} \mathrm{C} \mathrm{NMR}\left(75.5 \mathrm{MHz}, \mathrm{CDCl}_{3}, 25{ }^{\circ} \mathrm{C}\right): \delta=160.9(\mathrm{C}), 154.7$ (C), $134.9(\mathrm{CH}), 114.7(\mathrm{CH}), 111.0(\mathrm{C}), 87.4(\mathrm{C}), 79.7(\mathrm{C}), 63.6\left(\mathrm{CH}_{2}\right), 52.6\left(\mathrm{CH}_{3}\right), 14.6$ ppm $\left(\mathrm{CH}_{3}\right)$; MS (EI) m/z (\%): 204.1 (100) $\left[\mathrm{M}^{+}\right], 173.1(28), 145.1(75), 118.1$ (164); IR 
(KBr): 2361, 2339, 2216, 1700, 1653, 1507, 1288, 1255, 1199, 1164, 1114, 1040, 922, $884,830,807,745 \mathrm{~cm}^{-1}$; elemental analysis calcd $(\%)$ for $\mathrm{C}_{12} \mathrm{H}_{12} \mathrm{O}_{3}: \mathrm{C} 70.67, \mathrm{H} \mathrm{5.92}$; found: C 71.03, H 6.01 .

\section{General Procedure for the Formal Cycloaddition of Substituted Methyl Isocyanides to Acetylenes Mediated by Potassium tert-Butoxide (GP1, Method A)}

To a solution of the respective acetylene $168(5.0 \mathrm{mmol})$ and the respective substituted methyl isocyanide $63(5.5 \mathrm{mmol})$ in THF $(60 \mathrm{~mL})$ was added dropwise at $20{ }^{\circ} \mathrm{C}$ within $1 \mathrm{~h}$ a solution of $\mathrm{KO} t \mathrm{Bu}(616 \mathrm{mg}, 5.5 \mathrm{mmol})$ in THF $(35 \mathrm{~mL})$. The mixture was stirred at $20{ }^{\circ} \mathrm{C}$ for $1 \mathrm{~h}$, the reaction then quenched with glacial $\mathrm{AcOH}(1 \mathrm{~mL})$, and the solution concentrated under reduced pressure. The residue was triturated with $\mathrm{CH}_{2} \mathrm{Cl}_{2}(3 \times 30 \mathrm{~mL})$ at $20^{\circ} \mathrm{C}$ to extract the crude product, which was purified by column chromatography.

\section{General Procedure for the Copper-Catalyzed Formal Cycloaddition of Substituted Methyl Isocyanides to Acetylenes (GP2, Method B)}

The copper catalyst [preferably preactivated nanosize copper powder $(3 \mathrm{mg}, 0.05 \mathrm{mmol}$, $5 \mathrm{~mol} \%$ ), or copper thiophenolate ( $9 \mathrm{mg}, 0.05 \mathrm{mmol}, 5 \mathrm{~mol} \%)]$ was added to a solution of the respective substituted methyl isocyanide $\mathbf{6 3}(1.1 \mathrm{mmol})$ and the respective acetylene $168(1.0 \mathrm{mmol})$ in DMF $(2 \mathrm{~mL})$, and the mixture was vigorously stirred at $85^{\circ} \mathrm{C}$ (if not otherwise specified) for $16 \mathrm{~h}$. The solvent was removed in vacuo (0.05 mbar), and the residue was purified by column chromatography to give the corresponding pyrrole.

\section{Dimethyl 3-Cyclopropyl-1H-pyrrole-2,4-dicarboxylate (173aa)}<smiles>COC(=O)c1c[nH]c(C(=O)OC)c1C1CC1</smiles>

Following GP2 (Method B), the pyrrole 173aa (1.03 g, 93\%) was obtained from methyl cyclopropylpropiolate (168a) $(620 \mathrm{mg}, 5.0 \mathrm{mmol})$ and methyl isocyanoacetate $(\mathbf{2 5}-\mathrm{Me})$ (545 $\mathrm{mg}, \quad 5.5 \mathrm{mmol})$, after column chromatography (cyclohexane/ethyl acetate $4: 1$ ) as a colorless solid, m. p. $123{ }^{\circ} \mathrm{C} .{ }^{1} \mathrm{H}$ NMR $(300 \mathrm{MHz}$, $\left.\mathrm{CDCl}_{3}, 25{ }^{\circ} \mathrm{C}, \mathrm{TMS}\right): \delta=9.78($ br s, $1 \mathrm{H}, \mathrm{NH}), 7.43(\mathrm{~d}, J=3.6 \mathrm{~Hz}, 1 \mathrm{H}, \mathrm{NCH})$, 3.82 (s, $3 \mathrm{H}, \mathrm{CH}_{3}$ ), 3.76 (s, $3 \mathrm{H}, \mathrm{CH}_{3}$ ), 2.27-2.17 (m, $\left.1 \mathrm{H}, \mathrm{cPr}-\mathrm{H}\right), 0.96-0.83$ ppm (m, $4 \mathrm{H}$, 
$\left.\mathrm{CH}_{2}\right) ;{ }^{13} \mathrm{C} \mathrm{NMR}\left(75.5 \mathrm{MHz}, \mathrm{CDCl}_{3}, 25{ }^{\circ} \mathrm{C}\right): \delta=164.5(\mathrm{C}), 161.4(\mathrm{C}), 135.4(\mathrm{C})$, $127.5(\mathrm{CH}), 121.3(\mathrm{C}), 116.9(\mathrm{C}), 51.5\left(\mathrm{CH}_{3}\right), 51.0\left(\mathrm{CH}_{3}\right), 8.2\left(\mathrm{CH}_{2}\right), 7.3 \mathrm{ppm}(\mathrm{CH})$; IR (KBr): $3325 \mathrm{~cm}^{-1}$, 3146, 3010, 2951, 1719, 1696, 1541, 1437, 1276, 1199, 1059, 785; MS (EI): $m / z(\%): 223.1\left[\mathrm{M}^{+}\right]$; HRMS (ESI): $m / z$ calcd for $\mathrm{C}_{11} \mathrm{H}_{14} \mathrm{NO}_{4}{ }^{+}\left[\mathrm{M}+\mathrm{H}^{+}\right]: 224.0923$; found: 224.0917.

\section{Dimethyl 3-(Thiophen-2-yl)-1H-pyrrole-2,4-dicarboxylate (173ag)}

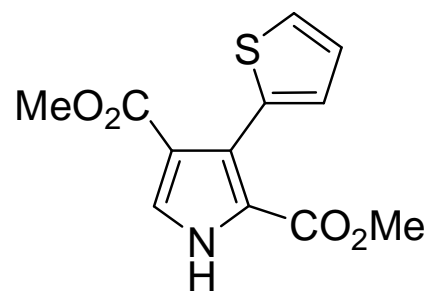

The pyrrole 173ag (250 mg, 94\%) was obtained from methyl (thiophen-2-yl)propiolate (168g) (166 mg, $1.0 \mathrm{mmol})$ and methyl isocyanoacetate (25-Me) (149 $\mathrm{mg}, 1.5 \mathrm{mmol})$ following GP2 (Method B) with $N P \mathrm{Cu}^{0}(3 \mathrm{mg}, 0.05 \mathrm{mmol}, 5 \mathrm{~mol} \%)$ at $120{ }^{\circ} \mathrm{C}$, after column chromatography (hexane/ethyl acetate $\left.2: 1, R_{\mathrm{f}}=0.20\right)$ as a yellow solid, m.p. $146{ }^{\circ} \mathrm{C} .{ }^{1} \mathrm{H} \mathrm{NMR}\left(300 \mathrm{MHz}, \mathrm{CDCl}_{3}, 25^{\circ} \mathrm{C}, \mathrm{TMS}\right)$ : $\delta=9.50(\mathrm{br} s, 1 \mathrm{H}, \mathrm{NH}), 7.56(\mathrm{~d}, J=3.3 \mathrm{~Hz}, 1 \mathrm{H}, \mathrm{NCH}), 7.38(\mathrm{t}, J=3.3 \mathrm{~Hz}, 1 \mathrm{H}$, thienyl-5H), 7.05 (d, $J=3.0 \mathrm{~Hz}, 2 \mathrm{H}$, thienyl-3,4H), $3.73\left(\mathrm{~s}, 3 \mathrm{H}, \mathrm{CH}_{3}\right), 3.70 \mathrm{ppm}(\mathrm{s}, 3 \mathrm{H}$, $\left.\mathrm{CH}_{3}\right) ;{ }^{13} \mathrm{C} \mathrm{NMR} \quad\left(75.5 \mathrm{MHz}, \mathrm{CDCl}_{3}, 25{ }^{\circ} \mathrm{C}\right): \quad \delta=163.7(\mathrm{C}), \quad 160.9(\mathrm{C}), \quad 132.9(\mathrm{C})$, $128.5(\mathrm{CH}), \quad 126.9(\mathrm{CH}), \quad 126.2(\mathrm{CH}), 126.0(\mathrm{CH}), 124.1(\mathrm{C}), 121.9(\mathrm{C}), 117.8(\mathrm{C})$, $51.8\left(\mathrm{CH}_{3}\right)$, 51.2 ppm $\left(\mathrm{CH}_{3}\right)$; IR (KBr): 2954, 1731, 1703, 1524, 1439, 1386, 1264, 1197 , 1015, 921, 784, $689 \mathrm{~cm}^{-1}$; MS (EI): m/z (\%): 265.2 (90) [ $\left.\mathrm{M}^{+}\right], 233.1$ (78), 202.1 (62), 43.1 (100); elemental analysis calcd (\%) for $\mathrm{C}_{12} \mathrm{H}_{11} \mathrm{NO}_{4} \mathrm{~S}$ : C 54.33, H 4.18, N 5.28; found: C 54.05, H 4.10, N 5.38.

\section{Dimethyl 3-(4-Ethoxyphenyl)-1H-pyrrole-2,4-dicarboxylate (173ac)}

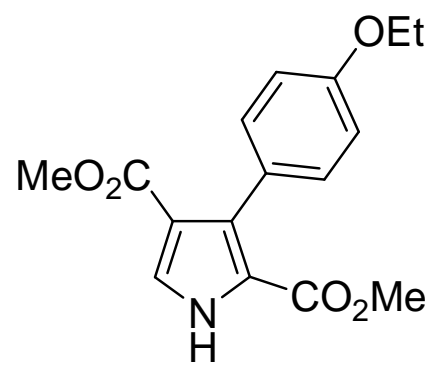

The pyrrole 173ac (226 mg, 75\%) was obtained from methyl (4-ethoxyphenyl)propiolate (168c) (204 mg, $1.0 \mathrm{mmol})$ and methyl isocyanoacetate $(\mathbf{2 5}-\mathrm{Me})(109 \mathrm{mg}, 1.1 \mathrm{mmol})$ following GP2 (Method B) with $N P \mathrm{Cu}^{0}(3 \mathrm{mg}, 0.05 \mathrm{mmol}, 5 \mathrm{~mol} \%)$ at $120{ }^{\circ} \mathrm{C}$, after column chromatography (hexane/ethyl acetate $\left.2: 1, R_{\mathrm{f}}=0.15\right)$ as a colorless solid, m.p. $136{ }^{\circ} \mathrm{C} .{ }^{1} \mathrm{H}$ NMR (300 MHz, $\left.\mathrm{CDCl}_{3}, 25^{\circ} \mathrm{C}, \mathrm{TMS}\right): \delta=9.73$ (br s, $\left.1 \mathrm{H}, \mathrm{NH}\right), 7.53(\mathrm{~d}, J=3.5 \mathrm{~Hz}, 1 \mathrm{H}, \mathrm{NCH})$, $7.27(\mathrm{~d}, J=8.7 \mathrm{~Hz}, 2 \mathrm{H}, \mathrm{Ar}), 6.90(\mathrm{~d}, J=8.7 \mathrm{~Hz}, 2 \mathrm{H}, \mathrm{Ar}), 4.07$ (q, J=7.4 Hz, $\left.2 \mathrm{H}, \mathrm{CH}_{2}\right)$, 
$3.68\left(\mathrm{~s}, 3 \mathrm{H}, \mathrm{CO}_{2} \mathrm{CH}_{3}\right), 1.43 \mathrm{ppm}\left(\mathrm{t}, J=6.7 \mathrm{~Hz}, 3 \mathrm{H}, \mathrm{CH}_{3}\right) ;{ }^{13} \mathrm{C} \mathrm{NMR}\left(75.5 \mathrm{MHz}, \mathrm{CDCl}_{3}\right.$, $\left.25^{\circ} \mathrm{C}\right): \delta=164.2(\mathrm{C}), 161.3(\mathrm{C}), 158.2(\mathrm{C}), 132.5(\mathrm{C}), 131.3(2 \mathrm{CH}), 127.2(\mathrm{C}), 125.0(\mathrm{C})$, $120.4(\mathrm{CH}), 116.4(\mathrm{C}), 113.1(2 \mathrm{CH}), 63.2\left(\mathrm{CH}_{2}\right), 51.5\left(\mathrm{CH}_{3}\right), 51.0\left(\mathrm{CH}_{3}\right), 14.9 \mathrm{ppm}\left(\mathrm{CH}_{3}\right)$; IR (KBr): 2989, 1732, 1695, 1522, 1436, 1388, 1264, 1006, 922, 829, 785, $522 \mathrm{~cm}^{-1}$; MS (EI): $m / z(\%): 303.2(100)\left[\mathrm{M}^{+}\right], 271.2$ (44), 243.2 (30), 212.1 (26); elemental analysis calcd (\%) for $\mathrm{C}_{16} \mathrm{H}_{17} \mathrm{NO}_{5}$ : 63.36, $\mathrm{H}$ 5.65, N 4.62; found: C 63.18, 5.53, 4.50.

\section{Dimethyl 3-(4-Fluorophenyl)-1H-pyrrole-2,4-dicarboxylate (173ad)}

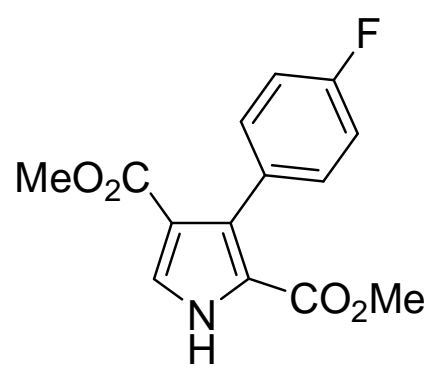

The pyrrole 173ad (215 mg, 78\%) was obtained from methyl (4-fluorophenyl)propiolate (168d) (178 $\mathrm{mg}, 1.0 \mathrm{mmol})$ and methyl isocyanoacetate $(25-\mathrm{Me})(149 \mathrm{mg}, 1.5 \mathrm{mmol})$ following GP2 (Method B) with $N P \mathrm{Cu}^{0}(3 \mathrm{mg}, 0.05 \mathrm{mmol}, 5 \mathrm{~mol} \%)$ at $120{ }^{\circ} \mathrm{C}$, after column chromatography (hexane/ethyl acetate $\left.2: 1, R_{\mathrm{f}}=0.20\right)$ as a colorless solid, m.p. $174{ }^{\circ} \mathrm{C} .{ }^{1} \mathrm{H} \mathrm{NMR}$ (300 MHz, $\left.\mathrm{CDCl}_{3}, 25^{\circ} \mathrm{C}, \mathrm{TMS}\right): \delta=9.56$ (br s, $\left.1 \mathrm{H}, \mathrm{NH}\right), 7.57(\mathrm{~d}, J=3.5 \mathrm{~Hz}, 1 \mathrm{H}, \mathrm{NCH})$, 7.38-7.26 (m, 2 H, Ar), 7.11-6.98 (m, 2 H, Ar), $3.69\left(\mathrm{~s}, 3 \mathrm{H}, \mathrm{CH}_{3}\right), 3.68 \mathrm{ppm}$ $\left(\mathrm{s}, 3 \mathrm{H}, \mathrm{CH}_{3}\right) ;{ }^{13} \mathrm{C} \mathrm{NMR}\left(75.5 \mathrm{MHz}, \mathrm{CDCl}_{3}, 25{ }^{\circ} \mathrm{C}\right): \delta=164.0(\mathrm{C}), 163.9(\mathrm{C}), 161.1(\mathrm{C})$, $131.9(\mathrm{CH}), \quad 131.8(\mathrm{CH}), \quad 131.5(\mathrm{C}), \quad 129.0(\mathrm{C}), \quad 127.1(\mathrm{CH}), \quad 120.7(\mathrm{C}), \quad 116.7(\mathrm{C})$, 114.3 (CH), $114.0(\mathrm{CH}), 51.6\left(\mathrm{CH}_{3}\right), 51.1$ ppm $\left(\mathrm{CH}_{3}\right)$; IR (KBr): 3002, 2955, 1702, 1695, 1598, 1522, 1435, 1386, 1262, 1164, 1098, 1002, 834, 816, 783, 716, 602, $518 \mathrm{~cm}^{-1}$; MS (EI): $m / z$ (\%): $277.2(100)\left[\mathrm{M}^{+}\right], 245.2$ (44), 214.1 (92); elemental analysis calcd (\%) for $\mathrm{C}_{14} \mathrm{H}_{12} \mathrm{FNO}_{4}$ : 60.65, $\mathrm{H}$ 4.36, N 5.05; found: 60.37, 4.24, 5.06. 


\section{Dimethyl 3-(4-(Trifluoromethyl)phenyl)-1H-pyrrole-2,4-dicarboxylate (173ae)}

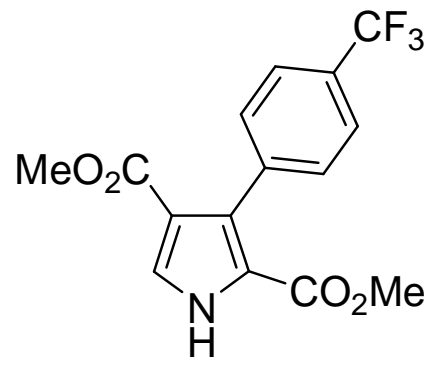

The pyrrole 173ae (341 mg, 70\%) was obtained from methyl (4-trifluoromethylphenyl)propiolate (168e) (340 mg, $1.5 \mathrm{mmol}$ ) and methyl isocyanoacetate (25-Me) $(254 \mathrm{mg}, 2.4 \mathrm{mmol})$ following GP2 (Method B) with $N P \mathrm{Cu}^{0}(5 \mathrm{mg}, 0.08 \mathrm{mmol}$, $5.5 \mathrm{~mol} \%)$ at $120{ }^{\circ} \mathrm{C}$, after column chromatography (hexane/ethyl acetate $2: 1$ to $1: 1, R_{\mathrm{f}}=0.63$, hexane/ethyl acetate $1: 1)$ as a yellow solid, m.p. 156-157. ${ }^{1} \mathrm{H}$ NMR $\left(300 \mathrm{MHz}, \mathrm{DMSO}-\mathrm{d}_{6}, 25{ }^{\circ} \mathrm{C}\right.$, TMS): $\delta=12.50-12.60$ (br s, $1 \mathrm{H}, \mathrm{NH}), 7.64(\mathrm{~d}, J=8.1 \mathrm{~Hz}, 2 \mathrm{H}, \mathrm{Ar}-\mathrm{CH}), 7.63-7.64$ (m, $1 \mathrm{H}, \mathrm{NCH}), 7.47$ (d, J=8.1 Hz, $2 \mathrm{H}, \mathrm{Ar}-\mathrm{CH}), 361$ (s, $\left.3 \mathrm{H}, \mathrm{CH}_{3}\right), 3.57$ ppm (s, $3 \mathrm{H}$, $\left.\mathrm{CH}_{3}\right) ;{ }^{13} \mathrm{C}$ NMR $\left(75.5 \mathrm{MHz}, \mathrm{DMSO}_{6}, 25{ }^{\circ} \mathrm{C}\right): \delta=163.2(\mathrm{C}), 160.1(\mathrm{C}), 138.3(\mathrm{C})$, $131.1(\mathrm{CH}), 130.2(\mathrm{CH}), 127.9(\mathrm{C}), 127.4\left(\mathrm{C}, \mathrm{q}, J_{\mathrm{C}-\mathrm{F}}=31.4 \mathrm{~Hz}\right), 125.6(\mathrm{C}), 123.5(\mathrm{C}, \mathrm{m}$, $\left.\mathrm{CF}_{3}\right), 120.4(\mathrm{C}), 115.0(\mathrm{CH}), 51.1\left(\mathrm{CH}_{3}\right), 50.6 \mathrm{ppm}\left(\mathrm{CH}_{3}\right)$; IR $(\mathrm{KBr}): 3300,1700,1617$ 1559, 1522, 1437, 1393, 1322, 1264, 1192, 1172, 1128, 1065, 1019, 847, $786 \mathrm{~cm}^{-1}$; MS (ESI): $m / z(\%): 350(76)\left[\mathrm{M}+\mathrm{Na}^{+}\right], 328(100)\left[\mathrm{M}+\mathrm{H}^{+}\right]$; elemental analysis calcd (\%) for $\mathrm{C}_{15} \mathrm{H}_{12} \mathrm{~F}_{3} \mathrm{NO}_{4}$ : 55.05, H 3.70, N 4.28; found: C 55.10, H 3.82, N 4.15.

\section{Dimethyl 3-(Pyridin-2-yl)-1H-pyrrole-2,4-dicarboxylate (173af)}<smiles>COC(=O)c1c[nH]c(C(=O)OC)c1-c1ccccn1</smiles>

The pyrrole 173af (177 mg, 68\%) was obtained from methyl (pyridin-2-yl)propiolate (168f) (161 mg, $1.0 \mathrm{mmol}$ ) and methyl isocyanoacetate (25-Me) (149 $\mathrm{mg}, 1.5 \mathrm{mmol})$ following GP2 (Method B) with $N P \mathrm{Cu}^{0}$ (3 mg, $0.05 \mathrm{mmol}, 5 \mathrm{~mol} \%$ ) at $120{ }^{\circ} \mathrm{C}$, after column chromatography (ethyl acetate, $R_{\mathrm{f}}=0.30$ ) as a colorless solid. ${ }^{1} \mathrm{H}$ NMR (300 MHz, $\left.\mathrm{CDCl}_{3}, 25{ }^{\circ} \mathrm{C}, \mathrm{TMS}\right): \delta=10.87$ (br s, $1 \mathrm{H}, \mathrm{NH}$ ), $7.78(\mathrm{~m}, \quad 2 \mathrm{H}, \quad \mathrm{Ar}-\mathrm{H}), \quad 7.44(\mathrm{~m}, \quad 3 \mathrm{H}, \quad \mathrm{Ar}-\mathrm{H}), \quad 3.64\left(\mathrm{~s}, \quad 3 \mathrm{H}, \quad \mathrm{CH}_{3}\right), \quad 3.59$ ppm $\left(\mathrm{s}, 3 \mathrm{H}, \mathrm{CH}_{3}\right) ;{ }^{13} \mathrm{C} \mathrm{NMR}\left(75.5 \mathrm{MHz}, \mathrm{CDCl}_{3}, 25{ }^{\circ} \mathrm{C}\right): \delta=163.9(\mathrm{C}), 160.7(\mathrm{C}), 153.4(\mathrm{C})$, $147.9(\mathrm{C}), 135.5(\mathrm{CH}), 131.0(\mathrm{C}), 127.0(2 \mathrm{CH}), 122.8(\mathrm{C}), 121.5(\mathrm{CH}), 116.6(\mathrm{CH})$, $51.5\left(\mathrm{CH}_{3}\right), 51.1 \mathrm{ppm}\left(\mathrm{CH}_{3}\right)$; IR (KBr): 3446, 1653(br), 902, $726 \mathrm{~cm}^{-1}$; MS (EI): $\mathrm{m} / \mathrm{z}(\%)$ : $260.2(52)\left[\mathrm{M}^{+}\right], 202.2$ (100), 197.1 (94), 171.1 (72), 144.2 (76), 44 (84); elemental analysis calcd (\%) for $\mathrm{C}_{12} \mathrm{H}_{11} \mathrm{NO}_{4} \mathrm{~S}$ : 54.33, $\mathrm{H}$ 4.18, N 5.28; found: 54.45, 4.20, 5.21. 


\section{Dimethyl 3-(1-Methoxyethyl)-1H-pyrrole-2,4-dicarboxylate (173ab)}

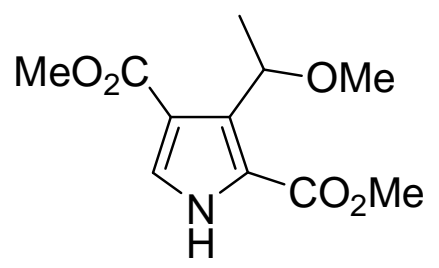

The pyrrole 173ab (130 mg, 54\%) was obtained from methyl 4-methoxypent-2-ynoate (168b) (340 mg, $1.0 \mathrm{mmol})$ and methyl isocyanoacetate 25-Me (109 mg, $1.1 \mathrm{mmol})$ following GP2 (Method B) with $N P \mathrm{Cu}^{0}(3 \mathrm{mg}, 0.05 \mathrm{mmol}, 5 \mathrm{~mol} \%)$ after column chromatography (hexane/ethyl acetate $2: 1$ to $1: 1, R_{\mathrm{f}}=0.58$, hexane/ethyl acetate 1 : 1) as a yellow solid, m.p. $109-110 .{ }^{1} \mathrm{H}$ NMR (300 $\left.\mathrm{MHz}, \mathrm{CDCl}_{3}, 25{ }^{\circ} \mathrm{C}, \mathrm{TMS}\right)$ : $\delta=9.20-9.40($ br s, $1 \mathrm{H}, \mathrm{NH}), 7.47(\mathrm{~d}, J=3.4 \mathrm{~Hz}, 1 \mathrm{H}, \mathrm{NCH}), 5.37(\mathrm{q}, J=6.6 \mathrm{~Hz}, 1 \mathrm{H}$, $\mathrm{CHOMe}), 3.87\left(\mathrm{~s}, 3 \mathrm{H}, \mathrm{CH}_{3}\right), 3.80\left(\mathrm{~s}, 3 \mathrm{H}, \mathrm{CH}_{3}\right), 3.20\left(\mathrm{~s}, 3 \mathrm{H}, \mathrm{OCH}_{3}\right), 1.61(\mathrm{~d}, J=6.6 \mathrm{~Hz}$, $\left.3 \mathrm{H}, \mathrm{CH}_{3} \mathrm{CH}\right) \mathrm{ppm} ;{ }^{13} \mathrm{C} \mathrm{NMR}\left(75.5 \mathrm{MHz}, \mathrm{CDCl}_{3}, 25{ }^{\circ} \mathrm{C}\right): \delta=164.2(\mathrm{C}), 161.0(\mathrm{C})$, $133.8(\mathrm{C}), 127.4(\mathrm{CH}), 121.0(\mathrm{C}), 116.4(\mathrm{C}), 71.0(\mathrm{CH}), 56.8\left(\mathrm{CH}_{3}\right), 51.8\left(\mathrm{CH}_{3}\right), 51.3$ $\left(\mathrm{CH}_{3}\right), 20.6\left(\mathrm{CH}_{3}\right)$ ppm; IR (KBr): 3383, 1700, 1559, 1506, 1437, 1403, 1340, 1269, 1197 , 1080, 1024, 988, 788, $731 \mathrm{~cm}^{-1}$; MS (ESI): $\mathrm{m} / z(\%): 505(55)\left[2 \mathrm{M}+\mathrm{Na}^{+}\right], 264(100)$ $\left[\mathrm{M}+\mathrm{Na}^{+}\right], \quad 242(12) \quad\left[\mathrm{M}+\mathrm{H}^{+}\right] ; \quad \operatorname{HRMS}(\mathrm{ESI}):$ calcd for $\mathrm{C}_{11} \mathrm{H}_{15} \mathrm{NNaO}_{5}^{+}\left[\mathrm{M}+\mathrm{Na}^{+}\right]$: 264.08424; found: 264.08434 .

\section{Methyl 2-(Ethoxycarbonyl)-3-cyclopropyl-1H-pyrrole-4-carboxylate (173ba)}

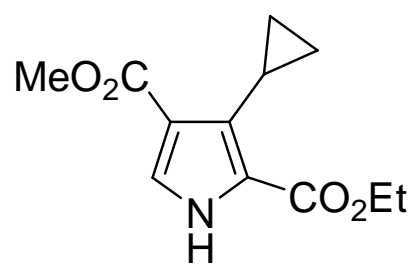

The pyrrole 173ba (422 mg, 89\%) was obtained from methyl cyclopropylpropiolate (168a) $(248 \mathrm{mg}, 2.0 \mathrm{mmol})$ and ethyl isocyanoacetate (25-Et) (249 $\mathrm{mg}, 2.2 \mathrm{mmol})$ following GP1

(Method A), after column chromatography (hexane/ethyl acetate $5: 1$ ) as a yellow oil, which crystallized to form a yellow solid, m.p. $45-46{ }^{\circ} \mathrm{C}$. Alternatively, this compound $(413 \mathrm{mg}, 89 \%)$ can be synthesized following GP2 (Method B). ${ }^{1} \mathrm{H}$ NMR (300 MHz, $\left.\mathrm{CDCl}_{3}, 25{ }^{\circ} \mathrm{C}, \mathrm{TMS}\right): \delta=9.56$ (br s, $\left.1 \mathrm{H}, \mathrm{NH}\right), 7.45$ $(\mathrm{d}, J=3.8 \mathrm{~Hz}, 1 \mathrm{H}, \mathrm{NCH}), 4.35\left(\mathrm{q}, J=7.2 \mathrm{~Hz}, 2 \mathrm{H}, \mathrm{Et}-\mathrm{CH}_{2}\right), 3.81\left(\mathrm{~s}, 3 \mathrm{H}, \mathrm{CO}_{2} \mathrm{CH}_{3}\right)$, 2.29-2.20 (m, $1 \mathrm{H}, \mathrm{CH}), 1.38 \mathrm{ppm}\left(\mathrm{t}, J=7.2 \mathrm{~Hz}, 3 \mathrm{H}, \mathrm{Et}_{-} \mathrm{CH}_{3}\right) ;{ }^{13} \mathrm{C}$ NMR $(75.5 \mathrm{MHz}$, $\left.\mathrm{CDCl}_{3}, 25^{\circ} \mathrm{C}\right): \delta=164.4(\mathrm{C}), 161.0(\mathrm{C}), 135.1(\mathrm{C}), 127.1(\mathrm{CH}), 121.8(\mathrm{C}), 117.1(\mathrm{C}), 60.6$ $\left(\mathrm{CH}_{3}\right), 51.0\left(\mathrm{CH}_{2}\right), 14.3(\mathrm{CH}), 8.4\left(\mathrm{CH}_{3}\right), 7.3 \mathrm{ppm}\left(\mathrm{CH}_{2}\right)$; IR $(\mathrm{KBr})$ : 3301, 2985, 1693, 1551, 1413, 1270, 1193, 1103, 1025, 931, $782 \mathrm{~cm}^{-1}$; MS (EI): $\mathrm{m} / z(\%): 237.2\left[\mathrm{M}^{+}\right](56)$, 205.1 (52), 176.1 (53), 132.1 (100); elemental analysis calcd (\%) for $\mathrm{C}_{12} \mathrm{H}_{15} \mathrm{NO}_{4}$ : $\mathrm{C}$ 60.75, H 6.37, N 5.90; found: C 60.81, H 6.28, N 6.09. 


\section{Methyl 2-(Ethoxycarbonyl)-1H-pyrrole-4-carboxylate (173bh) ${ }^{[181]}$}

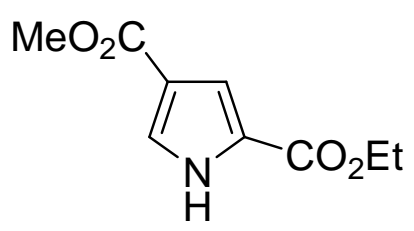

The pyrrole 173bh (73 mg, 37\%) was obtained from $84 \mathrm{mg}$ $(1.0 \mathrm{mmol})$ of methyl propiolate $\mathbf{( 1 6 8 h})$ and $113 \mathrm{mg}(1.0 \mathrm{mmol})$ of ethyl isocyanoacetate (25-Et) following GP2 (Method B) with $N P \mathrm{Cu}^{0}(3 \mathrm{mg}, 0.05 \mathrm{mmol}, 5 \mathrm{~mol} \%)$ at $60{ }^{\circ} \mathrm{C}$, after column chromatography (hexane/ethyl acetate $4: 1, R_{\mathrm{f}}=0.17$ ) as a colorless solid, m.p. 98-99 ${ }^{\circ} \mathrm{C} .{ }^{1} \mathrm{H}$ NMR $\left(300 \mathrm{MHz}, \mathrm{CDCl}_{3}, 25{ }^{\circ} \mathrm{C}\right.$, TMS) $\delta=9.98-9.76$ (br s, $\left.1 \mathrm{H}, \mathrm{NH}\right)$, $7.55(\mathrm{dd}, J=3.2,1.5 \mathrm{~Hz}, 1 \mathrm{H}, \mathrm{CH}) 7.31(\mathrm{dd}, J=2.4,1.6 \mathrm{~Hz}, 1 \mathrm{H}, \mathrm{NCH}), 4.35(\mathrm{q}, J=7.0$ $\left.\mathrm{Hz}, 2 \mathrm{H}, \mathrm{CH}_{2}\right), 3.84$ (s, $\left.3 \mathrm{H}, \mathrm{CO}_{2} \mathrm{CH}_{3}\right), 1.37 \mathrm{ppm}\left(\mathrm{t}, J=7.2 \mathrm{~Hz}, 3 \mathrm{H}, \mathrm{Et}-\mathrm{CH}_{3}\right) ;{ }^{13} \mathrm{C} \mathrm{NMR}$ $\left(75.5 \mathrm{MHz}, \mathrm{CDCl}_{3}, 2{ }^{\circ} \mathrm{C}\right): \delta=164.4(\mathrm{C}), 161.0(\mathrm{C}), 127.0(\mathrm{C}), 123.8(\mathrm{CH}), 117.8(\mathrm{C})$, $115.8(\mathrm{CH}), 60.9\left(\mathrm{CH}_{2}\right), 51.3\left(\mathrm{CH}_{3}\right), 14.3 \mathrm{ppm}\left(\mathrm{CH}_{3}\right)$; MS (EI) m/z (\%): $197.0(76)\left[\mathrm{M}^{+}\right]$, 166.1(53), 152.1(44), 120.1(100); IR (KBr): 3293, 2981, 1690, 1562, 1499, 1441, 1403, 1280, 1216, 1122, 1085, 1022, 989, 964, 927, 853, 762, 604, $504 \mathrm{~cm}^{-1}$; elemental analysis calcd (\%) for $\mathrm{C}_{9} \mathrm{H}_{11} \mathrm{NO}_{4}$ : C 54.82, H 5.62, N 7.10; found: C 54.92, H 5.82, N 6.98.

\section{Methyl 2-(4-Toluenesulfonyl)-1 $H$-pyrrole-4-carboxylate $(173 \mathrm{ch})^{[182]}$}

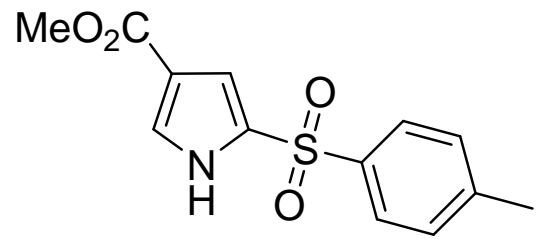

The pyrrole 173ch (83 mg, 30\%) was obtained from $84 \mathrm{mg}$ (1.0 $\mathrm{mmol})$ of methyl propiolate $(\mathbf{1 6 8 h})$ and $195 \mathrm{mg}(1.0 \mathrm{mmol})$ of tosylmethyl isocyanide $(41-\mathrm{H})$ following GP2 (Method B) with $N P \mathrm{Cu}^{0} \quad(3 \mathrm{mg}$, $0.05 \mathrm{mmol}, 5 \mathrm{~mol} \%$ ) at $60{ }^{\circ} \mathrm{C}$, after column chromatography (hexane/ethyl acetate $2: 1$, $\left.R_{\mathrm{f}}=0.22\right)$ as a colorless solid, m.p. $157-158^{\circ} \mathrm{C}$. Alternatively, it was prepared with $\mathrm{KO} t \mathrm{Bu}$ as a mediator $(105 \mathrm{mg}, 38 \%) .{ }^{1} \mathrm{H} \mathrm{NMR}\left(300 \mathrm{MHz}, \mathrm{CDCl}_{3}, 25{ }^{\circ} \mathrm{C}, \mathrm{TMS}\right): \delta=9.95$ (br s, $1 \mathrm{H}, \mathrm{NH}), 7.81$ (d, $J=8.1 \mathrm{~Hz}, 2 \mathrm{H}$, Ts-CH), 7.53 (dd, $J=3.1,1.6 \mathrm{~Hz}, 1 \mathrm{H}, \mathrm{CH}), 7.30$ (d, $J=8.1 \mathrm{~Hz}, 2 \mathrm{H}$, Ts-CH), $7.21(\mathrm{dd}, J=3.1,1.6 \mathrm{~Hz}, 1 \mathrm{H}, \mathrm{NCH}), 3.80\left(\mathrm{~s}, 3 \mathrm{H}, \mathrm{CO}_{2} \mathrm{CH}_{3}\right.$ ), $2.41 \mathrm{ppm}\left(\mathrm{s}, 3 \mathrm{H}, \mathrm{CH}_{3}\right) ;{ }^{13} \mathrm{C} \mathrm{NMR}\left(75.5 \mathrm{MHz}, \mathrm{CDCl}_{3}, 25{ }^{\circ} \mathrm{C}\right): \delta=163.8(\mathrm{C}), 144.6(\mathrm{CH})$, $138.4(\mathrm{C}), 130.2(\mathrm{C}), 130.0(2 \mathrm{CH}), 127.3(\mathrm{C}), 127.1(2 \mathrm{CH}), 118.5(\mathrm{C}), 115.7(\mathrm{CH}), 51.6$ $\left(\mathrm{CH}_{3}\right), 21.6 \mathrm{ppm}\left(\mathrm{CH}_{3}\right)$; MS (ESI): $\mathrm{m} / z(\%): 302.0\left[\mathrm{M}+\mathrm{Na}^{+}\right], 278.3\left[\mathrm{M}-\mathrm{H}^{-}\right]$; IR $(\mathrm{KBr})$ : 3250, 2950, 1691, 1595, 1546, 1473, 1433, 1392, 1319, 1228, 1183, 1145, 1116, 1076, 1017, 988, 930, 857, 813, 766, 744, 706, 676, 623, 604, 535, $492 \mathrm{~cm}^{-1}$; HRMS (ESI): calcd for $\mathrm{C}_{13} \mathrm{H}_{14} \mathrm{NO}_{4} \mathrm{~S}^{+}[\mathrm{M}+\mathrm{H}]^{+}$: 280.06381; found: 280.06403 . 


\section{Methyl 2-Phenyl-1H-pyrrole-4-carboxylate (173eh) ${ }^{[183]}$}

$\mathrm{MeO}_{2} \mathrm{C}$

The pyrrole 173eh (47 mg, 25\%) was obtained from $84 \mathrm{mg}(1.0$ mmol) of methyl propiolate $(\mathbf{1 6 8 h})$ and $102 \mathrm{mg}(1.0 \mathrm{mmol})$ of

phenylmethyl isocyanide (63e) following GP2 (Method B) with $N P \mathrm{Cu}^{0}(3 \mathrm{mg}, \quad 0.05 \mathrm{mmol}, 5 \mathrm{~mol} \%)$ at $60^{\circ} \mathrm{C}$, after column chromatography (hexane/ethyl acetate $4: 1, R_{\mathrm{f}}=0.19$ ) as a colorless solid, m.p. 163-164 ${ }^{\circ} \mathrm{C}$. Alternatively, it was prepared with $\mathrm{KOtBu}$ as a mediator (13 mg, 7\%). ${ }^{1} \mathrm{H}$ NMR $\left(300 \mathrm{MHz}, \mathrm{CDCl}_{3}, 25{ }^{\circ} \mathrm{C}, \mathrm{TMS}\right): \delta=8.90($ br s, $1 \mathrm{H}, \mathrm{NH}), 7.51-7.47(\mathrm{~m}, 3 \mathrm{H}$, $\mathrm{Ph}$ ), 3.39 (t, $J=2.8 \mathrm{~Hz}, 2 \mathrm{H}, \mathrm{Ph}), 7.26$ (t, $J=2.8 \mathrm{~Hz}, 1 \mathrm{H}, \mathrm{CH}), 6.92(\mathrm{~m}, 1 \mathrm{H}, \mathrm{NCH}), 3.84$ ppm (s, $\left.3 \mathrm{H}, \mathrm{CH}_{3}\right) ;{ }^{13} \mathrm{C}$ NMR (75.5 MHz, $\left.\mathrm{CDCl}_{3}, 25{ }^{\circ} \mathrm{C}\right): \delta=165.4(\mathrm{C}), 133.1(\mathrm{C}), 131.7$ (C), $129.0(\mathrm{CH}), 127.1(\mathrm{CH}), 124.2(\mathrm{CH}), 124.1(\mathrm{CH}), 117.7(\mathrm{C}), 106.6(\mathrm{C}), 51.2 \mathrm{ppm}$ $\left(\mathrm{CH}_{3}\right)$; MS (EI): m/z (\%): 201.1(86) [M+1, 170.1(100); IR (KBr): 3289, 3019, 1679, 1604, $1572,1515,1491,1441,1401,1352,1283,1222,1145,1132,996,928,833,808,767$, 725, 693, 659, 605, 524, $505 \mathrm{~cm}^{-1}$; HRMS (ESI): calcd for $\mathrm{C}_{12} \mathrm{H}_{12} \mathrm{NO}_{2}^{+}[\mathrm{M}+\mathrm{H}]^{+}$: 202.08626; found: 202.08629 .

\section{Methyl (4-Nitrophenyl)-1H-pyrrole-4-carboxylate (173fh)}

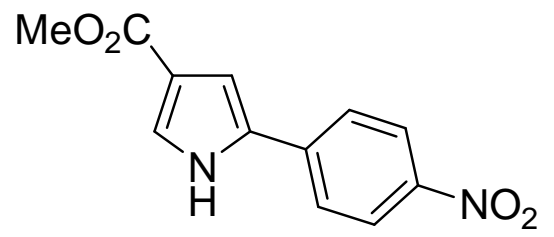

The pyrrole 173fh (109 mg, 44\%) was obtained from $84 \mathrm{mg}(1.0 \mathrm{mmol})$ of methyl propiolate $(\mathbf{1 6 8 h})$ and 162 $\mathrm{mg}(1.0 \mathrm{mmol})$ of 4-nitrophenylmethyl isocyanide $(\mathbf{6 3 f})$ following GP2 (Method B) with $N P \mathrm{Cu}^{0} \quad(3 \mathrm{mg}$, $0.05 \mathrm{mmol}, 5 \mathrm{~mol} \%$ ) at $60{ }^{\circ} \mathrm{C}$, after column chromatography (hexane/ethyl acetate $2: 1$, $\left.R_{\mathrm{f}}=0.30\right)$ as a yellow solid, m.p. $225{ }^{\circ} \mathrm{C} .{ }^{1} \mathrm{H}$ NMR $\left(300 \mathrm{MHz},[\mathrm{d} 6] \mathrm{DMSO}, 25{ }^{\circ} \mathrm{C}\right)$ : $\delta=12.29($ br s, $1 \mathrm{H}, \mathrm{NH}), 8.19(\mathrm{~d}, J=9.0 \mathrm{~Hz}, 2 \mathrm{H}, \mathrm{Ar}-\mathrm{CH}), 7.93(\mathrm{~d}, J=8.7 \mathrm{~Hz}, 2 \mathrm{H}$, Ar-CH), $7.65(\mathrm{dd}, J=3.1,1.6 \mathrm{~Hz}, 1 \mathrm{H}, \mathrm{CH}), 7.18(\mathrm{dd}, J=3.1,1.6 \mathrm{~Hz}, 1 \mathrm{H}, \mathrm{NCH}), 3.74$ ppm (s, $\left.3 \mathrm{H}, \mathrm{CH}_{3}\right) ;{ }^{13} \mathrm{C}$ NMR $\left(75.5 \mathrm{MHz},[\mathrm{d} 6] \mathrm{DMSO}, 25{ }^{\circ} \mathrm{C}\right): \delta=164.0(\mathrm{C}), 145.1(\mathrm{C})$, $137.9(\mathrm{C}), 130.5(\mathrm{C}), 127.0(\mathrm{CH}), 124.2(\mathrm{CH}), 124.1(\mathrm{CH}), 116.9(\mathrm{C}), 109.7(\mathrm{CH}), 50.7$ ppm $\left(\mathrm{CH}_{3}\right)$; MS (EI): $m / z(\%): 246.1$ (100) $\left[\mathrm{M}^{+}\right], 215.1$ (80); IR (KBr): 3268, 3121, 1674, 1599, 1509, 1486, 1449, 1433, 1391, 1335, 1288, 1228, 1140, 1108, 991, 928, 851, 818, $769,752,691,602,521 \mathrm{~cm}^{-1}$; elemental analysis calcd $(\%)$ for $\mathrm{C}_{12} \mathrm{H}_{10} \mathrm{~N}_{2} \mathrm{O}_{4}: \mathrm{C} 58.54$, H 4.09, N 11.38; found: C 58.26, H 3.92, N 11.00. 


\section{General Procedure A for the Synthesis of 2,3-Disubstituted Pyrroles 178 (GP3)}

An oven-dried Schlenk flask equipped with magnetic stirrer and rubber septum, was charged with $\mathrm{CuBr}$ (143.5 mg, $1.0 \mathrm{mmol}), \mathrm{Cs}_{2} \mathrm{CO}_{3}(326 \mathrm{mg}, 1 \mathrm{mmol})$ and DMF (5 mL), evacuated and refilled with nitrogen. The respective acetylene 167 (1.0 mmol) was added from a syringe with stirring, and the mixture was heated at $120^{\circ} \mathrm{C}$ for $10 \mathrm{~min}$, then a solution of the respective isocyanide $63(2.0 \mathrm{mmol})$ in DMF $(5 \mathrm{~mL})$ was injected over a period of $2 \mathrm{~h}$, after that the reaction mixture was stirred at $120{ }^{\circ} \mathrm{C}$ for another $1 \mathrm{~h}$. After cooling and evaporation of the solvent in vacuo, the residue was purified by column chromatography on silica gel (eluting with $5: 1$ to $1: 1$ hexane/ethyl acetate) to provide the desired product.

\section{General Procedure B for the Synthesis of 2,3-Disubstituted Pyrroles 178 (GP4)}

An oven-dried Schlenk flask equipped with magnetic stirrer and rubber septum was charged with $\mathrm{CuBr}(143.5 \mathrm{mg}, 1.0 \mathrm{mmol}), \mathrm{Cs}_{2} \mathrm{CO}_{3}(326 \mathrm{mg}, 1 \mathrm{mmol})$ and DMF (5 mL), evacuated and refilled with nitrogen. The respective acetylene 167 (1.0 mmol) was added from a syringe with stirring, and the mixture was heated at $120{ }^{\circ} \mathrm{C}$ for $10 \mathrm{~min}$, then solutions of the respective isocyanide $63(1.0 \mathrm{mmol})$ and the respective acetylene 167 $(1.0 \mathrm{mmol})$ in DMF $(5 \mathrm{~mL})$ were injected over a period of $2 \mathrm{~h}$, after that the reaction mixture was stirred at $120^{\circ} \mathrm{C}$ for another $1 \mathrm{~h}$. After cooling and evaporation of the solvent in vacuo, the residue was purified by column chromatography on silica gel (eluting with $5: 1$ to $1: 1$ hexane/ethyl acetate) to provide the desired product.

\section{Ethyl 3-Butyl-1-H-pyrrol-2-carboxylate (178ba)}

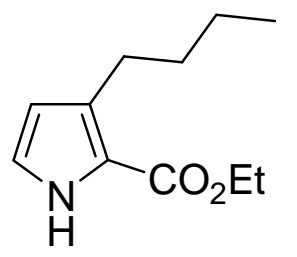

The pyrrole 178ba (250 mg, 64\%) was obtained from 1-hexyne (167a) (328 mg, $4 \mathrm{mmol}$ ), ethyl isocyanoacetate (25-Et) (226 mg, $2 \mathrm{mmol}$ ) following GP4, after column chromatography (hexane/ethyl acetate $\left.4: 1, R_{\mathrm{f}}=0.45\right)$ as a colorless oil. Alternatively it was obtained following GP3 (273 mg, 70\%). ${ }^{1} \mathrm{H}$ NMR (300 MHz, $\left.\mathrm{CDCl}_{3}, 25{ }^{\circ} \mathrm{C}, \mathrm{TMS}\right): \delta=9.10-8.89$ (br m, $1 \mathrm{H}, \mathrm{NH}), 6.81(\mathrm{t}, J=3 \mathrm{~Hz}, 1 \mathrm{H}, \mathrm{CH}), 6.10(\mathrm{t}, J=3 \mathrm{~Hz}, 1 \mathrm{H}, \mathrm{CH}), 4.29$ (q, $J=7 \mathrm{~Hz}, 2 \mathrm{H}$, Et-CH$)_{2}, 2.77\left(\mathrm{t}, J=8 \mathrm{~Hz}, 2 \mathrm{H}, \mathrm{CH}_{2}\right), 1.60-1.20(\mathrm{~m}, 7 \mathrm{H}), 0.91 \mathrm{ppm}$ $\left(\mathrm{t}, J=8 \mathrm{~Hz}, 3 \mathrm{H}, \mathrm{Et}-\mathrm{CH}_{3}\right) ;{ }^{13} \mathrm{C} \mathrm{NMR}\left(75.5 \mathrm{MHz}, \mathrm{CDCl}_{3}, 25{ }^{\circ} \mathrm{C}\right): \delta=161.7$ (C), $133.3(\mathrm{C})$, 
$121.5(\mathrm{CH}), 118.8(\mathrm{C}), 111.4(\mathrm{CH}), 59.9\left(\mathrm{CH}_{2}\right), 33.0\left(\mathrm{CH}_{2}\right), 26.6\left(\mathrm{CH}_{2}\right), 22.6\left(\mathrm{CH}_{2}\right), 14.4$ $\left(\mathrm{CH}_{3}\right), 13.9$ ppm $\left(\mathrm{CH}_{3}\right)$; IR (film): 3322, 2957, 2860, 1672, 1561, 1420, 1318, 1262, 1188 ,

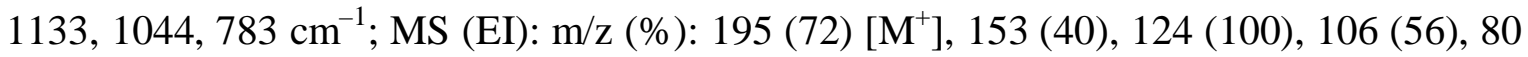
(40); elemental analysis calcd (\%) for $\mathrm{C}_{11} \mathrm{H}_{17} \mathrm{NO}_{2}$ : C 67.66, $\mathrm{H}$ 8.78, N 7.17; found: $\mathrm{C}$ 67.71, H 8.51, N 7.02.

\section{Ethyl 3-(Methoxymethyl)-1H-pyrrole-2-carboxylate (178bb)}

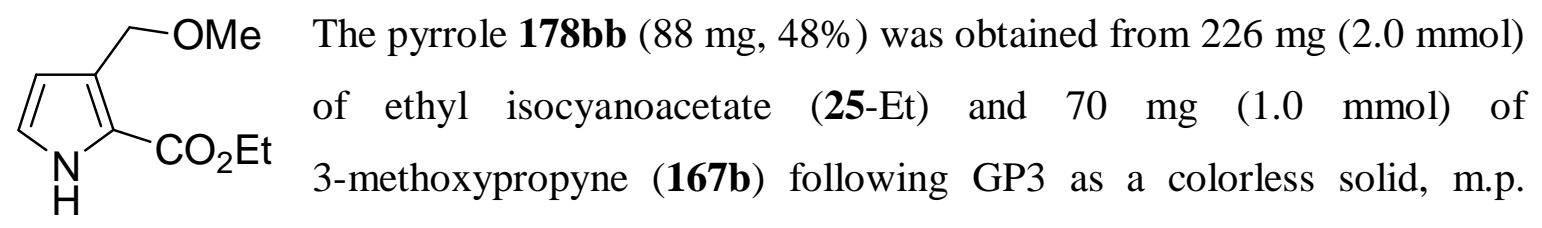

$74{ }^{\circ} \mathrm{C} . R_{\mathrm{f}}=0.27$ (hexane/ethylacetate $4: 1$ ). Alternatively, it was prepared following GP4 (83 mg, 45\%). ${ }^{1} \mathrm{H}$ NMR (300 MHz, $\left.\mathrm{CDCl}_{3}, 25{ }^{\circ} \mathrm{C}, \mathrm{TMS}\right): \delta=9.39$ (br s, $\left.1 \mathrm{H}, \mathrm{NH}\right), 6.88$ $(\mathrm{t}, J=2.6 \mathrm{~Hz}, 1 \mathrm{H}, \mathrm{CH}), 6.34(\mathrm{t}, J=2.6 \mathrm{~Hz}, 1 \mathrm{H}, \mathrm{CH}), 4.69\left(\mathrm{~s}, 2 \mathrm{H}, \mathrm{CH}_{2}\right), 4.34$ $\left(\mathrm{q}, J=7.2 \mathrm{~Hz}, 2 \mathrm{H}, \mathrm{Et}-\mathrm{CH}_{2}\right), 3.43\left(\mathrm{~s}, 3 \mathrm{H}, \mathrm{OCH}_{3}\right), 1.37 \mathrm{ppm}\left(\mathrm{t}, J=7.2 \mathrm{~Hz}, 3 \mathrm{H}, \mathrm{CH}_{3}\right)$; ${ }^{13} \mathrm{C}$ NMR (75 MHz, $\left.\mathrm{CDCl}_{3}, 25{ }^{\circ} \mathrm{C}, \mathrm{TMS}\right): \delta=161.2(\mathrm{C}), 128.4(\mathrm{C}), 121.9(\mathrm{CH}), 119.1(\mathrm{C})$, $111.1(\mathrm{CH}), 67.2\left(\mathrm{CH}_{2}\right), 60.3\left(\mathrm{CH}_{3}\right), 58.1\left(\mathrm{CH}_{2}\right), 14.4 \mathrm{ppm}\left(\mathrm{CH}_{3}\right)$; $\mathrm{MS}(\mathrm{EI}): \mathrm{m} / z(\%)$ : 183.2 (40) $\left[\mathrm{M}^{+}\right], 168.1$ (52), 154.2 (45), 122.1 (100); IR (KBr): 3288, 1671, 1490, 1426, $1373,1326,1271,1222,1193,1139,1111,963,782,751,601 \mathrm{~cm}^{-1}$; elemental analysis calcd (\%) for $\mathrm{C}_{9} \mathrm{H}_{13} \mathrm{NO}_{3}$ : C 59.00, H 7.15, N 7.65; found: C 59.06, H 6.80, N 7.35.

\section{Ethyl 3-Cyclopropyl-1H-pyrrole-2-carboxylate (178be)}

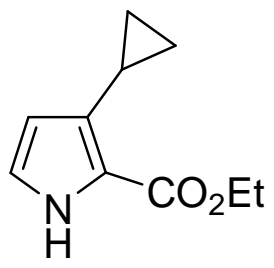

The pyrrole 178be (157 mg, 88\%) was obtained following GP3 from $226 \mathrm{mg}(2.0 \mathrm{mmol})$ of ethyl isocyanoacetate $(25-\mathrm{Et})$ and $66 \mathrm{mg}$ $(1.0 \mathrm{mmol})$ of cyclopropylacetylene $(\mathbf{1 6 7 e})$ as a colorless solid, m.p. $51-52{ }^{\circ} \mathrm{C}, R_{\mathrm{f}}=0.37$ (hexane/ethyl acetate $\left.5: 1\right) .{ }^{1} \mathrm{H}\left(300 \mathrm{MHz}, \mathrm{CDCl}_{3}\right.$, $\left.25^{\circ} \mathrm{C}, \mathrm{TMS}\right): \delta=8.92($ br s, $1 \mathrm{H}, \mathrm{NH}), 6.79(\mathrm{t}, J=2.9 \mathrm{~Hz}, 1 \mathrm{H}, \mathrm{CH}), 5.78$ $(\mathrm{t}, J=2.9 \mathrm{~Hz}, 1 \mathrm{H}, \mathrm{CH}), 4.35\left(\mathrm{q}, J=7.2 \mathrm{~Hz}, 2 \mathrm{H}, \mathrm{CH}_{2}\right), 2.57-2.48$ (m, $\left.1 \mathrm{H}, \mathrm{cPr}-\mathrm{CH}\right), 1.37$ (t, $\left.J=7.2 \mathrm{~Hz}, 3 \mathrm{H}, \mathrm{CH}_{3}\right), 0.99-0.93$ (m, $\left.2 \mathrm{H}, \mathrm{cPr}-\mathrm{CH}_{2}\right), 0.64-0.59$ ppm (m, $2 \mathrm{H}, \mathrm{cPr}^{-\mathrm{CH}_{2}}$ ); ${ }^{13} \mathrm{C}\left(75.5 \mathrm{MHz}, \mathrm{CDCl}_{3}, 25{ }^{\circ} \mathrm{C}\right): \delta=161.7(\mathrm{C}), 135.5(\mathrm{C}), 121.9(\mathrm{CH}), 119.7(\mathrm{C}), 106.2$ $(\mathrm{CH}), 60.0\left(\mathrm{CH}_{2}\right), 14.5(\mathrm{CH}), 9.3\left(\mathrm{CH}_{2}\right), 7.9 \mathrm{ppm}\left(\mathrm{CH}_{2}\right)$; MS (EI) $\mathrm{m} / z(\%): 179.2$ (100) $\left[\mathrm{M}^{+}\right], 150.2$ (45), 133.2 (39), 106.2 (62); IR (KBr): 3299, 1673, 1422, 1391, 1322, 1279, 
1218, 1185, 1141, 1036, 907, 781, 745, $602 \mathrm{~cm}^{-1}$; elemental analysis calcd $(\%)$ for $\mathrm{C}_{10} \mathrm{H}_{13} \mathrm{NO}_{2}$ : C 67.02, H 7.31, N 7.82; found: C 67.66, H 6.80, N 7.36.

\section{Ethyl 3-tert-Butyl-1H-pyrrole-2-carboxylate (178bf) and}

Ethyl 4-tert-butyl-1H-pyrrole-2-carboxylate (iso-178bf ${ }^{[184]}$

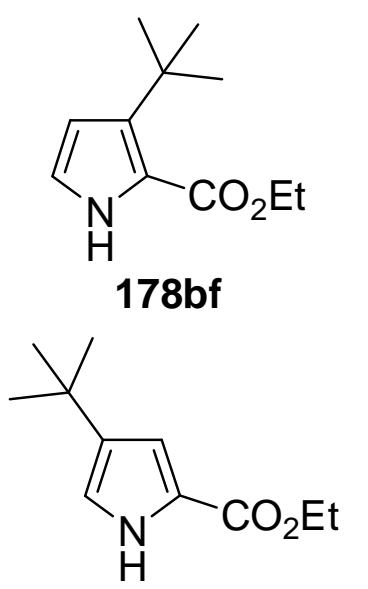

iso-178bf

A $5: 1$ mixture of the regioisomeric pyrroles $\mathbf{1 7 8 b f}$ and iso-178bf (10 mg, 5\%) was obtained following GP4 from $113 \mathrm{mg}(1.0 \mathrm{mmol})$ of ethyl isocyanoacetate $(25-\mathrm{Et})$ and $164 \mathrm{mg}(2.0 \mathrm{mmol})$ of tert-butylacetylene (167f), as a colorless oil, $R_{\mathrm{f}}=0.43$ (hexane/ethyl acetate 4 : 1). 178bf: ${ }^{1} \mathrm{H}\left(300 \mathrm{MHz}, \mathrm{CDCl}_{3}, 25{ }^{\circ} \mathrm{C}, \mathrm{TMS}\right): \delta=9.16$ (br s, $1 \mathrm{H}, \mathrm{NH}), 6.78(\mathrm{t}, J=2.6 \mathrm{~Hz}, 1 \mathrm{H}, \mathrm{CH}), 6.21$ $(\mathrm{t}, J=2.6 \mathrm{~Hz}, 1 \mathrm{H}, \mathrm{CH}), 4.32\left(\mathrm{q}, J=7.2 \mathrm{~Hz}, 2 \mathrm{H}, \mathrm{CH}_{2}\right), 1.40$ $(\mathrm{s}, 9 \mathrm{H}, t \mathrm{Bu}), 1.25 \mathrm{ppm}\left(\mathrm{s}, 3 \mathrm{H}, \mathrm{CH}_{3}\right) ;{ }^{13} \mathrm{C}\left(75.5 \mathrm{MHz}, \mathrm{CDCl}_{3}\right.$, $\left.25^{\circ} \mathrm{C}\right): \delta=160.4(\mathrm{C}), 142.6(\mathrm{C}), 120.0(\mathrm{CH}), 109.8(\mathrm{CH}), 109.2$ (C), $60.0\left(\mathrm{CH}_{2}\right), 31.6\left(\mathrm{CH}_{3}\right), 30.2\left(\mathrm{CH}_{3}\right), 22.6$ ppm (C); iso-178bf: ${ }^{1} \mathrm{H}\left(300 \mathrm{MHz}, \mathrm{CDCl}_{3}\right.$, $\left.25^{\circ} \mathrm{C}, \mathrm{TMS}\right): \delta=8.95(\mathrm{br} \mathrm{s}, 1 \mathrm{H}, \mathrm{NH}), 6.83(\mathrm{t}, J=2.6 \mathrm{~Hz}, 1 \mathrm{H}, \mathrm{CH}), 6.12(\mathrm{t}, J=2.6 \mathrm{~Hz}$, $1 \mathrm{H}, \mathrm{CH}), 4.31\left(\mathrm{q}, J=7.2 \mathrm{~Hz}, 2 \mathrm{H}, \mathrm{CH}_{2}\right), 1.37(\mathrm{t}, J=7.2 \mathrm{~Hz}, 9 \mathrm{H}, t \mathrm{Bu}), 0.93 \mathrm{ppm}(\mathrm{t}$, $\left.J=7.2 \mathrm{~Hz}, 3 \mathrm{H}, \mathrm{CH}_{3}\right) ;{ }^{13} \mathrm{C}\left(75.5 \mathrm{MHz}, \mathrm{CDCl}_{3}, 25{ }^{\circ} \mathrm{C}\right): \delta=160.4(\mathrm{C}), 142.6(\mathrm{C}), 121.4(\mathrm{C})$, $117.9(\mathrm{CH}), 111.4(\mathrm{CH}), 59.9\left(\mathrm{CH}_{2}\right), 33.0\left(\mathrm{CH}_{3}\right), 29.7\left(\mathrm{CH}_{3}\right), 26.6 \mathrm{ppm}(\mathrm{C})$; MS (EI) $\mathrm{m} / z$ (\%): $195.2(26)\left[\mathrm{M}^{+}\right], 180.2(28), 134.2(100)$.

\section{4,5-Dihydro-1- $H$-pyrano[3,4-b]pyrrol-7-one (179)}

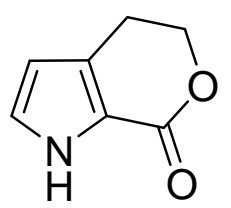

The $\delta$-lactone-annelated pyrrole 179 (51 mg, 37\%) was obtained from 113 $\mathrm{mg}(1.0 \mathrm{mmol})$ of ethyl isocyanoacetate $(25-\mathrm{Et})$ and $140 \mathrm{mg}(2.0 \mathrm{mmol})$ of but-3-yn-1-ol (167i) following GP4, as a colorless solid, m.p. 123-124 ${ }^{\circ} \mathrm{C}$. Alternatively, 179 was prepared in $44 \%$ yield following GP3, $R_{\mathrm{f}}=0.45$ (hexane/ethyl acetate $1: 1) .{ }^{1} \mathrm{H}$ NMR (300 MHz, $\left.\mathrm{CDCl}_{3}, 25{ }^{\circ} \mathrm{C}, \mathrm{TMS}\right): \delta=10.68$ (br s, $\left.1 \mathrm{H}, \mathrm{NH}\right), 7.08$ $(\mathrm{t}, J=2.8 \mathrm{~Hz}, 1 \mathrm{H}), 6.13(\mathrm{t}, J=2.8 \mathrm{~Hz}, 1 \mathrm{H}, \mathrm{CH}), 4.56\left(\mathrm{t}, J=6.2 \mathrm{~Hz}, 2 \mathrm{H}, \mathrm{CH}_{2}\right), 2.93 \mathrm{ppm}$ $\left(\mathrm{t}, J=6.2 \mathrm{~Hz}, 2 \mathrm{H}, \mathrm{CH}_{2}\right) ;{ }^{13} \mathrm{C} \mathrm{NMR}\left(75.5 \mathrm{MHz}, \mathrm{CDCl}_{3}, 25^{\circ} \mathrm{C}\right): \delta=161.2(\mathrm{C}), 130.8(\mathrm{C})$, $126.4(\mathrm{CH}), 117.9(\mathrm{C}), 107.2(\mathrm{CH}), 69.5\left(\mathrm{CH}_{2}\right), 23.0 \mathrm{ppm}\left(\mathrm{CH}_{2}\right)$; MS (EI) m/z (\%):137.1 (100) $\left[\mathrm{M}^{+}\right], 107.1$ (42), 79.1 (78); IR (KBr): 3274, 1686, 1400, 1308, 1274, 1209, 1185, 1123, 1078, 1049, 1013, 773, 739, 599, 496, $460 \mathrm{~cm}^{-1}$; elemental analysis calcd (\%) for $\mathrm{C}_{7} \mathrm{H}_{7} \mathrm{NO}_{2}$ : C 61.31, H 5.14, N 10.21; found: C 61.51, H 4.98, N 10.18. 


\section{Ethyl 3-(1-Methoxy-ethyl)-1H-pyrrole-2-carboxylate (178bc)}

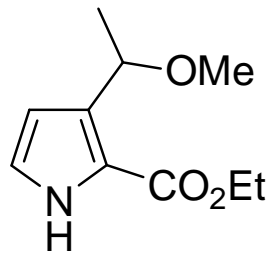

The pyrrole 178bc (145 mg, 74\%) was obtained from $226 \mathrm{mg}$ (2.0 mmol) of ethyl isocyanoacetate $(25-\mathrm{Et})$ and $84 \mathrm{mg}(1.0 \mathrm{mmol})$ of 3-methoxy but-1-yne (167c) following GP3, as a colorless solid, m.p. $53{ }^{\circ} \mathrm{C}$, $R_{\mathrm{f}}=0.31$ (hexane/ethyl acetate $\left.4: 1\right)$, m.p. $53{ }^{\circ} \mathrm{C} .{ }^{1} \mathrm{H}\left(300 \mathrm{MHz}, \mathrm{CDCl}_{3}\right.$, $\left.25^{\circ} \mathrm{C}, \mathrm{TMS}\right): \delta=9.32(\mathrm{br} \mathrm{s}, 1 \mathrm{H}, \mathrm{NH}), 6.90(\mathrm{t}, J=2.6 \mathrm{~Hz}, 1 \mathrm{H}, \mathrm{CH}), 6.35(\mathrm{t}, J=2.6 \mathrm{~Hz}$, $1 \mathrm{H}, \mathrm{CH}), 5.04(\mathrm{q}, J=6.2 \mathrm{~Hz}, 1 \mathrm{H}, \mathrm{OCH}), 4.35\left(\mathrm{q}, J=7.0 \mathrm{~Hz}, 2 \mathrm{H}, \mathrm{CH}_{2}\right), 3.29$ (s, $3 \mathrm{H}, \mathrm{OCH}_{3}$ ), 1.44 (d, $\left.J=6.5 \mathrm{~Hz}, 3 \mathrm{H}, \mathrm{CH}_{3}\right), 1.37 \mathrm{ppm}\left(\mathrm{t}, J=7.2 \mathrm{~Hz}, 3 \mathrm{H}, \mathrm{Et}-\mathrm{CH}_{3}\right)$; ${ }^{13} \mathrm{C}\left(75.5 \mathrm{MHz}, \mathrm{CDCl}_{3}, 25{ }^{\circ} \mathrm{C}\right): \delta=161.2(\mathrm{C}), 134.4(\mathrm{C}), 122.1(\mathrm{CH}), 118.8(\mathrm{C}), 108.4$ $(\mathrm{CH}), 72.1(\mathrm{CH}), 60.2\left(\mathrm{CH}_{3}\right), 56.3\left(\mathrm{CH}_{2}\right), 22.9\left(\mathrm{CH}_{3}\right), 14.4 \mathrm{ppm}\left(\mathrm{CH}_{3}\right) ; \mathrm{MS}(\mathrm{EI}): \mathrm{m} / z(\%)$ : $197.3(18)\left[\mathrm{M}^{+}\right], 182.2$ (100), 136.2 (50), 122.1 (62); IR (KBr): $3220 \mathrm{~cm}^{-1}, 2982,2928$, 2822, 1702, 1566, 1481, 1419, 1367, 1337, 1306, 1261, 1208, 1190, 1146, 1072, 1037, 902, 846, 785, 739, 610,572; elemental analysis calcd (\%) for $\mathrm{C}_{10} \mathrm{H}_{15} \mathrm{NO}_{3}: \mathrm{C} 60.90, \mathrm{H}$ 7.67, N 7.10; found: C 61.02, H 7.45, N 6.95.

\section{Ethyl 3-Phenyl-1H-pyrrole-2-carboxylate (178bd) ${ }^{[185]}$}

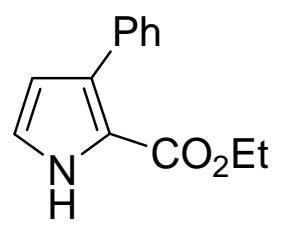

The pyrrole 178bd ( $85 \mathrm{mg}, 40 \%$ ), was obtained following GP3 from $226 \mathrm{mg}(2.0 \mathrm{mmol})$ of ethyl isocyanoacetate $(25-\mathrm{Et})$ and $102 \mathrm{mg}$ $(1.0 \mathrm{mmol})$ of phenylacetylene $(\mathbf{1 6 7 d})$, as a colorless solid, m.p. $54-55{ }^{\circ} \mathrm{C}, R_{\mathrm{f}}=0.40$ (hexane/ethyl acetate $\left.2: 1\right) .{ }^{1} \mathrm{H}\left(300 \mathrm{MHz}, \mathrm{CDCl}_{3}\right.$, $25^{\circ} \mathrm{C}$ ): $\delta=9.22$ (br s, $\left.1 \mathrm{H}, \mathrm{NH}\right), 7.58-7.54(\mathrm{~m}, 2 \mathrm{H}, \mathrm{Ph}), 7.40-7.27(\mathrm{~m}, 3 \mathrm{H}, \mathrm{Ph}), 6.95$ $(\mathrm{t}, J=2.6 \mathrm{~Hz}, 1 \mathrm{H}, \mathrm{CH}), 6.36(\mathrm{t}, J=2.6 \mathrm{~Hz}, 1 \mathrm{H}, \mathrm{CH}), 4.26\left(\mathrm{q}, J=7.2 \mathrm{~Hz}, 2 \mathrm{H}, \mathrm{CH}_{2}\right)$, $1.25 \mathrm{ppm}\left(\mathrm{t}, J=6.9 \mathrm{~Hz}, 3 \mathrm{H}, \mathrm{CH}_{3}\right) ;{ }^{13} \mathrm{C}\left(75.5 \mathrm{MHz}, \mathrm{CDCl}_{3}, 25^{\circ} \mathrm{C}\right): \delta=161.1(\mathrm{C})$, $135.1(\mathrm{C}), 132.0(\mathrm{C}), 129.5(\mathrm{CH}), 127.6(\mathrm{CH}), 126.9(\mathrm{CH}), 121.7(\mathrm{CH}), 118.2(\mathrm{C})$, $112.5(\mathrm{CH}), 60.3\left(\mathrm{CH}_{2}\right), 14.2 \mathrm{ppm}\left(\mathrm{CH}_{3}\right)$; $\mathrm{MS}(\mathrm{EI}): \mathrm{m} / \mathrm{z}(\%): 215.2$ (90) $\left[\mathrm{M}^{+}\right], 169.2(100)$ : IR (KBr): 3295, 2980, 1668, 1504, 1419, 1358, 1321, 1297, 1213, 1153, 1020, 896, 868, 791, 748, 700, $611 \mathrm{~cm}^{-1}$; elemental analysis calcd (\%) for $\mathrm{C}_{13} \mathrm{H}_{13} \mathrm{NO}_{2}$ : C 72.54, $\mathrm{H} 6.09$, N 6.51; found: C 72.32, H 6.20, N 6.33. 


\section{Ethyl 3-(Pyridin-2-yl-1)-1H-pyrrole-2-carboxylate (178bg)}

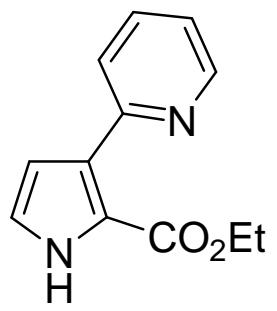

The pyrrole 178bg (34 mg, $16 \%$ ) was obtained following GP3 from $226 \mathrm{mg}(2.0 \mathrm{mmol})$ of ethyl isocyanoacetate $(25-\mathrm{Et})$ and $103 \mathrm{mg}$ $(1.0 \mathrm{mmol})$ of 2-ethynylpyridine $(\mathbf{1 6 7 g})$ as a yellow oil, $R_{\mathrm{f}}=0.33$ (hexane/ethyl acetate $2: 1) .{ }^{1} \mathrm{H}$ NMR $\left(300 \mathrm{MHz}, \mathrm{CDCl}_{3}, 25^{\circ} \mathrm{C}\right.$, TMS): $\delta=9.57($ br s, $1 \mathrm{H}, \mathrm{NH}), 8.66(\mathrm{~d}, \mathrm{~J}=4.9 \mathrm{~Hz}, 1 \mathrm{H}, \mathrm{CH}), 7.87(\mathrm{~d}, J=7.9$ $\mathrm{Hz}, 1 \mathrm{H}, \mathrm{CH}), 7.69$ (dt, $J=7.5,1.9 \mathrm{~Hz}, 1 \mathrm{H}, \mathrm{CH}), 7.19$ (ddd, $J=7.2,4.9,1.1 \mathrm{~Hz}, 1 \mathrm{H}, \mathrm{CH})$, $6.95(\mathrm{t}, J=2.6 \mathrm{~Hz}, 1 \mathrm{H}, \mathrm{CH}), 6.69(\mathrm{t}, J=2.6 \mathrm{~Hz}, 1 \mathrm{H}, \mathrm{CH}), 4.28\left(\mathrm{q}, J=7.2 \mathrm{~Hz}, 2 \mathrm{H}, \mathrm{CH}_{2}\right)$, $1.26 \mathrm{ppm}\left(\mathrm{t}, J=7.2 \mathrm{~Hz}, 3 \mathrm{H}, \mathrm{CH}_{3}\right) ;{ }^{13} \mathrm{C} \mathrm{NMR}\left(75.5 \mathrm{MHz}, \mathrm{CDCl}_{3}, 25{ }^{\circ} \mathrm{C}\right): \delta=160.7(\mathrm{C})$, $153.7(\mathrm{C}), 148.9(\mathrm{CH}), 135.4(\mathrm{CH}), 131.3(\mathrm{C}), 124.9(\mathrm{CH}), 121.8(\mathrm{CH}), 121.6(\mathrm{CH}), 118.9$ (C), $112.8(\mathrm{CH}), 60.4\left(\mathrm{CH}_{2}\right), 14.2 \mathrm{ppm}\left(\mathrm{CH}_{3}\right)$; MS (EI) $\mathrm{m} / \mathrm{z}(\%): 216.2(30)\left[\mathrm{M}^{+}\right], 170.1$ (28), 144.2 (100); IR (KBr): 3121, 2981, 1695, 1593, 1564, 1492, 1409, 1294, 1147, 1073 , 1024, 896, $776 \mathrm{~cm}^{-1}$; elemental analysis calcd (\%) for $\mathrm{C}_{12} \mathrm{H}_{12} \mathrm{~N}_{2} \mathrm{O}_{2}$ : C 66.65, H 5.59, N 12.96; found: C 66.85, H 5.42, N 12.79.

\section{Ethyl 3-(sec-Butyl)-1H-pyrrole-2-carboxylate (178bh)}

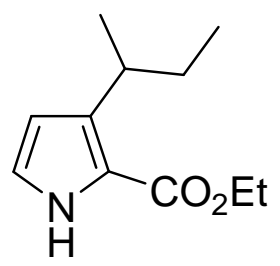

The pyrrole 178bh (114 mg, 58\%) was obtained following GP3 from $226 \mathrm{mg}(2.0 \mathrm{mmol})$ of ethyl isocyanoacetate $(25-\mathrm{Et})$ and $82 \mathrm{mg}$ $(1.0 \mathrm{mmol})$ of 3-methyl pent-1-yne $(\mathbf{1 6 7 h})$ as a yellow oil, $R_{\mathrm{f}}=0.41$ (hexane/ethyl acetate $5: 1) .{ }^{1} \mathrm{H}$ NMR $\left(300 \mathrm{MHz}, \mathrm{CDCl}_{3}, 25{ }^{\circ} \mathrm{C}\right.$, TMS): $\delta=9.03($ br s, $1 \mathrm{H}, \mathrm{NH}), 6.85(\mathrm{t}, J=2.6 \mathrm{~Hz}, 1 \mathrm{H}, \mathrm{CH}), 6.15(\mathrm{t}, J=2.6 \mathrm{~Hz}, 1 \mathrm{H}, \mathrm{CH}), 4.32$ $\left(\mathrm{q}, J=7.2 \mathrm{~Hz}, 1 \mathrm{H}, \mathrm{CH}_{2}\right), 4.31\left(\mathrm{q}, J=7.2 \mathrm{~Hz}, 1 \mathrm{H}, \mathrm{CH}_{2}\right), 3.42-3.30(\mathrm{~m}, 1 \mathrm{H}, \mathrm{CH})$, 1.67-1.46 (m, $2 \mathrm{H}$, sec-Bu-CH$), 1.36\left(\mathrm{t}, J=7.2 \mathrm{~Hz}, 3 \mathrm{H}\right.$, sec- $\left.\mathrm{Bu}-\mathrm{CH}_{2} \mathrm{CH}_{3}\right), 1.20$ $\left(\mathrm{d}, J=6.8 \mathrm{~Hz}, 3 \mathrm{H},(\mathrm{CH}) \mathrm{CH}_{3}\right), 0.86 \mathrm{ppm}\left(\mathrm{t}, J=7.2 \mathrm{~Hz}, 3 \mathrm{H}, \mathrm{Et}-\mathrm{CH}_{3}\right) ;{ }^{13} \mathrm{C} \mathrm{NMR}$ (75.5 MHz, $\left.\mathrm{CDCl}_{3}, 25^{\circ} \mathrm{C}\right): \delta=161.6(\mathrm{C}), 138.8(\mathrm{C}), 121.6(\mathrm{CH}), 118.4(\mathrm{C}), 108.5(\mathrm{CH})$, $59.8\left(\mathrm{CH}_{2}\right), 32.2(\mathrm{CH}), 31.0\left(\mathrm{CH}_{2}\right), 21.3\left(\mathrm{CH}_{3}\right), 14.4\left(\mathrm{CH}_{3}\right), 12.1 \mathrm{ppm}\left(\mathrm{CH}_{3}\right) ; \mathrm{MS}(\mathrm{EI}) \mathrm{m} / \mathrm{z}$ (\%): 195.3 (56) [ $\left.\mathrm{M}^{+}\right], 166.2$ (94), 120.2 (100); IR (film): 3326, 2964, 2932, 2873, 1672, 1557, 1455, 1421, 1371, 1318, 1266, 1193, 1132, 1088, 1045, 901, $784 \mathrm{~cm}^{-1}$; elemental analysis calcd (\%) for $\mathrm{C}_{11} \mathrm{H}_{17} \mathrm{NO}_{2}$ : C 67.66, $\mathrm{H}$ 8.78, N 7.17; found: C 67.80, H 7.50, N 7.01. 
tert-Butyl 3-(n-Butyl)-1H-pyrrole-2-carboxylate (178ca)

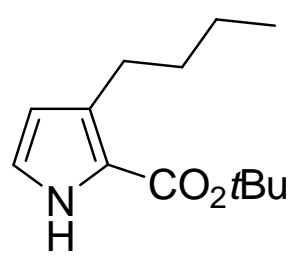

The pyrrole 178ca (127 mg, 47\%) was obtained from $170 \mathrm{mg}$ $(1.2 \mathrm{mmol})$ of tert-butyl isocyanoacetate $(\mathbf{2 5}-\mathrm{t} \mathrm{Bu})$ and $196 \mathrm{mg}$ (2.4 mmol) of 1-hexyne (167a) following GP4 as a light-brown solid, m.p. $42{ }^{\circ} \mathrm{C}, R_{\mathrm{f}}=0.48$ (hexane/ethyl acetate $\left.5: 1\right) .{ }^{1} \mathrm{H}(300 \mathrm{MHz}$, $\left.\mathrm{CDCl}_{3}, 25^{\circ} \mathrm{C}, \mathrm{TMS}\right): \delta=8.95(\mathrm{br} \mathrm{s}, 1 \mathrm{H}, \mathrm{NH}), 6.80(\mathrm{t}, J=2.6 \mathrm{~Hz}, 1 \mathrm{H}, \mathrm{CH})$, 6.09 (t, $J=2.6 \mathrm{~Hz}, 1 \mathrm{H}, \mathrm{CH}), 2.75\left(\mathrm{dd}, J=7.9 \mathrm{~Hz}, J=7.5 \mathrm{~Hz}, 2 \mathrm{H}, \mathrm{CH}_{2}\right), 1.64-1.52$ $\left(\mathrm{m}, 2 \mathrm{H}, \mathrm{CH}_{2}\right), 1.57(\mathrm{~s}, 9 \mathrm{H}, t \mathrm{Bu}), 1.38\left(\mathrm{~m}, 2 \mathrm{H}, \mathrm{CH}_{2}\right), 0.93 \mathrm{ppm}\left(\mathrm{t}, J=7.2 \mathrm{~Hz}, 3 \mathrm{H}, \mathrm{CH}_{3}\right)$; ${ }^{13} \mathrm{C}\left(75.5 \mathrm{MHz}, \mathrm{CDCl}_{3}, 25{ }^{\circ} \mathrm{C}\right): \delta=161.3(\mathrm{C}), 132.3(\mathrm{C}), 120.8(\mathrm{CH}), 120.0(\mathrm{C}), 111.3$ $(\mathrm{CH}), 80.51(\mathrm{C}), 33.1\left(\mathrm{CH}_{2}\right), 28.5\left(\mathrm{CH}_{3}\right), 26.8\left(\mathrm{CH}_{2}\right), 22.7\left(\mathrm{CH}_{2}\right), 14.1 \mathrm{ppm}\left(\mathrm{CH}_{3}\right) ; \mathrm{MS}(\mathrm{EI})$ $m / z$ (\%): 223.3 (22) $\left[\mathrm{M}^{+}\right], 167.2$ (38), 125.1 (100), 106.1 (26), 80.1 (22); IR (KBr): 3321, 2958, 1672, 1553, 1415, 1367, 1330, 1266, 1173, 1130, 902, 845, 783, 750, $604 \mathrm{~cm}^{-1}$; elemental analysis calcd (\%) for $\mathrm{C}_{13} \mathrm{H}_{21} \mathrm{NO}_{2}$ : C 69.92, $\mathrm{H}$ 9.48, N 6.27; found: C 70.17, H 9.19, N 6.09.

\section{3-Butyl-2-(4-nitrophenyl)-1H-pyrrole (178fa)}

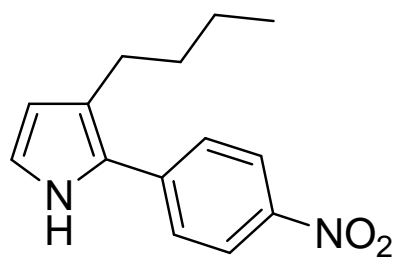

The pyrrole 178fa (45 mg, 18\%) was obtained following GP4 from $162 \mathrm{mg}$ (1.0 mmol) of (4-nitrophenyl)methyl isocyanide (63f) and $164 \mathrm{mg}(2.0 \mathrm{mmol})$ of 1-hexyne (167a) as a red solid, m.p. $95{ }^{\circ} \mathrm{C}, R_{\mathrm{f}}=0.35$ (hexane/ethyl acetate $\left.4: 1\right) .{ }^{1} \mathrm{H}(300 \mathrm{MHz}$, $\left.\mathrm{CDCl}_{3}, 25^{\circ} \mathrm{C}, \mathrm{TMS}\right): \delta=8.27$ (br s, $\left.1 \mathrm{H}, \mathrm{NH}\right), 8.25$ (d, $\left.J=9.0 \mathrm{~Hz}, 2 \mathrm{H}, \mathrm{Ar}-\mathrm{CH}\right)$, $7.51(\mathrm{~d}, J=9.0 \mathrm{~Hz}, 2 \mathrm{H}, \mathrm{Ar}-\mathrm{CH}), 6.90(\mathrm{t}, J=2.6 \mathrm{~Hz}, 1 \mathrm{H}, \mathrm{CH}), 6.25(\mathrm{t}, J=2.6 \mathrm{~Hz}, 1 \mathrm{H}$, $\mathrm{CH}), 2.68\left(\mathrm{dd}, J=7.7,7.5 \mathrm{~Hz}, 2 \mathrm{H}, \mathrm{CH}_{2}\right), 1.68-1.58\left(\mathrm{~m}, 2 \mathrm{H}, \mathrm{CH}_{2}\right), 1.47-1.34(\mathrm{~m}, 2 \mathrm{H}$, $\left.\mathrm{CH}_{2}\right), 0.93 \mathrm{ppm}\left(\mathrm{t}, J=7.2 \mathrm{~Hz}, 3 \mathrm{H}, \mathrm{CH}_{3}\right) ;{ }^{13} \mathrm{C}\left(75.5 \mathrm{MHz}, \mathrm{CDCl}_{3}, 25{ }^{\circ} \mathrm{C}\right): \delta=145.2(\mathrm{C})$, $140.0(\mathrm{C}), 125.9(\mathrm{CH}), 125.8(\mathrm{CH}), 125.4(\mathrm{C}), 124.3(\mathrm{CH}), 120.0(\mathrm{C}), 111.8(\mathrm{CH}), 33.0$ $\left(\mathrm{CH}_{2}\right), 26.6\left(\mathrm{CH}_{2}\right), 22.7\left(\mathrm{CH}_{2}\right), 14.0$ ppm $\left(\mathrm{CH}_{3}\right)$; MS (EI) m/z (\%): 244.3 (62) [M $\left.\mathrm{M}^{+}\right], 201.2$ (100), 155.2 (66); IR (KBr): 3374, 2923, 1593, 1496, 1418, 1316, 1172, 1109, 891, 849, 756, 697, $588 \mathrm{~cm}^{-1}$; UV (MeCN): $\lambda_{\max }(\varepsilon)=393$ (13940), 382 (9428), $197 \mathrm{~nm}(24045$ $\mathrm{mol}^{-1} \mathrm{dm}^{3} \mathrm{~cm}^{-1}$ ); elemental analysis calcd (\%) for $\mathrm{C}_{14} \mathrm{H}_{16} \mathrm{~N}_{2} \mathrm{O}_{2}$ : C 68.83, H 6.60, N 11.47; found: C 69.02, H 6.55, N 11.20. 
Partly Deuterated Methyl 3-Butyl-1-H-pyrrol-2-carboxylate (178aa-D)

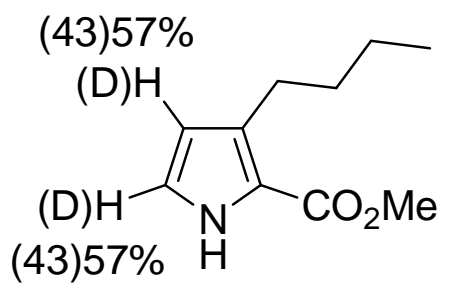

A mixture of pyrroles 178aa-D and 178aa-H (108 mg, 60\%) was obtained from 1-deutero hexyne-1 (167a-D) (166 mg, $2 \mathrm{mmol}$ ), methyl isocyanoacetate (25-Me) (99 $\mathrm{mg}, 1 \mathrm{mmol})$ following GP4, after column chromatography (hexane/ethyl acetate $\left.4: 1, R_{\mathrm{f}}=0.43\right)$ as a colorless oil. ${ }^{1} \mathrm{H} \mathrm{NMR}\left(300 \mathrm{MHz}, \mathrm{CDCl}_{3}, 25{ }^{\circ} \mathrm{C}, \mathrm{TMS}\right)$ : $\delta=8.95(\mathrm{br} \mathrm{m}, 1 \mathrm{H}, \mathrm{NH}), 6.83(\mathrm{t}, J=3 \mathrm{~Hz}, 0.57 \mathrm{H}, \mathrm{CH}), 6.13(\mathrm{t}, J=3 \mathrm{~Hz}, 0.57 \mathrm{H}, \mathrm{CH})$, $3.84\left(\mathrm{~s}, 3 \mathrm{H}, \mathrm{CH}_{3}\right), 2.79$ (t, $\left.J=8 \mathrm{~Hz}, 2 \mathrm{H}, \mathrm{CH}_{2}\right), 1.61-1.52\left(\mathrm{~m}, 2 \mathrm{H}, \mathrm{CH}_{2}\right), 1.45-1.30$ (m, $\left.2 \mathrm{H}, \mathrm{CH}_{2}\right), 0.93$ ppm (t, $\left.J=8 \mathrm{~Hz}, 3 \mathrm{H}, \mathrm{Et}-\mathrm{CH}_{3}\right)$; MS (EI): m/z (\%): 183.2 (18) [M+2], $182.2(40)\left[\mathrm{M}^{+}+1\right], 181.2(34)\left[\mathrm{M}^{+}\right]$. 


\section{Experimental Procedures for the Compounds Described in Chapter 2 \\ "ortho-Lithiophenyl Isocyanide: A Versatile Precursor for \\ 3H-Quinazolin-4-ones and 3H-Quinazolin-4-thiones"}

\section{$N$-Formyl-2-iodoaniline}

$\overbrace{\mathrm{H}^{-}}^{\mathrm{CHO}}$

A solution of o-iodoaniline $(8.0 \mathrm{~g}, 36.5 \mathrm{mmol})$ and ethyl formate $(15 \mathrm{~mL})$ in anhydrous THF $(250 \mathrm{~mL})$ was added dropwise to a suspension of $\mathrm{NaH}(60 \%$ in mineral oil, $1.82 \mathrm{~g}, 45.6 \mathrm{mmol})$ in anhydrous THF $(270 \mathrm{~mL})$. The resulting mixture was stirred at r.t. for $24 \mathrm{~h}$, and then the reaction was quenched with cold water $(10 \mathrm{~mL})$. The solvents were removed under reduced pressure, and the residue was dissolved in ethyl acetate/water $(400 / 100 \mathrm{~mL})$. The aqueous phase was extracted with ethyl acetate $(2 \times 100 \mathrm{~mL})$, the combined organic extracts were dried over anhydrous $\mathrm{Na}_{2} \mathrm{SO}_{4}$ and evaporated. The residue was washed thoroughly with hexane $(3 \times 100 \mathrm{~mL})$ and dried in vacuo to give $8.84 \mathrm{~g}(98 \%)$ of the title compound as a colorless solid, m. p. $118{ }^{\circ} \mathrm{C} . R_{\mathrm{f}}=0.4$ (hexane/EtOAc $\left.2: 1\right) .{ }^{1} \mathrm{H} \mathrm{NMR}(300$ MHz, DMSO-d6): $\delta 9.50$ (br s, $1 \mathrm{H}, \mathrm{NH}), 8.34$ (s, $1 \mathrm{H}, \mathrm{CHO}), 7.87$ (d, J= $7.7 \mathrm{~Hz}, 1 \mathrm{H}$ ), $7.78(\mathrm{~d}, J=8.1 \mathrm{~Hz}, 1 \mathrm{H}), 7.37(\mathrm{t}, J=7.3 \mathrm{~Hz}, 1 \mathrm{H}), 6.94(\mathrm{t}, J=7.3 \mathrm{~Hz}, 1 \mathrm{H}) ;{ }^{13} \mathrm{C} \mathrm{NMR}$ (75.5 MHz, DMSO-d6): $\delta 160.1(\mathrm{CH}), 139.0(\mathrm{CH}), 138.4(\mathrm{C}), 128.5(\mathrm{CH}), 126.8(\mathrm{CH})$,

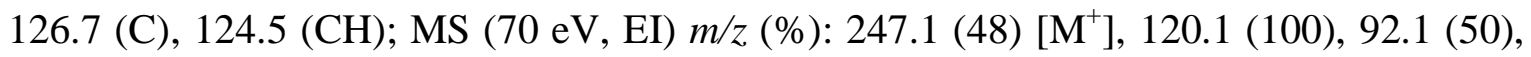
65.1 (60); IR (KBr): 3223, 2899, 1658 (C=O), 1583, 1572, 1524, 1463, 1435, 1394, 1281, 1240, 1163, 1151, 1017, 885, 746, 693, 644, 520, 461, $429 \mathrm{~cm}^{-1}$; Anal. Calcd for $\mathrm{C}_{7} \mathrm{H}_{6} \mathrm{INO}$ : C 34.03, H 2.45, N 5.67; found: C. 34.23; H. 2.22; N. 5.51.

\section{2-Iodophenyl isocyanide (159-I)}

$\overbrace{N C}^{\prime}$

To a solution of $N$-formyl-2-iodoaniline $(5.11 \mathrm{~g}, 20.7 \mathrm{mmol})$ in anhydrous $\mathrm{CH}_{2} \mathrm{Cl}_{2}(130 \mathrm{~mL})$ was added at $0{ }^{\circ} \mathrm{C}$ diisopropylamine $(17 \mathrm{~mL}, 120 \mathrm{mmol})$,

then dropwise over a period of $10 \mathrm{~min} \mathrm{POCl}_{3}(4.4 \mathrm{~mL}, 41.4 \mathrm{mmol})$. The mixture was stirred at $0{ }^{\circ} \mathrm{C}$ for $15 \mathrm{~min}$, then a saturated solution of $\mathrm{Na}_{2} \mathrm{CO}_{3}(40 \mathrm{~mL})$ was added slowly. The mixture was transferred into a separatory funnel, diluted with dichloromethane $(200 \mathrm{~mL})$, the organic phase washed with a half-saturated solution of $\mathrm{Na}_{2} \mathrm{CO}_{3}(100 \mathrm{~mL})$ and brine $(100 \mathrm{~mL})$, then dried over anhydrous $\mathrm{Na}_{2} \mathrm{SO}_{4}$ and evaporated. The crude product was purified by recrystallization from hexane to give $4.43 \mathrm{~g}$ (93\%) of the title compound as a colorless solid, m. p. $42{ }^{\circ} \mathrm{C} . R_{\mathrm{f}}=0.29$ (hexane/EtOAc $30: 1$ ). 
${ }^{1} \mathrm{H}$ NMR (300 MHz, $\left.\mathrm{CDCl}_{3}\right): \delta 7.90(\mathrm{~d}, J=7.8 \mathrm{~Hz}, 1 \mathrm{H}), 7.44-7.36$ (m, $\left.2 \mathrm{H}\right), 7.14-7.09$ $(\mathrm{m}, 1 \mathrm{H}) ;{ }^{13} \mathrm{C} \mathrm{NMR}\left(75.5 \mathrm{MHz}, \mathrm{CDCl}_{3}\right): \delta 167.4(\mathrm{C}), 139.6(\mathrm{CH}), 130.4(2 \mathrm{CH}), 129.0$

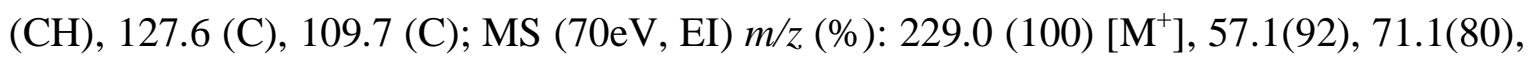
97.2(70); IR (KBr): $v=2123$ (NC), 1459, 1434, 1042,1019, 751, 643, $432 \mathrm{~cm}^{-1}$; Anal. Calcd for $\mathrm{C}_{7} \mathrm{H}_{4} \mathrm{IN}$ : C 36.71, H 1.76, N 6.12; found: C 36.88, H 1.88, N 5.87.

\section{$N$-Formyl-2-bromoaniline}

$\overbrace{\mathrm{H}^{-}}^{\mathrm{CHO}}$

The title compound was prepared in the same way as $N$-formyl-2-iodoaniline from $26.5 \mathrm{~g}$ (154 mmol) of 2-bromoanilin, 63 $\mathrm{mL}$ of ethyl formate and $7.7 \mathrm{~g}$ of a $60 \%$ suspension of $\mathrm{NaH}$ in mineral oil $(193 \mathrm{mmol})$ to give, after washing with hexane, $28.6(93 \%)$ of pure product as a colorless solid, m. p. $93{ }^{\circ} \mathrm{C} . R_{\mathrm{f}}=0.41$ (hexane/EtOAc $\left.2: 1\right) .{ }^{1} \mathrm{H}$ NMR (300 MHz, DMSOd6): $\delta 9.67$ (br s, $1 \mathrm{H}, \mathrm{NH}), 8.36$ (s, $1 \mathrm{H}, \mathrm{CHO}), 8.01$ (d, $J=7.9 \mathrm{~Hz}, 1 \mathrm{H}), 7.64$ (d, $J=8.3$ $\mathrm{Hz}, 1 \mathrm{H}), 7.35(\mathrm{t}, J=7.3 \mathrm{~Hz}, 1 \mathrm{H}), 6.94(\mathrm{t}, J=7.2 \mathrm{~Hz}, 1 \mathrm{H}) ;{ }^{13} \mathrm{C}$ NMR $(75.5 \mathrm{MHz}$, DMSO-d6): $\delta 160.3(\mathrm{CH}), 135.4(\mathrm{C}), 132.6(\mathrm{CH}), 128.0(\mathrm{CH}), 126.0(\mathrm{CH}), 123.9(\mathrm{CH})$, 114.4 (C); MS (70 eV, EI) m/z (\%): 199.1 (18) $\left[\mathrm{M}^{+}\right], 171.0$ (22), 120.1 (100), 92.1 (40), 65.1 (36); IR (KBr): 3256, 2904, 1666 (C=O), 1600, 1578, 1536, 1437, 1401, 1292, 1157 , 1117, 1024, 861, 742, 654, 528, $433 \mathrm{~cm}^{-1}$; Anal. Calcd for $\mathrm{C}_{7} \mathrm{H}_{6} \mathrm{BrNO}$ : C 42.03, H 3.02, N 7.00; found: C 42.35, H 2.88, N 6.80 .

\section{2-Bromophenyl isocyanide $(159-\mathrm{Br})^{[186]}$}

$\overbrace{\mathrm{NC}}^{\mathrm{Br}}$

2-Bromophenyl isocyanide $159-\mathrm{Br}$ was prepared in the same way as 2-iodophenyl isocyanide from $\mathrm{N}$-formyl-2-bromoaniline (28.6 g, $143 \mathrm{mmol})$, diisopropylamine $(116 \mathrm{~mL}, 829 \mathrm{mmol})$ and $\mathrm{POCl}_{3}(30.3 \mathrm{~mL}, 286 \mathrm{mmol})$ to give, after recrystallisation from hexane, $22.0 \mathrm{~g} \mathrm{(85 \% )} \mathrm{of} \mathrm{pure} \mathrm{product} \mathrm{as} \mathrm{a} \mathrm{colorless} \mathrm{solid,}$ m. p. $40{ }^{\circ} \mathrm{C}$. [lit $\left.{ }^{[186]} 41{ }^{\circ} \mathrm{C}\right] R_{\mathrm{f}}=0.4$ (hexane/EtOAc $\left.10: 1\right) .{ }^{1} \mathrm{H}$ NMR $\left(300 \mathrm{MHz}, \mathrm{CDCl}_{3}\right)$ : $\delta=7.66(\mathrm{dd}, J=8.3,1.5 \mathrm{~Hz}, 1 \mathrm{H}), \quad 7.44(\mathrm{dd}, J=7.9,1.5 \mathrm{~Hz}, 1 \mathrm{H}), \quad 7.36 \quad(\mathrm{dt}, J=7.9$, $1.5 \mathrm{~Hz}, 1 \mathrm{H}), 7.28(\mathrm{dt}, J=7.9,1.9 \mathrm{~Hz}, 1 \mathrm{H}) ;{ }^{13} \mathrm{C} \mathrm{NMR}\left(75.5 \mathrm{MHz}, \mathrm{CDCl}_{3}\right): \delta 168.3(\mathrm{C})$, $133.1(\mathrm{CH}), 130.3(2 \mathrm{CH}), 128.1(\mathrm{C}), 128.0(\mathrm{CH}), 119.7(\mathrm{C})$; MS (70eV, EI) m/z (\%): $181.1(18)\left[\mathrm{M}^{+}\right], 120.1(58), 102.1(100), 91.1(36)$; IR (KBr): 2125 (NC), 1468, 1047, 753, $439 \mathrm{~cm}^{-1}$; Anal. Calcd for $\mathrm{C}_{7} \mathrm{H}_{4} \mathrm{BrN}$ : C 46.19, H 2.22, N 7.70; found: C 46.38, H 2.10, N 7.61. 


\section{General Procedure for the Bromine-Lithium Exchange Reaction of 2-Bromophenyl Isocyanide 159-Br and Subsequent Trapping with Electrophiles to Give}

\section{2-Substituted Phenyl Isocyanides 192 (GP5)}

To a solution of 2-bromophenyl isocyanide 159- $\mathrm{Br}(364 \mathrm{mg}, 2 \mathrm{mmol})$ in anhydrous tetrahydrofuran $(20 \mathrm{~mL})$, kept in an oven-dried $25 \mathrm{~mL}-$ Schlenk flask under an atmosphere of dry nitrogen, was added dropwise with stirring a $2.5 \mathrm{M}$ solution of $n \mathrm{BuLi}$ in hexane $(0.8 \mathrm{~mL}, 2 \mathrm{mmol})$ at $-78{ }^{\circ} \mathrm{C}$ over a period of $5 \mathrm{~min}$. The mixture was stirred at $-78{ }^{\circ} \mathrm{C}$ for an additional $10 \mathrm{~min}$, then the electrophile $(2 \mathrm{mmol})$ in anhydrous THF $(2 \mathrm{~mL})$ was added dropwise. The mixture was stirred at $-78{ }^{\circ} \mathrm{C}$ for $3 \mathrm{~h}$, and the reaction was quenched with saturated $\mathrm{NH}_{4} \mathrm{Cl}$ solution $(2 \mathrm{~mL})$. The mixture was warmed to r.t., diluted with diethyl ether $(50 \mathrm{~mL})$, the organic phase washed with water $(2 \times 10 \mathrm{~mL})$, brine $(20 \mathrm{~mL})$ and dried over anhydrous $\mathrm{Na}_{2} \mathrm{SO}_{4}$. The solvents were removed under reduced pressure to give a crude product, which was purified by column chromatography on silica gel or Kugelrohr distillation.

\section{General Procedure for the Synthesis of 3-Substituted Quinazolin-4(3H)-ones (-thiones) (GP6)}

To a solution of 2-bromophenyl isocyanide 159- $\mathrm{Br}(364 \mathrm{mg}, 2 \mathrm{mmol})$ in anhydrous tetrahydrofuran $(20 \mathrm{~mL})$, kept in an oven-dried $25 \mathrm{~mL}-$ Schlenk flask under an atmosphere of dry nitrogen, was added dropwise with stirring a $2.5 \mathrm{M}$ solution of $n \mathrm{BuLi}$ in hexane $(0.8 \mathrm{~mL}, 2 \mathrm{mmol})$ at $-78{ }^{\circ} \mathrm{C}$ over a period of $5 \mathrm{~min}$. The mixture was stirred at $-78{ }^{\circ} \mathrm{C}$ for an additional $10 \mathrm{~min}$, and then the respective isocyanate $(2 \mathrm{mmol})$ in anhydrous THF (2 $\mathrm{mL}$ ) was added dropwise. The mixture was stirred at $-78{ }^{\circ} \mathrm{C}$ for $3 \mathrm{~h}$ and the reaction quenched with saturated $\mathrm{NH}_{4} \mathrm{Cl}$ solution $(2 \mathrm{~mL})$. The mixture was warmed to r.t., diluted with diethyl ether $(50 \mathrm{~mL})$, the organic phase washed with water $(2 \times 10 \mathrm{~mL})$, brine $(20$ $\mathrm{mL}$ ) and dried over anhydrous $\mathrm{Na}_{2} \mathrm{SO}_{4}$. The solvents were removed under reduced pressure to give a crude product, which was purified by column chromatography on silica gel. 


\section{General Procedure for the Synthesis of 2,3-Disubstituted Quinazolin-4(3H)-ones (GP7)}

The procedure is the same as GP5, but the intermediate was trapped by addition at $-78{ }^{\circ} \mathrm{C}$ of the respective second electrophile $(2 \mathrm{mmol})$, and after stirring at $-78{ }^{\circ} \mathrm{C}$ for an additional $1 \mathrm{~h}$, the reaction mixture was warmed gradually to r.t., diluted with diethyl ether $(50 \mathrm{~mL})$, washed with water $(2 \times 10 \mathrm{~mL})$, brine $(20 \mathrm{~mL})$ and dried over anhydrous $\mathrm{Na}_{2} \mathrm{SO}_{4}$. The solvents were removed under reduced pressure to give a crude product, which was purified by column chromatography on silica gel.

\section{2-Iodophenyl isocyanide (159-I)}

$\overbrace{1}^{N C}$

The isocyanide 159-I (403 $\mathrm{mg}, 88 \%$ ) was obtained from $o$-bromophenyl isocyanide (159-Br) (364 mg, $2 \mathrm{mmol})$ and iodine (708 $\mathrm{mg}, 2 \mathrm{mmol}$ ) following GP5, after column chromatography (hexane/EtOAc 30 : 1, $R_{\mathrm{f}}=0.29$ ). The analytical data are identical to those of an authentic sample described above.

\section{Methyl 2-isocyanobenzoate (192a) ${ }^{[187]}$}<smiles>COC(=O)c1ccccc1N</smiles>

The isocyanide 192a (254 $\mathrm{mg}, 79 \%)$ was obtained from 2-bromophenyl isocyanide (159-Br) (364 mg, $2 \mathrm{mmol}$ ) and methyl chloroformate (189 $\mathrm{mg}, 2 \mathrm{mmol})$ following GP5, after column chromatography (hexane/EtOAc $5: 1, R_{\mathrm{f}}=0.29$ ) as a yellow oil, which turned dark upon standing at r.t. ${ }^{1} \mathrm{H} \mathrm{NMR}\left(300 \mathrm{MHz}, \mathrm{CDCl}_{3}\right): \delta 8.01$ (d, $\left.J=7.2 \mathrm{~Hz}, 1 \mathrm{H}, \mathrm{Ar}-\mathrm{CH}\right), 7.61-7.45$ (m, $3 \mathrm{H}, \mathrm{Ar}-\mathrm{CH}), 3.99 \mathrm{ppm}\left(\mathrm{s}, 3 \mathrm{H}, \mathrm{CH}_{3}\right) ;{ }^{13} \mathrm{C} \mathrm{NMR}\left(75.5 \mathrm{MHz}, \mathrm{CDCl}_{3}\right): \delta 169.4(\mathrm{C})$, $164.5(\mathrm{C}), 133.0(\mathrm{CH}), 131.3(\mathrm{CH}), 129.2(\mathrm{CH}), 128.9(\mathrm{CH}), 128.6(\mathrm{C}), 127.1(\mathrm{C}), 52.7$ $\operatorname{ppm}\left(\mathrm{CH}_{3}\right) ; \mathrm{MS}$ (70 eV, EI) m/z (\%): 161.2 (44) [ $\left.\mathrm{M}^{+}\right], 146.2$ (42), 130.2 (100), 102.2 (74); IR (KBr): 2954, 2126 (NC), 1734 (C=O), 1598, 1488, 1436, 1268, 1135, 1082, $759 \mathrm{~cm}^{-1}$; HRMS (ESI) calcd for $\mathrm{C}_{9} \mathrm{H}_{7} \mathrm{NO}_{2}{ }^{+}\left[\mathrm{M}+\mathrm{H}^{+}\right]$: 162.05495; found: 162.05501 . 


\section{2-(Phenylthio)phenyl isocyanide (192b)}

$\overbrace{\mathrm{SPh}}^{\mathrm{NC}}$

The isocyanide 192b (354 mg, 84\%) was obtained from 2-bromphenyl isocyanide (159-Br) (364 mg, $2 \mathrm{mmol}$ ) and diphenyl disulfide (436 mg, $2 \mathrm{mmol}$ ) following GP5, after Kugelrohr distillation $\left(120-130{ }^{\circ} \mathrm{C}\right.$, 0.3 Torr) as a yellow oil. ${ }^{1} \mathrm{H}$ NMR $\left(300 \mathrm{MHz}, \mathrm{CDCl}_{3}\right): \delta 7.50-7.37(\mathrm{~m}, 6 \mathrm{H}, \mathrm{Ar}-\mathrm{H})$, 7.25-7.17 (m, $2 \mathrm{H}, \mathrm{Ar}-\mathrm{H}), 7.04 \mathrm{ppm}(\mathrm{dd}, J=7.2,2.2 \mathrm{~Hz}, 1 \mathrm{H}, \mathrm{Ar}-\mathrm{H}) ;{ }^{13} \mathrm{C} \mathrm{NMR}$ $\left(75.5 \mathrm{MHz}, \mathrm{CDCl}_{3}\right): \delta 168.4(\mathrm{C}), 135.3(\mathrm{C}), 133.6(2 \mathrm{CH}), 131.4(\mathrm{CH}), 129.7(2 \mathrm{CH})$, $129.6(\mathrm{CH}), 129.0(\mathrm{C}), 128.8(\mathrm{CH}), 127.4(\mathrm{C}), 127.3(\mathrm{CH}), 126.8$ ppm $(\mathrm{CH})$; MS

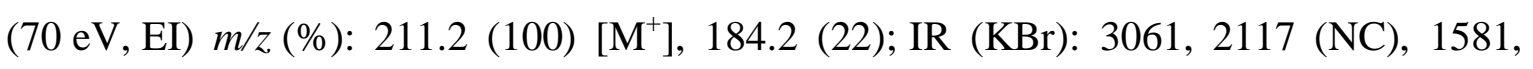
1464, 1440, 1066, 1024, 751, $690 \mathrm{~cm}^{-1}$; elemental analysis calcd $(\%)$ for $\mathrm{C}_{13} \mathrm{H}_{9} \mathrm{NS}$ : C 73.90, H 4.29, N 6.63; found: C 73.98, H 4.21, N 6.61

\section{2-Isocyanobenzaldehyde (192c)}<smiles>N#Cc1ccccc1C=O</smiles>
The isocyanide 192c (145 mg, 55\%) was obtained from 2-bromphenyl isocyanide (159-Br) (364 mg, $2 \mathrm{mmol}$ ) and methyl formiate (120 mg,

$2 \mathrm{mmol}$ ) following GP5, after column chromatography (hexane/EtOAc $\left.10: 1, R_{\mathrm{f}}=0.15\right)$ as a colorless solid, m. p. $49-50{ }^{\circ} \mathrm{C} .{ }^{1} \mathrm{H}$ NMR $\left(300 \mathrm{MHz}, \mathrm{CDCl}_{3}\right)$ : $\delta 10.44$ (s, $1 \mathrm{H}, \mathrm{CHO}), 7.97$ (d, $J=7.8 \mathrm{~Hz}, 1 \mathrm{H}, \mathrm{Ar}-\mathrm{H}), 7.69$ (t, $J=7.8 \mathrm{~Hz}, 1 \mathrm{H}, \mathrm{Ar}-\mathrm{H})$, $7.59(\mathrm{~d}, J=7.8 \mathrm{~Hz}, 1 \mathrm{H}, \mathrm{Ar}-\mathrm{H}), 7.54 \mathrm{ppm}(\mathrm{t}, J=7.8 \mathrm{~Hz}, 1 \mathrm{H}, \mathrm{Ar}-\mathrm{H}) ;{ }^{13} \mathrm{C}$ NMR $(75.5 \mathrm{MHz}$, $\left.\mathrm{CDCl}_{3}, \mathrm{APT}\right): \delta 187.7(\mathrm{CH}), 170.7(\mathrm{C}), 135.3(\mathrm{C}), 134.9(\mathrm{CH}), 129.9(\mathrm{C}), 129.9(\mathrm{CH})$,

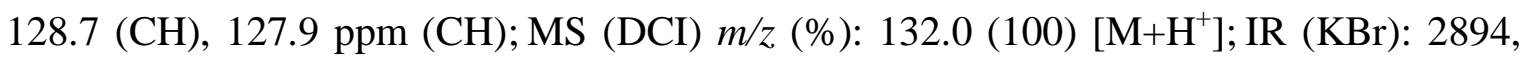
2119 (NC), 1705 (C=O), 1594, 1476, 1455, 1411, 1403, 1272, 1201, 1090, 831, $637 \mathrm{~cm}^{-1}$; HRMS (ESI) calcd for $\mathrm{C}_{8} \mathrm{H}_{5} \mathrm{NO}^{+}\left[\mathrm{M}+\mathrm{H}^{+}\right]$: 132.04439; found: 132.04443 .

\section{2-(Formylamino)benzaldehyde (196)}<smiles>O=CNc1ccccc1C=O</smiles>
The compound 196 (225 mg, 76\%) was obtained from 2-bromophenyl isocyanide (159-Br) (364 mg, $2 \mathrm{mmol}$ ) and dimethyl formamide (146 mg, $2 \mathrm{mmol}$ ) following GP5 and after column chromatography (hexane/EtOAc $2: 1, R_{\mathrm{f}}=0.30$ ) as a colorless solid, m. p. 74-75 ${ }^{\circ} \mathrm{C}$ [lit. $\left.{ }^{[188]} 75-77\right]$ ${ }^{1} \mathrm{H}$ NMR (300 MHz, $\mathrm{CDCl}_{3}$ ): $\delta 11.05$ (br s, $\left.1 \mathrm{H}, \mathrm{NH}\right), 9.94$ (s, $\left.1 \mathrm{H}, \mathrm{CHO}\right), 8.73$ $(\mathrm{d}, J=8.7 \mathrm{~Hz}, 1 \mathrm{H}, \mathrm{Ar}-\mathrm{H}), 8.54(\mathrm{~s}, 1 \mathrm{H}, \mathrm{NCHO}), 7.71(\mathrm{~d}, J=7.5 \mathrm{~Hz}, 1 \mathrm{H}, \mathrm{Ar}-\mathrm{H}), 7.63$ 
$(\mathrm{t}, J=7.2 \mathrm{~Hz}, 1 \mathrm{H}, \mathrm{Ar}-\mathrm{H}), 7.29 \mathrm{ppm}(\mathrm{t}, J=7.5 \mathrm{~Hz}, 1 \mathrm{H}, \mathrm{Ar}-\mathrm{H}) ;{ }^{13} \mathrm{C} \mathrm{NMR}(75.5 \mathrm{MHz}$, $\left.\mathrm{CDCl}_{3}, \mathrm{APT}\right): \delta 195.4(\mathrm{CH}), 159.9(\mathrm{CH}), 139.6(\mathrm{C}), 136.2(\mathrm{CH}), 136.0(\mathrm{CH}), 123.6(\mathrm{CH})$, 121.7 (C), 120.7 ppm (CH); MS (70 eV, EI) m/z (\%): 149.2 (50) $\left[\mathrm{M}^{+}\right], 121.2(68), 93.2$ (100); IR (KBr): 3274, 1671 (C=O), 1596, 1528, 1456, 1406, 1291, 1195, 1166, 1147, $875,757 \mathrm{~cm}^{-1}$; elemental analysis calcd $(\%)$ for $\mathrm{C}_{8} \mathrm{H}_{7} \mathrm{NO}_{2}$ : C 64.42, H 4.73, N 9.39; found: C 64.35, H 4.60, N 9.52.

\section{(2-Isocyanophenyl) (2-carbomethoxyphenyl) ketone (192d)}

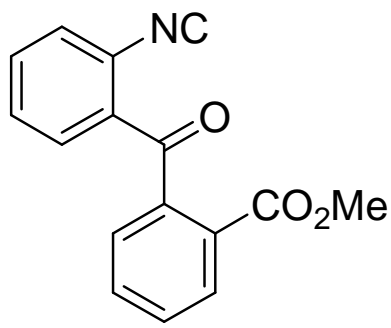

The isocyanide 192d (419 $\mathrm{mg}, 79 \%$ ) was obtained from 2-bromophenyl isocyanide (159-Br) (364 mg, $2 \mathrm{mmol})$ and methyl phthaloyl chloride (397 mg, $2 \mathrm{mmol}$ ) following GP5, after column chromatography (hexane/EtOAc $2: 1, R_{\mathrm{f}}=0.21$ ) as a yellow solid, m. p. $76-77{ }^{\circ} \mathrm{C}$. ${ }^{1} \mathrm{H}$ NMR $\left(300 \mathrm{MHz}, \mathrm{CDCl}_{3}\right)$ : $\delta 8.00(\mathrm{dd}, J=7.5,1.5 \mathrm{~Hz}, 1 \mathrm{H}, \mathrm{Ar}-\mathrm{CH}), 7.70-7.40(\mathrm{~m}, 7 \mathrm{H}, \mathrm{Ar}-\mathrm{CH}), 3.69 \mathrm{ppm}(\mathrm{s}, 3 \mathrm{H}$, $\left.\mathrm{CH}_{3}\right) ;{ }^{13} \mathrm{C}$ NMR (75.5 MHz, $\left.\mathrm{CDCl}_{3}, \mathrm{APT}\right): \delta 193.7$ (C), 169.9 (C), 166.5 (C), 140.9 (C), $133.9(\mathrm{C}), 132.8(\mathrm{CH}), 132.4(\mathrm{CH}), 130.7(2 \mathrm{CH}), 130.2(\mathrm{CH}), 129.7(2 \mathrm{C}), 129.1(\mathrm{CH})$, $129.0(\mathrm{CH}), 128.1(\mathrm{CH}), 52.4 \mathrm{ppm}\left(\mathrm{CH}_{3}\right)$; MS (DCI) $\mathrm{m} / z(\%): 283.3(8)\left[\mathrm{M}^{2} \mathrm{NH}_{4}{ }^{+}\right], 266.3$ (100) $\left[\mathrm{M}+\mathrm{H}^{+}\right]$; IR (KBr): $2125(\mathrm{NC}), 1718(\mathrm{C}=\mathrm{O}), 1684(\mathrm{C}=\mathrm{O}), 1595,1578,1284,1083$, 933, 756, $717 \mathrm{~cm}^{-1}$; HRMS (ESI) calcd for $\mathrm{C}_{16} \mathrm{H}_{12} \mathrm{NO}_{3}{ }^{+}\left[\mathrm{M}+\mathrm{H}^{+}\right]$: 266.08117; found: 266.08121 .

\section{3-Phenylquinazolin-4(3H)-one (191a)}<smiles>O=c1c2ccccc2ncn1-c1ccccc1</smiles>

The quinazolin-4(3H)-one 191a (404 mg, 91\%) was obtained from 2-bromophenyl isocyanide (159-Br) (364 mg, $2 \mathrm{mmol}$ ) and phenyl isocyanate $(238 \mathrm{mg}, 2 \mathrm{mmol})$ following GP6, after column chromatography (hexane/EtOAc $2: 1, R_{\mathrm{f}}=0.15$ ) as a colorless solid, m. p. $135-136{ }^{\circ} \mathrm{C}$. [lit. $\left.{ }^{[189]} 137-137.5 \quad{ }^{\circ} \mathrm{C}\right]{ }^{1} \mathrm{H}$ NMR $\left(300 \mathrm{MHz}, \mathrm{CDCl}_{3}\right): \delta 8.37$ (d, $J=8.1 \mathrm{~Hz}, 1 \mathrm{H}), 8.13(\mathrm{~s}, 1 \mathrm{H}), 7.84-7.75(\mathrm{~m}, 2 \mathrm{H}), 7.59-7.49$ (m, $4 \mathrm{H}), 7.45-7.41$ (m, $2 \mathrm{H}) ;{ }^{13} \mathrm{C}$ NMR (75.5 MHz, $\mathrm{CDCl}_{3}$, APT): $\delta 160.7$ (C), $147.8(\mathrm{C}), 146.0(\mathrm{CH}), 137.4$ (C), $134.5(2 \mathrm{CH}), 129.6(2 \mathrm{CH}), 129.1(\mathrm{CH}), 127.7(\mathrm{CH}), 127.6(\mathrm{CH}), 127.1(\mathrm{CH}), 127.0$

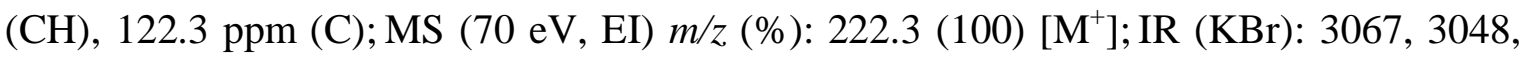


2360, 2338, $1618(\mathrm{C}=\mathrm{O}), 1227,1128,700 \mathrm{~cm}^{-1}$; elemental analysis calcd $(\%)$ for $\mathrm{C}_{14} \mathrm{H}_{10} \mathrm{~N}_{2} \mathrm{O}$ : C 75.66, H 4.54, N 12.60; found: C 75.45, H 4.60, N 12.38.

\section{3-p-Tolylquinazolin-4(3H)-one (191b)}<smiles>Cc1ccc(-n2cnc3ccccc3c2=O)cc1</smiles>

The compound 191b (420 mg, 89\%) was obtained from 2-bromophenyl isocyanide (159-Br) (364 mg, $2 \mathrm{mmol}$ ) and p-tolyl isocyanate $(266 \mathrm{mg}, 2 \mathrm{mmol})$ following GP6, after column chromatography (hexane/EtOAc $1: 1, R_{\mathrm{f}}=0.33$ ) as a colorless solid, m. p. $143-144{ }^{\circ} \mathrm{C}$. [lit. $\left.{ }^{[190]} 147{ }^{\circ} \mathrm{C}\right]{ }^{1} \mathrm{H}$ NMR $\left(300 \mathrm{MHz}, \mathrm{CDCl}_{3}\right): \delta 8.37$ $(\mathrm{d}, J=8.7 \mathrm{~Hz}, 1 \mathrm{H}), 8.12(\mathrm{~s}, 1 \mathrm{H}), 7.84-7.75(\mathrm{~m}, 2 \mathrm{H}), 7.55(\mathrm{dd}, J=6.4,1.9 \mathrm{~Hz}, 1 \mathrm{H})$, 7.37-7.29 (m, $5 \mathrm{H}) ;{ }^{13} \mathrm{C}$ NMR (75.5 MHz, $\mathrm{CDCl}_{3}$, APT): $\delta 160.9$ (C), 148.0 (C), 146.3 $(\mathrm{CH}), 139.2(\mathrm{C}), 135.0(\mathrm{C}), 134.5(\mathrm{CH}), 130.2(2 \mathrm{CH}), 127.6(\mathrm{CH}), 127.5(\mathrm{CH}), 127.2$ $(\mathrm{CH}), 126.8(2 \mathrm{CH}), 122.5(\mathrm{C}), 21.2 \mathrm{ppm}\left(\mathrm{CH}_{3}\right)$; MS (70 eV, EI) m/z (\%): 236.0 (100) [M"]; IR (KBr): 1688 (C=O), 1600, 1514, 1471, 1322, 1292, 1260, 1193, 917, 817, 770, $750,694,616,556,521,482 \mathrm{~cm}^{-1}$; elemental analysis calcd (\%) for $\mathrm{C}_{15} \mathrm{H}_{12} \mathrm{~N}_{2} \mathrm{O}: \mathrm{C} 76.25$, H 5.12, N 11.86; found: C 75.96, H 4.96, N 12.11 .

\section{3-(4-(Trifluoromethyl)phenyl)quinazolin-4(3H)-one (191c)}<smiles>O=c1c2ccccc2ncn1-c1ccc(C(F)(F)F)cc1</smiles>

The compound 191c (400 mg, 69\%) was obtained from 2-bromophenyl isocyanide (159-Br) (364 mg, $2 \mathrm{mmol})$ and 4-(trifluoromethyl)phenyl isocyanate $(374 \mathrm{mg}, 2 \mathrm{mmol})$

$\mathrm{CF}_{3}$ following GP6, after column chromatography (hexane/EtOAc $2: 1, R_{\mathrm{f}}=0.21$ ) as a colorless solid, m. p. $183-184{ }^{\circ} \mathrm{C}$. [lit. ${ }^{[190]} 132{ }^{\circ} \mathrm{C}$ ] ${ }^{1} \mathrm{H}$ NMR (300 MHz, $\left.\mathrm{CDCl}_{3}\right): \delta 8.39(\mathrm{~d}, J=7.5 \mathrm{~Hz}, 1 \mathrm{H}, \mathrm{Ar}-\mathrm{H}), 8.12(\mathrm{~s}, 1 \mathrm{H}, \mathrm{CH}=\mathrm{N})$, 7.87-7.78 (m, $4 \mathrm{H}, \mathrm{Ar}-\mathrm{H}), 7.60(\mathrm{~m}, 3 \mathrm{H}, \mathrm{Ar}-\mathrm{H}) ;{ }^{13} \mathrm{C} \mathrm{NMR}\left(75.5 \mathrm{MHz}, \mathrm{CDCl}_{3}, \mathrm{APT}\right)$ : $\delta 160.5(\mathrm{C}), 147.7(\mathrm{C}), 145.1(\mathrm{CH}), 140.4(\mathrm{C}), 135.0(2 \mathrm{CH}), 128.0(\mathrm{CH}), 127.8(\mathrm{CH})$, $127.5(2 \mathrm{CH}), 127.2(\mathrm{CH}), 126.9\left(\mathrm{q}, J_{\mathrm{CF}}=3.9 \mathrm{~Hz}, \mathrm{C}\right), 126.3(\mathrm{CH}), 122.1 \mathrm{ppm}(\mathrm{C}) ; \mathrm{MS}$

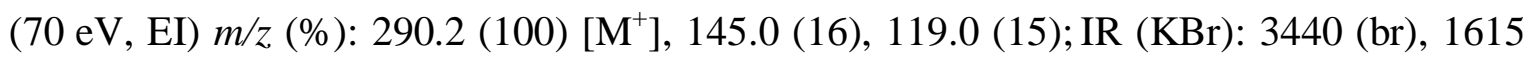
$(\mathrm{C}=\mathrm{O}), 1325,1167,1113,1064 \mathrm{~cm}^{-1}$; elemental analysis calcd $(\%)$ for $\mathrm{C}_{15} \mathrm{H}_{9} \mathrm{~F}_{3} \mathrm{~N}_{2} \mathrm{O}$ : C 62.07, H 3.13, N 9.65; found: C 61.96, H 3.11, N 10.01. 


\section{3-(4-Fluorophenyl)quinazolin-4(3H)-one (191d)}

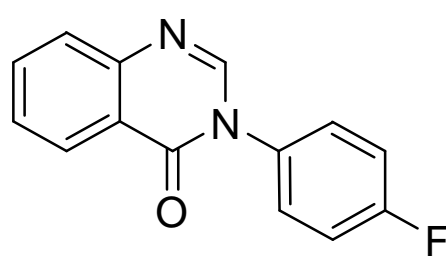

The compound 191d (360 mg, 75\%) was obtained from 2-bromophenyl isocyanide (159-Br) (364 $\mathrm{mg}, 2 \mathrm{mmol})$ and 4-fluorophenyl isocyanate $(274 \mathrm{mg}, 2 \mathrm{mmol}$ ) following $\left.R_{\mathrm{f}}=0.21\right)$ as a colorless solid, m. p. $189-190{ }^{\circ} \mathrm{C}$. [lit. $\left.{ }^{[191]} 170-171{ }^{\circ} \mathrm{C}\right]{ }^{1} \mathrm{H}$ NMR (300 MHz, $\left.\mathrm{CDCl}_{3}\right): \delta 8.36(\mathrm{dd}, J=8.3,1.1 \mathrm{~Hz}, 1 \mathrm{H}), 8.10(\mathrm{~s}, 1 \mathrm{H}), 7.85-7.76(\mathrm{~m}, 2 \mathrm{H})$, 7.59-7.54 (m, $2 \mathrm{H}), 7.44-7.39$ (m, $2 \mathrm{H}), 7.28-7.20$ ppm (m, $2 \mathrm{H}) ;{ }^{13} \mathrm{C}$ NMR $(75.5 \mathrm{MHz}$, $\left.\mathrm{CDCl}_{3}, \mathrm{APT}\right): \delta 161.0(\mathrm{C}), 147.8(\mathrm{C}), 145.8(\mathrm{CH}), 134.7(\mathrm{CH}), 133.4(\mathrm{C}), 129.0(\mathrm{CH})$, $128.8(\mathrm{CH}), 127.8(\mathrm{CH}), 127.7(\mathrm{CH}), 127.2(\mathrm{CH}), 122.2(\mathrm{C}), 116.8(\mathrm{CH}), 116.5 \mathrm{ppm}$

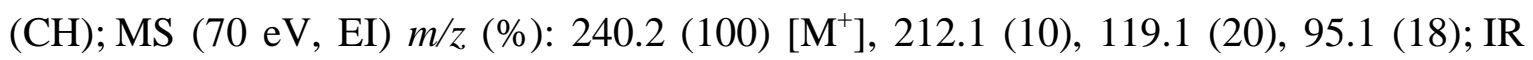
(KBr): $1660(\mathrm{C}=\mathrm{O}), 1614,1511,1469,1405,1329,1293,1262,1227,1102,927,833$, $775,697,613,552,526,436 \mathrm{~cm}^{-1}$; elemental analysis calcd (\%) for $\mathrm{C}_{14} \mathrm{H}_{9} \mathrm{FN}_{2} \mathrm{O}$ : C 69.99 , H 3.78, N 11.66; found: 69.79, H 4.03, N 11.80 .

\section{3-Benzylquinazolin-4(3H)-one (191e)}<smiles>O=c1c2ccccc2ncn1Cc1ccccc1</smiles>

The compound 191e (350 mg, 74\%) was obtained from 2-bromophenyl isocyanide (159-Br) (364 mg, $2 \mathrm{mmol})$ and benzyl isocyanate $(266 \mathrm{mg}, 2 \mathrm{mmol})$ following GP6, after column chromatography (hexane/EtOAc $1: 1, R_{\mathrm{f}}=0.25$ ) as a colorless solid, m. p. 116-117 ${ }^{\circ} \mathrm{C}$ [lit. $\left.{ }^{[192]} 117-118{ }^{\circ} \mathrm{C}\right] .{ }^{1} \mathrm{H}$ NMR $\left(300 \mathrm{MHz}, \mathrm{CDCl}_{3}\right)$ : $\delta 8.33(\mathrm{~d}, J=7.5 \mathrm{~Hz}, 1 \mathrm{H}), 8.11(\mathrm{~s}, 1 \mathrm{H}), 7.78-7.69(\mathrm{~m}, 2 \mathrm{H}), 7.51(\mathrm{t}, J=8.0 \mathrm{~Hz}, 1 \mathrm{H})$, $7.35(\mathrm{~m}, 5 \mathrm{H}),{ }^{13} \mathrm{C}$ NMR $\left(75.5 \mathrm{MHz}, \mathrm{CDCl}_{3}, \mathrm{APT}\right): \delta 161.1(\mathrm{C}), 148.1(\mathrm{C}), 146.3(\mathrm{CH})$, $135.8(\mathrm{C}), 134.2(\mathrm{CH}), 129.0(2 \mathrm{CH}), 128.3(\mathrm{CH}), 128.0(2 \mathrm{CH}), 127.6(\mathrm{CH}), 127.3(\mathrm{CH})$,

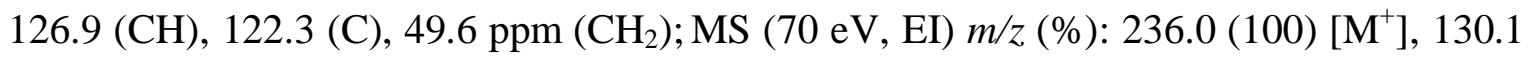
(27), 91.0 (70); IR (KBr): 1684 (C=O), 1605, 1475, 1365, 1321, 1150, 938, 774, 747, 706, 694, $606 \mathrm{~cm}^{-1}$; elemental analysis calcd $(\%)$ for $\mathrm{C}_{15} \mathrm{H}_{12} \mathrm{~N}_{2} \mathrm{O}: \mathrm{C} 76.25, \mathrm{H}$ 5.12, N 11.86; found: C 76.19, H 5.28, N 12.10. 


\section{3-Isopropylquinazolin-4(3H)-one (191f)}

$\overbrace{O}^{N}$

The compound 191f (306 mg, 81\%) was obtained from 2-bromophenyl isocyanide (159-Br) (364 mg, $2 \mathrm{mmol})$ and isopropyl isocyanate $(170 \mathrm{mg}, 2 \mathrm{mmol})$ following GP6, after column chromatography (hexane/EtOAc $2: 1, R_{\mathrm{f}}=0.10$ ) as a yellow solid, m. p. $87-88{ }^{\circ} \mathrm{C}\left[\mathrm{lit}^{[193]} 88-89{ }^{\circ} \mathrm{C}\right] .{ }^{1} \mathrm{H}$ NMR $\left(300 \mathrm{MHz}, \mathrm{CDCl}_{3}\right): \delta 8.32(\mathrm{~d}$, $J=7.9 \mathrm{~Hz}, 1 \mathrm{H}, \mathrm{Ar}-\mathrm{CH}), 8.13(\mathrm{~s}, 1 \mathrm{H}, \mathrm{CH}=\mathrm{N}), 7.78-7.69(\mathrm{~m}, 2 \mathrm{H}, \mathrm{Ar}-\mathrm{CH}), 7.50$ (dd, $J=6.4,1.5 \mathrm{~Hz}, 1 \mathrm{H}, \mathrm{Ar}-\mathrm{CH}), 5.21\left(\mathrm{~m}, 1 \mathrm{H}, \mathrm{CH}\left(\mathrm{CH}_{3}\right)_{2}\right), 1.50\left(\mathrm{~d}, J=6.8 \mathrm{~Hz}, 6 \mathrm{H}, \mathrm{CH}_{3}\right) ;{ }^{13} \mathrm{C}$ NMR (75.5 MHz, $\left.\mathrm{CDCl}_{3}, \mathrm{APT}\right): \delta 160.6(\mathrm{C}), 147.5(\mathrm{C}), 143.5(\mathrm{CH}), 134.1(\mathrm{CH}), 127.2$ $(\mathrm{CH}), 127.1(\mathrm{CH}), 126.8(\mathrm{CH}), 121.9(\mathrm{C}), 45.9\left(\mathrm{CH}_{3}\right), 22.0$ ppm $\left(\mathrm{CH}_{3}\right)$; MS (70 eV, EI)

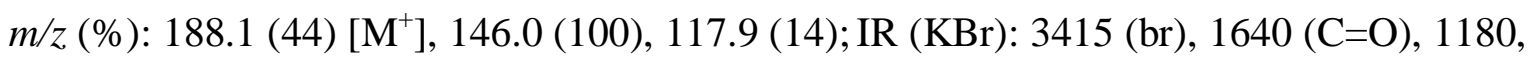
1130, 1076, $773 \mathrm{~cm}^{-1}$; elemental analysis calcd $(\%)$ for $\mathrm{C}_{11} \mathrm{H}_{12} \mathrm{~N}_{2} \mathrm{O}: \mathrm{C} 70.19, \mathrm{H} 6.43, \mathrm{~N}$ 14.88; found: C 69.96, H 6.39, N 14.49.

\section{3-Cyclopropylquinazolin-4(3H)-one (191g)}<smiles>O=c1c2ccccc2ncn1C1CC1</smiles>

The compound $191 \mathrm{~g}(260 \mathrm{mg}, 70 \%)$ was obtained from 2-bromophenyl isocyanide (159-Br) (364 mg, $2 \mathrm{mmol})$ and cyclopropyl isocyanate (166 mg, $2 \mathrm{mmol})$ following GP6, after column chromatography (hexane/EtOAc $1: 1, R_{\mathrm{f}}=0.18$ ) as a colorless solid, m. p. $96-97{ }^{\circ} \mathrm{C} .{ }^{1} \mathrm{H}$ NMR $\left(300 \mathrm{MHz}, \mathrm{CDCl}_{3}\right): \delta 8.31(\mathrm{~d}, J=7.9 \mathrm{~Hz}, 1 \mathrm{H}$, Ar-H), 8.11 (s, $1 \mathrm{H}, \mathrm{CH}=\mathrm{N}), 7.78-7.67$ (m, $2 \mathrm{H}, \mathrm{Ar}-\mathrm{H}), 7.50$ (t, $J=6.8 \mathrm{~Hz}, 1 \mathrm{H}, \mathrm{Ar}-\mathrm{H})$, 3.29-3.22 (m, 1 H, cPr-CH), 1.25-1.18 (m, 2 H, cPr- $\mathrm{CH}_{2}$ ), 0.97-0.91 (m, $2 \mathrm{H}, \mathrm{cPr}^{-\mathrm{CH}_{2}}$ ); ${ }^{13} \mathrm{C}$ NMR (75.5 MHz, $\left.\mathrm{CDCl}_{3}, \mathrm{APT}\right): \delta 162.2(\mathrm{C}), 147.6(\mathrm{C}), 146.7(\mathrm{CH}), 134.1(\mathrm{CH})$, 127.3 (CH), $127.2(\mathrm{CH}), 126.6(\mathrm{CH}), 121.9(\mathrm{C}), 29.2(\mathrm{CH}), 6.4 \mathrm{ppm}\left(\mathrm{CH}_{2}\right)$; MS (70 eV, EI) $m / z(\%): 186.1(100)\left[\mathrm{M}^{+}\right], 171.0(48)$; IR (KBr): 3424 (br), 1648 (C=O), 1561, 1470, 1259, 1176, 1105, $773 \mathrm{~cm}^{-1}$; elemental analysis calcd $(\%)$ for $\mathrm{C}_{11} \mathrm{H}_{10} \mathrm{~N}_{2} \mathrm{O}: \mathrm{C} 70.95$, H 5.41, N 15.04; found: C 70.73, H 5.70, N 14.86. 


\section{3-Cyclopropylquinazoline-4(3H)-thione (191h)}

$\prod_{S}^{N}{ }_{V}^{N}$

The compound $191 \mathrm{~h}(287 \mathrm{mg}, 71 \%)$ was obtained from 2-bromophenyl isocyanide (159-Br) (364 mg, $2 \mathrm{mmol})$ and isopropyl isothiocyanate $(198 \mathrm{mg}, 2 \mathrm{mmol})$ following a modified GP6 (the reaction was quenched by addition of water at $-40{ }^{\circ} \mathrm{C}$ ), after column chromatography (hexane/EtOAc $5: 1, R_{\mathrm{f}}=0.38$ ) as a yellow solid, m. p. 60-61 ${ }^{\circ} \mathrm{C} .{ }^{1} \mathrm{H}$ NMR $\left(300 \mathrm{MHz}, \mathrm{CDCl}_{3}\right): \delta 8.61(\mathrm{~s}, 1 \mathrm{H}, \mathrm{CH}=\mathrm{N}), 8.21(\mathrm{~d}, J=8.3 \mathrm{~Hz}, 1 \mathrm{H})$, 7.57-7.51 (m, $2 \mathrm{H}), 7.38(\mathrm{td}, J=8.3,6.0,2.6 \mathrm{~Hz}, 1 \mathrm{H}, \operatorname{Ar}-\mathrm{H}), 2.93-2.86(\mathrm{~m}, 1 \mathrm{H})$, 1.05-0.97 (m, $\left.2 \mathrm{H}, \mathrm{cPr}-\mathrm{CH}_{2}\right), 0.94-0.89$ (m, $\left.2 \mathrm{H}, \mathrm{cPr}-\mathrm{CH}_{2}\right),{ }^{13} \mathrm{C} \mathrm{NMR}\left(75.5 \mathrm{MHz}, \mathrm{CDCl}_{3}\right.$, APT): $\delta 148.9(\mathrm{CH}), 147.7(\mathrm{C}), 143.0(\mathrm{C}), 131.7(\mathrm{CH}), 130.4(\mathrm{CH}), 129.1(\mathrm{CH}), 124.4$ (CH), $121.8(\mathrm{C}), 35.4(\mathrm{CH}), 8.7$ ppm ( $\left.\mathrm{CH}_{2}\right)$; MS (70 eV, EI) m/z (\%): 202.1 (42) [ $\left.\mathrm{M}^{+}\right]$, 187.1 (56), 174.0 (72), 169.1 (56), 147.0 (49), 120.0 (100); IR (KBr): 1584 (C=S), 1550, $1469,1445,1266,1158,1020,937,856,765,750 \mathrm{~cm}^{-1}$; elemental analysis calcd (\%) for $\mathrm{C}_{11} \mathrm{H}_{10} \mathrm{~N}_{2} \mathrm{~S}$ : C 65.32, H 4.98, N 13.85; found: C 65.13, H 4.80, N 13.55.

\section{3-Cyclohexylquinazoline-4(3H)-thione (191i)}<smiles>S=c1c2ccccc2ncn1C1CCCCC1</smiles>

The compound 191i (380 mg, 78\%) was obtained from 2-bromophenyl isocyanide (159-Br) (364 mg, $2 \mathrm{mmol}$ ) and cyclohexyl isothiocyanate $(282 \mathrm{mg}, 2 \mathrm{mmol})$ following a modified GP6 (the reaction was quenched by addition of water at $-40{ }^{\circ} \mathrm{C}$ ), after column chromatography (hexane/EtOAc $5: 1, R_{\mathrm{f}}=0.42$ ) as a yellow solid, m. p. 91-92 ${ }^{\circ} \mathrm{C} .{ }^{1} \mathrm{H}$ NMR $\left(300 \mathrm{MHz}, \mathrm{CDCl}_{3}\right): \delta 8.61(\mathrm{~s}, 1 \mathrm{H}, \mathrm{CH}=\mathrm{N}), 8.31$ (d, $J=7.9 \mathrm{~Hz}, 1 \mathrm{H}, \mathrm{Ar}-\mathrm{H}), 7.56(\mathrm{~d}, J=3.4 \mathrm{~Hz}, 2 \mathrm{H}, \mathrm{Ar}-\mathrm{H}), 7.44-7.37$ (m, $1 \mathrm{H}, \mathrm{Ar}-\mathrm{H})$, 3.45-3.36 (m, $1 \mathrm{H}, \mathrm{CH}), 1.87-1.26\left(\mathrm{~m}, 10 \mathrm{H}, \mathrm{CH}_{2}\right) ;{ }^{13} \mathrm{C} \mathrm{NMR}\left(75.5 \mathrm{MHz}, \mathrm{CDCl}_{3}, \mathrm{APT}\right)$ : $\delta 149.4(\mathrm{CH}), 144.9(\mathrm{C}), 143.5(\mathrm{C}), 131.7(\mathrm{CH}), 130.4(\mathrm{CH}), 129.0(\mathrm{CH}), 125.1(\mathrm{CH})$, $122.0(\mathrm{C}), 61.6(\mathrm{CH}), 32.3\left(2 \mathrm{CH}_{2}\right), 25.8\left(\mathrm{CH}_{2}\right), 22.0 \mathrm{ppm}\left(2 \mathrm{CH}_{2}\right)$; MS (70 eV, EI) $\mathrm{m} / z$ (\%): $244.1(80)\left[\mathrm{M}^{+}\right], 211.1$ (70), 162.0 (80), 129.1 (100); IR (KBr): 2927, 2854, 1591 $(\mathrm{C}=\mathrm{S}), 1554,1444,1362,1268,1068,959,936,846,763,606 \mathrm{~cm}^{-1}$; elemental analysis calcd (\%) for $\mathrm{C}_{14} \mathrm{H}_{16} \mathrm{~N}_{2} \mathrm{~S}$ : C 68.81, H 6.60, N 11.46; found: C 68.75, H 6.40, N 11.20. 


\section{Methyl 3,4-dihydro-4-oxo-3-phenylquinazoline-2-carboxylate (191j)}

$\overbrace{\mathrm{O}}^{\mathrm{N}} \mathrm{CO}_{\mathrm{Ph}}^{\mathrm{CO}}$

The compound $\mathbf{1 9 1 j}$ (412 $\mathrm{mg}, 73 \%$ ) was obtained from 2-bromophenyl isocyanide (159-Br) (364 mg, $2 \mathrm{mmol}$ ), phenyl isocyanate $(238 \mathrm{mg}, 2 \mathrm{mmol})$ and methyl chloroformate (208 mg, $2 \mathrm{mmol}$ ) following GP7, after column chromatography (hexane/EtOAc $\left.2: 1, R_{\mathrm{f}}=0.32\right)$ as a colorless solid. ${ }^{1} \mathrm{H}$ NMR $\left(300 \mathrm{MHz}, \mathrm{CDCl}_{3}\right)$ : $\delta$ 7.57-7.36 (m, $9 \mathrm{H}, \mathrm{Ar}-\mathrm{H}), 3.68 \mathrm{ppm}\left(\mathrm{s}, 3 \mathrm{H}, \mathrm{CH}_{3}\right) ;{ }^{13} \mathrm{C} \mathrm{NMR}\left(75.5 \mathrm{MHz}, \mathrm{CDCl}_{3}, \mathrm{APT}\right)$ : $\delta 168.5(\mathrm{C}), 168.2(\mathrm{C}), 154.2(\mathrm{C}), 137.0(\mathrm{C}), 134.6(\mathrm{C}), 130.8(\mathrm{CH}), 129.6(\mathrm{CH}), 129.4$ (C), $128.8(\mathrm{CH}), 128.3(\mathrm{CH}), 128.1(\mathrm{CH}), 126.7(\mathrm{CH}), 121.7(\mathrm{C}), 54.3$ ppm $\left(\mathrm{CH}_{3}\right)$; MS (EI) $m / z(\%): 280.2$ (37) $\left[\mathrm{M}^{+}\right], 130.2$ (100), 119.1 (32), 102.1 (38); IR (KBr): 2126, 1753 $(\mathrm{C}=\mathrm{O}), 1693(\mathrm{C}=\mathrm{O}), 1597,1493,1433,1322,1260,1054,771,749,693,632 \mathrm{~cm}^{-1}$; HRMS (ESI) calcd for $\mathrm{C}_{16} \mathrm{H}_{12} \mathrm{~N}_{2} \mathrm{O}_{3} \mathrm{Na}^{+}\left[\mathrm{M}+\mathrm{Na}^{+}\right.$]: 303.07401 ; found: 303.07403 .

\section{3-Phenyl-2-(phenylthio)quinazolin-4(3H)-one (191k)}<smiles>O=c1c2ccccc2nc(S[SbH])n1-c1ccccc1</smiles>

The compound $191 \mathrm{k}$ (505 $\mathrm{mg}, 77 \%$ ) was obtained from 2-bromophenyl isocyanide (159-Br) (364 mg, $2 \mathrm{mmol}$ ), phenyl isocyanate $(238 \mathrm{mg}, 2 \mathrm{mmol})$ and diphenyl disulfide (436 mg, 2 mmol) following GP7, after column chromatography (hexane/EtOAc $5: 1, R_{\mathrm{f}}=0.26$ ) as a colorless solid, m. p. $130-131{ }^{\circ} \mathrm{C}$. ${ }^{1} \mathrm{H}$ NMR $\left(300 \mathrm{MHz}, \mathrm{CDCl}_{3}\right): \delta 8.21(\mathrm{dd}, J=7.8,1.6 \mathrm{~Hz}, 1 \mathrm{H}), 7.64-7.52(\mathrm{~m}, 6 \mathrm{H}), 7.45-7.32 \mathrm{ppm}$ $(\mathrm{m}, 7 \mathrm{H}) ;{ }^{13} \mathrm{C}$ NMR $\left(75.5 \mathrm{MHz}, \mathrm{CDCl}_{3}, \mathrm{APT}\right): \delta 161.9$ (C), 157.1 (C), 147.7 (C), 136.0 (C), $135.7(2 \mathrm{CH}), 134.4(\mathrm{CH}), 130.0(\mathrm{CH}), 129.7(2 \mathrm{CH}), 129.5(\mathrm{CH}), 129.2(2 \mathrm{CH})$, $129.0(2 \mathrm{CH}), 128.5(\mathrm{C}), 127.1(\mathrm{CH}), 126.6(\mathrm{CH}), 126.0(\mathrm{CH}), 119.9$ ppm $(\mathrm{C}) ; \mathrm{MS}(\mathrm{EI})$ $m / z$ (\%): 330.3 (100) $\left[\mathrm{M}^{+}\right], 221.2$ (36), 77.1 (28), 44.1 (28); IR (KBr): 1696 (C=O), 1540, 1467, 1296, 1260, 959, $764 \mathrm{~cm}^{-1}$; HRMS (ESI) calcd for $\mathrm{C}_{20} \mathrm{H}_{15} \mathrm{~N}_{2} \mathrm{OS}^{+}\left[\mathrm{M}+\mathrm{H}^{+}\right]$: 331.08996; found: 331.09010 . 


\section{2-Cyano-3-(phenyl)quinazolin-4(3H)-one (1911)}

$\overbrace{\mathrm{O}}^{\mathrm{CN}}$

The compound 1911 (123 mg, 54\%) was obtained from 2-bromophenyl isocyanide (159-Br) (182 mg, $1 \mathrm{mmol})$, phenyl isocyanate (119 mg, $1 \mathrm{mmol})$ and $p$-toluenesulfonyl cyanide $(181 \mathrm{mg}$, 1 mmol) following GP7, after column chromatography (hexane/EtOAc $4: 1, R_{\mathrm{f}}=0.16$ ) as a colorless solid, m. p. $195-196{ }^{\circ} \mathrm{C} .\left[\right.$ lit. $\left.{ }^{[194]} 198{ }^{\circ} \mathrm{C}\right]{ }^{1} \mathrm{H}$ NMR (300 MHz, $\left.\mathrm{CDCl}_{3}\right): \delta 7.69-7.45 \mathrm{ppm}(\mathrm{m}, 9 \mathrm{H}) ;{ }^{13} \mathrm{C} \mathrm{NMR}\left(75.5 \mathrm{MHz}, \mathrm{CDCl}_{3}, \mathrm{APT}\right)$ : $\delta 170.7(\mathrm{C}), 165.0(\mathrm{C}), 134.2(\mathrm{C}), 132.9(\mathrm{CH}), 129.9(2 \mathrm{CH}), 129.7(\mathrm{CH}), 129.6(\mathrm{CH})$, 129.4 (C), 128.9 (C), 128.7 (CH), 127.7 (CH), 125.5 (2 CH), 120.0 ppm (C); MS (EI) m/z. (\%): 247.3 (32) [ $\left.\mathrm{M}^{+}\right], 130.2$ (100), 102.2 (42); IR (KBr): $2239(\mathrm{CN}), 2131,1734(\mathrm{C}=\mathrm{O})$, $1593,1484,1270,1162,1053,754,690 \mathrm{~cm}^{-1}$; elemental analysis calcd (\%) for $\mathrm{C}_{15} \mathrm{H}_{9} \mathrm{~N}_{3} \mathrm{O}$ : C 72.87, H 3.67, N 16.99; found: 72.79, H 3.66, N 16.75.

\section{3-Benzyl-2-iodoquinazolin-4(3H)-one (191m)}<smiles>O=c1c2ccccc2nc(I)n1Cc1ccccc1</smiles>

The compound $191 \mathrm{~m}$ (543 $\mathrm{mg}, 75 \%)$ was obtained from 2-bromophenyl isocyanide (159-Br) (364 mg, $2 \mathrm{mmol})$, benzyl isocyanate $(266 \mathrm{mg}, 2 \mathrm{mmol})$ and iodine $(508 \mathrm{mg}, 2 \mathrm{mmol})$ following GP7, after column chromatography (hexane/EtOAc $\left.2: 1, R_{\mathrm{f}}=0.39\right)$ as a colorless solid, m. p. $151-152{ }^{\circ} \mathrm{C} .{ }^{1} \mathrm{H}$ NMR $\left(300 \mathrm{MHz}, \mathrm{CDCl}_{3}\right)$ : $\delta 8.27(\mathrm{dd}, J=8.9,1.5 \mathrm{~Hz}, 1 \mathrm{H}), 7.75(\mathrm{dt}, J=7.8,1.5 \mathrm{~Hz}, 1 \mathrm{H}), 7.65(\mathrm{~d}, J=6.8 \mathrm{~Hz} 1 \mathrm{H})$, $7.51(\mathrm{dt}, J=7.6,1.1 \mathrm{~Hz}, 1 \mathrm{H}), 7.35-7.29(\mathrm{~m}, 5 \mathrm{H}), 5.56 \mathrm{ppm}\left(\mathrm{s}, 2 \mathrm{H}, \mathrm{CH}_{2}\right) ;{ }^{13} \mathrm{C} \mathrm{NMR}$ $\left(75.5 \mathrm{MHz}, \mathrm{CDCl}_{3}\right): \delta 160.4(\mathrm{C}), 135.3(\mathrm{C}), 134.8(\mathrm{CH}), 128.7(\mathrm{CH}), 127.8(2 \mathrm{CH}), 127.3$ $(\mathrm{CH}), 127.2(\mathrm{CH}), 126.9(\mathrm{CH}), 121.0(\mathrm{C}), 112.9(\mathrm{C}), 55.6 \mathrm{ppm}\left(\mathrm{CH}_{2}\right)$; MS (EI) $\mathrm{m} / \mathrm{z}(\%)$ : $362.2(100)\left[\mathrm{M}^{+}\right], 235.2$ (52), 91.1 (52); IR (KBr): $1671(\mathrm{C}=\mathrm{O}), 1542,1467,1331,1150$, 1075, 957, $771 \mathrm{~cm}^{-1}$; elemental analysis calcd $(\%)$ for $\mathrm{C}_{15} \mathrm{H}_{8} \mathrm{~N}_{2} \mathrm{O}_{2}$ : C. 49.75, H. 3.06, N 7.73; found: 49.44, H 3.25, N 7.99. 


\section{2,3-Dihydropyrrolo[2,1-b]quinazolin-9(1H)-one (desoxyvascinone, 191n)}<smiles>O=c1c2ccccc2nc2n1CCC2</smiles>

The compound 191n (268 mg, 72\%) was obtained from 2-bromophenyl isocyanide (159-Br) (364 mg, $2 \mathrm{mmol})$ and 3-iodopropyl isocyanate $(422 \mathrm{mg}, 2 \mathrm{mmol})$ following GP7, after column chromatography (EtOAc, $\left.R_{\mathrm{f}}=0.11\right)$ as a colorless solid, m. $\mathrm{p}$. 104-105 ${ }^{\circ} \mathrm{C}$ [lit. ${ }^{[195]} 105-107{ }^{\circ} \mathrm{C}$ ]. ${ }^{1} \mathrm{H}$ NMR $\left(300 \mathrm{MHz}, \mathrm{CDCl}_{3}\right): \delta 8.27(\mathrm{dd}, J=8.4,1.6$ $\mathrm{Hz}, 1 \mathrm{H}, \mathrm{Ar}-\mathrm{H}), 7.72(\mathrm{t}, J=8.4 \mathrm{~Hz}, 1 \mathrm{H}, \mathrm{Ar}-\mathrm{H}), 7.63(\mathrm{~d}, J=8.1 \mathrm{~Hz} 1 \mathrm{H}, \operatorname{Ar}-\mathrm{H}), 7.44$ $(\mathrm{t}, J=8.1 \mathrm{~Hz}, 1 \mathrm{H}), 4.20(\mathrm{dd}, J=7.5,7.5 \mathrm{~Hz}, 2 \mathrm{H}), 3.17(\mathrm{dd}, J=7.8,7.8 \mathrm{~Hz}, 2 \mathrm{H})$, 2.34-2.23 (m, $2 \mathrm{H}$ ) ppm; ${ }^{13} \mathrm{C}$ NMR (75.5 MHz, $\left.\mathrm{CDCl}_{3}, \mathrm{APT}\right): \delta 160.9$ (C), 159.3 (C), $149.0(\mathrm{C}), 134.0(\mathrm{CH}), 126.7(\mathrm{CH}), 126.2(\mathrm{CH}), 126.1(\mathrm{CH}), 120.3(\mathrm{C}), 46.4\left(\mathrm{CH}_{2}\right), 32.4$

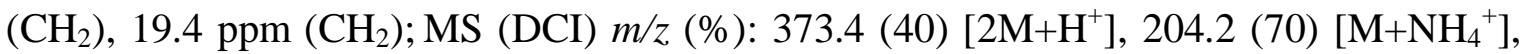
187.2 (100) $\left[\mathrm{M}+\mathrm{H}^{+}\right]$; IR (KBr): 2924, 1675 (C=O), 1621, 1465, 1384, 1336, 1268, 1022, 771, $694 \mathrm{~cm}^{-1}$; elemental analysis calcd $(\%)$ for $\mathrm{C}_{11} \mathrm{H}_{10} \mathrm{~N}_{2} \mathrm{O}$ : C 70.95, H 5.41, N 15.04; found: 71.13, H 5.09, N 14.80.

\section{Indolo[2,1-b]quinazoline-6,12-dione (trypthamine, 1910)}

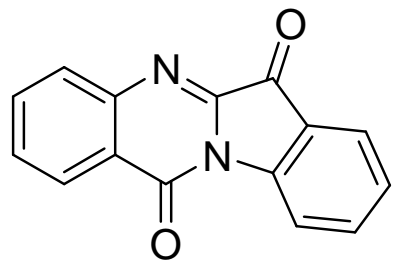

The compound 1910 ( $210 \mathrm{mg}, 85 \%$ ) was obtained from 2-bromophenyl isocyanide (159-Br) $(182 \mathrm{mg}, 1 \mathrm{mmol})$ and methyl (2-isocyanato)benzoate $(177 \mathrm{mg}, 1 \mathrm{mmol})$ following GP7, after column chromatography (EtOAc, $R_{\mathrm{f}}=0.55$ ) as a yellow solid, m. p. 261-262 ${ }^{\circ} \mathrm{C}$ [lit. ${ }^{[196]} 267-268{ }^{\circ} \mathrm{C}$ ]. ${ }^{1} \mathrm{H}$ NMR (300 MHz, DMSO[d6], $\left.100{ }^{\circ} \mathrm{C}\right): \delta 8.46(\mathrm{~d}, J=8.3 \mathrm{~Hz}, 1 \mathrm{H}, \mathrm{Ar}-\mathrm{H}), 8.29(\mathrm{~d}, J=7.9 \mathrm{~Hz}, 1 \mathrm{H}, \mathrm{Ar}-\mathrm{H}), 7.90(\mathrm{~d}, J=3.8$ Hz, 2 H, Ar-H), 7.83 (t, J= 7.2 Hz, 2 H, Ar-H), 7.73-7.68 (m, 1 H, Ar-H), 7.46 ppm (t, $J=7.5 \mathrm{~Hz}, 1 \mathrm{H}) ;{ }^{13} \mathrm{C}$ NMR $\left(75.5 \mathrm{MHz}, \mathrm{DMSO}[\mathrm{d} 6], 100{ }^{\circ} \mathrm{C}\right): \delta 181.6(\mathrm{C}), 157.1(\mathrm{C}), 146.0$ (C), $145.5(\mathrm{C}), 144.3(\mathrm{C}), 137.2(\mathrm{CH}), 134.4(\mathrm{CH}), 129.4(\mathrm{CH}), 129.3(\mathrm{CH}), 126.4(\mathrm{CH})$, $126.3(\mathrm{CH}), 124.1(\mathrm{CH}), 122.9(\mathrm{C}), 121.6(\mathrm{C}), 116.5 \mathrm{ppm}(\mathrm{CH})$; MS (EI) $\mathrm{m} / \mathrm{z}(\%): 248.2$ (100) $\left[\mathrm{M}^{+}\right], 220.2(15)$; IR (KBr): $1725(\mathrm{C}=\mathrm{O}), 1685(\mathrm{C}=\mathrm{O}), 1594,1458,1353,1312$, 1190, 1116, 1039, 925, 755, 690 $\mathrm{cm}^{-1}$; elemental analysis calcd $(\%)$ for $\mathrm{C}_{15} \mathrm{H}_{8} \mathrm{~N}_{2} \mathrm{O}_{2}$ : C 72.58, H 3.25, N 11.28; found: 72.29, H 3.13, N 10.97. 


\section{Experimental Procedures for the Compounds Described in Chapter 3 "Reactions of ortho-Lithiophenyl (-Hetaryl) Isocyanides with Carbonyl Compounds - Rearrangements of 2-Metallated 4H-3,1-Benzoxazines"}

\section{$N$-(2-Bromopyridin-3-yl)formamide}<smiles>O=CNc1cccnc1Br</smiles>

To a solution of 3-amino-2-bromopyridine (1.31 g, $7.57 \mathrm{mmol})$ and ethyl formate $(3 \mathrm{~mL})$ in anhydrous THF $(50 \mathrm{~mL})$ was added portionwise at r.t. a suspension of $\mathrm{NaH}(60 \%$ in mineral oil, $378 \mathrm{mg}$,

$9.46 \mathrm{mmol}$ ). The resulting mixture was stirred at r.t. for $24 \mathrm{~h}$, and then the reaction was quenched with cold water $(1 \mathrm{~mL})$. The solvents were removed under reduced pressure, and the residue was dissolved in ethyl acetate/water $(40 / 10 \mathrm{~mL})$. The aqueous phase was extracted with ethyl acetate $(2 \times 30 \mathrm{~mL})$, the combined organic extracts were dried over anhydrous $\mathrm{Na}_{2} \mathrm{SO}_{4}$ and concentrated. The residue was washed thoroughly with hexane $(3 \times 20 \mathrm{~mL})$ and dried in vacuo to give $1.38 \mathrm{~g}(91 \%)$ of the title compound as a colorless solid, m.p. $139-140{ }^{\circ} \mathrm{C} . \quad R_{\mathrm{f}}=0.13$ (hexane/EtOAc 2:1). ${ }^{1} \mathrm{H}$ NMR (300 MHz, DMSO[d6]): $\delta 9.87$ (br s, $1 \mathrm{H}, \mathrm{NH}), 8.41$ (s, $1 \mathrm{H}, \mathrm{CHO}), 8.38$ (d, $J=9.0 \mathrm{~Hz}, 1 \mathrm{H}), 8.16$ $(\mathrm{d}, J=4.1 \mathrm{~Hz}, 1 \mathrm{H}), 7.45 \mathrm{ppm}(\mathrm{dd}, J=8.1,4.7 \mathrm{~Hz}, 1 \mathrm{H}) ;{ }^{13} \mathrm{C}$ NMR $(75.5 \mathrm{MHz}$, DMSO[d6]): $\delta 160.8(\mathrm{CH}), 145.4(\mathrm{CH}), 133.9(\mathrm{C}), 133.1(\mathrm{C}), 131.2(\mathrm{CH}), 123.6$ ppm (CH); MS (70 eV, EI) m/z (\%): 201.0 (2) $\left[\mathrm{M}^{+}\right], 200.0$ (20), 121.1 (100), 93.1 (50); IR (KBr): 3243 (br), 1664 (C=O), 1585, 1517, 1449, 1400, 1379, 1288, 1150, 1117, 1047, 802, 735, $65 \mathrm{~cm}^{-1}$; Anal. Calcd for $\mathrm{C}_{6} \mathrm{H}_{5} \mathrm{BrN}_{2} \mathrm{O}: \mathrm{C}$ 35.85, H 2.51, N 13.94; found: C 35.68, H 2.70, N 13.81 .

\section{2-Bromo-3-isocyanopyridine}<smiles>[N-]=[N+]=[N+]=C(Br)Br</smiles>
To a solution of $N$-(2-bromopyridin-3-yl)formamide $(1.35 \mathrm{~g}, 6.72 \mathrm{mmol})$ in anhydrous $\mathrm{CH}_{2} \mathrm{Cl}_{2}(45 \mathrm{~mL})$ was added at $0{ }^{\circ} \mathrm{C}$ triethylamine $(5.95 \mathrm{~mL}, 43$ $\mathrm{mmol})$, then dropwise over a period of $10 \mathrm{~min} \mathrm{POCl}_{3}(1.29 \mathrm{~mL}, 13.44$ mmol). The mixture was stirred at $0{ }^{\circ} \mathrm{C}$ for $15 \mathrm{~min}$, then a saturated solution of $\mathrm{Na}_{2} \mathrm{CO}_{3}$ $(10 \mathrm{~mL})$ was added slowly. The mixture was transferred into a separatory funnel, diluted with dichloromethane $(50 \mathrm{~mL})$, the organic phase washed with a half-saturated solution of $\mathrm{Na}_{2} \mathrm{CO}_{3}(100 \mathrm{~mL})$ and brine $(100 \mathrm{~mL})$, then dried over anhydrous $\mathrm{Na}_{2} \mathrm{SO}_{4}$ and concentrated. The crude product was purified by column chromatography on silica gel 
(hexane/ethyl acetate $\left.2: 1, R_{\mathrm{f}}=0.30\right)$ to give $1.01 \mathrm{~g}(82 \%)$ of 2-bromo-3-isocyanopyridine as a colorless solid, m.p. $98-99{ }^{\circ} \mathrm{C} .{ }^{1} \mathrm{H}$ NMR $\left(300 \mathrm{MHz}, \mathrm{CDCl}_{3}\right): \delta 8.43(\mathrm{dd}, J=4.9,1.9$ $\mathrm{Hz}, 1 \mathrm{H}), 7.76(\mathrm{dd}, J=7.9,1.9 \mathrm{~Hz}, 1 \mathrm{H}), 7.39 \mathrm{ppm}(\mathrm{dd}, J=7.9,4.5 \mathrm{~Hz}, 1 \mathrm{H}) ;{ }^{13} \mathrm{C} \mathrm{NMR}$ (75.5 MHz, $\left.\mathrm{CDCl}_{3}\right): \delta 172.8(\mathrm{C}), 149.6(2 \mathrm{C}), 139.3(\mathrm{C}), 135.6(\mathrm{CH}), 122.9 \mathrm{ppm}(\mathrm{CH})$; MS (70eV, EI) m/z (\%): 185.0 (6) $\left[\mathrm{M}^{+}\right], 183.0$ (12) [M+2 $\left.{ }^{+}\right], 110.1$ (100), 105.1(50); IR (KBr): 2134 (NC), 1555, 1408, 1199,1064, 805, 722, 654, $517 \mathrm{~cm}^{-1}$; Anal. Calcd for $\mathrm{C}_{6} \mathrm{H}_{3} \mathrm{BrN}_{2}$ : C 39.38, H 1.65, N 15.31; found: C 39.30, H 1.71, N 15.02.

\section{$N$-(Thiophen-3-yl)formamide}

ethyl formiate $(10 \mathrm{~mL})$ in anhydrous $\mathrm{THF}(200 \mathrm{~mL})$ was added
portionwise at r.t. a suspension of $\mathrm{NaH}(60 \%$ in mineral oil, $2.26 \mathrm{~g}, 56.4$ mmol). The resulting mixture was stirred at r.t. for $24 \mathrm{~h}$, then the reaction was quenched with cold water $(10 \mathrm{~mL})$. The solvents were removed under reduced pressure, and the residue was dissolved in ethyl acetate/water $(200 / 50 \mathrm{~mL})$. The aqueous phase was extracted with ethyl acetate $(2 \times 50 \mathrm{~mL})$, the combined organic extracts were dried over anhydrous $\mathrm{Na}_{2} \mathrm{SO}_{4}$ and concentrated to give almost pure product $(5.80 \mathrm{~g}, 97 \%)$, which was used in the next step without further purification. $R_{\mathrm{f}}=0.13$ (hexane/EtOAc $2: 1$ ). (2 rotamers $0.8: 0.2){ }^{1} \mathrm{H}$ NMR $\left(300 \mathrm{MHz}, \mathrm{CDCl}_{3}\right): \delta 7.35$ (br s, $\left.0.8 \mathrm{H}, \mathrm{CHO}\right), 7.14$ (d, $J=10 \mathrm{~Hz}, 0.2 \mathrm{H}, \mathrm{CHO}), 6.53(\mathrm{~d}, J=11.6 \mathrm{~Hz}, 0.2 \mathrm{H}, \mathrm{NH}), 6.19(\mathrm{~d}, J=1.8 \mathrm{~Hz}, 0.8 \mathrm{H}, \mathrm{NH})$, $5.51(\mathrm{dd}, J=3.1,1.2 \mathrm{~Hz}, 0.8 \mathrm{H}, \mathrm{Ar}-\mathrm{CH}), 5.23(\mathrm{dd}, J=5.2,3.1 \mathrm{~Hz}, 0.2 \mathrm{H}, \mathrm{Ar}-\mathrm{CH}), 5.14$ (dd, $J=4.9,3.1 \mathrm{~Hz}, 0.8 \mathrm{H}, \mathrm{Ar}-\mathrm{CH}), 5.03(\mathrm{dd}, J=5.2,1.2 \mathrm{~Hz}, 0.8 \mathrm{H}, \mathrm{Ar}-\mathrm{CH}), 4.85$ (dd, $J=5.2,1.2 \mathrm{~Hz}, 0.2 \mathrm{H}, \mathrm{Ar}-\mathrm{CH}), 4.77(\mathrm{dd}, J=3.1,1.2 \mathrm{~Hz}, 0.2 \mathrm{H}, \mathrm{Ar}-\mathrm{CH}) ;{ }^{13} \mathrm{C} \mathrm{NMR}(62.5$ $\left.\mathrm{MHz}, \mathrm{CDCl}_{3}\right): \delta 163.1(\mathrm{C}), 159.0(\mathrm{C}), 135.2(\mathrm{C}), 134.4(\mathrm{C}), 126.5(\mathrm{CH}), 124.5(\mathrm{CH})$, $121.2(\mathrm{CH}), 120.5(\mathrm{CH}), 111.2(\mathrm{CH}), 109.5(\mathrm{CH})$; MS (70 eV, EI) m/z (\%): 127.1 (100) $\left[\mathrm{M}^{+}\right], 99.1$ (39), 72.0 (28); IR (KBr): 3279 (br), 3105, $1653(\mathrm{C}=\mathrm{O}), 1539,1418,1388$, 1208, $773 \mathrm{~cm}^{-1}$; 


\section{$N$-(2-Bromothiophen-3-yl)formamide}

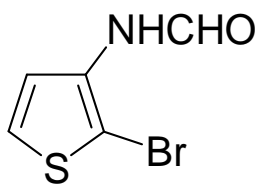

To a boiling solution of $N$-(thiophen-3-yl)formamide (2.54 g, $20 \mathrm{mmol})$ in anhydrous chloroform $(60 \mathrm{~mL})$ was added NBS $(3.52 \mathrm{~g}, 20 \mathrm{mmol})$ in one portion. After the initial reaction had ceased, the mixture was heated for $10 \mathrm{~min}$, then cooled. The solvent was evaporated under reduced pressure, and the residue was purified by column chromatography on silica gel (hexane/EtOAc 2 : 1, $\left.R_{\mathrm{f}}=0.25\right)$ to give $3.27 \mathrm{~g}(79 \%)$ of the title product as a colorless solid, m.p. $92-93{ }^{\circ} \mathrm{C} .{ }^{1} \mathrm{H}$ NMR (300 MHz, $\mathrm{CDCl}_{3}$ ) (2 rotamers $\left.0.8: 0.2\right): \delta 8.61(\mathrm{~d}, J=11.3 \mathrm{~Hz}, 0.2 \mathrm{H}, \mathrm{CHO}), 8.37$ (d, $J=1.5 \mathrm{~Hz}, 0.2 \mathrm{H}, \mathrm{CHO}$ ), 8.19 (br s, $0.2 \mathrm{H}, \mathrm{NH}), 8.04$ (br s, $0.8 \mathrm{H}, \mathrm{NH}), 7.70$ (d, J = 6.1 $\mathrm{Hz}, 0.8 \mathrm{H}, \mathrm{Ar}-\mathrm{H}), 7.32$ (d, $J=5.8 \mathrm{~Hz}, 0.2 \mathrm{H}, \mathrm{Ar}-\mathrm{H}), 7.27$ (d, $J=5.8 \mathrm{~Hz}, 0.8 \mathrm{H}, \mathrm{Ar}-\mathrm{H})$, $6.90 \mathrm{ppm}(\mathrm{d}, J=6.1 \mathrm{~Hz}, 0.2 \mathrm{H}, \mathrm{Ar}-\mathrm{H}) ;{ }^{13} \mathrm{C} \mathrm{NMR}\left(75.5 \mathrm{MHz}, \mathrm{CDCl}_{3}\right): \delta 158.2(\mathrm{CH}), 157.1$ $(\mathrm{CH}), 134.7(\mathrm{C}), 134.0(\mathrm{CH}), 127.2(\mathrm{C}), 126.7(\mathrm{C}), 125.3(\mathrm{CH}), 122.6(\mathrm{CH}), 119.9(\mathrm{C})$, 113.9 (CH); MS (70eV, EI) m/z (\%): 207.0 (51) $\left[\mathrm{M}^{+}\right], 205.0$ (57) $\left[\mathrm{M}^{+}\right], 179.0$ (29), 177.0 (31), 126.1(100), 98.1 (43); IR (KBr): 3220 (br), 1661 (C=O), 1594, 1499, 1393, 1258, 1211, 1001, 823, $708 \mathrm{~cm}^{-1}$; Anal. Calcd for $\mathrm{C}_{5} \mathrm{H}_{4}$ BrNOS: C 29.14, H 1.96, N 6.80; found: C 28.91, H 1.60, N 6.51

\section{2-Bromo-3-isocyanothiophene (234)}

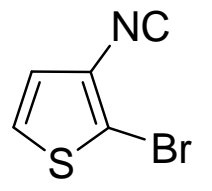

To a solution of $N$-(2-bromothiophen-3-yl)formamide $(3.0 \mathrm{~g}, 14.6 \mathrm{mmol})$ in anhydrous $\mathrm{CH}_{2} \mathrm{Cl}_{2}(50 \mathrm{~mL})$ was added at $0{ }^{\circ} \mathrm{C}$ triethylamine $(8.4 \mathrm{~mL}, 60.6$ $\mathrm{mmol})$, and then dropwise over a period of $10 \mathrm{~min} \mathrm{POCl}_{3}(1.82 \mathrm{~mL}, 18.93$ mmol). The mixture was stirred at $0{ }^{\circ} \mathrm{C}$ for $15 \mathrm{~min}$, then a saturated solution of $\mathrm{Na}_{2} \mathrm{CO}_{3}$ $(10 \mathrm{~mL})$ was added slowly. The mixture was transferred into a separatory funnel, diluted with $\mathrm{CH}_{2} \mathrm{Cl}_{2}(100 \mathrm{~mL})$, the organic phase washed with a half-saturated solution of $\mathrm{Na}_{2} \mathrm{CO}_{3}$ $(50 \mathrm{~mL})$ and brine $(50 \mathrm{~mL})$, then dried over anhydrous $\mathrm{Na}_{2} \mathrm{SO}_{4}$ and concentrated. The crude product was purified by column chromatography on silica gel (hexane/EtOAc $10: 1$, $\left.R_{\mathrm{f}}=0.31\right)$ and subsequent recrystallization from hexane at $-18{ }^{\circ} \mathrm{C}$ to give $2.33 \mathrm{~g}(85 \%)$ of 2-bromo-3-isocyanothiophene (234) as a yellow-red oil. ${ }^{1} \mathrm{H}$ NMR (300 $\left.\mathrm{MHz}, \mathrm{CDCl}_{3}\right)$ : $\delta 7.29(\mathrm{~d}, J=5.9 \mathrm{~Hz}, 1 \mathrm{H}), 6.98 \mathrm{ppm}(\mathrm{d}, J=5.9 \mathrm{~Hz}, 1 \mathrm{H}) ;{ }^{13} \mathrm{C} \mathrm{NMR}\left(125 \mathrm{MHz}, \mathrm{CDCl}_{3}\right)$ : $\delta 168.0(\mathrm{C}), 126.9(\mathrm{C}), 126.3(\mathrm{CH}), 124.6(\mathrm{CH}), 112.1 \mathrm{ppm}(\mathrm{C})$; MS (70eV, EI) $\mathrm{m} / \mathrm{z}(\%)$ : $189.0(100)\left[\mathrm{M}^{+}\right], 187.0(98)\left[\mathrm{M}^{+}\right], 108.1$ (45); IR (KBr): 3112, 2120 (NC), 1371, 1010, 
950, $713 \mathrm{~cm}^{-1}$; Anal. Calcd for $\mathrm{C}_{5} \mathrm{H}_{2}$ BrNS: C 31.94, H 1.07, N 7.45; found: C 32.06, H 1.02, N 7.36.

\section{General Procedure for the Reaction of ortho-Lithiophenyl (-Hetaryl) Isocyanides with Aldehydes and Ketones (GP8)}

To a solution of $o$-bromophenyl (-hetaryl) isocyanide $(2 \mathrm{mmol})$ in anhydrous tetrahydrofuran $(20 \mathrm{~mL})$, kept in an oven-dried $25 \mathrm{~mL}-$ Schlenk flask under an atmosphere of dry nitrogen, was added dropwise with stirring a $2.5 \mathrm{M}$ solution of $n$-BuLi in hexane $(0.8 \mathrm{~mL}, 2 \mathrm{mmol})$ at $-78{ }^{\circ} \mathrm{C}$ over a period of $10 \mathrm{~min}$. The mixture was stirred at $-78{ }^{\circ} \mathrm{C}$ for another $10 \mathrm{~min}$, before the respective aldehyde (ketone) $(2 \mathrm{mmol})$ in anhydrous THF $(2 \mathrm{~mL})$ was added dropwise. The mixture was stirred at $-78{ }^{\circ} \mathrm{C}$ for $3 \mathrm{~h}$ and was then treated in three different ways (variants $\mathrm{A}-\mathrm{C}$ )

(A) The reaction was quenched with water $(2 \mathrm{~mL})$ at $-78^{\circ} \mathrm{C}$.

(B) The mixture was gradually warmed to $0{ }^{\circ} \mathrm{C}$ within $2 \mathrm{~h}$, and then the reaction was quenched with water $(2 \mathrm{~mL})$ at $0{ }^{\circ} \mathrm{C}$.

(C) The mixture was treated with the solution of an electrophile in THF ( $2 \mathrm{~mL})$ at -78 ${ }^{\circ} \mathrm{C}$, the resulting mixture stirred at the same temperature for $2 \mathrm{~h}$ and warmed to r.t. overnight.

Then the mixture was diluted with diethyl ether $(50 \mathrm{~mL})$, washed with water $(2 \times 10 \mathrm{~mL})$, brine $(20 \mathrm{~mL})$ and dried over anhydrous $\mathrm{Na}_{2} \mathrm{SO}_{4}$. The solvents were removed under reduced pressure to give a crude product, which was purified by column chromatography on silica gel or by Kugelrohr distillation.

\section{(2-Isocyanophenyl)(phenyl)methanol (204a)}<smiles>N#[N+]c1ccccc1C(O)c1ccccc1</smiles>

The isocyanide 204a (350 mg, 84\%) was obtained from $o$-bromophenyl isocyanide (159-Br) (364 mg, $2 \mathrm{mmol})$ and benzaldehyde (202a) (212 mg, 2 mmol) following GP8 (A) and after column chromatography (hexane/ethyl acetate $4: 1, R_{\mathrm{f}}=0.27$ ) as a yellow oil. ${ }^{1} \mathrm{H}$ NMR $\left(300 \mathrm{MHz}, \mathrm{CDCl}_{3}\right): \delta 7.74(\mathrm{~d}, J=7.9 \mathrm{~Hz}, 1 \mathrm{H}, \mathrm{Ar}-\mathrm{H}), 7.47-7.25$ $(\mathrm{m}, 8 \mathrm{H}, \mathrm{Ar}-\mathrm{H}), 6.18$ (s, $1 \mathrm{H}, \mathrm{CH}), 2.51 \mathrm{ppm}(\mathrm{s}, 1 \mathrm{H}, \mathrm{OH}) ;{ }^{13} \mathrm{C} \mathrm{NMR}\left(75.5 \mathrm{MHz}, \mathrm{CDCl}_{3}\right.$, APT): $\delta 167.6(\mathrm{C}), 141.6(\mathrm{C}), 139.9(\mathrm{C}), 129.7(\mathrm{CH}), 128.7(2 \mathrm{CH}), 128.3(\mathrm{CH}), 128.2$ (CH), 127.0 (2 CH), 126.9 (2 CH), 124.4 (C), 71.9 ppm (CH); IR (film): 3393 (br, OH), 
3064, 3031, 2896, 2120 (NC), 1483, 1453, 1188, 1035, 1024, 761, $699 \mathrm{~cm}^{-1}$; MS (EI) $\mathrm{m} / z$ (\%): 209 (46) $\left[\mathrm{M}^{+}\right], 180$ (100), 77 (34); HRMS (EI): calcd for $\mathrm{C}_{14} \mathrm{H}_{11} \mathrm{NO}^{+}[\mathrm{M}]^{+}$: 209.0841; found: 209.0839 .

\section{(2-Isocyanophenyl)(4-methoxyphenyl)methanol (204b)}<smiles>COc1ccc(C(O)c2ccccc2[N+](=O)[O-])cc1</smiles>

The isocyanide 204b (397 $\mathrm{mg}, 83 \%$ ) was obtained from $o$-bromophenyl isocyanide (159-Br) (364 mg, $2 \mathrm{mmol}$ ) and 4-methoxybenzaldehyde (202b) (272 mg, $2 \mathrm{mmol}$ ) following GP8 (A) and after column chromatography (hexane/ethyl acetate $5: 1, R_{\mathrm{f}}=0.20$ ) as a colorless oil. ${ }^{1} \mathrm{H}$ NMR $\left(300 \mathrm{MHz}, \mathrm{CDCl}_{3}\right): \delta 7.76(\mathrm{~d}, J=7.9 \mathrm{~Hz}, 1 \mathrm{H}, \mathrm{Ar}-\mathrm{H}), 7.45$ (td, $(\mathrm{d}, J=8.7 \mathrm{~Hz}, 2 \mathrm{H}, \mathrm{Ar}-\mathrm{H}), 6.11(\mathrm{~d}, J=1.9 \mathrm{~Hz}, 1 \mathrm{H}, \mathrm{CH}), 3.77\left(\mathrm{~s}, 3 \mathrm{H}, \mathrm{CH}_{3}\right), 2.47$ $(\mathrm{d},=2.6 \mathrm{~Hz}, 1 \mathrm{H}, \mathrm{OH}) ;{ }^{13} \mathrm{C} \mathrm{NMR}\left(75.5 \mathrm{MHz}, \mathrm{CDCl}_{3}\right): \delta 167.5(\mathrm{C}), 159.4(\mathrm{C}), 140.1(\mathrm{C})$, $133.7(\mathrm{C}), 129.6(\mathrm{CH}), 128.4(2 \mathrm{CH}), 128.1(\mathrm{CH}), 126.9(\mathrm{CH}), 126.7(\mathrm{CH}), 124.3(\mathrm{C})$, $114.0(2 \mathrm{CH}), 71.6(\mathrm{CH}), 55.2\left(\mathrm{CH}_{3}\right)$; MS (70 eV, EI) m/z (\%): $239.2(100)\left[\mathrm{M}^{+}\right], 210.2$ (92); IR (KBr): 3404 (br, OH), 2933, 2837, 2120 (NC), 1611, 1585, 1511, 1482, 1451, $1304,1251,1174,1112,1032,811,761 \mathrm{~cm}^{-1}$; elemental analysis calcd (\%) for $\mathrm{C}_{15} \mathrm{H}_{13} \mathrm{NO}_{2}$ : C 75.30, H. 5.48, N 5.85; found: C 74.98, H. 5.18, N 5.55.

\section{(4-Chlorophenyl)(2-isocyanophenyl)methanol (204c)}<smiles>Cc1ccccc1C(O)c1ccc(Cl)cc1</smiles>

The isocyanide $204 \mathrm{c}$ (433 $\mathrm{mg}, 89 \%$ ) was obtained from $o$-bromophenyl isocyanide (159-Br) (364 $\mathrm{mg}, 2 \mathrm{mmol})$ and 4-chlorobenzaldehyde (202c) (281 mg, $2 \mathrm{mmol}$ ) following GP8 (A) and after column chromatography (hexane/ethyl acetate $5: 1, R_{\mathrm{f}}=0.15$ ) as a yellow oil. ${ }^{1} \mathrm{H}$ NMR $\left(300 \mathrm{MHz}, \mathrm{CDCl}_{3}\right): \delta 7.68(\mathrm{~d}, J=7.8 \mathrm{~Hz}, 1 \mathrm{H}, \mathrm{Ar}-\mathrm{H}), 7.45$ $(\mathrm{td}, J=7.0,2.2 \mathrm{~Hz}, 1 \mathrm{H}, \mathrm{Ar}-\mathrm{H}), 7.38-7.29(\mathrm{~m}, 6 \mathrm{H}, \mathrm{Ar}-\mathrm{H}), 6.16(\mathrm{~d}$, $J=2.8 \mathrm{~Hz}, 1 \mathrm{H}, \mathrm{CH}), 2.48(\mathrm{~d}, J=3.4 \mathrm{~Hz}, 1 \mathrm{H}, \mathrm{OH}) ;{ }^{13} \mathrm{C} \mathrm{NMR}\left(75.5 \mathrm{MHz}, \mathrm{CDCl}_{3}\right.$, APT): $\delta 167.8(\mathrm{C}), 140.0(\mathrm{C}), 139.5(\mathrm{C}), 134.0(\mathrm{C}), 129.9(\mathrm{CH}), 128.8(2 \mathrm{CH}), 128.6(\mathrm{CH}), 128.3$ (2 $\mathrm{CH}), 127.1(\mathrm{CH}), 126.9(\mathrm{CH}), 124.4(\mathrm{C}), 71.2 \mathrm{ppm}(\mathrm{CH})$; MS (70 eV, EI) m/z (\%): 243 (56) $\left[\mathrm{M}^{+}\right], 214$ (84), 180 (100), 77(74); IR (film): 3420 (br), 2361, 2339, 2120 (NC), 1491, 1091, 1035, 1014, $761 \mathrm{~cm}^{-1}$; HRMS (EI): calcd for $\mathrm{C}_{14} \mathrm{H}_{11} \mathrm{ClNO}^{+}[\mathrm{M}]^{+}: 244.05237$; found: 244.05243. 


\section{(2-Isocyanophenyl)(pyridin-4-yl)methanol (204d)}

NCH

The isocyanide 204d (344 mg, 82\%) was obtained from $o$-bromophenyl isocyanide (159-Br) (364 mg, $2 \mathrm{mmol})$ and 4-formylpyridine (202d) (214 mg, $2 \mathrm{mmol}$ ) following GP8 (A) and after column chromatography (dichloromethane/methanol $10: 1, R_{\mathrm{f}}=0.18$ ) as a colorless solid, m. p. 139-140 ${ }^{\circ} \mathrm{C} .{ }^{1} \mathrm{H}$ NMR $\left(300 \mathrm{MHz}, \mathrm{CDCl}_{3}\right): \delta 8.38(\mathrm{dd}, J=4.5,1.7 \mathrm{~Hz}$, $2 \mathrm{H}), 7.60(\mathrm{~d}, J=7.8 \mathrm{~Hz}, 1 \mathrm{H}), 7.43(\mathrm{td}, J=7.8,2.2 \mathrm{~Hz}, 1 \mathrm{H}), 7.38-7.29$ (m, $4 \mathrm{H}), 6.18$ (s, $1 \mathrm{H}), 5.42$ (br s, $1 \mathrm{H}) ;{ }^{13} \mathrm{C} \mathrm{NMR}\left(75.5 \mathrm{MHz}, \mathrm{CDCl}_{3}\right.$, APT): $\delta 167.8$ (C), $151.6(2 \mathrm{C}), 149.3(2 \mathrm{CH}), 139.2(\mathrm{C}), 130.1(2 \mathrm{CH}), 128.8(\mathrm{CH}), 127.5(\mathrm{CH}), 127.0(\mathrm{CH})$, $121.6(2 \mathrm{CH}), 69.8(\mathrm{CH})$; MS (70 eV, EI) m/z (\%): $210.2(100)\left[\mathrm{M}^{+}\right], 181.2(58), 132.1$ (34); IR (film): 3037 (br) (OH), 2850 (br), 2123 (NC), 1604, 1416, 1062, 1006, 798, 761 $\mathrm{cm}^{-1}$; elemental analysis calcd (\%) for $\mathrm{C}_{13} \mathrm{H}_{10} \mathrm{~N}_{2} \mathrm{O}: \mathrm{C}$ 74.27, H. 4.79, $\mathrm{N}$ 13.33; found: C 73.97, H 4.64, N 13.19.

\section{(2-Isocyanophenyl)(5-methylthiophen-2-yl)methanol (204e)}

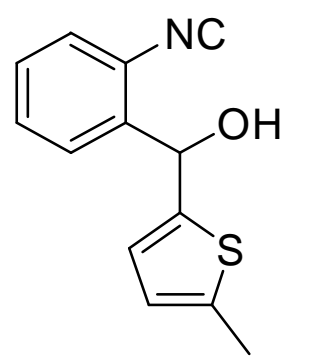

Compound 204e (357 mg, 78\%) was obtained from $o$-bromophenyl isocyanide (159-Br) (364 mg, $2 \mathrm{mmol}$ ) and 2-formyl-5-methylthiophene (202e) (252 mg, $2 \mathrm{mmol})$ following GP8 (A) and after column chromatography (hexane/ethyl acetate $5: 1, R_{\mathrm{f}}=0.24$ ) as a yellow oil. ${ }^{1} \mathrm{H}$ NMR $\left(300 \mathrm{MHz}, \mathrm{CDCl}_{3}\right): \delta 7.82(\mathrm{~d}, J=7.5 \mathrm{~Hz}, 1 \mathrm{H}$, Ar-H), 7.50-7.45 (m, $1 \mathrm{H}, \mathrm{Ar}-\mathrm{H}), 7.36-7.32$ (m, $2 \mathrm{H}, \mathrm{Ar}-\mathrm{H}), 6.80(\mathrm{~d}, J=3.4 \mathrm{~Hz}, 1 \mathrm{H}$, thienyl-H), 6.60-6.57 (m, $1 \mathrm{H}$, thienyl-H), 6.31 (d, $J=3.1 \mathrm{~Hz}, 1 \mathrm{H}, \mathrm{OCH}), 2.53(\mathrm{~d}, J=3.4$ $\mathrm{Hz}, 1 \mathrm{H}, \mathrm{OH}), 2.42 \mathrm{ppm}\left(\mathrm{s}, 3 \mathrm{H}, \mathrm{CH}_{3}\right) ;{ }^{13} \mathrm{C} \mathrm{NMR}\left(75.5 \mathrm{MHz}, \mathrm{CDCl}_{3}, \mathrm{APT}\right): \delta 167.9$ (C), $142.8(2 \mathrm{C}), 141.0(\mathrm{C}), 140.3(\mathrm{C}), 139.4(\mathrm{C}), 129.8(\mathrm{CH}), 128.5(\mathrm{CH}), 126.9(\mathrm{CH}), 126.4$ $(\mathrm{CH}), 126.0(\mathrm{CH}), 124.8(\mathrm{CH}), 68.1(\mathrm{CH}), 15.4 \mathrm{ppm}\left(\mathrm{CH}_{3}\right)$; MS (DCI) m/z (\%): 247.3 (12) $\left[\mathrm{M}+\mathrm{NH}_{4}{ }^{+}\right], 230.2(100)\left[\mathrm{M}+\mathrm{H}^{+}\right]$; IR (KBr): 3403 (br), 2121, 1686, 1482, 1449, 1022, 757 $\mathrm{cm}^{-1}$; HRMS (EI): calcd for $\mathrm{C}_{13} \mathrm{H}_{12} \mathrm{NOS}^{+}[\mathrm{M}+\mathrm{H}]^{+}: 230.06396$; found: 230.06382 . 


\section{(2-Isocyanophenyl)(5-methylfuran-2-yl)methanol (204f)}

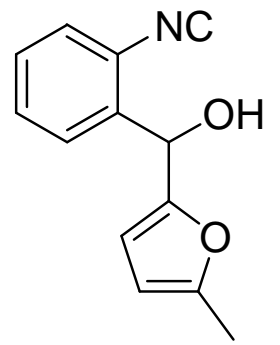

Compound $204 f$ (377 $\mathrm{mg}, 88 \%$ ) was obtained from $o$-bromophenyl isocyanide (159-Br) (364 mg, $2 \mathrm{mmol})$ and 5-methylfuran-2-carbaldehyde (202f) (220 mg, 2 mmol) following GP8 (A) and after column chromatography (hexane/ethyl acetate $5: 1, R_{\mathrm{f}}=0.12$ ) as a yellow oil. ${ }^{1} \mathrm{H}$ NMR (300 MHz, $\left.\mathrm{CDCl}_{3}\right): \delta 7.78(\mathrm{~d}, J=7.9 \mathrm{~Hz}, 1 \mathrm{H}), 7.50-7.44$ (m, $1 \mathrm{H}), 7.37-7.31(\mathrm{~m}, 2 \mathrm{H}), 6.11(\mathrm{~d}, J=3.0 \mathrm{~Hz}, 1 \mathrm{H}), 6.01(\mathrm{~d}, J=3.0 \mathrm{~Hz}, 1 \mathrm{H}), 5.90$ $(\mathrm{dd}, J=3.0,0.8 \mathrm{~Hz}, 1 \mathrm{H}), 2.63(\mathrm{~d}, J=3.8 \mathrm{~Hz}, 1 \mathrm{H}, \mathrm{OH}), 2.26 \mathrm{ppm}\left(\mathrm{s}, 3 \mathrm{H}, \mathrm{CH}_{3}\right)$; ${ }^{13} \mathrm{C}$ NMR $\left(75.5 \mathrm{MHz}, \mathrm{CDCl}_{3}\right): \delta 167.5(\mathrm{C}), 152.9(\mathrm{C}), 151.6(\mathrm{C}), 137.1(\mathrm{C}), 129.6(\mathrm{CH})$, $128.6(\mathrm{CH}), 127.4(\mathrm{CH}), 126.8(\mathrm{CH}), 109.15(\mathrm{C}), 109.20(\mathrm{CH}), 106.3(\mathrm{CH}), 65.9(\mathrm{CH})$, $13.6 \mathrm{ppm}\left(\mathrm{CH}_{3}\right)$; MS (EI) m/z (\%): 213.1 (52) $\left[\mathrm{M}^{+}\right], 184.1$ (38), 170.1 (100); IR (KBr): 3411 (br) (OH), 2121 (NC), 1557, 1449, 1267, 1217, 1200, 1018, 761, $736 \mathrm{~cm}^{-1}$; HRMS (ESI) calcd for $\mathrm{C}_{13} \mathrm{H}_{12} \mathrm{NO}_{2}^{+}\left[\mathrm{M}+\mathrm{H}^{+}\right]$: 214.08626; found: 214.08644.

\section{1-(2-Isocyanophenyl)-2,2-dimethylpropan-1-ol (204g)}<smiles>CC(C)(C)C(O)c1ccccc1[N+](=O)[O-]</smiles>

Compound 204g (303 mg, 80\%) was obtained from $o$-bromophenyl isocyanide (159-Br) (364 mg, $2 \mathrm{mmol}$ ) and 1,1,1-trimethylacetaldehyde (202g) (172 mg, $2 \mathrm{mmol})$ following GP8 (A), after column chromatography (hexane/ethyl acetate $5: 1, R_{\mathrm{f}}=0.25$ ) as a yellow oil. ${ }^{1} \mathrm{H}$ NMR $\left(300 \mathrm{MHz}, \mathrm{CDCl}_{3}\right): \delta 7.60(\mathrm{~d}, J=7.9 \mathrm{~Hz}, 1 \mathrm{H}, \mathrm{Ar}-\mathrm{H}), 7.41$ (t, $J=7.5 \mathrm{~Hz}, 1 \mathrm{H}$, Ar-H), 7.36-7.29 (m, 2 H, Ar-H), 4.95 (d, $J=2.3 \mathrm{~Hz}, 1 \mathrm{H}, \mathrm{CH}), 2.03$ (d, $J=2.6 \mathrm{~Hz}, 1 \mathrm{H}$, $\mathrm{OH}), 0.99 \mathrm{ppm}(\mathrm{s}, 9 \mathrm{H}, t \mathrm{Bu}) ;{ }^{13} \mathrm{C} \mathrm{NMR}\left(75.5 \mathrm{MHz}, \mathrm{CDCl}_{3}, \mathrm{APT}\right): \delta 166.9(\mathrm{C}), 138.7$ (2 C), $128.9(\mathrm{CH}), 128.7(\mathrm{CH}), 128.0(\mathrm{CH}), 126.7(\mathrm{CH}), 76.2(\mathrm{CH}), 37.2(\mathrm{C}), 25.6$ ppm

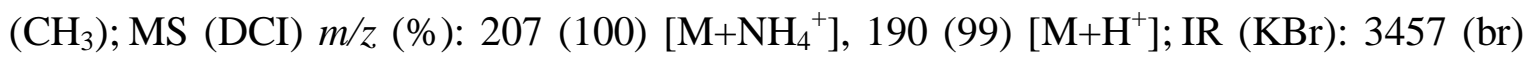
$(\mathrm{OH}), 2963,2121(\mathrm{NC}), 1478,1051,1006,757 \mathrm{~cm}^{-1}$; HRMS (ESI) calcd for $\mathrm{C}_{12} \mathrm{H}_{16} \mathrm{NO}^{+}$ $\left[\mathrm{M}+\mathrm{H}^{+}\right]$: 190.12264; found: 190.12267. 


\section{1-(2-Isocyanophenyl)-2-methylpropan-1-ol (204h)}

NCH

The isocyanide $\mathbf{2 0 4 h}$ (127 mg, 36\%) was obtained from $o$-bromophenyl isocyanide (159-Br) (364 $\mathrm{mg}, 2 \mathrm{mmol})$ and isobutyraldehyde (202h) (144 mg, $2 \mathrm{mmol}$ ) following GP8 (A), after column chromatography (hexane/ethyl acetate $\left.5: 1, R_{\mathrm{f}}=0.15\right)$ as a yellow oil. ${ }^{1} \mathrm{H}$ NMR (300 $\left.\mathrm{MHz}, \mathrm{CDCl}_{3}\right): \delta 7.57(\mathrm{~d}, J=7.9 \mathrm{~Hz}, 1 \mathrm{H}, \mathrm{Ar}-\mathrm{H}), 7.43(\mathrm{td}, J=7.5,1.5 \mathrm{~Hz}, 1 \mathrm{H}, \mathrm{Ar}-\mathrm{H})$, 7.37-7.27 (m, 2 H, Ar-H), 4.88 (dd, $J=6.2,3.6$ Hz, 1 H, Ar-H), 2.09-1.99 (m, 1 H, CH), $1.99(\mathrm{~d}, J=3.8 \mathrm{~Hz}, 1 \mathrm{H}, \mathrm{CHO}), 0.99\left(\mathrm{~d}, J=6.8 \mathrm{~Hz}, 3 \mathrm{H}, \mathrm{CH}_{3}\right), 0.94(\mathrm{~d}, J=6.8 \mathrm{~Hz}, 3 \mathrm{H}$, $\left.\mathrm{CH}_{3}\right) ;{ }^{13} \mathrm{C}$ NMR (75.5 MHz, $\left.\mathrm{CDCl}_{3}, \mathrm{APT}\right): \delta 166.9(\mathrm{C}), 140.2(\mathrm{C}), 129.5(\mathrm{CH}), 128.0$ $(\mathrm{CH}), 127.4(\mathrm{CH}), 126.7(\mathrm{CH}), 109.2(\mathrm{C}), 74.6(\mathrm{CH}), 34.6(\mathrm{CH}), 19.0\left(\mathrm{CH}_{3}\right), 17.2 \mathrm{ppm}$ $\left(\mathrm{CH}_{3}\right.$ ); IR (film): 3432 (br, OH), 2963, 2119 (NC), 1450, 1030, 761; MS (EI) $\mathrm{m} / \mathrm{z}$ (\%): $175.2(5)\left[\mathrm{M}^{+}\right], 132.2(100)$; HRMS (EI): $m / z$ calcd for $\mathrm{C}_{11} \mathrm{H}_{14} \mathrm{NO}^{+}\left[\mathrm{M}+\mathrm{H}^{+}\right]: 176.10699$; found: 176.10709 .

\section{1-(2-Isocyanophenyl)-3-methylbut-2-en-1-ol (204i)}

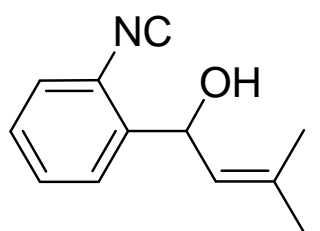

Compound 204i (260 mg, 70\%) was obtained from $o$-bromophenyl isocyanide (159-Br) (364 mg, $2 \mathrm{mmol}$ ) and 3-methylbut-2-enal (202i) (168 mg, $2 \mathrm{mmol}$ ) following GP8 (A) (the aldehyde was added at $-90{ }^{\circ} \mathrm{C}$ ), after column chromatography (hexane/ethyl acetate $5: 1$, $\left.R_{\mathrm{f}}=0.18\right)$ as a yellow oil. ${ }^{1} \mathrm{H} \mathrm{NMR}\left(300 \mathrm{MHz}, \mathrm{CDCl}_{3}\right): \delta 7.68(\mathrm{~d}, J=7.9 \mathrm{~Hz}, 1 \mathrm{H}, \mathrm{Ar}-\mathrm{H})$, 7.43 (dt, $J=7.2,1.5 \mathrm{~Hz}, 1 \mathrm{H}, \mathrm{Ar}-\mathrm{H}), 7.35-7.25$ (m, $2 \mathrm{H}, \mathrm{Ar}-\mathrm{H}), 5.81$ (dd, $J=9.0,2.6 \mathrm{~Hz}$, $1 \mathrm{H}, \mathrm{OCH}), 5.28$ (d, $J=9.8,1 \mathrm{H}, \mathrm{CH}), 1.96(\mathrm{~d}, J=2.6 \mathrm{~Hz}, 1 \mathrm{H}, \mathrm{OH}), 1.92\left(\mathrm{~s}, 3 \mathrm{H}, \mathrm{CH}_{3}\right)$, 1.76 ppm (s, $\left.3 \mathrm{H}, \mathrm{CH}_{3}\right) ;{ }^{13} \mathrm{C} \mathrm{NMR}\left(75.5 \mathrm{MHz}, \mathrm{CDCl}_{3}, \mathrm{APT}\right): \delta 167.0(\mathrm{C}), 140.8(\mathrm{C}), 138.0$ (C), $129.7(\mathrm{CH}), 127.9(\mathrm{CH}), 127.0(\mathrm{CH}), 126.6(\mathrm{CH}), 125.4(\mathrm{CH}), 124.0(\mathrm{C}), 66.9(\mathrm{CH})$, $25.8\left(\mathrm{CH}_{3}\right), 18.8 \mathrm{ppm}\left(\mathrm{CH}_{3}\right)$; MS (EI) m/z (\%): 187.2 (4) $\left[\mathrm{M}^{+}\right], 186.2$ (25), 77.0 (28), 51.0 (100); IR (KBr): 3389 (br) (OH), 2974, 2914, 2119 (NC), 1483, 1450, 1034, 1006, 762 $\mathrm{cm}^{-1}$; HRMS (ESI) calcd for $\mathrm{C}_{12} \mathrm{H}_{13} \mathrm{NONa}^{+}\left[\mathrm{M}+\mathrm{Na}^{+}\right]$: 210.08894; found: 210.08907 . 


\section{4,4-Diphenyl-4H-3,1-benzoxazine (201k)}

$\overbrace{P h}^{O}$

Compound 201k (274 mg, 48\%) was obtained from o-bromophenyl isocyanide (159-Br) (364 $\mathrm{mg}, 2 \mathrm{mmol})$ and benzophenone (202k)

(364 mg, 2 mmol) following GP8 (A) and after column chromatography (hexane/ethyl acetate $4: 1, R_{\mathrm{f}}=0.27$ ) as a colorless solid, m. p. $139{ }^{\circ} \mathrm{C} .{ }^{1} \mathrm{H}$ NMR $(300$ MHz, $\left.\mathrm{CDCl}_{3}\right): \delta 7.36-7.24(\mathrm{~m}, 9 \mathrm{H}), 7.23-7.18(\mathrm{~m}, 4 \mathrm{H}), 7.14(\mathrm{td}, J=7.5,1.6 \mathrm{~Hz}, 1 \mathrm{H})$, $6.69(\mathrm{~d}, J=7.8 \mathrm{~Hz}, 1 \mathrm{H}) ;{ }^{13} \mathrm{C} \mathrm{NMR}\left(75.5 \mathrm{MHz}, \mathrm{CDCl}_{3}, \mathrm{APT}\right): \delta 150.7(\mathrm{CH}), 142.6(2 \mathrm{C})$, 137.7 (C), 129.2 (2 CH), $128.8(\mathrm{C}), 128.3(2 \mathrm{CH}), 128.2(2 \mathrm{CH}), 127.9(4 \mathrm{CH}), 127.1$

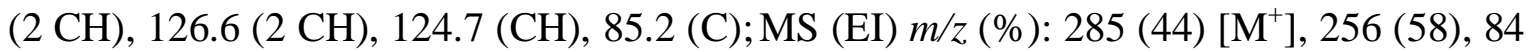
(100); IR (KBr): 1670, 1611, 1595, 1474, 1322, 1289, 1262, 769, $689 \mathrm{~cm}^{-1}$; elemental analysis calcd (\%) for $\mathrm{C}_{20} \mathrm{H}_{15} \mathrm{NO}$ : C 84.19, H 5.30, N 4.91; found: C 83.95, H 5.07, N 5.12.

\section{4-(Trifluoromethyl)-4-phenyl-4H-3,1-benzoxazine (2011)}

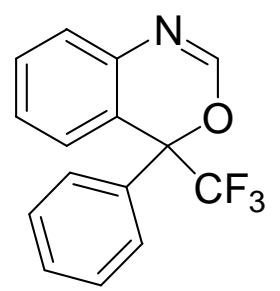

Compound 2011 (403 mg, 78\%) was obtained from o-bromophenyl isocyanide (159-Br) (364 mg, $2 \mathrm{mmol}$ ) and 1,1,1-trifluoroacetophenone (202l) (348 mg, $2 \mathrm{mmol})$ following GP8 (A) after column chromatography (hexane/ethyl acetate $5: 1, R_{\mathrm{f}}=0.46$ ) and Kugelrohr distillation (0.4 Torr, $\left.100-110{ }^{\circ} \mathrm{C}\right)$ as a colorless oil. ${ }^{1} \mathrm{H}$ NMR (300 $\left.\mathrm{MHz}, \mathrm{CDCl}_{3}\right): \delta 7.51-7.48(\mathrm{~m}, 2 \mathrm{H}, \mathrm{Ar}-\mathrm{H}), 7.36-7.34(\mathrm{~m}, 4 \mathrm{H}, \mathrm{Ar}-\mathrm{H}), 7.30-7.20 \mathrm{ppm}$ (m, $4 \mathrm{H}, \mathrm{Ar}-\mathrm{H}) ;{ }^{13} \mathrm{C}$ NMR $\left(75.5 \mathrm{MHz}, \mathrm{CDCl}_{3}\right): \delta 147.5(\mathrm{CH}), 136.8(\mathrm{C}), 136.3(\mathrm{C}), 130.5$ $(\mathrm{CH}), 129.4(\mathrm{CH}), 128.4(2 \mathrm{CH}), 127.5(\mathrm{CH}), 127.3\left(\mathrm{q}, J_{\mathrm{CF}}=1.6 \mathrm{~Hz}, 2 \mathrm{CH}\right), 126.6$ $\left(\mathrm{q}, J_{\mathrm{CF}}=2.2 \mathrm{~Hz}, \mathrm{CH}\right), 126.0(2 \mathrm{CH}), 123.8(\mathrm{q}, J=287 \mathrm{~Hz}, \mathrm{C}), 121.9(\mathrm{C}), 81.2 \mathrm{ppm}(\mathrm{q}$, $J=31 \mathrm{~Hz}, \mathrm{C}$ ); MS (EI) m/z (\%): 277.1 (14) $\left[\mathrm{M}^{+}\right], 208.1$ (100); IR (KBr): 3067 (br), 2362, $1632,1603,1478,1458,1279,1221,1101,985,943,765 \mathrm{~cm}^{-1}$; elemental analysis calcd (\%) for $\mathrm{C}_{15} \mathrm{H}_{10} \mathrm{~F}_{3} \mathrm{NO}$ : C 64.78, H 3.64, N 5.05; found: C 64.98, H 3.57, N 5.39.

\section{4,4-Dimethyl-4H-3,1-benzoxazine (201m)}<smiles>CC1(C)OC=Nc2ccccc21</smiles>

Compound 201m (166 mg, 52\%) was obtained from $o$-bromophenyl isocyanide (159-Br) (364 mg, $2 \mathrm{mmol})$ and acetone (202m) (116 mg, 2 mmol) following GP8 (A) and after column chromatography (hexane/ethyl acetate $5: 1, R_{\mathrm{f}}=0.20$ ) as a colorless oil. ${ }^{1} \mathrm{H}$ NMR $\left(300 \mathrm{MHz}, \mathrm{CDCl}_{3}\right)$ : 
$\delta$ 7.28-7.13 (m, $4 \mathrm{H}, \mathrm{Ar}-\mathrm{H}, \mathrm{CH}=\mathrm{N}), 7.07(\mathrm{~d}, J=7.5 \mathrm{~Hz}, 1 \mathrm{H}, \mathrm{Ar}-\mathrm{H}), 1.64\left(\mathrm{~s}, 6 \mathrm{H}, \mathrm{CH}_{3}\right)$ ppm; ${ }^{13} \mathrm{C}$ NMR (75.5 MHz, $\mathrm{CDCl}_{3}$, APT): $\delta 150.8(\mathrm{CH}), 136.5(\mathrm{C}), 131.7$ (C), 128.4 $(\mathrm{CH}), 127.1(\mathrm{CH}), 124.8(\mathrm{CH}), 122.5(\mathrm{CH}), 77.8(\mathrm{C}), 29.1\left(\mathrm{CH}_{3}\right)$; MS (EI) $m / z(\%): 161.2$ (24), 146.2 (100); IR (film): 2980, 1621, 1485, 1452, 1366, 1227, 1133, 1105, 1080, 768 $\mathrm{cm}^{-1}$; HRMS (EI): $\mathrm{m} / z$ calcd for $\mathrm{C}_{10} \mathrm{H}_{11} \mathrm{NO}^{+}\left[\mathrm{M}^{+}\right]$: 161.0841 ; found: 161.0840 .

\section{(2-Isocyanophenyl)(pyridin-4-yl)methyl methyl carbonate (205)}<smiles></smiles>

Compound 205 (301 $\mathrm{mg}$, 56\%) was obtained from $o$-bromophenyl isocyanide (159-Br) (376 $\mathrm{mg}, 2 \mathrm{mmol})$, 4-formylpyridine (202d) (214 $\mathrm{mg}, 2 \mathrm{mmol})$ and methyl chloroformate (189 mg, $2 \mathrm{mmol}$ ) following GP8 (C), and after column chromatography on silica gel (hexane/ethyl acetate $1: 1$, $\left.R_{\mathrm{f}}=0.33\right)$ as a yellow oil. ${ }^{1} \mathrm{H} \mathrm{NMR}\left(300 \mathrm{MHz}, \mathrm{CDCl}_{3}\right): \delta 8.62(\mathrm{dd}, J=4.4,1.6 \mathrm{~Hz}, 2 \mathrm{H}$, Ar-H), 7.52-7.39 (m, 4 H, Ar-H), 7.34 (dd, J= 4.4, 1.6 Hz, 2 H, Ar-H), 6.97 (s, 1 H, CH), 3.83 ppm (s, $\left.3 \mathrm{H}, \mathrm{CH}_{3}\right) ;{ }^{13} \mathrm{C}$ NMR $\left(75.5 \mathrm{MHz}, \mathrm{CDCl}_{3}\right): \delta 169.3(\mathrm{C}), 154.4(\mathrm{C}), 150.3$ $(2 \mathrm{CH}), 146.1(\mathrm{C}), 134.7(\mathrm{C}), 130.0(\mathrm{CH}), 129.7(\mathrm{CH}), 127.5(2 \mathrm{CH}), 124.7(\mathrm{C}), 121.4$ $(2 \mathrm{CH}), 74.9(\mathrm{CH}), 55.5$ ppm $\left(\mathrm{CH}_{3}\right)$; MS (EI) $m / z(\%): 268.2$ (48) $\left[\mathrm{M}^{+}\right], 209.1$ (100); IR (KBr): 3032, 2958, 2120 (NC), 1751, 1599, 1441, 1259, 984, 950, $764 \mathrm{~cm}^{-1}$; HRMS (ESI) calcd for $\mathrm{C}_{15} \mathrm{H}_{13} \mathrm{~N}_{2} \mathrm{O}_{3}{ }^{+}\left[\mathrm{M}+\mathrm{H}^{+}\right]$: 269.09262; found: 269.09268 .

\section{3-(Trifluoromethyl)-3-methylisobenzofuran-1(3H)-imine (210o)}<smiles>CC1(C)OC(=N)c2ccccc21</smiles>

The compound $210 \mathrm{o}$ ( $250 \mathrm{mg}, 58 \%$ ) was obtained from $o$-bromophenyl isocyanide (159-Br) (364 mg, $2 \mathrm{mmol})$ and 1,1,1-trifluoroacetone (2020) (224 mg, $2 \mathrm{mmol}$ ) following GP8 (B) and after Kugelrohr distillation (0.1 Torr, 85-95 ${ }^{\circ} \mathrm{C}$ ) as a colorless oil. ${ }^{1} \mathrm{H}$ NMR $\left(300 \mathrm{MHz}, \mathrm{CDCl}_{3}\right)$ : $\delta 7.39(\mathrm{td}, J=7.2,1.9 \mathrm{~Hz}, 1 \mathrm{H}, \mathrm{Ar}-\mathrm{H}), 7.30-7.21(\mathrm{~m}, 3 \mathrm{H}, \mathrm{Ar}-\mathrm{H}), 7.15$ (s, $1 \mathrm{H}, \mathrm{NH}), 1.87$ $\left(\mathrm{s}, 3 \mathrm{H}, \mathrm{CH}_{3}\right) ;{ }^{13} \mathrm{C} \mathrm{NMR}\left(125 \mathrm{MHz}, \mathrm{CDCl}_{3}, \mathrm{APT}\right): \delta 148.4(\mathrm{C}), 136.7(\mathrm{C}), 130.7(\mathrm{CH})$, $127.9(\mathrm{CH}), 125.8(\mathrm{CH}), 125.3(\mathrm{CH}), 124.1\left(\mathrm{q}, J_{C F}=287 \mathrm{~Hz}, \mathrm{C}\right), 121.4(\mathrm{C}), 77.2$ $\left(\mathrm{q}, J_{C F}^{2}=31 \mathrm{~Hz}, \mathrm{C}\right), 22.0 \mathrm{ppm}\left(\mathrm{CH}_{3}\right) ; \mathrm{MS}(\mathrm{EI}) \mathrm{m} / z(\%): 215.0$ (39) $\left[\mathrm{M}^{+}\right], 146.0$ (100); IR (KBr): 3304 (br) (NH), 1676, 1636, 1456, 1295, 1225, 1179, 1096, $769 \mathrm{~cm}^{-1}$; elemental analysis calcd (\%) for $\mathrm{C}_{10} \mathrm{H}_{8} \mathrm{~F}_{3} \mathrm{NO}$ : C 55.82, $\mathrm{H} \mathrm{3.75,} \mathrm{N} \mathrm{6.51;} \mathrm{found:} \mathrm{C} \mathrm{55.74,} \mathrm{H} \mathrm{3.51,}$ N 6.30. 


\section{Methyl 4-(Trifluoromethyl)-4-phenyl-4H-3,1-benzoxazine-2-carboxylate $\left(2011-\mathrm{CO}_{2} \mathrm{Me}\right)$}<smiles>COC(OC)C1=Nc2ccccc2C(C)(c2ccccc2)O1</smiles>

Compound 2011-CO $\mathrm{CO}_{2} \mathrm{Me}(302 \mathrm{mg}, 45 \%)$ was obtained from o-bromophenyl isocyanide (159-Br) (376 $\mathrm{mg}, 2 \mathrm{mmol})$, 1,1,1-trifluoroacetophenone (202l) (348 $\mathrm{mg}, 2 \mathrm{mmol})$ and methyl chloroformate (189 mg, $2 \mathrm{mmol}$ ) following GP8 (C), and after column chromatography on silica gel (hexane/ethyl acetate $4: 1, R_{\mathrm{f}}=0.26$ ) as a yellow oil. ${ }^{1} \mathrm{H}$ NMR (300 MHz, $\left.\mathrm{CDCl}_{3}\right): \delta 7.50(\mathrm{~m}, 4 \mathrm{H}, \mathrm{Ar}-\mathrm{H}), 7.39(\mathrm{~m}, 5 \mathrm{H}, \mathrm{Ar}-\mathrm{H}), 3.98 \mathrm{ppm}\left(\mathrm{s}, 3 \mathrm{H}, \mathrm{CH}_{3}\right) ;{ }^{13} \mathrm{C} \mathrm{NMR}$ (125 MHz, $\mathrm{CDCl}_{3}$, APT): $\delta 159.3$ (C), 145.6 (C), 137.0 (C), 135.0 (C), 130.7 (CH), 129.7 $(\mathrm{CH}), 129.3(\mathrm{CH}), 128.4(\mathrm{CH}), 127.4(\mathrm{CH}), 127.3(\mathrm{CH}), 126.1(\mathrm{q}, J=2.3 \mathrm{~Hz}, \mathrm{CH}), 123.4$ $(\mathrm{q}, J=285.4 \mathrm{~Hz}, \mathrm{C}), 121.1(\mathrm{C}), 83.0(\mathrm{q}, J=30.8 \mathrm{~Hz}, \mathrm{C}), 53.8 \mathrm{ppm}\left(\mathrm{CH}_{3}\right) ; \mathrm{MS}(\mathrm{EI}) \mathrm{m} / z$ (\%): 335 (16) $\left[\mathrm{M}^{+}\right], 266$ (88), 43 (100); IR (KBr): 2955, 1745, 1647, 1601, 1327, 1293, 1211, 1180, 990, 767, $702 \mathrm{~cm}^{-1}$; HRMS (ESI) calcd for $\mathrm{C}_{17} \mathrm{H}_{12} \mathrm{NF}_{3} \mathrm{O}_{3} \mathrm{Na}^{+}\left[\mathrm{M}+\mathrm{Na}^{+}\right]$: 358.0661; found: 358.0666 .

\section{Ethyl 2-(4-(Trifluoromethyl)-4-phenyl-4H-3,1-benzoxazin-2-yl)acetate (201I- $\mathrm{CH}_{2} \mathrm{CO}_{2} \mathrm{Et}$ )}

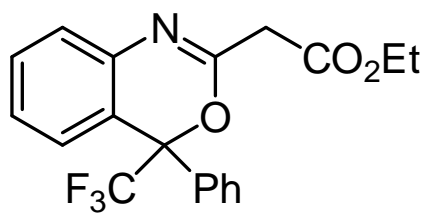

Compound 2011- $\mathrm{CH}_{2} \mathrm{CO}_{2} \mathrm{Et}$ (338 mg, 47\%) was obtained from $o$-bromophenyl isocyanide (159-Br) $(376 \mathrm{mg}, 2 \mathrm{mmol})$ and 1,1,1-trifluoroacetophenone (202l) $\quad(348 \quad \mathrm{mg}, \quad 2 \mathrm{mmol})$ following GP8 (C) and after column chromatography on silica gel (hexane/ethyl acetate $\left.5: 1, R_{\mathrm{f}}=0.20\right)$ as a colorless solid, m.p. 56-57 ${ }^{\circ} \mathrm{C}$. ${ }^{1} \mathrm{H}$ NMR $\left(300 \mathrm{MHz}, \mathrm{CDCl}_{3}\right)$ :

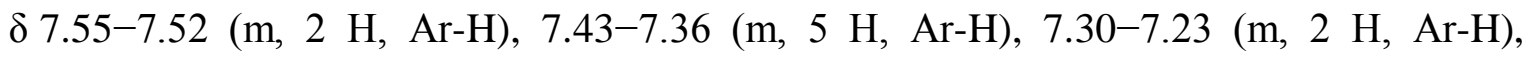
4.19-3.95 (m, $4 \mathrm{H}, \mathrm{CH}_{2}$ ), 1.73 ppm (s, $\left.3 \mathrm{H}, \mathrm{CH}_{3}\right) ;{ }^{13} \mathrm{C} \mathrm{NMR}\left(125 \mathrm{MHz}, \mathrm{CDCl}_{3}, \mathrm{APT}\right)$ : $\delta 157.0(\mathrm{C}), 137.7(\mathrm{C}), 136.2(\mathrm{C}), 130.5(2 \mathrm{CH}), 129.5(\mathrm{CH}), 128.4(2 \mathrm{CH}), 127.54(\mathrm{CH})$, $127.45(\mathrm{CH}), 126.5(\mathrm{CH}), 126.4(\mathrm{CH}), 123.9$ (q, $\left.J_{C F}=287 \mathrm{~Hz}, \mathrm{C}\right), 120.4(\mathrm{C}), 105.8(\mathrm{C})$, $82.0\left(\mathrm{q}, J_{C F}^{2}=31 \mathrm{~Hz}, \mathrm{C}\right), 65.8\left(\mathrm{CH}_{2}\right), 65.4\left(\mathrm{CH}_{2}\right), 22.3 \mathrm{ppm}\left(\mathrm{CH}_{3}\right) ; \mathrm{MS}(\mathrm{EI}) \mathrm{m} / \mathrm{z}(\%)$ : 363.2 (16) $\left[\mathrm{M}^{+}\right], 320.2$ (44), 87.1 (100); IR (KBr): 2991, 2911, 1657, 1484, 1454, 1247, 1181, 1165, 1119, 1028, 949, $777 \mathrm{~cm}^{-1}$; HRMS (ESI) calcd for $\mathrm{C}_{19} \mathrm{H}_{17} \mathrm{~F}_{3} \mathrm{NO}_{3}{ }^{+}\left[\mathrm{M}+\mathrm{H}^{+}\right]$: 364.11550; found: 364.11561 . 


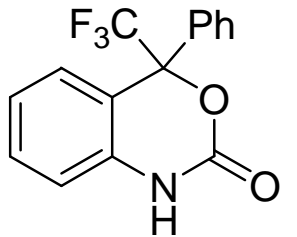

Compound 206 (450 mg, 77\%) was obtained from o-bromophenyl isocyanide (159-Br) (376 mg, $2 \mathrm{mmol}$ ), 1,1,1-trifluoroacetophenone (202l) (348 mg, $2 \mathrm{mmol}$ ) and iodine (508 $\mathrm{mg}, 2 \mathrm{mmol}$ ) following GP8

(C) and after column chromatography on silica gel (hexane/ethyl acetate $\left.5: 1, R_{\mathrm{f}}=0.12\right)$ as a colorless solid, m.p. $158-159{ }^{\circ} \mathrm{C} .{ }^{1} \mathrm{H}$ NMR $(300 \mathrm{MHz}$, $\left.\mathrm{CDCl}_{3}\right): \delta 9.49(\mathrm{~s}, 1 \mathrm{H}, \mathrm{NH}), 7.50-7.34(\mathrm{~m}, 7 \mathrm{H}, \mathrm{Ar}-\mathrm{H}), 7.19(\mathrm{dt}, J=7.9,1.1 \mathrm{~Hz}, 1 \mathrm{H}$, Ar-H), $6.98 \mathrm{ppm}(\mathrm{d}, J=8.3 \mathrm{~Hz}, 1 \mathrm{H}, \mathrm{Ar}-\mathrm{H}) ;{ }^{13} \mathrm{C} \mathrm{NMR}\left(75.5 \mathrm{MHz}, \mathrm{CDCl}_{3}, \mathrm{APT}\right): \delta 150.7$ (C), $135.0(\mathrm{C}), 134.3(\mathrm{C}), 130.7(\mathrm{CH}), 129.9(\mathrm{CH}), 128.6(2 \mathrm{CH}), 127.4(2 \mathrm{CH}), 126.1$ $\left(\mathrm{q}, J_{C F}=2.8 \mathrm{~Hz}, \mathrm{CH}\right), 123.7(\mathrm{CH}), 123.2\left(\mathrm{q}, J_{C F}=285 \mathrm{~Hz}, \mathrm{C}\right), 116.8(\mathrm{C}), 115.7(\mathrm{CH})$, $85.5 \mathrm{ppm}\left(\mathrm{q}, J^{2}{ }_{C F}=31.4 \mathrm{~Hz}, \mathrm{C}\right) ; \mathrm{MS}(\mathrm{DCI}) \mathrm{m} / z(\%): 604.4(60)\left[2 \mathrm{M}+\mathrm{Na}^{+}\right], 328.2(88)$ $\left[\mathrm{M}+\mathrm{NH}_{3}+\mathrm{NH}_{4}^{+}\right], 311.2(100)\left[\mathrm{M}+\mathrm{NH}_{4}^{+}\right]$; IR $(\mathrm{KBr}): 3100(\mathrm{NH}), 1724(\mathrm{C}=\mathrm{O}), 1599,1498$, 1365, 1283, 1174, 1057, 984, 790, 764, $722 \mathrm{~cm}^{-1}$; elemental analysis calcd (\%) for $\mathrm{C}_{15} \mathrm{H}_{10} \mathrm{~F}_{3} \mathrm{NO}_{2}$ : C 61.44, H 3.44, N 4.78; found: C 61.16, H 3.17, N 5.02.

\section{4-(Trifluoromethyl)-2-morpholino-4-phenyl-4H-3,1-benzoxazine (207)}

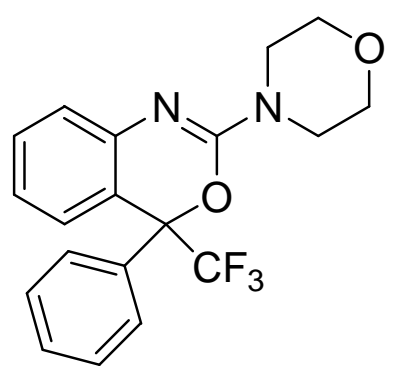

Compound 207 (395 $\mathrm{mg}, \quad 55 \%$ ) was obtained from o-bromophenyl isocyanide (159-Br) (376 $\mathrm{mg}, 2 \mathrm{mmol})$, 1,1,1-trifluoroacetophenone (202l) (348 $\mathrm{mg}, 2 \mathrm{mmol})$ and iodine (508 mg, $2 \mathrm{mmol}$ ) following GP8 (C) [morpholine (348 mg, 4 mmol) was added, and the mixture was stirred at r.t. for $1 \mathrm{~h}$ before aqueous work up] and after column chromatography on silica gel (hexane/ethyl acetate $2: 1, R_{\mathrm{f}}=0.30$ ) as a colorless solid, m.p. $106-107{ }^{\circ} \mathrm{C}$. ${ }^{1} \mathrm{H}$ NMR $\left(300 \mathrm{MHz}, \mathrm{CDCl}_{3}\right): \delta 7.41-7.34(\mathrm{~m}, 5 \mathrm{H}, \mathrm{Ar}-\mathrm{H}), 7.32(\mathrm{dt}, J=7.8,1.6 \mathrm{~Hz}, 1 \mathrm{H}$, Ar-H), 7.26-7.23 (m, $1 \mathrm{H}, \mathrm{Ar}-\mathrm{H}), 7.05$ (d, $J=7.8 \mathrm{~Hz}, 1 \mathrm{H}, \mathrm{Ar}-\mathrm{H}), 7.04$ (dt, $J=6.9,1.3$ $\mathrm{Hz}, 1 \mathrm{H}, \mathrm{Ar}-\mathrm{H}), 3.75-3.65 \mathrm{ppm}\left(\mathrm{m}, 8 \mathrm{H}, \mathrm{CH}_{2}\right) ;{ }^{13} \mathrm{C} \mathrm{NMR}\left(75.5 \mathrm{MHz}, \mathrm{CDCl}_{3}, \mathrm{APT}\right)$ :

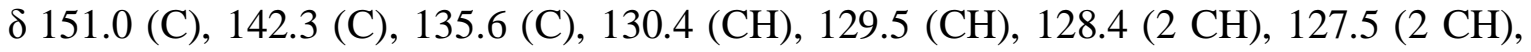
$125.9(\mathrm{C}), 125.5\left(\mathrm{q}, J_{C F}=2.3 \mathrm{~Hz}, \mathrm{CH}\right), 123.3(\mathrm{CH}), 122.6(\mathrm{CH}), 122.1(\mathrm{C}), 118.7(\mathrm{C})$, $66.5\left(\mathrm{CH}_{2}\right), 44.6 \mathrm{ppm}\left(\mathrm{CH}_{2}\right)$; MS (DCI) $\mathrm{m} / z(\%): 363.3(100)\left[\mathrm{M}+\mathrm{H}^{+}\right]$; IR (KBr): 2862, 1634, 1592, 1483, 1426, 1290, 1254, 1168, 1118, 1072, 1029, 988, 924, 862, 766, 719, $653 \mathrm{~cm}^{-1}$; elemental analysis calcd (\%) for $\mathrm{C}_{19} \mathrm{H}_{17} \mathrm{~F}_{3} \mathrm{~N}_{2} \mathrm{O}_{2}$ : C 62.98, H 4.73, N 7.73; found: C 62.66, H 4.53, N 7.90 


\section{General Procedure for the $\mathrm{Cu}_{2} \mathrm{O}$-Catalyzed Cyclization of (2-Isocyanophenyl)methanols 204 (GP9)}

To a solution of isocyanobenzylalcohol $204(2 \mathrm{mmol})$ in benzene $(10 \mathrm{~mL})$ was added $\mathrm{Cu}_{2} \mathrm{O}$ (14.4 mg, $5 \mathrm{~mol} \%$ ), and the resulting mixture was heated under reflux for $1 \mathrm{~h}$. Then, the mixture was cooled to r.t., the solvent was removed under reduced pressure, and the product was purified by column chromatography on silica gel.

\section{4-Phenyl-4H-3,1-benzoxazine (201a)}

Compound 201a $(301 \mathrm{mg}, \quad 86 \%)$ was obtained from
isocyanobenzylalcohol 204a $(350 \mathrm{mg}, 1.67 \mathrm{mmol})$ following GP9, and $\left.5: 1: 1, R_{\mathrm{f}}=0.38\right)$ as a slightly yellow solid, m.p. $62-63{ }^{\circ} \mathrm{C} .{ }^{1} \mathrm{H}$ NMR (300 MHz, $\left.\mathrm{CDCl}_{3}\right): \delta$ 7.40-7.22 (m, $\left.7 \mathrm{H}, \mathrm{Ar}-\mathrm{H}\right), 7.19(\mathrm{~s}, 1 \mathrm{H}, \mathrm{CH}=\mathrm{N}), 7.12(\mathrm{dt}, J=7.5$, $1.5 \mathrm{~Hz}, 1 \mathrm{H}, \mathrm{Ar}-\mathrm{H}), 6.73(\mathrm{~d}, J=7.5 \mathrm{~Hz}, 1 \mathrm{H}, \mathrm{Ar}-\mathrm{H}), 6.29 \mathrm{ppm}(\mathrm{s}, 1 \mathrm{H}, \mathrm{CH}) ;{ }^{13} \mathrm{C} \mathrm{NMR}$ (75.5 MHz, $\left.\mathrm{CDCl}_{3}\right): \delta 150.4(\mathrm{CH}), 139.8(\mathrm{C}), 137.1(\mathrm{C}), 129.1(\mathrm{CH}), 129.0(\mathrm{CH}), 128.7$ $(\mathrm{CH}), 127.8(\mathrm{CH}), 127.1(\mathrm{CH}), 125.5(\mathrm{CH}), 125.3(\mathrm{C}), 124.8(\mathrm{CH}), 77.4$ ppm $(\mathrm{CH})$; MS (EI) $m / z(\%): 209.0(56)\left[\mathrm{M}^{+}\right], 180.0$ (100); IR (KBr): 1612, 1601, 1489, 1455, 1219, 1125, 1096, $773 \mathrm{~cm}^{-1}$; elemental analysis calcd $(\%)$ for $\mathrm{C}_{14} \mathrm{H}_{11} \mathrm{NO}$ : C 80.36, H 5.30, N 6.69; found: C 80.71, H 5.19, N 6.88.

\section{4-(4-Methoxyphenyl)-4H-3,1-benzoxazine (201b)}<smiles>COc1ccc(C2OC=Nc3ccccc32)cc1</smiles>

Compound 201b (222 $\mathrm{mg}, \quad 74 \%)$ was obtained from isocyanobenzylalcohol $\mathbf{2 0 4 b}$ (300 $\mathrm{mg}, 1.26 \mathrm{mmol}$ ) following GP9, and after column chromatography on silica gel (hexane/ethyl acetate/ $\mathrm{Et}_{3} \mathrm{~N}$ $\left.5: 1: 1, R_{\mathrm{f}}=0.29\right)$ as a yellow oil. ${ }^{1} \mathrm{H} \mathrm{NMR}\left(300 \mathrm{MHz}, \mathrm{CDCl}_{3}\right)$ : $\delta$ 7.32-7.22 (m, $4 \mathrm{H}, \mathrm{Ar}-\mathrm{H}), 7.17(\mathrm{~s}, 1 \mathrm{H}, \mathrm{CH}=\mathrm{N}), 7.13(\mathrm{dt}, J=7.5,1.5$ $\mathrm{Hz}, 1 \mathrm{H}, \mathrm{Ar}-\mathrm{H}), 6.90(\mathrm{~d}, J=8.7 \mathrm{~Hz}, 2 \mathrm{H}, \mathrm{Ar}-\mathrm{H}), 6.73$ (d, J=7.5 Hz, $1 \mathrm{H}$, Ar-H), 6.26 (s, $1 \mathrm{H}, \mathrm{CH}), 3.80 \mathrm{ppm}\left(\mathrm{s}, 3 \mathrm{H}, \mathrm{CH}_{3}\right) ;{ }^{13} \mathrm{C} \mathrm{NMR}\left(75.5 \mathrm{MHz}, \mathrm{CDCl}_{3}\right): \delta 160.1$ (C), $150.5(\mathrm{CH}), 137.3(\mathrm{C}), 132.1(\mathrm{C}), 129.4(2 \mathrm{CH}), 129.0(\mathrm{CH}), 127.1(\mathrm{CH}), 125.5(\mathrm{CH})$, $125.5(\mathrm{C}), 124.7(\mathrm{CH}), 114.1(2 \mathrm{CH}), 77.1(\mathrm{CH}), 55.3 \mathrm{ppm}\left(\mathrm{CH}_{3}\right)$; $\mathrm{MS}(\mathrm{EI}) \mathrm{m} / z(\%): 239.0$ (100) $\left[\mathrm{M}^{+}\right], 210.0$ (99); IR (KBr): 2957, 2933, 1605, 1510, 1455, 1250, 1175, 1122, 1092, 
1032, 827, $770 \mathrm{~cm}^{-1}$; HRMS (ESI) calcd for $\mathrm{C}_{15} \mathrm{H}_{14} \mathrm{NO}_{2}{ }^{+}\left[\mathrm{M}+\mathrm{H}^{+}\right]$: 240.10191; found: 240.10206.

\section{4-(4-Chlorophenyl)-4H-3,1-benzoxazine (201c)}<smiles>Clc1ccc(C2OC=Nc3ccccc32)cc1</smiles>

Compound 201c (331 $\mathrm{mg}, \quad 75 \%)$ was obtained from isocyanobenzylalcohol 204c (443 $\mathrm{mg}, 1.82 \mathrm{mmol}$ ) following GP9, and after column chromatography on silica gel (hexane/ethyl acetate/Et ${ }_{3} \mathrm{~N}$ $\left.5: 1: 1, R_{\mathrm{f}}=0.40\right)$ as a yellow oil. ${ }^{1} \mathrm{H} \mathrm{NMR}\left(300 \mathrm{MHz}, \mathrm{CDCl}_{3}\right)$ : 7.37-7.22 (m, 6 H, Ar-H), $7.18(\mathrm{~s}, 1 \mathrm{H}, \mathrm{CH}=\mathrm{N}), 7.14$ (dt, $J=7.5,1.5 \mathrm{~Hz}$, $1 \mathrm{H}, \operatorname{Ar}-\mathrm{H}), 6.72(\mathrm{~d}, J=7.5 \mathrm{~Hz}, 2 \mathrm{H}, \mathrm{Ar}-\mathrm{H}), 6.27 \mathrm{ppm}(\mathrm{s}, 1 \mathrm{H}, \mathrm{CH})$; ${ }^{13} \mathrm{C}$ NMR (75.5 MHz, $\left.\mathrm{CDCl}_{3}\right): \delta 150.1(\mathrm{CH}), 138.2(\mathrm{C}), 137.0(\mathrm{C}), 135.0(\mathrm{C}), 129.3(\mathrm{CH})$, $129.2(2 \mathrm{CH}), 129.0(2 \mathrm{CH}), 127.3(\mathrm{CH}), 125.4(\mathrm{CH}), 125.0(\mathrm{CH}), 124.8(\mathrm{C}), 76.6 \mathrm{ppm}$

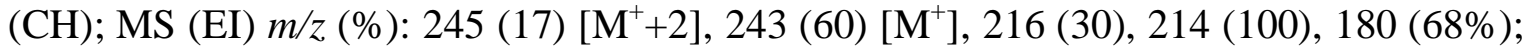
IR (KBr): 3051, 1610, 1485, 1457, 1215, 1120, 1085, 1016, 832, $770 \mathrm{~cm}^{-1}$; HRMS (ESI) calcd for $\mathrm{C}_{14} \mathrm{H}_{11} \mathrm{NOCl}^{+}\left[\mathrm{M}+\mathrm{H}^{+}\right]$: 244.05237; found: 244.05252 .

\section{4-(Pyridin-4-yl)-4H-3,1-benzoxazine (201d)}<smiles>C1=Nc2ccccc2C(c2ccncc2)O1</smiles>

Compound 201d (252 $\mathrm{mg}, 73 \%)$ was obtained from isocyanobenzylalcohol 204d (346 mg, $1.20 \mathrm{mmol}$ ) following GP9, and after column chromatography on silica gel (ethyl acetate/Et ${ }_{3} \mathrm{~N} 20: 1$, $\left.R_{\mathrm{f}}=0.40\right)$ as a colorless solid, m.p. $76-77{ }^{\circ} \mathrm{C}{ }^{1} \mathrm{H}$ NMR $(300 \mathrm{MHz}$, $\left.\mathrm{CDCl}_{3}\right): \delta 8.64(\mathrm{dd}, J=4.1,1.5 \mathrm{~Hz}, 2 \mathrm{H}, \mathrm{Ar}-\mathrm{H}), 7.34(\mathrm{dt}, J=7.9,1.5 \mathrm{~Hz}$, $1 \mathrm{H}, \mathrm{Ar}-\mathrm{H}), 7.27-7.24$ (m, $4 \mathrm{H}, \mathrm{Ar}-\mathrm{H}, \mathrm{CH}=\mathrm{N}), 7.19$ (dt, $J=7.5,1.5 \mathrm{~Hz}, 1 \mathrm{H}, \mathrm{Ar}-\mathrm{H}), 6.79$ $(\mathrm{d}, J=7.5 \mathrm{~Hz}, 1 \mathrm{H}, \mathrm{Ar}-\mathrm{H}), 6.27 \mathrm{ppm}(\mathrm{s}, 1 \mathrm{H}, \mathrm{CH}) ;{ }^{13} \mathrm{C} \mathrm{NMR}\left(75.5 \mathrm{MHz}, \mathrm{CDCl}_{3}\right): \delta 150.3$ $(2 \mathrm{CH}), 149.8(\mathrm{CH}), 147.8(\mathrm{C}), 136.7(\mathrm{C}), 129.6(\mathrm{CH}), 127.4(\mathrm{CH}), 125.1(\mathrm{CH}), 123.6(\mathrm{C})$, 121.9 (2 CH), 75.6 ppm (CH); MS (EI) m/z (\%): 210 (90) $\left[\mathrm{M}^{+}\right], 181$ (100), 132 (28); IR (KBr): 1612, 1557, 1485, 1452, 1411, 1393, 1326, 1268, 1220, 1130, 1098, 960, 918 , 834, 784, 650, $605 \mathrm{~cm}^{-1}$; elemental analysis calcd (\%) for $\mathrm{C}_{13} \mathrm{H}_{10} \mathrm{~N}_{2} \mathrm{O}: \mathrm{C} 74.27, \mathrm{H} 4.79$; found: C 74.26, H 4.98 . 


\section{4-tert-Butyl-4H-3,1-benzoxazine (201g)}

Compound $\mathbf{2 0 1 g}(152 \mathrm{mg}, \quad 83 \%)$ was obtained from
isocyanobenzylalcohol $\mathbf{2 0 4 g}(184 \mathrm{mg}, 0.97 \mathrm{mmol})$ following GP9, and
after column chromatography on silica gel (hexane/Et $\left.3 \mathrm{~N} 10: 1, R_{\mathrm{f}}=0.36\right)$
as a colorless oil. Alternatively, $\mathbf{2 0 1 g}$ was obtained with $\mathrm{KO} t \mathrm{Bu}$ as a catalyst: To the solution of $\mathbf{2 0 4} \mathbf{g}(100 \mathrm{mg}, 0.53 \mathrm{mmol})$ in dichloromethane $(5 \mathrm{~mL})$ was added at r.t. $\mathrm{KO} t \mathrm{Bu}(12 \mathrm{mg}, 0.11 \mathrm{mmol})$. The mixture was stirred for $2 \mathrm{~h}$, diluted with dichloromethane $(20 \mathrm{~mL})$, washed with water $(2 \times 5 \mathrm{~mL})$, the organic phase was dried over $\mathrm{Na}_{2} \mathrm{SO}_{4}$, filtrated and concentrated under reduced pressure to give a crude product, which was purified by column chromatography on silica gel (hexane/Et $3 \mathrm{~N} 10: 1$, $\left.R_{\mathrm{f}}=0.36\right)$ to give $65 \mathrm{mg}(65 \%)$ of $\mathbf{2 0 1 g}$ as a colorless oil. ${ }^{1} \mathrm{H}$ NMR (300 $\left.\mathrm{MHz}, \mathrm{CDCl}_{3}\right)$ : $\delta 7.28(\mathrm{dt}, J=7.5,2.3 \mathrm{~Hz}, 1 \mathrm{H}, \mathrm{Ar}-\mathrm{H}), 7.21$ (s, $1 \mathrm{H}, \mathrm{CH}=\mathrm{N}), 7.18-7.13$ (m, $2 \mathrm{H}, \mathrm{Ar}-\mathrm{H})$, $7.90(\mathrm{~d}, J=7.5 \mathrm{~Hz}, 1 \mathrm{H}, \mathrm{Ar}-\mathrm{H}), 4.92(\mathrm{~s}, 1 \mathrm{H}, \mathrm{CH}), 0.97 \mathrm{ppm}(\mathrm{s}, 9 \mathrm{H}, t \mathrm{Bu}) ;{ }^{13} \mathrm{C} \mathrm{NMR}(75.5$ $\left.\mathrm{MHz}, \mathrm{CDCl}_{3}, \mathrm{APT}\right): \delta 151.5(\mathrm{CH}), 138.1(\mathrm{C}), 128.8(\mathrm{CH}), 126.7(\mathrm{CH}), 126.0(\mathrm{CH}), 124.5$ $(\mathrm{CH}), 122.8(\mathrm{C}), 83.7(\mathrm{CH}), 38.8(\mathrm{C}), 25.1 \mathrm{ppm}\left(\mathrm{CH}_{3}\right)$; MS (DCI) m/z (\%): 207.2 (4) $\left[\mathrm{M}+\mathrm{NH}_{4}{ }^{+}\right], 189.2(14)\left[\mathrm{M}^{+}\right], 132.1$ (100), 122.1 (26); IR (KBr): 3281, 2957, 1695, 1621, 1479, 1218, 1124, 1098, $767 \mathrm{~cm}^{-1}$; HRMS (ESI) calcd for $\mathrm{C}_{12} \mathrm{H}_{16} \mathrm{NO}^{+}\left[\mathrm{M}+\mathrm{H}^{+}\right]$: 190.12264; found: 190.12263 .

\section{3-(5-Methylfuran-2-yl)isobenzofuran-1(3H)-imine (210f)}

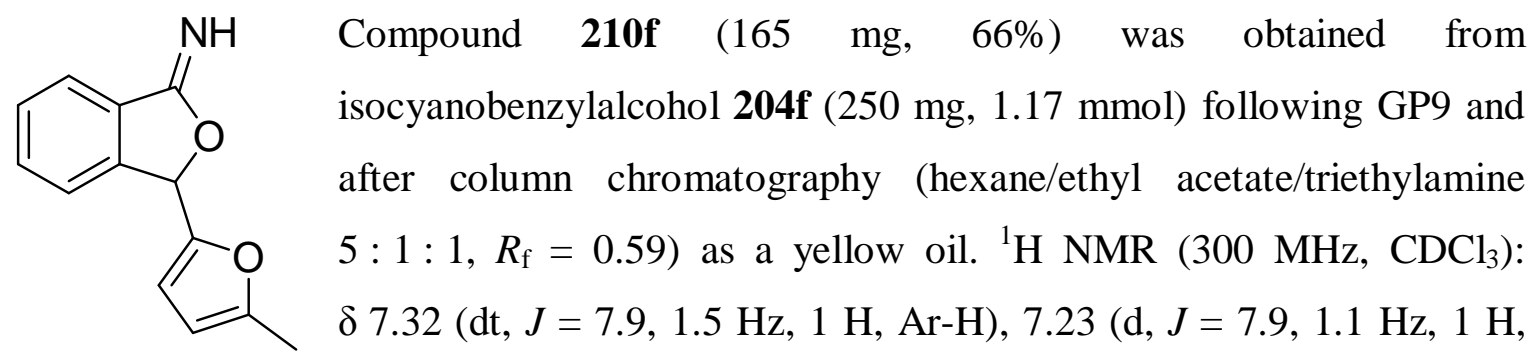
Ar-H), 7.18 (dt, $J=7.5,1.5 \mathrm{~Hz}, 1 \mathrm{H}, \mathrm{Ar}-\mathrm{H}), 7.14(\mathrm{~s}, 1 \mathrm{H}, \mathrm{NH}), 6.92(\mathrm{~d}, J=7.5 \mathrm{~Hz}, 1 \mathrm{H}$, Ar-H), 6.29 (s, $1 \mathrm{H}, \mathrm{CH}), 6.03$ (d, $J=3.4 \mathrm{~Hz}, 1 \mathrm{H}$, furyl-H), $5.92(\mathrm{~m}, 1 \mathrm{H}$, furyl-H), 2.29 ppm (s, $\left.3 \mathrm{H}, \mathrm{CH}_{3}\right) ;{ }^{13} \mathrm{C}$ NMR (125 MHz, $\left.\mathrm{CDCl}_{3}, \mathrm{APT}\right): \delta 153.7$ (C), 150.3 (C), 149.9 (C), $137.3(\mathrm{C}), 129.3(\mathrm{CH}), 126.9(\mathrm{CH}), 125.3(\mathrm{CH}), 124.9(\mathrm{CH}), 122.8(\mathrm{C}), 111.4(\mathrm{CH}), 106.4$ $(\mathrm{CH}), 70.1(\mathrm{CH}), 13.7$ ppm $\left(\mathrm{CH}_{3}\right)$; IR (film): 3423 (br, NH), $1621(\mathrm{C}=\mathrm{N}), 1215,1121$,

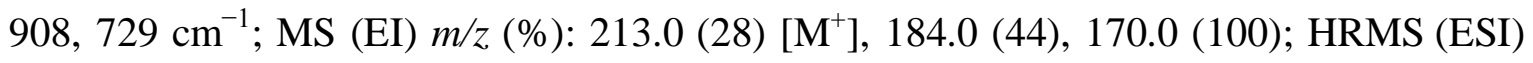
calcd for $\mathrm{C}_{13} \mathrm{H}_{12} \mathrm{NO}_{2}{ }^{+}\left[\mathrm{M}+\mathrm{H}^{+}\right]$: 214.08626; found: 214.08638 . 


\section{3-Isopropylisobenzofuran-1(3H)-imine $(210 \mathrm{~h})$}

$\mathrm{NH}$ Compound 210h (68 mg, 68\%) was obtained from isocyanobenzylalcohol $\mathbf{2 0 4 h}(100 \mathrm{mg}, 0.57 \mathrm{mmol})$ following GP9 and after column chromatography (hexane/ethyl acetate/triethylamine $\left.5: 1: 0.5, R_{\mathrm{f}}=0.40\right)$ as a yellow oil. ${ }^{1} \mathrm{H} \mathrm{NMR}\left(300 \mathrm{MHz}, \mathrm{CDCl}_{3}\right): \delta 7.24$ $(\mathrm{dd}, J=7.5,1.9 \mathrm{~Hz}, 1 \mathrm{H}, \mathrm{Ar}-\mathrm{H}), 7.17(\mathrm{~s}, 1 \mathrm{H}, \mathrm{NH}), 7.19-7.12(\mathrm{~m}, 2 \mathrm{H}, \mathrm{Ar}-\mathrm{H}), 6.89$ (d, $J=6.8 \mathrm{~Hz}, 1 \mathrm{H}), 5.12(\mathrm{~d}, J=4.1 \mathrm{~Hz}, 1 \mathrm{H}, \mathrm{C}(3)-\mathrm{H}), 2.15-2.02(\mathrm{~m}, 1 \mathrm{H}, \mathrm{Pr}-\mathrm{CH}), 1.03$ $\left(\mathrm{d}, J=6.8 \mathrm{~Hz}, 3 \mathrm{H}, \mathrm{CH}_{3}\right), 0.95 \mathrm{ppm}\left(\mathrm{d}, J=6.8 \mathrm{~Hz}, 3 \mathrm{H}, \mathrm{CH}_{3}\right) ;{ }^{13} \mathrm{C} \mathrm{NMR}(125 \mathrm{MHz}$, $\left.\mathrm{CDCl}_{3}, \mathrm{APT}\right): \delta 151.0(\mathrm{C}), 137.4(\mathrm{C}), 128.6(\mathrm{CH}), 126.6(\mathrm{CH}), 125.0(\mathrm{C}), 124.7(\mathrm{CH})$, $124.5(\mathrm{CH}), 80.5(\mathrm{CH}), 35.3(\mathrm{CH}), 18.5\left(\mathrm{CH}_{3}\right), 16.2$ ppm $\left(\mathrm{CH}_{3}\right)$; IR (film): 3422 (br, NH), 2965, 1624, 1130, $765 \mathrm{~cm}^{-1}$; MS (EI) $\mathrm{m} / z$ (\%): 175.1 (17) $\left[\mathrm{M}^{+}\right], 132.0$ (100); HRMS (EI): $m / z$ calcd for $\mathrm{C}_{11} \mathrm{H}_{14} \mathrm{NO}^{+}\left[\mathrm{M}+\mathrm{H}^{+}\right]$: 176.10699; found: 176.10701 .

\section{6-(Pyridin-4-yl)thieno[3,2-c]furan-4(6H)-imine (211d)}

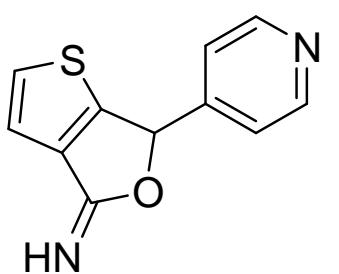

The crude isocyanobenzylalcohol 212d was obtained from 2-bromo-3-isocyanothiophene (234) (376 $\mathrm{mg}, 2 \mathrm{mmol})$ and pyridine-4-carbaldehyde (202d) (214 $\mathrm{mg}, 2 \mathrm{mmol})$ following GP8 (A) as a yellow oil (TLC: hexane/ethyl acetate $5: 1, R_{\mathrm{f}}=0.15$ ). Compound 211d (320 mg, 74\% over two steps) was obtained following GP2 and after column chromatography on silica gel (ethyl acetate/triethylamine $15: 1, R_{\mathrm{f}}=0.38$ ) as a colorless solid, m.p. 133-134 ${ }^{\circ} \mathrm{C} .{ }^{1} \mathrm{H}$ NMR (300 MHz, DMSO[d6]): $\delta 8.57$ (dd, $J=4.1$, $1.5 \mathrm{~Hz}, 2 \mathrm{H}), 7.59$ (d, $J=5.3 \mathrm{~Hz}, 1 \mathrm{H}), 7.39$ (dd, $J=4.5,1.9 \mathrm{~Hz}, 2 \mathrm{H}), 7.19$ (d, J = 5.3 Hz, $1 \mathrm{H}), 6.82(\mathrm{~d}, J=4.5 \mathrm{~Hz}, 1 \mathrm{H}), 6.08 \mathrm{ppm}(\mathrm{d}, J=4.1 \mathrm{~Hz}, 1 \mathrm{H}) ;{ }^{13} \mathrm{C}$ NMR $(125 \mathrm{MHz}$, DMSO[d6], APT): $\delta 166.5$ (C), $150.7(\mathrm{C}), 149.6$ (2 CH), $145.6(\mathrm{C}), 125.9(\mathrm{CH}), 124.7$

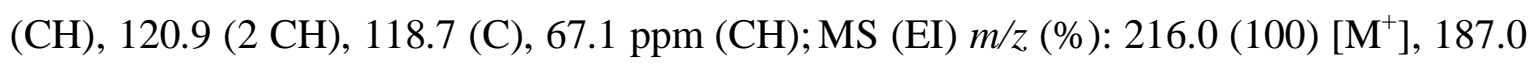
(24); IR (KBr): 2824 (br) (NH), 2118, 1603, 1415, 1270, 1066, 1008, 966, 720, 695, 617 $\mathrm{cm}^{-1}$; elemental analysis calcd $(\%)$ for $\mathrm{C}_{11} \mathrm{H}_{8} \mathrm{~N}_{2} \mathrm{OS}$ : C 61.09, H 3.73, N 12.95; found: C 60.97, H 3.57, N 12.78 . 


\section{3-(Pyridin-2-yl)indolin-2-one (215n)}

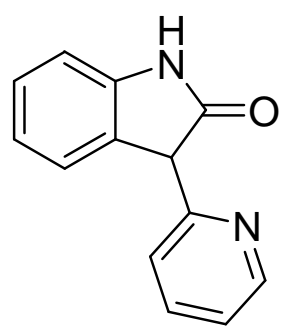

The compound 215n (330 mg, 79\%) was obtained from $o$-bromophenyl isocyanide (159-Br) (364 $\mathrm{mg}, 2 \mathrm{mmol})$ and pyridyl-2-carbaldehyde (202n) (214 mg, $2 \mathrm{mmol}$ ) following GP8 (A) and after column chromatography [hexane/ethyl acetate $1: 1$ to ethyl acetate, $R_{\mathrm{f}}=0.10$ $(1: 1)]$ as a colorless solid, m. p. $98-99{ }^{\circ} \mathrm{C} .{ }^{1} \mathrm{H}$ NMR $(300 \mathrm{MHz}$, $\mathrm{CDCl}_{3}, 2$ rotamers $\left.0.4: 0.6\right): \delta 9.51(\mathrm{~m}, 1 \mathrm{H}), 8.52(\mathrm{~d}, J=5.0 \mathrm{~Hz}, 1 \mathrm{H}), 8.40$ $(\mathrm{d}, J=11.5 \mathrm{~Hz}, 0.4 \mathrm{H}), 8.26(\mathrm{~d}, J=1.9 \mathrm{~Hz}, 0.6 \mathrm{H}), 8.03(\mathrm{~d}, J=8.1 \mathrm{~Hz}, 0.6 \mathrm{H}), 7.66$ $(\mathrm{dt}, J=7.8,1.9 \mathrm{~Hz}, 1 \mathrm{H}), 7.45(\mathrm{dd}, J=7.8,1.9 \mathrm{~Hz}, 0.4 \mathrm{H}), 7.37-7.11(\mathrm{~m}, 5 \mathrm{H}), 5.92$ $(\mathrm{s}, 0.4 \mathrm{H}), 5.88(\mathrm{~s}, 0.6 \mathrm{H}), 4.64 \mathrm{ppm}($ br s, $1 \mathrm{H}) ;{ }^{13} \mathrm{C} \mathrm{NMR}\left(75.5 \mathrm{MHz}, \mathrm{CDCl}_{3}, \mathrm{APT}\right)$ : $\delta 162.4(\mathrm{CH}), 160.7(\mathrm{C}), 160.4(\mathrm{C}), 159.1(\mathrm{CH}), 148.1(\mathrm{CH}), 147.7(\mathrm{CH}), 137.5(\mathrm{CH})$, $137.4(\mathrm{CH}), 135.5(\mathrm{C}), 135.2(\mathrm{C}), 133.4(\mathrm{C}), 131.7(\mathrm{C}), 129.0(\mathrm{CH}), 128.8(\mathrm{CH}), 128.3$ $(\mathrm{CH}), 128.1(\mathrm{CH}), 125.4(\mathrm{CH}), 124.8(\mathrm{CH}), 123.7(\mathrm{CH}), 122.8(\mathrm{CH}), 122.7(\mathrm{CH}), 120.7$ $(\mathrm{CH}), 120.5(\mathrm{CH}), 119.9(\mathrm{CH}), 74.0(\mathrm{CH}), 73.3 \mathrm{ppm}(\mathrm{CH})$; MS (EI) m/z (\%): 210.1 (74) $\left[\mathrm{M}^{+}\right], 181.1$ (100), 132.1 (68); IR (KBr): 3332 (br), 1682, 1590, 1520, 1453, 1437, 1300, 1267, 1059, 757, $732 \mathrm{~cm}^{-1}$; HRMS (EI): $\mathrm{m} / z$ calcd for $\mathrm{C}_{13} \mathrm{H}_{11} \mathrm{~N}_{2} \mathrm{O}^{+}\left[\mathrm{M}+\mathrm{H}^{+}\right]: 211.08659$; found: 211.08654.

\section{3,3-Diphenylindolin-2-one $(215 k)^{[197]}$}<smiles>O=C1Nc2ccccc2C1(c1ccccc1)c1ccccc1</smiles>

Compound 215k (239 mg, 42\%) was obtained from $o$-bromophenyl isocyanide (159-Br) (364 $\mathrm{mg}, 2 \mathrm{mmol})$ and benzophenone (202k) (364 mg, 2 mmol) following GP8 (B) and after column chromatography on silica gel (hexane/ethyl acetate $4: 1, R_{\mathrm{f}}=0.11$ ) as a colorless solid, m. p. $224-225{ }^{\circ} \mathrm{C}$ (lit. ${ }^{[197]} 227-228{ }^{\circ} \mathrm{C}$ ). ${ }^{1} \mathrm{H}$ NMR (300 MHz, $\mathrm{CDCl}_{3}$ ): $\delta 9.20$ (br s, $1 \mathrm{H}$, NH), 7.30-7.19 (m, 12 H, Ar-H), 7.03 (t, J=7.2 Hz, $1 \mathrm{H}, \mathrm{Ar}-\mathrm{H}), 6.95 \mathrm{ppm}(\mathrm{d}, J=7.2 \mathrm{~Hz}$,

$1 \mathrm{H}, \mathrm{Ar}-\mathrm{H}) ;{ }^{13} \mathrm{C}$ NMR $\left(75.5 \mathrm{MHz}, \mathrm{CDCl}_{3}\right): \delta 180.3$ (C), 141.6 (2 C), 140.3 (C), 133.5 (C), $128.4(8 \mathrm{CH}), 128.2(\mathrm{CH}), 127.3(2 \mathrm{CH}), 126.2(\mathrm{CH}), 122.8(\mathrm{CH}), 110.5(\mathrm{CH}), 63.1 \mathrm{ppm}$ (C); MS (EI) m/z (\%): 285.1 (100) $\left[\mathrm{M}^{+}\right], 256.1$ (74); IR (KBr): 3250 (br) (NH), 1725, $1683,1472,1322,1204,742,698,609 \mathrm{~cm}^{-1}$; elemental analysis calcd (\%) for $\mathrm{C}_{20} \mathrm{H}_{15} \mathrm{NO}$ : C 84.19, H 5.30, N 4.91; found: C 84.40, H 5.46, N 5.07. 


\section{6,6-Diphenyl-4H-thieno[3,2-b]pyrrol-5(6H)-one (217k)}

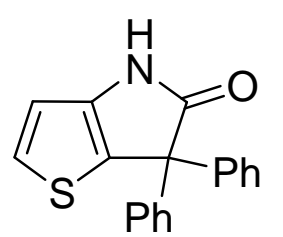

Compound 217k (303 $\mathrm{mg}, \quad 52 \%)$ was obtained from 2-bromo-3-isocyanothiophene (234) (376 $\mathrm{mg}, 2 \mathrm{mmol})$ and benzophenone (202k) (364 mg, $2 \mathrm{mmol}$ ) following GP8 (B) and after column chromatography on silica gel (hexane/ethyl acetate $4: 1$, $\left.R_{\mathrm{f}}=0.13\right)$ as a colorless solid, m.p. $197-198{ }^{\circ} \mathrm{C} .{ }^{1} \mathrm{H}$ NMR $\left(300 \mathrm{MHz}, \mathrm{CDCl}_{3}\right): \delta 9.38$ (br s, $1 \mathrm{H}, \mathrm{NH}), 7.36-7.22(\mathrm{~m}, 11 \mathrm{H}, \mathrm{Ar}-\mathrm{H}), 6.76 \mathrm{ppm}(\mathrm{d}, J=5.1 \mathrm{~Hz}, 1 \mathrm{H}, \mathrm{Ar}-\mathrm{H})$; ${ }^{13} \mathrm{C}$ NMR $\left(125 \mathrm{MHz}, \mathrm{CDCl}_{3}, \mathrm{APT}\right): \delta 182.8(\mathrm{C}), 141.6(2 \mathrm{C}), 141.1(\mathrm{C}), 128.6(4 \mathrm{CH})$, $128.0(\mathrm{CH}), 128.1(4 \mathrm{CH}), 127.4(2 \mathrm{CH}), 125.6(\mathrm{C}), 112.8(\mathrm{CH}), 64.2 \mathrm{ppm}(\mathrm{C})$; MS (EI)

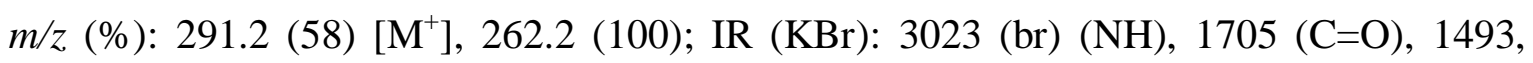
1270, 1092, 836, 756, $696 \mathrm{~cm}^{-1}$; elemental analysis calcd (\%) for $\mathrm{C}_{18} \mathrm{H}_{13} \mathrm{NOS}$ : C 74.20, H 4.50, N 4.81; found: C 74.05, H 4.32, N 4.77.

\section{6-(Trifluoromethyl)-6-phenylthieno[2,3-c]furan-4(6H)-imine (217l)}

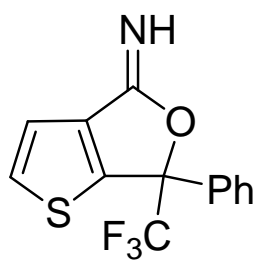

Compound 2171 (425 mg, 75\%) was obtained from 2-bromo-3-isocyanothiophene (234) (376 $\mathrm{mg}, 2 \mathrm{mmol})$ and 1,1,1-trifluoroacetophenone (2021) (348 mg, 2 mmol) following GP8 (B) and after column chromatography on silica gel (hexane/ethyl acetate $\left.10: 1, R_{\mathrm{f}}=0.13\right)$ as a yellow oil. ${ }^{1} \mathrm{H}$ NMR $\left(300 \mathrm{MHz}, \mathrm{CDCl}_{3}\right): \delta 7.65-7.62(\mathrm{~m}, 2 \mathrm{H})$, 7.46-7.37 (m, $3 \mathrm{H}), 7.32(\mathrm{~d}, J=5.3 \mathrm{~Hz}, 1 \mathrm{H}), 7.26(\mathrm{~s}, 1 \mathrm{H}), 6.98 \mathrm{ppm}(\mathrm{d}, J=5.3 \mathrm{~Hz}, 1 \mathrm{H})$; ${ }^{13} \mathrm{C}$ NMR (125 MHz, $\left.\mathrm{CDCl}_{3}, \mathrm{APT}\right): \delta 147.1$ (C), $140.0(\mathrm{C}), 136.0$ (C), 129.7 (2 CH), $128.7(2 \mathrm{CH}), 126.4(\mathrm{CH}), 126.3(\mathrm{CH}), 124.5(\mathrm{CH}), 123.2$ (q, $\left.J_{C F}=287 \mathrm{~Hz}, \mathrm{C}\right), 116.3(\mathrm{C})$, $82.1 \mathrm{ppm}\left(\mathrm{q}, \mathrm{J}^{2}{ }_{C F}=33 \mathrm{~Hz}, \mathrm{C}\right)$; MS (EI) $\mathrm{m} / z(\%): 283.2(16)\left[\mathrm{M}^{+}\right], 254.1$ (58), 214.1 (100); IR (KBr): 3067, 1613, 1293, 1181, 1086, 955, $741 \mathrm{~cm}^{-1}$; HRMS (EI): $\mathrm{m} / \mathrm{z}$ calcd for $\mathrm{C}_{13} \mathrm{H}_{9} \mathrm{~F}_{3} \mathrm{NOS}^{+}\left[\mathrm{M}+\mathrm{H}^{+}\right]$: 284.03515; found: 284.03515 . 


\section{7-(Trifluoromethyl)-7-phenylfuro[3,4-b]pyridin-5(7H)-imine (219l)}<smiles>CC1(c2ccccc2)OC(=N)c2cccnc21</smiles>

Compound 2191 (179 mg, 64\%) was obtained from 2-bromo3-isocyanopyridine (183 mg, $1 \mathrm{mmol})$ and 1,1,1-trifluoroacetophenone (202l) (174 mg, $1 \mathrm{mmol})$ following GP8 (B) and after column chromatography on silica gel (hexane/ethyl acetate $5: 1, R_{\mathrm{f}}=0.18$ ) as a colorless solid, m. p. $82-83{ }^{\circ} \mathrm{C} .{ }^{1} \mathrm{H}$ NMR $\left(300 \mathrm{MHz}, \mathrm{CDCl}_{3}\right): \delta 8.57(\mathrm{dd}, J=4.8,1.8 \mathrm{~Hz}$, $1 \mathrm{H}), 7.69-7.66(\mathrm{~m}, 2 \mathrm{H}), 7.55$ (dd, $J=7.7,1.5 \mathrm{~Hz}, 1 \mathrm{H}), 7.40-7.33 \mathrm{ppm}(\mathrm{m}, 5 \mathrm{H})$; ${ }^{13} \mathrm{C}$ NMR (125 MHz, $\left.\mathrm{CDCl}_{3}, \mathrm{APT}\right): \delta 148.31(\mathrm{C}), 148.25(\mathrm{CH}), 141.3(\mathrm{C}), 134.6(\mathrm{C})$, $133.4(\mathrm{C}), 132.9(\mathrm{CH}), 129.6(2 \mathrm{CH}), 128.4(2 \mathrm{CH}), 127.1(\mathrm{CH}), 125.4(\mathrm{CH}), 123.2(\mathrm{q}$, $\left.J_{C F}=287 \mathrm{~Hz}, \mathrm{C}\right), 81.3 \mathrm{ppm}\left(\mathrm{q}, J_{C F}^{2}=30 \mathrm{~Hz}, \mathrm{C}\right) ; \mathrm{MS}(\mathrm{EI}) \mathrm{m} / z(\%): 278.2(54)\left[\mathrm{M}^{+}\right], 109.2$ (100), 181.2 (43), 105.1 (58); IR (KBr): 3435 (br) (NH), 1635, $1169 \mathrm{~cm}^{-1}$; elemental analysis calcd (\%) for $\mathrm{C}_{14} \mathrm{H}_{9} \mathrm{~F}_{3} \mathrm{~N}_{2} \mathrm{O}$ : C 60.44, H 3.26, N 10.07; found: C 60.15, H 3.12, N 9.89 .

\section{General Procedure for the Synthesis of 4H-3,1-Benzoxazine-4-ones 199-Nu and Isatoic Anhydride (209) (GP10)}

To a solution of $o$-bromophenyl isocyanide (159-Br) $(364 \mathrm{mg}, 2 \mathrm{mmol})$ in anhydrous THF $(20 \mathrm{~mL})$, kept in an oven-dried $25 \mathrm{~mL}-$ Schlenk flask under an atmosphere of dry nitrogen, was added dropwise with stirring a $2.5 \mathrm{M}$ solution of $n$-BuLi in hexane $(0.8 \mathrm{~mL}, 2 \mathrm{mmol})$ at $-78{ }^{\circ} \mathrm{C}$ over a period of $10 \mathrm{~min}$. The mixture was stirred at $-78{ }^{\circ} \mathrm{C}$ for $10 \mathrm{~min}$, and $\mathrm{CO}_{2}$ was bubbled through the mixture at $-78{ }^{\circ} \mathrm{C}$ for $1 \mathrm{~min}$. The mixture was stirred at $-78{ }^{\circ} \mathrm{C}$ for $1 \mathrm{~h}$, then a solution of $\mathrm{I}_{2}(508 \mathrm{mg}, 2 \mathrm{mmol})$ in anhydrous THF $(2 \mathrm{~mL})$ was added dropwise, and the temperature was allowed to rise to $20{ }^{\circ} \mathrm{C}$ over a period of $1 \mathrm{~h}$. Water (for the synthesis of 209) or the solution of the corresponding amine (2 mmol) and triethylamine ( $2 \mathrm{mmo}$ ) in THF ( $2 \mathrm{~mL}$ ) was added, and the mixture was stirred at r.t. for $2 \mathrm{~h}$ After addition of saturated $\mathrm{NH}_{4} \mathrm{Cl}$ solution $(20 \mathrm{~mL})$, the mixture was diluted with diethyl ether $(50 \mathrm{~mL})$, washed with $\mathrm{Na}_{2} \mathrm{~S}_{2} \mathrm{O}_{5}$ solution $(20 \mathrm{~mL})$, water $(10 \mathrm{~mL})$, brine $(20 \mathrm{~mL})$ and dried over anhydrous $\mathrm{Na}_{2} \mathrm{SO}_{4}$. The solvents were removed under reduced pressure, and the crude product was purified by column chromatography on silica gel. 


\section{2-Morpholino-4H-3,1-benzoxazin-4-one (199-morph) ${ }^{[198]}$}

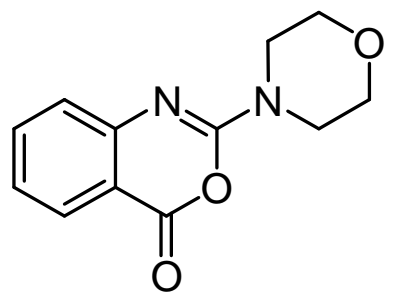

Compound 199-morph (209 mg, 45\%) was obtained following GP10 from $o$-bromophenyl isocyanide (159-Br) (364 $\mathrm{mg}$, $2 \mathrm{mmol}$ ) and morpholine (174 $\mathrm{mg}, 2 \mathrm{mmol})$ and after column chromatography on silica gel (hexane/ethyl acetate $2: 1$, $\left.R_{\mathrm{f}}=0.28\right)$ as a colorless solid, m. p. $150-151^{\circ} \mathrm{C}$ [lit. ${ }^{[198}$ ] 150.5-151.5]. ${ }^{1} \mathrm{H}$ NMR (300 MHz, $\left.\mathrm{CDCl}_{3}\right): \delta 8.01$ (dd, $\left.J=8.1,1.3 \mathrm{~Hz}, 1 \mathrm{H}, \mathrm{Ar}-\mathrm{H}\right), 7.66$ (ddd, $J=8.6,7.2,1.9 \mathrm{~Hz}, 1 \mathrm{H}, \mathrm{Ar}-\mathrm{H}), 7.24$ (d, $J=8.4 \mathrm{~Hz}, 1 \mathrm{H}, \mathrm{Ar}-\mathrm{H}), 7.16$ (ddd, $J=8.1$, 7.2, $1.3 \mathrm{~Hz}, 1 \mathrm{H}, \mathrm{Ar}-\mathrm{H}), 3.80-3.72 \mathrm{ppm}\left(\mathrm{m}, 8 \mathrm{H}, \mathrm{CH}_{2}\right) ;{ }^{13} \mathrm{C} \mathrm{NMR}\left(75.5 \mathrm{MHz}, \mathrm{CDCl}_{3}\right)$ : $\delta 159.6(\mathrm{C}), 153.2(\mathrm{C}), 150.4(\mathrm{C}), 136.7(\mathrm{CH}), 128.7(\mathrm{CH}), 124.2(\mathrm{CH}), 123.6(\mathrm{CH}), 112.5$ (C), $66.3\left(\mathrm{CH}_{2}\right), 44.3 \mathrm{ppm}\left(\mathrm{CH}_{2}\right)$; MS (EI) m/z (\%): 232.2 (60) $\left[\mathrm{M}^{+}\right], 146.1$ (100); IR (KBr): 2918, 2871, 1768, 1602, 1475, 1308, 1238, 1115, 991, 762, $687 \mathrm{~cm}^{-1}$; elemental analysis calcd (\%) for $\mathrm{C}_{12} \mathrm{H}_{12} \mathrm{~N}_{2} \mathrm{O}_{3}$ : C 62.06, H 5.21, N 12.06; found: C 61.26, H 5.11, N 12.01.

\section{2-(Aziridin-1-yl)-4H-3,1-benzoxazin-4-one (199-azirid)}

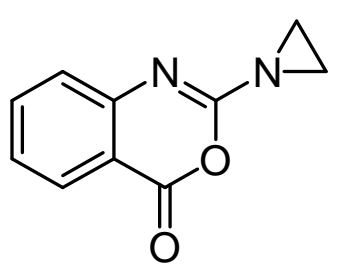

Compound 199-azirid (188 mg, 50\%) was obtained following GP10 from $o$-bromophenyl isocyanide (159-Br) $(364 \mathrm{mg}, 2 \mathrm{mmol})$ and aziridine ( $86 \mathrm{mg}, 2 \mathrm{mmol}$ ) and after column chromatography on silica gel (ethyl acetate, $R_{\mathrm{f}}=0.26$ ) as a colorless solid, m. p. 154-155 ${ }^{\circ} \mathrm{C} .{ }^{1} \mathrm{H}$ NMR $\left(300 \mathrm{MHz}, \mathrm{CDCl}_{3}\right): \delta 8.15(\mathrm{dd}, J=7.5,1.3 \mathrm{~Hz}, 1 \mathrm{H}, \mathrm{Ar}-\mathrm{H}), 7.66$ (ddd, $J=8.4,7.2,1.6 \mathrm{~Hz}, 1 \mathrm{H}, \mathrm{Ar}-\mathrm{H}), 7.50$ (d, $J=8.1 \mathrm{~Hz}, 1 \mathrm{H}, \mathrm{Ar}-\mathrm{H}), 7.32$ (ddd, $J=8.1$, 7.2, $1.3 \mathrm{~Hz}, 1 \mathrm{H}, \mathrm{Ar}-\mathrm{H}), 4.76\left(\mathrm{t}, J=8.4 \mathrm{~Hz}, 2 \mathrm{H}, \mathrm{CH}_{2}\right), 4.37 \mathrm{ppm}\left(\mathrm{t}, J=8.4 \mathrm{~Hz}, 2 \mathrm{H}, \mathrm{CH}_{2}\right)$; ${ }^{13} \mathrm{C}$ NMR (75.5 MHz, $\left.\mathrm{CDCl}_{3}\right): \delta 160.8(\mathrm{C}), 155.4(\mathrm{C}), 148.9(\mathrm{C}), 134.8(\mathrm{CH}), 126.5(\mathrm{CH})$, $126.1(\mathrm{CH}), 124.7(\mathrm{CH}), 118.3(\mathrm{C}), 65.8\left(\mathrm{CH}_{2}\right), 42.2 \mathrm{ppm}\left(\mathrm{CH}_{2}\right)$; MS (EI) $\mathrm{m} / z(\%): 188.1$ (100) $\left[\mathrm{M}^{+}\right], 146.1$ (86); IR (KBr): 1696, 1640, 1609, 1562, 1473, 1418, 1263, 1135, 1015, 980, 863, 769, $692 \mathrm{~cm}^{-1}$; elemental analysis calcd (\%) for $\mathrm{C}_{10} \mathrm{H}_{8} \mathrm{~N}_{2} \mathrm{O}_{2}: \mathrm{C} 63.82, \mathrm{H} \mathrm{4.28,}$ N 14.89; found: C 63.62, H 4.21, N 14.67. 
<smiles>O=c1[nH]c2ccccc2c(=O)o1</smiles>

Compound 209 (199 mg, 61\%) was obtained employing the same procedure as for 199-morph, using water $(1 \mathrm{~mL})$ instead of morpholine, and after column chromatography on silica gel (hexane/ethyl acetate $1: 1, R_{\mathrm{f}}=0.12$ ) as a colorless solid, m. p. $233-234{ }^{\circ} \mathrm{C}$ [lit. $\left.{ }^{[199]} 233{ }^{\circ} \mathrm{C}\right]$. ${ }^{1} \mathrm{H}$ NMR (300 MHz, DMSO[d6]): $\delta 11.68$ (br s, $\left.1 \mathrm{H}, \mathrm{NH}\right), 7.91(\mathrm{dd}, J=7.5,1.1 \mathrm{~Hz}, 1 \mathrm{H}$, Ar-H), 7.73 (ddd, $J=7.9,7.2,1.5 \mathrm{~Hz}, 1 \mathrm{H}$, Ar-H), 7.25 (ddd, $J=8.3,8.3,1.1 \mathrm{~Hz}, 1 \mathrm{H}$, Ar-H), 7.16 ppm (d, J = 8.3 Hz, $1 \mathrm{H}, \mathrm{Ar}-\mathrm{H}) ;{ }^{13} \mathrm{C}$ NMR (75.5 MHz, DMSO[d6]): $\delta 159.7$ (C), $147.0(\mathrm{C}), 141.3(\mathrm{C}), 136.8(\mathrm{CH}), 128.8(\mathrm{CH}), 123.4(\mathrm{CH}), 115.2(\mathrm{CH}), 110.1 \mathrm{ppm}$ (C); MS (EI) m/z (\%): 163.0 (48) [M+], 119.1 (100), 92.1 (54); IR (KBr): 3068 (br) (NH), $1772(\mathrm{C}=\mathrm{O}), 1616,1488,1364,1261,1009,765,680,649 \mathrm{~cm}^{-1}$; elemental analysis calcd (\%) for $\mathrm{C}_{8} \mathrm{H}_{5} \mathrm{NO}_{3}$ : C 58.90, H 3.09, N 8.59; found: C 58.55, H 3.05, N 8.19. 


\section{Experimental Procedures for the Compounds Described in Chapter 4 "Synthesis of 1-Substituted Benzimidazoles from o-Bromophenyl Isocyanide and Amines"}

\section{General Procedure for the Synthesis of 1-Substituted Benzimidazoles 232 and 3-Substituted $3 H$-thieno[2,3-d]imidazoles 235 (G11)}

In a $10 \mathrm{~mL}$ Schlenk flask were placed 2-bromophenyl isocyanide (159-Br) (364 mg, 2 mmol) or 2-bromo-3isocyanothiophene (234) (376 mg, $2 \mathrm{mmol}$ ), cesium carbonate (652 $\mathrm{mg}, 4 \mathrm{mmol}), \mathrm{CuBr}$ (14.4 mg, $5 \mathrm{~mol} \%)$, 1,10-phenanthroline (36 mg, $10 \mathrm{~mol} \%$ ) and the respective amine (if solid). The flask was sealed with a rubber septum, evacuated and refilled with dry nitrogen three times. Anhydrous degassed DMF (or a solution of a respective liquid amine in DMF) was introduced to the flask from a syringe. The septum was replaced with a glass stopper. The mixture was stirred at r.t. for $2 \mathrm{~h}$, then warmed to $90{ }^{\circ} \mathrm{C}$ for ca. $30 \mathrm{~min}$ and stirred at this temperature for $14 \mathrm{~h}$. After this time, the mixture was cooled, and the solvent was removed in vacuo. The residue was dissolved in $\mathrm{CH}_{2} \mathrm{Cl}_{2}$ and water (60 and $15 \mathrm{~mL}$, respectively), the aqueous phase was extracted with $\mathrm{CH}_{2} \mathrm{Cl}_{2}$ $(2 \times 20 \mathrm{~mL})$, and the combined organic phases were washed with brine, dried over $\mathrm{Na}_{2} \mathrm{SO}_{4}$ and concentrated to give a crude product, which was purified by flash chromatography on silica gel.

\section{2-(1-Methyl-1H-indol-3-yl)ethanamine $(230 \mathrm{~d})^{[200]}$}

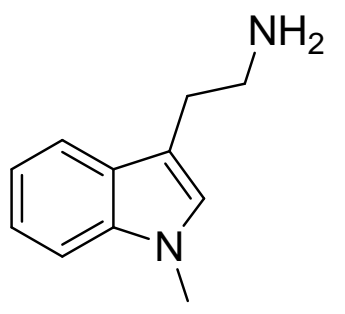

A solution of tryptamine $(3.2 \mathrm{~g}, 20 \mathrm{mmol})$ in anhydrous DMF (40 $\mathrm{mL}$ ) was added dropwise at r.t. within 20 min to a $60 \%$ suspension of sodium hydride in mineral oil $(0.88 \mathrm{~g}, 22 \mathrm{mmol})$ in anhydrous DMF (60 mL). The mixture was stirred at r.t. for $30 \mathrm{~min}$, cooled to 0 ${ }^{\circ} \mathrm{C}$, and $\mathrm{MeI}(3.12 \mathrm{~g}, 1.37 \mathrm{~mL}, 22 \mathrm{mmol})$ was added dropwise. The resulting mixture was stirred at r.t. for $1 \mathrm{~h}$, and the solvent was removed in vacuo. The residue was dissolved in water $(300 \mathrm{~mL})$ and extracted with EtOAc $(3 \times 50 \mathrm{~mL})$. The combined organic phases were dried over $\mathrm{Na}_{2} \mathrm{SO}_{4}$, and the solvents were removed under reduced pressure to give a crude product, which was purified by column chromatography on silica gel $\left(\mathrm{CH}_{2} \mathrm{Cl}_{2} / \mathrm{MeOH} / \mathrm{Et}_{3} \mathrm{~N} 85: 10: 5, R_{\mathrm{f}}=0.37\right)$ to give $2.58 \mathrm{~g}(74 \%)$ of the title 
compound as a yellow oil. ${ }^{1} \mathrm{H}$ NMR $\left(300 \mathrm{MHz}, \mathrm{CDCl}_{3}\right): \delta 7.57(\mathrm{~d}, J=7.9 \mathrm{~Hz}, 1 \mathrm{H}, \mathrm{Ar}-\mathrm{H})$, 7.29-7.18 (m, 2 H, Ar-H), 7.09 (t, J = 7.9 Hz, 1 H, Ar-H), 6.87 (s, 1 H, 2-H), 3.71 (s, 3 H, $\mathrm{CH}_{3}$ ), 3.00-2.96 (m, $2 \mathrm{H}, \mathrm{CH}_{2}$ ), 2.90-2.86 (m, $2 \mathrm{H}, \mathrm{CH}_{2}$ ), 2.16 ppm (br s, $2 \mathrm{H}, \mathrm{NH}_{2}$ ); ${ }^{13} \mathrm{C}$ NMR (75.5 MHz, $\left.\mathrm{CDCl}_{3}\right): \delta 137.0(\mathrm{C}), 127.7(\mathrm{C}), 126.8(\mathrm{CH}), 121.5(\mathrm{CH}), 118.8$ $(\mathrm{CH}), 118.6(\mathrm{CH}), 111.9(\mathrm{C}), 109.1(\mathrm{CH}), 42.2\left(\mathrm{CH}_{3}\right), 32.5\left(\mathrm{CH}_{2}\right), 28.9$ ppm $\left(\mathrm{CH}_{2}\right)$; MS (70 eV, EI) m/z (\%): 174 (16) [M+1, 144 (100); IR (KBr): 3051, 2929. 1615, 1473, 1377, $1327,1250,1131,1012,741 \mathrm{~cm}^{-1}$.

\section{$N$-Benzyl- $N^{\prime}$-(2-bromophenyl)formamidine (231a)}

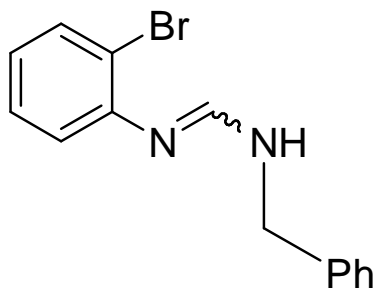

To a stirred solution of 2-bromophenyl isocyanide (159-Br) (364 mg, $2 \mathrm{mmol})$ and benzylamine (230a) (214 mg, $2 \mathrm{mmol})$ in DMF (2 mL) was added CuI (19.1 mg, $0.01 \mathrm{mmol})$, and the mixture was stirred at r.t. until no more isocyanide was detectable by TLC. The solvent was removed in vacuo, and the product ( 425 mg, $74 \%)$ was isolated by column chromatography on silica gel $\left(\mathrm{CH}_{2} \mathrm{Cl}_{2} / \mathrm{MeOH} 30: 1\right.$, $\left.R_{\mathrm{f}}=0.31\right)$ as a yellow solid, m.p. $89-90{ }^{\circ} \mathrm{C}$. This product was identical with an authentic sample isolated from the reaction of 2-bromophenyl isocyanide (159- $\mathrm{Br})$ and benzylamine (230a) with $\mathrm{Et}_{3} \mathrm{~N}$ as a base (see Table 13, entry 6 of main part). ${ }^{1} \mathrm{H}$ NMR (300 MHz, $\left.\mathrm{CDCl}_{3}\right): \delta 7.59(\mathrm{~s}, 1 \mathrm{H}, \mathrm{N}=\mathrm{CH}), 7.53(\mathrm{~d}, J=7.9 \mathrm{~Hz}, 1 \mathrm{H}, \mathrm{Ar}-\mathrm{H}), 7.45-7.23(\mathrm{~m}, 5 \mathrm{H}, \mathrm{Ar}-\mathrm{H})$, 7.19 (t, $J=7.5 \mathrm{~Hz}, 1 \mathrm{H}, \mathrm{Ar}-\mathrm{H}), 6.88$ (d, $J=7.2 \mathrm{~Hz}, 2 \mathrm{H}, \mathrm{Ar}-\mathrm{H}), 5.04$ (br s, $1 \mathrm{H}, \mathrm{NH}), 4.62$ ppm (br s, $\left.2 \mathrm{H}, \mathrm{CH}_{2}\right) ;{ }^{13} \mathrm{C}$ NMR (75.5 MHz, $\left.\mathrm{CDCl}_{3}\right)$ : $\delta 150.0(\mathrm{CH}), 150.5(\mathrm{CH}), 138.4(\mathrm{C})$, $132.7(\mathrm{CH}), 128.5(2 \mathrm{CH}), 128.0(2 \mathrm{CH}), 127.3(\mathrm{CH}), 123.8(\mathrm{CH}), 121.0(\mathrm{C}), 118.5(\mathrm{C})$, 44.9 ppm $\left(\mathrm{CH}_{2}\right)$; MS (ESI) $m / z$ (\%): 289.0/291.0 (100/95) [M+Na $\left.{ }^{+}\right]$; IR (KBr): 3214, 3018, 1698, 1493, 1469, 1449, 1369, 1201, 1024, 751, $719 \mathrm{~cm}^{-1}$; HRMS (ESI) calcd for $\mathrm{C}_{14} \mathrm{H}_{14} \mathrm{~N}_{2} \mathrm{Br}^{+}\left[\mathrm{M}+\mathrm{H}^{+}\right]$: 289.0335; found: 289.0339 .

\section{1-Benzyl-1H-benzo[d]imidazole $(232 a){ }^{[201]}$}

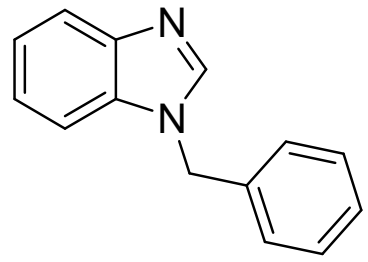

Compound 232a (283 mg, 68\%) was obtained from 2-bromophenyl isocyanide (159-Br) (364 mg, $2 \mathrm{mmol})$ and benzylamine (230a) (214 $\mathrm{mg}, 2 \mathrm{mmol}$ ) following the GP11, after column chromatography $\left(\mathrm{CH}_{2} \mathrm{Cl}_{2} / \mathrm{MeOH} 20: 1, R_{\mathrm{f}}=0.27\right)$ as a colorless solid, m. p. $115-116{ }^{\circ} \mathrm{C}$. [lit. $116-117{ }^{\circ} \mathrm{C}$ ] ${ }^{1} \mathrm{H}$ NMR $\left(300 \mathrm{MHz}, \mathrm{CDCl}_{3}\right): \delta 7.93$ (s, $1 \mathrm{H}, \mathrm{N}=\mathrm{CH}), 7.83(\mathrm{~d}, J=7.2 \mathrm{~Hz}, 1 \mathrm{H}, \mathrm{Ar}-\mathrm{H}), 7.35-7.21(\mathrm{~m}, 6 \mathrm{H}, \mathrm{Ar}-\mathrm{H}), 7.16(\mathrm{~m}, 2 \mathrm{H}$, 
Ar-H), $5.32 \mathrm{ppm}\left(\mathrm{s}, 2 \mathrm{H}, \mathrm{CH}_{2}\right) ;{ }^{13} \mathrm{C} \mathrm{NMR}\left(75.5 \mathrm{MHz}, \mathrm{CDCl}_{3}\right): \delta 144.2(\mathrm{C}), 135.4(\mathrm{CH})$, $128.9(\mathrm{CH}), 128.5(\mathrm{C}), 128.2(\mathrm{CH}), 127.4(\mathrm{C}), 127.0(\mathrm{CH}), 123.0(\mathrm{CH}), 122.0(\mathrm{CH}), 120.4$

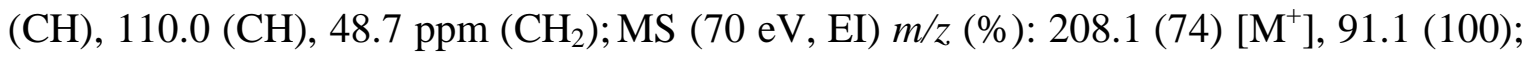
IR (KBr): 3010, 2943, 2154, 1609, 1466, 1184, 1076, 753, 720, $694 \mathrm{~cm}^{-1}$; HRMS (ESI) calcd for $\mathrm{C}_{14} \mathrm{H}_{13} \mathrm{~N}_{2}^{+}\left[\mathrm{M}+\mathrm{H}^{+}\right]$: 209.10732; found: 209.10730.

\section{1-n-Propyl-1H-benzo[d]imidazole $(232 b)^{[202]}$}

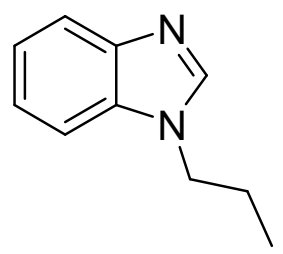

Compound 232b (209 mg, 65\%) was obtained from 2-bromophenyl isocyanide (159-Br) (364 mg, $2 \mathrm{mmol})$ and $n$-propylamine (230b) (118 $\mathrm{mg}, 2 \mathrm{mmol}$ ) following the GP11, after column chromatography $\left(\mathrm{CH}_{2} \mathrm{Cl}_{2} / \mathrm{MeOH} 20: 1, R_{\mathrm{f}}=0.38\right)$ as a yellow oil. ${ }^{1} \mathrm{H} \mathrm{NMR}(300 \mathrm{MHz}$, $\left.\mathrm{CDCl}_{3}\right): \delta 7.87(\mathrm{~s}, 1 \mathrm{H}, \mathrm{NCH}), 7.84-7.78(\mathrm{~m}, 1 \mathrm{H}, \mathrm{Ar}-\mathrm{H}), 7.40-7.37$ (m, $\left.1 \mathrm{H}, \mathrm{Ar}-\mathrm{H}\right)$, 7.32-7.24 (m, $2 \mathrm{H}, \mathrm{Ar}-\mathrm{H}), 4.10$ (t, $\left.J=7.2 \mathrm{~Hz}, 2 \mathrm{H}, \mathrm{CH}_{2}\right), 1.89$ (m, $\left.2 \mathrm{H}, \mathrm{CH}_{2}\right), 0.93$ ppm $\left(\mathrm{t}, J=7.2 \mathrm{~Hz}, 3 \mathrm{H}, \mathrm{CH}_{3}\right) ;{ }^{13} \mathrm{C} \mathrm{NMR}\left(75.5 \mathrm{MHz}, \mathrm{CDCl}_{3}, \mathrm{APT}\right): \delta 143.8(\mathrm{C}), 142.9(\mathrm{CH})$, $122.6(\mathrm{CH}), 121.8(\mathrm{CH}), 120.2(\mathrm{CH}), 109.6(\mathrm{CH}), 46.6\left(\mathrm{CH}_{2}\right), 23.0\left(\mathrm{CH}_{2}\right), 11.2 \mathrm{ppm}$ $\left(\mathrm{CH}_{3}\right)$; IR (KBr): 2966, 2933, 2876, 1635, 1496, 1459, 1384, 1367, 1331, 1288, 1259, 1212, $745 \mathrm{~cm}^{-1}$; MS (70 eV, EI) m/z (\%): $160.0(58)\left[\mathrm{M}^{+}\right], 131.0$ (100); HRMS (ESI) calcd for $\mathrm{C}_{10} \mathrm{H}_{13} \mathrm{~N}_{2}^{+}\left[\mathrm{M}+\mathrm{H}^{+}\right]$: 161.10732; found: 161.10730 .

\section{1-(3-(Benzyloxy)propyl)-1H-benzo[d]imidazole (232c)}

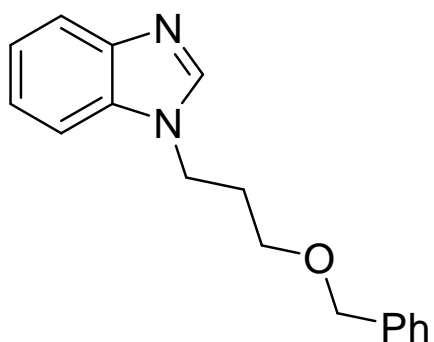

Compound 232c (350 mg, 66\%) was obtained from 2-bromophenyl isocyanide (159-Br) (364 mg, $2 \mathrm{mmol})$ and 3-(benzyloxy)propyl-1-amine (230c) (330 mg, $2 \mathrm{mmol})$ following the GP11, after column chromatography $\left(\mathrm{CH}_{2} \mathrm{Cl}_{2} / \mathrm{MeOH} 20: 1, R_{\mathrm{f}}=0.34\right)$ as a yellow oil. ${ }^{1} \mathrm{H} \mathrm{NMR}$ (300 MHz, $\left.\mathrm{CDCl}_{3}\right): \delta$ 7.82-7.79 (m, $\left.2 \mathrm{H}\right), 7.41-7.31(\mathrm{~m}, 6 \mathrm{H}), 7.29-7.24(\mathrm{~m}, 2 \mathrm{H}), 4.46$ (s, $2 \mathrm{H}, \mathrm{PhCH}_{2}$ ), 4.29 (t, $\left.J=6.8 \mathrm{~Hz}, 2 \mathrm{H}, \mathrm{OCH}_{2}\right), 3.38\left(\mathrm{t}, J=5.6 \mathrm{~Hz}, 2 \mathrm{H}, \mathrm{NCH}_{2}\right), 2.11$ ppm (hept, $\left.J=5.6 \mathrm{~Hz}, 2 \mathrm{H}, \mathrm{CH}_{2}\right) ;{ }^{13} \mathrm{C} \mathrm{NMR}\left(75.5 \mathrm{MHz}, \mathrm{CDCl}_{3}\right): \delta 143.7(\mathrm{C}), 143.2(\mathrm{C})$, $137.8(\mathrm{C}), 128.4(\mathrm{CH}), 127.8(\mathrm{CH}), 127.7(2 \mathrm{CH}), 126.8(\mathrm{CH}), 122.8(\mathrm{CH}), 122.0(2 \mathrm{CH})$, $120.2(\mathrm{CH}), 109.6(\mathrm{CH}), 73.1\left(\mathrm{CH}_{2}\right), 65.9\left(\mathrm{CH}_{2}\right), 41.5\left(\mathrm{CH}_{2}\right), 29.8 \mathrm{ppm}\left(\mathrm{CH}_{2}\right)$; IR $(\mathrm{KBr})$ : 3060, 2929, 2861, 1496, 1456, 1366, 1286, 1254, 1201, 1106, 748, $699 \mathrm{~cm}^{-1}$; MS (70 eV, 
EI) $m / z(\%): 266.2(16)\left[\mathrm{M}^{+}\right], 175.1$ (16), 160.1 (80), 132.1 (100), 91.0 (52); HRMS (ESI) calcd for $\mathrm{C}_{17} \mathrm{H}_{19} \mathrm{~N}_{2} \mathrm{O}^{+}\left[\mathrm{M}+\mathrm{H}^{+}\right]$: 267.1492; found: 267.1499 .

\section{1-(2-(1-Methyl-1H-indol-3-yl)ethyl)-1H-benzo[d]imidazole (232d)}

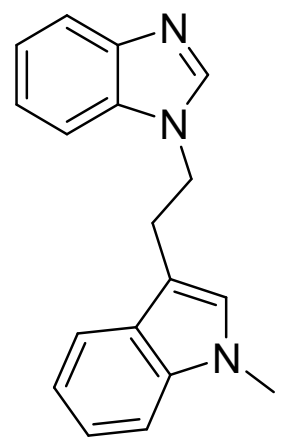

Compound 232d (322 mg, 59\%) was obtained from 2-bromophenyl isocyanide (159-Br) (364 $\mathrm{mg}, \quad 2 \mathrm{mmol}) \quad$ and 2-(1-methyl-1H-indol-3-yl)ethylamine (230d) (348 mg, $2 \mathrm{mmol})$ following the GP11, after column chromatography $\left(\mathrm{CH}_{2} \mathrm{Cl}_{2} / \mathrm{MeOH}\right.$ $\left.30: 1, R_{\mathrm{f}}=0.23\right)$ as a colorless solid, m. p. $110-111^{\circ} \mathrm{C} .{ }^{1} \mathrm{H}$ NMR $(300$ $\left.\mathrm{MHz}, \mathrm{CDCl}_{3}\right): \delta 7.83-7.78(\mathrm{~m}, 1 \mathrm{H}, \mathrm{Ar}-\mathrm{H}), 7.60(\mathrm{~s}, 1 \mathrm{H}, \mathrm{N}=\mathrm{CH}), 7.56$ $(\mathrm{d}, J=7.9 \mathrm{~Hz}, 1 \mathrm{H}, \mathrm{Ar}-\mathrm{H}), 7.43-7.37(\mathrm{~m}, 1 \mathrm{H}, \mathrm{Ar}-\mathrm{H}), 7.32-7.23(\mathrm{~m}$, $4 \mathrm{H}, \mathrm{Ar}-\mathrm{H}), 7.15$ (ddd, $J=7.9,6.8,1.1 \mathrm{~Hz}, 1 \mathrm{H}, \mathrm{Ar}-\mathrm{H}), 6.52(\mathrm{~s}, 1 \mathrm{H}, \mathrm{NCH}), 4.44(\mathrm{t}, J=6.8$ $\left.\mathrm{Hz}, 2 \mathrm{H}, \mathrm{CH}_{2}\right), 3.66\left(\mathrm{~s}, 3 \mathrm{H}, \mathrm{CH}_{3}\right), 3.28 \mathrm{ppm}\left(\mathrm{t}, J=6.8 \mathrm{~Hz}, 2 \mathrm{H}, \mathrm{CH}_{2}\right) ;{ }^{13} \mathrm{C}$ NMR $(75.5$ MHz, $\left.\mathrm{CDCl}_{3}, \mathrm{APT}\right): \delta 143.9(\mathrm{C}), 143.2(\mathrm{CH}), 137.1(\mathrm{C}), 133.6(\mathrm{C}), 127.3(\mathrm{CH}), 127.2(\mathrm{C})$, $122.7(\mathrm{CH}), 121.94(\mathrm{CH}), 121.86(\mathrm{CH}), 120.4(\mathrm{CH}), 119.2(\mathrm{CH}), 118.2(\mathrm{CH}), 109.9(\mathrm{C})$, 109.54 (CH), $109.51(\mathrm{CH}), 45.7\left(\mathrm{CH}_{2}\right), 32.6\left(\mathrm{CH}_{3}\right), 26.0$ ppm $\left(\mathrm{CH}_{2}\right)$; IR 3053, 2923, 1636, $1614,1493,1474,1326,1287,1223,1150,1126,1065,1008,925,890,861,745,731$ $\mathrm{cm}^{-1}$; MS (ESI) $\mathrm{m} / z(\%): 573.3(8)\left[2 \mathrm{M}+\mathrm{Na}^{+}\right], 298.1(23)\left[\mathrm{M}+\mathrm{Na}^{+}\right], 276.1(100)\left[\mathrm{M}+\mathrm{H}^{+}\right]$; HRMS (ESI) calcd for $\mathrm{C}_{18} \mathrm{H}_{18} \mathrm{~N}_{3}^{+}\left[\mathrm{M}+\mathrm{H}^{+}\right]$: 276.1495; found: 276.1501 .

\section{1-(2-(1H-Benzo[d]imidazol-1-yl)ethyl)-1H-benzo[d]imidazole $(232 \mathrm{e})^{[203]}$}

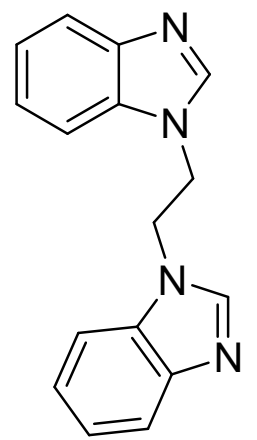

Compound 232e (220 mg, 42\%) was obtained from 2-bromophenyl isocyanide (159-Br) (728 mg, $4 \mathrm{mmol})$ and ethylenediamine (230e) (120 mg, $2 \mathrm{mmol}$ ) following the GP11, after column chromatography $\left(\mathrm{CH}_{2} \mathrm{Cl}_{2} / \mathrm{MeOH} 10: 1, R_{\mathrm{f}}=0.25\right)$ as a colorless solid, m. p. $223-224{ }^{\circ} \mathrm{C}$. ${ }^{1} \mathrm{H}$ NMR (300 MHz, DMSO[D 6$)$ : $\delta 7.90$ (s, 2 H, NCH), 7.62-7.59 (m, 2 H, Ar-H), 7.43-7.40 (m, 2 H, Ar-H), 7.19-7.14 (m, 4 H, Ar-H), $4.73 \mathrm{ppm}\left(\mathrm{s}, 4 \mathrm{H}, \mathrm{CH}_{2}\right) ;{ }^{13} \mathrm{C} \mathrm{NMR}(75.5 \mathrm{MHz}, \mathrm{DMSO}[\mathrm{d} 6]): \delta 143.7$ (C), $143.2(\mathrm{CH}), 133.6(\mathrm{C}), 122.2(\mathrm{CH}), 121.5(\mathrm{CH}), 119.3(\mathrm{CH}), 109.9(\mathrm{CH}), 43.8$ ppm $\left(\mathrm{CH}_{2}\right)$; IR (KBr): 3091, 3052, 1609, 1489, 1458, 1361, 1328, 1288, 1261, 1201, 1170, 1149, 1119 , $883,747 \mathrm{~cm}^{-1}$; MS (ESI) $\mathrm{m} / z(\%): 547.2$ (27) $\left[2 \mathrm{M}+\mathrm{Na}^{+}\right], 285.1(57)\left[\mathrm{M}+\mathrm{Na}^{+}\right], 263.1$ (100) $\left[\mathrm{M}+\mathrm{H}^{+}\right]$; HRMS (ESI) calcd for $\mathrm{C}_{16} \mathrm{H}_{15} \mathrm{~N}_{4}{ }^{+}\left[\mathrm{M}+\mathrm{H}^{+}\right]$: 263.1291; found: 263.1290 . 


\section{1-(2-Methoxybenzyl)-1H-benzo[d]imidazole (232f)}

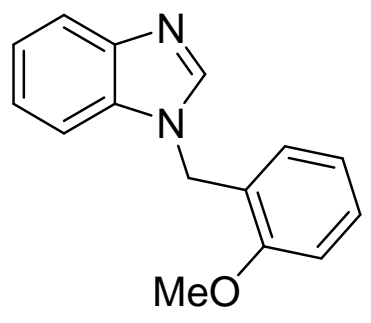

Compound 232f (318 mg, 67\%) was obtained from 2-bromophenyl isocyanide (159-Br) (364 mg, $2 \mathrm{mmol})$ and 2-methoxybenzylamine (230f) (274 $\mathrm{mg}, 2 \mathrm{mmol})$ following the GP11, after column chromatography $\left(\mathrm{CH}_{2} \mathrm{Cl}_{2} / \mathrm{MeOH} 20: 1\right.$, $\left.R_{\mathrm{f}}=0.33\right)$ as a colorless solid, m. p. $75-77^{\circ} \mathrm{C} .{ }^{1} \mathrm{H}$ NMR $(300 \mathrm{MHz}$, $\left.\mathrm{CDCl}_{3}\right): \delta 7.97(\mathrm{~s}, 1 \mathrm{H}, \mathrm{N}=\mathrm{CH}), 7.83-7.77(\mathrm{~m}, 1 \mathrm{H}, \mathrm{Ar}-\mathrm{H}), 7.41-7.37(\mathrm{~m}, 1 \mathrm{H}, \mathrm{Ar}-\mathrm{H})$, 7.31-7.22 (m, 3 H, Ar-H), 7.03 (d, $J=7.5,1.9$ Hz, $1 \mathrm{H}$, Ar-H), 6.88 (m, 2 H, Ar-H), 5.33 (s, $2 \mathrm{H}, \mathrm{CH}_{2}$ ), 3.85 ppm (s, $\left.3 \mathrm{H}, \mathrm{CH}_{3}\right) ;{ }^{13} \mathrm{C} \mathrm{NMR}\left(75.5 \mathrm{MHz}, \mathrm{CDCl}_{3}, \mathrm{APT}\right): \delta 157.1$ (C), $129.7(\mathrm{CH}), 129.0(\mathrm{CH}), 123.7(\mathrm{C}), 123.1(\mathrm{C}), 122.7(\mathrm{CH}), 121.9(\mathrm{CH}), 120.6(\mathrm{CH}), 120.2$ $(\mathrm{CH}), 112.4(\mathrm{C}), 110.5(\mathrm{CH}), 110.0(\mathrm{C}), 55.3\left(\mathrm{CH}_{3}\right), 44.2 \mathrm{ppm}\left(\mathrm{CH}_{2}\right)$; IR $(\mathrm{KBr})$ : 3051, 2934, 1600, 1495, 1457, 1286, 1249, 1024, $745 \mathrm{~cm}^{-1}$; MS (70 eV, EI) m/z (\%): 238.1 (62) $\left[\mathrm{M}^{+}\right], 121.1$ (100), 91.1 (66); HRMS (ESI) calcd for $\mathrm{C}_{15} \mathrm{H}_{15} \mathrm{~N}_{2} \mathrm{O}^{+}\left[\mathrm{M}+\mathrm{H}^{+}\right]$: 239.1179; found: 239.1169 .

\section{1-(3,5-Dimethoxybenzyl)-1H-benzo[d]imidazole (232g)}

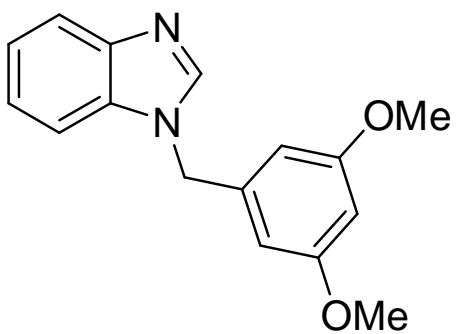

Compound 232g (350 mg, 65\%) was obtained from 2-bromophenyl isocyanide (159-Br) (364 mg, $2 \mathrm{mmol}$ ) and 3,5-dimethoxybenzylamine $\quad(\mathbf{2 3 0 g}) \quad(401 \mathrm{mg}, \quad 2 \mathrm{mmol})$ following the GP11, after column chromatography $\left(\mathrm{CH}_{2} \mathrm{Cl}_{2} / \mathrm{MeOH} 20: 1, R_{\mathrm{f}}=0.36\right)$ as a yellow oil. ${ }^{1} \mathrm{H} \mathrm{NMR}$ (300 MHz, $\left.\mathrm{CDCl}_{3}\right): \delta 7.95(\mathrm{~s}, 1 \mathrm{H}, \mathrm{NCH}), 7.84-7.81(\mathrm{~m}, 1 \mathrm{H}), 7.33-7.25(\mathrm{~m}, 3 \mathrm{H})$, 6.43-6.31 (m, $3 \mathrm{H}), 5.28\left(\mathrm{~s}, 2 \mathrm{H}, \mathrm{CH}_{2}\right), 3.72 \mathrm{ppm}\left(\mathrm{s}, 6 \mathrm{H}, \mathrm{OCH}_{3}\right),{ }^{13} \mathrm{C} \mathrm{NMR}(75.5 \mathrm{MHz}$, $\left.\mathrm{CDCl}_{3}, \mathrm{APT}\right): \delta 161.3(\mathrm{C}), 144.0(\mathrm{C}), 143.2(\mathrm{CH}), 137.8(\mathrm{C}), 134.0(\mathrm{C}), 123.1(\mathrm{CH}), 122.3$ $(\mathrm{CH}), 120.4(\mathrm{CH}), 110.0(\mathrm{CH}), 105.2(\mathrm{CH}), 99.7(\mathrm{CH}), 55.3\left(\mathrm{CH}_{3}\right), 48.9$ ppm $\left(\mathrm{CH}_{2}\right)$; IR (KBr): 1614, 1497, 1459, 1431, 1351, 1290, 1205, 1158, 1066, 832, $745 \mathrm{~cm}^{-1}$; MS (70 eV, EI) $m / z(\%): 268.2(40)\left[\mathrm{M}^{+}\right], 194.1$ (100), 151.1 (44), 121.1 (26); HRMS (ESI) calcd for $\mathrm{C}_{16} \mathrm{H}_{17} \mathrm{~N}_{2} \mathrm{O}_{2}{ }^{+}\left[\mathrm{M}+\mathrm{H}^{+}\right]$: 269.1285; found: 269.1286. 


\section{1-[(Fur-2-yl)methyl]-1H-benzo[d]imidazole (232h)}

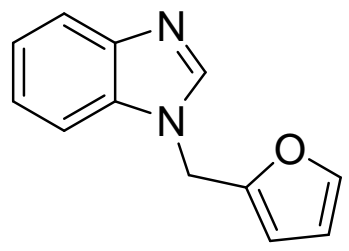

Compound 232h (181 mg, 46\%) was obtained from 2-bromophenyl isocyanide (159-Br) (364 mg, $2 \mathrm{mmol}$ ) and furfurylamine (230h) (194 $\mathrm{mg}, \quad 2 \mathrm{mmol})$ following the GP11, after column chromatography $\left(\mathrm{CH}_{2} \mathrm{Cl}_{2} / \mathrm{MeOH} 20: 1, R_{\mathrm{f}}=0.30\right)$ as a yellow oil. ${ }^{1} \mathrm{H}$ NMR $\left(300 \mathrm{MHz}, \mathrm{CDCl}_{3}\right): \delta 7.92(\mathrm{~s}, 1 \mathrm{H}, \mathrm{N}=\mathrm{CH}), 7.83-7.76(\mathrm{~m}, 1 \mathrm{H}, \mathrm{Ar}-\mathrm{H}), 7.47-7.41$ (m, $1 \mathrm{H}, \mathrm{Ar}-\mathrm{H}), 7.37$ (t, $J=1.1 \mathrm{~Hz}, 1 \mathrm{H}$, furyl-H), 7.33-7.24 (m, $2 \mathrm{H}, \operatorname{Ar}-\mathrm{H}), 6.33$ (m, $2 \mathrm{H}$, furyl-H), $5.28 \mathrm{ppm}\left(\mathrm{s}, 2 \mathrm{H}, \mathrm{CH}_{2}\right) ;{ }^{13} \mathrm{C} \mathrm{NMR}\left(75.5 \mathrm{MHz}, \mathrm{CDCl}_{3}, \mathrm{APT}\right): \delta 152.6(\mathrm{C}), 148.4$ (C), $143.1(\mathrm{CH}), 123.1(\mathrm{C}), 123.1(\mathrm{CH}), 122.2(\mathrm{CH}), 120.4(\mathrm{CH}), 110.6(\mathrm{CH}), 110.3(\mathrm{CH})$, $109.7(\mathrm{CH}), 109.1(\mathrm{CH}), 41.7$ ppm $\left(\mathrm{CH}_{2}\right)$; IR (KBr): 1615, 1495, 1459, 1364, 1287, 1270 , 1238, 1200, 1167, 1147, 1012, 885, $746 \mathrm{~cm}^{-1}$; MS (70 eV, EI) $\mathrm{m} / z(\%): 198.0(38)\left[\mathrm{M}^{+}\right]$, 81 (100), 53 (26); HRMS (ESI) calcd for $\mathrm{C}_{12} \mathrm{H}_{11} \mathrm{~N}_{2} \mathrm{O}^{+}\left[\mathrm{M}+\mathrm{H}^{+}\right]$: 199.08659; found: 199.08658 .

\section{1-[4-(Trifluoromethyl)benzyl]-1H-benzo[d]imidazole (232i)}

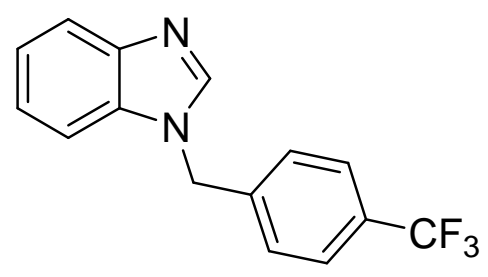

Compound 232i (302 mg, 55\%) was obtained from 2-bromophenyl isocyanide (159-Br) (364 mg, $2 \mathrm{mmol})$ and 4-(trifluoromethyl)benzylamine (230i) (350 mg, $2 \mathrm{mmol}$ ) $\left(\mathrm{CH}_{2} \mathrm{Cl}_{2} / \mathrm{MeOH} 20: 1, R_{\mathrm{f}}=0.34\right)$ as a colorless solid, m. p. $75-76{ }^{\circ} \mathrm{C} .{ }^{1} \mathrm{H}$ NMR $(300 \mathrm{MHz}$, $\left.\mathrm{CDCl}_{3}\right): \delta 7.96(\mathrm{~s}, 1 \mathrm{H}, \mathrm{N}=\mathrm{CH}), 7.84(\mathrm{~d}, J=6.8 \mathrm{~Hz}, 1 \mathrm{H}, \mathrm{Ar}-\mathrm{H}), 7.58(\mathrm{~d}, J=7.9 \mathrm{~Hz}, 2 \mathrm{H}$, Ar-H), 7.33-7.21 (m, $5 \mathrm{H}, \mathrm{Ar}-\mathrm{H}), 5.41 \mathrm{ppm}\left(\mathrm{s}, 2 \mathrm{H}, \mathrm{CH}_{2}\right) ;{ }^{13} \mathrm{C} \mathrm{NMR}\left(75.5 \mathrm{MHz}, \mathrm{CDCl}_{3}\right.$, APT): $\delta 139.5$ (q, $J=1.1 \mathrm{~Hz}, \mathrm{C}), 130.8(\mathrm{C}), 130.3(\mathrm{C}), 127.5(\mathrm{CH}), 127.1(\mathrm{CH}), 126.0$ $(\mathrm{q}, J=3.9 \mathrm{~Hz}, \mathrm{CH}), 125.6(\mathrm{C}), 123.4(\mathrm{CH}), 122.5(\mathrm{CH}), 122.0(\mathrm{CH}), 120.6(\mathrm{CH}), 109.8$ $(\mathrm{CH}), 48.2$ ppm $\left(\mathrm{CH}_{2}\right)$; IR (KBr): 1617, 1496, 1420, 1326, 1162, 1109, 1066, 1015, 826, $745 \mathrm{~cm}^{-1}$; MS (70 eV, EI) m/z (\%): 276.2 (100) $\left[\mathrm{M}^{+}\right], 159.0$ (89); HRMS (ESI) calcd for $\mathrm{C}_{15} \mathrm{H}_{12} \mathrm{~N}_{2} \mathrm{~F}_{3}^{+}\left[\mathrm{M}+\mathrm{H}^{+}\right]$: 277.09471; found: 277.09482. 


\section{1-Cyclopropyl-1H-benzo[d]imidazole $(232 \mathbf{j})^{[204]}$}

$\overbrace{N}^{N}$

Compound 232j (125 mg, 40\%) was obtained from 2-bromophenyl isocyanide (159-Br) (364 $\mathrm{mg}, 2 \mathrm{mmol})$ and cyclopropylamine $(\mathbf{2 3 0 j})$ (114 mg, $2 \mathrm{mmol}$ ) following the GP11, after column chromatography $\left(\mathrm{CH}_{2} \mathrm{Cl}_{2} / \mathrm{MeOH} 20: 1, R_{\mathrm{f}}=0.26\right)$ as a yellow oil. ${ }^{1} \mathrm{H} \mathrm{NMR}(300 \mathrm{MHz}$, $\left.\mathrm{CDCl}_{3}\right): \delta 7.91(\mathrm{~s}, 1 \mathrm{H}, \mathrm{NCH}), 7.79-7.75(\mathrm{~m}, 1 \mathrm{H}, \mathrm{Ar}-\mathrm{H}), 7.57-7.53(\mathrm{~m}, 1 \mathrm{H}, \mathrm{Ar}-\mathrm{H})$, 7.33-7.24 (m, 2 H, Ar-H), 3.38-3.31 (m, 1 H, cPr-CH), 1.16-1.08 (m, 2 H, cPr-CH$)$, 1.04-0.99 ppm (m, $2 \mathrm{H}, \mathrm{cPr}-\mathrm{CH}) ;{ }^{13} \mathrm{C} \mathrm{NMR}\left(75.5 \mathrm{MHz}, \mathrm{CDCl}_{3}\right): \delta 143.6(\mathrm{C}), 143.3(\mathrm{CH})$, $135.0(\mathrm{C}), 122.9(\mathrm{CH}), 122.2(\mathrm{CH}), 120.2(\mathrm{CH}), 110.2(\mathrm{CH}), 25.2(\mathrm{CH}), 5.6 \mathrm{ppm}\left(\mathrm{CH}_{2}\right)$; IR (KBr): 3094, 1643, 1615, 1494, 1460, 1315, 1289, 1239, 1031, $746 \mathrm{~cm}^{-1}$; MS $(70 \mathrm{eV}$, EI) $m / z(\%): 158.0(74)\left[\mathrm{M}^{+}\right], 157$ (100), 131 (47); HRMS (ESI) calcd for $\mathrm{C}_{10} \mathrm{H}_{11} \mathrm{~N}_{2}{ }^{+}$ $\left[\mathrm{M}+\mathrm{H}^{+}\right]:$159.09167; found: 159.09171 .

\section{1-Cyclohexyl-1H-benzo[d]imidazole $(232 \mathrm{k})^{[205]}$}

$\left[{ }_{1}^{N}\right.$

Compound 232k (184 mg, 46\%) was obtained from 2-bromophenyl isocyanide (159-Br) (364 $\mathrm{mg}, 2 \mathrm{mmol})$ and cyclohexylamine (230k) $198 \mathrm{mg}, 2 \mathrm{mmol}$ ) following the GP11, after column chromatography $\left(\mathrm{CH}_{2} \mathrm{Cl}_{2} / \mathrm{MeOH} 40: 1, R_{\mathrm{f}}=0.22\right)$ as a yellowish solid, m.p. $72-74{ }^{\circ} \mathrm{C}$ [lit. $74-75{ }^{\circ} \mathrm{C}$ ]. ${ }^{1} \mathrm{H}$ NMR $\left(300 \mathrm{MHz}, \mathrm{CDCl}_{3}\right): \delta 7.98(\mathrm{~s}, 1 \mathrm{H}, \mathrm{N}=\mathrm{CH})$, 7.83-7.78 (m, 1 H, Ar-H), 7.45-7.40 (m, 1 H, Ar-H), 7.30-7.23 (m, 2 H, Ar-H), 4.18 (s, $1 \mathrm{H}, \mathrm{CH}), 2.20\left(\mathrm{~d}, J=11.3 \mathrm{~Hz}, 2 \mathrm{H}, \mathrm{CH}_{2}\right), 1.96$ (d, $\left.J=13.2 \mathrm{~Hz}, 2 \mathrm{H}, \mathrm{CH}_{2}\right), 1.85-1.72$ $\left(\mathrm{m}, 3 \mathrm{H}, \mathrm{CH}_{2}\right), 1.57-1.42\left(\mathrm{~m}, 2 \mathrm{H}, \mathrm{CH}_{2}\right), 1.38-1.27 \mathrm{ppm}\left(\mathrm{m}, 1 \mathrm{H}, \mathrm{CH}_{2}\right) ;{ }^{13} \mathrm{C} \mathrm{NMR}(75.5$ $\left.\mathrm{MHz}, \mathrm{CDCl}_{3}, \mathrm{APT}\right): \delta 143.8(\mathrm{C}), 140.3(\mathrm{CH}), 133.3(\mathrm{C}), 122.4(\mathrm{CH}), 121.9(\mathrm{CH}), 120.3$ $(\mathrm{CH}), 110.0(\mathrm{CH}), 55.3(\mathrm{CH}), 33.2\left(\mathrm{CH}_{2}\right), 25.6\left(\mathrm{CH}_{2}\right), 25.3 \mathrm{ppm}\left(\mathrm{CH}_{2}\right)$; IR $(\mathrm{KBr})$ : 3109, 3052, 2933, 2855, 1634, 1490, 1456, 1287, 1216, 889, $744 \mathrm{~cm}^{-1}$; MS (70 eV, EI) m/z (\%): 200 (100) $\left[\mathrm{M}^{+}\right], 157$ (27), 118 (66); HRMS (ESI) calcd for $\mathrm{C}_{13} \mathrm{H}_{17} \mathrm{~N}_{2}{ }^{+}\left[\mathrm{M}+\mathrm{H}^{+}\right]: 201.13862$; found: 201.13863 . 


\section{1-p-Tolyl-1H-benzo[d]imidazole $(2321)^{[206]}$}

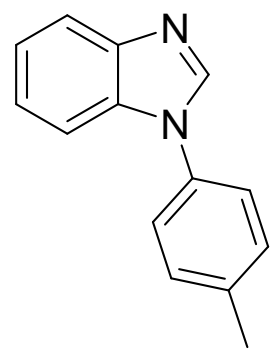

Compound 2321 (172 mg, 41\%) was obtained from 2-bromophenyl isocyanide (159-Br) (364 mg, $2 \mathrm{mmol}$ ) and $p$-toluidine (230l) (214 mg, 2 mmol) following the GP11, after column chromatography $\left(\mathrm{CH}_{2} \mathrm{Cl}_{2} / \mathrm{MeOH} 40: 1, R_{\mathrm{f}}=0.35\right)$ as a colorless solid, m. p. $51-52{ }^{\circ} \mathrm{C}$ [lit. ${ }^{[206]}$ 50-54]. ${ }^{1} \mathrm{H}$ NMR $\left(300 \mathrm{MHz}, \mathrm{CDCl}_{3}\right): \delta 8.08(\mathrm{~s}, 1 \mathrm{H}, \mathrm{NCH})$, 7.89-7.86 (m, 1 H, Ar-H), 7.52-7.49 (m, 1 H, Ar-H), 7.39-7.30 (m, 6 H, Ar-H), 2.44 ppm (s, $\left.3 \mathrm{H}, \mathrm{CH}_{3}\right) ;{ }^{13} \mathrm{C} \mathrm{NMR}\left(75.5 \mathrm{MHz}, \mathrm{CDCl}_{3}, \mathrm{APT}\right): \delta 143.9(\mathrm{C}), 138.0(\mathrm{C}), 134.1(\mathrm{CH})$, $133.8(\mathrm{C}), 133.7(\mathrm{C}), 130.5(\mathrm{CH}), 123.9(\mathrm{CH}), 123.5(\mathrm{CH}), 122.6(\mathrm{CH}), 120.4(\mathrm{CH}), 110.4$ (CH), 21.0 ppm $\left(\mathrm{CH}_{3}\right)$; IR (KBr): 3055, 3062, 1692, 1611, 1518, 1490, 1456, 1289, 1231 , 1205, 822, $744 \mathrm{~cm}^{-1}$; MS (70 eV, EI) $\mathrm{m} / \mathrm{z}(\%)$ : 208.0 (100) $\left[\mathrm{M}^{+}\right]$; HRMS (ESI) calcd for $\mathrm{C}_{14} \mathrm{H}_{13} \mathrm{~N}_{2}^{+}\left[\mathrm{M}+\mathrm{H}^{+}\right]$: 209.10732; found: 209.10734.

\section{1-(2-Bromophenyl)-1H-benzo[d]imidazole (232n)}<smiles>Brc1ccccc1-n1cnc2ccccc21</smiles>

The compound 232n (105 mg, 38\%) was obtained from 2-bromophenyl isocyanide (159-Br) (364 mg, $2 \mathrm{mmol})$ and tert-butylamine (230m) (146 mg, $2 \mathrm{mmol})$ following GP11, after column chromatography $\left(\mathrm{CH}_{2} \mathrm{Cl}_{2} / \mathrm{MeOH} 30: 1, R_{\mathrm{f}}=0.32\right)$ as a red oil. An authentic sample of benzimidazole 232n prepared from 159- $\mathrm{Br}$ and $o$-bromoaniline (230n) in $42 \%$ yield, was identical with the previous one. ${ }^{1} \mathrm{H}$ NMR $\left(300 \mathrm{MHz}, \mathrm{CDCl}_{3}\right): \delta 8.04(\mathrm{~s}, 1 \mathrm{H}, \mathrm{NCH}), 7.90(\mathrm{dd}, J=6.4,1.5 \mathrm{~Hz}, 1 \mathrm{H}), 7.81$ $(\mathrm{dd}, J=7.9,1.1 \mathrm{~Hz}, 1 \mathrm{H}), 7.53-7.26(\mathrm{~m}, 5 \mathrm{H}), 7.19 \mathrm{ppm}(\mathrm{dd}, J=6.8,1.9 \mathrm{~Hz}, 1 \mathrm{H})$; ${ }^{13} \mathrm{C}$ NMR (75.5 MHz, $\left.\mathrm{CDCl}_{3}, \mathrm{APT}\right): \delta 143.1(\mathrm{C}), 142.9(\mathrm{CH}), 135.1(\mathrm{C}), 134.2(\mathrm{C}), 134.1$ $(\mathrm{CH}), 130.5(\mathrm{CH}), 129.0(\mathrm{CH}), 128.6(\mathrm{CH}), 123.6(\mathrm{CH}), 122.7(\mathrm{CH}), 121.4(\mathrm{C}), 120.4$ (CH), 110.5 ppm (CH); IR (KBr): 1613, 1586, 1494, 1454, 1306, 1288, 1230, 1203, 1056, 1030, 786, 744, $721 \mathrm{~cm}^{-1}$; MS (ESI) $\mathrm{m} / z(\%): 567.0\left(2 \mathrm{M}+\mathrm{Na}^{+}\right), 273.0$ (100) $\left[\mathrm{M}+\mathrm{H}^{+}\right]$; HRMS (ESI) calcd for $\mathrm{C}_{13} \mathrm{H}_{10} \mathrm{BrN}_{2}^{+}\left[\mathrm{M}+\mathrm{H}^{+}\right]$: 273.0022; found: 273.0030 . 


\section{3-Benzyl-3H-thieno[2,3-d]imidazole (235a)}<smiles>c1ccc(Cn2cnc3ccsc32)cc1</smiles>

Compound 235a (210 mg, 49\%) was obtained from 2-bromo-3isocyanothiophene (234) (376 mg, $2 \mathrm{mmol}$ ) and benzylamine (230a) (214 mg, $2 \mathrm{mmol})$ following the GP11, after column chromatography $\left(\mathrm{CH}_{2} \mathrm{Cl}_{2} / \mathrm{MeOH} 40: 1, R_{\mathrm{f}}=0.30\right)$ as a colorless solid, m. p. $102-103{ }^{\circ} \mathrm{C}$. ${ }^{1} \mathrm{H}$ NMR (300 MHz, $\mathrm{CDCl}_{3}$ ): $\delta 7.72(\mathrm{~s}, 1 \mathrm{H}, \mathrm{NCH}), 7.36$ (m, $\left.3 \mathrm{H}, \mathrm{Ph}\right), 7.27$ (m, $\left.2 \mathrm{H}, \mathrm{Ph}\right)$, $7.12\left(\mathrm{~d}, J=5.3,1 \mathrm{H}\right.$, thienyl-H), $6.92\left(\mathrm{~d}, J=5.3,1 \mathrm{H}\right.$, thienyl-H), $5.19 \mathrm{ppm}\left(\mathrm{s}, 2 \mathrm{H}, \mathrm{CH}_{2}\right)$; ${ }^{13} \mathrm{C}$ NMR (75.5 MHz, $\left.\mathrm{CDCl}_{3}, \mathrm{APT}\right): \delta 148.7(\mathrm{C}), 141.8(\mathrm{CH}), 134.1(\mathrm{C}), 131.6(\mathrm{C}), 129.0$ $(\mathrm{CH}), 128.7(\mathrm{CH}), 128.1(\mathrm{CH}), 120.7(\mathrm{CH}), 116.6(\mathrm{CH}), 51.2 \mathrm{ppm}\left(\mathrm{CH}_{2}\right)$; IR $(\mathrm{KBr})$ : 1635, 1516, 1456, 1436, 1392, 1354, 1252, 1188, 1092, 1035, 907, $734 \mathrm{~cm}^{-1}$; MS (EI) $\mathrm{m} / \mathrm{z}(\%)$ : 214.2 (44) $\left[\mathrm{M}^{+}\right], 91.1$ (100); HRMS (ESI) calcd for $\mathrm{C}_{12} \mathrm{H}_{11} \mathrm{~N}_{2} \mathrm{~S}\left[\mathrm{M}+\mathrm{H}^{+}\right]$: 215.06375; found: 215.06369 .

\section{3-(3-(Benzyloxy)propyl)-3H-thieno[2,3-d]imidazole (235c)}

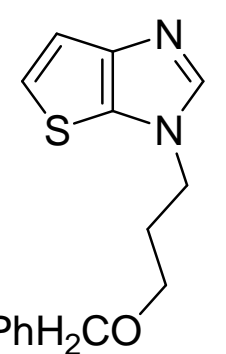

Compound 235c (242 mg, 44\%) was obtained from 2-bromo-3-isocyanothiophene (234) (376 $\mathrm{mg}, \quad 2 \mathrm{mmol}) \quad$ and 3-(benzyloxy)prop-1-yl-amine (230c) (330 $\mathrm{mg}, 2 \mathrm{mmol}$ ) following the GP11, after column chromatography $\left(\mathrm{CH}_{2} \mathrm{Cl}_{2} / \mathrm{MeOH} 40: 1, R_{\mathrm{f}}=0.23\right)$ as a yellow oil. ${ }^{1} \mathrm{H}$ NMR $\left(300 \mathrm{MHz}, \mathrm{CDCl}_{3}\right): \delta 7.55(\mathrm{~s}, 1 \mathrm{H}, \mathrm{NCH})$, 7.39-7.28 (m, $5 \mathrm{H}, \mathrm{Ph}), 7.14$ (d, $J=5.3,1 \mathrm{H}$, thienyl-H), 6.98 (d, $J=5.3,1 \mathrm{H}$, thienyl-H), $4.48\left(\mathrm{~s}, 2 \mathrm{H}, \mathrm{OCH}_{2}\right), 4.21\left(\mathrm{t}, J=6.8 \mathrm{~Hz}, 2 \mathrm{H}, \mathrm{CH}_{2}\right), 3.42\left(\mathrm{t}, J=6.0 \mathrm{~Hz}, 2 \mathrm{H}, \mathrm{CH}_{2}\right), 2.14$ ppm (pent, $\left.J=6.0 \mathrm{~Hz}, 2 \mathrm{H}, \mathrm{CH}_{2}\right) ;{ }^{13} \mathrm{C}$ NMR (75.5 MHz, $\left.\mathrm{CDCl}_{3}, \mathrm{APT}\right): \delta 148.5(\mathrm{C}), 142.2$ $(\mathrm{CH}), 137.9(\mathrm{C}), 131.4(\mathrm{C}), 128.4(\mathrm{CH}), 127.7(\mathrm{CH}), 127.6(\mathrm{CH}), 120.2(\mathrm{CH}), 116.8(\mathrm{CH})$, $73.1\left(\mathrm{CH}_{2}\right), 65.8\left(\mathrm{CH}_{2}\right), 43.9\left(\mathrm{CH}_{2}\right), 29.3 \mathrm{ppm}\left(\mathrm{CH}_{2}\right)$; IR (KBr): 2926, 2862, 1634, 1517 ,

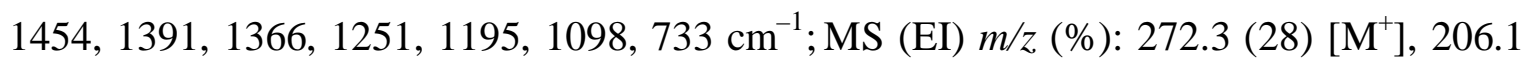
(100) 91.1 (94); HRMS (ESI) calcd for $\mathrm{C}_{15} \mathrm{H}_{17} \mathrm{~N}_{2} \mathrm{OS}^{+}\left[\mathrm{M}+\mathrm{H}^{+}\right]$: 273.10561; found: 273.10560 . 


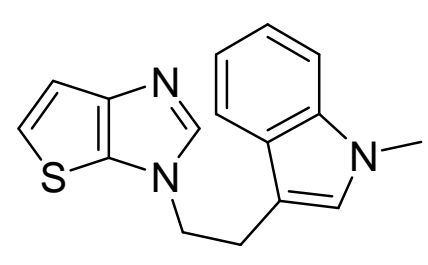

Compound 235d (250 mg, 44\%) was obtained from 2-bromo-3isocyanothiophene (234) (376 $\mathrm{mg}, 2 \mathrm{mmol})$ and 2-(1-methyl$1 H$-indol-3-yl)ethanamine (230d) $(348 \mathrm{mg}, 2 \mathrm{mmol})$ following the GP11, after column chromatography $\left(\mathrm{CH}_{2} \mathrm{Cl}_{2} / \mathrm{MeOH} 40: 1\right.$, $\left.R_{\mathrm{f}}=0.23\right)$ as a yellow oil. ${ }^{1} \mathrm{H} \mathrm{NMR}\left(300 \mathrm{MHz}, \mathrm{CDCl}_{3}\right): \delta 7.54(\mathrm{~d}, J=7.5,1 \mathrm{H}), 7.41(\mathrm{~s}$, $1 \mathrm{H}, \mathrm{NCH}), 7.31-7.22(\mathrm{~m}, 2 \mathrm{H}), 7.16-7.11(\mathrm{~m}, 2 \mathrm{H}), 6.98(\mathrm{dd}, J=5.3,1.1 \mathrm{~Hz}, 1 \mathrm{H}$, thienyl-H), 6.59 (s, $1 \mathrm{H}$, indolyl-2H), 4.33 (t, $\left.J=7.2 \mathrm{~Hz}, 2 \mathrm{H}, \mathrm{CH}_{2}\right), 3.67\left(\mathrm{~s}, 3 \mathrm{H}, \mathrm{CH}_{3}\right)$, $3.31 \mathrm{ppm}\left(\mathrm{t}, J=7.2 \mathrm{~Hz}, 2 \mathrm{H}, \mathrm{CH}_{2}\right) ;{ }^{13} \mathrm{C} \mathrm{NMR}\left(75.5 \mathrm{MHz}, \mathrm{CDCl}_{3}, \mathrm{APT}\right): \delta 148.5(\mathrm{C})$, $142.2(\mathrm{CH}), 137.0(\mathrm{C}), 131.3(\mathrm{C}), 127.8(\mathrm{C}), 127.2(\mathrm{CH}), 121.8(\mathrm{CH}), 120.2(\mathrm{CH}), 119.1$ $(\mathrm{CH}), 118.2(\mathrm{CH}), 116.8(\mathrm{CH}), 109.6(\mathrm{C}), 109.5(\mathrm{CH}), 48.0\left(\mathrm{CH}_{2}\right), 32.6\left(\mathrm{CH}_{3}\right), 25.4 \mathrm{ppm}$ $\left(\mathrm{CH}_{2}\right)$; IR (KBr): 3443, 1640, 1517, 1474, 1435, 1380, 1328, 1250, 1201, 903, $738 \mathrm{~cm}^{-1}$; MS (ESI) $m / z(\%): 585.2(33)\left[2 \mathrm{M}+\mathrm{Na}^{+}\right], 304.1(100)\left[\mathrm{M}+\mathrm{Na}^{+}\right]$; HRMS (ESI) calcd for $\mathrm{C}_{16} \mathrm{H}_{16} \mathrm{~N}_{3} \mathrm{~S}^{+}\left[\mathrm{M}+\mathrm{H}^{+}\right]$: 282.1059; found: 282.1061 


\section{Summary and Outlook}

A variety of transformations, which isocyanides can undergo en route to different $N$-heterocycles is almost as diverse and versatile, as organic chemistry itself. The examples shown in the Introduction of this thesis covered only cases, in which both $\mathrm{C}$ and $\mathrm{N}$ atoms of the isocyano group are integrated into newly formed $N$-heterocycles. In the major part of such catalyzed or base-induced processes two possible routes are realized: 1) an initial deprotonation of the isocyanide is followed by its addition and (or) cyclization or 2) an addition to the isocyano group (or its insertion) is followed by a cyclization of the thus formed reactive intermediate. Base-induced anionic cyclizations are supplemented with some radical processes and transition metal-catalyzed (mediated) reactions as well as organocatalytic transformations. Some shown cyclizations have been found to proceed with high stereo- and enantioselectivities. The versatility and simplicity of such processes has found its reflection in syntheses of various natural products themelves as well as key precursors. Although much of isocyanide chemistry and particularly the syntheses of $N$-heterocycles, have been explored in last 30-40 years, we were convinced even before starting this work, that many methods still remained uncovered. Thus, the main objective of this doctoral thesis has been to find and explore new approaches to $N$-heterocycles from isocyanides.

Two different new syntheses of substituted pyrroles from isocyanides and acetylenes have been developed (see Chapter 1). The formal cycloaddition of $\alpha$-metallated methyl isocyanides 63 onto the triple bond of electron-deficient acetylenes 64 reported recently by de Meijere and Larionov represents a direct and convenient approach to 2,3,4-trisubstituted pyrroles 65. The scope and limitations of this reaction were further elaborated in this study. Some new alkyl-, aryl- and hetarylpropiolates 168 were employed in the efficient synthesis of 2,3,4-trisubstituted pyrroles 173 (7 examples, 68-94\%). The terminal acceptor-substituted acetylenes, such as methyl propiolate $(\mathbf{1 6 8 h})$ have been shown to provide the corresponding 2,4-disubstituted pyrroles in their reaction with substituted methyl isocyanides 63, albeit in lower yields (4 examples, 7-44\%). Some test experiments towards optimization of the reaction conditions (solvent, temperature, catalyst) are presented herein along with the description of a plausible mechanism. Next, we tried to fathom the possibility of employing unactivated acetylenes in their reaction with $\mathbf{6 3}$. Thus, a novel $\mathrm{Cu}(\mathrm{I})$-mediated synthesis of 2,3-disubstituted pyrroles $\mathbf{1 7 8}$ by reaction of copper 
acetylides derived from unactivated terminal alkynes 167 with substituted methyl isocyanides 63 has been developed. After the optimization of reaction conditions, 11 examples of such 2,3-disubstituted pyrroles 178 have been synthesized (5-88\% yield). The proposed mechanism of this new transformation was confirmed by some additional experiments.

Metallated isocyanides, as mentioned above, may be versatile precursors for various $\mathrm{N}$-heterocycles. We envisaged, that ortho-metallated phenyl isocyanide 188 - $\mathrm{Li}$ and related compounds (200) which have not been known before, might be versatile intermediates for the synthesis of particular heterocycles as well. In Chapter 2, the generation and further reactions of ortho-lithiophenyl isocyanide 188 - $\mathrm{Li}$, the first example of a ring- metallated aryl isocyanide known so far, are described. Thus, 188-Li conveniently obtained by halogen-lithium exchange on ortho-bromophenyl isocyanide (159-Br), was trapped with various electrophiles to provide corresponding 2-substituted phenyl isocyanides 192 (5 examples, $55-88 \%$ yield). In the reaction of $188-\mathrm{Li}$ with dimethylformamide, 2-(formylamino)-benzaldehyde 196 was formed unexpectedly and isolated in 76\% yield. The latter presumably arose by hydrolysis of the initially formed 1,3-benzoxazine derivative 194. The reactions of 188- $\mathrm{Li}$ with isocyanates and isothiocyanates afforded, after treatment of the reaction mixture with water, pharmaceutically relevant 3-substituted $3 H$-quinazoline-4-ones and 3H-quinazolin-4-thiones 191 (9 examples, 69-91\% yield). Treatment of the same mixtures after the reaction of ortho-lithiophenyl isocyanide 188-Li with an isocyanate containing lithiated intermediates $190-\mathrm{Li}$ with a second electrophile, provided the corresponding 2,3-disubstituted 3H-quinazoline-4-ones 191 (6 examples, $54-85 \%$ yield). In two cases, this trapping could proceed intramolecularly as an appropriate functional group was provided in the isocyanates themselves. Thus, the naturally occurring alkaloids deoxyvasicinone (191n) and tryptanthrine (1910) were synthesized in 72 and $85 \%$ yield, respectively, in a one-pot procedure following this strategy.

In Chapter 3, the reactions of ortho-lithiophenyl isocyanide (188-Li) and some of its heteroanalogues (3-isocyano-2-thienyllithium 216 and 3-isocyano-2-pyridyllithium 218) with aldehydes, ketones and carbon dioxide are considered in detail. ortho-Lithiophenyl (-hetaryl) isocyanides of the general type 200 react at $-78{ }^{\circ} \mathrm{C}$ with aldehydes to provide the corresponding isocyanobenzylalcohols 204 (36-89\%, 9 examples), and with ketones 
to form the respective $4 H-3,1$-benzoxazines 201 (48-78\%, 3 examples), when the mixture was treated with water before work-up. Treatment of the same mixtures at $-78{ }^{\circ} \mathrm{C}$ with other electrophiles provided in moderate to good yields 2-substituted 4H-3,1-benzoxazines 2011-R, 206, 207 and in one case, the mixed carbonate 205 of the isocyanoalcohol $204 \mathrm{~d}$. 2-Lithiated 4H-3,1-benzoxazines of type 198 (and their heteroanalogues generated from lithiated isocyanides of type 200) have been shown to undergo two types of unprecedented rearrangements providing isobenzofuran-1(3H)-imines (iminophthalanes) 210 (and its heteroanalogues 211, 219l) or indolin-2-ones 215 (and its heteroanalogue 217k), depending on the reaction conditions and substitution patterns. Proposed mechanisms of these novel rearrangements include pericyclic ring opening in $\mathbf{1 9 8}$ with destruction of benzene ring aromatic character followed by two types of recyclizations to give $\mathrm{N}$-metallated oxoindoles 215 or isobenzofuran-1(3H)-imines 210. Isocyanoalcohols 204 in turn were converted to $4 H-3,1$-benzoxazines 201 or isobenzofuran-1(3H)-imines 210 (or its heteroanalogue 211d) under $\mathrm{Cu}(\mathrm{I})$ catalysis (66-86\%, 8 examples). 4H-3,1Benzoxazin-4-ones 199- $\mathrm{Nu}$ and isatoic anhydride 209 were obtained by the reaction of 188-Li with carbon dioxide followed by trapping of the lithiated intermediate with iodine and subsequent reactions with nucleophiles (45-60\%, 3 examples).

Transition-metal catalyzed processes have become one of the most important parts of modern organic chemistry in general and particularly in the synthesis of heterocycles. Therefore, the exploration of new such processes employing isocyanides is strongly required. In the last part of this thesis (Chapter 4), a novel copper-catalyzed synthesis of 1-substituted benzimidazoles 232 from $o$-bromoaryl isocyanide $(\mathbf{1 5 9}-\mathrm{Br})$ and primary amines (230) is presented. The optimization of the reaction conditions revealed that the best yields of benzimidazoles are achieved, when the reaction is performed in DMF with $\mathrm{Cs}_{2} \mathrm{CO}_{3}$ as a base and $\mathrm{CuBr} / 1,10$-Phenanthroline as a catalyst. Importantly, the temperature of the reaction mixture should be gradually increased up to $90{ }^{\circ} \mathrm{C}$ to achieve highest yields. Under optimized conditions, $159-\mathrm{Br}$ reacts with various primary amines in the presence of the $\mathrm{Cu}(\mathrm{I})$ catalyst to afford 1-substituted benzimidazoles $\mathbf{2 3 2}$ in moderate to good yields (38-70\%, 13 examples). Analogously, 2-bromo-3-isocyanothiophene (234) furnishes 3 -substituted $3 H$-thieno[2,3-d]imidazoles 235 (44-49\%, 3 examples). Mechanistically, 1-substituted benzimidazoles 232 and their heteroanalogues 235 are believed to result from a sequential reaction consisting of a copper-catalyzed addition of an amine 230 onto an isocyano group of $159-\mathrm{Br}$ followed by a copper-catalyzed 
intramolecular $\mathrm{N}$-arylation of the thus formed formamidine (231). Interestingly, the $\mathrm{Cu}(\mathrm{I})$-catalyzed reaction of $159-\mathrm{Br}$ with tert-butylamine did not provide the corresponding $N$-tert-butyl benzimidazoles (232m), but gave 1-(2-bromophenyl)benzimidazole $232 \mathrm{n}$ in $38 \%$ yield. The supposed rationale for this fact involves the in situ formation of 2-bromoaniline (230n) and subsequent reaction of 159-Br with it. This assumption was confirmed by independent reaction of $159-\mathrm{Br}$ with $230 \mathrm{n}$, which also provided $232 \mathrm{n}$ in $42 \%$ yield. 


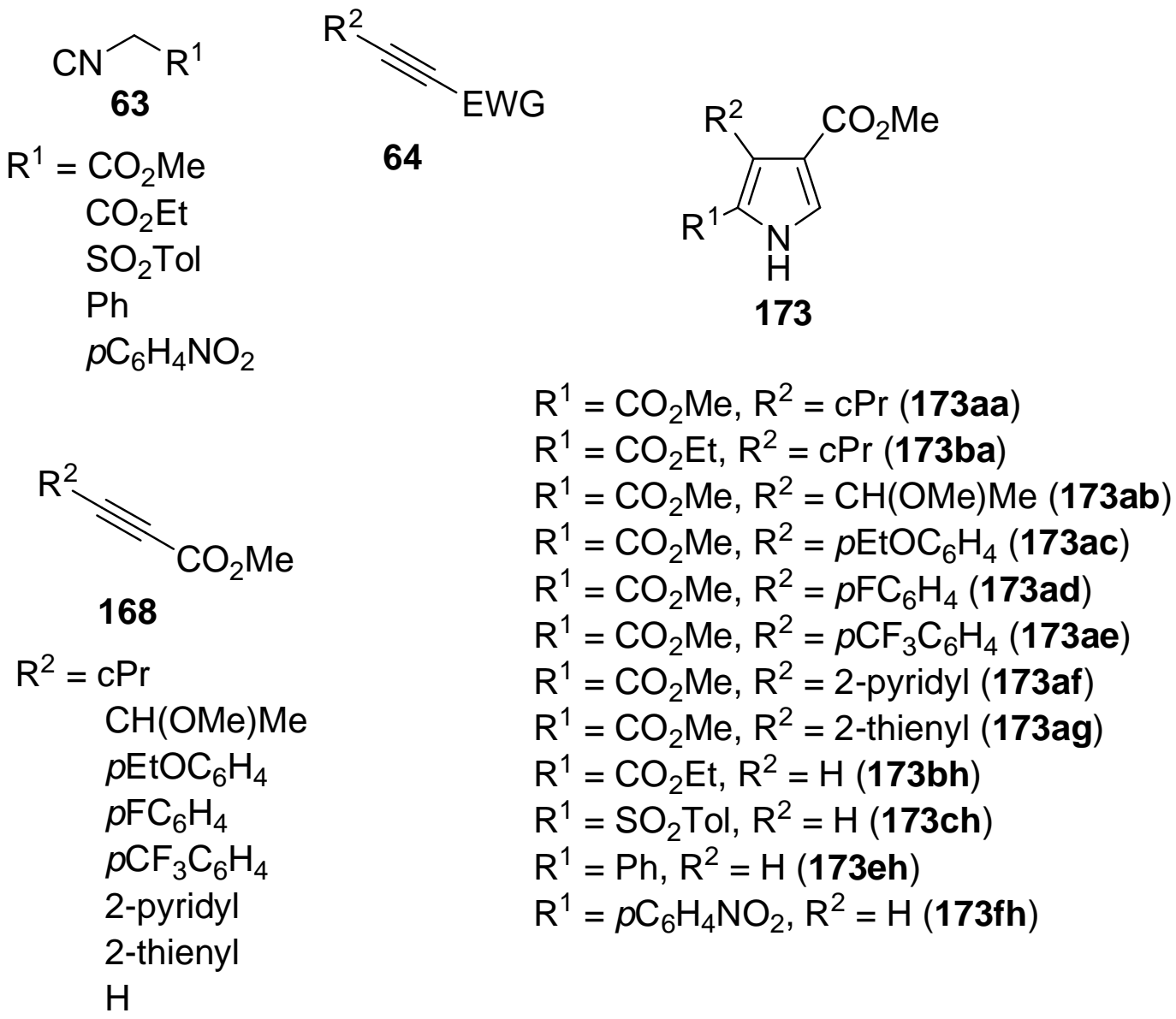<smiles>C#C[Tl]</smiles>

167<smiles>[R]c1cc[nH]c1[R]</smiles>

178<smiles>O=C1OCCc2cc[nH]c21</smiles>

179

$$
\begin{array}{ll}
\mathrm{R}^{1}=\mathrm{nBu} & \mathrm{R}^{1}=n \mathrm{Bu}, \mathrm{R}^{2}=\mathrm{CO}_{2} \mathrm{Et}(\mathbf{1 7 8 b a}) \\
\mathrm{CH}_{2} \mathrm{OMe} & \mathrm{R}^{1}=\mathrm{CH}_{2} \mathrm{OMe}, \mathrm{R}^{2}=\mathrm{CO}_{2} \mathrm{Et}(\mathbf{1 7 8 b} \mathbf{b}) \\
\mathrm{CH}(\mathrm{OMe}) \mathrm{Me} & \mathrm{R}^{1}=\mathrm{CH}(\mathrm{OMe}) \mathrm{Me}, \mathrm{R}^{2}=\mathrm{CO}_{2} \mathrm{Et}(\mathbf{1 7 8 b}) \\
\mathrm{Ph} & \mathrm{R}^{1}=\mathrm{Ph}, \mathrm{R}^{2}=\mathrm{CO}_{2} \mathrm{Et}(\mathbf{1 7 8 b d}) \\
\mathrm{cPr} & \mathrm{R}^{1}=\mathrm{cPr}, \mathrm{R}^{2}=\mathrm{CO}_{2} \mathrm{Et}(\mathbf{1 7 8 b e}) \\
t \mathrm{Bu} & \mathrm{R}^{1}=t \mathrm{Bu}, \mathrm{R}^{2}=\mathrm{CO}_{2} \mathrm{Et}(\mathbf{1 7 8 b f}) \\
2-\mathrm{pyridyl} & \mathrm{R}^{1}=2-\mathrm{pyridyl}, \mathrm{R}^{2}=\mathrm{CO}_{2} \mathrm{Et}(\mathbf{1 7 8 b g}) \\
\text { secBu } & \mathrm{R}^{1}=\mathrm{secBu}, \mathrm{R}^{2}=\mathrm{CO}_{2} \mathrm{Et}(\mathbf{1 7 8 b}) \\
\left(\mathrm{CH}_{2}\right)_{2} \mathrm{OH} & \mathrm{R}^{1}=n \mathrm{Bu}, \mathrm{R}^{2}=\mathrm{CO}_{2} \mathrm{Et}(\mathbf{1 7 8 b i}) \\
& \mathrm{R}^{1}=n \mathrm{Bu}, \mathrm{R}^{2}=\mathrm{CO}_{2} t \mathrm{Bu}(\mathbf{1 7 8} \mathbf{c a}) \\
& \mathrm{R}^{1}=n \mathrm{Bu}, \mathrm{R}^{2}=\mathrm{pC}_{6} \mathrm{H}_{4} \mathrm{NO}_{2} \text { (178bi) }
\end{array}
$$<smiles>CCOC(=O)c1cc(C(Br)(Br)c2ccccc2)c[nH]1</smiles> 


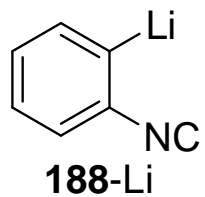<smiles>Cc1ccccc1Br</smiles>

$159-\mathrm{Br}$<smiles></smiles><smiles></smiles>

$X=O, E I=H, R=P h(191 a)$

4- $\mathrm{MeC}_{6} \mathrm{H}_{4}$ (191b)

$4-\mathrm{CF}_{3} \mathrm{C}_{6} \mathrm{H}_{4}$ (191c)

4- $\mathrm{FC}_{6} \mathrm{H}_{4}$ (191d)

$\mathrm{CH}_{2} \mathrm{Ph}(191 \mathrm{e})$

iPr (191f)

cPr (191g)

$X=S, E I=H, R=c P r(191 h)$

cHex (191i)

$\mathrm{X}=\mathrm{O}, \mathrm{El}=\mathrm{CO}_{2} \mathrm{Me}, \mathrm{R}=\mathrm{Ph}(\mathbf{1 9 1 j})$

$\mathrm{X}=\mathrm{O}, \mathrm{El}=\mathrm{SPh}, \mathrm{R}=\mathrm{Ph}(\mathbf{1 9 1 k})$

$X=O, E l=C N, R=P h(191 \mathrm{I})$

$\mathrm{X}=\mathrm{O}, \mathrm{El}=\mathrm{I}, \mathrm{R}=\mathrm{CH}_{2} \mathrm{Ph}$ (191m)

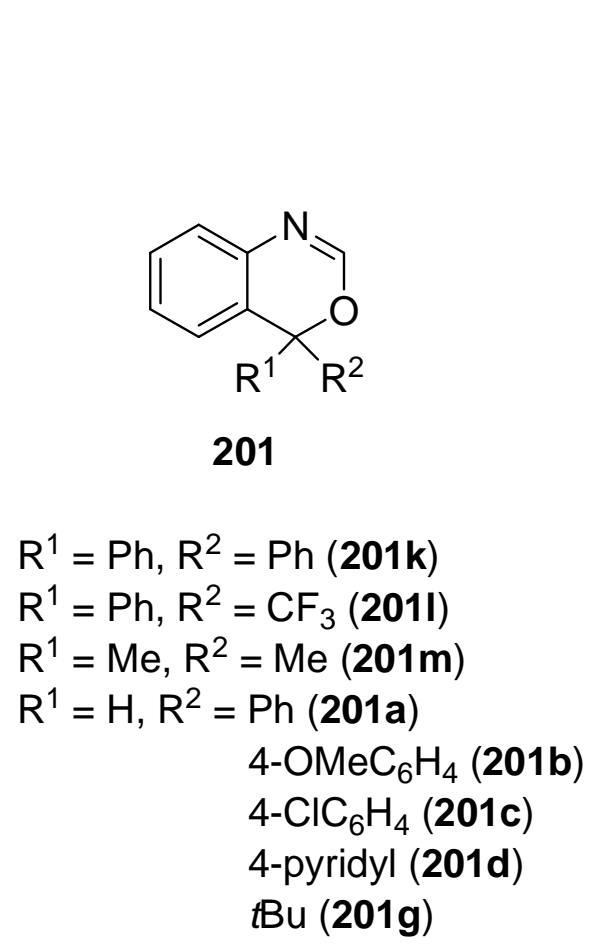<smiles>N#Cc1ccccc1F</smiles>

192

$E=I(159-I)$

$\mathrm{CO}_{2} \mathrm{Me} \mathrm{(192a)}$

$\mathrm{SPh}$ (192b)

$\mathrm{CHO}(192 \mathrm{c})$<smiles>O=c1c2ccccc2nc2n1CCC2</smiles><smiles>[N-]=[N+]=[N+]c1ccsc1Cl</smiles>

216<smiles></smiles>

204

$\mathrm{R}=\mathrm{Ph}$ (204a)

4- $\mathrm{OMeC}_{6} \mathrm{H}_{4}$ (204b)

4- $\mathrm{ClC}_{6} \mathrm{H}_{4}$ (204c)

4-pyridyl (204d)

2-(5-methylthienyl) (204e)

2-(5-methylfuryl) (204f)

tBu (204g)

iPr (204h)

1-(2-methyl-

2-butene-1-yl) (204i)<smiles>[R]C1=Nc2ccccc2C(F)(c2ccccc2)O1</smiles>

201I-R

$\mathrm{R}=\mathrm{CO}_{2} \mathrm{Me}\left(201 \mathrm{I}-\mathrm{CO}_{2} \mathrm{Me}\right)$

$\mathrm{CH}_{2} \mathrm{CO}_{2} \mathrm{Et}$

(201I-CH ${ }_{2} \mathrm{CO}_{2} \mathrm{Et}$ )

$\mathrm{N}$-morpholino (207)
$\mathrm{CO}_{2} \mathrm{Me}$<smiles></smiles><smiles>[N-]=[N+]=Cc1cccnc1Cl</smiles>

218<smiles>CC(=O)OC(c1ccncc1)c1ccccc1[N+]#N</smiles>

205<smiles>O=C1Nc2ccccc2C(c2ccccc2)(C(F)(F)F)OC1=O</smiles>

206<smiles>O=CNc1ccccc1C=O</smiles> 
<smiles>[R]C1([R])OC([AlH2])=Nc2ccccc21</smiles>

198<smiles>[R]C1([R7])OC(=N)c2ccccc21</smiles>

$210 \mathrm{NH}$<smiles>[Z15]c1ccccc1C1([R7])C(=O)Nc2ccccc21</smiles>

$$
\begin{array}{ll}
R^{1}=H, R^{2}=2-(5-\text { methyl- } & R^{1}=H, R^{2}=2 \text {-pyridyl (215n) } \\
\text { furyl) }(\mathbf{2 1 0 f}) & R^{1}=P h, R^{2}=P h(215 k) \\
R^{1}=H, R^{2}=\operatorname{iPr}(\mathbf{2 1 0 h}) & \\
R^{1}=M e, R^{2}=C_{3}(2100) &
\end{array}
$$<smiles>O=C1Nc2ccsc2C1(c1ccccc1)c1ccccc1</smiles>

217k<smiles></smiles>

$\mathrm{Nu}=\mathrm{N}$-morpholine (199-morph) $\mathrm{Nu}=\mathrm{N}$-aziridine (199-azirid)<smiles>[Mg][Mg]</smiles><smiles>c1ccc2c(c1)ncn2CCn1cnc2ccccc21</smiles>

232e<smiles>[R6]n1cnc2ccccc21</smiles>
$\mathrm{RNH}_{2}$ 230

$$
\mathrm{R}=\mathrm{Ph}(232 \mathrm{a})
$$
$n \operatorname{Pr}(\mathbf{2 3 2 b})$

$\left(\mathrm{CH}_{2}\right)_{3} \mathrm{OCH}_{2} \mathrm{Ph}(232 \mathrm{c})$ $\left(\mathrm{CH}_{2}\right)_{2}$ (3-N-methylindolyl) (232d)

$\mathrm{CH}_{2}\left(2-\mathrm{MeOC}_{6} \mathrm{H}_{4}\right)$ (232f) $\mathrm{CH}_{2}\left(3,5-\mathrm{MeOC}_{6} \mathrm{H}_{3}\right)(\mathbf{2 3 2 g})$ $\mathrm{CH}_{2}$ (2-furyl) (232h) $\mathrm{CH}_{2}\left(4-\mathrm{CF}_{3} \mathrm{C}_{6} \mathrm{H}_{4}\right)(232 \mathrm{i})$ CPr (232j) cHex (232k) 4- $\mathrm{MeC}_{6} \mathrm{H}_{4}$ (232I) tBu (232m) 2- $\mathrm{BrC}_{6} \mathrm{H}_{4}$ (232n)<smiles>[R]NC=Nc1ccccc1Br</smiles>
131 


\section{E. References and Comments}

[1] a) A. Gautier, Ann. Chem. Pharm. 1868, 146, 119-124; Isocyanides as new isomers of cyanides are mentioned and announced previously (but not described) in: A. Gautier, Ann. Chem. Pharm. 1867, 142, 289-294.

[2] A. W. Hofmann, Ann. Chem. Pharm. 1867, 144, 114-120.

[3] a) I. Ugi, R. Meyr, Angew. Chem. 1958, 70, 702-703; b) I. Ugi, U. Fetzer, U. Eholzer, H. Knupfer, K. Offermann, Angew. Chem. 1965, 77, 492-504; Angew. Chem. Int. Ed. Engl. 1965, 4, 472-484.

[4] a) W. P. Weber, G. W. Gokel, Tetrahedron Lett. 1972, 1637-1640; b) W. P. Weber, G. W. Gokel, I. K. Ugi, Angew. Chem. 1972, 84, 587; Angew. Chem. Int. Ed. Engl. 1972, 11,530-531.

[5] For a general review, see: a) M. Suginome, Y. Ito, In Science of Synthesis Vol. 19 (Ed.: S.-I. Murahashi), Thieme, Stuttgart, 2004, pp. 445-530, and references cited therein.

[6] For reviews, see: a) A. Dömling, I. Ugi, Angew. Chem. 2000, 112, 3300-3344; Angew. Chem. Int. Ed. 2000, 39, 3168-3210; b) H. Bienayme, C. Hulme, G. Oddon, P. Schmitt, Chem. Eur. J. 2000, 6, 3321-3329; c) J. Zhu, Eur. J. Org. Chem. 2003, 1133-1144; d) V. Nair, C. Rajesh, A. U. Vinod, S. Bindu. A. R. Sreekanth, J. S. Mathen, L. Balagopal, Acc. Chem. Res. 2003, 36, 899-907; d) A. Dömling, Chem. Rev. 2006, 106, 17-89; e) L. El Kaim, L. Grimaud, Tetrahedron 2009, 65, 2153-2171.

[7] For some representative examples, see: a) N. Chatani, T. Hanafusa, J. Org. Chem. 1991, 56, 2166-2170; b) E. Kroke, S. Willms, M. Weidenbruch, W. Saak, S. Pohl, H. Marsmann, Tetrahedron Lett. 1996, 37, 3675-3678; c) S. Kamijo, Y. Yamamoto, J. Am. Chem. Soc. 2002, 124, 11940-11945; d) N. Chatani, M. Oshita, M. Tobisu, Y. Ishii, S. Murai, J. Am. Chem. Soc. 2003, 125, 7812-7813; e) G. Bez, C.-G. Zhao, Org. Lett. 2003, 5, 4991-4993; f) M. Oshita, K. Yamashita, M. Tobisu, N. Chatani, J. Am. Chem. Soc. 2005, 127, 761-766; g) P. Fontaine, G. Masson, J. Zhu, Org. Lett. 2009, 11, 1555-1558.

[8] a) R. F. Heck, In: Palladium Reagents in Organic Synthesis; Academic Press: New York, 1985. b) J. Tsuji, In: Palladium Reagents and Catalysts; John Wiley: Chichester,U.K., 1995. c) Y. Ito, M. Suginome, In: Handbook of Organopalladium 
Chemistry for Organic Synthesis (Eds.: Negishi, E.; de Meijere, A.), Wiley, New York 2002.

[9] For reviews on metal-isocyanide complexes, see: a) Y. Yamamoto, H. Yamazaki, Coord. Chem. Rev. 1972, 8, 225-239; b) P. M. Treichel, Adv. Organomet. Chem. 1973, 11, 21-86; c) E. Shingleton, H. E. Oosthuizen, Adv. Organomet. Chem. 1983, 22, 209-310.

[10] M. Suginome, Y. Ito, Adv. Polym. Sci. 2004, 171 (polymer synthesis) 77-136.

[11] a) T. Fukuyama, X. Chen, G. Peng, J. Am. Chem. Soc. 1994, 116, 3127-3128; b) Y. Kobayashi, T. Fukuyama, J. Heterocycl. Chem. 1998, 35, 1043-1055; c) H. Tokuyama, Y. Kaburagi, X. Chen, T. Fukuyama, Synthesis 2000, 429-434; For a review, see d) H. Tokuyama, T. Fukuyama, Chem. Rec. 2002, 2, 37-45.

[12] H. Josien, S.-B. Ko, D. Born, D. P. Curran, Chem. Eur. J. 1998, 4, 67-83:

[13] a) For a review on tandem radical reactions with isocyanides, see: I. Ryu, N. Sonoda, D. P. Curran, Chem. Rev. 1996, 96, 177-194.

[14] U. Schöllkopf, F. Gerhart, Angew. Chem. 1968, 80, 842-843; Angew. Chem. Int. Ed. Engl. 1968, 7, 805-806.

[15] For reviews, see: a) D. Hoppe, Angew. Chem. 1974, 86, 878-893; b) U. Schöllkopf, Angew.Chem. 1977, 89, 351-360; Angew. Chem. Int. Ed. Engl. 1977, 16, 339-348; c) U Schöllkopf, Pure Appl. Chem. 1979, 51, 1347-1355; d) K. Matsumoto, T. Moriya, M. Suzuki, J. Synth. Org. Chem., Jpn. 1985, 43, 764-776.

[16] a) D. H. R. Barton, S. Z. Zard, J. Chem. Soc., Chem. Commun. 1985, 1098-1100; b) D. H. R. Barton, J. Kervagoret, S. Z. Zard, Tetrahedron 1990, 46, 7587-7598; c) J. L. Sessler, A. Mozattari, M. Johnson, Org. Synth. 1992, 70, 68-77; Coll. Vol. 9 1998, 242-251.

[17] T. D. Lash, J. R. Belletini, J. A. Bastian, K. B. Couch, Synthesis 1994, 170-172.

[18] J. Tang, J. G. Verkade, J. Org. Chem. 1994, 59, 7793-7802.

[19] A. Bhattacharya, S. Cherukuri, R. E. Plata, N. Patel, V. Tamez, Jr., J. A. Grosso, M. Peddicordb, V. A. Palaniswam, Tetrahedron Lett. 2006, 47, 5481-5484.

[20] a) N. Ono, H. Hironaga, K. Ono, S. Kaneko, T. Murashima, T. Ueda, C. Tsukamura, T. Ogawa, J. Chem. Soc., Perkin Trans. 1 1996, 417-423; b) T D. Lash, P. Chandrasekar, A. T. Osuma, S. T. Chaney, J. D. Spence, J. Org. Chem., 1998, 63, 8455-8469. 
[21] a) P. Magnus, P. Halazy, Tetrahedron Lett. 1984, 25, 1421-1424; b) G. Haake, D. Struve, F.-P. Montforts, Tetrahedron Lett. 1994, 35, 9703-9704; c) D. P. Arnold, L. Burgess-Dean, J. Hubbard, M. A. Rahman, Aust. J. Chem. 1994, 47, 969-974; d) Y. Abel, F.-P. Montforts, Tetrahedron Lett. 1997, 38, 1745-1748; e) W. Schmidt, F.-P. Montforts, Synlett 1997, 903-904; f) S. Ito, T. Murashima, N. Ono, J. Chem. Soc., Perkin Trans. 1 1997, 3161-3165; g) Y. Abel, E. Haake, G. Haake, W. Schmidt, D. Struve, A. Walter, F.-P. Montforts, Helv. Chim. Acta 1998, 81, 19781996; h) H. Uno, M. Tanaka, T. Inoue, N. Ono, Synthesis, 1999, 3, 471-474.

[22] a) W. Huebsch, R. Angerbauer, P. Fey, H. Bischoff, D. Petzinna, D. Schmidt, G. Thomas, Eur. Pat. Appl.; Bayer, A.-G.; Fed. Rep. Ger.: Ep, 1989; p 36; b) J. L. Bullington, R. R. Wolff, P. F. Jackson, J. Org. Chem., 2002, 67, 9439-9442.

[23] N. C. Misra, K. Panda, H. Ila, H. Junjappa, J. Org. Chem. 2007, 72, 1246-1251.

[24] Y. Fumoto, T. Eguchi, H. Uno, N. Ono, J. Org. Chem., 1999, 64, 6518-6521.

[25] U. Robben, I. Lindner, W. Gärtner, J. Am. Chem. Soc. 2008, 130, 11303-11311.

[26] N. Ono, H. Kawamura, M. Bougauchi, K. Maruyama, Tetrahedron, 1990, 46, 7483-7496.

[27] A. M. van Leusen, G. J. M. Boerma, R. B. Helmholdt, H. Siderius, J. Strating, Tetrahedron Lett. 1972, 23, 2367-2368. For Reviews, see: d) Review: D. van Leusen, A. M. van Leusen, Org. React. 2001, 57, 417-666; e) V. K. Tandon, S. Rai, Sulfur Rep. 2003, 24, 307-385.

[28] For reviews, see: a) A. M. van Leusen, D. van Leusen In Encyclopedia for Organic Synthesis; L. A. Paquette Ed.; Wiley: New York, 1995, Vol. 7, pp 4973-4979; b) A. M. van Leusen, Lect. Heterocycl. Chem. 1980, 5, S111-S122;

[29] a) A. M. van Leusen, B. E. Hoogenboom, H. Siderius, Tetrahedron Lett. 1972, 13, 2369-2372; b) B. A. Kulkarni, A. Ganesan, Tetrahedron Lett. 1999, 40, 56375638.

[30] a) A. M. van Leusen, J. Wildeman, O. Oldenziel, J. Org. Chem. 1977, 42, 11531159; b) R. ten Have, M. Huisman, A. Meetsma, A. M. van Leusen, Tetrahedron 1997, 53, 11355-11368.

[31] For synthesis of imidazoles fused to other heterocyclic systems with TosMIC, see: a) P. Chen, J. C. Barrish, E. Iwanowicz, J. Lin, M. S. Bednarz, B.-C. Chen, 
Tetrahedron Lett. 2001, 42, 4293-4295; b) B.-C. Chen, R. Zhao, M. S. Bednarz, B. Wang, J. E. Sundeen, J. C. Barrish, J. Org. Chem. 2004, 69, 977-979.

b) A. M. van Leusen, H. Siderius, B. E. Hoogenboom, D. van Leusen, Tetrahedron Lett. 1972, 13, 5337-5340; c) D. van Leusen E. Flentge, A. M. van Leusen, Tetrahedron 1991, 47, 4639-4644.

[33] H. P. Dijkstra, R. ten Have, A. M. van Leusen, J. Org. Chem. 1998, 63, 53325338.

[34] N. D. Smith, D. Huang, N. D. P. Cosford, Org. Lett. 2002, 4, 3537-3539.

[35] a) J. Moskal, R. van Stralen, D. Postma, A. M. van Leusen, Tetrahedron Lett. 1986, 27, 2173-2176; b) J. Moskal, A. M. van Leusen, J. Org. Chem. 1986, 51, 4131-4139.

[36] a) A. R. Katritzky, Y. X. Chen, K. Yannakopoulou, P. Lue, Tetrahedron Lett. 1989, 30, 6657-6660; b) A. R. Katritzky, D. Cheng, R. P. Musgrave, Heterocycles 1997, 44, 67-70.

[37] a) T. Saegusa, Y. Ito, H. Kinoshita, S. Tomita, J. Org. Chem. 1971, 36, 33163323; b) Y. Ito, T. Matsuura, T. Saegusa, Tetrahedron Lett. 1985, 26, 5781-5784;

[38] T. Hayashi, E. Kishi, V. Soloshonok, Y. Uozumi, Tetrahedron Lett. 1996, 37, 4969-4972.

[39] R. Grigg, M. I. Lansdell, M. Thornton-Pett, Tetrahedron, 1999, 55, 2025-2044.

[40] B. Trost, Science 1991, 254, 1471-1477.

[41] a) Y. Ito, M. Sawamura, T. Hayashi, J. Am. Chem. Soc. 1986, 108, 6405-6406; b) Y. Ito, M. Sawamura, M. Kobayashi, T. Hayashi, Tetrahedron Lett. 1987, 28, 6215-6218; c) Y. Ito, M. Sawamura, E. Shirakawa, K. Hayashizaki, T. Hayashi, Tetrahedron Lett. 1988, 29, 235-238; d) Y. Ito, M. Sawamura, E. Shirakawa, K. Hayashizaki, T. Hayashi, Tetrahedron 1988, 44, 5253-5262; e) Y. Ito, M. Sawamura, T. Hayashi, Tetrahedron Lett. 1988, 29, 239-240; f) Y. Ito, M. Sawamura, H. Hamashima, T. Emura, T. Hayashi, Tetrahedron Lett. 1989, 30, 4681-4684; e) T. Hayashi, M. Sawamura, Y. Ito, Tetrahedron 1992, 48, 19992012; For a concise review, see: E. M. Carreira, A. Fetters, C. Marti, Org. React. (Hoboken, NY) 2006, 67, 1-216.

[42] a) Y. Ito, M. Sawamura, T. Hayashi, Tetrahedron Lett. 1988, 29, 6321-6324; b) M. Sawamura, Y. Ito, T. Hayashi, Tetrahedron Lett.1989, 30, 2247-2250; c) 
Sawamura, Y. Ito, T. Hayashi, J. Org. Chem. 1990, 55, 5935-5936; d) M. Sawamura, Y. Nakayama, T. Kato, Y. Ito, J. Org. Chem. 1995, 60, 1727-1732.

[43] a) S. D. Pastor, A. Togni, J. Am. Chem. Soc. 1989, 111, 2333-2334; b) A. Togni, R. Häusel, Synlett, 1990, 633-; c) A. Togni, S. D. Pastor, G. Rihs, J. Organomet. Chem. 1990, 381, C21-; d) A. Togni, S. D. Pastor, J. Org. Chem. 1990, 55, 16491664.

[44] a) R. Nesper, P. S. Pregosin, K. Püntener, M. Wörle, Helv. Chim. Acta 1993, 76, 2239-2249; b) F. Gorla, A. Togni, L. M. Venanzi, A. Albinati, F. Lianza, Organometallics 1994, 13, 1607-1616; c) J. M. Longmire, X. Zhang, M. Shang, Organometallics 1998, 17, 4374-4379; c) Y. Motoyama, H. Kawakami, K. Shimozono, K. Aoki, H. Nishiyama, Organometallics, 2002, 21, 3408-3416.

[45] a) X.-T. Zhou, Y.-R. Lin, L.-X. Dai, J. Sun, L.-J. Xia, M.-H. Tang, J. Org. Chem. 1999, 64, 1331-1334; b) X.-T. Zhou, Y.-R. Lin, L.-X. Dai, Tetrahedron Asymm. 1999, 10, 855-862.

[46] Y.-R. Lin, X.-T. Zhou, L.-X. Dai, J. Org. Chem. 1997, 62, 1799-1803.

[47] J. Audin, K. S. Kumar, L. Eriksson, K. J. Szabo, Adv. Synth. Cat. 2007, 349, 25852594.

[48] J. Aydin, A. Ryden, K. J. Szabo, Tetrahedron Assym. 2008, 19, 1867-1870.

[49] D. Benito-Garagorri, V. Bocokic, K. Kirchner, Tetrahedron Lett. 2006, 47, 86418644.

[50] a) S. Kamijo, C. Kanazawa, Y. Yamamoto, J. Am. Chem. Soc. 2005, 127, 92609266; b) S. Kamijo, C. Kanazawa, Y. Yamamoto, Tetrahedron Lett. 2005, 46, 2563-2566.

[51] O. V. Larionov, A. de Meijere, Angew. Chem. 2005, 117, 5809-5813; Angew. Chem. Int. Ed. 2005, 44, 5664-5667

[52] D. Gao, H. Zhai, M. Parvez, T. G. Back, J. Org. Chem. 2008, 73, 8057-8068.

[53] C. Kanazawa, S. Kamijo, Y. Yamamoto, J. Am. Chem. Soc. 2006, 128, 1066210663.

[54] H. Takaya, S. Kojima, S.-I. Murahashi, Org. Lett. 2001, 3, 421-424.

[55] U. Schöllkopf, F. Gerhart, R. Schröder, Angew. Chem. 1969, 81, 701; Angew. Chem. Int. Ed. Engl. 1969, 8, 672. 
[56] a) Y. Ito, K. Kobayashi, T. Saegusa, J. Am. Chem. Soc. 1977, 99, 3532-3534; b) Y. Ito, K. Kobayashi, N. Seko, T. Saegusa, Bull. Chem. Soc. Jpn. 1984, 57, 73-84.

[57] Y. Ito, Y. Inubushi, T. Sugaya, K. Kobayashi, T. Saegusa, Bull. Soc. Chem. Jpn. 1978, 51, 1186-1188.

[58] Ito, Y. Kobayashi, K.; Saegusa, T. J. Org. Chem. 1979, 44, 2030-2032.

[59] Y. Ito, T. Konoike, T. Saegusa, J. Organomet. Chem. 1975, 85, 395-401.

[60] Y. Ito, K. Kobayashi, T. Saegusa, Tetrahedron Lett. 1978, 2087-2090.

[61] Y. Ito, K. Kobayashi, T. Saegusa, Tetrahedron Lett. 1979, 1039-1042.

[62] Y. Ito, K. Kobayashi, M. Maeno, T. Saegusa, Chem. Lett. 1980, 487-490.

[63] Y. Ito, K. Kobayashi, T. Saegusa, Chem. Lett. 1980, 1563-1566.

[64] a) W. D. Jones, W. P. Kosar, J. Am. Chem. Soc. 1986, 108, 5640-5641; b) G. C. Hsu, W. P. Kosar, W. D. Jones Organometallics 1994, 13, 385-396.

[65] K. Kobayashi, T. Nakashima, M. Mano, O. Morikawa, H. Konishi, Chem. Lett. 2001, 602-603.

[66] K. Kobayashi, K. Yoneda, T. Mizumoto, H. Umakoshi, O. Morikawa, H. Konishi, Tetrahedron Lett. 2003, 44, 4733-4736.

[67] a) H. M. Walborsky, G. E. Niznik, J. Am. Chem. Soc. 1969, 91, 7778;

[68] G. E. Niznik, W. H. Morrison III, H. M. Walborsky, J. Org. Chem. 1974, 39, 600-604.

[69] a) H. M. Walborsky, P. Ronman, J. Org. Chem. 1978, 43, 731-734; b) J. Heinicke, J. Organomet. Chem. 1989, 364, C17-C21.

[70] A. Orita, M. Fukudome, K. Ohe, S. Murai, J. Org. Chem. 1994, 59, 477-481.

[71] M. Suginome, T. Fukuda, Y. Ito, Org. Lett. 1999, 1, 1977-1979.

[72] Y. Ito, E. Ihara, M. Hirai, H. Ohsaki, A. Ohnishi, M. Murakami, J. Chem. Soc., Chem. Commun. 1990, 403-405.

[73] a) K. Kobayashi, K. Yoneda, M. Mano, O. Morikawa, H. Konishi, Chem. Lett. 2003, 32, 76-77; b) K. Kobayashi, K. Yoneda, K. Miyamoto, O. Morikawa, H. Konishi, Tetrahedron 2004, 60, 11639-11645.

[74] J. Ichikawa, Y. Wada, H. Miyazaki, T. Mori, H. Kuroki, Org. Lett. 2003, 5, $1455-1458$.

[75] J. Ichikawa, T. Mori, H. Miyazaki, Y. Wada, Synlett 2004, 1219-1222. 
[76] a) M. Westling, T. Livinghouse, Tetrahedron Lett. 1985, 26, 5389-5392; b) M. Westling, R. Smith, T. Livinghouse, J. Org. Chem. 1986, 51, 1159-1165.

[77] G. Luedtke, M. Westling, T. Livinghouse, Tetrahedron, 1992, 48, 2209-2222.

[78] G. Luedtke, T. Livinghouse, J. Chem. Soc., Perkin Trans. 1, 1995, 2369-2371.

[79] C. H. Lee, M. Westling, T. Livinghouse, A. C. Williams, J. Am. Chem. Soc. 1992 , 114, 4089-4095.

[80] M. Westling, T. Livinghouse, J. Am. Chem. Soc. 1987, 109, 590-592.

[81] a) D. J. Hughes, T. Livinghouse, J. Chem. Soc., Perkin Trans. 1 1995, 2373-2374;

b) T. Kercher, T. Livinghouse, J. Org. Chem. 1997, 62, 805-812.

[82] R. Bossio, S. Marcaccini, R. Pepino, Heterocycles, 1986, 24, 2003-2005.

[83] R. Bossio, S. Marcaccini, R. Pepino, C. Polo, G. Valle, Synthesis, 1989, 641-643.

[84] R. Bossio, S. Marcaccini, R. Pepino, Heterocycles, 1986, 24, 2411-2413.

[85] For proposed by authors mechanism of this transformation, see: R. Bossio, S. Marcaccini, R. Pepino, T. Torroba, G. Valle, Synthesis, 1987, 1138-1139.

[86] E. Bulka, K. D. Ahlers, E. Tucek, Chem. Ber. 1967, 100, 1367-1372.

[87] a) N. Sonoda, G. Yamamoto, S. Tsutsumi, Bull. Soc. Chem. Jpn. 1972, 45, 2937-2938; b) S. Fujiwara, T. Matsuya, H. Maeda, T. Shin-ike, N. Kambe, N. Sonoda, Synlett 1999, 75-76.

[88] S. Fujiwara, Y. Asanuma, T. Shin-ike, N. Kambe, J. Org. Chem. 2007, 72, 8087-8090.

[89] L. L. Joyce, G. Evindar, R. A. Batey, Chem. Commun. 2004, 446-447.

[90] H. Maeda, T. Matsuya, N. Kambe, N. Sonoda, S. Fujiwara, T. Shin-ike, Tetrahedron 1997, 53, 12159-12166.

[91] A. V. Lygin, O. V. Larionov, V. S. Korotkov, A. de Meijere Chem. Eur. J. 2009, 15, 227-236.

[92] a) B. D. Roth, C. J. Blankley, A. W. Chucholowski, E. Ferguson, M. L. Hoefle, D. F. Ortwine, R. S. Newton, C. S. Sekerke, D. R. Slikovic, C. D. Stratton, M. W. Wilson, J. Med. Chem. 1991, 34, 357-366; b) J. M. Gottesfeld, L. Neely, J. W. Trauger, E. E. Baird, P. B. Dervan, Nature 1997, 387, 202-205; c) M. Adamczyk, D. D. Johnson, R. E. Reddy, Angew. Chem. 1999, 111, 3751-3753; Angew. Chem. Int. Ed. 1999, 38, 3537-3539; d) S. Depraetere, M. Smet, W. Dehaen, Angew. Chem. 1999, 111, 3556-3558; Angew. Chem. Int. Ed. 1999, 38, 3359-3361; e) D. 
E. N. Jacquot, M. Zöllinger, T. Lindel, Angew. Chem. 2005, 117, 2336-2338; Angew. Chem. Int. Ed. 2005, 44, 2295-2298; f) T. Lindel, M. Hochgürtel, M. Assmann, M. Köck, J. Nat. Prod. 2000, 63, 1566-1569; g) G. Dannhardt, W. Kiefer, Arch. Pharm. 2001, 334, 183-188; h) D. Seidel, V. Lynch, J. L. Sessler, Angew. Chem. 2002, 114, 1480-1483; Angew. Chem. Int. Ed. 2002, 41, 1422-1425; i) J. A. Johnson, N. Li, D. Sames, J. Am. Chem. Soc. 2002, 124, 6900-6903; j) H. Hoffmann, T. Lindel, Synthesis 2003, 1753-1783; k) H. Garrido-Hernandez, M. Nakadai, M. Vimolratana, Q. Li, T. Doundoulakis, P. G. Harran, Angew. Chem. 2005, 117, 775-779; Angew. Chem. Int. Ed. 2005, 44, 765-769.

[93] a) K. Yamaji, M. Masubuchi, F. Kawahara, Y. Nakamura, A. Nishio, S. Matsukuma, M. Fujimori, N. Nakada, J. Watanabe, T. Kamiyama, J. Antibiot. 1997, 50, 402-411; b) B. Fournier, D. C. Hooper, Antimicrob. Agents \& Chemother. 1998, 42, 121-128; c) D. Perrin, B. van Hille, J.-M. Barret, A. Kruczynski, C. Etievant, T. Imbert, B. T. Hill, Biochem. Pharmacol. 2000, 59, 807-819; d) F. Micheli, R. Di Fabio, R. Benedetti, A. M. Capelli, P. Cavallini, P. Cavanni, S. Davalli, D. Donati, A. Feriani, S. Gehanne, M. Hamdan, M. Maffeis, F. M. Sabbatini, M. E. Tranquillini, M. V. A. Viziano, Farmaco 2004, 175-183.

[94] a) H. Miyaji, W. Sato, J. L. Sessler, Angew. Chem. 2000, 112, 1847-1850; Angew. Chem. Int. Ed. 2000, 39, 1777-1780; b) F.-P. Montforts, O. Kutzki, Angew. Chem. 2000, 112, 612-614; Angew. Chem. Int. Ed. 2000, 39, 599-601; c) D. W. Yoon, H. Hwang, C.-H. Lee, Angew. Chem. 2002, 114, 1835-1837; Angew. Chem. Int. Ed. 2002, 41, 1757-1759; d) J. O. Jeppesen, J. Becher, Eur. J. Org. Chem. 2003, 3245-3266.

[95] a) V. F. Ferreira, M. C. B. V. de Souza, A. C. Cunha, L. O. R. Pereira, M. L. G. Ferreira, Org. Prep. Proced. Int. 2001, 33, 411-454; b) D. X. Zeng, Y. Chen, Synlett 2006, 490-492, and references therein; c) M. R. Tracey, R. P. Husung, R. H. Lambeth, Synthesis 2004, 918-922, and references therein; for reviews see: d) T. L. Gilchrist, J. Chem. Soc., Perkin Trans. 1999, 1, 2849-2866; e) Chemistry of Heterocyclic Compounds: Pyrroles (Ed.: R. A. Jones) Wiley: New York, 1990; Vol. 48; f) D. S. Black in Science of Synthesis, Vol. 5 (Ed.: G. Maas) Thieme, Stuttgart, 2001, pp. 441-552. 
[96] For some recent reports on the synthesis of oligosubstituted pyrroles, see: a) D. J. S. Cyr, N. Martin, B. A. Arndtsen, Org. Lett. 2007, 9, 449-452; b) B.C. Milgram, K. Eskildsen, S. M. Richter, W. R. Scheidt, K. A. Scheidt, J. Org.Chem. 2007, 72, 3941-3944; c) D. J. S. Cyr, N. Martin, B. A. Arndtsen, Org. Lett. 2007, 9, 449452; d) R. M. Rodriguez, S. L. Buchwald, Org. Lett. 2007, 9, 973-976; e) M. Shindo, Y. Yoshimura, M. Hayashi, H. Soejima, T. Yoshikawa, K. Matsumoto, K. Shishido, Org. Lett. 2007, 9, 1963-1966; f) S. Su, J. A. Porco, Jr., J. Am. Chem. Soc. 2007, 129, 7744-7745; g) F. M. Istrate, F. Gagosz, Org. Lett. 2007, 9, 31813184; h) R. Martin, C. H. Larsen, A. Cuenca, S. L. Buchwald, Org. Lett. 2007, 9, 3379-3382; i) H. Dong, M. Shen, J. E. Redford, B. J. Stokes, A. L. Pumphrey, T. G. Driver, Org. Lett. 2007, 9, 5191-5194; j) S. Chiba, Y.-F. Wang, G. Lapointe, K. Narasaka, Org. Lett. 2008, 10, 313-316; k) A. S. Dudnik, A. W. Sromek, M. Rubina, J. T. Kim, A. V. Kel'in, V. Gevorgyan, J. Am. Chem. Soc. 2008, 130, 1440-1452; 1) Y. Lu, X. Fu, H. Chen, X. Du, X. Jia, Y. Liu, Adv. Synth. Catal. 2009, 351, 129-134; m) P. Fontaine, G. Masson, Y. Zhu, Org. Lett. 2009, 74, 1555-1558; n) L. Ackermann, R. Sandmann, L. T. Kaspar, Org. Lett. 2009, 11, 2031-2034.

[97] Only pyrroles prepared by the author are included in this table.

[98] a) Y. Matsuya, K. Hayashi, H. Nemoto, J. Am. Chem. Soc. 2003, 125, 646-647; b)

E. Winterfeldt, Chem. Ber. 1964, 97, 1952-1958; c) A.W. McCulloch, A.G. McInnes, Can. J. Chem. 1974, 52, 3569-3576.

[99] A. Skatteboel, Acta Chem. Scand. 1959, 13, 191-198.

[100] a) H. C. Kolb, M. G. Finn, K. B. Sharpless, Angew. Chem. 2001, 113, 2056-2075; Angew. Chem. Int. Ed. 2001, 40, 2004-2021; b) V. V. Rostovtsev, L. G. Green, V. V. Fokin, K. B. Sharpless, Angew. Chem. 2002, 114, 2708-2711; Angew. Chem. Int. Ed. 2002, 41, 2596-2599; c) C. M. Tornoe, C. Christensen, M. J. Meldal, J. Org. Chem. 2002, 67, 3057-3064.

[101] a) G. Wilkinson, T. S. Piper, J. Inorg. Nucl. Chem. 1956, 2, 32-34; b) F. A. Cotton, T. J. Marks, J. Am. Chem. Soc. 1970, 92, 5114-5117.

[102] D. B. Beach, F. K. LeGoues, C.-K. Hu, Chem. Mater. 1990, 2, 216-219.

[103] T. Saegusa, Y. Ito, S. Tomita, J. Am. Chem. Soc. 1971, 93, 5656-5661. 
[104] T. Tsuda, H. Habu, S. Horiguchi, T. Saegusa, J. Am. Chem. Soc. 1974, 96, 59305931.

[105] a) T. Saegusa, Y. Ito, S. Tomita, H. Kinoshita, J. Org. Chem. 1970, 88, 670-675; b) T. Saegusa, Y. Ito. H. Kinoshita, S. Tomita, Bull. Chem. Soc. Jap. 1970, 48, 877-879; c) T. Saegusa, I. Murase, Y. Ito, J. Org. Chem. 1971, 36, 2876-2880; d) T. Saegusa, Y. Ito, S. Tomita, H. Kinoshita, Bull. Chem. Soc. Jap. 1972, 45, 496499.

[106] T. Saegusa, K. Yonezawa, I. Murase, T. Konoike, S. Tomita, Y. Ito, J. Org. Chem. 1973, 38, 2319-2328.

[107] P. C. J. Kamer, M. C. Cleij, R. J. M. Nolte, T. Harada, A. M. F. Hezemans, W. Drenth, J. Am. Chem. Soc. 1988, 110, 1581-1587.

[108] a) M. Komatsu, Y. Yoshida, M. Uesaka, Y. Ohshiro, T. Agawa, J. Org. Chem. 1984, 49, 1300-1302; b) V. Amarnath, D. C. Anthony, K. Amarnath, W. M. Valentine, L. A. Wetterau, D. G. Graham, J. Org. Chem. 1991, 56, 6924-6931; c) G. Dana, O. Convert, J.-P. Girault, E. M. Mulliez, Can. J. Chem. 1976, 54, 18271835; d) H. O. Bayer, Chem. Ber. 1970, 103, 2356-2367.

[109] For a review, see: J. F. Normant, A. Alexakis, Synthesis 1981, 841-870.

[110] W. J. Gensler, A. P. Mahadevan, J. Org. Chem. 1956, 180-182.

[111] For some recently published transformations of pyrroles, see: direct C-arylation of free (NH)-pyrroles: a) X. Wang, B. S. Lane, D. Sames, J. Am. Chem. Soc. 2005, 127, 4996-4997; b) R. D. Rieth, N. P. Mankad, E. Calimano, J. P. Sadighi, Org. Lett. 2004, 6, 3981-3983; addition of pyrroles to unfunctionalized enediynes: c) A. Odedra, C.-J. Wu, T. B. Pratap, C.-W. Huang, Y.-F. Ran, R.-S. Liu, J. Am. Chem. Soc. 2005, 127, 3406-3412; oxidative cyanation of pyrroles: d) T. Dohi, K. Morimoto, Y. Kiyono, H. Tohma, Y. Kita, Org. Lett. 2005, 7, 537-540; [4+3] cycloadditions onto pyrroles: e) R. P. Reddy, L. Davies, J. Am. Chem. Soc. 2007, 129, 10312-10313; f) asymmetric hydrogenation of pyrroles: R. Kuwano, M. Kashiwabara, M. Ohsumi, H. Kusano, J. Am. Chem. Soc. 2008, 130, 808-809.

[112] a) K. Sakai, M. Suzuki, K.-i. Nunami, N. Yoneda, Y. Onoda, Y. Iwasawa, Chem. Pharm. Bull. 1980, 28, 2384-2393; b) M. Bergauer, P. Gmeiner, Synthesis 2001, $15,2281-2288$.

[113] A. V. Lygin, A. de Meijere Org. Lett. 2009, 11, 389-392. 
[114] S. Sinha, M. Srivastava, Prog. Drug Res. 1994, 43, 143.

[115] T. Nagase, T. Mizutani, S. Ishikawa, E. Sekino, T. Sasaki, T. Fujimura, S. Ito, Y. Mitobe, Y. Miyamoto, R. Yoshimoto, T. Tanaka, A. Ishihara, N. Takenaga, S. Tokita, T. Fukami, N. Sato, J. Med. Chem. 2008, 51, 4780-4789.

[116] S. E. de Laszlo, C. S. Quagliato, W. J. Greenlee, A. A. Patchett, R. S. L. Chang, V. J. Lotti, T.-B. Chen, S. A. Scheck, K. A. Faust, S. S. Kivlighn, T. S. Schorn, G. J. Zingaro, P. K. S. Siegl, J. Med. Chem. 1993, 36, 3207-3210.

[117] a) N. J. Liverton, D. J. Armstrong, D. A. Claremon, D. C. Remy, J. J. Baldwin, R. J. Lynch, G. Zhang, R. J. Gould, Bioorg. Med. Chem. Lett. 1998, 8, 483-486; b) W. Zhang, J. P. Mayer, S. E. Hall, J. A. Weigel, J. Comb. Chem. 2001, 3, 255-256.

[118] A. Gopalsamy, H. Yang, J. Comb. Chem. 2000, 2, 378-381.

[119] B. E. Evans, K. E. Rittle, M. G. Bock, R. M. DiPardo, R. M. Freidinger, W. L. Whitter, G. F. Lundell, D. F. Veber, P. S. Anderson, R. S. L. Chang, V. J. Lotti, D. J. Cerino, T. B. Chen, P. J. Kling, K. A. Kunkel, J. P. Springer, J. Hirshfield, J. Med. Chem. 1988, 31, 2235-2246.

[120] D. A. Horton, G. T. Bourne, M. L. Smythe, Chem. Rev. 2003, 103, 893-930.

[121] a) B. B. Snider, X. Wu, Org. Lett. 2007, 9, 4913-4915; b) C. H. Oh, C. H. Song, Synth. Commun. 2007, 37, 3311-3317; c) M. R. Linder, A. R. Heckeroth, M. Najdrowski, A. Daugschies, D. Schollmeyer, C. Miculka, Bioorg. Med. Chem. Lett. 2007, 17, 4140-4143; d) W. R. Bowman, M. R. J. Elsegood, T. Stein, G. W. Weaver, Org. Biomol. Chem. 2007, 5, 103-113; e) J. R. Duvall, F. Wu, B. B. Snider, J. Org. Chem. 2006, 71, 8579-8590; f) S. H. Shim, J. S. Kim, K. H. Son, K. H. Bae, S. S. Kang, J. Nat. Prod. 2006, 69, 400-402; g) C.-W. Jao, W.-C. Lin, Y.-T. Wu, P.-L. Wu, J. Nat. Prod. 2008, 71, 1275-1279.

(122) For recent reviews on quinazoline alkaloids, see: a) J. P. Michael, Nat. Prod. Rev. 2004, 21, 650-668; b) J. P. Michael, Nat. Prod. Rep. 2008, 166-187.

[123] For reviews, see: a) K. Undheim, T. Benneche, In: Comprehensive Heterocyclic Chemistry II, Vol. 6; Pergamon: Oxford, 1998; b) D. J. Connolly, D. Cusack, T. P. O’Sullivan, P. J. Guiry, Tetrahedron 2005, 61, 10153-10202.

[124] For some recently published syntheses of $3 H$-quinazolin-4-ones, see: a) W. Zeghida, J. Debray, S. Chierici, P. Dumy, M. Demeunynck, J. Org. Chem. 2008, 
73, 2473-2475; b) S. B. Mhaske, N. P. Argade, J. Org. Chem. 2004, 69, 45634566.

[125] a) A. Krasovskiy, P. Knochel, Angew. Chem. 2004, 116, 3396-3399; Angew. Chem. Int. Ed. 2004, 43, 3333-3336; b) H. Ren, A. Krasovskiy, P. Knochel, Org. Lett. 2004, 6, 4215-4217.

[126] Some other electrophiles, such as aldehydes, ketones and carbon dioxide have also been tested. The results are summarized in the next chapter.

[127] U. Schöllkopf, K.-W. Henneke, K. Madawinata, R. Harms, Justus Liebigs Ann. Chem. 1977, 1, 40-50.

[128] a) R. Murdoch, W. R. Tully, R. Westwood, J. Heterocycl. Chem. 1986, 23, 833841; b) B. L. Chenard, W. M. Welch, J. F. Blake, T. W. Butler, A. Reinhold, F. E. Ewing, F. S. Menniti, M. J. Pagnozzi, J. Med. Chem. 2001, 44, 1710-1717; c) Y. V. Bilokin, S. M. Kovalenko, Heterocycl. Commun. 2000, 6, 409-414.

[129] a) W. R. Bowman, M. R. J. Elsegood, T. Stein, G. W. Weaver, Org. Biomol. Chem. 2007, 5, 103-113; b) R. Tangirala, S. Antony, K. Agama, D. P. Curran, Synlett 2005, 18, 2843-2846; c) C. Kaneko, K. Kasai, N. Katagiri, T. Chiba, Chem. Pharm. Bull. 1986, 34, 3672-3681.

[130] A. Perdicaro, G. Granata, A. Marrazzo, A. Santagati, Synth. Commun. 2008, 38, 723-737.

[131] For selected examples of recent syntheses of deoxyvasicinone, see: a) S. B. Mhaske, N. P. Argade, J. Org. Chem. 2001, 66, 9038-9040; b) J.-F. Liu, P. Ye, K. Sprague, K. Sargent, D. Yohannes, C. M. Baldino, C. J. Wilson, S.-C. Ng, Org. Lett. 2005, 7, 3363-3366; c) E. S. Lee, J.-G. Park, Y. Jahng, Tetrahedron Lett. 2003, 44, 1883-1886; d) A. Hamid, A. Elomri, A. Daich, Tetrahedron Lett. 2006, 47, 1777-1781; e) W. R. Bowman, M. R. J. Elsegood, T. Stein, G. W. Weaver, Org. Biomol. Chem. 2007, 5, 103-113.

[132] For recent syntheses of tryptanthrine, see: a) K. C. Jahng, S. I. Kim, D. H. Kim, C. S. Seo, J.-K. Son, S. H. Lee, E. S. Lee, Y. Jahng, Chem. Pharm. Bull. 2008, 56, 607-609; b) B. Batanero, F. Barba, Tetrahedron Lett. 2006, 47. 8201-8203.

[133] A. V. Lygin, A. de Meijere J. Org. Chem. 2009, 74, 4554-4559.

[134] a) U. Schöllkopf, F. Gerhart, I. Hoppe, R. Harms, K. Hantke, K.-H. Scheunemann, E. Eilers, E. Blume, Justus Liebigs Ann. Chem. 1976, 183-202; b) W. A. Böll, A. 
Gerhart, A. Nürrenbach, U. Schöllkopf, Angew. Chem. 1970, 82, 482-483; Angew. Chem. Int. Ed. Engl. 1970, 9, 458-459; c) U. Schöllkopf, P. Böhmes, Angew. Chem. 1971, 83, 490-491; Angew. Chem. Int. Ed. Engl. 1971, 10, 491-492.

[135] For reviews, see: a) M. E. Jung, G. Piizzi, Chem. Rev. 2005, 105, 1735-1766; b) P. G. Sammes, D. J. Weller, Synthesis, 1995, 1205-1222.

[136] For a review, see: E. V. Gromachevskaya, F. V. Kvitkovskii, T. P. Kosulina, V. G. Kul'nevich, Chem. Heterocycl. Compd. (N.Y) 2003, 39, 137-155.

[137] For a few examples of such compounds published to date, see: a) I. Fleming, M. A. Loreto, I. H. M. Wallace, J. Chem. Soc., Perkin Trans. 1 1986, 349-359; b) R. R. Gataullin, I. S. Afonkin, A. A. Fatykhov, L. V. Spirikhin, E. V. Tal'vinskii, I. B. Abdrakhmanov, Russ. Chem. Bull. 2001, 50, 659-664.

[138] K. Kobayashi, S. Nagato, M. Kawakita, O. Morikawa, H. Konishi, Chem. Lett. 1995, 24, 575-576.

[139] For examples of naturally occurring 4H-3,1-benzoxazin-4-ones, see: a) J. J. Mason, J. Bergman, T. Janosik, J. Nat. Prod. 2008, 71, 1447-1450; b) H. Wang, A. Ganesan, J. Org. Chem. 1998, 63, 2432-2433.

[140] a) G. Fenton, C. G. Newton, B. M. Wyman, P. Bagge, D. I. Dron, D. Riddell, G. D. Jones, J. Med. Chem., 1989, 32, 265-272; b) L. Hedstrom, A. R. Moorman, J. Dobbs, R. H. Abeles, Biochemistry, 1984, 23, 1753-1759; For reviews on 4H-3,1benzoxazin-4-ones, see: c) G. M. Coppola, J. Heterocycl. Chem. 1999, 36, 563588; d) G. M. Coppola, J. Heterocycl. Chem. 2000, 37, 1369-1388.

[141] a) K. Ding, Y. Lu, Z. Nikolovska-Coleska, G. Wang, S. Qiu, S. Shangary, W. Gao, D. Qin, J. Stuckey, K. Krajewski, P. P. Roller, S. Wang, J. Med. Chem. 2006, 49, 3432-3435; b) T. Jiang, K. L. Kuhen, K. Wolff, H. Yin, K. Bieza, J. Caldwell, B. Bursulaya, T. Y.-H. Wu, Y. He, Bioorg. Med. Chem. Lett. 2006, 16, 2105-2108; c) K. C. Luk, S. S. So, J. Zhang, Z. Zhang, (F. Hoffman-LaRoche AG), WO 2006/136606 A3, 2006; d) P. Hewawasam, V. K. Gribkoff, Y. Pendri, S. I. Dworetzky, N. A. Meanwell, E. Martinez, C. G. Boissard, D. J. Post-Munson, J. T. Trojnacki, K. Yeleswaram, L. M. Pajor, J. Knipe, Q. Gao, R. Perrone, J. E., Jr. Starrett, Bioorg. Med. Chem. Lett. 2002, 12, 1023-1026; e) R. Sarges, H. R. Howard, K. Koe, A. Weissman, J. Med. Chem. 1989, 32, 437-444. 
[142] For some syntheses of iminophthalanes, see: a) R. Sato, M. Ohmori, F. Kaitani, A. Kurosawa, T. Senzaki, T. Goto, M. Saito, Bull. Chem. Soc. Jpn. 1988, 61, 24812485; b) H. Suzuki, M. Koge, A. Inoue, T. Hanafusa, Bull. Chem. Soc. Jpn. 1978, 51, 1168-1171; c) H. Suzuki, M. Koge, T. Hanafusa, J. Chem. Soc. Chem. Commun. 1977, 341-342.

[143] a) D. Lednicer, E. D. Emmert, J. Heterocycl. Chem. 1970, 7, 575-581; b) R. R. Schmidt, B. Beitzke, Chem. Ber. 1983, 116, 2115-2135.

[144] For reviews on [1,2]-Wittig rearrangement, see: a) K. Tomooka, H. Yamamoto, T. Nakai, Liebigs Ann./Recueil 1997, 1275-1281; b) K. Tomooka, In The Chemistry of OrganolithiumCompounds; Rappoport, Z., Marek, I., Eds.; Wiley: London, 2004; Vol. 2, pp 749-828.

[145] For reviews, see: a) J. A. Vanecko, H. Wan, F. G. West, Tetrahedron 2006, 62, 1043-1062; b) I. E. Markó, B. M. Trost, I. Fleming, Eds.; In Comprehensive Organic Synthesis; Pergamon: Oxford, 1991; Vol. 3, pp 913-973.

[146] The author is grateful to one of the referees who pointed out this possibility during the submition of the article (J. Org. Chem.).

[147] a) T. Saegusa, Y. Ito, Synthesis, 1975, 291-300; b) T. Saegusa, Y. Ito, N. Takeda, K. Hirota, Tetrahedron Lett. 1967, 8, 1273-1275; c) T. Saegusa, Y. Ito, S. Kobayashi, K. Hirota, Tetrahedron Lett. 1967, 8, 521-524.

[148] A mixture of 91 in benzene with $10 \mathrm{~mol} \%$ of $\mathrm{Cu}_{2} \mathrm{O}$ was heated under reflux for $1 \mathrm{~h}$. No changes were detected according to TLC.

[149] A. V. Lygin, A. de Meijere, Eur. J. Org. Chem. 2009, 5138-5141.

[150] For reviews, see: a) A. Kamal, K. L. Reddy, V. Devaiah, N. Shankaraiah, M. V. Rao, Mini Rev. Med. Chem. 2006, 6, 71-89; b) R. R. Wexler, W. J. Greenlee, J. D. Irvin, M. R. Goldberg, K. Prendergast, R. P. Smith, P. B. M. W. M. Timmermans, J. Med. Chem. 1996, 39, 625-656.

[151] a) Y.-F. Li, G.-F. Wang, P.-L. He, W.-G. Huang, F.-H. Zhu, H.-Y. Gao, W. Tang, Y. Luo, C.-L. Feng, L.-P. Shi, Y.-D. Ren, W. Lu, J.-P. Zuo, J. Med. Chem. 2006, 49, 4790-4794; b) P. L. Beaulieu, Y. Bousquet, J. Gauthier, J. Gillard, M. Marquis, G. McKercher, C. Pellerin, S. Valois, G. Kukolj, J. Med. Chem., 2004, 47, 6884-6892; c) S. Hirashima, T. Suzuki, T. Ishida, S. Noji, S. Yata, I. Ando, M. Komatsu, S. Ikeda, H. Hashimoto, J. Med. Chem. 2006, 49, 4721-4736. 
[152] M. Sabat, J. C. Vanrens, M. J. Laufersweiler, T. A. Brugel, J. Maier, A. Golebiowski, B. De, V. Easwaran, L. C. Hsieh, R. L. Walter, M. J. Mekel, A. Evdokimov, M. J. Janusz, Bioorg. Med. Chem. Lett. 2006, 16, 5973-5977.

[153] N. H. Hauel, H. Nar, H. Priepke, U. Ries, J. Stassen, W. Wienen, J. Med. Chem. 2002, 45, 1757-1766.

[154] H. Nakano, T. Inoue, N. Kawasaki, H. Miyataka, H. Matsumoto, T. Taguchi, N. Inagaki, H. Nagai, T. Satoh, Bioorg. Med. Chem. 2000, 8, 373-380.

[155] a) P. N. Preston, Benzimidazoles and Congeneric Tricyclic Compounds. In The Chemistry of Heterocyclic Compounds (Eds.: A. Weissberger, E. C. Taylor), Wiley-VCH, New York, 1981, vol. 40, pp. 6-60; b) M. R. Grimmett, Imidazoles and their Benzo Derivatives. In Comprehensive Heterocyclic Chemistry (Eds.: A. R. Katritzky, C. W. Rees), Pergamon, Oxford, 1984, vol. 5, pp. 457-487.

[156] For catalytic syntheses of benzimidazoles and related cyclizations, see: a) S. Murru, B. K. Patel, J. Le Bras, J. Muzart, J. Org. Chem. 2009, 74, 2217-2220; b) Z. Li, H. Sun, H. Jiang, H. Liu, Org. Lett. 2008, 10, 3263-3266; c) G. Brasche, S. L. Buchwald, Angew. Chem. 2008, 120, 1958-1960; Angew. Chem. Int. Ed. 2008, 47, 1932-1934; d) J. Alen, K. Robeyns, W. M. De Borggraeve, L. Van Meervelt, F. Compernolle, Tetrahedron, 2008, 64, 8128-8133; e) B. Zou, Q. Yuan, D. Ma, Angew. Chem. 2007, 119, 2652-2655; Angew. Chem. Int. Ed. 2007, 46, 25982601; f) C. Venkatesh, G. S. M. Sundram, H. Ila, H. Junjappa, J. Org. Chem. 2006, 71, 1280-1283; g) K. G. Nazarenko, T. I. Shyrokaya, K. V. Shvidenko, A. A. Tolmachev, Synth. Commun. 2003, 33, 4303-4311; h) G. Evindar, R. A. Batey, Org. Lett. 2003, 5, 133-136; i) C. T. Brain, J. T. Steer, J. Org. Chem. 2003, 68, 6814-6816; g) C. T. Brain, S. A. Brunton, Tetrahedron Lett. 2002, 43, 1893-1895.

[157] T. Saegusa, Y. Ito, K. Kobayashi, K. Hirota, H. Yoshioka, Tetrahedron. Lett. 1966, 6121-6124.

[158] T. Saegusa, Y. Ito, K. Kobayashi, K. Hirota, H. Yoshioka, Bull. Chem. Soc. Jpn. 1969, 42, 3310-3313.

[159] For recent reviews on copper-catalyzed cross-coupling reactions, see: a) S. V. Ley, A. W. Thomas, Angew. Chem., 2003, 115, 5558-5607; Angew. Chem., Int. Ed. 2003, 42, 5400-5449; b) K. Kunz, U. Scholz, D. Ganzer, Synlett 2003, 2428-2439; c) I. P. Beletskaya, A. V. Cheprakov, Coord. Chem. Rev. 2004, 248, 2337-2364. 
[160] a) For a review, see: H. W. Gschwend, H. R. Rodriquez, Org. React. (N. Y.), 1979, 26, 1-360; b) A. R. Katritzky, W. H. Ramer, J. N. Lam, J. Chem. Soc, Perkin Trans. 1 1987, 775-780.

[161] For relevant reviews on transition-metal-catalyzed C-C bond formation via C-H bond cleavage, see: a) D. A. Colby, R. G. Bergman, J. A. Ellman, Chem. Rev. 2009, Article ASAP; b) J. C. Lewis, R. G. Bergman, J. A. Ellman, Acc. Chem. Res. 2008, 41, 1013-1025; c) F. Kakiuchi, T. Kochi, Synthesis 2008, 3013-3039; d) D. Alberico, M. E. Scott, M. Lautens, Chem. Rev. 2007, 107, 174-238; e) I. V. Seregin, V. Gevorgyan, Chem. Soc. Rev. 2007, 36, 1173-1193.

[162] a) J. Ezquerra, C. Lamas, Tetrahedron 1997, 53, 12755-12764; b) Y. Gong, W. He, Org. Lett. 2002, 4, 3803-3805; c) B. B. Wang, P. J. Smith, Tetrahedron Lett. 2003, 44, 8967-8969; d) M. W. Hooper, M. Utsunomiya, J. F. Hartwig, J. Org. Chem. 2003, 68, 2861-2873.

[163] a) A. G. Mistry, K. Smith, M. R. Bye, Tetrahedron Lett. 1986, 27, 1051-1054; b) I. Kawasaki, N. Taguchi, Y. Yoneda, M. Yamashita, S. Ohta, Heterocycles 1996, 43, 1375-1379.

[164] The same benzimidazole 217n was also observed as a major product in the reaction of 147-Br with 2,4,6-trimethylaniline.

[165] R. Obrecht, R. Herrmann, I. Ugi, Synthesis, 1985, 400-402.

[166] G. Bengtson, S. Keyaniyan, A. de Meijere, Chem. Ber. 1986, 119, 3607-3630.

[167] R. S. Bon, B. van Vliet, N. E. Sprenkels, R. F. Schmitz, F. J. J. de Kanter, C. V. Stevens, M. Swart, F. M. Bickelhaupt, M. B. Groen, R. V. A. Orru, J. Org. Chem. 2005, 70, 3542-3553.

[168] K. L. Stevens, D. K. Jung, M. J. Alberti, J. G. Badiang, G. E. Peckham, J. M. Veal, M. Cheung, P. A. Harris, S. D. Chamberlain, M. R. Peel, Org. Lett. 2005, 7, 47534756.

[169] I. J. Solomon, R. Filler, J. Am. Chem. Soc. 1963, 85, 3492-3496.

[170] D. H. Wadsworth, S. M. Geer, M. R. Detty, J. Org. Chem. 1987, 52, 3662-3668.

[171] J. Cossy, J.-P. Pete, Bull. Soc. Chim. Fr. 1979, 559-567.

[172] M. E. Pierce, R. L. Parsons, L. A. Radesca, Y. S. Lo, S. Silverman, J. Org. Chem. 1998, 63, 8536-8543.

[173] C. Housseman, J. Zhu, Synlett, 2006, 1777-1779. 
[174] U. Schöllkopf, R. Schröder, D. Stafforst, Liebigs Ann. Chem. 1974, 44-53.

[175] L. J. Goossen, M. Blanchot, C. Brinkmann, K. Goossen, R. Karch, A. Rivas-Nass, J. Org. Chem. 2006, 71, 9506-9509.

[176] R. Moffett, J. Med. Chem. 1972, 15, 1079-1081.

[177] A. Krantz, B. Hoppe, Tetrahedron Lett. 1975, 9; 695-698.

[178] J. M. Barker, P. R. Huddleston, M. L. Wood, Synth. Commun. 1995, 3729-3734.

[179] X. E. Hu, J. M. Cassady, Synth. Commun. 1995, 25, 907-913.

[180] W. C. Still, M. Kahn, A. Mitra, J. Org. Chem. 1978, 43, 2923-2925.

[181] M. Suzuki, M. Miyoshi, K. Matsumoto, J. Org. Chem. 1974, 39, 1980-1980.

[182] H. Saikachi, T. Kitagawa, H. Sasaki, Chem. Pharm. Bull. 1979, 27, 2857-2861.

[183] A. Padwa, J. R. Gasdaska, G. Hoffmanns, H. Rebello, J. Org. Chem. 1987, 52, 1027-1035.

[184] R. J. Cherney, P. Carter, J. V. Duncia, D. S. Gardner, J. B. Santella (Bristol-Myers Squibb Company), WO 2004071460 A2 20040826, 2004.

[185] H. Horikawa, T. Iwasaki, K. Matsumoto, M. Miyoshi, J. Org. Chem. 1978, 43, 335-337.

[186] J. H. Rigby, S. Laurent, J. Org. Chem. 1998, 63, 6742-6744.

[187] K. Kobayashi, T. Nakashima, M. Mano, O. Morikawa, H. Konishi, Chem. Lett. 2001, 7, 602-603.

[188] P. Hrvatin, A. G. Sykes, Synlett 1997, 9, 1069-1070.

[189] B. Scherrer, J. Org. Chem. 1972, 37, 1681-1685.

[190] B. V. Lingaiah, G. Ezikiel, T. Yakaiah, G. V. Reddy, P. S. Rao, Synlett 2006, 15, 2507-2509.

[191] L. Wang, J. Xia, F. Qin, C. Qian, J. Sun, Synthesis 2003, 8, 1241-1247.

[192] D. E. Ames, S. Chandrasekhar, R. Simpson, J. Chem. Soc., Perkin Trans. 1, 1975; 2035-2036.

[193] R. C. R. Gilbert, Seances Acad. Sci. C 1974, 279, 159.

[194] M. Pesson, D. C. R. Richer, Hebd. Seances Acad. Sci. 1965, 260, 603-605.

[195] J. F. Liu, P. Ye, K. Sprague, K. Sargent, D. Yohannes, C. M. Baldino, C. J. Wilson, S. C. Ng, Org. Lett. 2005, 7, 3363-3366.

[196] J. Bergman, J.-O. Lindstroem, U. Tilstam, Tetrahedron 1985, 41, 2879-2882.

[197] J. C. Sheehan, J. W. Frankenfeld, J. Am. Chem. Soc. 1961, 83, 4792-4795. 
[198] M. Gütschow, J. Org. Chem. 1999, 64, 5109-5115.

[199] E. C. Wagner, U. F. Fegley, Org. Synth. 1955 Coll. Vol. 3, 488; Org. Synth. 1947, Ann. Vol. 27, 45.

[200] J. C. Barrish, S. D. Kimball, J. Krapcho, US 4946820, 7.08.1990, Application: US 89-334025.

[201] Z.-G. Le, Z.-C. Chen, Y. Hu, Q.-G. Zheng, Synthesis 2004, 208-212.

[202] J. T. Ralph, Synth. Commun. 1989, 19, 1381-1387.

[203] J. Torres, J. L. Lavandera, P. Cabildo, R. M. Claramunt, J. Elguero, J. Heterocycl. Chem. 1988, 25, 771-782.

[204] S. Benard, L. Neuville, J. Zhu, J. Org. Chem. 2008, 73, 6441-6444.

[205] E. Cuevas-Yanez, J. M. Serrano, G. Huerta, J. M. Muchowski, R. Cruz-Almanza, Tetrahedron 2004, 60, 9391-9396.

[206] B. D. Palmer, J. B. Smaill, M. Boyd, D. H. Boschelli, A. M. Doherty, J. M. Hamby, S. S. Khatana, J. B. Kramer, A. J. Kraker, R. L. Panek, G. H. Lu, T. K. Dahring, R. T. Winters, H. D. H. Showalter, W. A. Denny, J. Med. Chem. 1998, 41, $5457-5465$. 
F. Representative ${ }^{1} \mathrm{H}$ and ${ }^{13} \mathrm{C}$ Spectra of the prepared compounds

Dimethyl 3-(4-Ethoxyphenyl)-1H-pyrrole-2,4-dicarboxylate (173ac)
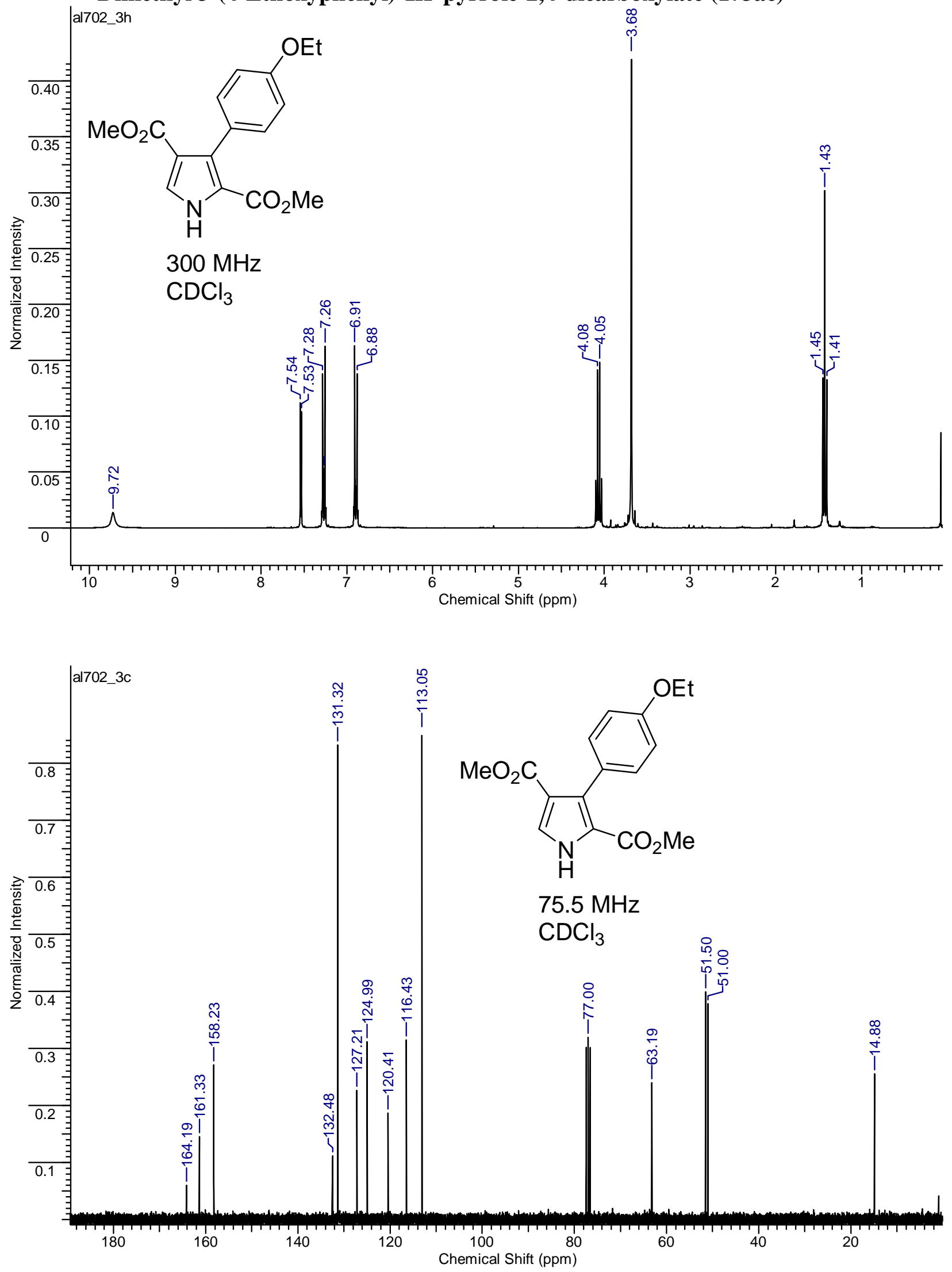

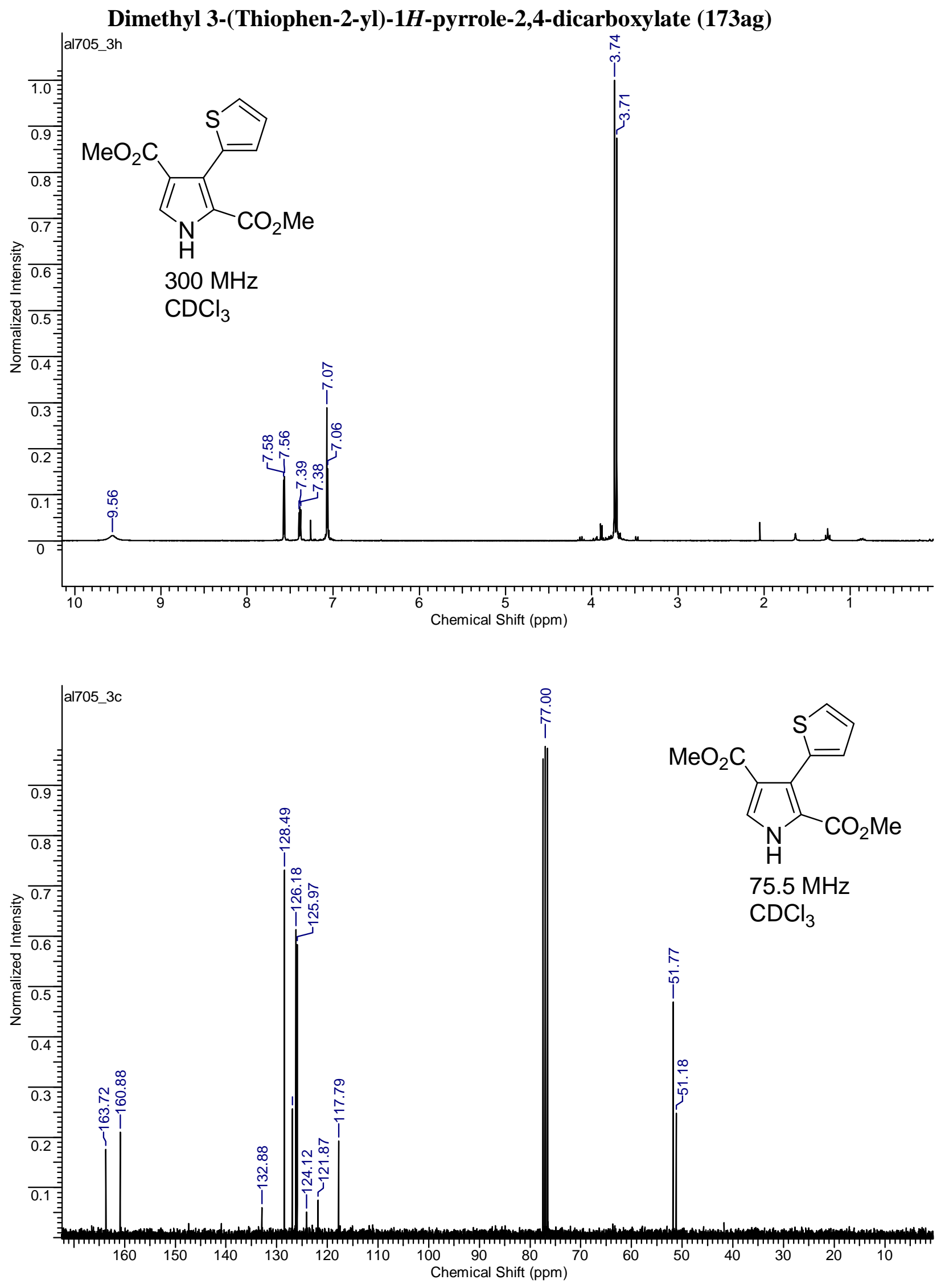

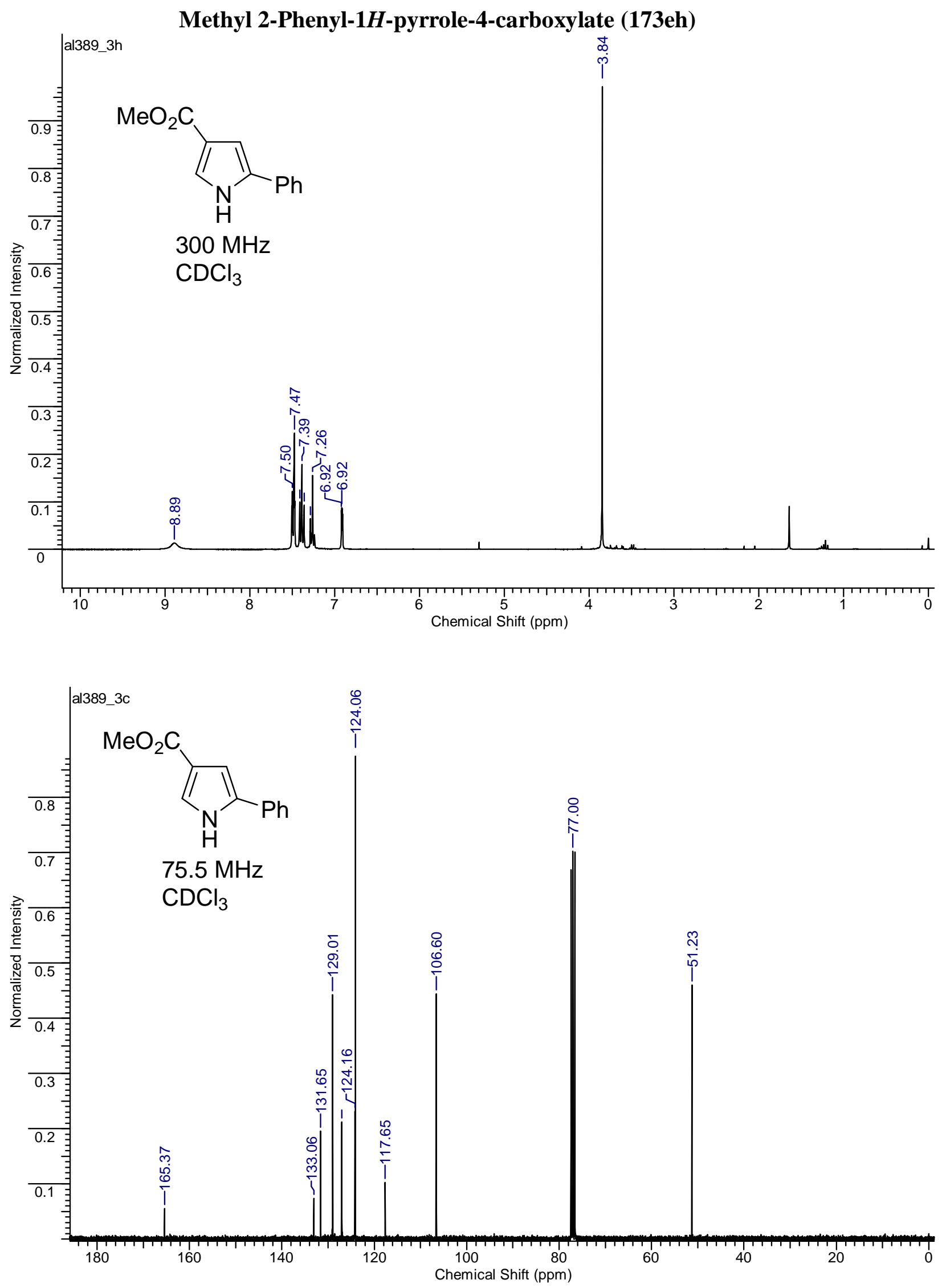

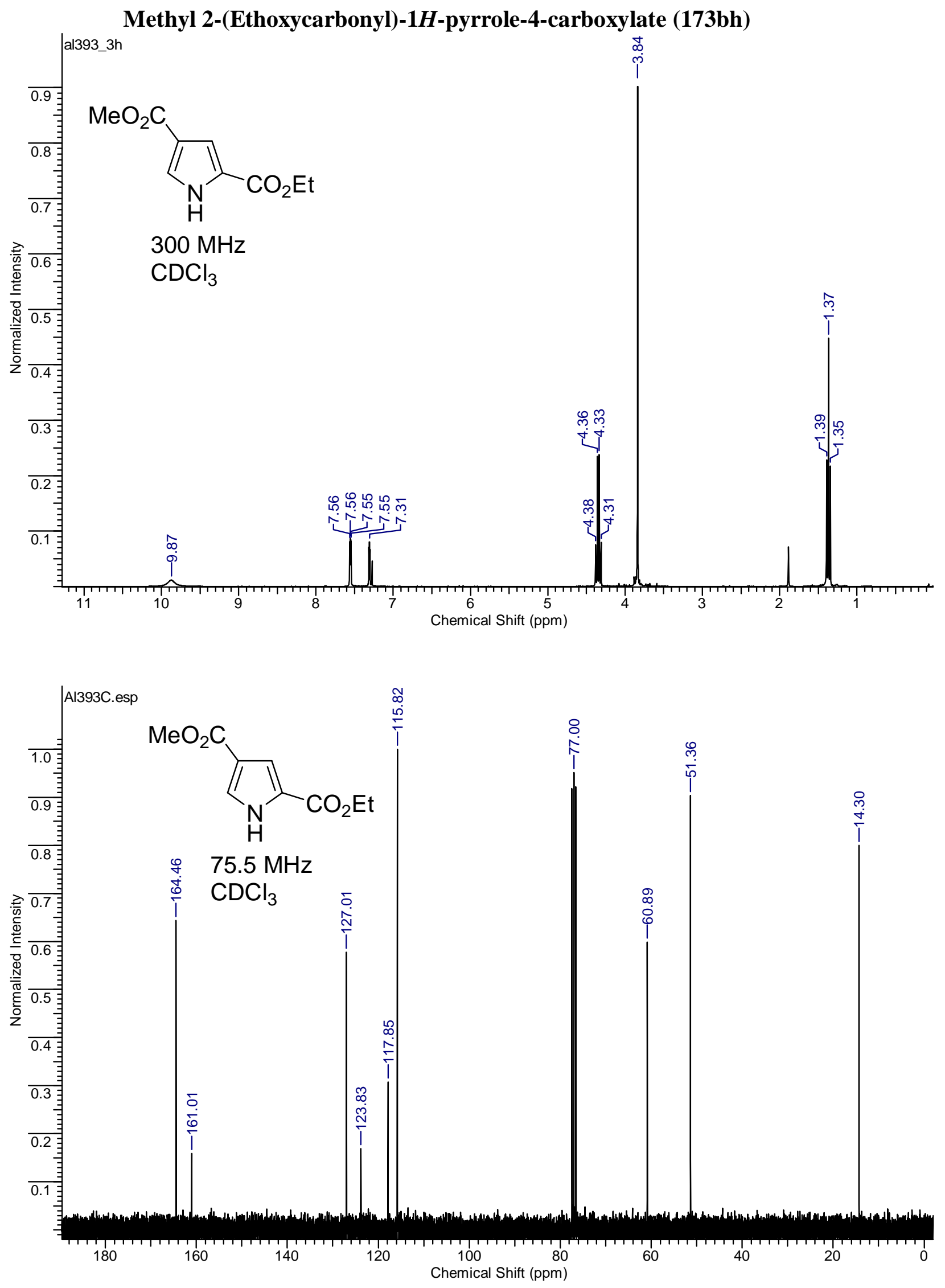

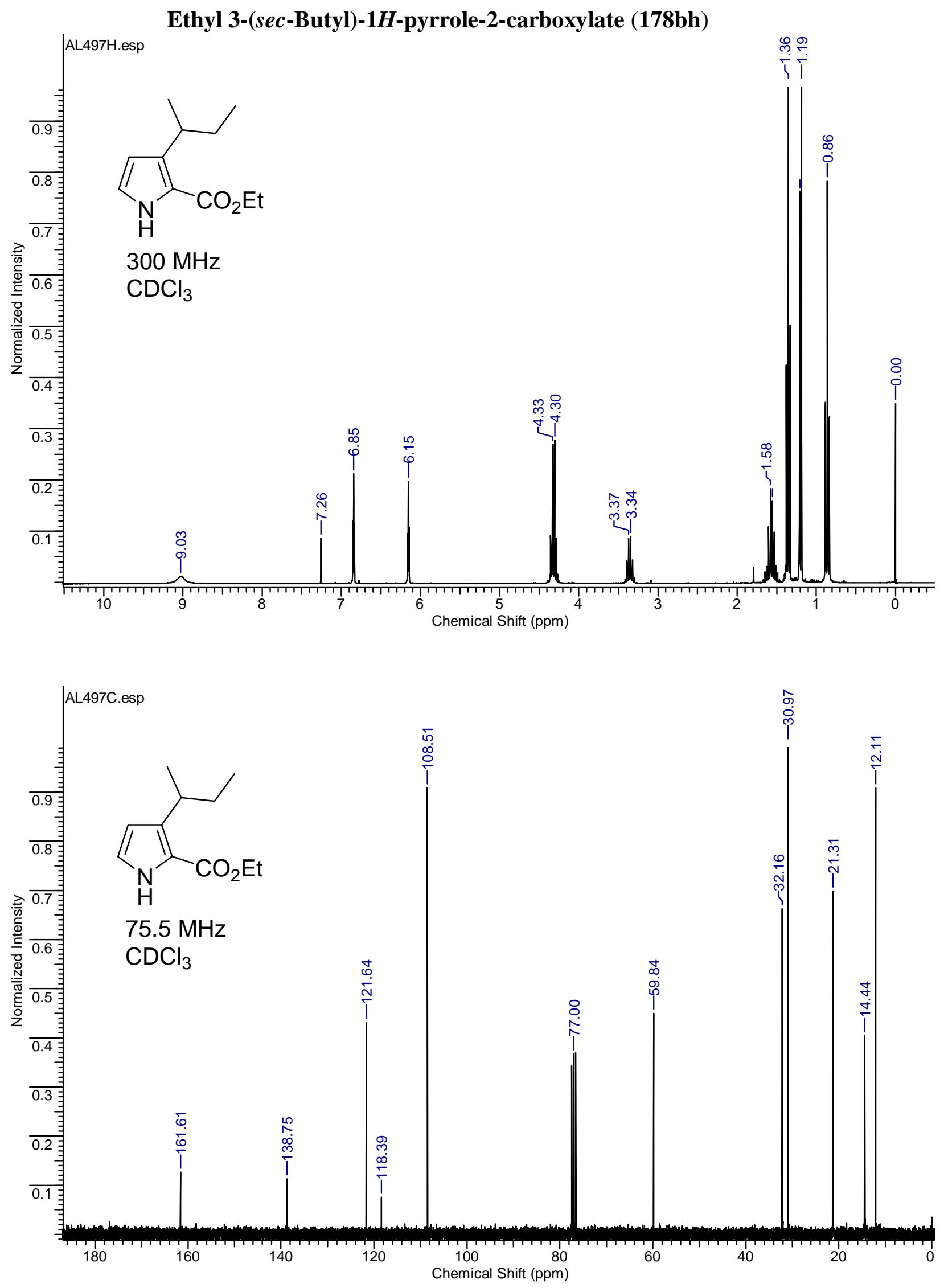

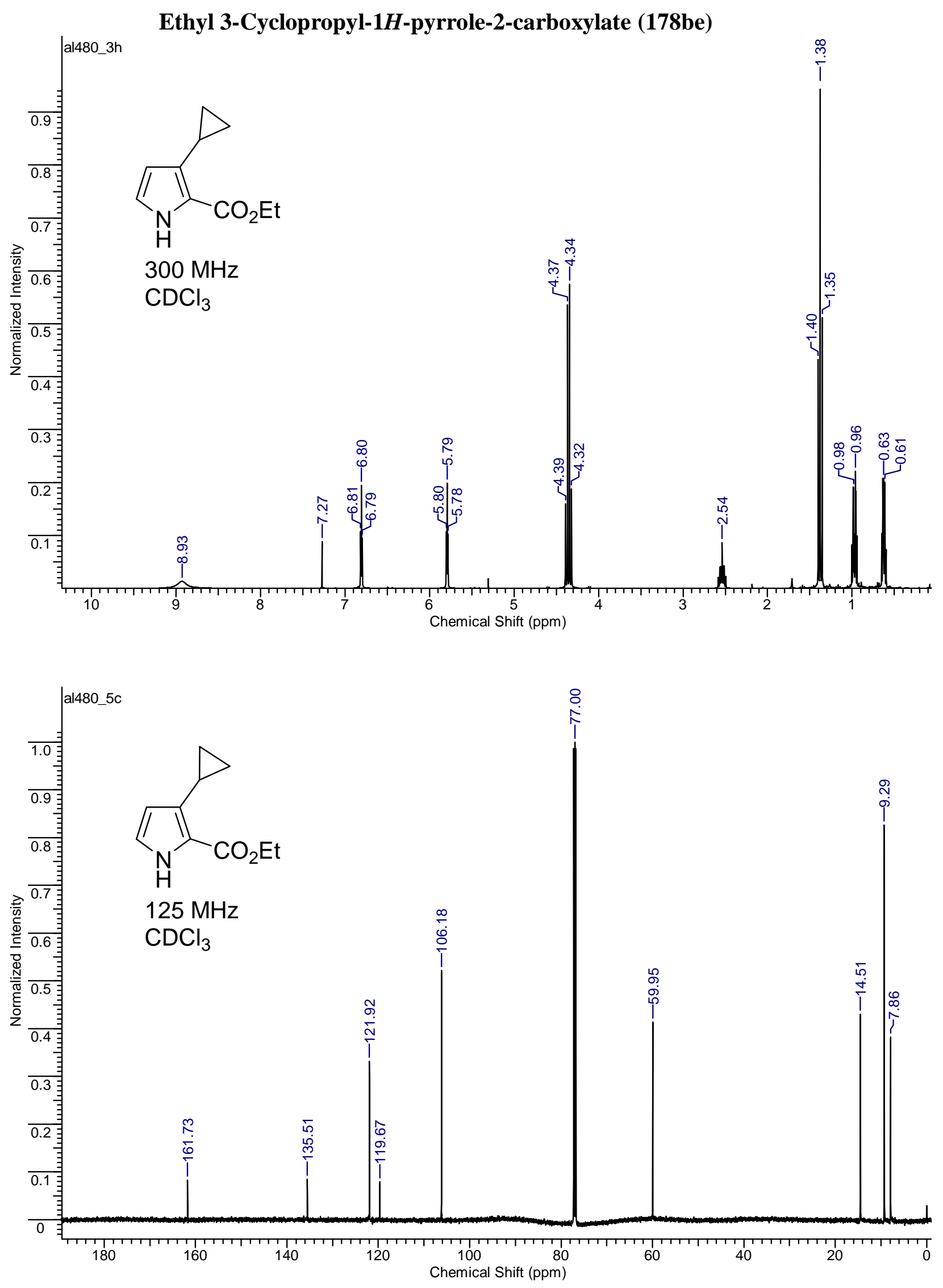

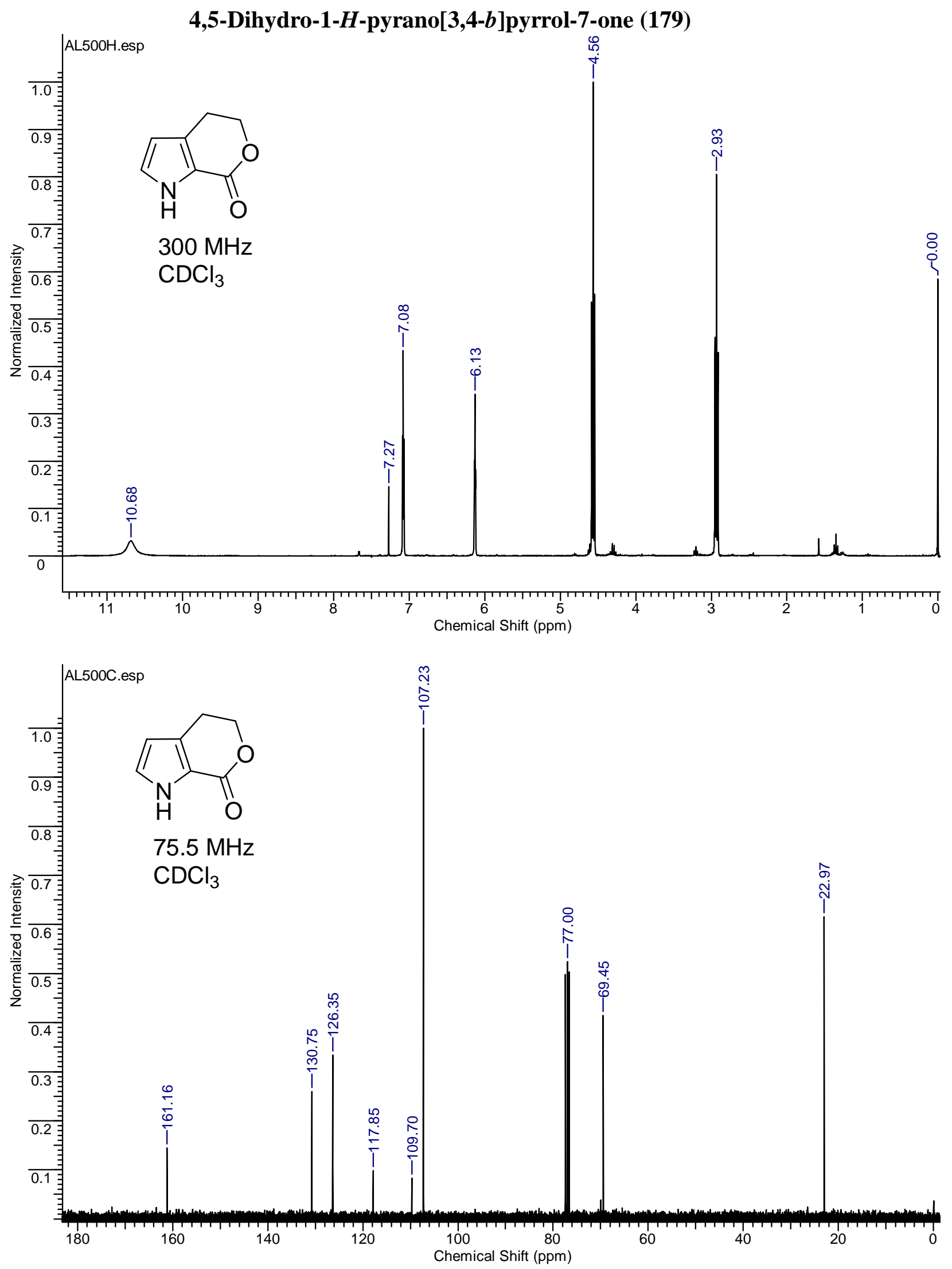

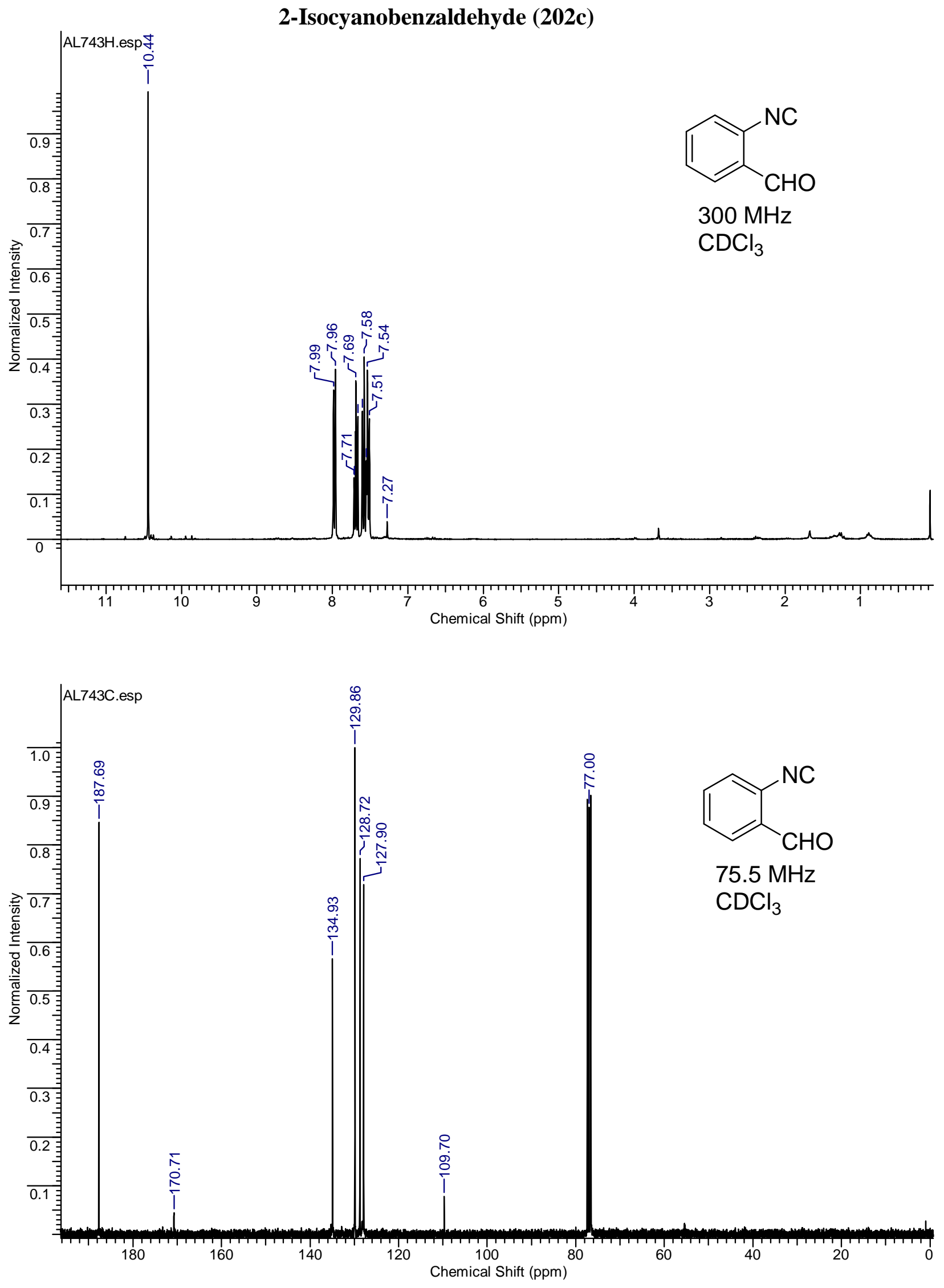

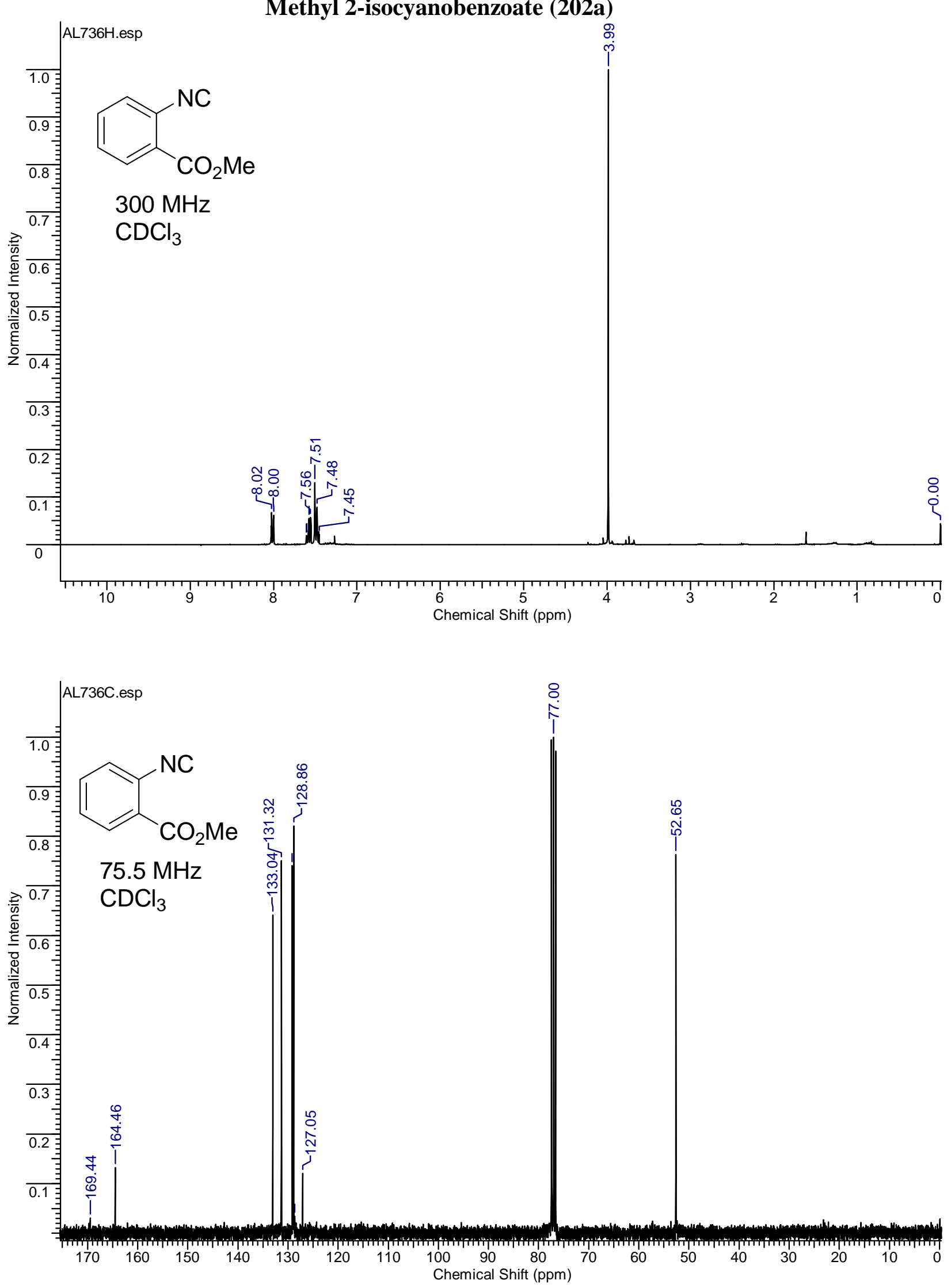

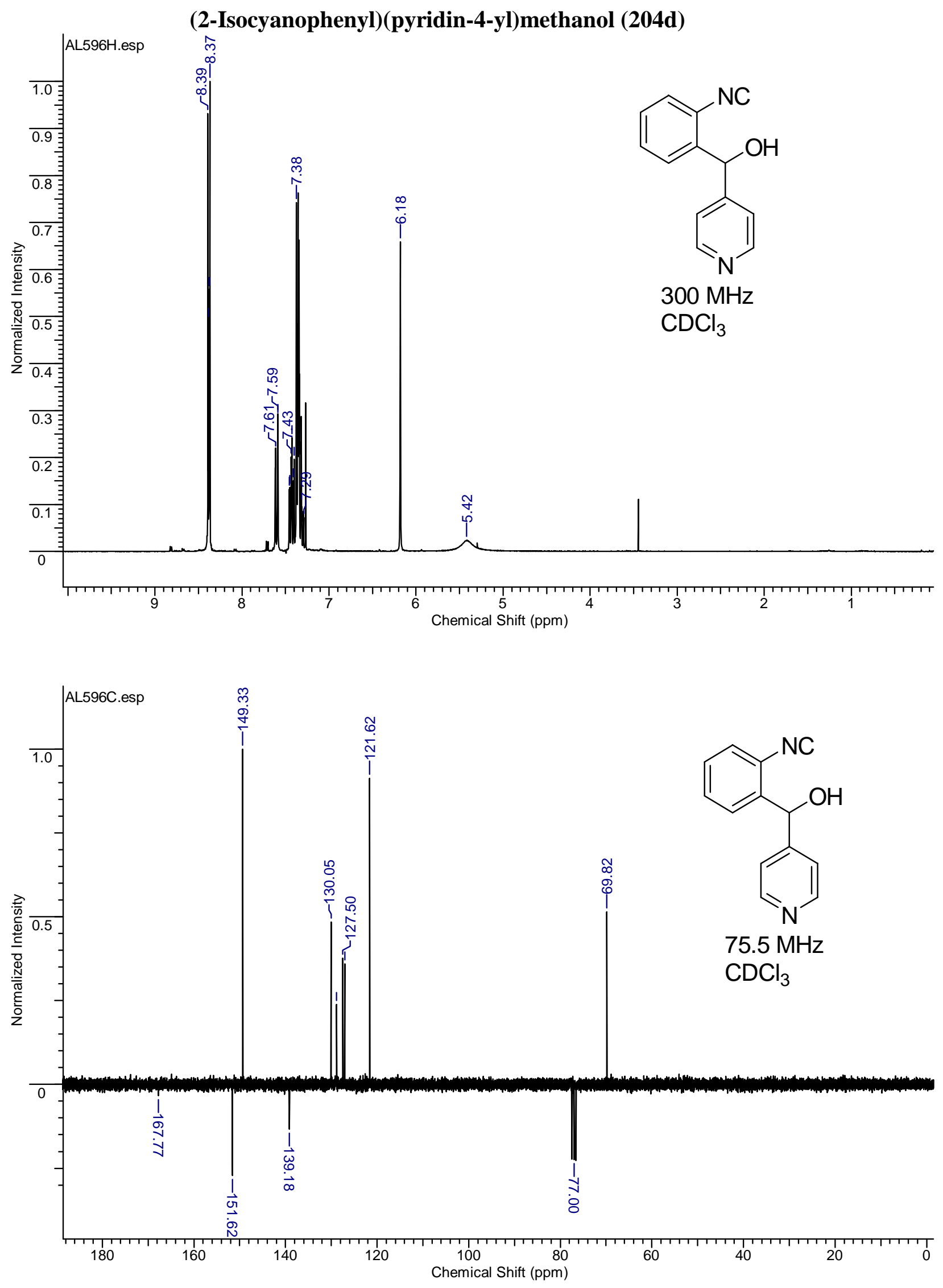

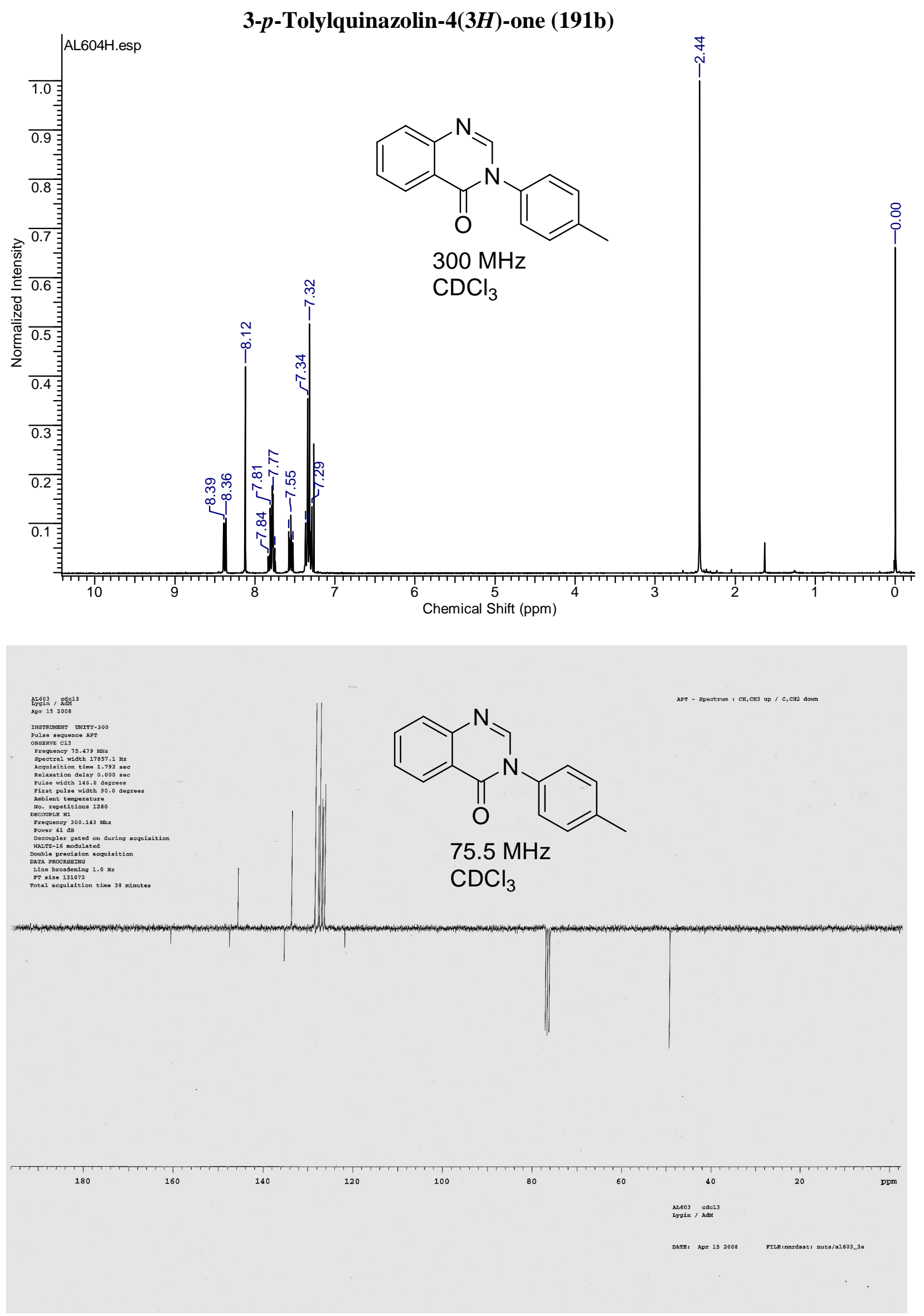

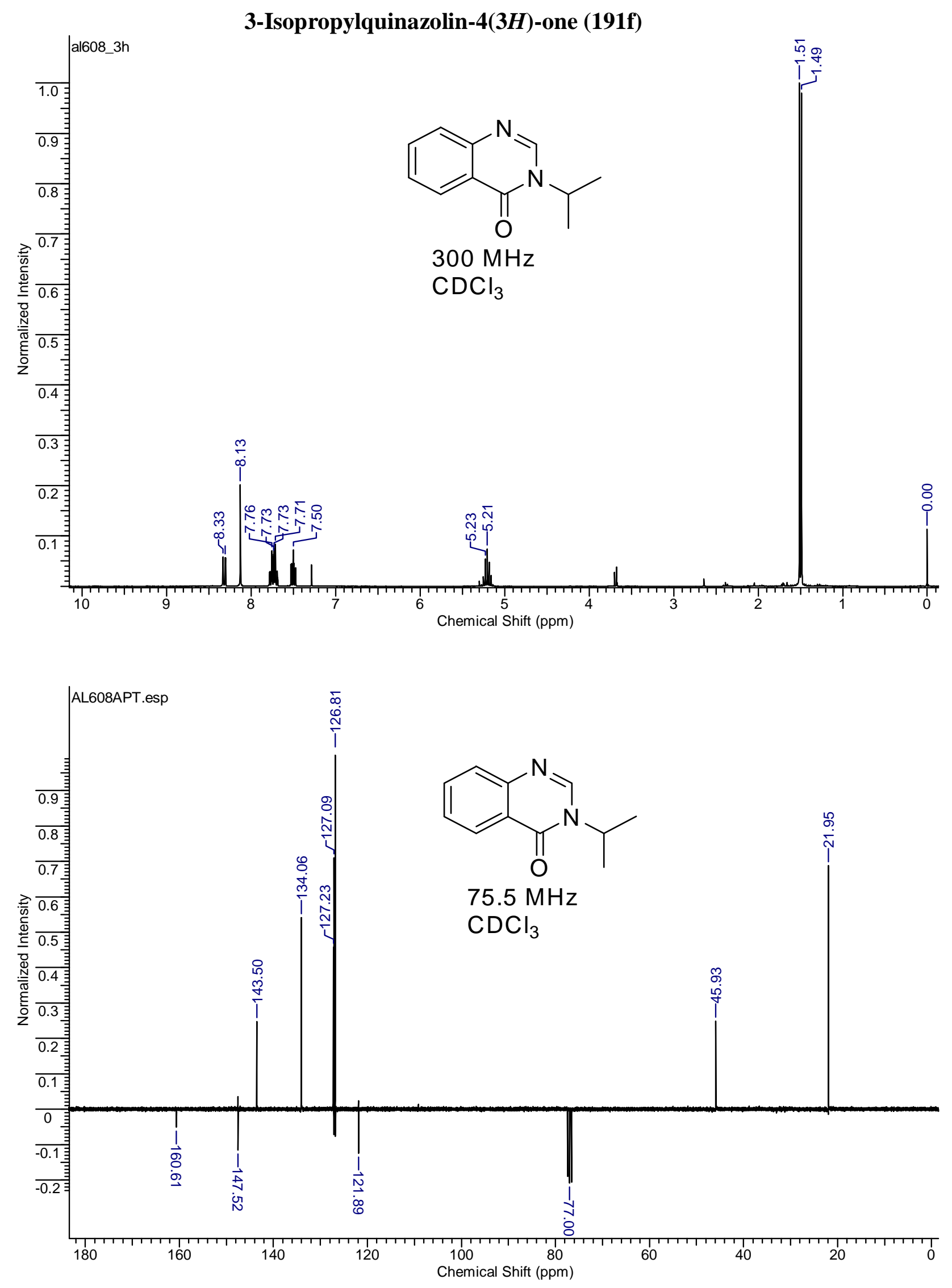

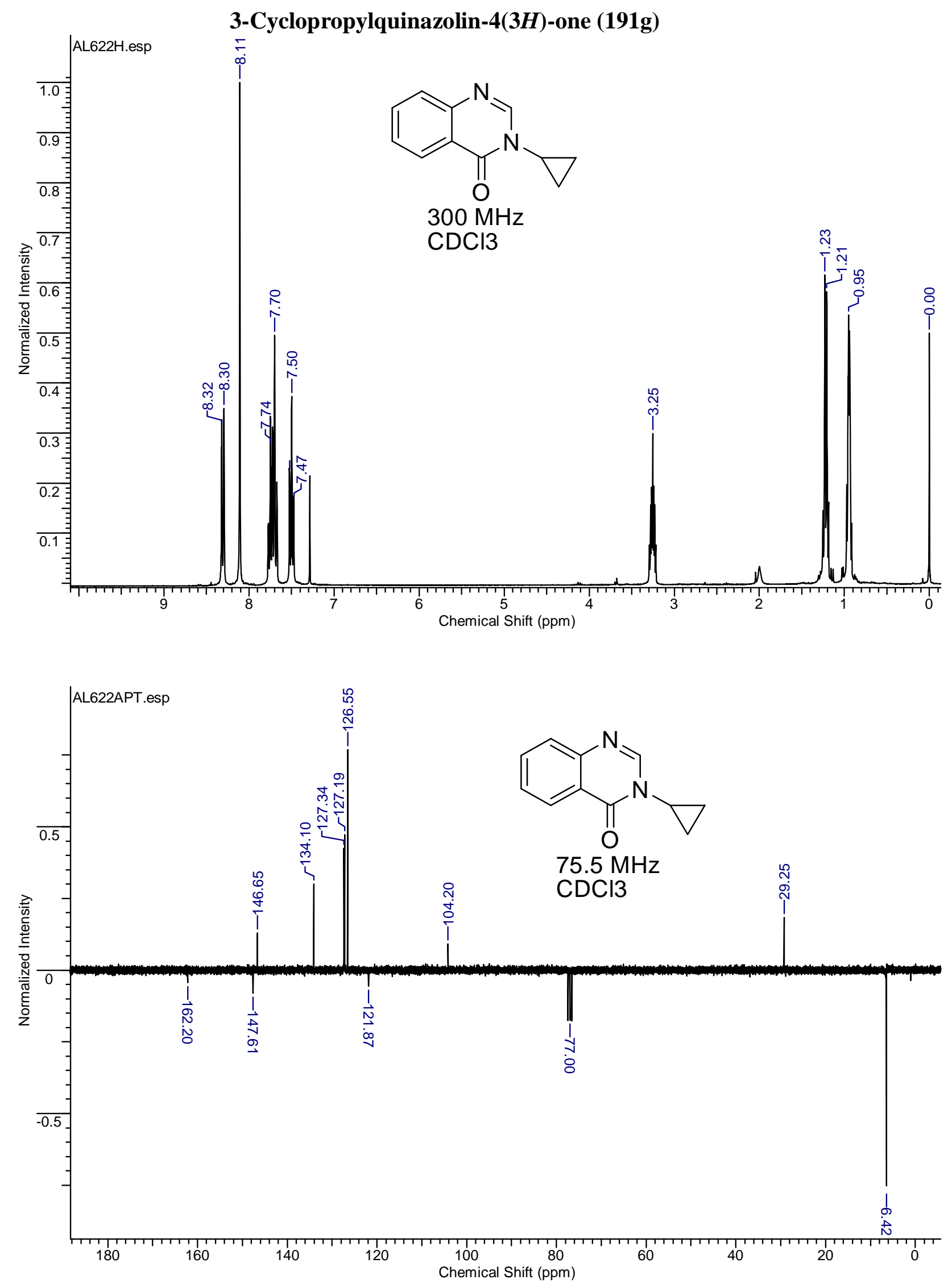

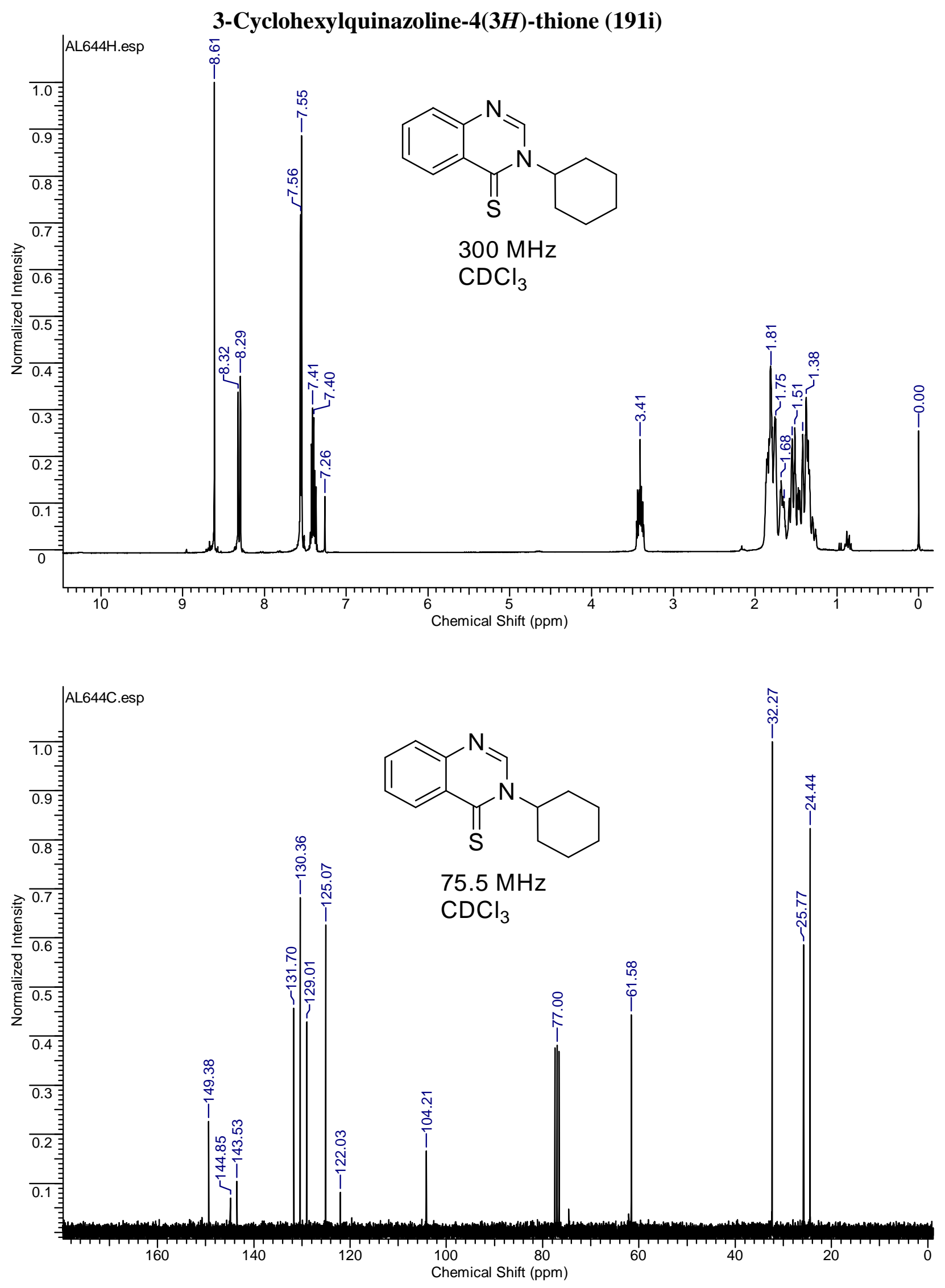

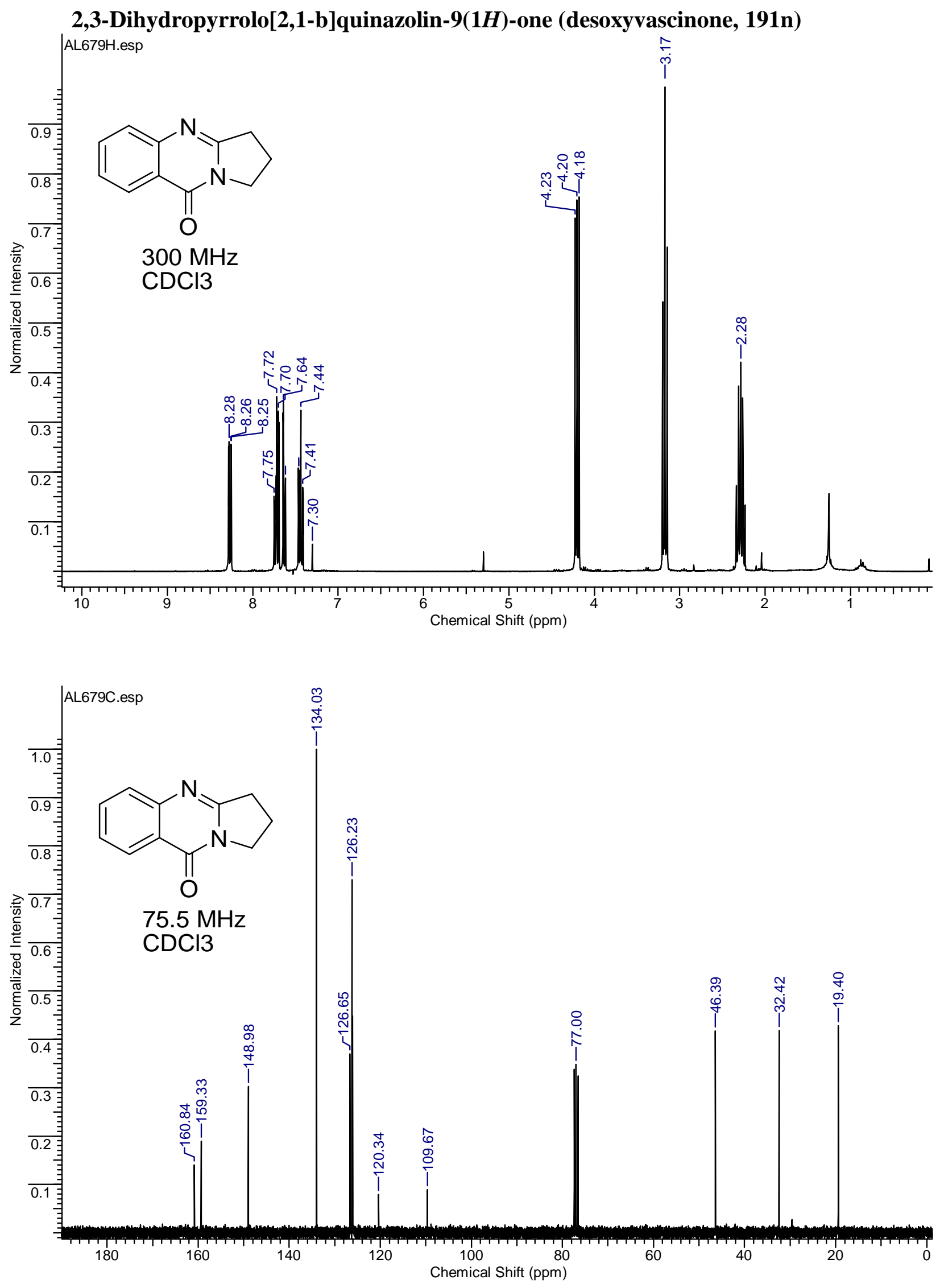
Indolo[2,1-b]quinazoline-6,12-dione (trypthamine, 1910)
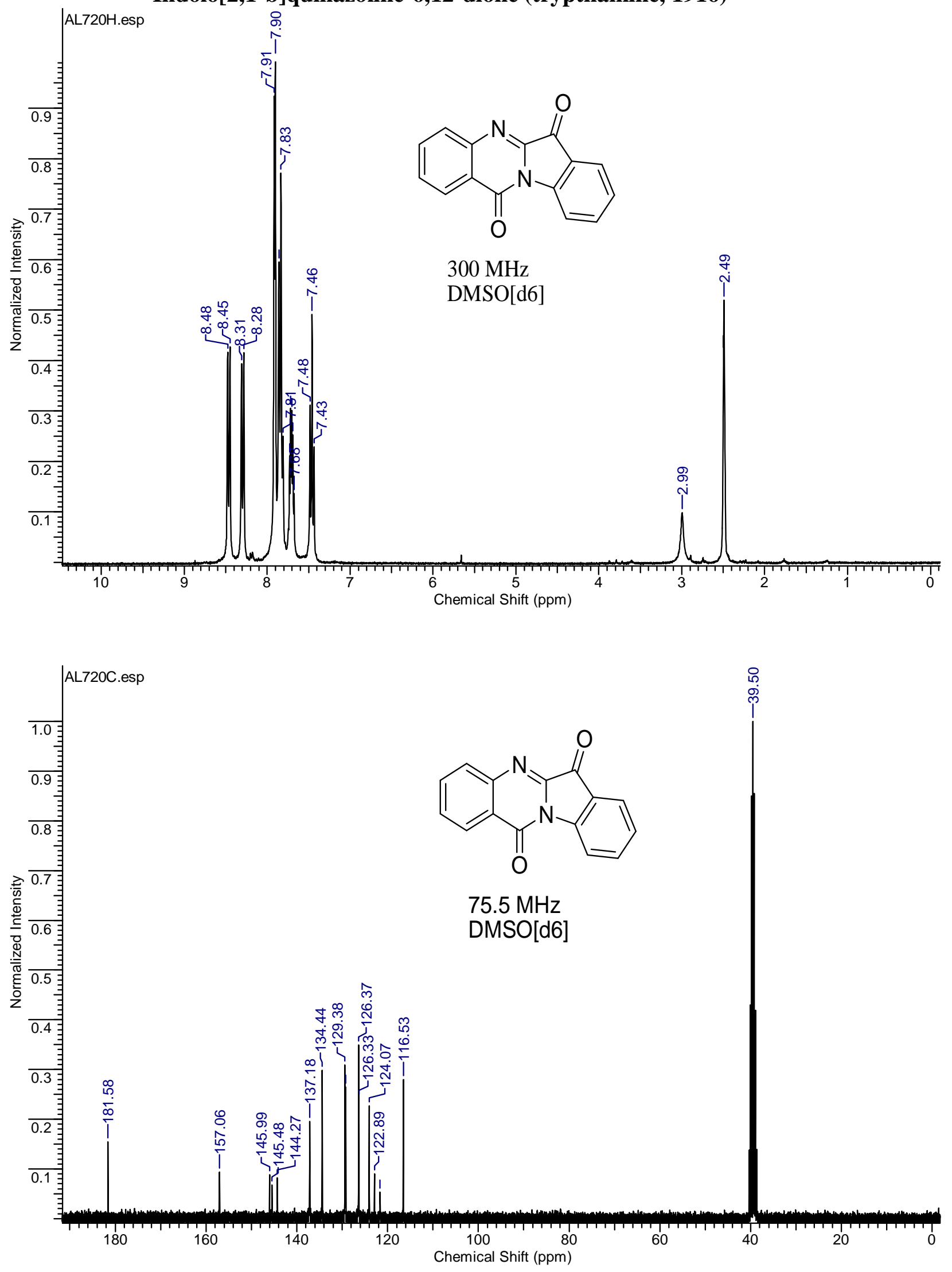

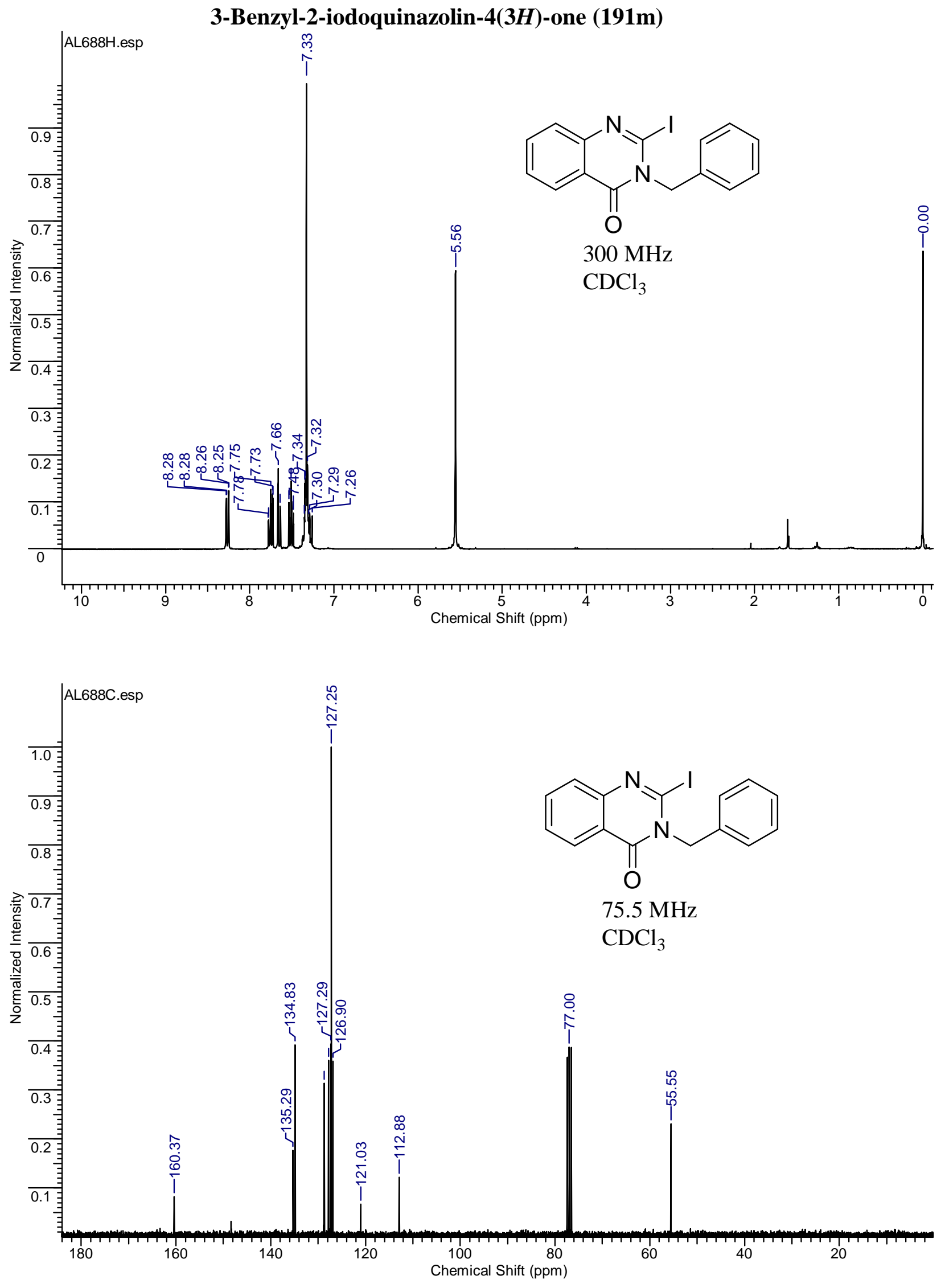

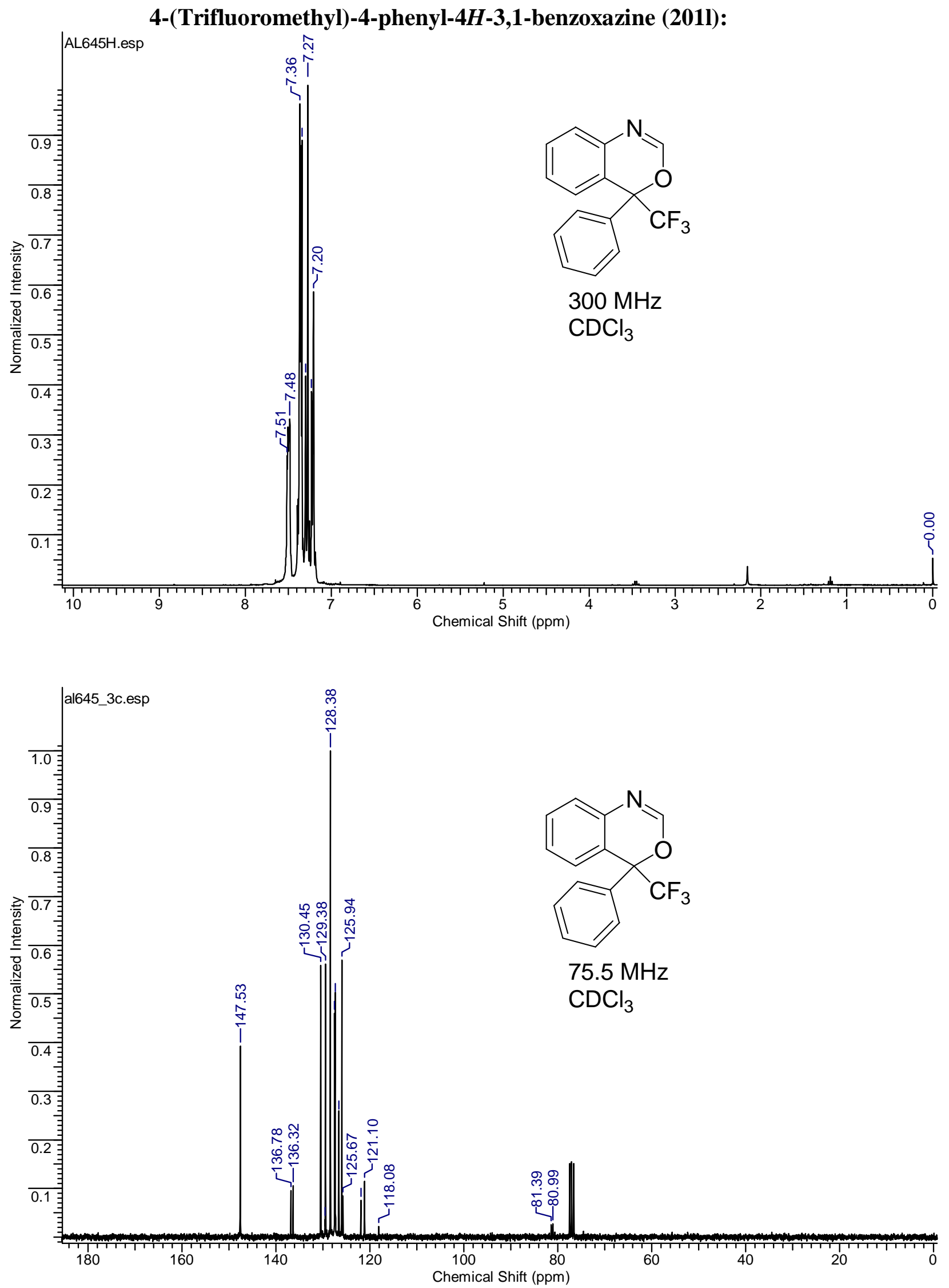

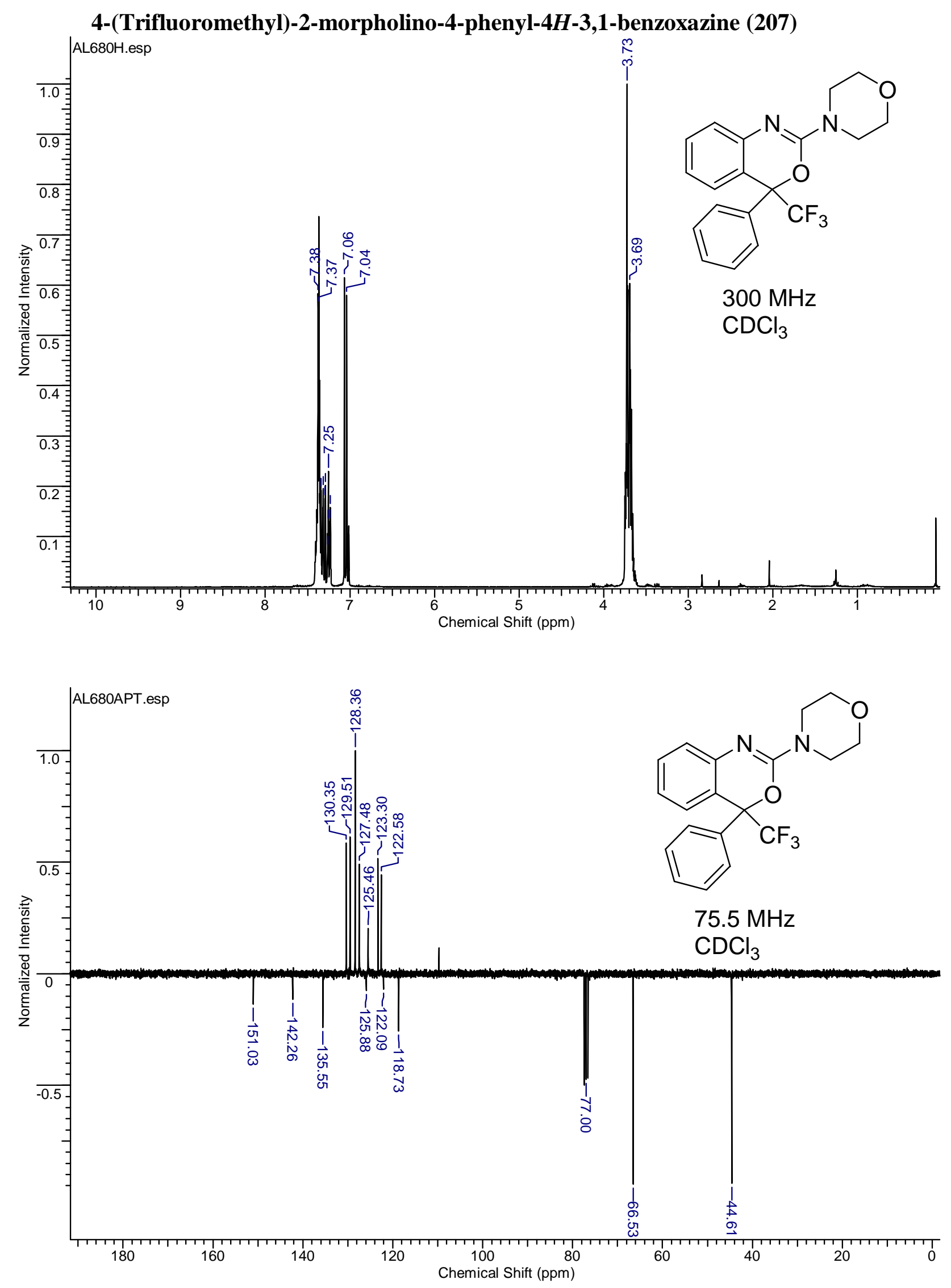

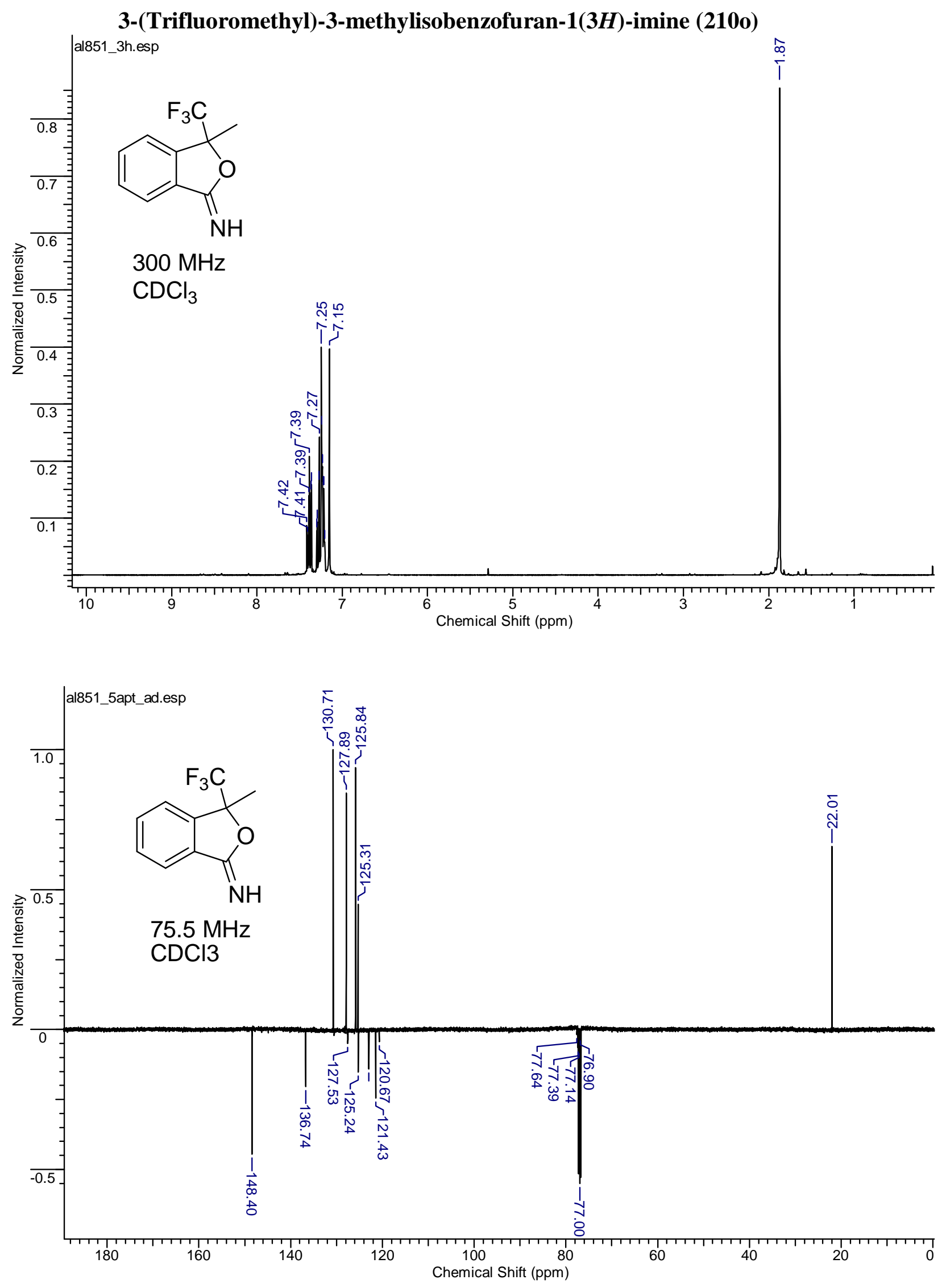

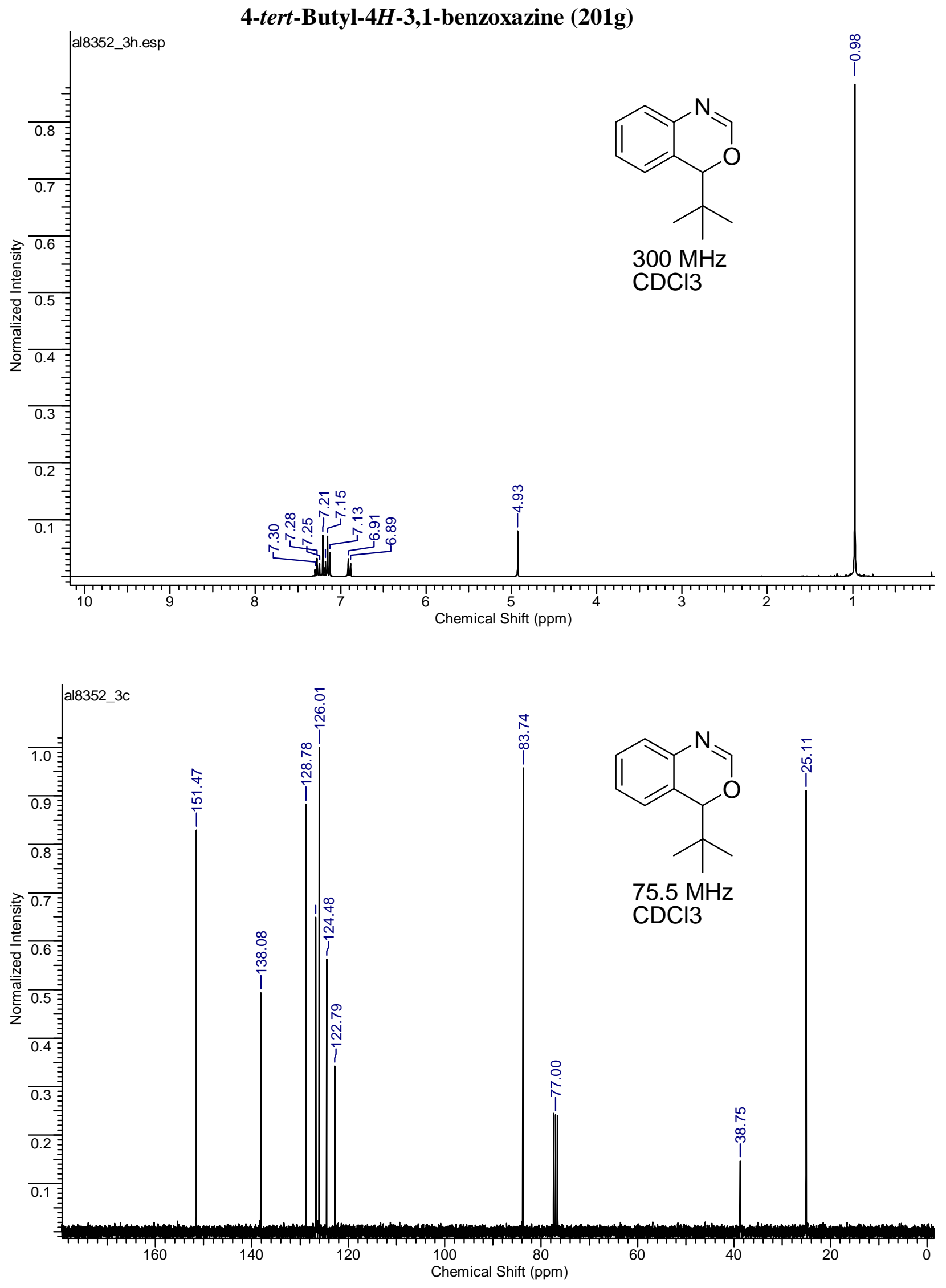

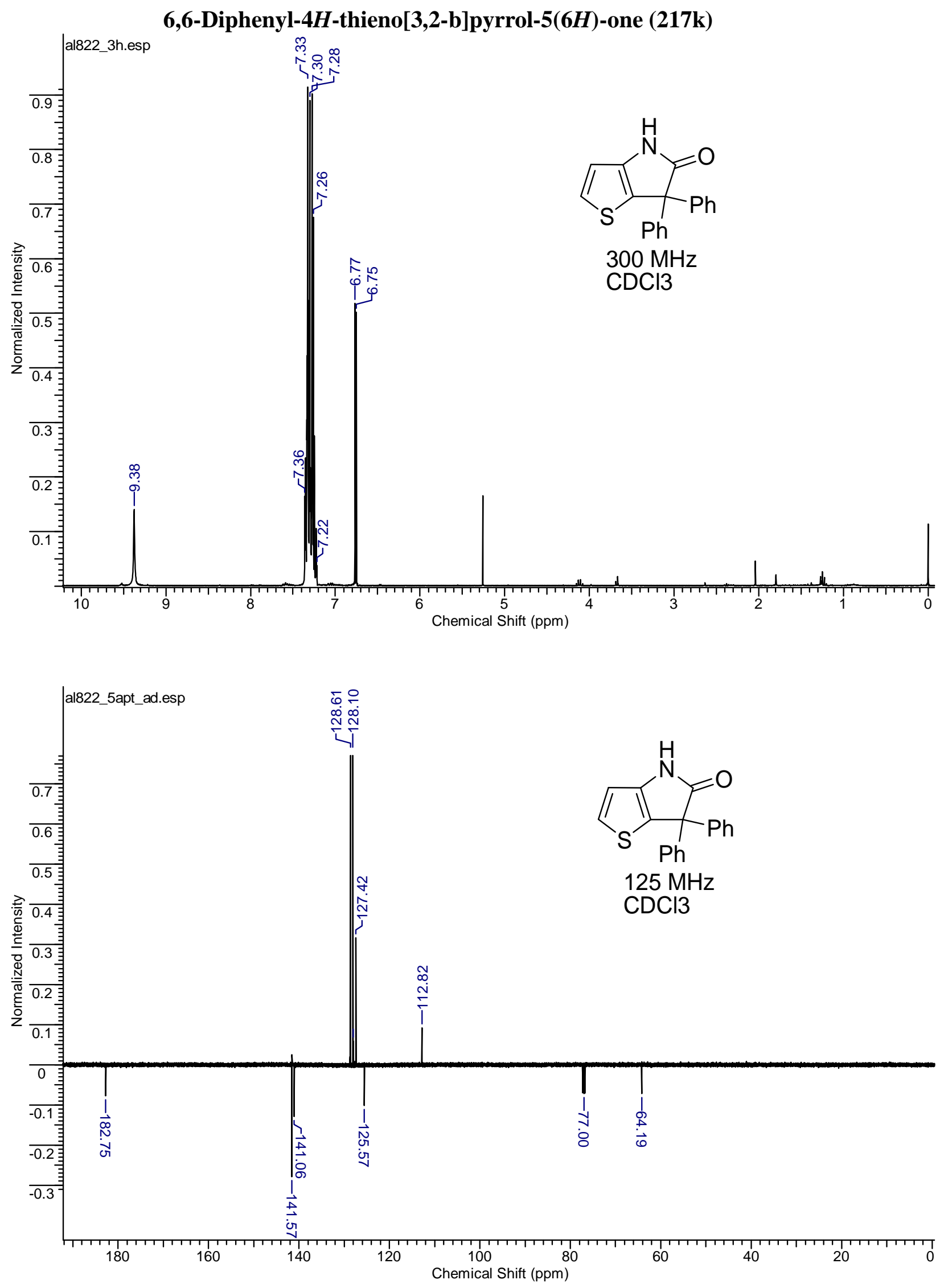

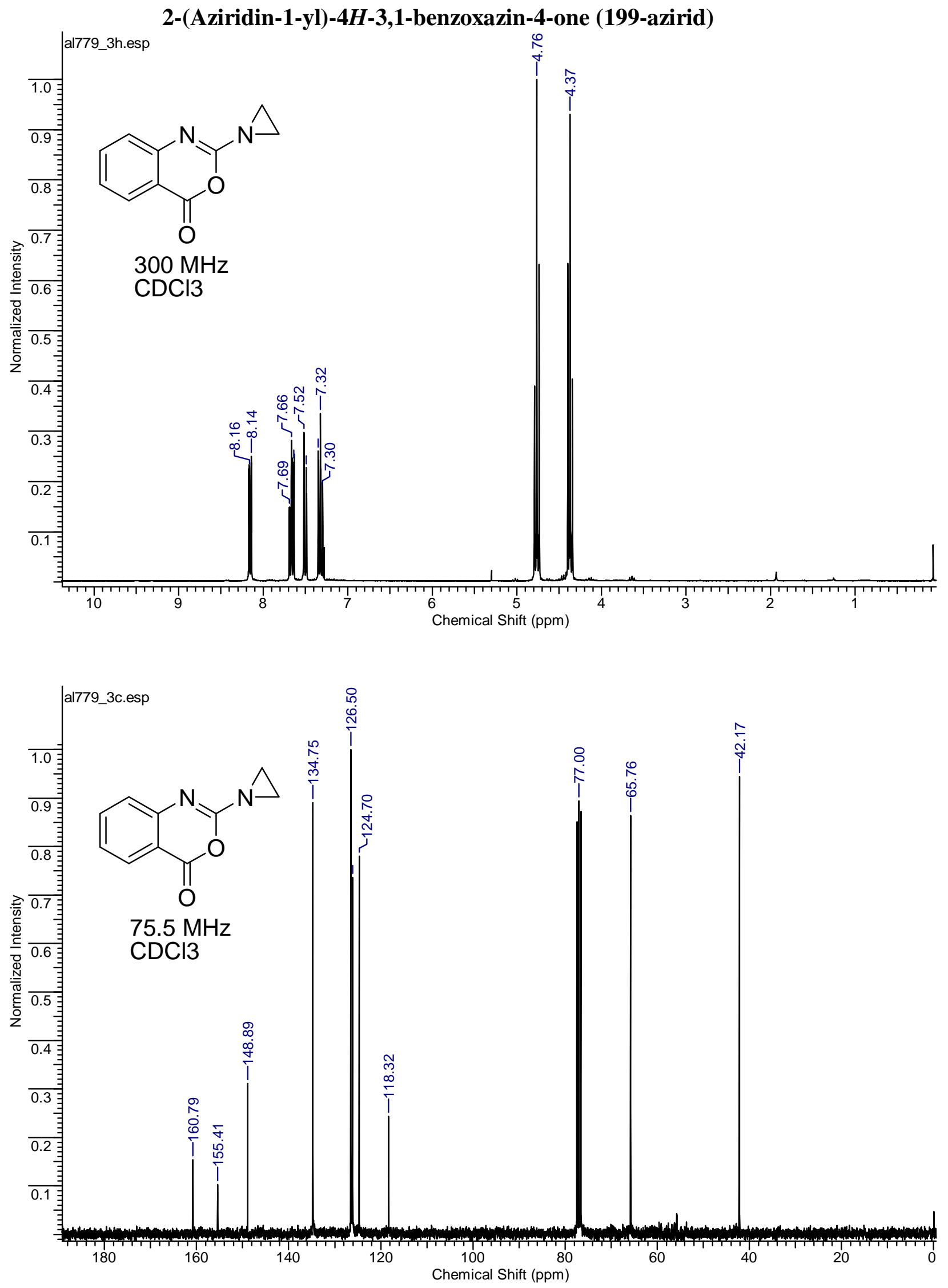

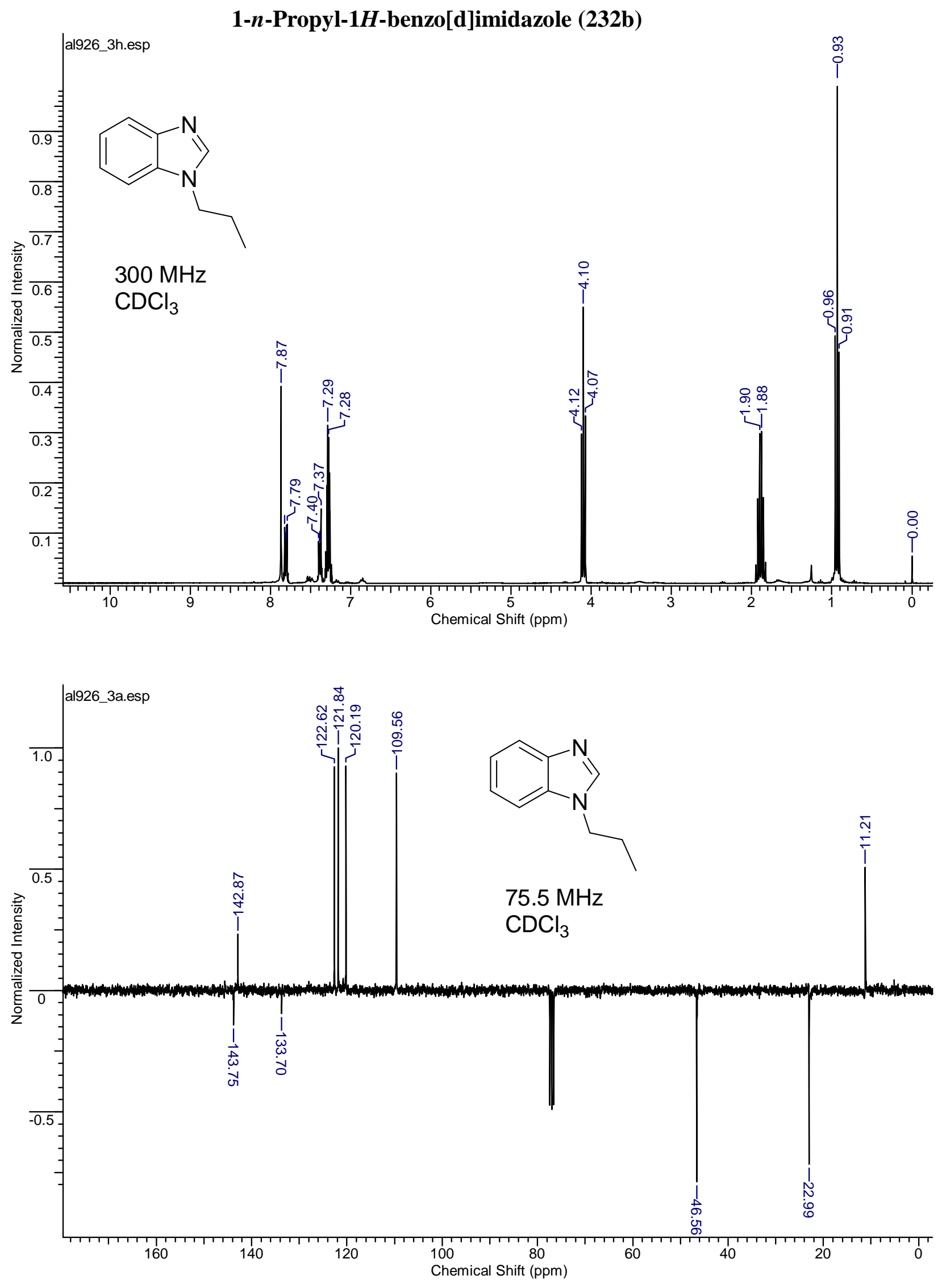
1-(2-(1H-Benzo[d]imidazol-1-yl)ethyl)- $1 H$-benzo[d]imidazole $(232 \mathrm{e})$
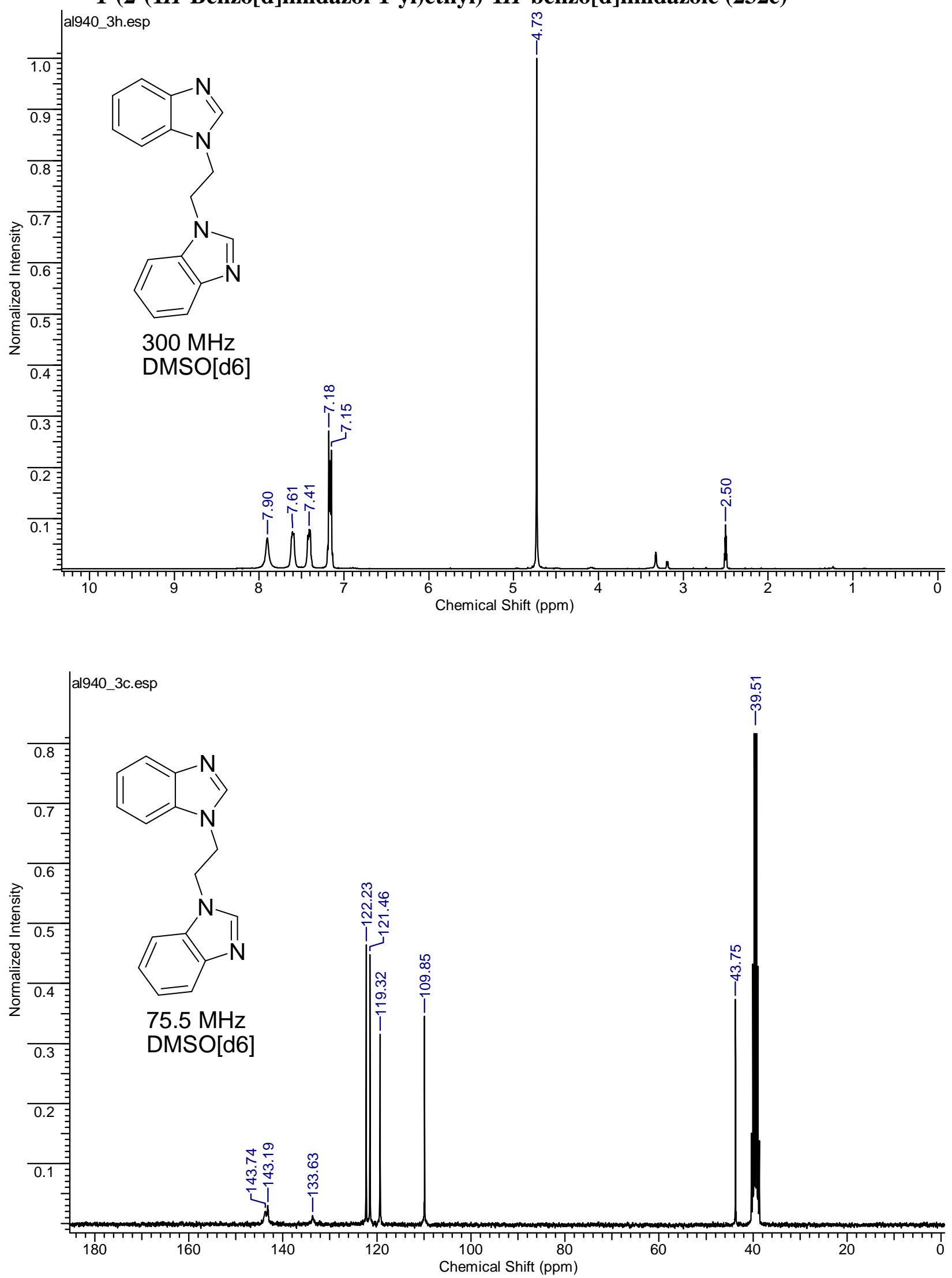
1-(2-(1-Methyl-1H-indol-3-yl)ethyl)-1H-benzo[d]imidazole (232d)
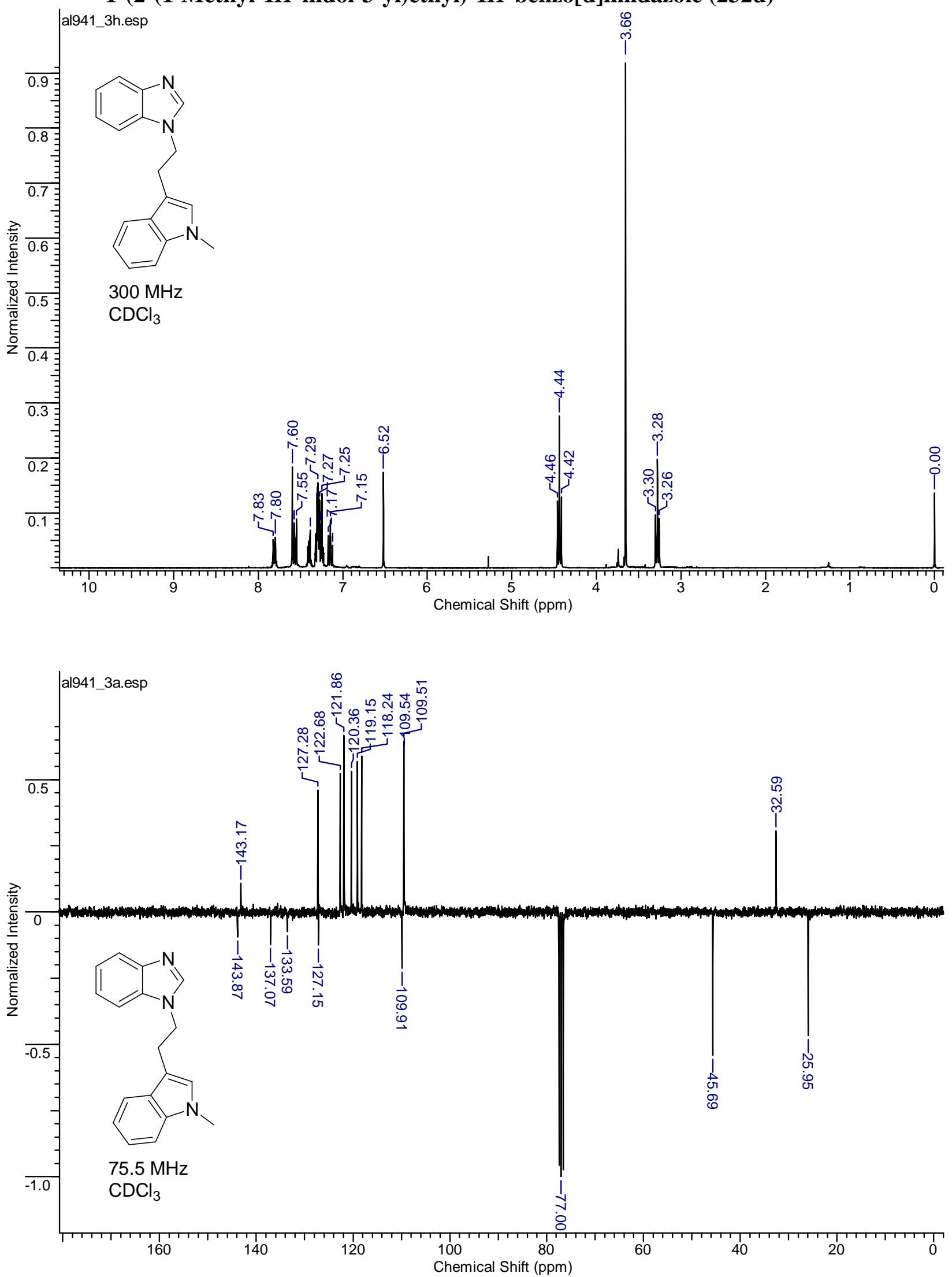

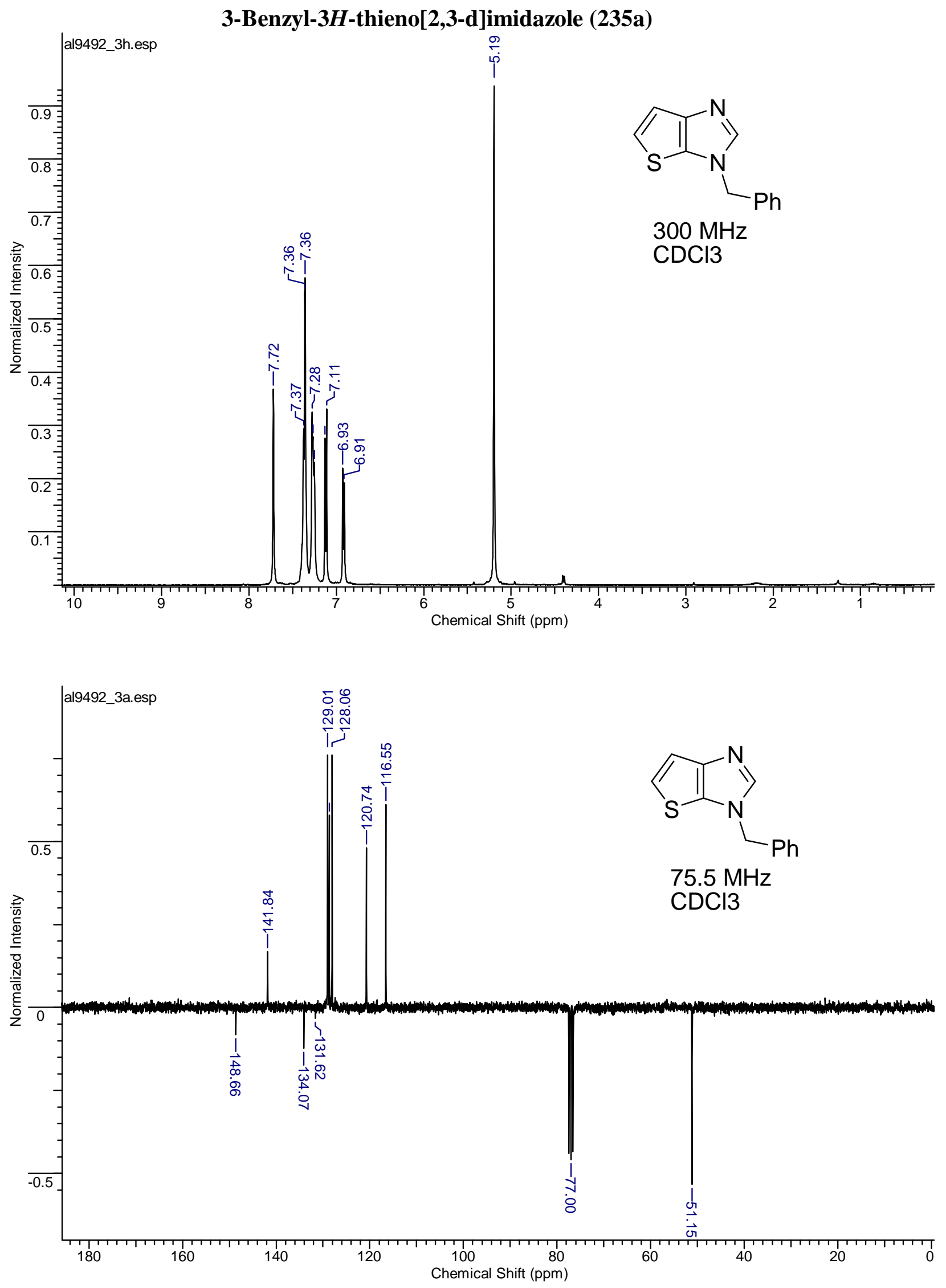


\section{Acknowledgements}

First of all, I thank my superviser and teacher Prof. Dr. A. de Meijere for giving me an opportunity to work on this thesis in Göttingen, for permanent support during the work and for his priceless help in preparation and correction of our common published works. The financial support of my participation in European-Asean Symposium in Obernai, France by Prof. de Meijere is also gratefully acknowledged.

I express my cordial gratitude and dedicate this work to my wife Tonja and daughter Masha, who have always been supported me on my way.

I am indebted to Degussa (Evonik)-Stiftung for a graduate student fellowship (20082009) and personally to Prof. Dr. W. Leuchtenberger, Dr. F. Sholl, Mrs. S. Peitzmann and Mrs. E. Sicht for perfect organisation of their work and help.

I thank Prof. Dr. de Meijere and Dr. M. Es-Sayed (Bayer Crop Science AG) for financial support at the beginning of my work in Göttingen (2006-2007).

I am also gratefull to Dr. M. Es-Sayed for his usefull advises and our fruitful collaboration.

I would like to say the words of gratitude to all people, with whom I have ever worked together in the de Meijere's group and who have shared with me their great experience and knowledge: Vadim Korotkov, Vitaliy Raev, Shamil Nizamov, Sergey M. Korneev, Dmitry Zabolotnev, Daniel Frank, Heiko Shill, Irina Martynova, Nikolai Ulin, Anna Osipova, Vladimir N. Belov, Sergey I. Kozhushkov, Viktor Bagutski, Andrey Savchenko and all short-time visitors.

For the unvaluable help with internet, software and all kinds of problems with computers I thank Heiko Shill, Daniel Frank and Stefan Beußhausen.

I am grateful to Alexey Nizovtzev for careful proofreading of this thesis.

I thank the former members of the group, Oleg Larionov and Tine Graef, with whom we had some fruitful collaborations concerning pyrrol syntheses (Oleg) and syntheses of Belactosine $\mathrm{C}$ analogues (Tine). I am also gratefull to Oleg and Vadim for discussions, motivation and co-working on the publications.

I am very thankful to Prof. Dr. U. Diederichsen for co-refering this thesis.

I appreciate the lectures and excersises held by Prof. Dr. F. Meyer, Prof. Dr. L. Ackermann, Prof. Dr. M. Buback, Dr. H.-P. Vogele, Prof. Dr. H. Laatsch that I attended and thank all these people for making their subjects clear and interesting. 
I thank Prof. Dr. F. Meyer and Prof. Dr. M. Buback for being my examenators on subsidiary subjects "Catalysis" and "Technical Chemistry", respectively.

I am gratefull to Prof. Dr. H. Laatsch, Prof. Dr. S. Tsogoeva, Prof. Dr. M. Suhm, Prof. Dr. U. Klingebiel for acceptance of my diploma thesis from the M. V. Lomonosov Moscow State University and admitting so this study.

I would like to express my sincere gratitude to Mrs. G. Keil-Knepel for a lot of organisational problems she helped me to solve.

Some words of gratitude, which I must say about the staff of Institut für Organishe und Biomolekulare Chemie: I am indebted to Dipl.-Chem. R. Machinek and all his team as well as Dr. H. Frauendorf and Mrs. G. Udvarnoki for their fast and irreproachable work measuring NMR-spectra and mass-spectra, respectively. I thank Mr. F. Hambloch for the measurements of elemental analyses, Dipl.-Chem. O. Senge for the assistance by work with HPLC, Mrs. E. Pfeil for measurements of optical rotations and some of IR spectra. I am also grateful to Mr. R. Schrommek, Mr. H. Tucholla and Daniel Frank for the good organisation of the work and convenient supply of chemicals.

Special thanks to some of my friends, who helped me feel myself more comfortable in Germany, to learn German and not forget Russian: Katarina and Robert, Michael and Gelja, Vika and Vaciliy, Artyom and others.

Thank you all very much!!! 


\section{Curriculum Vitae}

\section{Alexander V. Lygin}

DATE OF BIRTH

PLACE OF BIRTH

CITIZENSHIP

EDUCATION

11/2006-12/2009

$9 / 2001-6 / 2006$
$7 / 7 / 1984$

Krasnokamensk, Russia

Russia

Institut für Organische und Biomolekulare Chemie,

Georg-August-Universität Göttingen, Germany

Dr. rer. nat. (Organic Chemistry), to be completed on

Dec. 11 th, 2009

Research advisor: Prof. Dr. Armin de Meijere

Department of Chemistry, M. V. Lomonosov Moscow State

University Moscow, Russia

M.Sc. (Organic Chemistry, Diploma with Excellence)

Research advisor: Dr. Alexander Z. Voskoboynikov

\section{AWARDS AND HONORS}

$1 / 2008-12 / 2009$

Evonik (Degussa)-Stiftung Doctoral Fellowship

$4 / 2007$

Otto-Vahlbruch-Stiftung

$6 / 2006$

Diploma with Excellence, Department of Chemistry,

M. V. Lomonosov Moscow State University

\section{RESEARCH EXPERIENCE}

$11 / 2006-12 / 2009$

Doctoral Research: Institut für Organische und Biomolekulare Chemie, Georg-August-Universität Göttingen Research advisor: Prof. A. de Meijere

$7 / 2006-10 / 2006$

Visiting Researcher: KAdeMCustomChem GmbH, Göttingen, Germany 
Chemistry,

M. V. Lomonosov Moscow State University

Research advisor: Dr. A. Z. Voskoboynikov

\section{PUBLICATIONS}

15. A. V. Lygin, A. de Meijere, Eur. J. Org. Chem. 2009, 5138-5141.

"Synthesis of 1-Substituted Benzimidazoles from o-Bromophenyl Isocyanide and Amines"

14. M. Limbach, A. V. Lygin, V. S. Korotkov, M. Es-Sayed, A. de Meijere, Org. Biomol. Chem. 2009, 7, 3338-3342.

"Facile Synthesis of Structurally Diverse 5-Oxopiperazine-2-carboxylates as Templates and Dipeptide Mimics"

13. A. V. Lygin, A. de Meijere, J. Org. Chem. 2009, 74, 4554-4559.

"Reactions of ortho-Lithiophenyl (-Hetaryl) Isocyanides with Carbonyl Compounds: Rearrangements of 2-Metalated 4H-3,1-Benzoxazines"

12. M. Limbach, A. Lygin, M. Es-Sayed, A. de Meijere, Eur. J. Org. Chem. 2009, 13571364.

"Methyl 2-(benzyloxycarbonylamino)-2-cyclopropylideneacetate: a versatile building block for cyclopropyl-containing amino acids"

11. A. de Meijere, A. V. Lygin "Methyltitanium Triisopropoxide" In Experiments in Green and Sustainable Chemistry (Eds.: H. W. Roesky, D. Kennepohl), Wiley-VCH, Weinheim, 2009, 173-177.

10. A. A. Tsarev, M. V. Nikulin, A. V. Lygin, A. N. Ryabov, A. Z. Voskoboinikov, I. P. Beletskaya, Dokl. Chem., 2009, 424, 31-34 (a translation of Doklady Akademii Nauk 2009, 424, 493-496).

"A study of palladium-catalyzed arylation of bis(3-bromo-5-methyl-6Hcyclopenta[b]thien-6-yl)(dimethyl)silane" 
9. A. V. Lygin, O. V. Larionov, V. S. Korotkov, A. de Meijere, Chem. Eur. J. 2009, 15, $227-236$.

"Oligosubstituted pyrroles directly from substituted methyl isocyanides and acetylenes"

8. A. V. Lygin, A. de Meijere, Org. Lett. 2009, 11, 389-392.

"ortho-Lithiophenyl Isocyanide: A Versatile Precursor for 3H-Quinazolin-4-ones and 3HQuinazolin-4-thiones"

7. A. Z. Voskoboynikov, A. N. Ryabov, M. V. Nikulin, A. V. Lygin, D. V. Uborsky, C. L. Coker, J. A. M. Canich, U.S. Pat. Appl. Publ. US 2007135623 (14.06.2007, ExxonMobil), $74 \mathrm{pp}$.

"Halogen substituted heteroatom-containing metallocene compounds for olefin polymerization"

6. A. Z. Voskoboynikov, M. V. Nikulin, A. N. Ryabov, A. V. Lygin, C. L. Coker, J. A. M. Canich, U.S. Pat. Appl. Publ. US 2007135596 (14.06.2007, ExxonMobil), 116pp.

"Preparation of substituted bridged indenyl and related ligands"

5. A. Z. Voskoboynikov, A. N. Ryabov, D. V. Uborsky, A. V. Lygin, C. L. Coker, J. A. M. Canich, U.S. Pat. Appl. Publ. US 2007135594 (14.06.2007, ExxonMobil), 55 pp.

"Halogen substituted metallocene compounds for olefin polymerization"

4. A. Z. Voskoboynikov, A. N. Ryabov, M. V. Nikulin, A. V. Lygin, C. L. Coker, J. A. M. Canich, U.S. Pat. Appl. Publ. US 2007135595 (14.06.2007, ExxonMobil), 64 pp.

"Halogen substituted metallocene compounds for olefin polymerization"

3. A. Z. Voskoboynikov, A. N. Ryabov, M. V. Nikulin, A. V. Lygin, V. V. Izmer, V. V. Asachenko, C. L. Coker, J. A. M. Canich, U.S. Pat. Appl. Publ. US 2007135593 (14.06.2007, ExxonMobil), 40 pp.

"Halogen substituted metallocene compounds for olefin polymerization"

2. C. L. Coker, J. A. M. Canich, A. Z. Voskoboynikov, A. N. Ryabov, M. V. Nikulin, A. V. Lygin, V. V. Izmer, A. Asachenko, PCT Int. Appl. WO 2006065906 (22.06.2006, ExxonMobil), 205 pp. 
"Halogen substituted metallocene compounds for olefin polymerization"

1. V. V. Izmer, A. Y. Lebedev, M. V. Nikulin, A. N. Ryabov, A. F. Asachenko, A. V. Lygin, D. A. Sorokin, A. Z. Voskoboynikov Organometallics 2006, 25, 1217-1229.

"Palladium-Catalyzed Pathways to Aryl-Substituted Indenes: Efficient Synthesis of Ligands and the Respective ansa-Zirconocenes"

\section{POSTERS AND REPORTS}

4. "ortho-Lithiophenyl Isocyanide: A Versatile Precursor for Some N-Heterocycles", A. V. Lygin, A. de Meijere, 3. Göttinger Chemie-Forum, Göttingen, Germany, 3 Juli, 2009.

3. "Methyl 2-(Benzyloxycarbonylamino)-2-Cyclopropylideneacetat: Ein vielseitig anwendbarer Baustein für Cyclopropyl-Gruppen enthaltende Aminosäuren", A. Lygin, M. Limbach, A. de Meijere, 2. Göttinger Chemie-Forum, Göttingen, Germany, 4 Juli, 2008.

2. "Oligosubstituted Pyrroles Directly from Substituted Methyl Isocyanides and Acetylenes", A. V. Lygin, O. V. Larionov, V. S. Korotkov, A. de Meijere, $5^{\text {th }}$ Asian-European Symposium, Obernai, France, 25-28 Mai, 2008

1. "A Novel Approach to 2-Arylindenes via Negischi Coupling" (oral report), A. V. Lygin, A. Z. Voskoboynikov, Undergraduate and Postgraduate Student International Conference on Fundamental Sciences "Lomonosov-2006".Moscow, Russia, 12-15 April, 2006. 